University of Massachusetts Amherst

ScholarWorks@UMass Amherst

Open Access Dissertations

$2-2010$

\title{
A Stitch In Time: The Needlework of Aging Women in Antebellum America
}

Aimee E. Newell

University of Massachusetts Amherst

Follow this and additional works at: https://scholarworks.umass.edu/open_access_dissertations

Part of the History Commons

\section{Recommended Citation}

Newell, Aimee E., "A Stitch In Time: The Needlework of Aging Women in Antebellum America" (2010). Open Access Dissertations. 181.

https://doi.org/10.7275/1264737 https://scholarworks.umass.edu/open_access_dissertations/181

This Open Access Dissertation is brought to you for free and open access by ScholarWorks@UMass Amherst. It has been accepted for inclusion in Open Access Dissertations by an authorized administrator of ScholarWorks@UMass Amherst. For more information, please contact scholarworks@library.umass.edu. 


\section{A STITCH IN TIME: \\ THE NEEDLEWORK OF AGING WOMEN IN ANTEBELLUM AMERICA}

A Dissertation Presented

by

AIMEE E. NEWELL

Submitted to the Graduate School of the

University of Massachusetts Amherst in partial fulfillment

of the requirements for the degree of

DOCTOR OF PHILOSOPHY

February 2010

Department of History 
(C) Copyright by Aimee E. Newell 2010

All Rights Reserved 


\title{
A STITCH IN TIME: \\ THE NEEDLEWORK OF AGING WOMEN IN ANTEBELLUM AMERICA
}

\author{
A Dissertation Presented \\ by \\ AIMEE E. NEWELL
}

Approved as to style and content by:

Marla R. Miller, Chair

Joyce Avrech Berkman, Member

N.J. Demerath III, Member

Martha Saxton, Member

Audrey Altstadt, Department Chair

Department of History 


\section{ACKNOWLEDGMENTS}

A project of this length - put together over almost seven years - incurs a lot of gratitude. First, I would like to thank Professor Marla R. Miller for her enthusiastic assistance with this dissertation from the beginning. My entire doctoral path has been richly informed by her knowledge and experience. She always helped to make the dissertation better and offered reassurance and motivation whenever I needed it. I am deeply indebted to her for her insightful comments and her support. I also thank the members of my dissertation committee, Joyce Avrech Berkman, Jay Demerath and Martha Saxton, who read and commented from beginning to end. Their comments and suggestions have always helped me to improve this work. In addition to my committee, I thank Carrie Alyea and Ned Lazaro for reading a draft and offering their supportive comments.

I must give a very big thank you to Alden O’Brien, Curator of Costume and Textiles at the Daughters of the American Revolution Museum. Unfailingly helpful, no matter how many emails I sent asking about the smallest details, Alden was only generous to a fault. She went above and beyond by sharing her own research, emailing me about objects she discovered that might fit, hosting my two site visits to the museum, and commenting on an earlier draft. I am deeply grateful to have her as a colleague.

I was fortunate to receive support for my research through three grants along the way. In 2005, I was awarded a partial Bauer-Gordon Fellowship by the University of Massachusetts History Department, which funded travel to four New York City museums and helped me to identify pertinent examples of needlework by aging antebellum women. In 2009, I was the recipient of a Lucy Hilty Research Grant from the American Quilt 
Study Group to help with photography costs and a trip to Washington, D.C., to review some of the quilts discussed here. And, I also received a Beveridge Grant from the American Historical Association in 2009 to support additional travel and costs associated with completing my dissertation.

I presented parts of earlier drafts of this work at three conferences: the 2007 conference, "Fields of Vision: The Material and Visual Culture of New England, 16001830," co-sponsored by the Center for Historic American Visual Culture (CHAViC), American Antiquarian Society, and the Colonial Society of Massachusetts; the 2008 American Quilt Study Group Seminar in Columbus, Ohio; and the 2008 Berkshire Conference on Women's History in Minneapolis, Minnesota. I thank all who commented on my work at these conferences for their suggestions. An earlier version of part of chapter 4 on gift needlework appeared in the annual journal of the American Quilt Study Group, Uncoverings 29 (2008). I appreciate the suggestions offered by the reviewers and editors.

To do justice to the needlework discussed here, I required many images. I am indebted to the following people and institutions, who provided images at little or no cost, often waiving fees for me: Gary J. Albert and Jennifer Bean Bower, Museum of Early Southern Decorative Arts (MESDA) at Old Salem; Suzanne B. Anderson; Juliette Arai, National Archives and Records Administration; Olivia Arnone, Newark Museum; Aileen Bastos, Wadsworth Atheneum; Selina Bartlett, Allen Memorial Art Museum; Debra Basham, West Virginia Division of Culture and History; Doris Bowman, National Museum of American History, Smithsonian Institution; Joan Brownstein; Mary Jaene Edmonds; Amy Finkel and Jamie Banks, M. Finkel and Daughter; Julie Frey, Litchfield 
Historical Society; Jeanne Gamble, Historic New England; Rene Gonzales and Michaele Haynes, Witte Museum; Charles Greene, Princeton University Library; Carol Haines, Concord Museum; Tom Hobbs, University of South Carolina - Aiken; Laura Keim, National Society of the Colonial Dames of America in the Commonwealth of Pennsylvania at Stenton; Sara L.S. Lawrence, Buffalo and Erie County Historical Society; Penny Leveritt, Historic Deerfield; Erin Locke, F+W Media, Inc.; Christine Michelini, Peabody Essex Museum; Susan Newton, Winterthur Museum and Country Estate; Northeast Auctions; Andrian Paquette, Slater Mill Historic Site; Stephanie Randall, Daughters of the American Revolution Museum; Sue Reich, Connecticut Quilt Search Project; Cheryle Robertson, Los Angeles County Museum of Art; Jeannette Robichaud, Old Sturbridge Village; Jennifer Scheetz, The Charleston Museum; Ben Simons, Tony Dumitru and Marie Henke, Nantucket Historical Association; Jill Slaight, New-York Historical Society; Charlene Smith, Kentucky Historical Society; Ian Swart, Plains Indians and Pioneers Museum; Thomas Nelson Inc.; Courtney Wagner, American Folk Art Museum; Merikay Waldvogel, Quilts of Tennessee Project; Becky Weiser, Erie County Historical Society; Linda Welters, Rhode Island Quilt Documentation Project; Matthew Westerly, The Metropolitan Museum; and Brenda Wetzel and Christy White, State Museum of Pennsylvania.

While I do not have space to thank every person who assisted me along the way by answering questions and pointing me in new directions, I would like to thank a few who offered extra help: Elizabeth Oldham, Research Associate, Nantucket Historical Association; Jeannette Robichaud and Rebecca Beall, Old Sturbridge Village; Stacy C. Hollander, Senior Curator/Director of Exhibitions, American Folk Art Museum; Virginia 
Vis and Olive Blair Graffam, Daughters of the American Revolution Museum; Heather Bourdeau, O.D.; Amy Finkel and Jamie Banks, M. Finkel and Daughter; Paula B. Richter, Curator of Textiles and Costumes, Peabody Essex Museum; Laurel Thatcher Ulrich; and Pilar Garro, Historic New England. I am also indebted to the administrative staff in the University of Massachusetts History Department: Audrey Altstadt, Brian Ogilvie, Patty Ryan and Jean Ball. And, to my colleagues past and present at the National Heritage Museum and Old Sturbridge Village, who offered support and a listening ear, I thank: Hilary Anderson Stelling, Jeff Croteau, Joanne Myers, Bruce Craven, Christie Higginbottom and Tom Kelleher.

Finally, I also owe a debt of gratitude to my family and friends who supported me in many different ways during this process. My friends, Carrie Alyea, Ned Lazaro, Linzy Brekke-Aloise, Annann Hong and Jillian Jeffrey Ehrenberg always encouraged me and asked about how it was going - and were interested in the answer! Although my grandmothers, Sybil Hartley Eshbach and Faith Hill Newell, will not be able to read this, I thought of them often as I learned about the lives of these aging antebellum women. I appreciate the love and support of my parents, Norman and Marion Newell, in all that I do. And, to Bill Guy, my best friend, who has such faith in my abilities and never had any doubts I would finish - thank you for being there all along the way. 


\begin{abstract}
A STITCH IN TIME:

THE NEEDLEWORK OF AGING WOMEN IN ANTEBELLUM AMERICA
\end{abstract}

FEBRUARY 2010

\author{
AIMEE E. NEWELL, B.A., AMHERST COLLEGE \\ M.A., NORTHEASTERN UNIVERSITY \\ Ph.D., UNIVERSITY OF MASSACHUSETTS AMHERST \\ Directed by: Professor Marla R. Miller
}

In October 1852, Amy Fiske (1785-1859) of Sturbridge, Massachusetts, stitched a sampler. But she was not a schoolgirl making a sampler to learn her letters. Instead, as she explained: "The above is what I have taken from my sampler that I wrought when I was nine years old. It was w[rough]t on fine cloth it tattered to pieces. My age at this time is 66 years." Drawing from 167 examples of decorative needlework - primarily samplers and quilts from 114 collections across the United States - made by individual women aged forty years and over between 1820 and 1860, this dissertation explores how Fiske and women like her experienced social and cultural change in antebellum America, and probes their personal reactions to growing older.

Falling at the intersection of women's history, material culture study and the history of aging, this dissertation brings together objects, diaries, letters, portraits, and prescriptive literature to consider how middle-class American women experienced the aging process. 
Chapter 1 explores the physical and mental effects of "old age" on antebellum women and their needlework. It considers samplers modified later in life through the removal of the maker's age or the date when the sampler was made. Chapter 2 examines epistolary needlework, that which relates a message or story in the form of stitched words. Chapter 3 focuses on technological developments related to needlework during the antebellum period, particularly indelible ink and the rise of the sewing machine, and the tensions that arose from the increased mechanization of textile production. Chapter 4 considers how gift needlework functioned among friends and family members. The materials, style and techniques represented in these gifts often passed along an embedded message, allowing the maker to share her opinions, to demonstrate her skill and creativity, and to leave behind a memorial of her life.

Far from being a decorative ornament or a functional household textile, these samplers and quilts served their own ends. They offered aging women a means of coping, of sharing and of expressing themselves. In the end, the study argues that these "threads of time" provide a valuable and revealing source on the lives of mature antebellum women. 
TABLE OF CONTENTS

Page

ACKNOWLEDGMENTS ……………………………........................................ iv

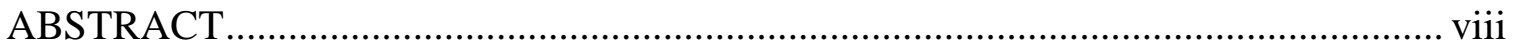

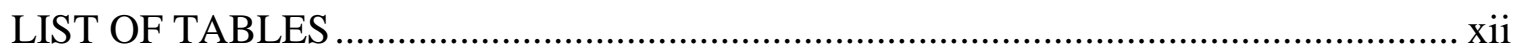

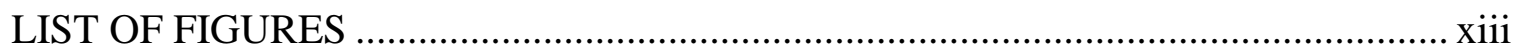

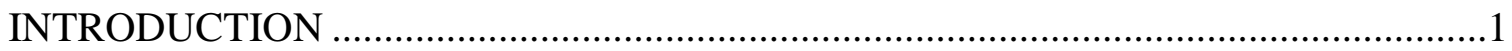

\section{CHAPTER}

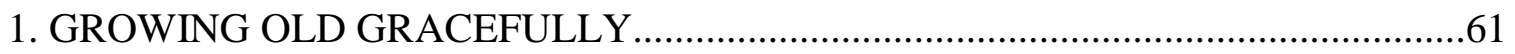

Hiding Her Age ..............................................................................................63

The Physical Challenges of Needlework ...............................................................77

"a wonderful beauty even in growing old": The Cultural Ideal of the Aging

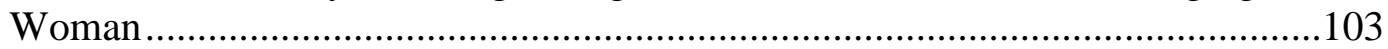

Mediating the Ideal and the Real ...............................................................114

2. BIOGRAPHICAL NEEDLEWORK: TELLING A LIFE STORY.............................125

Epistolary Needlework: Telling Stories and Bearing Witness .............................144

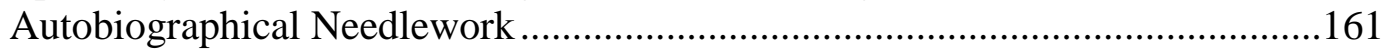

Memorial Needlework: Keeping the Family Alive .........................................178

3. THE TECHNOLOGICAL RESHAPING OF ANTEBELLUM NEEDLEWORK....201

Antebellum Needlework Innovations .............................................................205

Agricultural Fairs: A Means of Recognition or Marginalization?.......................222

Navigating Generational Tension with a Needle ................................................241

4. FAMILY CURRENCY: THE GIFT NEEDLEWORK OF AGING

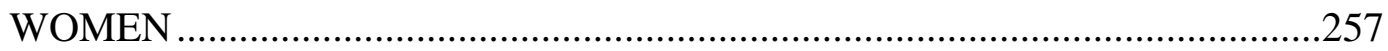

I give and bequeath this quilt: Needlework as Property ……………...................271

"the productions of our own industry": The Social Nature of Gifts .....................296

At my grandmother's feet: The Cultural Nature of Gifts ........................................326

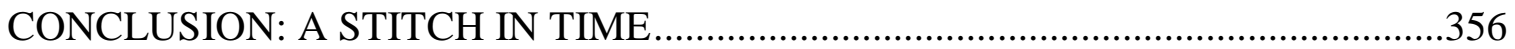


APPENDIX: DECORATIVE NEEDLEWORK MADE BY WOMEN FORTY AND

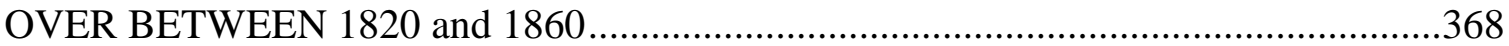

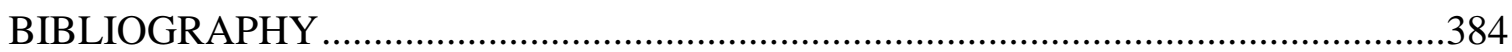




\section{LIST OF TABLES}

Table

Page

1.1: Samplers Altered by Having Date or Age Picked Out ......................................64

2.1: Samplers Submitted to the Pension Office

4.1: Antebellum Needlework Given as Gifts by Aging Women....................348 


\section{LIST OF FIGURES}

$\begin{array}{lll}\text { Figure } & \text { Page }\end{array}$

I.1.: Sampler by Amy Fiske (1785-1859), 1852, Sturbridge, Massachusetts ................2

I.2.: Quilt by Maria Cadman Hubbard (b. 1769), 1848, New York............................. 4

I.3.: Heroes of the Revolution quilt by Rhoda Warner (b. 1784), 1855, Painesville,

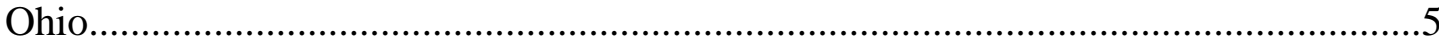

I.4.: Esther Belcher Bird (1792-1840) by an unidentified artist, 1835-1845, probably

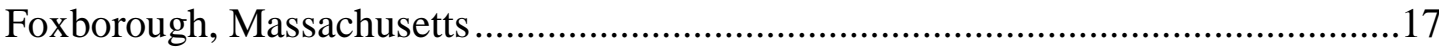

I.5.: Eliza Macy Howland Barney (1783-1867) by Bierstadt Brothers, circa 1860, New Bedford, Massachusetts

I.6.: Quilt by Eliza Macy Howland Barney (1783-1867), circa 1830, New Bedford, Massachusetts

I.7.: Sampler by Caroline M. Bracket (b. 1842), 1852, Sturbridge, Massachusetts ....58

1.1.: Sampler by Eleanor Caroline Malone (1828-1894), 1836, Boston, Massachusetts

1.2.: Sampler by Sally M. Bowen (1789-1872), circa 1800, Marblehead, Massachusetts

1.3: Sampler by Emily C. Rawlings, circa 1820, probably Baltimore, Maryland ......69

1.4.: Detail of sampler by Emily C. Rawlings .69

1.5.: Sampler by Sarah L. Art (1793-1875), 1806, Lewes, Delaware .70

1.6.: Farmer Giles and his wife showing off their daughter Betty to their neighbours, on her return from school by James Gillray (1757-1815), 1809, London, England ...72

1.7.: Sampler by Lucretia Buttrick (1801-1892), Concord, Massachusetts.................75

1.8.: Detail of Buttrick sampler showing stitches removed at right...........................75

1.9.: Quilt attributed to Lavinia Prigmore Moore (1811-1861), Tennessee ................79

1.10.: Mary Swain Tucker Paddack (1792-1878) by William Swain (1803-1847), 1846, Nantucket, Massachusetts 
1.11.: Unidentified Quaker Woman by unidentified artist, circa 1820, probably Nantucket, Massachusetts

1.12.: Quilt by Mary Frye Van Voorhis (b. ca. 1788), circa 1850, Pennsylvania .......89

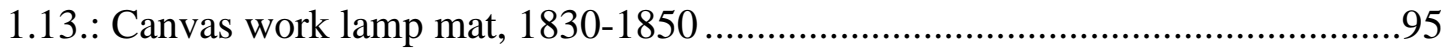

1.14.: Muslin work detail from gown by Marion Chandler (1800-1857), 1828,

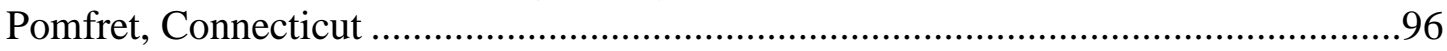

1.15.: Embroidery pattern, 1790-1830, probably Providence, Rhode Island ..............96

1.16.: Table by Joseph True (1785-1873); table cover by Mary Berry True (1788-

1858), 1840, Salem, Massachusetts .........................................................................99

1.17.: Marked textiles from the Wilber family, 1830-1850, Swansea, Massachusetts

1.18.: Two portraits, Widow Phebe Hunt aged 68 years, by J.A. Davis (1821-1855), 1849. 106

1.19.: Post-1934 reproduction of portrait of Deborah Norris Logan (1761-1839) by

Charles Willson Peale (1741-1827), 1822, Philadelphia, Pennsylvania.

1.20.: Allethenia Fisk Holt (1792-1838) attributed to Asahel Powers (1813-1843),

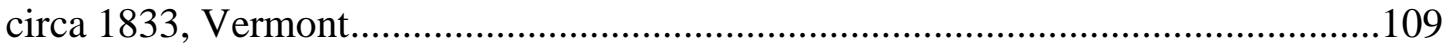

1.21.: Sampler by Ann Maria Foltz (b. 1820), 1830, Pennsylvania ..........................112

1.22.: Counterpane by Mary Tayloe Lloyd Key (1786-1859), circa 1840, Georgetown, Maryland ....

2.1.: Sampler by Esther Banister Richards (1795-1864), 1853, Sturbridge, Massachusetts 126

2.2.: Quilt by Margaret Steeley Kelley (1784-1865), pieced 1852, quilted 1857,

Pennsylvania

2.3.: Detail of signature on Kelley quilt. 134

2.4.: Quilt by Nancy Ward Butler (1779-1863), 1842, New York

2.5.: Quilt by Betsey M. Seely Sears (1813-1901), 1855, Wisconsin ...

2.6.: Betsey M. Seely Sears (1813-1901), late 1890s, Wisconsin 142 
2.7.: Quilt by Betsey M. Seely Sears (1813-1901), circa 1855, Wisconsin. 145

2.8.: Quilt by Maria Cadman Hubbard (b. 1769), 1848, New York 147

2.9.: Sampler by Mary Hearn (b. 1782), 1793, Nantucket, Massachusetts 155

2.10.: Sampler by Elcey Patterson (1803-1862), 1845, Union Village, Ohio 163

2.11.: Sampler by Patty Bartlett Sessions (1795-1892), 1848, Utah 167

2.12.: Sampler by Ruth Pierce Croswell (1765-1862), 1827, Catskill, New York....173 2.13.: Family Record Sampler by Dorothy Knight (1803-1854), 1817, Phillipston,

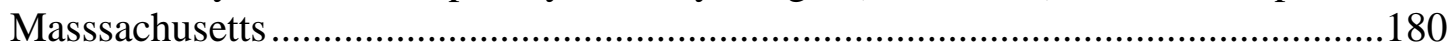

2.14.: Sampler by Sarah Holmes (1793-1842), 1801, New Jersey .............................184

2.15: Detail of dates added to sampler by Sarah Holmes ........................................184

2.16.: Quilt by Mary Rooker Norris (1785-1868), 1846, Hagerstown, Maryland.....186

2.17.: Family Record Sampler by Mary W. Evans (1814-1888), 1824, Providence, Rhode Island 190

2.18.: Family Record Sampler by Frances Fales (1794-1824), 1807

2.19.: Graveyard Quilt by Elizabeth Roseberry Mitchell (1799-1857), circa 1839, Lewis County, Kentucky 195

2.20.: Quilt by Cynthia Wells Standish, 1855, Wethersfield, Connecticut 197

3.1.: Quilt by Emily Vandergrift Snyder (b. 1804), circa 1850, Philadelphia, Pennsylvania 206

3.2.: Detail of center medallion from quilt by Emily Vandergrift Snyder. 207

3.3.: Quilt by Frances Swanson Shaw (1808-1876), circa 1850, Hagerstown, Maryland 214

3.4.: Quilt by Mary Deloach Sneed (1807-1905), 1850-1860, Waco, Texas 219

3.5.: Nantucket Agricultural Society Quilt, 1856, Nantucket, Massachusetts. .230

3.6.: Detail of signed block on Nantucket Agricultural Society quilt .232 
3.7.: Detail of center block on Nantucket Agricultural Society quilt

3.8.: Quilt by Euphemia Wilson Righter (1790-1873), 1850, Beaver Meadow,

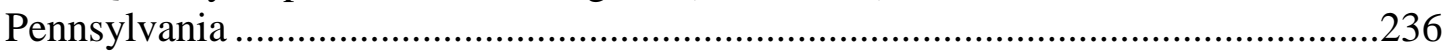

3.9.: Detail of central medallion from quilt by Euphemia Wilson Righter................237

3.10.: Quilt by Submit Gay, 1842, Connecticut...................................................244

3.11.: Marina Jones Gregg (1811-1899), circa 1890 ...........................................246

3.12.: Quilt by Marina Jones Gregg (1811-1899), 1852, Charleston, South Carolina

3.13.: Lucy Hiller Cleveland (1780-1866) by D.W. Bowdoin, 1863, Salem, Massachusetts

3.14.: "The Sick Chamber" by Lucy Hiller Cleveland (1780-1866), 1831, Salem, Massachusetts

3.15.: "The Foot Bath" by Lucy Hiller Cleveland (1780-1866), 1845-1855, Salem, Massachusetts

4.1.: Quilt by Amelia Heiskell Lauck (1760-1842), circa 1822, Winchester, Virginia

4.2.: Amelia Heiskell Lauck (1760-1842) by Jacob Frymire (1770-1822), 1801,

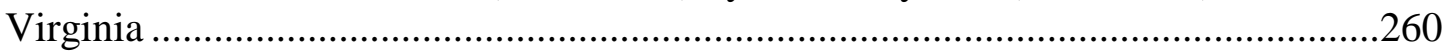

4.3.: Sampler by Mary R. Dearborn, early 1830s ................................................273

4.4.: Sampler by Betsey Maria Ayer, 1835, St. Johnsbury, Vermont.......................274

4.5.: Quilt by Catharine Penniman Bradford (1778-1827), 1825, Boston,

Massachusetts

4.6.: Quilt by Martha Washington (1732-1802) and Eliza Parke Custis (1776-1832),

completed in 1815 , Virginia

4.7.: Quilt by Mary (Betsey) Totten Polhemus Williams (1781-1861), circa 1830,

Staten Island, New York ............................................................................28

4.8.: Quilt by Sarah Wadsworth Mahan (1802-1885), 1851, Ohio...........................288

4.9.: Detail of quilt by Sarah Wadsworth Mahan .................................................289 
4.10.: Quilt by Rebecca Scattergood Savery (1770-1855), 1827, Philadelphia, Pennsylvania

4.11.: Anna Catharine Hummel Markey Garnhart (1773-1860), circa 1850 299

4.12.: Quilt by Anna Catharine Hummel Markey Garnhart (1773-1860), circa 1815, Frederick, Maryland. .301

4.13.: Quilt by Anna Catharine Hummel Markey Garnhart (1773-1860), circa 1850, Frederick, Maryland. 303

4.14.: Quilt by Harriet Kirk Marion (1782-1856), circa 1830, South Carolina.........305

4.15.: Quilt by Catherine Marion Palmer (1807-1895), 1847, South Carolina ..........308

4.16.: Quilt by Harriet Kirk Marion (1782-1856), circa 1840 or by Elizabeth Marion Porcher (1760-1796) and Elizabeth Catherine Porcher Palmer (1781-1841), 1790 and 1830, South Carolina 310

4.17.: Quilt by Esther Johnson Parkinson Slater (1778-1859), 1851, Pawtucket, Rhode Island 318

4.18.: Sampler by Esther Johnson, 1787, England 320

4.19.: Quilt by Susan Kuhns (circa 1787-circa 1865), circa 1830, Greenburg, Pennsylvania 324

4.20.: Quilt by Rachel Smith (b. 1795), 1870s, New Jersey 330

4.21.: Doll quilt by Ella Mygatt Whittlesey (b. 1845), 1852 335

4.22.: Quilt by Mary Laman Kemp (1758-1845), 1840, Rocky Springs, Maryland .339

4.23.: Detail of inscription on quilt by Mary Laman Kemp 340

4.24.: Quilt by Abigail Reynolds Greene (1794-1889), 1860, East Greenwich, Rhode Island

4.25.: Quilt by Catherine Crast Sloat (1798-1873), circa 1845, New York 346

C.1.: Heroes of the Revolution quilt by Rhoda Warner (b. 1784), 1855, Painesville, Ohio.

C.2.: Detail from Heroes of the Revolution quilt by Rhoda Warner...... 358 


\section{INTRODUCTION}

In October 1852, Amy Fiske (1785-1859) of Sturbridge, Massachusetts, stitched a sampler (figure I.1). But Amy was not a young schoolgirl making a sampler to learn her letters or to reinforce household sewing skills. Instead, as she explained on her sampler, "The above is what I have taken from my sampler that I wrought when I was nine years old. It was w[rough]t on fine cloth it tattered to Pieces My age at this time is 66 years." Indeed, when she stitched the sampler, Amy Fiske was a great-aunt who had raised four children of her own and was living at the farm her husband owned. Girls and young women traditionally made most extant samplers as educational exercises in a school setting. Why did Amy Fiske re-stitch her childhood sampler so late in her life?

Like most women of her generation, those who reached the age of forty between 1820 and 1860, Amy Fiske's life story is frustratingly vague in the documents she left behind. There are few details to explain her accomplishments, her tastes or her outlook on life. But her sampler is almost more telling than a letter would be; both the text on the sampler and the materials used to make it offer insight into her life and the life of her community. Amy Fiske's action, re-stitching her sampler, is a personal response to the changing roles of aging women during the antebellum era (1820-1860).

$$
* * *
$$

\footnotetext{
${ }^{1}$ Amy Fiske's sampler is in the collection of Old Sturbridge Village, Sturbridge, Massachusetts. Alphabets and verses are standard elements of American samplers, while more personal or expository messages like the one on Amy Fiske's sampler are rare, but not without English precedent. For a description of seventeenth- and eighteenth-century English epistolary samplers that "relate a message in the form of a prose letter," see Marsha Van Valin, "Epistolary Samplers: When Needles were Pens" in Common Thread, Common Ground: A Collection of Essays on Early Samplers and Historic Needlework, ed. Marsha Van Valin (Sullivan, WI: The Scarlet Letter, 2001), 50-55. See also Maureen Daly Goggin, "One English Woman's Story in Silken Ink: Filling in the Missing Strands in Elizabeth Parker's Circa 1830 Sampler," Sampler and Antique Needlework Quarterly 8 (Winter 2002): 38-49. American antebellum epistolary needlework will be explored in Chapter 2.
} 


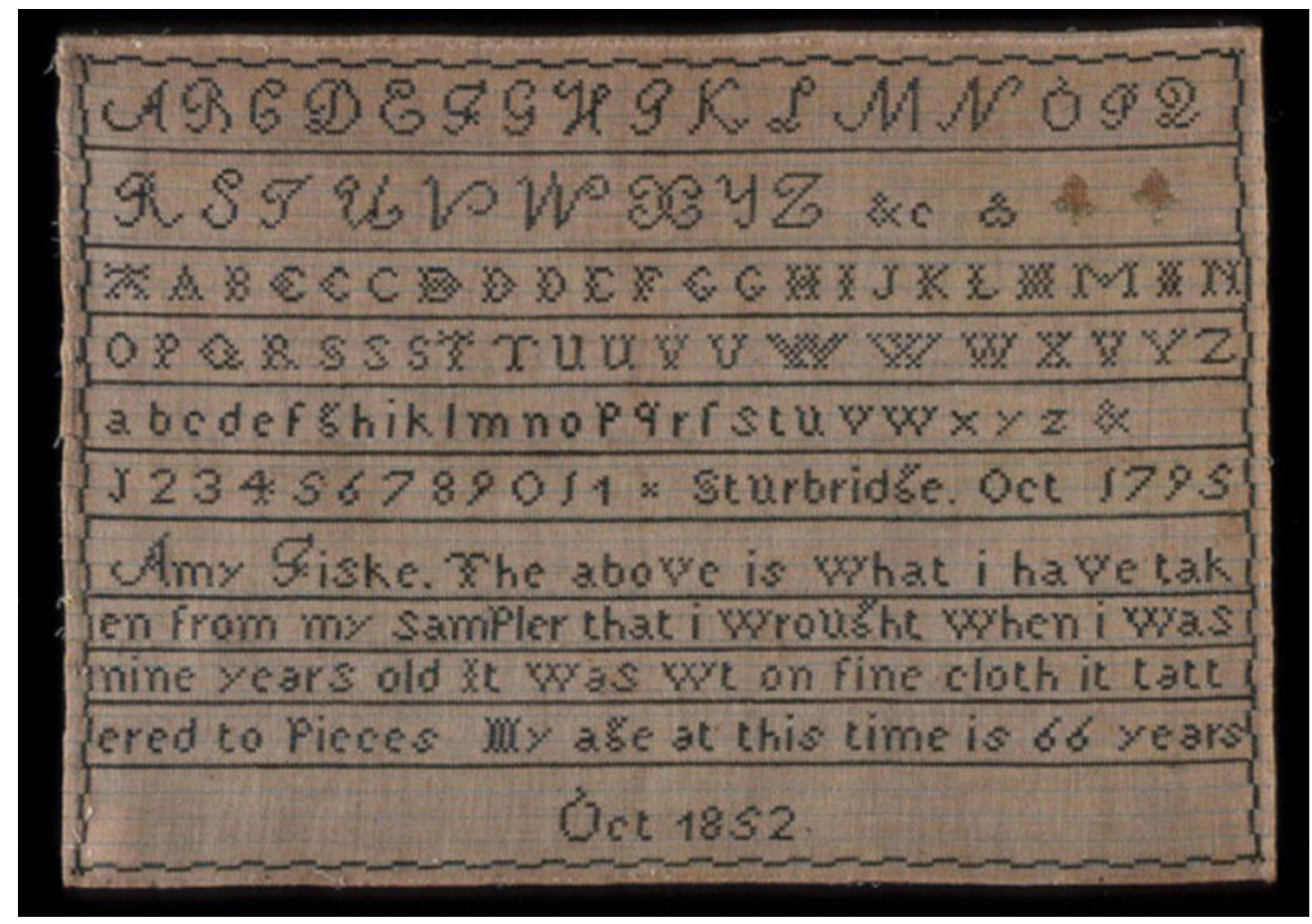

Figure I.1. Sampler by Amy Fiske (1785-1859), 1852, Sturbridge, Massachusetts. Courtesy of Old Sturbridge Village, Sturbridge, Massachusetts, 64.1.121, photograph by Thomas Neill.

Verse: Amy Fiske. The above is what I have taken from my sampler that I wrought when I was nine years old It was wt on fine cloth it tattered to pieces My age at this time is 66 years.

As she explained on the sampler itself, Amy Fiske stitched this piece at the age of sixtysix years. She based it on the sampler that she made when she was nine years old, which had "tattered to pieces." While most extant samplers were made by girls and young women, Fiske's sampler demonstrates that older women did make samplers during the antebellum decades, contrary to many published histories of American needlework. The fabric she used has horizontal blue lines woven at regular intervals. These made counting the stitches easier. 
The needlework (including samplers, quilts and other decorative needlework) that aging white, middle-class women like Amy Fiske left behind offers a way to explore how these women experienced social and cultural changes taking place between 1820 and 1860, as well as their own personal reactions to growing older. There are numerous extant artifacts that provide extraordinary glimpses into the world of aging women in antebellum America. Some are stunning in their direct address to viewers then and now. The quilt made by seventy-nine-year-old Maria Cadman Hubbard (b. 1769) of New York in 1848 (explored in chapter 2), for instance, incorporates her own personal manifesto. Verses drawn from a variety of published sources are pieced in red and white, in between quilt blocks made in the Delectable Mountains pattern (see figure I.2). Seventy-one-yearold Rhoda Warner's (b. 1784) elaborate quilt, Heroes of the Revolution, made in 1855 and explored in the Conclusion, provides a history lesson about both its maker and her nation (see figure I.3). In the center Warner pieced thirteen star blocks to represent the original thirteen colonies. She inked the names of the signers of the Declaration on the quilt, and included verses inspired by the Revolution that also comment on the divisive 1855 political issue of slavery.

These quilts, and other needlework like them, were generally made of the women's own volition. They chose the materials and the patterns as they pleased, in direct contrast to the needlework made by girls and young women that was stitched in a school setting under the guidance of a teacher. ${ }^{2}$ For aging middle-class women in antebellum America, this difference meant that their needlework served as a source of

\footnotetext{
${ }^{2}$ Laurel Horton, Mary Black's Family Quilts: Memory and Meaning in Everyday Life (Columbia: University of South Carolina Press, 2005), 8.
} 


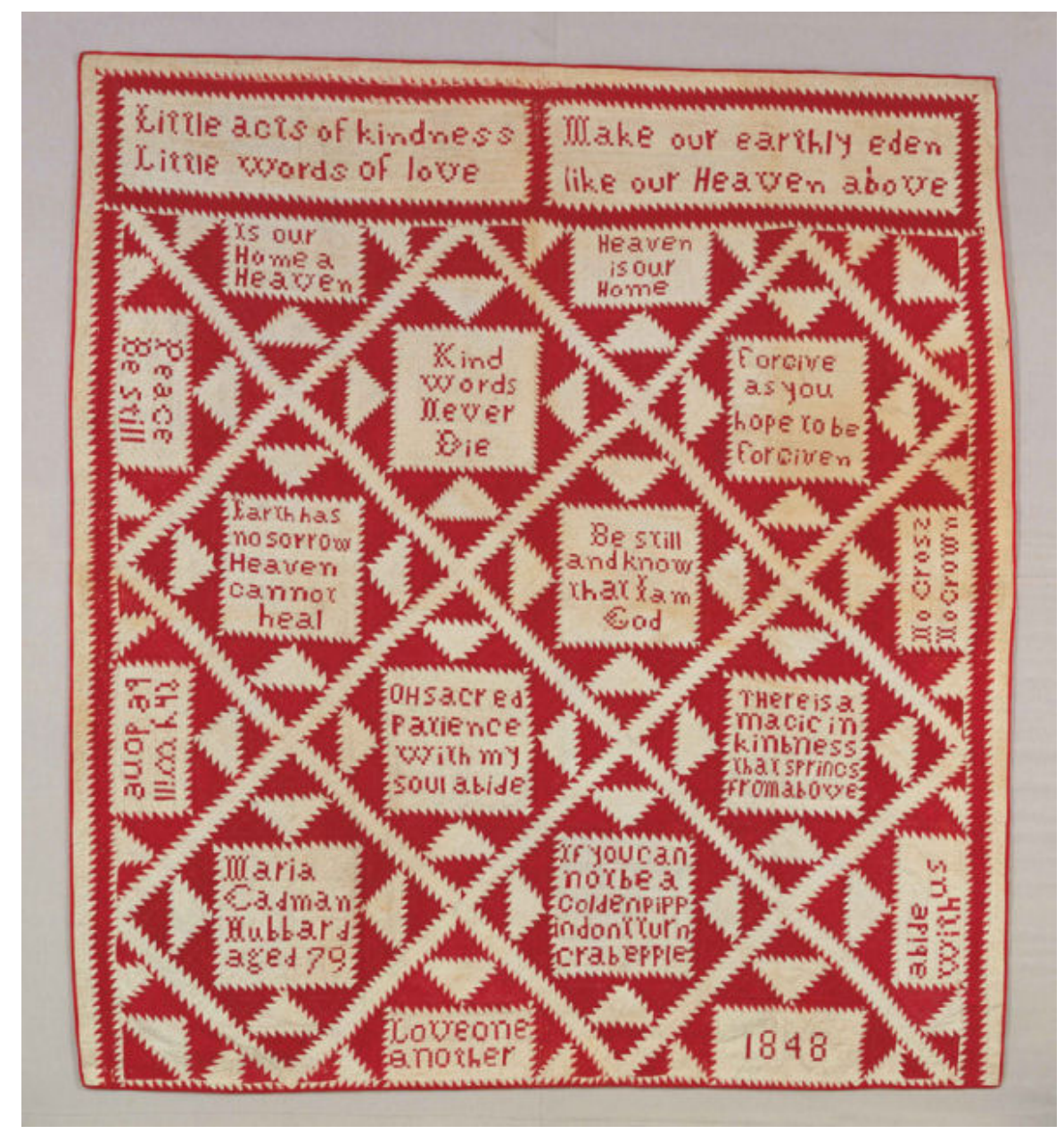

Figure I.2. Quilt by Maria Cadman Hubbard (b. 1769), 1848, New York. Courtesy of the American Folk Art Museum, New York, New York.

Aging antebellum women used needle and thread to leave many types of messages. While Amy Fiske's sampler tells her personal story, Maria Cadman Hubbard's quilt reminded all who looked at it to pursue a virtuous life. 


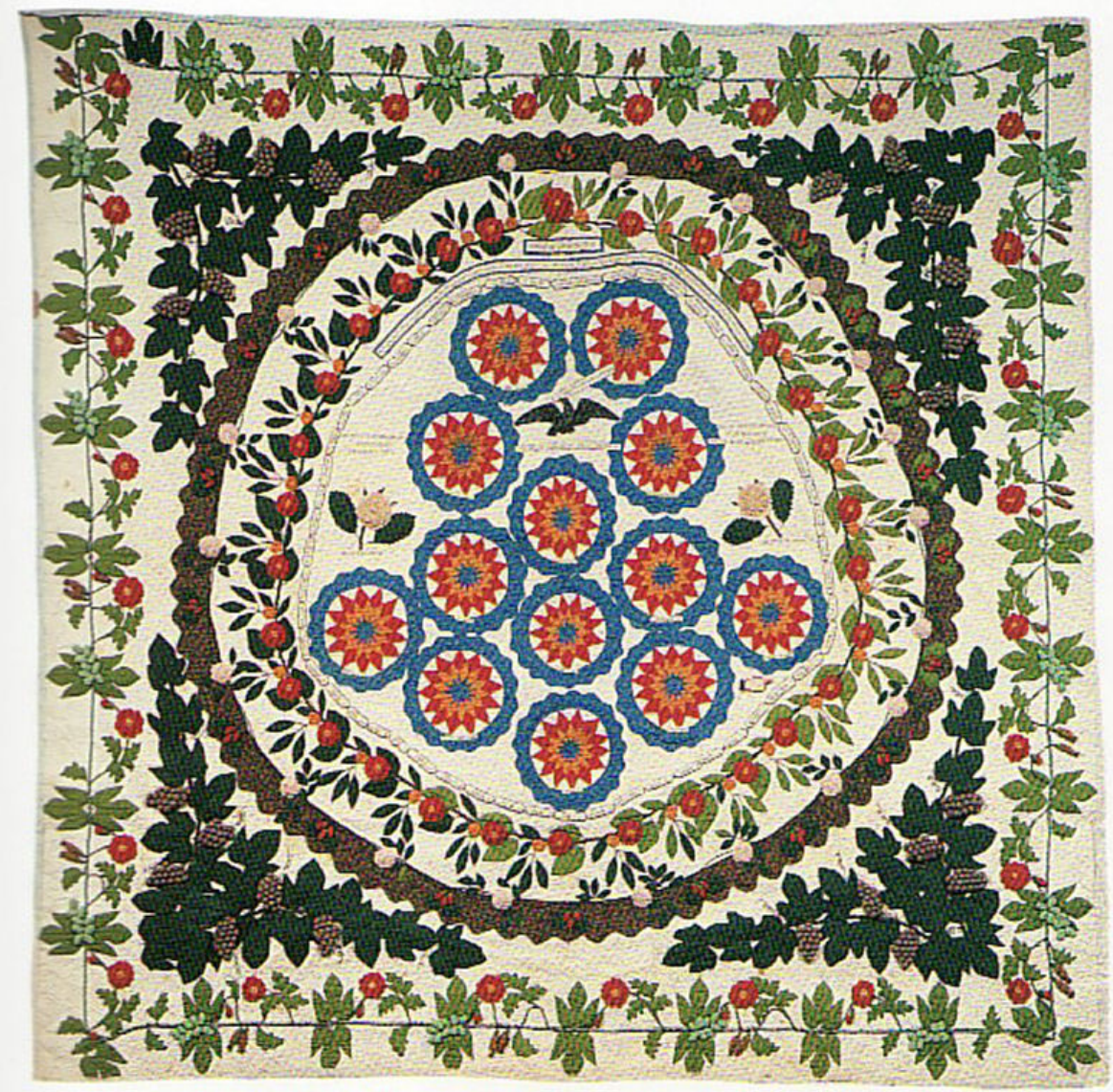

Figure I.3. Heroes of the Revolution quilt by Rhoda Warner (b. 1784), 1855, Painesville, Ohio. Courtesy of the Buffalo and Erie County Historical Society, Buffalo, New York.

Seventy-one-year-old Rhoda Warner's elaborate quilt includes "2,404 pieces, 57 names, 80 words, and 1,063 letters of needlework." Warner reproduced the names of all of the signers of the Declaration of Independence on her quilt, along with some favorite verses. The remarkable appliqué and piecing work in the quilt attracted notice and it won a prize at a local agricultural fair. 
identity allowing them to define themselves, serve as a model for others, and leave a piece of themselves behind.

In a survey of early nineteenth-century letters and diaries written by older women, historian Terri Premo determined that aging women "found much of nineteenth-century life unsettling," as "political and technological change seemed rampant and not necessarily welcome."3 Yet, the aging process was neither all positive nor all negative. Instead, some women experienced a loss of power and other negative effects as they grew older, while others embraced the new stage of their life and enjoyed its benefits. Many experienced a combination of negative and positive effects. The samplers, quilts and other decorative needlework made by these maturing women help to demonstrate their complicated response to the changes around them. The objects they created carry cultural meanings and reactions - both positive and negative - to the events taking place in the antebellum era, including industrialization, the abolition movement, and women's rights activities.

Of course, some of the motivations to stitch are ageless - women, old and young alike, used needlework to express love and to be remembered - but these motivations could often become more acute as women aged. ${ }^{4}$ The familiar medium of needle and thread employed by women from childhood to old age offered the comfort of continuity during personal, community and national transitions. As one antebellum needlework guide explained, "We find [the needle] the first instrument of use placed in the hand of

\footnotetext{
${ }^{3}$ Terri L. Premo, Winter Friends: Women Growing Old in the New Republic, 1785-1835 (Urbana: University of Illinois Press, 1990), 137.

${ }^{4}$ Premo, Winter Friends, 5, 92; Susan M. Stabile, Memory's Daughters: The Material Culture of Remembrance in Eighteenth-Century America (Ithaca: Cornell University Press, 2004), 134; Carl N. Degler, At Odds: Women and the Family in America from the Revolution to the Present (New York: Oxford University Press, 1980), 191; Marilyn Ferris Motz, True Sisterhood: Michigan Women and Their Kin 1820-1920 (Albany: State University of New York Press, 1983), 68.
} 
budding childhood, and it is found to retain its usefulness and charm, even when trembling in the grasp of fast declining age." to have been motivated by nostalgia when they picked up their needles, something that set them apart from girls and young women. Needlework allowed nostalgic women to both produce objects that resembled items they made and owned in the past, and to recapture memories of picking up their needles as girls, prospective brides and young mothers.

While the action of stitching needlework could provide a sense of continuity for aging women, evidence of generational struggle can also be seen in the needlework products made by women born during the late eighteenth and early nineteenth centuries who matured and became elderly during the antebellum period. These aging stitchers were often inspired by the example set by their mothers and grandmothers and were taught needlework when educational opportunities for white middle- and upper-class girls flourished during the Federal era. But, by the 1820 s and 1830s, and increasingly into the 1850s, the skills that these women learned were becoming less and less necessary. Their own daughters and granddaughters no longer learned to stitch at school and instead relied more and more on factory-produced and store-bought thread, yarn and cloth, as well as published patterns. ${ }^{6}$ How did these societal and cultural changes alter the appearance and meaning of antebellum needlework for its makers and for their families? And how did needlework help aging women in antebellum America express their beliefs, values and fears in a changing world?

\footnotetext{
${ }^{5}$ The Ladies' Work-Table Book (New York: J. Winchester, 1844), vi.

${ }^{6}$ Susan Burrows Swan, Plain and Fancy: American Women and Their Needlework, 1650-1850 (Austin, Texas: Curious Works Press, 1995), 170; Glee Krueger, New England Samplers to 1840 (Sturbridge: Old Sturbridge Village, 1978), 19.
} 
Sometimes artifacts of needlework, like quilts and samplers, are as telling or even more so than the documentary record. Scholar Kenneth L. Ames has pointed out that paper was traditionally made from cloth scraps, illuminating the close relationship between these two media and casting new light on the relationship of women to textiles and to more traditional documentary sources. ${ }^{7}$ Laurel Thatcher Ulrich asserts that "because far more women were accustomed to using needles than pens, textiles may offer the richest unexplored body of information in early American women's history." Drawing on poet Anne Bradstreet's (1612-1672) line, “I am obnoxious to each carping tongue, Who says my hand a needle better fits," Ulrich brought attention to the "creative tension" between pens and needles, and invited women's historians to take oral traditions and material sources more seriously, as well as to examine more closely the "roots of the written documents we take so much for granted."9 Ulrich's words offer inspiration for this study of aging antebellum women and their needlework, which places the material record first and then looks back to the documentary evidence, weaving them together to contextualize the experiences of an understudied generation.

\section{Historiographical Underpinnings: Histories of Old Age, Women and Needlework}

This study falls at the intersection of three large literatures: the history of aging; women's history; and curatorial scholarship on decorative needlework. Looking at all three subjects together suggests both what we already know and what we do not yet

\footnotetext{
${ }^{7}$ Kenneth L. Ames, Death In the Dining Room and Other Tales of Victorian Culture (Philadelphia: Temple University Press, 1992), 98.

${ }^{8}$ Laurel Thatcher Ulrich, "Of Pens and Needles: Sources in Early American Women's History," The Journal of American History 77 (June 1990), 202.

${ }^{9}$ Ulrich, "Of Pens and Needles," 202.
} 
understand about how middle-class American women experienced the aging process during the transformative years between 1820 and 1860 .

\section{History of Aging and the Definition of Old Age}

The study of the history of aging grew out of the social history movement of the 1960s and 1970s, as historians began to explore the everyday experiences of Americans. Initially, these early historians of aging focused on pinpointing the replacement of veneration of the aged with the derision that was so common in Vietnam-era American society. In 1977, David Hackett Fischer, one of the first to study the history of aging in America, interpreted his evidence to mean that veneration was replaced with derision after the American Revolution, between 1770 and $1820{ }^{10}$ A year later, in 1978, W. Andrew Achenbaum placed this transition after 1865, during the rise of industrialization. ${ }^{11}$ More recently, most scholars of the history of aging have agreed that the shift took place in the mid- to late-nineteenth century and turned their attention to explaining what caused this shift. ${ }^{12}$ Yet, few of these authors specifically considered the situation and experience of aging women.

In 1983, Carole Haber reviewed the literature on the history of aging and came to the conclusion that there never was a "golden age of senescence;" instead, the roles of the elderly were based on a "transformation in the way society attempted to eliminate disease

\footnotetext{
${ }^{10}$ David Hackett Fischer, Growing Old in America (New York: Oxford University Press, 1977), 99.

${ }^{11}$ Andrew W. Achenbaum, Old Age in the New Land: The American Experience Since 1790 (Baltimore: The Johns Hopkins University Press, 1978), 36, 39.

${ }^{12}$ For example, see Carole Haber, Beyond Sixty-Five: The Dilemma of Old Age in America's Past (Cambridge: Cambridge University Press, 1983), 41; Thomas R. Cole, The Journey of Life: A Cultural History of Aging in America (Cambridge: Cambridge University Press, 1992); Howard P. Chudacoff, How Old Are You? Age Consciousness in American Culture (Princeton: Princeton University Press, 1989), 9; and David Van Tassel and Peter N. Stearns, eds., Old Age in a Bureaucratic Society: The Elderly, the Experts, and the State in American History (New York: Greenwood Press, 1986), 9.
} 
and dependence" during the nineteenth century. ${ }^{13}$ Like her predecessors, Haber did not address any gender differences in the aging process. She did agree with Achenbaum (and others) that a change took place during the mid-nineteenth century, but rather than a switch from veneration to derision, she suggested that the elderly were assumed to be difficult and needy from the eighteenth century forward. ${ }^{14}$

In 1985, Marjorie Chary Feinson lamented that despite the "proliferation of feminist scholarship, the historical experiences of aging women have not been examined systematically by either historians of aging, family historians, or feminist historians." Feinson called for future analysis of the history of aging that included gender and class distinctions, but few scholars responded. Five years after Feinson, in 1990, Terri L. Premo made what remains the seminal contribution to the study of aging women. She asserted that in the 1830 s the American view of old age shifted, citing increased geographic mobility, which "imposed restrictions on an adult child's ability to care for parents," and changing religious perspectives that "reduced the feasibility of a theological argument based on decay and dependency." Premo suggested that these changes altered how Americans understood and coped with old age. Old ideas about aging that revolved around religious preparation to cultivate acceptance of death along with the promise of veneration "no longer seemed entirely appropriate or reasonable." women experienced aging differently than men during the decades after the Revolution, suggesting that "aging women found new opportunities for developing strong and

\footnotetext{
${ }^{13}$ Haber, Beyond Sixty-Five, 5.

${ }^{14}$ Haber, Beyond Sixty-Five, 41.

${ }^{15}$ Marjorie Chary Feinson, "Where are the Women in the History of Aging?," Social Science History 9 (Autumn 1985): 436.

${ }^{16}$ Premo, Winter Friends, 2.
} 
purposeful identities in old age."17 She outlined six "elements that reflect areas of meaning and value to aging women in the new republic": relationships; organic orientation to life; domesticity; interdependency; conservation and transmission of culture; and spiritual awareness. ${ }^{18}$

The end goal of many early studies of the history of aging was to understand the evolution of public policy regarding Social Security and Medicare, which colored the historians' use and analysis of evidence. Picking and choosing historical evidence to make a point about contemporary policy did not help to advance our understanding of the experience of aging antebellum women (or men). Cultural historian Thomas R. Cole offered his own counterpoint in 1992, writing that "growing old cannot be understood apart from its subjective experience, mediated by social condition and cultural significance." 19 Ten years later, historian Pat Thane echoed Cole's words, encouraging historians of aging to "unite all of the approaches currently available... and no doubt others of which we are not yet aware. We need to draw together historical knowledge of the demographic and material experience of old age in different times and places with cultural histories..."20 Looking at the needlework of mature women shifts the study of aging away from public policy and offers the promise of insight into how women of the antebellum era understood the changes that they experienced as a result of growing older.

As a result of the focus on exploring current public policy issues around aging, most historians of aging do not seem to have turned to a study of generational relations or to have considered how generational memory and nostalgia might have affected the aging

\footnotetext{
${ }^{17}$ Premo, Winter Friends, 46.

${ }^{18}$ Premo, Winter Friends, 183-184.

${ }^{19}$ Cole, The Journey of Life, xxii.

${ }^{20}$ Pat Thane, "Social Histories of Old Age and Aging," Journal of Social History 37 (2003): 94.
} 
process. However, several historians of the memory of the Revolutionary generation have considered the aging process. ${ }^{21}$ Whether elderly people were venerated or not, Revolutionary memory was valued, beginning in the 1810s and continuing through midcentury. Pauline Maier points to the appearance of decorative engravings of the Declaration of Independence produced in 1818 and 1819, as well as the publication of books about the lives of the signers and of Revolutionary soldiers in the 1820s. She sees these developments as evidence that "a new generation turned its back in time, and made preservation of the nation's revolutionary history its peculiar mission."22

In 1991's Mystic Chords of Memory, historian Michael Kammen explored the question, "when and how did the United States become a land of the past," by using a cultural history approach and looking not at entire generations or specific people, but at the development of national memory. ${ }^{23}$ Kammen suggested that by the middle decades of the nineteenth century, Americans used history to provide "ornaments of memory," the orations, monuments and published books that offered a story of the nation's past. ${ }^{24}$ For the fledgling United States government, struggling to define itself as a nation, memory, tradition and history offered a "bulwark for social and political stability," as well as "a

\footnotetext{
${ }^{21}$ Pauline Maier, American Scripture: Making the Declaration of Independence (New York: Alfred A. Knopf, 1997); Michael Kammen, Mystic Chords of Memory: The Transformation of Tradition in American Culture (New York: Alfred A. Knopf, 1991); Michael Kammen, A Season of Youth: The American Revolution and the Historical Imagination (Ithaca: Cornell University Press, 1978); Joyce Appleby, Inheriting the Revolution: The First Generation of Americans (Cambridge: Belknap Press, 2000); Sarah J. Purcell, Sealed with Blood: War, Sacrifice and Memory in Revolutionary America (Philadelphia: University of Pennsylvania Press, 2002); Stabile, Memory's Daughters; Len Travers, Celebrating the Fourth: Independence Day and the Rites of Nationalism in the Early Republic (Amherst: University of Massachusetts Press, 1997); and Alfred F. Young, The Shoemaker and the Tea Party: Memory and the American Revolution (Boston: Beacon Press, 1999). See also John Bodnar, "Generational Memory in an American Town," The Journal of Interdisciplinary History 26 (Spring 1996): 619-637 and Robert N. Butler, "The Life Review: An Interpretation of Reminiscence in the Aged," Psychiatry 26 (February 1963): 65-76.

${ }^{22}$ Maier, American Scripture, 176-177.

${ }^{23}$ Kammen, Mystic Chords of Memory, 7.

${ }^{24}$ Kammen, Mystic Chords of Memory, 69.
} 
means of valorizing resistance to change. ${ }^{25}$ In his earlier work, A Season of Youth, focused on the memory of the American Revolution, Kammen asserted that the Revolution was the "single most important source for our national sense of tradition." ${ }^{26}$ Living up to the expectations of the Revolutionary generation, while also finding ways to preserve their achievements, was a weighty theme in antebellum literature and images, and became the project of a wide swath of American society. ${ }^{27}$ Though Kammen did not specifically address it, this included women and their needlework.

Where Kammen took a wide-lens, cultural approach, historian Joyce Appleby pursued a more personal methodology to study Revolutionary memory. She read more than 200 autobiographies about members of the Revolutionary generation to better understand how they remembered the era they survived - and how they passed those memories to subsequent generations. ${ }^{28}$ Appleby aimed to correct what she saw as a "distortion" in previous scholarship that highlighted the members of one generation while ignoring those younger and older people who were living alongside them. Her argument that this is a methodological mistake is compelling. As she explains, Americans of the early nineteenth century were a diverse group during an era with "deep political divisions, competing religious insights, and profound disagreements about slavery." ${ }^{29}$ While her study provides a new model, there is still much to learn about how the postRevolutionary generations related to each other and to those who came even later.

If interior responses to aging and the passing of time may seem by definition intangible, there can be an artifactual element to these processes. While concerned

\footnotetext{
${ }^{25}$ Kammen, Mystic Chords of Memory, 59.

${ }^{26}$ Kammen, A Season of Youth, 256.

${ }^{27}$ Kammen, A Season of Youth, 51.

${ }^{28}$ Appleby, Inheriting the Revolution, vii-viii.

${ }^{29}$ Appleby, Inheriting the Revolution, 3-4.
} 
primarily with the history of one document - the Declaration of Independence - Pauline Maier commented briefly on Thomas Jefferson's (1743-1826) desk. She asserted that Jefferson himself understood the intrinsic value of his desk for future generations. "The sight of things," Maier explains, "was important because Jefferson and others of his time believed it could arouse in Americans...the deepest feelings and bring their minds "to a condition of moral sensitivity and reflection.",30

More recently, English professor Susan Stabile explored similar ideas in her study of a coterie of well-to-do Philadelphia women, approaching memory as a "lived practice rather than as a reinvented tradition." 31 By undertaking a "new material understanding of women's intellectual work," Stabile demonstrated that women gathered different memories than men, using them to "authenticate" personal experience rather than to "manufacture national memory." 32 Antebellum women focused on the local and the specific, using their homes, gardens and objects to create cultural memory in order to teach the rising generations and to ensure their own lives would be remembered. ${ }^{33}$ Applying Stabile's ideas to decorative antebellum needlework suggests that these textile items were yet another tool that women used to create cultural memory. Chapter 2, which explores "epistolary needlework" - that which has life stories and personal values spelled out across its face - and chapter 4, which examines needlework gifts from aging women to younger relatives, provide several examples, asserting that textiles were chosen as a purposeful medium to accomplish this task.

\footnotetext{
${ }^{30}$ Maier, American Scripture, 187.

${ }^{31}$ Stabile, Memory's Daughters, 16.

${ }^{32}$ Stabile, Memory's Daughters, 8, 16.

${ }^{33}$ Stabile, Memory's Daughters, 4, 71.
} 
While scholars of the history of aging have debated the status and treatment of the elderly for almost thirty years, they have all been forced to define "old age" and this work must do the same, but with a particular focus on the definition of female "old age." There is no consensus about the nineteenth-century definition of "old age." Most scholars suggest that sixty was widely considered to be "old" by people of the early nineteenth century. Indeed, according to David Hackett Fischer's research, in 1850, only $4.3 \%$ of the U.S. population was aged sixty and over and only $1.5 \%$ was aged seventy and over. ${ }^{34}$ However, this determination often differed depending on gender, with women considered to be "old" once they reached menopause. Yet others make the case for sixty-five or seventy as the definition of "old." 35 Writing in 1856, sixty-five-year-old Lydia H. Sigourney (1791-1865) asserted that "only five in one hundred of our race attain the age of seventy." ${ }^{36}$ One of Sigourney's contemporaries explained that few live to "three score

\footnotetext{
${ }^{34}$ Fischer, Growing Old In America, 222.

${ }^{35}$ Several scholars state that there was no hard and fast definition of old age. These include: Achenbaum, Old Age in the New Land, 2; Haber, Beyond Sixty-Five, 8-10; Fischer, Growing Old in America, 27, 56; Cole, The Journey of Life, 49-52, 67; and Chudacoff, How Old Are You?, 13. For those who do define old age, sixty is a popular definition: Premo, Winter Friends, 12; Thane, "Social Histories of Old Age," 97-98; and John Demos, "Old Age in Early New England," in John Demos and Saranne Spence Bocock, eds., Turning Points: Historical and Sociological Essays on the Family (Chicago: The University of Chicago Press, 1978), 249. Some scholars suggest that, for women, old age began with menopause: Janet Roebuck, "Grandma as Revolutionary: Elderly Women and Some Modern Patterns of Social Change," International Journal of Aging and Human Development 17 (1983): 253; and Peter N. Stearns, "Old Women: Some Historical Observations," Journal of Family History 5 (Spring 1980): 45. At least one scholar suggests that the nineteenth-century sources she studied considered people in their forties and fifties to be old, perhaps in light of the widely-held belief that the age of seventy was the upper limit for human old age. See Paula A. Scott, Growing Old in the Early Republic: Spiritual, Social and Economic Issues, 1790-1830 (New York: Garland Publishing, Inc., 1997), 10-11.

${ }^{36}$ Mrs. L.H. Sigourney, Past Meridian (Hartford: F.A. Brown, 1856), 15. Lydia Huntley Sigourney was born in Connecticut in 1791, the daughter of Ezekial Huntley and Zerviah Wentworth. In 1819, Lydia married Charles Sigourney, a bank president and owner of a hardware business. A teacher before she married, Lydia focused on writing after her marriage. The couple had five children, although only two reached adulthood. Lydia Sigourney continued to publish poetry, fiction and prose through the $1850 \mathrm{~s}$. She died in 1865. Biographical information from the North American Women's Letters and Diaries database, http://solomon.nwld.alexanderstreet.com.silk.library.umass.edu:2048/bios/A2462BIO.html, accessed September 11, 2009.
} 
and ten" citing the statistic that 970 out of 1000 died before they reached seventy. ${ }^{37}$

Based on a biblical reference, the age of seventy became a traditional benchmark for the human life span. In the Bible, Psalms 90 reads, "The days of our years are threescore years and ten; and if by reason of strength they be fourscore years, yet is their strength labor and sorrow; for it is soon cut off, and we fly away."38 On her seventieth birthday, Joanna Bethune (1770-1860) wrote in her diary, "According to Scripture, I have lived the years allotted to man, and must now, if I have not before, daily expect to be called to give an account of my stewardship."39

Leaving Bethune aside, steps in the biological cycle - motherhood, widowhood and menopause - defined "old" for most antebellum women. An early 1830s portrait of Esther Belcher Bird (1792-1840) of Foxborough, Massachusetts, resembles countless others from that decade (figure I.4). Bird is seated on one end of a sofa and wears a dark dress with a white embroidered collar and a gray embroidered scarf. As befit a woman of her station at that time - a married woman in her late thirties or early forties and mother to six daughters - Bird wears a white ruffled cap on her head. On the back of the portrait

\footnotetext{
${ }^{37}$ Rev. John Stanford, The Aged Christian's Companion (New York: Stanford \& Swords, 1849), 9-10.

${ }^{38}$ The Holy Bible, King James Version (New York: American Bible Society: 1999; Bartleby.com, 2000), www.bartleby.com/108/, accessed March 12, 2009. During the antebellum era, reaching the age of seventy was often considered the upper limit with anything after that considered unusual. Scott, Growing Old in the Early Republic, 9-10.

${ }^{39}$ George Washington Bethune, comp., Memoirs of Mrs. Joanna Bethune (New York: Harper \& Brothers, 1863), 213. Joanna Graham Bethune was born at Fort Niagara, Canada, in 1770, the daughter of John Graham and Isabella Marshall. Educated in Scotland and the Netherlands, Bethune moved to New York City with her family in 1789, where she taught at her mother's school for young women. In 1795, she married Divie Bethune and the couple had six children. Throughout her life, Joanna and her husband were involved in many charitable and evangelical causes. After her husband's death in 1824, she focused on charitable activities to benefit children. She died in 1860. Anne M. Boylan, "Bethune, Joanna Graham," http://www.anb.org.silk.library.umass.edu:2048/articles/09/09-00861.html, American National Biography Online, February 2000, accessed September 11, 2009.
} 


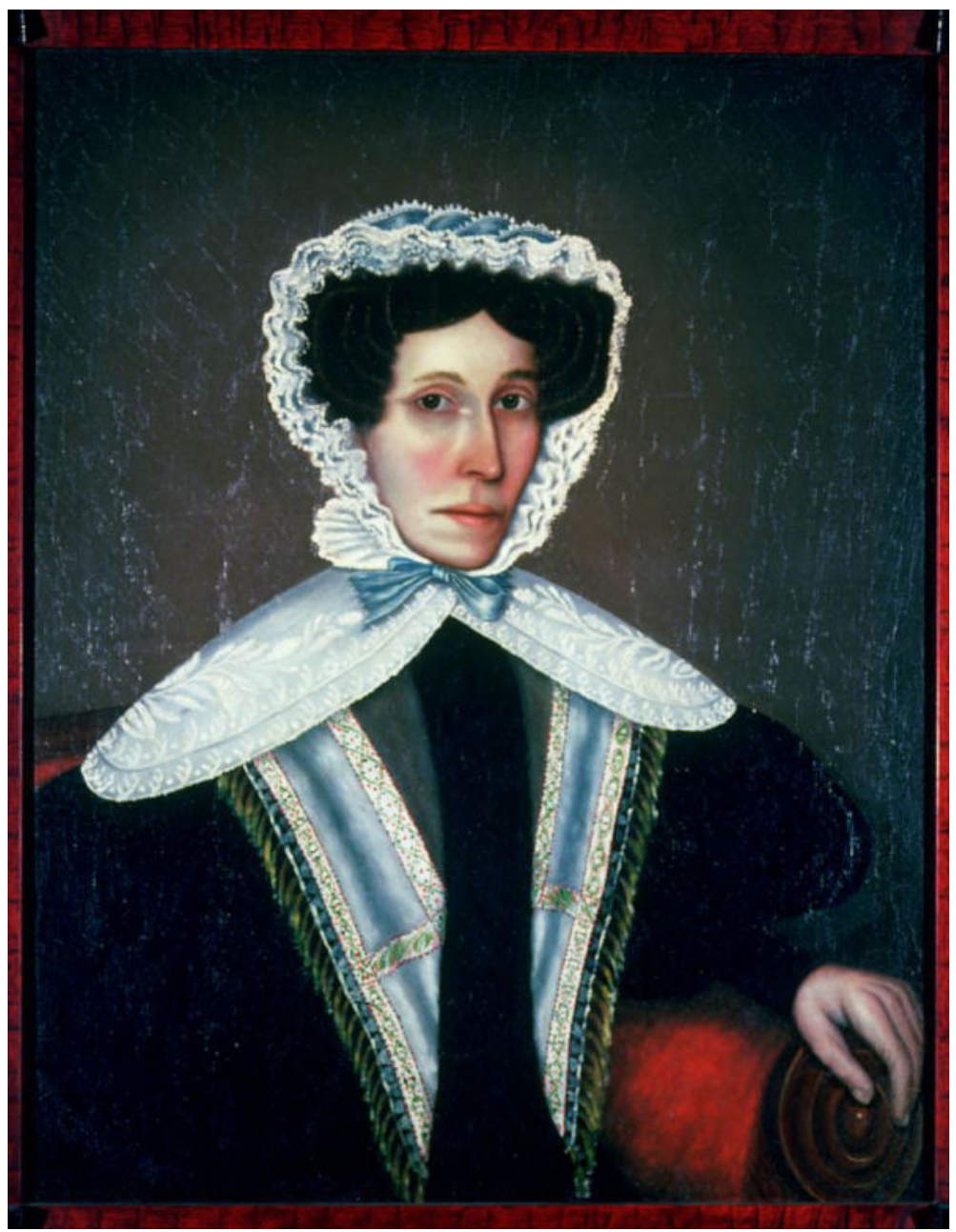

Figure I.4. Esther Belcher Bird (1792-1840) by an unidentified artist, 1835-1845, probably Foxborough, Massachusetts. Courtesy of Old Sturbridge Village, Sturbridge, Massachusetts, 64.1.50, photograph by Henry Peach.

Inscribed on a paper label on the back of this portrait is: "Put on cap when first baby was born 1814 Old woman then." Despite Bird's presumably tongue-in-cheek comment (she was only twenty-two in 1814), most antebellum women associated the aging process with steps in their biological cycle - motherhood, widowhood and menopause. 
is a paper label with a handwritten inscription, "Put on cap when first baby was born 1814 Old woman then. ${ }^{40}$ Bird's caption may have been at least partly tongue-in-cheek (since she was only twenty-two when her first child was born), but she was not the only woman to associate the wearing of her cap with the aging process. Traditionally, women began to wear caps over their hair when they married and became mothers. Women who had not married by the age of thirty or so also began to wear a cap each day. ${ }^{41}$ Indeed, unmarried fifty-year-old Rebecca Dickinson (1738-1813), a generation older than Bird, wrote in a 1788 diary entry that she "felt the pott on her head," probably referring to the conspicuousness of her cap, a signal of maturity at odds with her never-married status. ${ }^{42}$ Entering widowhood was another marker by which antebellum aging women defined growing old, although many widows had not yet reached their forties, as women could be widowed at any age. Becoming a widow was often difficult since women could face uncertain economic status with limited ways to make a living. ${ }^{43}$ Through her study of the letters and diaries of aging women in the early republic, Premo found that "widowhood elicited anger, loneliness, and depression; it was often considered the point at which life began to decline." 44

\footnotetext{
${ }^{40}$ The portrait is now in the collection of Old Sturbridge Village, Sturbridge, Massachusetts. The portrait was painted in the early 1830s by an unidentified artist. In 1813, Esther Belcher married Warren Bird in Foxborough, Massachusetts. The couple had six children together. Caroline Sloat, ed., Meet Your Neighbors: New England Portraits, Painters, \& Society, 1790-1850 (Sturbridge, Massachusetts: Old Sturbridge Village, 1992), 77-78.

${ }^{41}$ Eliza Leslie, The Behaviour Book (Philadelphia: Willis P. Hazard, 1854), 121-122; Michelle Boardman, "Picturing the Past: Studying Clothing Through Portraits" (unpub. research paper, Old Sturbridge Village, Sturbridge, Massachusetts, 1990), 32-36; Lois W. Banner, American Beauty (Chicago: The University of Chicago Press, 1983), 220.

${ }^{42}$ Rebecca Dickinson, diary entry for September 22, 1788, quoted in Marla R. Miller, “"My Part Alone”: The World of Rebecca Dickinson, 1787-1802," New England Quarterly 71 (September 1998): 373.

${ }^{43}$ Lisa Wilson, Life After Death: Widows in Pennsylvania 1750-1850 (Philadelphia: Temple University Press, 1992), 5-6; Premo, Winter Friends, 29-38.

${ }^{44}$ Premo, Winter Friends, 30.
} 
Mid-nineteenth century sources found the most agreement in equating old age in women with their late forties and early fifties, not coincidentally a time also associated with menopause. Sixty-five-year-old Connecticut poet and novelist Lydia Sigourney wrote, in a book about aging, "it must be, doubtless, admitted that the meridian of life is fully passed at fifty. It would be an exceedingly liberal construction to extend to sixty, the dividing line between the ante and the post-meridian people." ${ }^{45}$ She went on to justify her definition of old age, "Those who have completed a half century, if not literally numbered among the aged, have yet reached a period of great gravity and importance...to a future generation they should pay the debt which they have incurred from the past." 46

Whether she realized it or not, Sigourney's words found consensus with many of the medical guides of the era, which linked menopause with the definition of old age for women. Antebellum medical guides show consistent agreement that a woman could expect to enter menopause in her forties and imply that at this time she was entering into the latter part of her life, often calling it the "turn of life." In 1847, Dr. A.M. Mauriceau explained, "The nearer a woman approaches her forty-fifth year... will be the risk of some irregularity in the menses. ${ }^{, 47}$ Most medical experts acknowledged that there was no uniform age for menopause to start, instead indicating a range of ages. As Dr. Frederick

\footnotetext{
${ }^{45}$ Sigourney, Past Meridian, 10.

${ }^{46}$ Sigourney, Past Meridian, 15.

${ }^{47}$ Dr. A.M. Mauriceau, The Married Woman's Private Medical Companion (New York, 1847), 28. Other sources that identify the early forties as the time to expect the onset of menopause include: Samuel Bard, M.D., A Compendium of the Theory and Practice of Midwifery (New York: Collins and Company, 1819), 78-79; Frederick Hollick, M.D., The Diseases of Woman (New York: T.W. Strong, 1849), 234; Frederick Hollick, The Marriage Guide, or Natural History of Generation (New York: T.W. Strong, circa 1860), 103; Albert Isaiah Coffin, A Treatise on Midwifery (London: W.B. Ford, 1849), 22; Charles Morrill, The Physiology of Woman (Boston: Bela Marsh, 1848), 125; A.G. Hall, The Mother's Own Book and Practical Guide to Health (Rochester, New York, 1843), 143-144; H.B. Skinner, The Female Medical Guide and Married Woman's Advisor (Boston: Skinner's Publication Rooms, 1849), 63-64.
} 
Hollick noted, "The usual age when this change commences is from forty to forty-five. It is sometimes, however, protracted to fifty, and even sixty, and in this country it not unfrequently takes place as early as thirty-five or thirty!"48 However, the cause of this wide age range for menopause confounded most of the authors. A.I. Coffin suggested that climate had an effect, writing, "In warmer climates, menstruation generally commences much earlier, and ends sooner." ${ }^{49}$ Another expert hedged his bets explaining that age at menopause depended "much on the constitution and habits of the individual." ${ }^{, 50}$ In light of the antebellum evidence cited here, this study includes examples of needlework that can be documented to have been made by women who were aged forty or older. Generally, by their early forties, women had completed their childbearing years and were well past school age - suggesting that they were motivated to make their quilts, samplers and other decorative needlework for personal reasons and by their own choice, rather than out of necessity or at the behest of an authority figure.

\section{Women's History}

In the roughly thirty years that women's history has been a flourishing field, its main narrative has swirled around the concept of "separate spheres" for men and women. In 1966, Barbara Welter coined the phrase "the cult of true womanhood" and articulated the ideology of separate spheres prevailing in antebellum America, by which women were understood to live in the domestic or private sphere while men inhabited the public

\footnotetext{
${ }^{48}$ Hollick, The Diseases of Women, 235.

${ }^{49}$ Coffin, A Treatise on Midwifery, 11.

${ }^{50}$ Morrill, The Physiology of Woman, 125.
} 
sphere. ${ }^{51}$ Gerda Lerner's groundbreaking 1969 essay "The Lady and the Mill Girl” identified ideological shifts that "occurred in American society concerning the "proper" role of women." She found that "as class distinctions sharpened, social attitudes toward women became polarized. The image of "the lady" was elevated to the accepted ideal of femininity toward which all women would strive." ${ }^{, 52}$ Ever since, women's historians have debated whether women were "better off" during the colonial period in the seventeenth and early-eighteenth centuries, or whether the American Revolution afforded American women new opportunities (particularly in education). Denied the right to vote or to play an active role in their government after Independence, white middle- and upper-class women were told that their job was far more glorious - as "Republican mothers" they would raise virtuous sons and serve as the moral compass for their households. ${ }^{53}$ Their skill with the needle was one important way for them to display the value they brought to their home.

In the 1970s, embracing the concept of "separate spheres," Nancy Cott examined the "bonds of womanhood" in the major areas of New England women's daily lives. As she points out, "bond" has a double meaning, signifying both constraint and affective ties. Cott found that the 1830s were a turning point and that social and economic changes sharpened distinctions between young, unmarried women and matrons. As Lerner and Welter suggested, "home" became synonymous with "retirement" or "retreat" from the world at large. However, Cott found that "religious identity allowed women to assert

\footnotetext{
${ }^{51}$ Barbara Welter, Dimity Convictions: The American Woman in the Nineteenth Century (Athens: Ohio University Press, 1976), 21-41.

${ }^{52}$ Gerda Lerner, "The Lady and the Mill Girl: Changes in the Status of Women in the Age of Jackson," MidContinent American Studies Journal 10 (1969): 5, 11.

${ }^{53}$ Linda K. Kerber, Women of the Republic: Intellect and Ideology in Revolutionary America (Chapel Hill: University of North Carolina Press, 1987), 11-12; Mary Beth Norton, Liberty's Daughters: The Revolutionary Experience of American Women, 1750-1800 (Boston: Little, Brown and Company, 1980), 245-255.
} 
themselves," providing support and showing them sources of authority beyond the world of men. Cott presented examples of women who were able to subvert the dominant cultural precepts of women as moral and nurturing to achieve their own ends. Religious activity offered women one means toward having a voice. ${ }^{54}$ Indeed, many samplers include verses and phrases adapted from the Bible and other prescriptive literature. By extending these ideas, we can see that through the use of socially-acceptable needlework, women gained agency to express opinions, explore creativity, and serve as a model for younger generations.

As social history methodologies became popular, they combined with women's history to focus attention on the lives of everyday women. ${ }^{55}$ But the "everyday women" of these studies represent only a small percentage of the women who lived during the early- and mid-nineteenth century. Historians of antebellum women often focused on the most self-aware eighteenth- and nineteenth-century white, middle-class women who manipulated the changing relationship of gender roles to their advantage during the Revolutionary and early Republic eras. ${ }^{56}$ These were women with the time, money and training to write letters and diaries that were valued enough by subsequent generations to be passed down and donated to libraries and archives.

\footnotetext{
${ }^{54}$ Nancy F. Cott, The Bonds of Womanhood: “Woman's Sphere” in New England, 1780-1835 (New Haven: Yale University Press, 1977), 57, 138, 140.

${ }^{55}$ For example, see: Laurel Thatcher Ulrich, Good Wives: Image and Reality in the Lives of Women in Northern New England 1650-1750 (New York: Alfred A. Knopf, 1987); Suzanne Lebsock, The Free Women of Petersburg: Status and Culture in a Southern Town, 1784-1860 (New York: W.W. Norton and Company, 1985); and Joan M. Jensen, Loosening the Bonds: Mid-Atlantic Farm Women, 1750-1850 (New Haven: Yale University Press, 1988).

${ }^{56}$ For a detailed examination of women's lives in America before and after the Revolution, see: Carol Berkin, First Generations: Women in Colonial America (New York: Hill and Wang, 1996); Ruth H. Bloch, "American Feminine Ideals in Transition: The Rise of the Moral Mother, 1785-1815," Feminist Studies 4 (June 1978): 100-126; Kerber, Women of the Republic; Norton, Liberty's Daughters; Ulrich, Good Wives; Sandra F. VanBurkleo, Belonging to the World: Women's Rights and American Constitutional Culture (New York: Oxford University Press, 2001).
} 
More recently, social history methodology for the study of women evolved into what is now known as microhistory - studying a tightly defined place, event or record for one person or a group of people and relentlessly unpacking every possible detail and path of inquiry. The mother of this methodology may well be Laurel Thatcher Ulrich who used this technique to great effect in her award-winning book from 1990, A Midwife's Tale: The Life of Martha Ballard, Based on Her Diary, 1785-1812. ${ }^{57}$ And, Marla R. Miller's 2006 study of the needle trades in the Connecticut River Valley between 1760 and 1810 employs a similar methodology in order to advance the understanding of women's work, as well as how they kept track of it. Miller explains that "women may not have kept account books recording the exchange of goods, cash, or services, but their diary narratives recording the arrivals and departures of friends, family, and strangers are account books of another sort, in which reciprocal obligations were tracked and remembered." ${ }^{58}$ Using this methodology to study the women who left behind only a sampler or a quilt offers an important counterpoint to those who wrote about their lives using pen and paper. Using objects as sources pushes past the women's histories discussed here, suggesting new perspectives and understandings about the lives of antebellum women. ${ }^{59}$

\footnotetext{
${ }^{57}$ Laurel Thatcher Ulrich, A Midwife's Tale: The Life of Martha Ballard, Based on Her Diary, 1785-1812 (New York: Alfred A. Knopf, 1990).

${ }^{58}$ Marla R. Miller, The Needle's Eye: Women and Work in the Age of Revolution (Amherst: University of Massachusetts Press, 2006), 108.

59 Material culture scholar Kenneth Ames has urged scholars to "study objects because objects open minds." Ames, Death in the Dining Room, 241. Material culture studies have abounded over the past thirty years, using non-traditional sources to expand our understanding of history. For example, see Ames, Death in the Dining Room; Katherine C. Grier, Culture and Comfort: People, Parlors, and Upholstery 1850-1930 (Rochester, NY: The Strong Museum, 1988); James Deetz, In Small Things Forgotten: The Archaeology of Early American Life (New York: Doubleday, 1977); Henry Glassie, Material Culture (Bloomington: Indiana University Press, 1999); and more recently, D. Brenton Simons and Peter Benes, eds., The Art of Family: Genealogical Artifacts in New England (Boston: New England Historic Genealogical Society, 2002) and Margaretta L. Lovell, Art in a Season of Revolution: Painters, Artisans,
} 
Recent scholarship on women's history has qualified, if not altogether dismantled, the "separate spheres" trope. In 2003, Nancy Cott offered an assessment of the state of the field that questioned the efficacy of the separate spheres model based on the work of those who had followed her lead. ${ }^{60}$ Attention had shifted to the history of American labor - inside and outside the home - and then to the economics of housework. For example, Jeanne Boydston studied women's working lives, in part to trace how women's housework became devalued. As she explained, "Clarifying both the nature of the changes that had occurred and the origins of the paradoxical status of housework in the antebellum period seemed to me essential to understanding the intimate relationship between the gender and labor systems that characterized industrializing America." ${ }^{\prime 61}$

Focusing on labor and economics during the early republic as they related to women's lives prompted Boydston to assert that "with the departure of any general social acknowledgement of her material value to the family had gone the traditional basis of a wife's claim to some voice in the distribution of economic resources and to social status as a "productive" member of society." ${ }^{2}$ Yet, it was not just industrialization that caused this change; instead, it was part of larger social patterns. In her book, Home and Work, Boydston added population growth, land speculation, and the increase of money in

and Patrons in Early America (Philadelphia: University of Pennsylvania Press, 2005), to name just a few examples.

${ }^{60}$ See the recent article on the "state of the field": Nancy Cott, et al, "Considering the State of US Women's History," Journal of Women's History 15 (2003): 145-163. Examples of scholars who have called into question the "separate spheres" analysis include: Linda K. Kerber, "Separate Spheres, Female Worlds, Woman's Place: The Rhetoric of Women's History," Journal of American History 75 (1988): 9-39; Mary P. Ryan, The Cradle of the Middle-Class: The Family in Oneida County, New York, 1780-1865 (Cambridge: Cambridge University Press, 1978); and Mary Kelley, Learning to Stand \& Speak: Women, Education, and Public Life in America's Republic (Chapel Hill: University of North Carolina Press, 2006). ${ }^{61}$ Jeanne Boydston, Home and Work: Housework, Wages, and the Ideology of Labor in the Early Republic (New York: Oxford University Press, 1990), xii.

${ }^{62}$ Boydston, Home and Work, xi. Boydston built on the work of Ruth Schwartz Cowan who suggested that technological "improvements" both pushed women further into the home and added to their workload, rather than decreasing it. See Ruth Schwartz Cowan, More Work for Mother: The Ironies of Household Technology from the Open Hearth to the Microwave (New York: Basic Books, 1983). 
market relations as factors that "[dissociated] wives and wives' work from the symbols of economic value." ${ }^{63}$ She pointed out that far from inhabiting a sphere of retreat and reflection, antebellum women worked hard in the home, contributing to the survival and prosperity of their families. But the gradual gendering of housework as "women's work" in the antebellum era, combined with a societal switch to a cash economy, devalued the unpaid work women performed in the home, which, by extension, also devalued the products of women's efforts.

While Boydston's analysis aptly applies to the production of functional household textiles, like bedding, towels and clothing, an exploration of the decorative needlework of middle-class antebellum women offers new avenues of inquiry. Several of the examples in these pages will show that many women were able to turn society's definition of needlework as "women's work" to their own advantage. Through display at local agricultural fairs, use in the home, and gifts to family and friends, decorative quilts and samplers ostensibly kept female fingers busy while offering an outlet for creativity, lessons and values, and, sometimes, political views. As they aged, American women from all geographical regions and social classes continued to stitch, using the materials they had on hand. Their work helps to suggest that even if "women's work" was devalued by certain segments of antebellum American society, it did not mean that it was universally devalued. Many women maintained their own work and the exchanges of knowledge, support, and sometimes money, which accompanied it.

Where Boydston studied women's labor and economics, Martha Saxton's recent book, Being Good, examined the moral values that pushed women into the home as cherished models of good behavior. Rather than explaining why men created this role for

\footnotetext{
${ }^{63}$ Boydston, Home and Work, 3, 24.
} 
women or demonstrating how a few well-known women fought the characterization, she asked "how did early American women think about trying to lead a good life?"64 To answer this question, she looked at how "everyday women" struggled with the moral code they were supposed to exemplify.

Saxton, like Boydston, did not challenge gender spheres analysis but instead built on some of the scholarship that did. For example, Mary P. Ryan, who challenged the separate spheres trope, found that men and women worked together for familial, economic and community goals. ${ }^{65}$ She also asserted that antebellum women were active in the public sphere in four ways: they were "conscripted into a code of public conduct which prescribed that they present themselves as "ladies" outside the home"; they occupied public space; they were the subjects of public policy; and they were "central actors in public discourse about the most consequential issues."66

Indeed, analysis of the rise of antebellum women's activism, such as that by Anne Boylan, Deborah Van Broekhoven and Debra Gold Hansen, who traced women's reform and anti-slavery groups in New York, Rhode Island and Boston, respectively, shows that women did act politically in the antebellum era, and to great effect. ${ }^{67}$ More recently,

\footnotetext{
${ }^{64}$ Martha Saxton, Being Good: Women's Moral Values in Early America (New York: Hill and Wang, 2003), 3.

${ }^{65}$ Ryan, The Cradle of the Middle-Class, 238-239.

${ }^{66}$ Mary P. Ryan, Women in Public: Between Banners and Ballots 1825-1880 (Baltimore: The Johns Hopkins University Press, 1990), 3.

${ }^{67}$ Anne M. Boylan, The Origin of Women's Activism: New York and Boston, 1797-1840 (Chapel Hill: The University of North Carolina Press, 2002); Deborah Bingham Van Broekhoven, The Devotion of These Women: Rhode Island in the Antislavery Network (Amherst: University of Massachusetts Press, 2002); Debra Gold Hansen, Strained Sisterhood: Gender and Class in the Boston Female Anti-Slavery Society (Amherst: University of Massachusetts Press, 1993). Each of these scholars also devotes attention to the fundraising fairs that antebellum women organized. Needlework was often sold at these fairs to raise money for the cause. While some examples of this needlework are extant today, none was found that fit the criteria of the study herein - often the maker could not be identified, or she was not age forty or over. For more on the fairs and their merchandise, see Boylan, The Origin of Women's Activism, 182-186; Van Broekhoven, The Devotion of These Women, 173-197; and Hansen, Strained Sisterhood, 124-139. In
} 
Mary Kelley explored the idea of "civil society," suggesting that the rise in female attendance at academies and seminaries during the antebellum era helped women learn to speak out in their society and to effect many of the social and political changes that mark these decades. ${ }^{68}$

Scholarly debate over the status and experience of antebellum women continues as studies of women's civic activism and of eighteenth- and nineteenth-century businesswomen have helped to show that, at no time, did all women follow the same path, or even choose from two paths. ${ }^{69}$ These scholars chafed against the binary formulation of the separate spheres trope - private vs. public, home vs. work, men vs. women - instead showing that many women lived both a private and a public life. In a 2008 article, Jeanne Boydston reflected on how women's history evolved into the study of gender history, in part as a reaction against binary systems of understanding. She called for new conceptual approaches to gender history that "interrogates it anew as a set of relatively open questions applied to a discrete time and place of inquiry." ${ }^{, 0}$ The same is needed for the study of age and women. Despite the enormous number of pages written about the lives of antebellum women, little attention has been paid to the experiences of their twilight years. Instead, the bulk of these works, explicitly and implicitly, focus on women in their thriving years. What gets lost in standard

\footnotetext{
addition, see Julie Roy Jeffrey, The Great Silent Army of Abolitionism: Ordinary Women in the Antislavery Movement (Chapel Hill: The University of North Carolina Press, 1998), 108-126.

${ }^{68}$ Kelley, Learning to Stand \& Speak, 5-15.

${ }^{69}$ For example, see Nancy A. Hewitt, Women's Activism and Social Change: Rochester, New York $1822-$ 1872 (Ithaca: Cornell University Press, 1984); Jeffrey, The Great Silent Army of Abolitionism; Kelley, Learning to Stand and Speak; Ellen Hartigan-O'Connor, “Abigail's Accounts: Economy and Affection in the Early Republic," Journal of Women's History 17 (Fall 2005): 37-58; and Lisa Norling, Captain Ahab Had a Wife: New England Women and the Whalefishery, 1720-1870 (Chapel Hill: University of North Carolina Press, 2000).

70 Jeanne Boydston, "Gender as a Question of Historical Analysis," Gender and History 20 (November 2008): 559.
} 
periodizations - and in all of the major works of women's history described here - is how women who had already reached maturity responded when the changes of the early republic and industrial revolution began to unfold.

Scholarly attention to the inner lives of antebellum women has slowly gained ground, offering a counterpoint to the studies of women's public lives and civic activism. In her study of the women of nineteenth-century St. Louis, Missouri, Martha Saxton examined the intellectual life of her subjects, exploring their moral struggles as well as their understanding of who they were supposed to be. She found that "two emotional and moral modes" developed with the growth of a middle class: "sentimental individualism," which "embraced the right of white Americans to pursue their destinies and companions"; and "relatedness," by which "women define their own moral worth on the basis of their ability to care for and respond to the needs of others." ${ }^{.71}$ Saxton demonstrated how women's historians can use their subjects' own words to touch the most ephemeral "artifact" - human feelings - and by doing this, better understand the lives of women of the past.

Saxton relied on traditional documentary sources where women recorded their feelings, such as letters and diaries. As she explained, she was able to do this because "feelings achieved new validity in moral and family life in the nineteenth century," due in part to the growing emphasis on emotion in religious life and the Revolutionary War-era insistence on the pursuit of one's own happiness. ${ }^{72}$ Yet she did have the material life of women in the back of her mind, acknowledging that "just as material objects sometimes substituted for emotions, so emotions sometimes became objects in middle-class life." In

\footnotetext{
${ }^{71}$ Saxton, Being Good, 181-182.

${ }^{72}$ Saxton, Being Good, 13.
} 
other words, emotions could be "shared and considered" between intimates or within one's own mind. ${ }^{73}$

Where Saxton studied the women of nineteenth-century St. Louis, Catherine E. Kelly focused on the women of early nineteenth-century rural New England, advancing the study of the "great transformation" that took place in that region. While previous studies identified the elements of the transformation - including industrialization, urbanization, and the rise of rural capitalism - Kelly examined how those changes affected everyday women. ${ }^{74}$ Part of the response to these changes was the rise of a provincial middle class that used artifacts, in part, to identify, establish and demonstrate their new position. Kelly adroitly showed how women's words and actions can be used to understand their motives and reactions to larger cultural changes. ${ }^{75}$ Seeing a cultural and intellectual process in the transformation of New England, where previous scholars focused on the economic and social, Kelly examined published stories and narratives from the period that allowed women (and men) to navigate their changing society, and, ultimately, to shape a "distinctive, rural middle class." In doing so, she pointed out how the past guided the present. ${ }^{76}$ Indeed, many of the quilts and samplers discussed here served as physical talismans during that process. Made by one generation, they were used to educate and remind a younger one of what came before, while allowing the older makers to express their nostalgia for an earlier time.

\footnotetext{
${ }^{73}$ Saxton, Being Good, 295.

${ }^{74}$ Catherine E. Kelly, In the New England Fashion: Reshaping Women's Lives in the Nineteenth Century (Ithaca: Cornell University Press, 1999). Previous studies of this transformation include: Christopher Clark, The Roots of Rural Capitalism: Western Massachusetts, 1780-1860 (Ithaca: Cornell University Press, 1994); Nathan O. Hatch, The Democratization of American Christianity (New Haven: Yale University Press, 1989); Jonathan Prude, The Coming of Industrial Order: Town and Factory Life in Rural Massachusetts 1810-1860 (Cambridge: Cambridge University Press, 1983); and Charles Sellers, The Market Revolution: Jacksonian America, 1815-1846 (New York: Oxford University Press, 1991).

${ }^{75}$ Kelly, In the New England Fashion, 248, 250.

${ }^{76}$ Kelly, In the New England Fashion, 7-8, 16, 251.
} 
Decorative needlework and fancywork, previously the purview of a limited group of Americans who achieved a certain economic standing, were quickly adopted by the new provincial middle class as markers of the genteel style of life in the early nineteenth century. ${ }^{77}$ In her examination of New England agricultural fairs, Kelly found that by giving physical form to the abstract values of leisure, cultivation and ornament, antebellum fancywork extended the democratization of refinement that had begun a century earlier...fancywork was...emblematic of bourgeois culture in its individual expressiveness, for the production of explicitly decorative objects allowed for a play of imagination not afforded by the simple sewing that absorbed so much of women's time. ${ }^{78}$

Making decorative needlework, like a sampler or a quilt, allowed women a chance to express themselves while also demonstrating an understanding of social codes and a measure of social status. In addition, women "imbued their needlework with special significance," Kelly wrote, noting that sewing "rivaled nursing and child care in its power to evoke women's love for their kin."79

Scholarship on the generations that came of age following the Revolution has pointed out that some of those young women despaired of ever living up to the example set by their mothers and grandmothers. ${ }^{80}$ But the scholarship on women who believed that they were doing their duty by becoming a "Republican mother" rarely extends into the later years of these women's lives. The pages that follow focus on how mature

\footnotetext{
${ }^{77}$ Nancy Dunlap Bercaw, "Solid Objects/Mutable Meanings: Fancywork and the Construction of Bourgeois Culture, 1840-1880," Winterthur Portfolio 26 (1991): 231-248; Beverly Gordon, "Victorian Fancywork in the American Home: Fantasy and Accommodation," in Making the American Home: MiddleClass Women and Domestic Material Culture 1840-1940 eds. Marilyn Ferris Motz and Pat Browne (Bowling Green, Ohio: Bowling Green State University Popular Press, 1988), 48-68; Amy Boyce Osaki, "A “Truly Feminine Employment": Sewing and the Early Nineteenth-Century Woman," Winterthur Portfolio 23 (Winter 1988): 225-241.

${ }^{78}$ Catherine E. Kelly, “'The Consummation of Rural Prosperity and Happiness': New England Agricultural Fairs and the Construction of Class and Gender, 1810-1860," American Quarterly 49 (September 1997): 589.

${ }^{79}$ Kelly, In the New England Fashion, 50.

80 See Norton, Liberty's Daughters, 193-194; Premo, Winter Friends, 58-60; Travers, Celebrating the Fourth, 206, 216-217; Appleby, Inheriting the Revolution, 2-6, 123; Kammen, A Season of Youth, 31, 194195; and Young, The Shoemaker and the Tea Party, 133-134.
} 
women experienced the onset of industrialization and the changes to social relations that accompanied the new economy and expressed that experience with their needles.

\section{The story of samplers (and other needlework)}

Material culture offers an invaluable method for studying the history of women. The techniques of this field focus on the objects of the past that persist in the present and are often the only way to study the lives of those who left no written words. Utilizing a material culture approach to study these artifacts offers an opportunity to see the women of the past in a new way. The things that they made are loaded with the values they espoused. Kenneth Ames asserts that "people rely heavily on goods to know and define themselves and others, to structure and give meaning to life, to make and find meaning in the world around them, and to express and advocate systems and patterns of belief." ${ }^{\prime \prime}$ In turn, the objects offer a key to unlocking these meanings and values.

Numerous scholars have commented on how difficult it is to find "traditional" documentary sources written by and about women in the eighteenth and nineteenth centuries. The material record left behind, however, offers a vast collection of source material. Women's historians have barely scratched the surface on this treasure trove: there are thousands of samplers, quilts and other forms of decorative needlework in American museum collections, often undercataloged and understudied. In part, there is a "fear factor" about studying artifacts among historians trained in traditional graduate programs. Yet, just because artifacts do not consist of words written in pen and ink does not mean that they cannot be "read." For example, samplers offer a fairly smooth transition; many, like Amy Fiske's, have letters stitched into words and sentences across

\footnotetext{
${ }^{81}$ Ames, Death in the Dining Room, 233.
} 
their face to identify their makers and, occasionally, to tell a life story. By digging a bit deeper into the materials, the style and the modifications made to these artifacts, they offer layers of evidence for the historian to sift through, propelling the scholarship forward and adding new information to what we already think we know.

The study of artifacts uncovers women who are often invisible in traditional types of sources. It broadens the available evidence for women's history by alerting the scholar to new topics and questions (as well as to the answers for those questions) and fills in context. Laurel Thatcher Ulrich described the benefits of material evidence with eloquence: "Understanding the ubiquity of women [from the wealth of artifacts they left behind], historians can begin to frame more sophisticated inquiries, taking surviving documents less literally, teasing out of the cracks and margins of their sources a more balanced picture of American life." ${ }^{82}$ For example, through her study of a chest originally owned by a woman named Hannah Barnard (1684-1716), Ulrich was able to assert that women did have some ownership rights during the eighteenth and nineteenth centuries. She also suggested that women had the agency to distribute the goods they owned to their daughters and granddaughters, helping them to attain a sense of individualism. $^{83}$

Ulrich has explained that "needlework was simultaneously a site of cultural production and a field for personal expression." ${ }^{, 84}$ Women - at least those of a certain class position - were limited by their society in terms of how they could make their personal feelings known. Needlework filled a void, acting in several different ways.

\footnotetext{
${ }^{82}$ Ulrich, "Of Pens and Needles," 202.

${ }^{83}$ Laurel Thatcher Ulrich, "Furniture as Social History: Gender, Property, and Memory in the Decorative Arts," in American Furniture, ed. Luke Beckerdite (Milwaukee: Chipstone Foundation, 1995), 55-58.

${ }^{84}$ Laurel Thatcher Ulrich, The Age of Homespun: Objects and Stories in the Creation of an American Myth (New York: Alfred A. Knopf, 2001), 40.
} 
Stitching a sampler, quilt or other piece of needlework made something tangible demonstrating a woman's hard work, skill and pride. At the same time, needlework was considered an appropriate way for white, middle-class women to spend their leisure time. Amy Fiske, and the other women examined here, stitched their stories into their samplers and quilts because they were women and women stitched - it offered a comfortable way for many to leave their stories behind.

In 1997, folklorist Michael Owen Jones extended material culture methodology through the idea of "material behavior." Coming out of the study of folklore, "material behavior includes not only objects that people construct but also the processes by which their artificers conceptualize them, fashion them, and use them or make them available for others to utilize." ${ }^{85}$ The idea of material behavior suggests that objects can be mined not only for tangible evidence related to their construction and use, but also for personality, psychological states and processes, social interaction, and the ideas and meanings that people associate with objects. ${ }^{86}$ Employing this methodology offers promise for this study, since age - with its processes, ideas and meanings - is the determining factor for the objects discussed. These are not just samplers and quilts that were fashioned by women's hands; they were made by aging women with "cognitive, sensory, communicative, and interactional processes occurring within unique circumstances having their own dynamic," and, ultimately, affecting the artifacts produced. ${ }^{87}$

\footnotetext{
${ }^{85}$ Michael Owen Jones, "How Can We Apply Event Analysis to "Material Behavior," and Why Should We?," Western Folklore 56 (Summer/Fall 1997): 202.

${ }^{86}$ Jones, "How Can We Apply Event Analysis," 202-203.

${ }^{87}$ Jones, "How Can We Apply Event Analysis," 208-209.
} 
While needlework is only beginning to take its place among sources of historical insight in academic studies, this is not to say that few studies exist. To the contrary: the attention paid by collectors, curators and scholars to samplers, quilts and other needlework produced in America between 1700 and 1900 is immense. These artifacts have attracted significant scholarly and connoisseur attention in and of themselves, and as sources of information on the lives of women and girls as well as on female education. Samplers and needlework pictures are pictured in numerous works about eighteenth- and nineteenth-century women's history to convey the daily work of women during these centuries. They are also occasionally used as evidence of the growing gentility of the middle-class. ${ }^{88}$ But, few works have considered samplers and quilts and other types of needlework together. In general, most books and catalogs focus on one type of needlework, without examining how these different artifacts relate to one another.

American samplers have been heavily collected and exhibited in recent decades. Overwhelmingly, samplers are studied as a group, comparing one to the next in order to identify teachers and schools. This methodology follows from the museum curator's pursuit of connoisseurship - the study of the object itself to discover how it was made and to assist in dating and assessing similar artifacts. While the connoisseurship model has allowed curators and scholars to link certain groups of samplers geographically, few have moved beyond this process of identification to analyze how the samplers were used by the women who made them, how they were understood at the time they were made,

\footnotetext{
${ }^{88}$ Richard L. Bushman, The Refinement of America: Persons, Houses, Cities (New York: Vintage Books, 1992), 299-302; Kerber, Women of the Republic, 186-187, 251, 266-267; Norton, Liberty's Daughters, 286-287; Jennifer Van Horn, "Samplers, Gentility, and the Middling Sort," Winterthur Portfolio 40 (Winter 2006): 219-247; and Ulrich, The Age of Homespun, 116-118, 404.
} 
and as they were passed down in the family. In short, there are few studies approaching samplers as sources of larger historical insight.

Almost all work on samplers has focused on "schoolgirl art" - samplers and needlework pictures made by girls of school age (generally sixteen and younger), which were often the product of a specialized private academy or lessons from a local teacher. These books often begin by acknowledging the earliest known extant American sampler, made by Loara Standish (d. 1656) in Plymouth, Massachusetts, around 1640, and then tracing its English roots. ${ }^{89}$ The Standish sampler is a band sampler that followed the prevailing English form and aesthetic - long and thin with horizontal rows, or bands, of stitching, showing off particular motifs or stitches. Gradually over the seventeenth and eighteenth centuries, American samplers took a squarer shape and employed naturalistic motifs of flowers and animals. The use of a verse became more common and the composition became more pictorial. American samplers reached their peak in terms of both quality and quantity during the first quarter of the nineteenth century. ${ }^{90}$

Contemporary diary accounts and memoirs suggest that many nineteenth-century girls looked forward to their needlework training. When reflecting on her early education, Sarah Anna Emery (1787-1879) of Newburyport, Massachusetts, used language reminiscent of religious worship or conversion to convey her excitement at learning to stitch: "Miss Emerson was a most accomplished needlewoman, inducting her pupils into the mysteries of ornamental marking and embroidery. This fancy work

\footnotetext{
${ }^{89}$ The exact date of Loara Standish's sampler is unknown, but she certainly made it before her death in 1656. It is owned by Pilgrim Hall Museum, Plymouth, Massachusetts. See Eileen Bennett, The Evolution of Samplers - Embroidery and Sampler Time Line - A 400 Year History of Sampler Making (privately printed, 2001), 14, which dates the Standish sampler to circa 1635-1641; and Mary Jaene Edmonds, Samplers and Samplermakers: An American Schoolgirl Art 1700-1850 (London: Rizzoli, 1991), 16, and Krueger, New England Samplers to 1840, 12, who simply date it prior to 1656.

${ }^{90}$ Krueger, New England Samplers to 1840, 13; Edmonds, Samplers and Samplermakers, 18; Swan, Plain and Fancy, 55.
} 
opened a new world of delight. I became perfectly entranced over a sampler that was much admired..." M1 Miss Emerson's "accomplished" needlework skills made her a role model for young Sarah. With words like "mysteries," "delight" and "entranced," Sarah was clearly being drawn into the cult of true womanhood. She was learning skills to set herself apart from a certain class of women in her community and starting along the path to wifehood and motherhood.

But, starting in the late $1820 \mathrm{~s}$, samplermaking began to decline. ${ }^{92}$ By the $1840 \mathrm{~s}$ and 1850s, beginning in New England, educational opportunities widened for girls, with needlework dropping out of curricula across the United States. At Mount Holyoke Female Seminary in the late 1830s, Mary Lyon (1797-1849) established a house-keeping department but "labored to show her friends that she did not design a manual-labor school in any sense, nor a school where young ladies would be taught domestic duties...."93 Catharine Beecher (1800-1878) had even more extreme views about female education. She insisted that "young women should not be educated to be genteel ornaments...the purpose of a young woman's education was to enable her to translate her knowledge into action." 94 The practical reason for stitching a sampler - to learn how to mark one's household linens - ceased to be quite so important at this time as indelible inks came into common use. ${ }^{95}$ Other innovations also simplified needlework. By the

\footnotetext{
${ }^{91}$ Sarah Anna Emery, Reminiscences of a Nonagenarian (Newburyport: William H. Huse and Company, 1879), 21.

${ }^{92}$ Swan, Plain and Fancy, 170. See also Krueger, New England Samplers, 19, where she describes a decline in skill and quality in early-nineteenth century samplers. She notes the increasing popularity of the simple cross-stitch and a decrease in embellishments, types of materials and challenging stitches used.

${ }^{93}$ Fidelia Fisk, Recollections of Mary Lyon (Boston: American Tract Society, 1866), 108.

${ }^{94}$ Kathryn Kish Sklar, Catharine Beecher: A Study in American Domesticity (New York: W.W. Norton and Company, 1976), 76.

${ }^{95}$ Barbara Brackman, Clues in the Calico: A Guide to Identifying and Dating Antique Quilts (McLean, VA: EPM Publications, Inc., 1989), 118. See chapter 3 for an exploration of the use of indelible ink on antebellum quilts.
} 
time Amy Fiske stitched her sampler in 1852, for instance, her sampler fabric was woven with a colored thread at regular intervals to assist with counting the stitches, suggesting recognition of the decline in the needlework skill of American girls.

The existing body of curatorial scholarship argues that samplers served two purposes: to educate young women and to offer evidence of their parents' gentility. Major works, like Betty Ring's seminal book Girlhood Embroidery, offer an excellent group of samplers to study and compare, yet they stop short of analyzing the samplers as cultural artifacts. ${ }^{96}$ How do the samplers reflect the lives that their makers lived?

Examining their materials, verses, forms, and motifs can tell us about the reading habits, religious beliefs, educational and commercial networks of their makers. For this reason, these samplers are a valuable source of insight. How did the meaning of needlework change, on personal and societal levels, as antebellum women aged?

Despite the significant amount of text written about American samplers, there has been little interest in samplers that do not fit the schoolgirl pattern. A survey of the major books and catalogs (some thirty works) reveals three understandings of samplers made by older women. The majority - twenty-one out of thirty books - either state directly that older women did not make samplers, or do not address the possibility at all. ${ }^{97}$ This is not

\footnotetext{
${ }^{96}$ Betty Ring, Girlhood Embroidery: American Samplers and Pictorial Needlework 1650-1850 (New York: Alfred A. Knopf, 1993).

${ }^{97}$ The books in this group are: Mary M. Davidson, Plimoth Colony Samplers (Marion, MA: The Channings, 1975); Edmonds, Samplers and Samplermakers, 12; Olive Blair Graffam, "Youth Is the Time for Progress": The Importance of American Schoolgirl Art 1780-1860 (Washington, DC: The DAR Museum, 1998); Georgiana Brown Harbeson, American Needlework (New York: Bonanza Books, 1938); Jan Hiester and Kathleen Staples, This Have I Done: Samplers and Embroideries from Charleston and the Lowcountry (Charleston: Curious Works Press and The Charleston Museum, 2001); Stephen and Carol Huber, Miller's Samplers: How to Compare and Value (London: Octopus Publishing Group Ltd., 2002); Kimberly Smith Ivey, In the Neatest Manner: The Making of the Virginia Sampler Tradition (Austin, TX: Curious Works Press and The Colonial Williamsburg Foundation, 1997); Glee F. Krueger, A Gallery of American Samplers: The Theodore H. Kapnek Collection (New York: Bonanza Books, 1984); John F. LaBranche and Rita F. Conant, In Female Worth and Elegance: Sampler and Needlework Students and Teachers in Portsmouth, New Hampshire 1741-1840 (Portsmouth: The Portsmouth Marine Society, 1996);
} 
a new trend. As early as 1921 (in one of the earliest works of contemporary needlework scholarship), Candace Wheeler wrote "embroidery was work for grown-up people, while samplers were baby-work."98 Almost seven decades later, Judith Reiter Weissman and Wendy Lavitt echoed her words, "marking samplers...teach little girls the knowledge they would need to initial[;]...more elaborate pieces were primarily made in seminaries or academies...[by] older girls ages 12 to $18 ., " 99$

A second group of these books (six of the thirty) acknowledges that some samplers were made by older women, but qualifies the observation by suggesting either that these women were teachers, marking their samplers as models for their students, or that older women made samplers in the sixteenth and seventeenth centuries, but not during the eighteenth and nineteenth centuries. Betty Ring, the foremost scholar of American samplers, fits within this group. In Girlhood Embroidery she asserted that, "Most likely samplers were always made by young people under the instruction of an experienced needlewoman...There is no convincing evidence that samplers were made by mature women other than those engaged in teaching.,"100 So entrenched is this

Rose Wilder Lane, Woman's Day Book of American Needlework (New York: Simon and Schuster, 1963); Pamela Parmal, Samplers from A to Z (Boston: MFA Publications, 2000); Gayle A. Rettew, William H. Siener and Janice Turner Wass, "Behold the Labour of my Tender Age": Children and Their Samplers, 1780-1850 (Rochester, NY: Rochester Museum and Science Center, 1984); Paula Bradstreet Richter, Painted with Thread: The Art of American Embroidery (Salem, MA: Peabody Essex Museum, 2002); Betty Ring, Let Virtue Be a Guide to Thee: Needlework in the Education of Rhode Island Women, 1730-1830 (Providence: Rhode Island Historical Society, 1983); Margaret B. Schiffer, Historical Needlework of Pennsylvania (New York: Charles Scribner's Sons, 1968); The Story of Samplers (Philadelphia: Philadelphia Museum of Art, 1971); Swan, Plain and Fancy, 129; Van Valin, Common Thread; Margaret Vincent, The Ladies' Work Table: Domestic Needlework in $19^{\text {th }}$-Century America (Allentown, PA: Allentown Art Museum, 1988); Judith Reiter Weissman and Wendy Lavitt, Labors of Love: America's Textiles and Needlework, 1650-1930 (New York: Wings Books, 1987); and Candace Wheeler, The Development of Embroidery in America (New York: Harper and Brothers, 1921).

${ }^{98}$ Wheeler, The Development of Embroidery in America, 48.

${ }^{99}$ Weissman and Lavitt, Labors of Love, 120.

${ }^{100}$ Ring, Girlhood Embroidery, 9-10. The other books in this group are: Gloria Seaman Allen, Family Record: Genealogical Watercolors and Needlework (Washington, DC: DAR Museum, 1989); Embroidered Samplers in the Collection of the Cooper-Hewitt Museum (Washington, DC: The Smithsonian Institution, 1984); Sue Studebaker, Ohio Is My Dwelling Place: Schoolgirl Embroideries 1800-1850 (Athens: Ohio 
conventional wisdom that even in books illustrating a sampler made by an older woman, the authors either neglect to explore what this might mean or go to great lengths to fit the sampler and its maker into the category of teacher. When writing about a sampler made by twenty-eight-year-old Martha Mulford (b. 1796), for instance, Sue Studebaker felt it necessary "to find an explanation for the married name of Mulford appearing on the canvas [because] sampler making was a schoolgirl art.",101

Finally, there is a small group of these books and catalogs, just three out of thirty, that does acknowledge that samplers were made by older women and that they were not, by necessity, teaching exercises, or from the sixteenth and seventeenth centuries. Showing just how truly groundbreaking they were, Ethel Stanwood Bolton and Eva Johnston Coe, authors of the 1921 work American Samplers, explained that while most of the nineteenth-century samplers they found were made by young children, some samplers were made by older women. They cite a sampler made by a sixty-year-old woman named Hannah Crafts. Instead of finding an excuse or fitting her neatly into the category of teacher, Bolton and Coe gave some thought to what this sampler might have meant for its maker. "Her heart probably reverted to the days of her youth," they suggested, "when samplers were even more prevalent, and she doubtless reproduced those she remembered, instead of copying the work of the young people about her."102

University Press, 2002); Sue Studebaker, Ohio Samplers: Schoolgirl Embroideries 1803-1850 (Lebanon, OH: The Warren County Historical Society Museum, 1988); and Susan Swan, A Winterthur Guide to American Needlework (New York: Rutledge Books, 1976).

${ }^{101}$ Studebaker, Ohio Samplers, 17.

${ }^{102}$ Ethel Stanwood Bolton and Eva Johnston Coe, American Samplers (1921; repr., New York: Dover Publications, Inc, 1987), 94. More recently, sampler scholar Glee Krueger recognized that "occasionally adults made samplers" but did not expand her study of these samplers, nor did she offer any thoughts on why older women might have stitched a sampler. Krueger, New England Samplers, 18. The third book in this group is Patricia V. Veasey, Virtue Leads and Grace Reveals: Embroideries and Education in Antebellum South Carolina (Greenville, SC: Curious Works Press, 2003), who acknowledges that adults 
Unlike samplers, quiltmaking is not typically understood as the work of women at a particular period in their lives, or at least not strictly so. There are examples of artifacts, as well as documentary evidence, showing that young girls quilted in addition to young women and older women. ${ }^{103}$ Even when the focus of a particular study is on the quilts made by younger women - for example, as they prepared for impending marriage it is often presented in the context of group work and the group includes mothers, grandmothers and aunts, as well as the bride-to-be. One study of almost 450 diary entries that referenced quiltmaking in New England in the early nineteenth century found that in just over half of the entries women "recorded assistance from outside the quilter's household for the completion of all types of quilting projects." ${ }^{\prime 104}$ While both older and younger antebellum women quilted, the circumstances under which they did so were different. For example, compared to younger women, older women did not quilt as often at social events. Instead, older women were more likely to quilt alone or with members of their immediate family. ${ }^{105}$ Yet while it is acknowledged that older women made quilts, there has not been a study devoted to exploring these quilts.

The majority of existing literature on quilt history focuses on the period from 1850 to 1900 , with less attention paid to pre-1850 quilts. ${ }^{106}$ The pieced quilt that most think of as the traditional American quilt only started to emerge and become widespread

made samplers and suggests that it was a Southern pursuit, but without fully exploring the idea, or providing any comparison to similar samplers in other regions.

${ }^{103}$ Lynne Z. Bassett and Jack Larkin, Northern Comfort: New England's Early Quilts 1780-1850 (Nashville: Rutledge Hill Press, 1998), 91-101. The many books published by state quilt documentation projects provide a wealth of evidence by presenting quilts made by women of all ages. This was not true simply in New England. See, for example, Fawn Valentine, West Virginia Quilts and Quiltmakers: Echoes from the Hills (Athens: Ohio University Press, 2000); Sandi Fox, Quilts: California Bound, California Made 1840-1940 (Los Angeles: FIDM Museum and Library, Inc., 2002); and Ricky Clark, ed., Quilts in Community: Ohio's Traditions (Nashville: Rutledge Hill Press, 1991).

${ }^{104}$ Bassett and Larkin, Northern Comfort, 91-92.

${ }^{105}$ Miller, The Needle's Eye, 110-111.

${ }^{106}$ A notable exception to this trend is the recent book, Lynne Zacek Bassett, ed., Massachusetts Quilts: Our Common Wealth (Lebanon, New Hampshire: University Press of New England, 2009). 
in the 1820s, after the invention of the cylinder-printing machine. This development caused a revolution in the way that fabric was printed and drove down costs sharply while increasing supply. Colorful cotton quilts pieced in blocks became popular throughout the 1820s and 1830s, reaching their peak in the 1850s and 1860s.

Similar to the sampler literature, there is also a gap in the scholarship concerning how quilts functioned within their society. ${ }^{107}$ Like samplers, quilts have been the focus of connoisseurship and its resulting literature. A large number of books and catalogs identify a chronological and geographical matrix for quilts. Over the past twenty years several states conducted quilt documentation projects and produced catalogs highlighting the most attractive and well-provenanced quilts. ${ }^{108}$ While these works are often excellent books and perform the great service of making thousands of quilts accessible at one's fingertips, they also suggest a bias. By grouping the quilts geographically, without looking carefully at what the quilts might have in common for their makers, they do not study quilts as sources of cultural insight.

And, just like Amy Fiske's sampler, quilts have much to teach us, particularly when we apply the criteria of age, along with class, geography and style. A quilt made around 1830 by a Massachusetts widow, for instance, offers analytical potential on several levels. Eliza Macy Howland Barney (1783-1867) made at least one quilt in her

\footnotetext{
${ }^{107}$ For an overview of scholarship on American quilting see: Bassett and Larkin, Northern Comfort; Pat Ferrero, Elaine Hedges, and Julie Silber, Hearts and Hands: Women, Quilts and American Society (Nashville: Rutledge Hill Press, 1987); Horton, Mary Black's Family Quilts; Patsy and Myron Orlofsky, Quilts in America (New York: Abbeville Press, 1992); Brackman, Clues in the Calico; Linda Eaton, Quilts in a Material World: Selections from the Winterthur Collection (New York: Abrams, 2007); and Roderick Kiracofe, The American Quilt: A History of Cloth and Comfort 1750-1950 (New York: Clarkson Potter Publishers, 2004).

${ }^{108}$ For especially useful works produced by state quilt documentation projects see: Bassett, ed., Massachusetts Quilts; Linda Welters and Margaret T. Ordonez, eds., Down by the Old Mill Stream: Quilts in Rhode Island (Kent, OH: The Kent State University Press, 2000); Clark, ed., Quilts in Community; and Gloria Seaman Allen, First Flowerings: Early Virginia Quilts (Washington, DC: The DAR Museum, 1987).
} 
late forties or early fifties, when she was living in New Bedford, probably after being widowed for the second time (figure I.5). ${ }^{109}$ Barney used a simple strip-pieced pattern, stitching long pieces of fabric lengthwise to make her bed covering (figure I.6). The quilt employs a mix of fabrics, some dating back thirty years or more. The three red fabrics include two that are block printed, suggesting that they date from the late-eighteenth century or the early-nineteenth century, prior to the invention of the cylinder-printing machine. Two of the blue and white prints are newer, dating to the late 1810s. Cylinderprinted in England, one depicts a wild boar hunt. ${ }^{110}$ While we cannot be sure, Barney's choice to use the older prints in her quilt may indicate a frugal nature, that she sought a means of remembering happier times, or both.

The evidence presented by the quilt itself suggests that it was initially intended as a functional bed covering rather than as a treasured keepsake. The strip-pieced style was simple and verged on unfashionable in the 1830s. ${ }^{111}$ In addition, a close look at the individual strips shows that Barney made some of them by stitching together smaller pieces of fabric, rather than cutting them whole from yardage. There are also several patched areas on the strips, as well as uniform fading on some strips, but not others,

\footnotetext{
${ }^{109}$ The quilt is now in the collection of Historic Deerfield, Inc., Deerfield, Massachusetts. I am indebted to Ned Lazaro, Collections Manager at Historic Deerfield, for facilitating my site visit in February 2009 and for sharing its curatorial file with me. Eliza Macy was born on Nantucket Island in 1783. Around 1808, she married Allen Howland (d. 1809), who was lost at sea in 1809. The couple had one daughter, Hannah Howland (1809-1855). By 1830, Eliza married Peter Barney (dates unknown); according to the U.S. Census that year, the couple was living in New Bedford with two other females, one aged ten to fifteen and one aged fifteen to twenty (probably Eliza's daughter Hannah). Peter Barney appears to have died prior to the 1840 Census, when Eliza is listed alone, living in New Bedford, with real estate valued at $\$ 11,500$. In 1860, she was living in Providence, Rhode Island with forty-one-year-old clergyman Samuel C. Brown (b. 1819) and his family. Her own daughter, Hannah Howland Russell, died in 1855. Eliza died in 1867 in Rhode Island. Barney Genealogical Record, Nantucket Historical Association, accessed at www.nha.org on January 4, 2009; U.S. Census records accessed at www.ancestry.com on January 4, 2009 and March 13, 2009.

${ }^{110}$ Lynne Z. Bassett, Telltale Textiles: Quilts from the Historic Deerfield Collection (Deerfield, Massachusetts: Historic Deerfield, Inc., 2003), 23.

${ }^{111}$ Brackman, Clues in the Calico, 124. The strip-pieced technique was more popular in England than in the United States.
} 


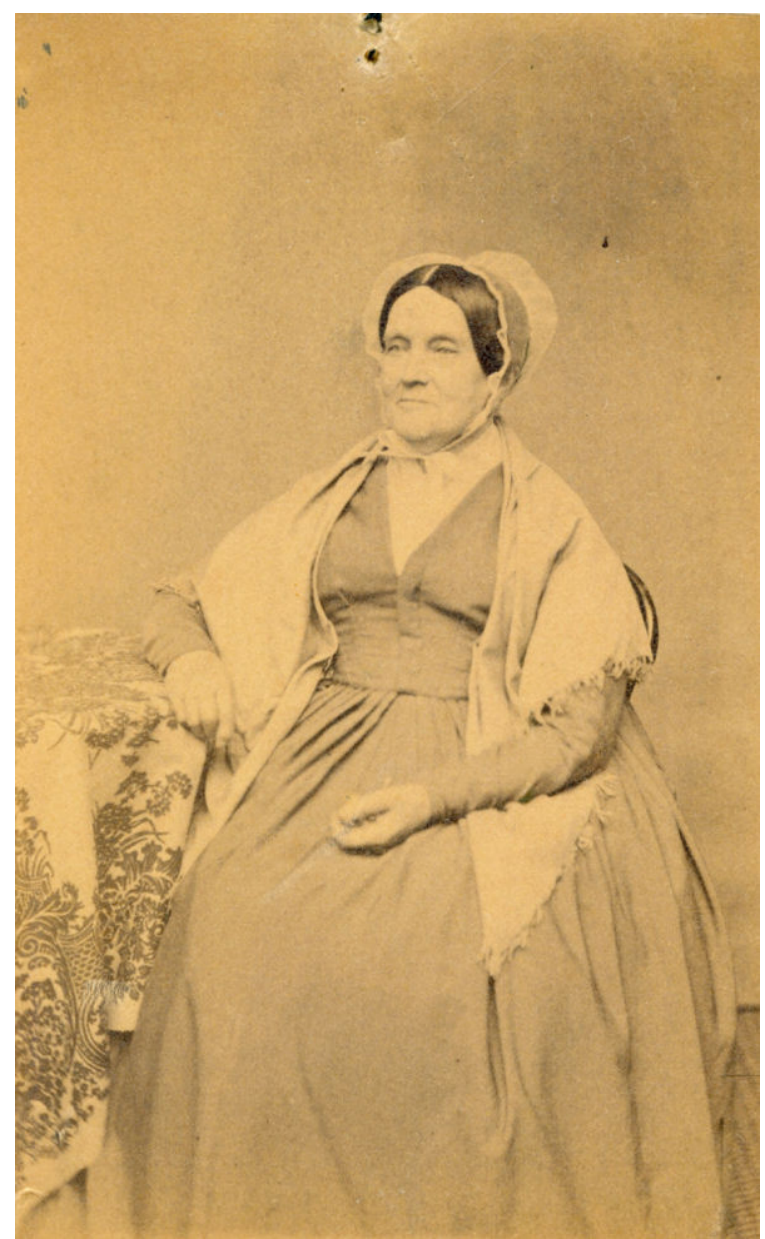

Figure I.5. Eliza Macy Howland Barney (1783-1867) by Bierstadt Brothers, circa 1860, New Bedford, Massachusetts. Courtesy of the Nantucket Historical Association, Nantucket, Massachusetts.

By the time she made her quilt around 1830, Eliza Macy Howland Barney had been married and widowed twice. In contrast to the frugal techniques and materials she used to make her quilt, Eliza was listed on the 1840 U.S. Census as the owner of real estate valued at $\$ 11,500$. 


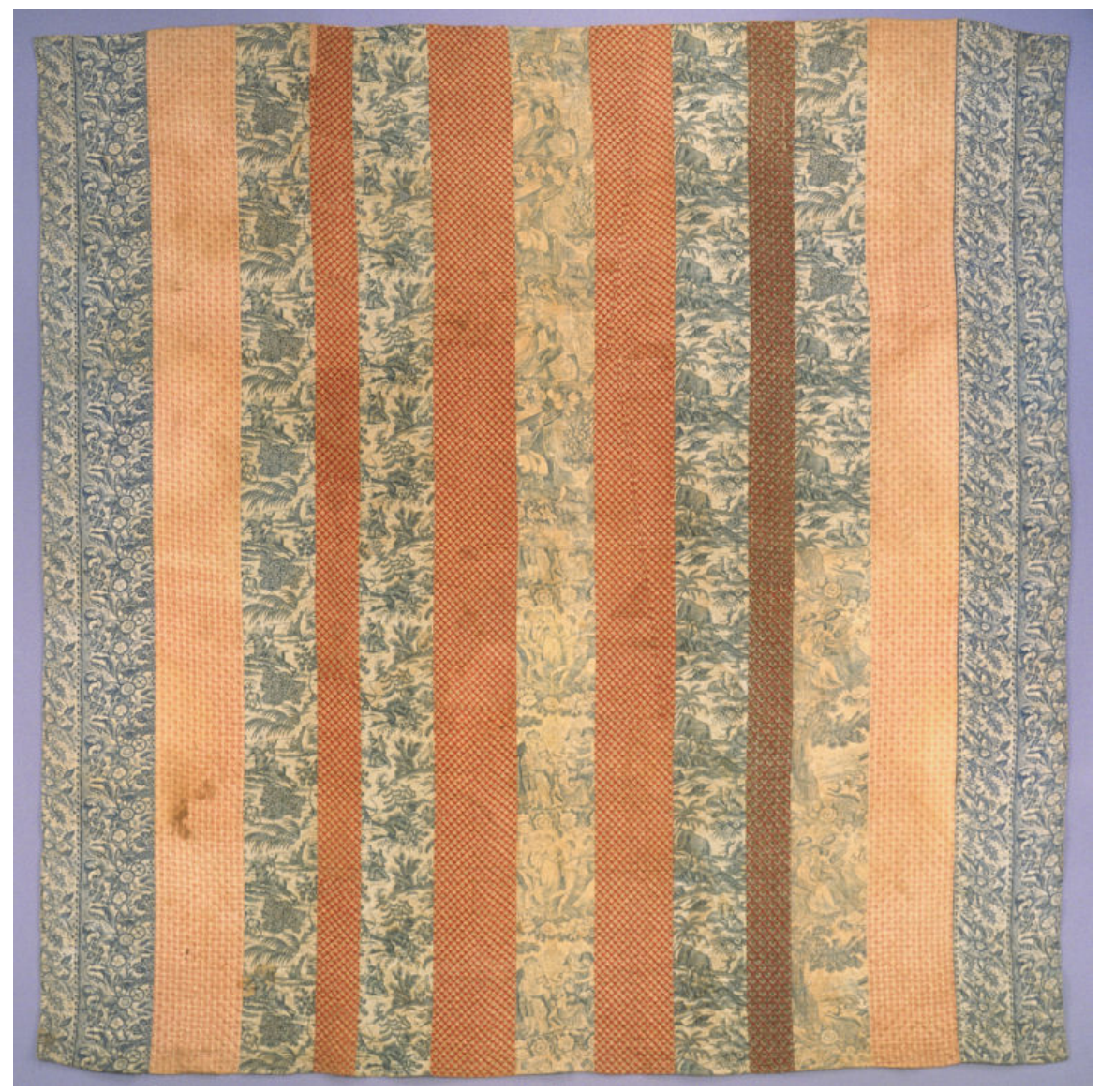

Figure I.6. Quilt by Eliza Macy Howland Barney (1783-1867), circa 1830, New Bedford, Massachusetts. Collection of Historic Deerfield, F.10B, photograph by Penny Leveritt.

The quilt that Eliza Macy Howland Barney made around 1830, when she was in her late forties, shows dated fabrics and techniques. The strip-pieced pattern and knife-edge binding are more commonly seen on quilts from the late-eighteenth and early-nineteenth centuries. Composed of top and backing fabrics that appear to have been recycled from household textiles, Barney's quilt may have served as a record of her past, combining techniques familiar from her childhood and fabrics she used in her home as a young wife. 
suggesting that the fabrics used in the quilt may have been recycled from other household textiles, like window treatments or bed hangings.

Cross-stitched initials "EH" appear on the back of the quilt. Like the front of the quilt, the backing is pieced from many scraps of plain muslin and linen fabrics, again suggesting that these pieces were recycled, this time from old sheets and towels. The initials "EH" date to Barney's first marriage, around 1808, to Allen Howland (d. 1809), who was lost at sea in 1809 . The piece of the quilt's backing with these initials was probably recycled from a worn-out sheet or other household textile that Eliza made in preparation for her first marriage. Between 1809 and 1829, Eliza remarried to Peter Barney (dates unknown) and probably would have used her then-current initials, "EB," if the mark dated from when she made the quilt around 1830.

The quilt employed techniques that were dated in 1830: the strip-pieced pattern, along with the knife-edge binding, which is often seen on New England wholecloth wool quilts from the late-eighteenth century, but was superseded by applied bindings as printed cotton fabrics became more affordable in the early-nineteenth century. ${ }^{112}$ The quilting pattern is simple, adding credence to its intended functional use as a warm bed covering.

As a native Nantucketer, Eliza may have been a Quaker and this may have affected the type of quilt she chose to make. ${ }^{113}$ The Society of Friends was well-

\footnotetext{
${ }^{112}$ Knife-edge binding is a technique used to finish and secure the edges of the quilt (the last step in making a quilt) so that it will not come unraveled or become ragged along the edges. The edges of the quilt's top fabric and its backing fabric are turned inside and then secured using a whip stitch or running stitch to join them together. The name "knife-edge" comes from the finished appearance of this binding technique; both fabrics are crisply turned in so that the outside edge is as flat as a knife. An applied binding is one where a third, separate, piece of fabric or twill tape is folded over the top and bottom fabrics of the quilt and stitched (or applied) to the quilt's edges. Bassett and Larkin, Northern Comfort, 21.

${ }^{113}$ While the question of Eliza's Quaker membership is unanswered, both of her husbands were Quakers. The presumption is that she was also part of the Society of Friends, since marrying a non-Quaker was grounds for being "read out" or removed from the church. Email correspondence with Elizabeth Oldham,
} 
established on the island by the late-eighteenth century. Even if Eliza was not a member herself, she would have been familiar with that faith and its principal tenets. Quakerism advocated plainness of speech and dress, in order to avoid worldly concerns that threatened to impair the Quaker pursuit of "inner light," or the spirit of God, that Friends believed dwelt within everyone. Barney's quilt combines frugal construction techniques with a colorful fabric palette, perhaps offering her a way to mediate theological ideals and worldly temptations. ${ }^{114}$ Despite its rather utilitarian appearance, the quilt was saved and passed down after her death, perhaps taking on new meaning later in its life: as a means of connection to its maker.

Existing literature has focused on how quilts related to the lives of their specific makers. ${ }^{115}$ But what about those who used the quilts and those who inherited them? Many quilts were made by one woman (or group of women) with the express purpose of being used by another woman or family. A number of books and articles have considered the album and friendship quilts that were popular in antebellum America, often signed by a group of women, and given as a send-off to a couple moving westward, or used as a

Research Associate, Nantucket Historical Association Research Library, Nantucket, Massachusetts, August 10, 2009.

${ }^{114}$ Patricia J. Keller, “Quaker Quilts from the Delaware River Valley 1760-1890,” The Magazine Antiques 156 (August 1999): 185-191. While the strip-pieced style was more popular with quilters in England than in the United States, it was favored by Quaker quiltmakers in America. Keller, "Quaker Quilts," 190. Ties between American Quakers and English Quakers may explain its use by American Quaker quilters.

Nantucket, with its high percentage of Friends during the early nineteenth century may also have turned out a higher than average number of strip-pieced quilts.

${ }^{115}$ For examples of scholarship on a specific quiltmaker, see: Horton, Mary Black's Family Quilts; Carolyn O'Bagy Davis, Pioneer Quiltmaker: The Story of Dorinda Moody Slade 1808-1895 (Tucson: Sanpete Publications, 1990); Carolyn O’Bagy Davis, Quilted All Day: The Prairie Journals of Ida Chambers Melugin (Tuscon: Sanpete Publications, 1993); Nancilu Burdick, Legacy: The Story of Talula Gilbert Bottoms and Her Quilts (Nashville: Rutledge Hill Press, 1988); Gwen Marston and Joe Cunningham, Mary Schafer and Her Quilts (East Lansing: Michigan State University Museum, 1990); and Grace Snyder, No Time on My Hands (Lincoln: University of Nebraska Press, 1986). Like much existing quilt scholarship, these works that focus on individual quiltmakers are skewed to the late nineteenth and early twentieth centuries. 
fundraiser at a church or agricultural fair. ${ }^{116}$ But there is almost no literature considering the quilts made by a mother, grandmother or aunt and given to a daughter, granddaughter or niece from the perspective of the maker and giver. ${ }^{117}$ Examining these quilts could offer a personal context for understanding their makers and recipients. Instead of being the product of group consensus, the quilts made by one woman reflect her individual choices and can be read as evidence of her skill and preferences.

Artifacts can help us to see how women interacted with their societies. The very symbols of the goodwife, the Republican mother or the clubwoman can often suggest a rebellious undercurrent if we are able to fully examine them. Our literature is full of examples from history where women seized agency under the cover of morality and feminine virtue. The decorative needlework here adds to this tradition. It was not an end in and of itself, but a means to several particular ends - a way for antebellum women to have a voice, to express their political views, to tell their life story, or to pass on a lesson to their daughters and granddaughters.

\footnotetext{
${ }^{116}$ See Brackman, Clues in the Calico; Jessica F. Nicoll, Quilted for Friends: Delaware Valley Signature Quilts (Winterthur, DE: Winterthur Museum, 1986); Mimi Sherman, "A Fabric of One Family: A Saga of Discovery," The Clarion (Spring 1989): 55-62; Jessica F. Nicoll, "Signature Quilts and the Quaker Community, 1840-1860," Uncoverings 7 (1986): 27-37; Cathy Rose Klimaszewski, Made to Remember: American Commemorative Quilts (Ithaca: Cornell University Press, 1991); Linda Otto Lipsett, Remember Me: Women and Their Friendship Quilts (San Francisco: The Quilt Digest Press, 1985); Barbara Brackman, "Signature Quilts: Nineteenth-Century Trends," Uncoverings 10 (1989): 25-37; Bassett, ed., Massachusetts Quilts, 269-270; and Ricky Clark, "Fragile Families: Quilts as Kinship Bonds," The Quilt Digest 5 (1987): 5-19. See Ulrich, The Age of Homespun, 5-8, 409-412, 418, for an exploration of how textiles enter museum and historical society collections.

${ }^{117}$ Theoretical literature on gift-giving abounds, however. For example, see: Marcel Mauss, The Gift: The Form and Reason for Exchange in Archaic Societies (New York: W.W. Norton, 1990); Aafke E. Komter, Social Solidarity and the Gift (Cambridge: Cambridge University Press, 2005); Karen Sykes, Arguing with Anthropology: An Introduction to Critical Theories of the Gift (New York: Routledge, 2005); Natalie Zemon Davis, The Gift in Sixteenth-Century France (Madison: The University of Wisconsin Press, 2000); David J. Cheal, "The Social Dimensions of Gift Behaviour," Journal of Social and Personal Relationships 3 (1986): 423-439; James Carrier, "Gifts, Commodities, and Social Relations: A Maussian View of Exchange," Sociological Forum 6 (1991): 119-136; Jonathan Parry, "The Gift, the Indian Gift and the "Indian Gift," Man 21 (September 1986): 453-473; and Barry Schwartz, "The Social Psychology of the Gift," The American Journal of Sociology 73 (July 1967): 1-11.
} 


\section{Methodology}

While material evidence is extremely promising for the study of women's history and comprises the major type of evidence for this dissertation, it cannot answer every question. The following chapters focus on the decorative needlework of white, middleclass women because these women were able to spend time and money making nonessential textiles that were marked with their names, valued enough to be saved by their families, and subsequently housed in museum collections, with their histories documented and preserved.

Just as "traditional" documentary sources are subject to biases, needlework, like all material sources, also needs to be carefully assessed. The historian must find ways to evaluate the sources available and attempt to find paths around any obstacles, whether a letter or a quilt. To do this, I have combined a material culture methodology with a traditional document-based approach to move beyond the classification of samplers and quilts into time, place and style. The foundation of this project is a survey of 167 samplers, quilts and other needlework from fifty museums and sixty-four private owners made (or altered) by women who were aged forty and over between the years 1820 and 1860 (see Appendix). Only artifacts where the identity and age of the maker and the date of construction can be identified are sources for this study.

In recent years, quilts made by African American women have been studied, but few can be conclusively documented to date from the period under consideration here and even fewer have the maker's name attached, which is essential to identify the needlework of mature women. ${ }^{118}$ Likewise, the beadwork made by Native American

\footnotetext{
${ }^{118}$ For example, see: John Beardsley, The Quilts of Gee's Bend (Alberta, Georgia: Tinwood Books in association with the Museum of Fine Arts, Houston, 2002); Cuesta Benberry, A Piece of My Soul: Quilts by
} 
women during the nineteenth century is also a promising source for new interpretations of the lives of women of color, but it is also rarely signed, and thus difficult to identify as the product of a woman of a certain age. ${ }^{119}$ The same is also true of needlework made by Irish, German and other ethnic immigrants to the United States. Women from a wide variety of backgrounds traveled to America before and during the antebellum period. And they brought the sewing skills and knowledge of their home cultures with them, which they used to make samplers, quilts and other forms of needlework in this country. But, these items have not been incorporated into museum collections in significant numbers and are difficult to find today. Like the work of African American and Native American women, the needlework of immigrant women is rarely saved with a specific history of its maker's name and life dates, meaning that it could not be determined to fit the constraints of this study. Examples of needlework made by a group of women are also not considered here. Objects made by such groups were often intergenerational. And, the names of all of the makers are rarely included in the records for the object, making it impossible to determine their ages at the time that the object was made.

\footnotetext{
Black Arkansans (Fayetteville: University of Arkansas Press, 2000); Barbara Brackman, Facts and Fabrications: Unraveling the History of Quilts and Slavery (Lafayette, California: C \& T Publishers, 2006); Gladys-Marie Fry, Stitched from the Soul: Slave Quilts from the Antebellum South (New York: Dutton Studio Books, 1990); and Kyra E. Hicks, Black Threads: An African American Quilting Sourcebook (Jefferson, North Carolina: McFarland and Company, 2003).

${ }^{119}$ See Janet Catherine Berlo and Ruth B. Phillips, Native North American Art (New York: Oxford University Press, 1998); Gilbert T. Vincent, Sherry Brydon, and Ralph T. Coe, eds., Art of the North American Indians: The Thaw Collection (Cooperstown, New York: Fenimore Art Museum, 2000); Gretchen Fearon Faulkner, Nancy T. Prince, and Jennifer Sapiel Neptune, "Beautifully Beaded: Northeastern Native American Beadwork," American Indian Art Magazine 24 (Winter 1998): 32-41; Christian F. Feest, Native Arts of North America (London: Thames and Hudson, 1992); Beverly Gordon, "The Niagara Falls Whimsey: The Object as a Symbol of Cultural Interface" (Ph.D. diss., University of Wisconsin - Madison, 1984); Gifts of the Spirit: Works by $19^{\text {th }}$-Century and Contemporary Native American Artists (Salem, Massachusetts: Peabody Essex Museum, 1996); and Ruth B. Phillips, Trading Identities: The Souvenir in Native North American Art from the Northeast, 1700-1900 (Seattle: University of Washington Press, 1998).
} 
Samplers and quilts make up the largest groups of needlework found for this study, so they offer the bulk of the specific examples discussed in these pages. In addition to the 109 quilts located and the fifty samplers found, fitting the criteria, the survey also turned up one rug, three coverlets, one table cover, two mourning pictures, and a group of fabric sculptures, all made between 1820 and 1860 by women who could be determined to be forty or older when these objects were made. ${ }^{120}$ The samplers fall into three categories: those made by women aged forty and over; samplers stitched by the woman when she was a young girl and later modified in some way (such as having the age or date or other identifying information picked out of the sampler); and samplers that were modified to trace the life and death of the maker - such as a family record sampler where the maker's death date was added. The quilts surveyed for this study are also ones conclusively determined to have been made by women aged forty and over. Special attention has been paid to quilts that were entered in agricultural fairs, ones that have some kind of message or biographical information pieced into their tops, those with machine sewing, and those given as gifts to another person. When additional types of needlework (including needlework pictures and other decorative household textiles) made by women aged forty and over between 1820 and 1860 were found, they were considered as well.

All of the needlework examined here falls into the category of "decorative" rather than primarily "functional." This bias stems from the very survival of these artifacts they were generally not used everyday, but rather served as "special" objects, stored

\footnotetext{
${ }^{120}$ Antebellum women also made other types of decorative needlework, using techniques like knitting and tatting. These items were not purposefully excluded from these pages, rather no examples that conclusively fit the criteria of this study were located. These sources offer additional potential for the study of women in antebellum America.
} 
away carefully and passed down from generation to generation. By definition, these were also the types of items that had their history preserved. Because they were "special" and saved, they often retained an association with a particular maker, making it possible to determine that person's age at the time. The age of the maker was the primary criteria for this study. Examples are drawn from all over the antebellum United States, with no particular geographic focus. The survey turned up objects made in twenty-three different states, with an additional twelve objects made in unknown places. Regionally, these objects break down into forty-six with a history of origin in New England; forty-one from the Mid-Atlantic states; forty-six from the South; twenty from the Mid-west; and two from the western region of the country. However, this points to another bias, a preponderance of examples from the northeast and mid-Atlantic. ${ }^{121}$ Vast areas of what we know today as the western United States were just beginning to be settled between 1820 and 1860 and those settlers, on the whole, had little access to the time and materials required to make the kind of needlework often saved by subsequent generations.

To build context and add to my pool of evidence, I surveyed published diaries and letters written by women aged forty and over between 1820 and 1860 to learn more about how they viewed the aging process and how needlework was described in their own words. $^{122}$ A third major group of sources for this project consisted of published

\footnotetext{
${ }^{121}$ While forty-six items were made in the South (matching the total from New England), this is skewed by eleven objects made by one woman. Taking this into consideration, New England has the most objects represented in this survey. See Heather Ruth Palmer, "Where is Nineteenth-Century Southern Decorative Needlework?," The Southern Quarterly 27 (1988): 58-59, who offers several common reasons cited for the lack of extant Southern needlework, compared to the wealth of examples from New England and the midAtlantic, such as the deleterious effects of the climate, the variety of insects that flourish in the region, and the effects of the Civil War.

${ }^{122}$ The majority of these published diaries and letters were accessed via the North American Women's Letters and Diaries (NAWLD) database (http://solomon.nwld.alexanderstreet.com). This database includes more than 150,000 pages of published and unpublished letters and diaries of over 1,300 North American women that were originally written between 1675 and 1950. I looked at all entries written by women who
} 
materials, including newspapers, magazines, novels, medical guides, etiquette and needlework manuals, and graphic illustrations (such as broadsides and prints). These sources offered a societal perspective on the roles and appearance of aging women as well as on why needlework was considered an appropriate activity for them.

Returning to the story of Amy Fiske illustrates how material and documentary sources can work together to enhance our understanding of aging women during the antebellum era. Amy Fiske was born on November 9, 1785, in Sturbridge, Massachusetts, the daughter of Henry Fiske Jr. (1745-1815) and Sarah Fiske (17461815). Her father, Henry Jr., was the oldest surviving son of one of the town's founders, Henry Fiske (1707-1790), and his wife, Mary Stone (1705-1805). In 1774, Amy's father, Henry Jr., married his cousin, Sarah Fiske, the daughter of his father's brother and cofounder of Sturbridge, Daniel Fiske (1748-1836). ${ }^{123}$ One of the wealthiest men in Sturbridge in 1798, Amy's father's land and houses were worth almost \$7,000, making him one of the top five property owners among Sturbridge's 215 propertied households at that time. ${ }^{124}$ When Amy stitched a sampler in 1795 at age nine, she demonstrated, in part, her father's success and financial position. As a daughter of her father's household,

were 40 and over between 1820 and 1860. I supplemented this by looking at manuscript diaries at the Massachusetts Historical Society, the Rhode Island Historical Society, the American Antiquarian Society and Old Sturbridge Village.

${ }^{123}$ Frederick Clifton Pierce, Fiske and Fisk Family (Chicago: F.C. Pierce, 1896), 254; Vital Records of Sturbridge, Massachusetts to the Year 1850 (Boston: New England Historic Genealogical Society, 1906). For more on Amy Fiske and her sampler see Aimee E. Newell, “'Tattered to Pieces': Amy Fiske's Sampler and the Changing Roles of Women in Antebellum New England," in Women and the Material Culture of Needlework and Textiles, 1750-1950, eds. Maureen Daly Goggin and Beth Fowkes Tobin (Aldershot, England: Ashgate Publishing Ltd., 2009) and Aimee E. Newell, ““'Tattered to Pieces”: Samplers by Aging Women in Antebellum New England," Sampler and Antique Needlework Quarterly 13 (Fall 2007): 28-35.

${ }^{124} 1798$ Federal Direct Tax, Research files, Old Sturbridge Village, Sturbridge, Massachusetts. 
Amy followed the steps toward becoming a proper genteel lady by stitching her sampler, probably under the instruction of a local schoolmistress.

In 1812, at the age of twenty-seven, Amy married her second cousin, Daniel Fiske (1786-1859). Daniel, often referred to as "Daniel Jr." was, in fact, Daniel III. Born on May 10, 1786, in Sturbridge, he was the son of Daniel Fiske and Elizabeth Morse (17571839). Like Amy, Daniel descended from the Fiske brothers who settled Sturbridge in 1731. ${ }^{125}$ Family history explains that Daniel Jr., Amy's husband, was “a carpenter by trade, but always followed farming."126 Tax records from 1827 show that he owned a house and barn with Amy's sister, Matilda (1784-1880), along with one-quarter of a sawmill and 131 acres of land, suggesting that the Fiskes led a comfortable life. ${ }^{127}$

Daniel continued to do well over the next two decades. The 1850 census provides a picture of Amy and Daniel's household shortly before she made her sampler. The couple were both sixty-four years of age at that time and lived with their daughter Sarah (1817-1909), their son Henry (1818-1896) and his wife, Lydia (1815-1887), and a laborer, Hiram H. Ransom (b. ca. 1825). ${ }^{128}$ Daniel and Amy had four children, but only Henry married. Lucius Colwell Fiske was born in 1813 and died in California in 1874. Sarah, the only daughter, was born in 1817 and remained single until her death in 1909 in Southbridge. Henry Morse Fiske was born in 1818, married his cousin Lydia Belknap in

\footnotetext{
${ }^{125}$ Pierce, Fiske and Fisk Family, 259-260; Vital Records of Sturbridge.

${ }^{126}$ Pierce, Fiske and Fisk Family, 384.

${ }^{127} 1827$ town tax records, Research files, Old Sturbridge Village, Sturbridge, Massachusetts.

${ }^{128} 1850$ United States Census and 1840 town tax records, transcription in research department files, Old Sturbridge Village, Sturbridge, Massachusetts. In 1840, Daniel Fiske Jr. owned one horse, four cows, two swine, four oxen, eight two-year old cattle, and thirty sheep. By 1850, it seems likely that Daniel and Amy's son, Henry, and his wife, were living at the family farmstead in order to oversee the operation of the farm. In October 1853, a year after Amy re-stitched her sampler, Daniel and Amy deeded the home farm to their son Henry, but retained part of the house for their use "during the term of their natural lives." When they died in 1859, neither Daniel nor Amy owned any real estate - it had been deeded to Henry six years earlier. Worcester County Deeds, Book 516, 476-477, Worcester, Massachusetts.
} 
1847, and lived a long life in Sturbridge and neighboring Southbridge, dying in 1896. George Daniel Fiske, Amy and Daniel's youngest son, was born in 1823, when Amy was thirty-eight. George did not marry, but moved out West at some point, dying in the Dakota Territory in $1861 .{ }^{129}$

Amy's 1852 sampler is stitched entirely in cross-stitch. This could be an effect of failing eyesight. Like many aging women, Amy Fiske may have had to adapt in order to continue producing needlework. In order to understand how Amy, and women like her, adapted to the physical realities of aging, chapter 1 explores the physical and mental effects of "old age" on antebellum women and their needlework. This chapter also considers samplers that were modified later in their lives through the removal of the maker's age or the date when the sampler was made. While Amy Fiske did not modify her earlier sampler, she did recreate it, aligning it with these other samplers.

By 1852, the purpose of Amy Fiske's sampler had changed. While it was still meant to be framed and hung on the wall, the location of the wall had changed from Amy's parents' parlor to her own. Rather than an act of obedience, Amy's sampler was now an act of assertion, giving her a voice for her nostalgia for her personal past and her community's history. In her study of women growing old during the early nineteenth century, historian Terri L. Premo found that older women set themselves the task "not only to continue serving the needs of family and friends...but to act as living reminders of a peculiarly feminine moral order."

Amy Fiske re-stitched her sampler as a conscious act of expression. Raised in the 1790s and early 1800s, Amy knew her place in the home and in society. She did not

\footnotetext{
${ }^{129}$ Pierce, Fiske and Fisk Family, 384-385.

${ }^{130}$ Premo, Winter Friends, 5.
} 
leave letters and documents except those few signed by herself under her husband's signature. She left instead a sampler that is with us today because it was valued by her family and passed down. ${ }^{131}$ As Laurel Thatcher Ulrich has pointed out, "needlework that is saved requires two parts - ego enough to sign it in the first place and also descendants who understand it and cherish it enough to save it." ${ }^{\prime 132}$ Amy Fiske's sampler was a badge of her womanhood, her skill at needlework and her mastery of the proper values of wife and mother. But, at sixty-six years, she faced a world that no longer required excellence with the needle or interpreted it as a symbol of gentility.

Chapter 2 offers an exploration of epistolary needlework, that which relates a message in the form of stitched words. Sometimes samplers and quilts became "biographical objects" for their makers - personally meaningful possessions that took on a "life" of their own. ${ }^{133}$ From simple signatures in fabric and thread, documenting the maker and the date, to family information, moral codes and political commentary,

\footnotetext{
${ }^{131}$ The sampler was most likely part of Amy's bequest to her daughter, Sarah, when she died in 1859 . Her probate inventory is not itemized, but the last clause of her will reads, "All the remainder and residue of my Estate of every description...I give and bequeath to my daughter Sarah Fiske..." Will of Amy Fiske, Docket \#20823, Worcester County Probate Court, Worcester, Massachusetts. Sarah lived in the Sturbridge area until her death in 1909, when she was living in neighboring Southbridge with family. At some point in the mid-1990s, the sampler was part of a local auction and purchased by the parents of the woman who sold the sampler to Old Sturbridge Village in 2003. Old Sturbridge Village curatorial department files. Amy's daughter Sarah also stitched a sampler when she was nine, in 1826. The top of Sarah's sampler is almost identical to Amy's 1852 sampler, suggesting that she used her mother's 1795 sampler as a model, and, in turn, perhaps Amy used her daughter's sampler as a model in 1852. Both samplers include several alphabets - upper-case and lower-case, Roman and cursive - sometimes including multiple versions of one letter. Sarah's sampler is in the collection of Old Sturbridge Village, Sturbridge, Massachusetts.

${ }^{132}$ Ulrich, Age of Homespun, 247.

133 Janet Hoskins, Biographical Objects: How Things Tell the Stories of People's Lives (New York: Routledge, 1998), 11. Hoskins defines and explores the idea of gendered "biographical objects" through her field study of Kodi natives in Indonesia. While she believes that objects in Western societies don't act in the same way as they do in Indonesia, she does concede that "anthropologists who have recently turned to analyzing forms of consumption in Western industrial society have noted that some older objects can acquire a certain biographical dimension." Hoskins, Biographical Objects, 193. For additional perspectives on the idea of "biographical objects," see Igor Kopytoff, "The Cultural Biography of Things: Commoditization as Process," in The Social Life of Things: Commodities in Cultural Perspective ed. Arjun Appadurai (New York: Cambridge University Press, 1986), 64-91 and Annette B. Weiner, Inalienable Possessions: The Paradox of Keeping-While-Giving (Berkeley: University of California Press, 1992).
} 
epistolary samplers and quilts provide a layer of context for the lives of their antebellum makers.

While Amy Fiske continued to live in Sturbridge after her marriage, not far from her parents' home (where she may have stitched her first sampler), the town did not remain static around her. One of the most striking differences between the Sturbridge of Amy's girlhood and that of her old age was the rise of textile factories. In 1837, six cotton mills in Sturbridge manufactured 829,749 yards of cotton goods and employed 117 women and seventy-one men. In 1855, three cotton mills manufactured over 1.5 million yards of fabric. ${ }^{134}$

Amy's second sampler reflects these developments. The fabric is machine-woven with a thread count of thirty-two stitches to the inch and a blue weft thread every tenth thread. The use of this fabric suggests a growing preference for machine-made goods in needlework projects. This development supports the idea that needlework was not being taught the same way as it had been twenty years previously. Girls were in school side by side with boys by the 1850 s, following a much more similar program of study than they had earlier in the century. With the rise of industrialization, advances in manufacturing goods for the household meant that women did not have to make as many textiles from scratch; they were able to spend their time in other endeavors.

Chapter 3 focuses on the technological developments related to needlework that took place between the late-eighteenth and early-nineteenth centuries, and the ways in

\footnotetext{
${ }^{134}$ John Warner Barber, Historical Collections...of Every Town in Massachusetts (Worcester: Dorr, Howland and Company, 1840), 608; Joseph S. Clark, An Historical Sketch of Sturbridge, MA (Brookfield, Massachusetts: E. and L. Merriam, 1838), 25-26; George Davis, An Historical Sketch of Sturbridge and Southbridge (West Brookfield, Massachusetts: O.S. Cooke and Company, 1856), 199-201; Levi B. Chase, "Sturbridge" in History of Worcester County, ed. D. Hamilton Hurd (Philadelphia: J.W. Lewis and Company, 1889), 118-119; Francis DeWitt, Statistical Information Relating to Certain Branches of Industry in Massachusetts (Boston: William White, 1856), 539.
} 
which aging women responded to these changes. By the 1830 s, especially in the northeastern United States, industrial manufacturing removed spinning and weaving from the home, taking it to the factory where it could be accomplished more cheaply. This profoundly changed women's work, more than any other single factor. ${ }^{135}$ Few women had to spend time spinning and weaving cloth to make up clothes and household textiles, or to trade at the local store for other types of goods. As a result, they were able to follow new life patterns. With some women starting to work in the factories, still pursuing the traditional women's work of textile production, though in radically-altered settings, those who remained in the home needed a new way not only to define their femininity, but also to set themselves apart from the women working in the factories. Decorative needlework served as one symbol of this difference.

Rather than being the student, by 1852 Amy Fiske was now the teacher. A sampler by her grand-niece, Caroline M. Bracket (b. 1842), dated December 1852, follows the same pattern as Amy's sampler and employs the same thread, fabric and stitches (figure I.7). ${ }^{136}$ Caroline was the daughter of Amy’s niece, Cornelia Taylor Bracket (b. 1807). Cornelia's mother, Mary Fiske Taylor (1780-1827), was Amy's older sister; she had died in 1827. In 1850, when Caroline was eight, the U.S. Census listed her as living next door to Amy, in the household of another great-aunt, her grandmother's and Amy's sister, Matilda Fiske. Matilda never married yet maintained a household of her own, sometimes living with Amy and her husband and, by 1850, living on her own

\footnotetext{
${ }^{135}$ Cott, The Bonds of Womanhood, 36. In his study of women's work, Thomas Dublin also found that increasing industrialization radically altered the patterns of women's lives in early-nineteenth century New England. See Thomas Dublin, Transforming Woman's Work: New England Lives in the Industrial Revolution (Ithaca: Cornell University Press, 1994), 7.

${ }^{136}$ Caroline Bracket's sampler is in the collection of Old Sturbridge Village, Sturbridge, Massachusetts.
} 


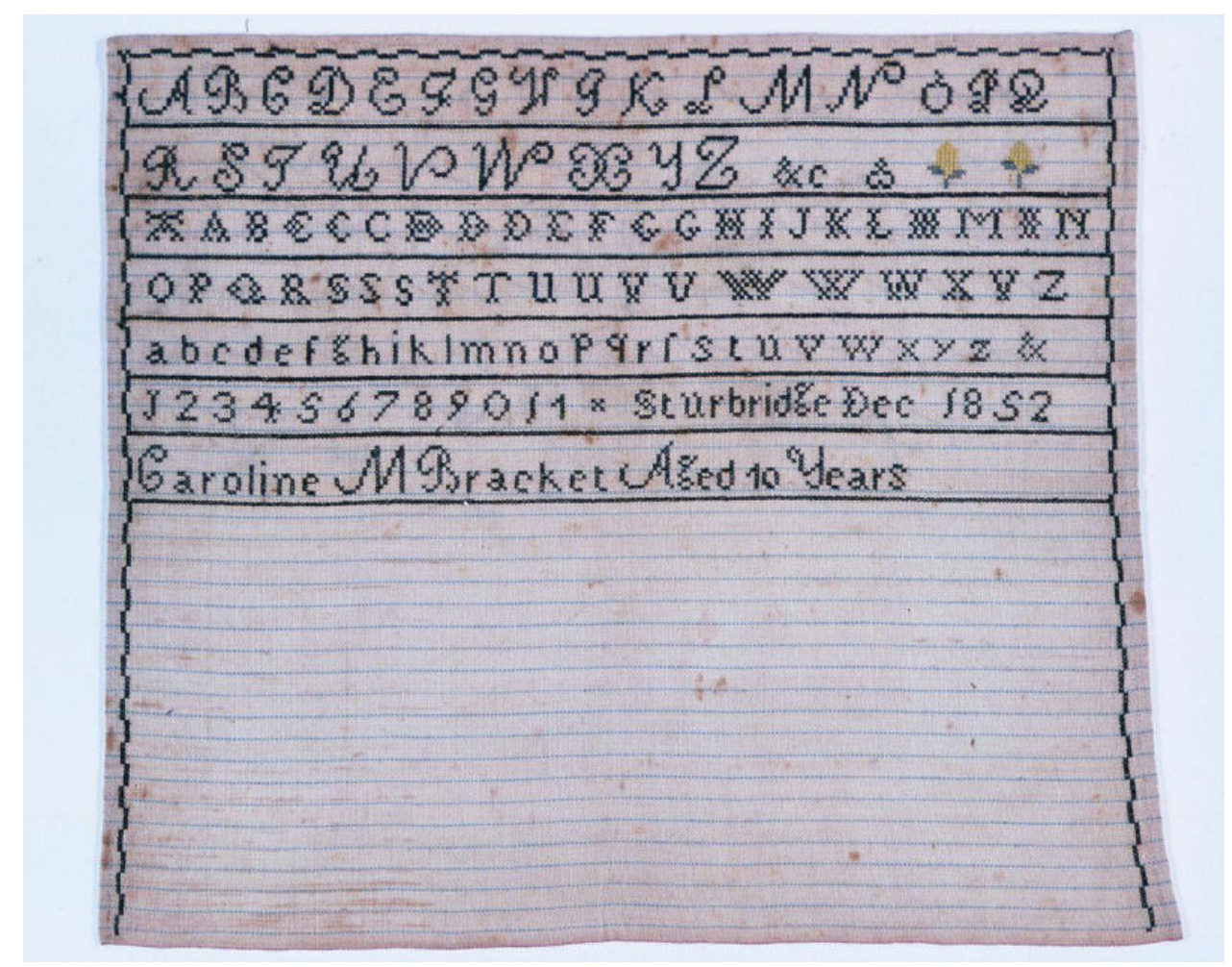

Figure I.7. Sampler by Caroline M. Bracket (b. 1842), 1852, Sturbridge, Massachusetts. Courtesy of Old Sturbridge Village, Sturbridge, Massachusetts, 64.1.15, photograph by Henry Peach.

Caroline M. Bracket's sampler is strikingly similar to her great-aunt Amy Fiske's sampler. She used the same dark brown thread, the same fabric with horizontal blue guidelines, and the same pattern. Bracket also dated her sampler "Dec 1852," just two months after the date of "Oct 1852" on Fiske's sampler. Fiske may have been trying to instill the same needlework lessons she learned as a girl in her young grand-niece. But, Caroline's sampler is unfinished, perhaps reflecting the decreasing need for young girls to mark clothes and make their own textiles. 
with Caroline. ${ }^{137}$ The record is silent on why Caroline was living with her sixty-six-yearold great aunt in 1850. Perhaps she was there to provide assistance and companionship for Matilda. Whatever the reason, her sampler suggests she was also learning the proper skills to run her own household someday, under the tutelage of her grandmother's sisters, who were probably playing the role that their deceased sister could not. ${ }^{138}$

By creating her sampler, Amy Fiske was making something that would preserve the female tradition of textile arts. Caroline Bracket used Amy's 1852 sampler as a guide, continuing a tradition, showing the skills of womanhood and instilling proper values into the Fiske family female line. However, Caroline's sampler is unfinished, perhaps suggesting the decline of interest in needlework among the rising generation, which was taking place in the 1850s. The quality of Caroline's sampler was several notches below that of samplers made during the early nineteenth century: the fabric had a lower thread count; it was stitched entirely in the basic cross-stitch; and there were blue threads woven in as a guideline for counting.

Chapter 4 considers how needlework (both finished products and lessons) functioned as a gift between an aging woman and her friends and family members. What were the embedded meanings in these gifts for both the maker/giver and the recipient? A woman's needlework was implicitly considered hers to give away as she saw fit. And, as anthropologist Annette Weiner points out, giving is not solely motivated by receiving, nor is it completely altruistic. Instead, there are messages that accompany the gift. The type of gift and how and when it was given reflect cultural understandings. The gift of a sampler or quilt from a grandmother to her granddaughter was a way to pass on some of

\footnotetext{
${ }^{137}$ Vital Records of Sturbridge; 1850 United States Census; Pierce, Fiske and Fisk Family, 254.

${ }^{138}$ Premo, Winter Friends, 37, 40.
} 
her identity while also suggesting the kind of woman that she wanted her relative to be.

As Weiner explained, “in general, all personal possessions invoke an intimate connection with their owners, symbolizing personal experience that...adds value to the person's social identity." ${ }^{139}$ When samplers and quilts were passed down from generation to generation, they gained not only personal or familial value but also cultural value, becoming symbols of an earlier period of American history. ${ }^{140}$ Long after she died, a woman's needlework could serve as a memorial of her life. ${ }^{141}$

When Amy Fiske sat down to stitch her sampler in 1852, she figuratively drew four generations of women around her - her mother, herself, her daughter and her greatniece. She combined the new products of her old age with the traditions of her youth to cope with the changes taking place around her and to leave a lasting message for her family. Amy Fiske died in 1859, at the age of seventy-four, leaving a sampler that bridges her lessons as a schoolgirl and her accomplishments as a woman. As these pages will show, she was not alone in using her needle to do this.

\footnotetext{
${ }^{139}$ Weiner, Inalienable Possessions, 36.

${ }^{140}$ Ulrich, The Age of Homespun, passim.

${ }^{141}$ Swan, Plain and Fancy, 57, 60.
} 


\section{CHAPTER 1}

\section{GROWING OLD GRACEFULLY}

During the mid 1830s, eight-year-old Eleanor Caroline Malone (1828-1894) of Boston, Massachusetts, made a sampler (figure 1.1). ${ }^{1}$ The sampler, with its flowering vine, alphabets, verse, trees and house motif, resembles countless schoolgirl samplers. Malone signed hers in traditional fashion along the bottom, "Eleanor Caroline Malone aged 8 years." When she originally stitched the sampler, it also included the year it was made, stitched after her age. But, at some later date, that year was removed from the sampler, each digit deliberately picked out.

The alteration of Malone's sampler seems distinctly at odds with antebellum prescriptive literature, which provided specific goals for aging women: "The woman that knows how to grow old gracefully, will adapt her dress to her figure and her age, and wear colours that suit her present complexion...She will allude to her age as a thing, of course; she will speak without hesitation of former times, though the recollection proves her to be really old."2 Women like Malone did not leave letters or diaries explaining the choice to unstitch part of their samplers so the nagging question of why it happened

\footnotetext{
${ }^{1}$ The sampler is currently in a private collection. It is pictured in Mary Jaene Edmonds, Samplers and Samplermakers: An American Schoolgirl Art 1700-1850 (London: Rizzoli, 1991), 60. In 1847, when she was about nineteen, Malone married Walter E. Dodge (b. 1821) in Wisconsin. A Dodge family genealogy gives Malone's date of birth as February 21, 1828. Dodge was a carpenter, but also worked the gold mines in California in 1849, as well as running a boardinghouse there. He became a Mormon in the 1850s and the family followed Brigham Young to Utah. Eleanor died in Utah on March 4, 1894. The couple had eight children. See Joseph Thompson Dodge, Genealogy of the Dodge Family of Essex County, Mass., 16291894 (Madison, WI: Democrat Printing Company, 1898), 583-585. Additional genealogical information from www.ancestry.com, accessed on February 18, 2008.

${ }^{2}$ Eliza Leslie, The Behaviour Book (Philadelphia: Willis P. Hazard, 1854), 335-336. Eliza Leslie (17871858) was born in Philadelphia, Pennsylvania, to Robert Leslie (a watchmaker) and Lydia Baker. The family lived in London from 1793 to 1799. After her father's death in 1803, Leslie and her mother took in boarders, while Leslie also taught drawing. In the early 1820s she began her writing career by publishing a cookbook, and was then encouraged by her publisher to write juvenile stories. She continued writing throughout her life. She died in Gloucester, New Jersey, in 1858. Jean Pfaelzer, "Leslie, Eliza,"
} 


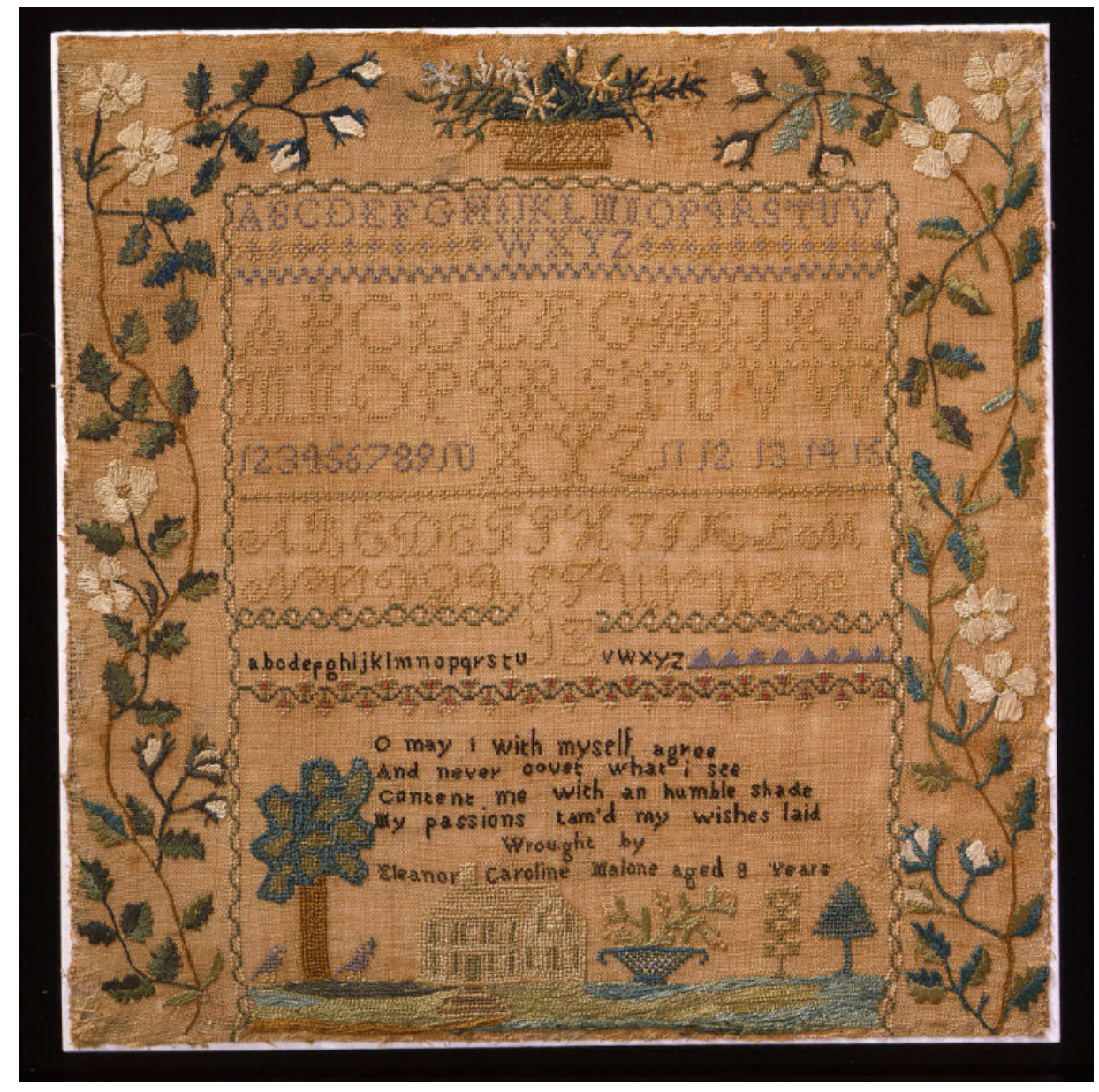

Figure 1.1. Sampler by Eleanor Caroline Malone (1828-1894), 1836, Boston, Massachusetts. Gene Ogami, photographer; courtesy Los Angeles County Museum of Art; copyright: Mary Jaene Edmonds.

Verse: $O$ may I with myself agree, And never covet what I see, Content me with an humble shade, My passions tam'd my wishes laid. Wrought by Eleanor Caroline Malone aged 8 years.

Abrasions in the fabric of this sampler, next to the maker's age, suggest that she originally included the year that she stitched it. At a later time, these numbers were picked out of the sampler, hiding the maker's age to those who might see it hanging in her parlor as she grew older.

http://www.anb.org.silk.library.umass.edu:2048/articles/16/16-00985.html, American National Biography Online Feb. 2000; accessed November 21, 2009. 
remains. Vanity seems a likely explanation for why antebellum women wanted to turn back time: to stem the tide of growing older by recapturing their youth, or to escape the encroaching reality of life's end, perhaps shedding light on a question that others have explored - when did aging become regarded in a negative light? In addition, as mature women experienced menopause, signaling the end of their childbearing years, they were set free from the biological restraints of menstruation and pregnancy, giving some a second lease on life along with a new sense of freedom and purpose. ${ }^{3}$ Period etiquette guides and prescriptive literature, in addition to portraits of mature women, present the cultural ideal of the aging antebellum woman; the words of the women, in letters and diaries, illuminate the reality of the aging process; and their needlework mediates the tension between the two.

\section{Hiding Her Age}

Malone was not alone in removing age-identifying information from her girlhood sampler. Twenty-eight such samplers have been identified for this study (see table 1.1). ${ }^{4}$

As the images reproduced here show, these samplers are generally in good condition with just a few numbers missing in key spots; they are not suffering from deterioration throughout, nor do they have tears or rips that have rendered them illegible.

\footnotetext{
${ }^{3}$ Carroll Smith-Rosenberg, Disorderly Conduct: Visions of Gender in Victorian America (New York: Oxford University Press, 1985), 191.

${ }^{4}$ These samplers were made by American girls and were altered in some manner by having part of the original stitching picked out. They were carefully examined in person or in photographs to determine that the information was intentionally picked out and that it did not simply deteriorate due to age or materials. If it was not possible to determine whether the missing stitches were removed intentionally, the sampler was not included in the group. A silk needlework picture was also uncovered during this survey. Originally stitched in 1819, the year was reverse-painted on the glass covering the picture when it was framed. At an unknown time, the year was painted over. This piece was appraised on an episode of PBS's Antiques Roadshow, first aired on January 5, 2009; the transcript of the appraisal, along with photographs of the picture, were accessed at www.pbs.org/wgbh/roadshow/archive/20001A14.html on January 6, 2009.
} 


\section{Table 1.1. Samplers Altered by Having Date or Age Picked Out}

\begin{tabular}{|c|c|c|c|c|}
\hline $\begin{array}{l}\text { Name and Life } \\
\text { Dates }\end{array}$ & $\begin{array}{l}\text { Sampler } \\
\text { Date }\end{array}$ & Town and State & $\begin{array}{l}\text { Age when } \\
\text { sampler } \\
\text { made }\end{array}$ & $\begin{array}{l}\text { Information } \\
\text { Picked Out }\end{array}$ \\
\hline $\begin{array}{l}\text { Sarah L. Art } \\
(1793-1875)^{5}\end{array}$ & 1806 & Lewes, DE & 13 & Age \\
\hline $\begin{array}{l}\text { Martha Jane } \\
\text { Avery }^{6}\end{array}$ & & & & Year \\
\hline Sarah Berry $^{7}$ & Circa 1820 & & 13 & Year \\
\hline $\begin{array}{l}\text { Eveline Borden (b. } \\
1816)^{8}\end{array}$ & $182 ?$ & Tiverton, MA & & Year \\
\hline $\begin{array}{l}\text { Henrietta } \\
\text { Bradford }^{9}\end{array}$ & $18 ? 3$ & MA & & Age, year \\
\hline $\begin{array}{l}\text { Sarah Stanley } \\
\text { Brown }^{10}\end{array}$ & $\begin{array}{l}\text { Circa 1820- } \\
1830\end{array}$ & Honeybrook, PA & & Birthdate \\
\hline $\begin{array}{l}\text { Lucretia Buttrick } \\
(1801-1892)^{11}\end{array}$ & & Concord, MA & & Age, year \\
\hline $\begin{array}{l}\text { Adeline Eliza } \\
\text { Clark (b. 1818) }\end{array}$ & Circa 1830 & $\begin{array}{l}\text { Schenectady, } \\
\text { NY }\end{array}$ & 12 & Year \\
\hline $\begin{array}{l}\text { Tamson C. Evans } \\
\text { (poss. b. 1796) }^{13}\end{array}$ & & Possibly VT & 11 & Birthdate \\
\hline $\begin{array}{l}\text { Ann Maria Foltz } \\
\text { (b. 1820) }\end{array}$ & Circa 1830 & PA & 10 & Year \\
\hline Eliza Goddard $^{15}$ & $\begin{array}{l}\text { Possibly } \\
1813 \\
\end{array}$ & $\begin{array}{l}\text { Possibly Athol, } \\
\text { MA }\end{array}$ & 8 & Year \\
\hline Agnes Grubb $^{16}$ & 1825 & Mid-Atlantic & & Age \\
\hline $\begin{array}{l}\text { Hetty Rosalia } \\
\text { Gruet }^{17}\end{array}$ & Circa 1820 & Probably PA & 12 & Year \\
\hline Mary Halfline ${ }^{18}$ & Circa 1780 & Probably PA & 11 & Year \\
\hline
\end{tabular}

${ }^{5}$ Collection of Winterthur Museum and Country Estate, Winterthur, DE.

${ }^{6}$ Collection of Historic New England, Haverhill, MA.

${ }^{7}$ Private collection; illustrated in M. Finkel and Daughter, Samplings 1 (1992), 5.

${ }^{8}$ Collection of Plymouth Antiquarian Society, Plymouth, MA. Referenced in Mary M. Davidson, Plimoth Colony Samplers (Marion, MA: The Channings, 1975), 42.

${ }^{9}$ Referenced in Davidson, Plimoth Colony Samplers, 43.

${ }^{10}$ Private Collection; illustrated in The Sampler Engagement Calendar 1992 by Stephen and Carol Huber.

${ }^{11}$ Collection of the Concord Museum, Concord, Massachusetts.

${ }^{12}$ Private collection; illustrated in M. Finkel and Daughter, Samplings 13 (1998), 2.

${ }^{13}$ Collection of Old Sturbridge Village, Sturbridge, Massachusetts.

${ }^{14}$ Private collection; illustrated in M. Finkel and Daughter, Samplings 5 (1994), 10.

${ }^{15}$ Collection of Old Sturbridge Village, Sturbridge, Massachusetts.

${ }^{16}$ Private collection; illustrated in M. Finkel and Daughter, Samplings 22 (2002), 3.

${ }^{17}$ Illustrated in Betty Ring, American Needlework Treasures: Samplers and Silk Embroideries from the Collection of Betty Ring (New York: E.P. Dutton, 1987).

${ }^{18}$ Illustrated in Sotheby Parke Bernet Inc., The Theodore H. Kapnek Collection of American Samplers (New York: Sotheby Parke Bernet Inc., 1981), lot 14. 


\begin{tabular}{|c|c|c|c|c|}
\hline $\begin{array}{l}\text { Mary Hearn (b. } \\
1782)^{19}\end{array}$ & 1793 & Nantucket, MA & 10 & Birthdate \\
\hline $\begin{array}{l}\text { Margaret } \\
\text { Larkum }^{20}\end{array}$ & 1799 & Philadelphia, PA & & Age \\
\hline $\begin{array}{l}\text { Eleanor Caroline } \\
\text { Malone }(1828- \\
1894)^{21}\end{array}$ & 1836 & Boston, MA & 8 & Year \\
\hline Lucretia Mulford $^{22}$ & 1785 & CT & & Age \\
\hline $\begin{array}{l}\text { Emily C. } \\
\text { Rawlings }^{23}\end{array}$ & Circa 1820 & $\begin{array}{l}\text { Probably } \\
\text { Baltimore, MD }\end{array}$ & 10 & Age \\
\hline Eliza Sibbett ${ }^{24}$ & Circa 1830 & $\begin{array}{l}\text { Probably } \\
\text { Philadelphia, PA }\end{array}$ & $\begin{array}{l}\text { Probably } \\
18\end{array}$ & Age \\
\hline $\begin{array}{l}\text { Eliza Sockman } \\
(1807-1887)^{25}\end{array}$ & 1821 & Wheeling, WV & 14 & Year \\
\hline $\begin{array}{l}\text { Sally Bowen Story } \\
(1789-1872)^{26}\end{array}$ & Circa 1800 & $\begin{array}{l}\text { Marblehead, } \\
\text { MA }\end{array}$ & Ca. 11 & Year \\
\hline $\begin{array}{l}\text { Susanna Bradford } \\
\text { Tillson }(1807- \\
1835)^{27}\end{array}$ & 1817 & Plymouth, MA & 10 & Year \\
\hline $\begin{array}{l}\text { Ann Titus (1811- } \\
1886)^{28}\end{array}$ & 1823 & NY & 12 & Age \\
\hline Chloe Trask $^{29}$ & Circa 1820 & MA & & Year \\
\hline C.A. Wetmore ${ }^{30}$ & & New York & & Age, date or year \\
\hline $\begin{array}{l}\text { Margaret } \\
\text { Wetmore (1810- } \\
1843)^{31}\end{array}$ & 1823 & $\mathrm{OH}$ & & Age \\
\hline S.E. Wheeler ${ }^{32}$ & 1840 & $\mathrm{OH}$ & & Unknown \\
\hline
\end{tabular}

${ }^{19}$ Collection of the National Archives; illustrated and discussed in Jennifer Davis Heaps, "Remember Me: Six Samplers in the National Archives," Prologue 34 (Fall 2002): 185-195.

${ }^{20}$ Illustrated in The Sampler Engagement Calendar 1992 by Stephen and Carol Huber.

${ }^{21}$ Private collection; illustrated in Edmonds, Samplers and Samplermakers, 60.

${ }^{22}$ Illustrated in The Sampler Engagement Calendar 2000 by Stephen and Carol Huber.

${ }^{23}$ Collection of the Daughters of the American Revolution Museum, Washington, DC.

${ }^{24}$ Illustrated in Stephen and Carol Huber, Samplers: How to Compare and Value (London: Mitchell Beazley, 2002), 148.

${ }^{25}$ Collection of the Ohio Historical Society, Columbus, $\mathrm{OH}$.

${ }^{26}$ Collection of Peabody Essex Museum, Salem, MA.

${ }^{27}$ Private collection; illustrated in M. Finkel and Daughter, Samplings 19 (2001), 25.

${ }^{28}$ Illustrated in The Sampler Engagement Calendar 2001 by Stephen and Carol Huber.

${ }^{29}$ Illustrated in Huber, Samplers: How to Compare and Value, 101.

${ }^{30}$ Collection of Litchfield Historical Society, Litchfield, CT.

${ }^{31}$ Collection of Western Reserve Historical Society, Cleveland, OH.

${ }^{32}$ Private collection; illustrated in Jeanmarie Andrews, "The Stories Behind the Samplers," Early American Life 35 (June 2004): 55. 
The missing numbers are clearly the conscious work of the maker or another person. Take, for example, the sampler made by Sally M. Bowen (1789-1872), of Marblehead, Massachusetts (figure 1.2). ${ }^{33}$ Based on its similarities to other samplers from Marblehead, Bowen probably stitched her sampler around 1800 when she was eleven. ${ }^{34}$ At a later date, the year that she made the sampler was removed.

In this group of twenty-eight samplers, almost half (13) were altered by having part or all of the year the sampler was originally made picked out. Another eleven samplers were altered by having part or all of the maker's age or birth year picked out. Three samplers were altered by especially determined women; they have part or all of both the age or birth year and the year the sampler was made removed. And, one sampler had stitching picked out, but it is unclear what the missing information conveyed. In many cases - seventeen out of the twenty-eight samplers identified - these alterations, designed to conceal information, remain successful in the twenty-first century despite the wide accessibility of genealogical records at research libraries and on the internet. Without crucial bits of information such as the maker's birth year or age in a particular year, the lives of these makers cannot be traced, particularly when there is more than one girl with the same name born around the same time. For example, the sampler made by Emily C. Rawlings (dates unknown) cannot be conclusively identified or dated today

\footnotetext{
${ }^{33}$ The sampler is in the collection of the Peabody Essex Museum, Salem, Massachusetts. I am indebted to Paula Bradstreet Richter, Curator of Textiles and Costumes, for showing me the sampler and sharing the curatorial file. Bowen married Isaac Story Jr. in 1813 and the couple had at least twelve children. Paula Bradstreet Richter, Painted with Thread: The Art of American Embroidery (Salem, MA: Peabody Essex Museum, 2002), 42.

${ }^{34}$ Betty Ring, Girlhood Embroidery: American Samplers and Pictorial Needlework 1650-1850 (New York: Alfred A. Knopf, 1993), 131-142; Richter, Painted with Thread, $42-43$.
} 


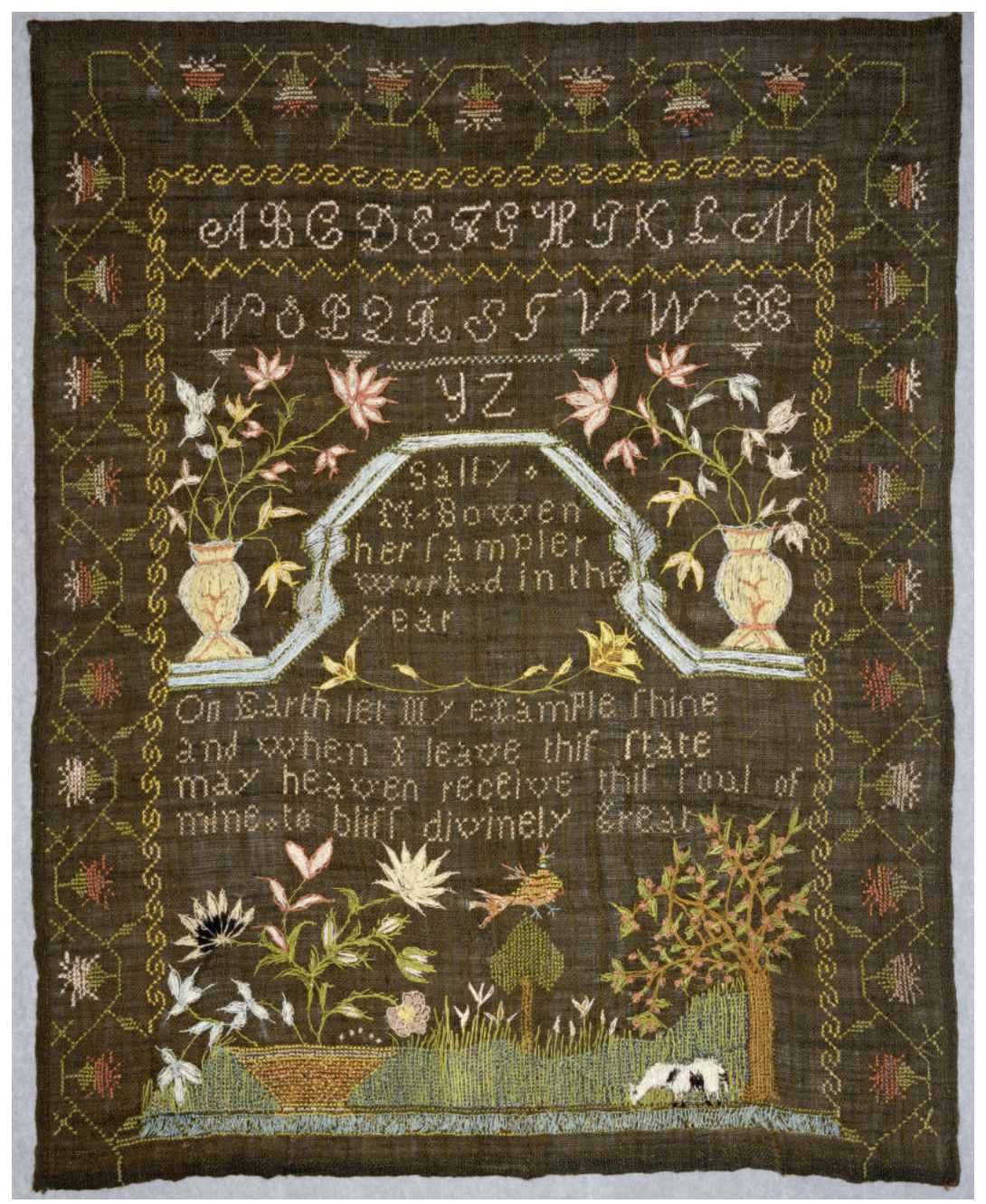

Figure 1.2. Sampler by Sally M. Bowen (1789-1872), circa 1800, Marblehead, Massachusetts. Courtesy Peabody Essex Museum, Salem, Massachusetts.

Verse: On Earth let my example shine, and when I leave this state, may heaven receive this soul of mine to bliss divinely great.

Like several other examples shown here, someone later altered Sally M. Bowen's sampler by picking out the year that she initially stitched it. Based on similarities to dated samplers from the Marblehead, Massachusetts, area, Bowen's sampler was probably stitched around 1800 . She signed it with her birth name, strongly suggesting that she made it as a young girl, rather than after she married, despite a verse that acknowledges life's end. 
(figure 1.3). ${ }^{35}$ When she originally stitched the piece, she included a line along the bottom with her name, "Emily C. Rawlings wrought this [picked out]." The remaining part of the line probably read "in her $10^{\text {th }}$ year," based on the few stitches that remain and the "ghosting" of the previously-stitched letters visible on the fabric (see figure 1.4 for a detail of the sampler's picked out area). A comparison of the design and format to other samplers, whose origin is conclusively identified, suggests that Rawlings made her sampler in Baltimore in the 1820s, but we cannot know for sure, as there were several girls named Emily Rawlings in Maryland at the time. ${ }^{36}$

For the other altered samplers identified in this study (11), the maker can be identified and her life dates at least partially filled in. With the help of published sources, the sampler made by Sarah L. Art (1793-1875) in 1806 can be determined to have been made when she was thirteen (figure 1.5). ${ }^{37}$ At the time she made the sampler she included her age, but these numbers were later picked out, though when and why we do not know.

The literature on American samplers shows that the act of altering them was not uncommon. As one scholar explains, "A large number of sampler embroideries

\footnotetext{
${ }^{35}$ The sampler is now in the collection of the Daughters of the American Revolution Museum, Washington, DC. I am indebted to Olive Blair Graffam, Curator of Collections/Research Associate at the Museum, for bringing it to my attention.

${ }^{36}$ Ring, Girlhood Embroidery, 509; Gloria Seaman Allen, A Maryland Sampling: Girlhood Embroidery 1738-1860 (Baltimore: Maryland Historical Society, 2008), 208.

${ }^{37}$ The sampler is now in the collection of Winterthur Museum and Country Estate in Delaware. Sarah Lees Art was born in Delaware in 1793, the daughter of Baily Art (d. 1820) and Sarah Lees (1773-1797). She married James Rowland (1784-1851) in January 1813. The Art family lived in Lewes, Delaware, where the men worked as river pilots. The sampler was handed down in the family until it was given to Winterthur. Information from the curatorial files at Winterthur Museum and Country Estate. I am indebted to Linda Eaton, Curator of Textiles at Winterthur Museum and Country Estate, for bringing this sampler to my attention.
} 


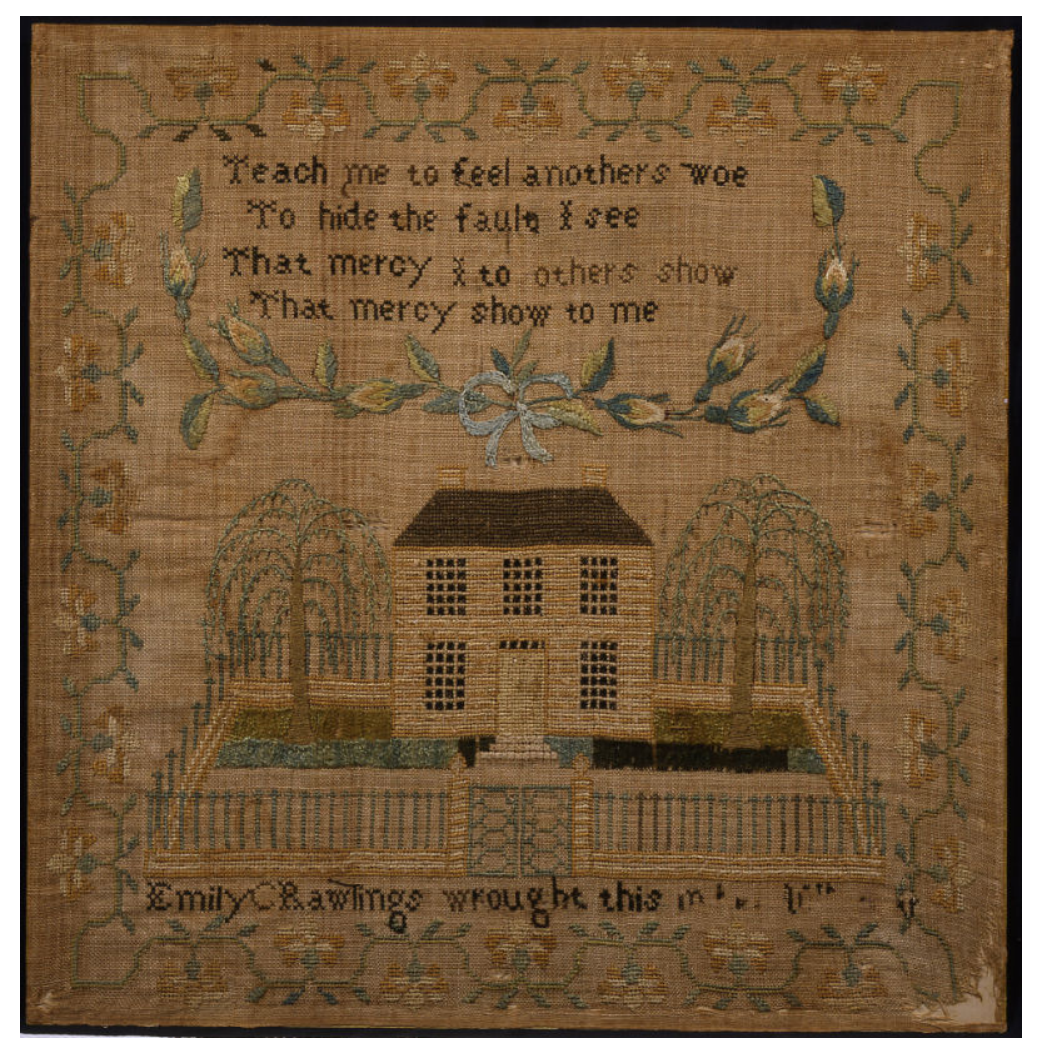

Figure 1.3. Sampler by Emily C. Rawlings, circa 1820, probably Baltimore, Maryland. Collection of the Daughters of the American Revolution Museum, Washington, DC.

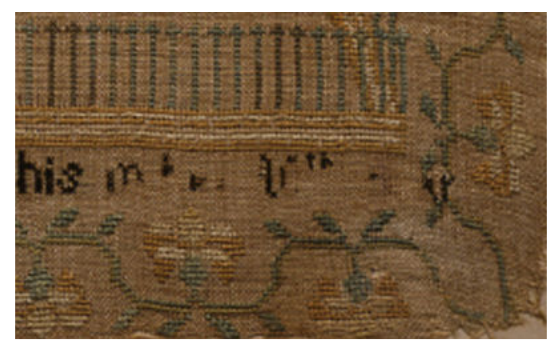

Figure 1.4. Detail of sampler by Emily C. Rawlings.

While genealogical records allow us to fill in the missing data on some picked-out samplers, others remain a mystery. Someone altered the section that told the maker's age on Emily C. Rawlings' sampler (see the detail above). Even though it appears to read "in her $10^{\text {th }}$ year," there are too many girls named Emily Rawlings to know which one might have made this sampler. 


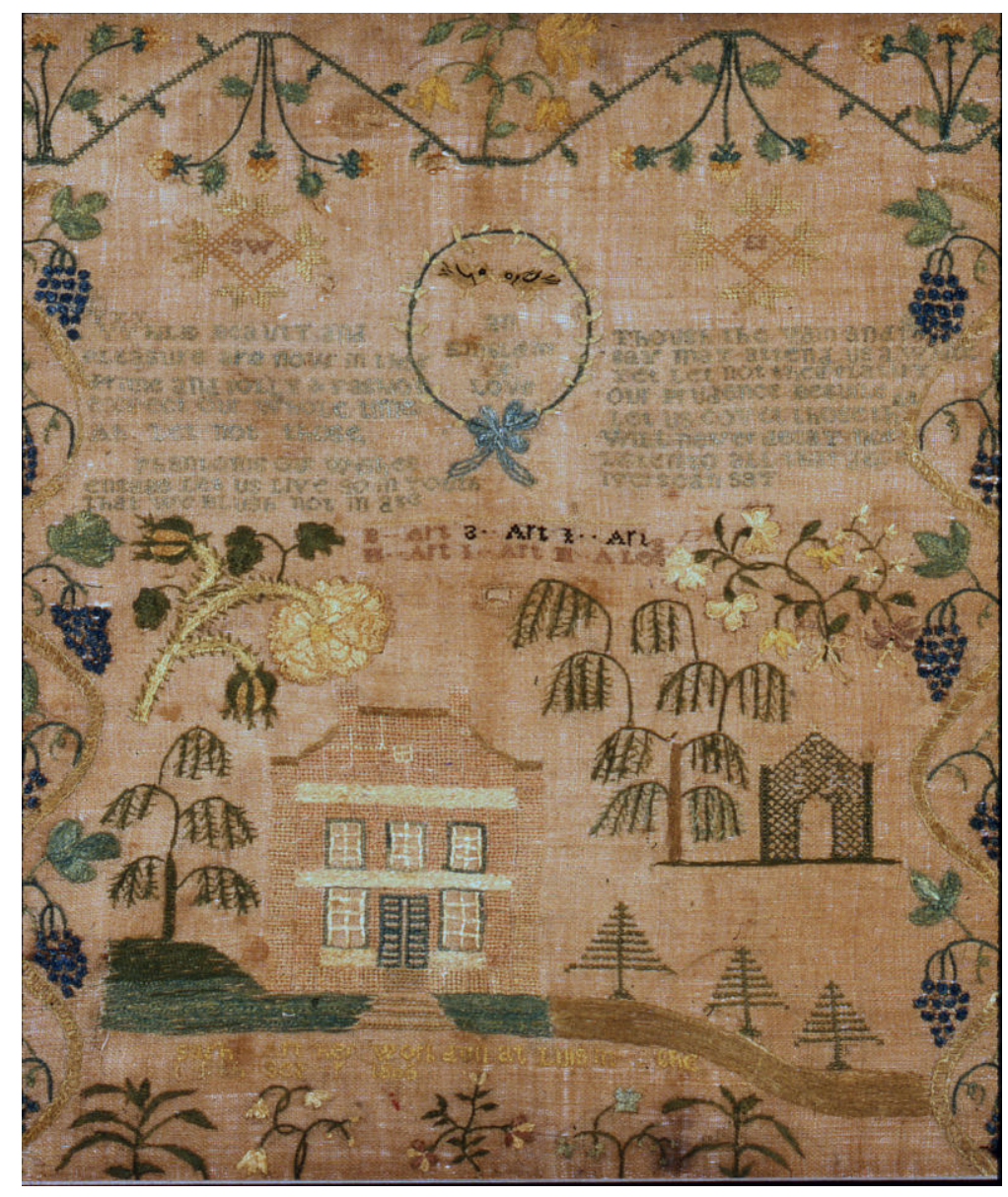

Figure 1.5. Sampler by Sarah L. Art (1793-1875), 1806, Lewes, Delaware. Collection of Winterthur Museum and Country Estate, Delaware.

Verses:

While beauty and pleasure are now in ther prime and folly \& fashion exact our whole time, Ah let not those phantoms our wishes engage, let us live so in youth that we blush not in age.

Though the vain and the gay may attend us a while, Yet let not their flattery our prudence beguile, Let us covet those that will never decay, noy listen to all that [illeg] [illeg]s can say.

While the precise identity of the Emily C. Rawlings who made the sampler shown in figures 1.3 and 1.4 is still unknown, the maker of this sampler can be determined. Despite the fact that her sampler was altered, we know that Sarah L. Art of Lewes, Delaware stitched this when she was thirteen in 1806. 
underwent similar alterations as their makers grew to adulthood." ${ }^{38}$ Overwhelmingly, these same sources explain this act as one of vanity, stating that "many women disliked such conspicuous evidence of their age." ${ }^{, 39}$ But, these authors, products of our own time, accept that a woman would want to hide her age, and do not problematize the act in a historical context.

Decorative schoolgirl samplers like the ones identified here were made to be framed and hung proudly on the wall of the family parlor. Countless newspaper ads from the early nineteenth century offered frames specifically to display needlework. ${ }^{40}$ An English cartoon from 1809 shows the prominent placement of one girl's framed sampler in her parents' parlor (figure 1.6); the same tradition was followed in America. ${ }^{41}$ Sarah Anna Smith Emery (1787-1879) of Newbury, Massachusetts, remembered that "One was considered very poorly educated who could not exhibit a sampler; some of these were large and elaborate specimens of handiwork; framed and glazed, they often formed the chief ornament of the sitting room or best parlor." 42 While continuing to showcase a woman's skill with the needle and her familiarity with the elements of a genteel lifestyle, by the time she entered her forties and beyond the sampler also continued to proclaim its maker's age to all who entered the parlor.

\footnotetext{
${ }^{38}$ Edmonds, Samplers and Samplermakers, 60.

${ }^{39}$ Ring, American Needlework Treasures, 66.

${ }^{40}$ See examples cited in: Susan Burrows Swan, Plain and Fancy: American Women and Their Needlework, 1650-1850 (Austin, Texas: Curious Works Press, 1995), 57; Glee Krueger, New England Samplers to 1840 (Sturbridge: Old Sturbridge Village, 1978), 10-11; Ring, Girlhood Embroidery, 24.

${ }^{41}$ Titled Farmer Giles and his Wife showing off their daughter Betty to their Neighbours on her return from School, the print is by James Gillray (1757-1815) of London. The copy in figure 1.5 is in the collection of Princeton University Library, Department of Rare Books and Special Collections, Princeton, New Jersey.

${ }^{42}$ Sarah Anna Emery, Reminiscences of a Nonagenarian (Newburyport, MA: W.H. Huse and Company, 1879), 222.
} 


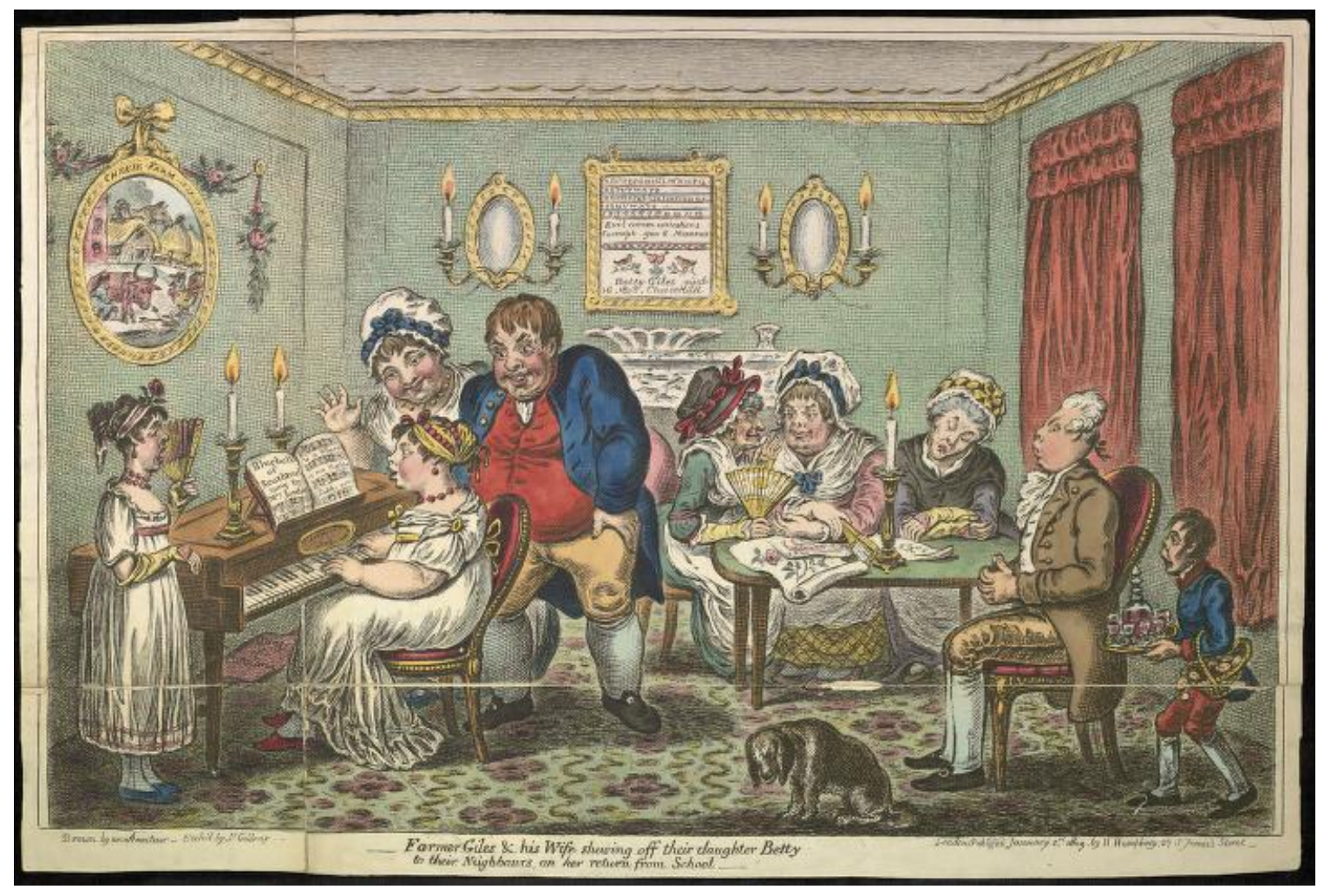

Figure 1.6. Farmer Giles and his wife showing off their daughter Betty to their neighbours, on her return from school by James Gillray (1757-1815), 1809, London, England. Collection of Princeton University Library, Princeton, New Jersey.

This satirical English print shows the prominence given to young ladies' samplers - one is framed and hung in a central spot on the parlor wall. Given this high visibility, many women seem to have become shy about broadcasting their age in this manner later in life, perhaps explaining why so many samplers show evidence of having dates or ages picked out. 
The interpretation that aging women picked out numbers from their samplers themselves to hide their age is compelling. ${ }^{43}$ But this seems to be a direct contrast to prevailing cultural prescriptions to act one's age. The authors of prescriptive literature did not specifically discourage the act of altering one's sampler, but they did counsel women to act their age and to be proud of their life experiences by "speak[ing] without hesitation of former times. ${ }^{, 44}$ By implication, they offered reasons not to alter a schoolgirl sampler, instead encouraging women to cherish an item like their sampler as a touchstone to the past, even though the sampler would indicate its maker's aging station in life.

But, prescriptive literature routinely contradicts practice, and the choice made by these women to act with their needles is revealing. The sampler itself was generally a girlhood project, and, like other forms of sewing, was taught, in part, by requiring the girl to take out stitches that were not correct. The narrator of one 1852 story explained the frustration that this method often involved: "very seldom did [my teacher] let me put up

\footnotetext{
${ }^{43}$ More perplexing is a subset of samplers whose makers died before reaching their 30s yet still have the date and/or age picked out. Did the maker do the picking out in her teens or twenties, suggesting that she was already conscious of growing older? This seems to have been the case for Elizabeth Sockman (18071887) of Wheeling, West Virginia, who, according to a family story, picked out two digits of the year she made her sampler in order to hide her true age from a beau. The sampler is now in the collection of the Ohio Historical Society, Columbus, Ohio; Sockman initially stitched it when she was fourteen. Email correspondence from Jason A. Crabill, Assistant Registrar, Ohio Historical Society, April 25, 2008. I am indebted to Jason A. Crabill and to Cheryl Straker, Curator of History, Ohio Historical Society, for sharing this story with me. Lifedates for Sockman from www.ancestry.com, accessed February 18, 2008. In other cases, it may have been a relative who picked out the dates, perhaps urged on by their own modesty or aging process. This could also have been a reaction to the untimely death of the maker, picking out information to make the death of a loved one less real. The sampler made by Susanna Bradford Tillson (1807-1835) of Plymouth, Massachusetts, in 1817, provides an example of this subset (the sampler is now in a private collection but is published in M. Finkel and Daughter, Samplings 19 (2001): 25). Tillson died in 1835 when she was just twenty-eight years old. She married in 1831 and had a daughter who survived to adulthood, Susan Elizabeth Barnes, born in January 1834. Benjamin Shurtleff and N.B. Shurtleff, The Descendants of William Shurtleff of Plymouth and Marshfield, Massachusetts (Revere, Massachusetts: [n.p.], 1912), 583. Unfortunately, it is impossible to know whether Susanna herself tampered with her age on the sampler before her early death, or whether her daughter, or another relative, made the alteration to cover their own age, or to preserve the memory of Susanna herself.

${ }^{44}$ Leslie, The Behaviour Book, 335-336.
} 
my work till the "stint" was done. And so, with much inward fuming and fretting, I

learned to sew, and very neatly too; for what was done ill must be picked out."45 No less an authority than Catharine Beecher (1800-1878) set out the ideal. "The neatest sewers always fit and baste their work, before sewing," she claimed, "and they say they always save time in the end, by so doing, as they never have to pick out work, on account of mistakes." 46 Picking out her age from her sampler may have offered a sense of agency to these women, in comparison to their girlhood sewing lessons.

Lucretia Buttrick’s (1801-1892) sampler, originally stitched in the 1810s, was also altered later in its life when her age was removed (figure 1.7). ${ }^{47}$ And, Buttrick was not exact about her age on the U.S. Census as she grew older. In 1850, she was listed as forty-nine years old - her correct age - but in 1860, she was listed as fifty-three years old, six years younger than she actually was. And, in 1870, she gave her age as

\footnotetext{
${ }^{45}$ Mrs. E.B. Hall, My Thimbles (Boston: Crosby, Nichols and Company, 1852), 7. See also Pat Ferrero, Elaine Hedges, and Julie Silber, Hearts and Hands: Women, Quilts and American Society (Nashville: Rutledge Hill Press, 1987), 19, who write that "many women painfully recalled patchwork "smudged and blackened" from being worked and reworked, or knitting "soiled with constant handling by dirty fingers.", ${ }^{46}$ Catharine E. Beecher, A Treatise on Domestic Economy (Boston: Marsh, Capen, Lyon and Webb, 1841), 378. Catharine Esther Beecher was born in New York in 1800, the daughter of Evangelical Episcopalian preacher Lyman Beecher and Roxana Foote. The family moved to Litchfield, Connecticut in 1810 where Catharine attended private school. After her fiancée died in 1822, Catharine opened the Hartford Female Seminary in 1823 and ran the school until 1830. In 1831, she moved to Cincinnati with her family and opened another school, which she ran until 1837. She never married, instead writing and speaking on woman's role in society through the 1860s. Catharine Beecher died in 1878. Biographical information from North American Women's Letters and Diaries database, http://solomon.nwld.alexanderstreet.com.silk.library.umas.edu:2048/bios/A2557BIO.html, accessed September 12, 2009.

${ }^{47}$ The sampler is now in the collection of the Concord Museum, Concord, Massachusetts. I am indebted to Curator David Wood and Registrar Erin McGough for facilitating my study visit in September 2005. Lucretia Buttrick was born in Concord, Massachusetts in 1801 and married John Buttrick (1796-1880) of Waltham, Massachusetts in 1828. John was a carpenter and the couple lived in Lowell, where they had four children. See William Richard Cutter, Historic Homes and Places and Genealogical and Personal Memoirs Relating to the Families of Middlesex County, Massachusetts (New York: Lewis Historical Pub. Co., 1908), 451-452 and George Tolman, Concord, Massachusetts: Births, Marriages and Deaths, 16351850 (Boston: T.Todd, printer, 1895), 279, 391.
} 


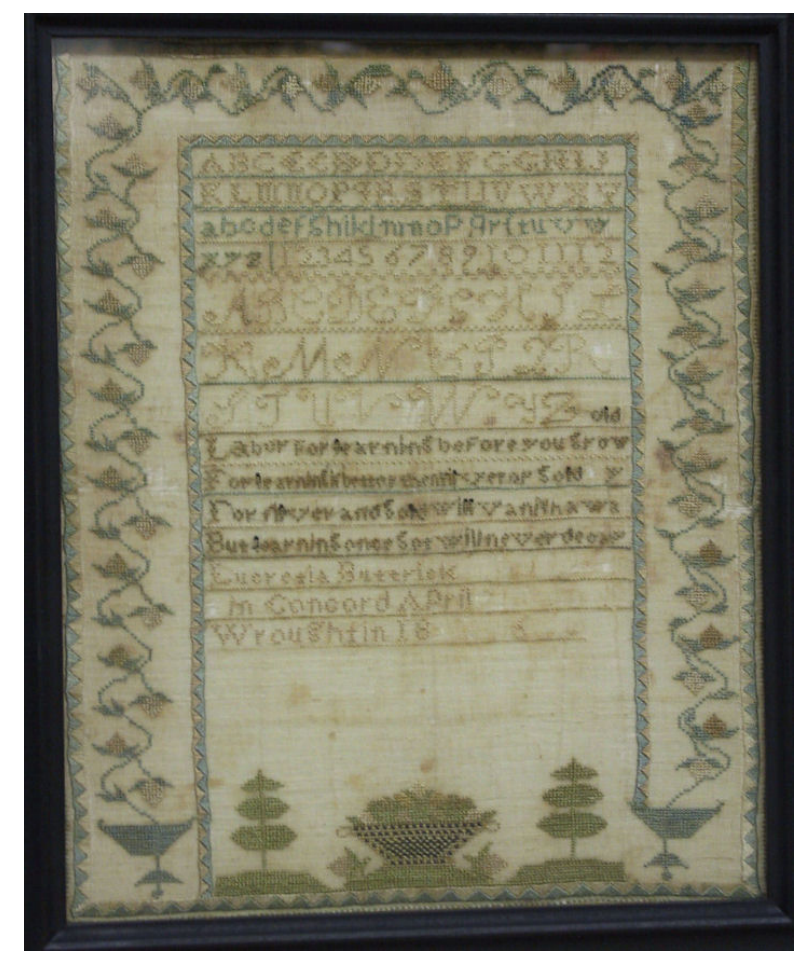

Figure 1.7. Sampler by Lucretia Buttrick (1801-1892), Concord, Massachusetts. Courtesy Concord Museum, Concord, Massachusetts, www.concordmuseum.org.

Verse: Labor for learning before you grow old, For learning is better than silver or gold, For silver and gold will vanish away, But learning once got will never decay.

In addition to removing the date she made the sampler and her age at the time from the piece, Lucretia Buttrick was not always truthful with the Census takers who visited her home as she aged. As she grew older in the late 1800s, Buttrick shaved several years off of her actual age on more than one occasion.

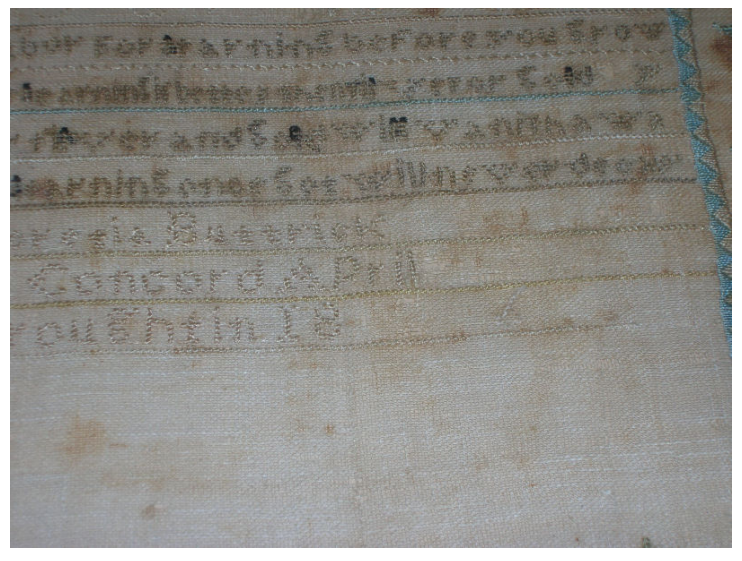

Figure 1.8. Detail of Buttrick sampler showing stitches removed at right. 
fifty-eight, eleven years less than her true age. ${ }^{48}$ In his study of the history of aging in America, David Hackett Fischer discovered that a certain type of "age heaping," providing an incorrect age to the census taker, increased on late-nineteenth century census results. During the eighteenth century, it was quite common for people to round off their ages to end in a five or a zero because they either did not know how old they were, or did not care. However, Fischer found that as literacy increased, this kind of age heaping decreased; instead, people pretended to be younger than they were. He asserts that it was most common for men in their forties and fifties to lie about their age on the census, but the large number of samplers with picked out ages and years suggests that women were equally conscious of their age in the mid-nineteenth century. ${ }^{49}$

By 1880, Buttrick had slightly lessened the gap between her actual age and the age she gave the census taker; she was listed as seventy-five years old (instead of her actual age of seventy-nine). ${ }^{50}$ At some point as a girl she made a sampler that initially included both the year that she made it and her age at that time (see figure 1.8 for detail). Although that information has not been recovered, genealogical records do provide

${ }^{48}$ U.S. Census for 1850 and 1860 from www.ancestry.com, accessed April 2008. U.S. Census for 1870 from www.ancestry.com, accessed November 21, 2009. Buttrick is listed incorrectly as "Lucretia Bultrick" in the online 1870 Census records.

49 David Hackett Fischer, Growing Old in America (New York: Oxford University Press, 1977), 82-84. To supplement the prescriptive evidence, the twelve sampler makers who could be conclusively identified were also tracked through federal Census records to see whether they modified their age when reporting to the Census taker. This sample is quite small to begin with, and only six women of the twelve could be tracked in the Census returns. Of these six, three are listed with incorrect ages. For example, Adeline Eliza Clark Morton (b. 1818) seems to have shaved a few years off her age when the census taker came to call. In 1860, she is listed as forty years old, although her real age at the time was forty-two. Her sampler is in a private collection. It is pictured in M. Finkel and Daughter, Samplings 13 (1998): 2. Adeline Eliza Clark was born on July 12, 1818 in Schenectady, New York. Her sampler is signed along the bottom, "Adeline Eliza Clarks work Aged 12 years 183." The top two-thirds of the sampler provides family information, reading "Charles W. Clark / Died 5 ${ }^{\text {th }}$ Dec. 1829 / Aged 9 years / Joseph Clark died / March $16^{\text {th }} 1828$ / Aged 8 weeks." Adeline married John Morton, a dealer in building materials, according to the 1860 U.S. Census. The Census records that the couple had four children living with them in 1860; their oldest child was born about 1846. U.S. Census information from www.ancestry.com, accessed April 7, 2008. ${ }^{50} 1880$ U.S. Census information from www.ancestry.com, accessed April 2008. The 1890 U.S. Census was destroyed by fire and all records were lost, so we do not know what age Buttrick gave that year when the Census taker came around. 
information about her birthdate and subsequent marriage. In addition, when Buttrick died at the grand old age of ninety, her family produced an elegant memorial card in her honor. Black with gold-stamped lettering, the card includes an image of a book with lettering on the cover, "In Loving Remembrance / of / Mrs. Lucretia Buttrick / Died January 14, 1892 / Aged 90 Years." ${ }^{51}$ The actions of Lucretia Buttrick and the other women discussed here help to show that the aging process was not always embraced in antebellum America. Reactions to growing older varied from woman to woman and from decade to decade. Yet, all of these women shared a common bond - their girlhood sampler - which remained with them throughout their lives, for better or for worse.

\section{The Physical Challenges of Needlework}

Growing older resulted in increasing infirmity and changes in appearance as Catharine Dean Flint (1802-1869) of Boston noted on her fifty-seventh birthday in 1859. "I have lost much in health and strength since my last birth day," she wrote, "and look very much older - a very distressing and long illness in the Autumn has probably made in roads on my frame, which can never again be effaced."52 Exploring the physical effects of aging offers insight about what led a woman to unstitch her sampler.

\footnotetext{
${ }^{51}$ The memorial card is now part of the Buttrick and Buttrick-related papers and ephemera collection, Concord Library, Concord, Massachusetts. The source of the poem is unknown, but an internet search in July 2008 turned up numerous transcriptions of gravestones that quote all or part of the poem during the last half of the nineteenth century. The entire poem on the card reads, "A precious one from us has gone, A voice we loved is stilled; A place is vacant in our home Which never can be filled. God, in His wisdom, has recalled The boon His love had given. And though the body slumbers here, The soul is safe in Heaven."

${ }^{52}$ Diary of Catharine Dean Flint, 1859-1861, Flint Family Papers, American Antiquarian Society, Worcester, Massachusetts. Catherine Dean was born in Charlestown, New Hampshire. In 1828, she married Waldo Flint (1794-1879) of Leicester, Massachusetts. Flint was a lawyer, served as a state senator and representative, and later became president of Boston's Eagle Bank. Flint Family Papers, American Antiquarian Society, Worcester, Massachusetts.
} 
At the age of fifty-six, Vermont wife and mother Roxana Brown Walbridge Watts (1802-1862) considered herself to be growing old. She found that she had less energy and that her fingers were "old and stiff," making it hard to sew and knit. ${ }^{53}$ Watts was certainly not the only antebellum woman to be troubled by the pain of arthritis as she aged. Yet numerous examples of samplers and quilts remain to show that a large number of women continued to stitch and sew as they aged past forty into their fifties, sixties, seventies and beyond. According to family history, while in her fifties or sixties, Lavinia Prigmore Moore (1811-1861) quilted an elegant appliqué quilt with her teeth because the arthritis in her hands was so painful (figure 1.9). ${ }^{54}$ Unfortunately, material evidence suggests that it is doubtful that Lavinia made this particular quilt. She died in 1861, while the quilt employs a green cotton fabric that is usually seen in quilts from the 1870 s and 1880s. ${ }^{55}$ Despite the uncertainty about whether Lavinia Moore made this quilt, the

\footnotetext{
${ }^{53}$ Lynn A. Bonfield and Mary C. Morrison, Roxana's Children: The Biography of a Nineteenth-Century Vermont Family (Amherst: University of Massachusetts Press, 1995), 18-19.

${ }^{54}$ The quilt is currently in a private collection but is pictured as part of the Quilt Index (www.quiltindex.org). Lavinia Eleanor Prigmore was born in 1811 in Tennessee and married Caleb Moore (1808-1864) in 1833. The couple had ten children, the last in 1853. Caleb was in the mercantile business and also farmed. In 1847, he was elected to the state legislature and also became director of the Bank of Tennessee. See biography of Captain James R. Moore, History of Meigs County, Tennessee, www.rootsweb.ancestry.com/ tnmiegs/g moore.html, accessed April 6, 2008. For the family story about quilting with her teeth, see www.quiltindex.org/fulldisplay.php?pbd=tennesseetest-a0a0e3-a, accessed May 1, 2006. Quilting with one's teeth seems physically possible, but would have taken strong motivation and some practice. It seems more likely that Moore combined the use of her hands and her teeth to quilt. The experience of New Hampshire artist Sally Rogers (circa 1789-1871), who was born without the use of her arms and legs, yet toured the country painting watercolors and cutting silhouettes, suggests that women who were motivated to create - whether quilts or paintings - did so. See collections database records for two watercolors by Rogers now in the collection of Historic Deerfield, Inc., http://museums.fivecolleges.edu, accessed March 12, 2009. I am indebted to Ned Lazaro, Collections Manager, Historic Deerfield, for bringing these watercolors, and their artist, to my attention.

${ }^{55} \mathrm{On}$ the dating of the green fabric in the quilt, see email correspondence to the author from Merikay Waldvogel, Co-Director, Quilts of Tennessee Project, April 10, 2009; and Barbara Brackman, Clues in the Calico A Guide to Identifying and Dating Antique Quilts (McLean, VA: EPM Publications, Inc., 1989), 5961.
} 


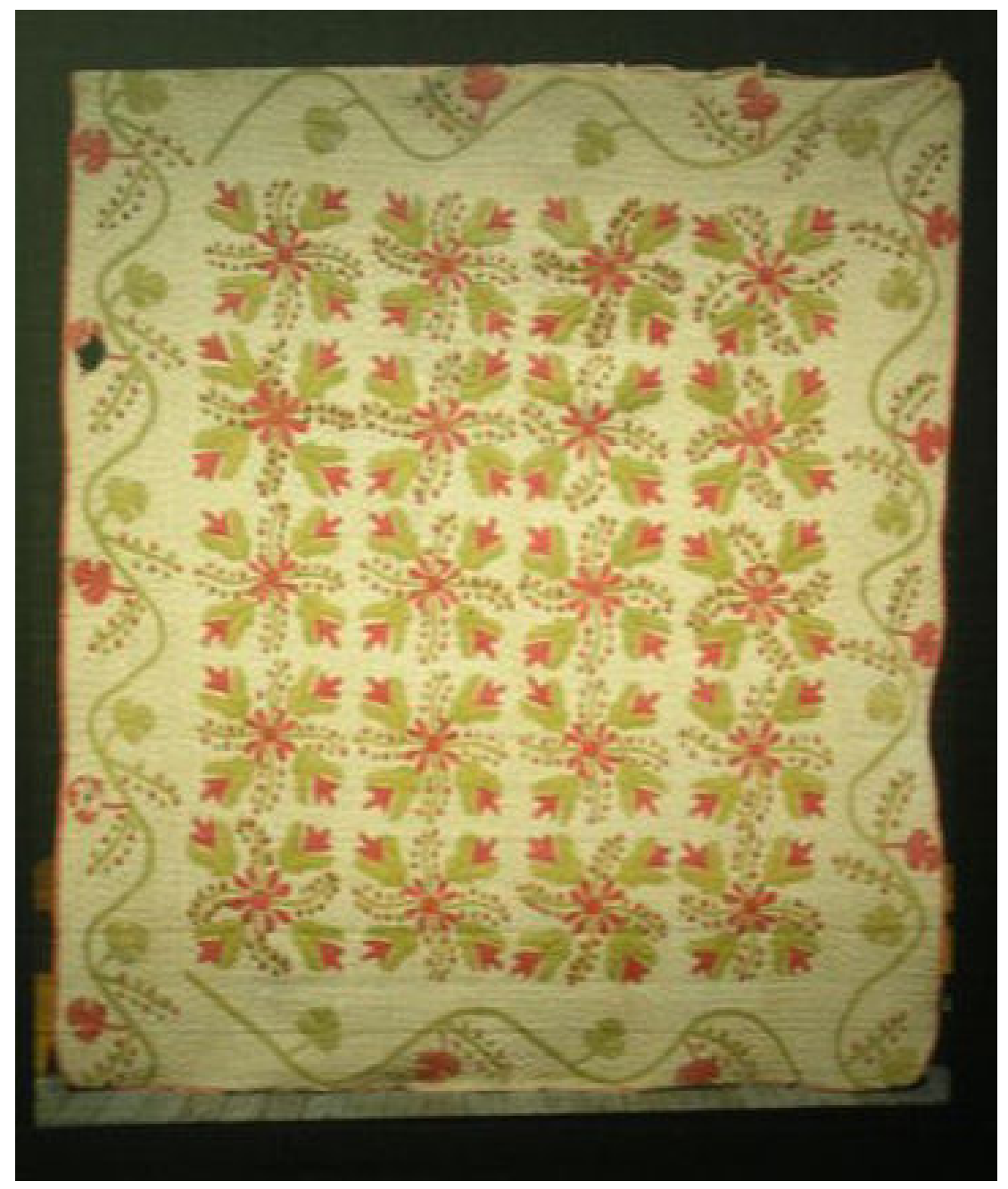

Figure 1.9. Quilt attributed to Lavinia Prigmore Moore (1811-1861), Tennessee. Courtesy of Quilts of Tennessee/Tennessee State Library and Archives.

According to a family story, Lavinia Prigmore Moore quilted this bedcovering with her teeth because the arthritis in her hands was so painful. The family story also suggests that this quilt was made around 1860. Unfortunately, the material evidence in the quilt itself makes a strong case that Moore did not make this particular quilt. The green fabric is typical of those colored with a synthetic dye during the 1870 s and 1880 s, well after Lavinia Prigmore Moore died. When exposed to light and washing, these dyes took on a brownish cast. 
family story tells us that she was known to quilt, and that she was strongly motivated to do so, choosing to find a way around any obstacles.

Few period medical guides and etiquette books addressed the physical effects of aging. Little specific information remains today in published sources to provide a sense of how aging women coped with failing eyesight and hearing, as well as the aches and pains of rheumatism and arthritis, but artifacts for coping - such as canes, spectacles and ear trumpets - can be found. The reason for this, of course, is not that antebellum women did not suffer from these problems, but stems from how physicians understood (or not) the process of aging. Rather than isolating the effects of old age, antebellum physicians, just like doctors today, looked on aging as a natural process - one that could not be cured. So, they treated most adults alike, without considering chronological age. ${ }^{56}$ Survival and longevity were more noteworthy than the physical problems of the elderly. ${ }^{57}$ However, the words of antebellum women themselves help define the most common complaints. Some complained of joint pain. "I have been trying to do something towards making Edward some shirts," noted forty-year-old Ellen Birdseye Wheaton (1816-1858) in a January 1856 diary entry, "I am troubled somewhat, with the Rheumatism in my right arm, and I don't think sewing helps it much."58 Yet, observations like Wheaton's turned up less frequently in antebellum diaries and letters than complaints about other effects of aging.

\footnotetext{
${ }^{56}$ Carole Haber, Beyond Sixty-Five: The Dilemma of Old Age in America's Past (Cambridge: Cambridge University Press, 1983), 47.

${ }^{57}$ Haber, Beyond Sixty-Five, 53.

${ }^{58}$ Donald Gordon, The Diary of Ellen Birdseye Wheaton (Boston: privately printed, 1923), 304-305. Ellen Douglas Birdseye was born in New York in 1816, the daughter of Victory Birdseye and Electa Beebee. She married Charles Augustus Wheaton in 1834 and the couple had twelve children. She died in 1858 at age forty-two. Biographical information from North American Women's Letters and Diaries database, http://solomon.nwld.alexanderstreet.com.silk.library.umass.edu:2048/bios /A219BIO.html, accessed September 12, 2009.
} 
According to sixty-five-year-old Lydia Sigourney (1791-1865), the most frequent problem of age was a loss of hearing. She explained that when it was lost it awakened "the least sympathy...Deafness, more than other infirmities, repels intercourse, and cuts the links that bind man to society." (b. 1770) wrote to her grandson, John Clapp (b. 1822), of Worthington, Massachusetts, in 1852, "I cannot expect to hear many more sermons at my age, but I ought to be thankful that I can see to read them." 60

When it came to needlework, arguably the most difficult effect of aging was changing eyesight. As fifty-eight-year-old Elizabeth Emma Stuart (1792-1866) noted in an 1850 letter to her daughter, Kate (1820-1853), “Today I am fifty-eight years old! Every thing around me admonishes me that winding up is at hand - I am entirely alone...I read \& write, but sew little I cannot see to thread my needle with ease."61 Many mid-century medical books devoted pages to this problem, identifying causes of eye pain and vision loss as well as offering ways to prevent and mitigate vision trouble. ${ }^{62}$ In addition, eye wash products were available from antebellum shops. An 1838 issue of Concord, New Hampshire's New Hampshire Patriot and State Gazette newspaper advertised Dr. Dana's Eye Wash, which claimed to be "excellent for sore eyes, and

\footnotetext{
${ }^{59}$ Lydia H. Sigourney, Past Meridian (Hartford: F.A. Brown, 1856), 30.

${ }^{60}$ Abigail Clapp to John D. Clapp, December 4, 1852, Clapp Family Letters, American Antiquarian Society, Worcester, Massachusetts.

${ }^{61}$ Helen Stuart Mackay-Smith Marlatt, Stuart Letters of Robert and Elizabeth Sullivan Stuart and Their Children 1819-1864 (New York: privately published, 1961), 93.

${ }^{62}$ For example, see: William-Edward Coale, Hints on Health (Boston: Phillips, Sampson and Company, 1852), 147-151; John Harrison Curtis, Observations on the Preservation of Sight (Worcester: C. Harris, 1839), 55-56; J. Henry Clark, M.D., Sight and Hearing, How Preserved, and How Lost (New York: C. Scribner, 1856), 175-179, 200.
} 
peculiar to remove inflammation around the eyes and strengthen the sight, and enable you to see longer without glasses."63

Then, as now, the lenses in the eyes grew continuously over time, becoming less flexible. As a result, as the body ages the muscle that focuses the lens has a harder time focusing on near targets; this is called "presbyopia" and is the reason that people over forty need reading glasses. Those that are far-sighted usually become presbyopic earlier in their lives than those that are not. At the same time, UV light causes cataracts in the lenses. The most common cataracts change the focus of the eyes closer to the body (known as "myopia"). ${ }^{64}$ Indeed, mid-century medical guides observed that eyesight started to change around the age of forty. "Most persons begin to feel the necessity for some assistance to their eyes in reading and working after the age of forty," noted John Harrison Curtis. ${ }^{65}$ The age of forty as a common onset for vision deterioration is supported by antebellum women themselves in their letters and diaries. For example, forty-four-year-old Sarah Jones Hildreth Butler (1816-1876) wrote to her daughter in October 1860, "My eyes still trouble me. I have for a time given up reading and sewing, and walk more than I did when you were at home."66

\footnotetext{
${ }^{63}$ New Hampshire Patriot and State Gazette, October 15, 1838. Also see the broadside for "Dr. Isaac Thompson's celebrated eye-water" in the collection of the American Antiquarian Society, Worcester, Massachusetts.

${ }^{64} \mathrm{I}$ am indebted to Heather Bourdeau, O.D., for explaining this process to me, email correspondence, July 14, 2008.

${ }^{65}$ Curtis, Observations on the Preservation of Sight, 55. The same author went on to explain, "The average time at which glasses are first needed for reading may be said to be from thirty-five to forty-five. After this latter period of life, the power of adjustment possessed by the eye in youth fails." Curtis, Observations on the Preservation of Sight, 55-56.

${ }^{66}$ Blanche Butler Ames, comp., Chronicles from the Nineteenth Century: Family Letters of Blanche Butler and Adelbert Ames Married July $21^{\text {st }}$. 1870, vol. 1 (Clinton, Massachusetts: privately published, 1957), 59. Sarah Jones Hildreth was born in 1816 in Lowell, Massachusetts, to Dr. Israel Hildreth. She pursued an acting career between 1837 and 1842, but retired when she married Benjamin F. Butler in 1844. Benjamin Butler had a law practice in Lowell, later becoming a Massachusetts state senator and a Union general during the Civil War. The couple had three children. Sarah Jones Hildreth Butler died in Boston, Massachusetts, in 1876. Biographical information from North American Women's Letters and Diaries
} 
The documentary evidence linking women's deteriorating vision with aging is further supported by visual evidence in the form of portraits showing mature women wearing or holding spectacles. For example, fifty-four-year-old Mary Swain Tucker Paddack (1792-1878) had her portrait painted in 1846 (figure 1.10). ${ }^{67}$ A resident of Nantucket, Paddack exemplifies the Quaker style of dress in her portrait, wearing a dark gown with light-colored fichu and sheer cap. She faces the artist with her head slightly tilted and wears her spectacles, which give her a wise, benevolent countenance. In addition to suggesting that the sitter needed assistance with her vision, women like Paddack may have included their spectacles in their portraits as a symbol of the wisdom gained through age or of the prosperity to afford them. While spectacles are far from universal in portraits of antebellum women over forty, they do appear from time to time. Sometimes the woman held her glasses in one hand (figure 1.11), just like children held the props of youth (flowers and toys) and men were pictured with symbols of their occupation (books, pens, ledgers, wallets). ${ }^{68}$

database, http://solomon.nwld.alexanderstreet.com.silk.library.umass.edu:2048/bios/A353BIO.html; accessed November 21, 2009.

${ }^{67}$ Paddack's portrait is in the collection of the Nantucket Historical Association, Nantucket, Massachusetts. The portrait was painted by William Swain in 1846. Mary Swain was born December 14, 1792, the daughter of Tristram Swain (1747-1825) and Rachael Bunker (1752-1831). She first married Benjamin Tucker (dates unknown). She later married Laban Paddack (1790-1847) and they had one child. Mary Swain Tucker Paddack died on February 23, 1878. Barney Genealogical Record, Nantucket Historical Association, Nantucket, Massachusetts; Michael A. Jehle, ed., Picturing Nantucket: An Art History of the Island with Paintings from the Collection of the Nantucket Historical Association (Nantucket: Nantucket Historical Association, 2000), 172.

${ }^{68}$ For example, see the portrait of an unidentified Quaker woman in figure 1-10, which is now owned by the Nantucket Historical Association, Nantucket, Massachusetts. It was painted by an unidentified artist around 1820. Other portraits of aging women who hold their spectacles include: the portrait of Sarah Barnard, painted by Joseph T. Harris in 1835 and now in the collection of the Nantucket Historical Association; and the portrait of Mrs. David Stevens attributed to Ruth Whittier Shute in the 1830s and now in a private collection (see auction record for this portrait, which was sold by Skinner on June 7, 2009). Skinner, Inc., American Furniture and Decorative Arts (Boston: Skinner, 2009), 136-137. 


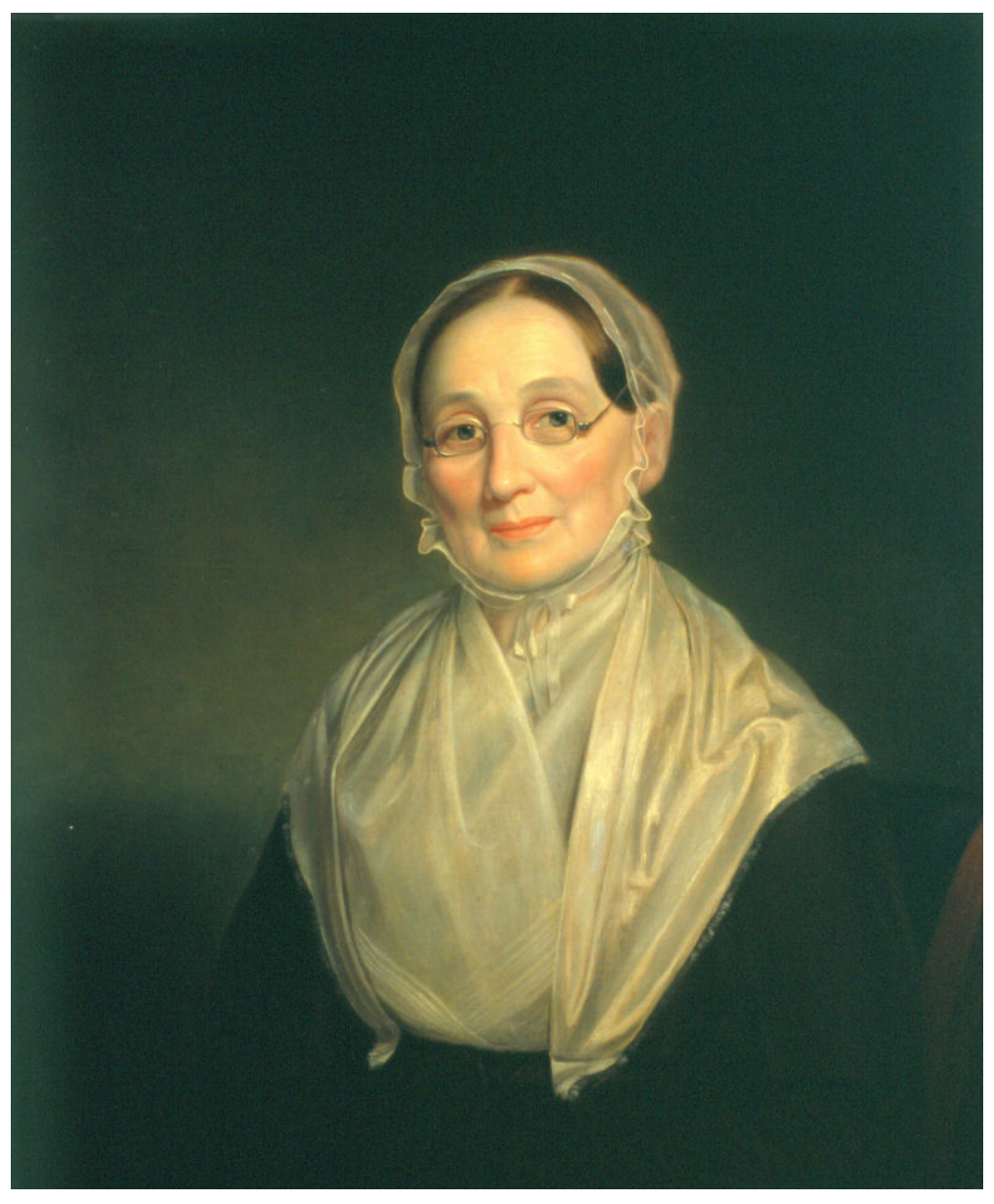

Figure 1.10. Mary Swain Tucker Paddack (1792-1878) by William Swain (1803-1847), 1846, Nantucket, Massachusetts. Courtesy of the Nantucket Historical Association, Nantucket, Massachusetts.

While spectacles are far from universal in portraits of older antebellum women, they do appear from time to time, suggesting that the sitter needed assistance with her vision. 


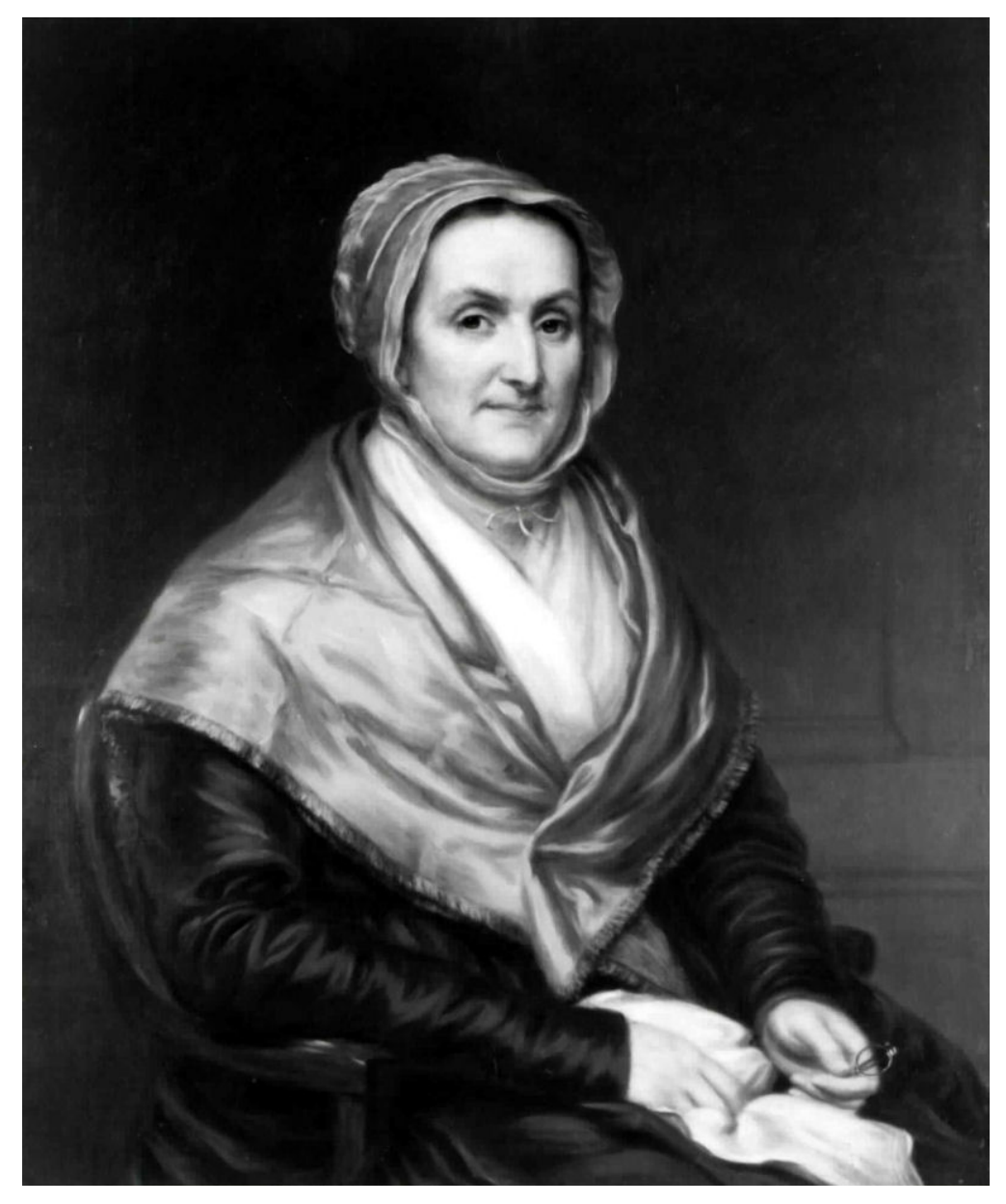

Figure 1.11. Unidentified Quaker Woman by unidentified artist, circa 1820, probably Nantucket, Massachusetts. Courtesy of the Nantucket Historical Association, Nantucket, Massachusetts.

While some women chose to be painted while wearing their spectacles, others preferred to hold them. Just as children were often painted holding symbolic props, and men were pictured with an item related to their profession, a woman who held her spectacles was conveying a message to the viewer. She may have been conveying her education or her financial wellbeing, which allowed her to own this expensive accessory. 
Sewing or reading in low light was cited as the most common enemy of eye health. One 1844 needlework manual strongly recommended pursuing needlework in "the clear bright light of morning," stating that it not only was important for accuracy and "proper choice of color," but also for health reasons, "We should, indeed, strongly advise our fair readers seduously to avoid candlelight, not only with reference to the accuracy of their work, but with a view also to the "good keeping" of that delicate organ, the eye."69 An 1852 medical guide concurred, writing that for people "attempting to read, or to finish off the last stitches of their work, by twilight[...c]ommon sense should tell them...that such efforts cannot be made without detriment to the eyes."70

Yet, author Lydia Maria Child (1802-1880) counseled her readers not to "read or sew...by too dazzling a light."71 ${ }^{, 71}$ Perhaps the most detail-oriented author provided the following list of the causes of eye damage and problems: "habitual errors in living, the high temperatures of our houses, sitting before the intense glow of anthracite fires, want of out-door exercise, wearing thin shoes, reading badly-printed books...too great application to study, constant nerves excitation and... ga general overestimation of mind and body, without any hygiene correctives."72 He also believed that it was not the amount of light, but its position, writing "light should always come from above... an immense deal of the bad eyesight and weariness of the eyes so often complained of by

\footnotetext{
${ }^{69}$ The Ladies' Hand-Book of Fancy Needlework, and Embroidery (New York: J.S. Redfield, 1844), 56-57.

${ }^{70}$ Coale, Hints on Health, 148.

${ }^{71}$ Lydia Maria Child, The American Frugal Housewife (1844; repr., Mineola, New York: Dover Publications, Inc., 1999), 88. Lydia Maria Child (1802-1880) was born in Medford, Massachusetts, the daughter of David Convers Francis and Susannah Rand. Trained as a teacher, she opened a school in Watertown, Massachusetts, in the early 1820s. She also began writing novels at this time. In 1828, Lydia married David Lee Child, a lawyer who also served in the state legislature. Child introduced his wife to the abolitionist cause and the couple remained active in the movement. Lydia's writing supported the couple for many years. She died in Wayland, Massachusetts, in 1880. Catherine Teets-Parzynski, "Child, Lydia Maria Francis," http://www.anb.org.silk.library.umass.edu:2048/articles/15/15-00127.html, American National Biography Online Feb. 2000; accessed November 21, 2009.

${ }^{72}$ Coale, Hints on Health, 148.
} 
needle-women is caused" by sewing with misplaced light sources. ${ }^{73}$ Still another medical text argued that, "Old women, having little else to do, sometimes read too constantly, and frequently with the very same glasses that they used twenty years before. Thus the eyes are kept constantly inflamed.,"74

Mature women expressed familiarity with this advice, although they did not always follow it. For example, seventy-year-old Dolley Payne Todd Madison (17681849) wrote to her friend, sixty-year-old Margaret Bayard Smith (1778-1844), in 1838:

I found myself involved in a variety of business - reading, writing, and flying about the house, garden, and grove - straining my eyes to the height of my spirits, until they became inflamed, and frightened into idleness and to quietly sitting in drawing-room with my kind connexions and neighbours...being thus obliged to give up one of my most prized enjoyments that of corresponding with enlightened and loved friends like yourself. ${ }^{75}$

In July 1853, sixty-four-year-old Catherine Maria Sedgwick (1789-1867) lamented her dependence on her spectacles, when she wrote to her niece, Katherine Maria Sedgwick Minot (1820-1880):

There are miseries in human life that Job, or Solomon, or Jeremiah have never described, because probably prophecy never revealed to them the folly of those fools who attempt after their eyes lie in a pair of spectacles. For the last quart d'heure (of infinite length) I have been looking for my spectacles with the desperate conviction that I have dropped them in my flower-beds, and shall never find them! And I have looked up an old pair with one glass (typically) looking heavenward and the other earthward, and now I proceed what I should have begun my letter with but for this accident - if that can be called accident which is as regular as my pulses. ${ }^{76}$

\footnotetext{
${ }^{73}$ Coale, Hints on Health, 151.

74 J. Henry Clark, Sight and Hearing, 179.

${ }^{75}$ Allen C. Clark, Life and Letters of Dolly Madison (Washington, DC: Press of W.R. Roberts Co., 1914), 288. Dolley Madison was wife of President James Madison (1751-1836).

${ }^{76}$ Mary E. Dewey, ed., Life and Letters of Catherine M. Sedgwick (New York: Harper and Row, 1871), 351. Catherine Maria Sedgwick was born in 1789 in Stockbridge, Massachusetts, to Theodore Sedgwick and Pamela Dwight. She began writing for publication in the early 1820s, eventually writing successful novels. She also pursued a number of social reform initiatives, including prison reform. Sedgwick never married. She died in West Roxbury, Massachusetts, in 1867. Biographical information from the North American Women's Letters and Diaries database,
} 
Despite the many opinions about the causes of eye trouble and women's own experiences, there was hope. Eye problems late in life could be avoided. According to one expert, there was no reason why the eyes of the elderly should be blood-shot, red and disfigured. Dr. J. Henry Clark believed that it was a common mistake to regard this as a "necessary infirmity" of old age. Even among those who suffered from these symptoms, he believed that they could be avoided. In his opinion, the elderly, having passed "the active period of life...have little use for the eyes." Since they did not need to use their eyes as much, they could rest them more often and prevent the symptoms of eye strain altogether. ${ }^{77}$ And, John Harrison Curtis noted "there are many persons upwards of eighty years of age who are able to see to read and write without spectacles. Had they abused their sight, they would not now have been in such perfect enjoyment of it." ${ }^{, 78}$ Indeed, a quilt made in 1854 includes the inscription, "Mrs. Elsey D. Wheeler / Aged 57 years Feb. $8^{\text {th }} 1854$ / I quilted this without spectacles." 79

The natural changes that took place in the eyes as women aged allowed some to recapture the ability to do fine work. According to family history, sixty-two-year-old Mary Frye Van Voorhis (b. circa 1788) made a quilt around 1850 after receiving her “second sight" (figure 1.12). ${ }^{80}$ Van Voorhis, who was probably farsighted and developed

http://solomon.nwld.alexanderstreet.com.silk.library.umass.edu:2048/bios/A198BIO.html; accessed November 21, 2009.

${ }^{77} \mathrm{~J}$. Henry Clark, Sight and Hearing, 178.

${ }^{78}$ Curtis, Observations on the Preservation of Sight, 55.

79 As described in Ricky Clark, "Mid-Nineteenth Century Album and Friendship Quilts 1860-1920" in Pieced By Mother: Symposium Papers, ed. Jeannette Lasansky (Lewisburg, PA: Oral Traditions Project, 1988), 79. The current location of this quilt is unknown.

${ }^{80}$ Information from the catalog file on the quilt, now in the collection of the Witte Museum, San Antonio, Texas. I am grateful to curator Michaele Haynes for generously sharing the file on this quilt. The quilt is pictured in Patsy and Myron Orlofsky, Quilts in America (New York: Abbeville Press, 1992), 516 and in Carleton L. Safford and Robert Bishop, America's Quilts and Coverlets (New York: Weathervane Books, 1974), 152. A second quilt by Van Voorhis is illustrated in Cyril I. Nelson and Carter Houck, Treasury of American Quilts (New York: Greenwich House, 1984), 163. Employing a similar style and motifs, this 


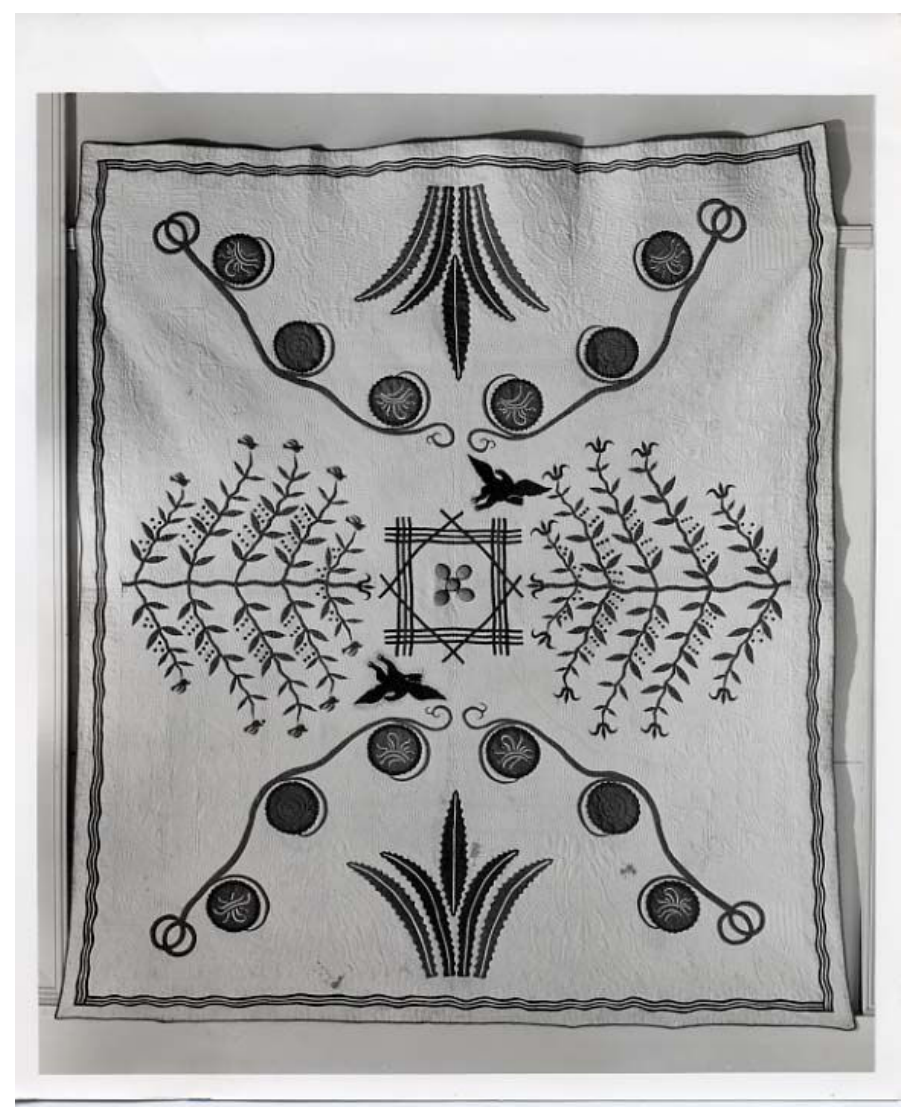

Figure 1.12. Quilt by Mary Frye Van Voorhis (b. ca. 1788), circa 1850, Pennsylvania. Courtesy of the Witte Museum, San Antonio, Texas.

According to family history, Mary Frye Van Voorhis made this quilt when she received her "second sight." Like many aging people, then and now, her eyesight changed from farsightedness to nearsightedness. As a result, she would have been able to see clearly more closely, making it easier to appliqué and quilt.

quilt is inscribed, "Made by Mrs. D. Van Voorhis, aged 7[?] 1865." This signature conflicts with the information associated with the quilt in the Witte Museum collection. Information provided by the donor when the quilt was given to the Witte Museum dated the quilt to about 1850 and stated that the maker was in her late eighties when she made it. However, the signature on the second quilt provides evidence that she was in her seventies in 1865 when she made that one. According to the 1850 U.S. Census, Daniel Van Voorhis of Carroll Township, Pennsylvania, had a wife named Mary who was sixty-three. This information supports the age and date information in the signature on the second quilt. Mary Van Voorhis was born Mary Frye in Pennsylvania in 1788. The two quilts share strong similarities in terms of overall style, individual motifs and color schemes. They also show Pennsylvania German influence. Both Daniel and Mary Van Voorhis were raised in Pennsylvania in families of German descent. Because the two quilts employ unusual original patterns, it is difficult to date them precisely, but the evidence suggests that the maker is the Mary Van Voorhis who was born around 1788 and thus, made the Eagle's Nest quilt when she was in her sixties. U.S. Census and genealogical information from www.ancestry.com, accessed March 8, 2009 and April 19, 2009; Samuel P. Bates, A Biographical History of Greene County, Pennsylvania (Baltimore: Genealogical Pub. Co., 1975), 646. 
cataracts, would have experienced the focal point of her eyes shifting closer to her body as she aged, resulting in nearsightedness. The nearsightedness allowed Mary to see near targets again after years of only seeing clearly far away, and this was probably what she and her family called "second sight." ${ }^{\text {" } 11}$ Her quilt, appliquéd in red, green, brown and blue on a white background, shows an original design called "The Eagle's Nest." The bed covering is elaborately quilted around a depiction of eagles guarding their nest. The choice of the pattern reflected events Van Voorhis ostensibly knew, having reared her family and watched them leave her home. Several of the quilts examined here, like this one, show designs with strong contrast between dark and light sections. While these color combinations were popular for quiltmakers of all ages during the mid-nineteenth century, the contrast may have been especially helpful for older quilters because it was easier to see and to work with.

While growing older was marked by decreasing vision and achy joints for many, it also had benefits. Sixty-five-year-old Lydia Sigourney offered a succinct comparison of the positive sides to both youth and old age in an 1856 book. She considered that the "A.M."s (for ante-meridians, or the young) were "the beauty and the rigor," while the "P.M."s (post-meridians or older folks) had "a more rational happiness; for they have winnowed the chaff from the wheat, and tested both what is worth pursuing, and worth possessing. ${ }^{\prime 82}$ In addition to bringing wisdom and respect, old age - and particularly the menopause that accompanied it - offered freedom:

The full conviction that age has stamped them with its irrevocable seal may indeed cast a momentary gloom over the imagination, but in a well-trained mind it must soon be dispelled...by the knowledge that this epoch proclaims an immunity

\footnotetext{
${ }^{81}$ I am indebted to Heather Bourdeau, O.D., for explaining "second sight" to me, email correspondence, July 14, 2008.

${ }^{82}$ Sigourney, Past Meridian, 10-11.
} 
from the perils of child-bearing and the tedious annoyances of a monthly restraint...This period of freedom has been employed by many eminent women in literary pursuits, or in governing with great discretion that circle of society, limited or extensive, in which they have been placed... ${ }^{83}$

Being set free from the biology of womanhood, knowing that she would not become pregnant again, and done with the discomfort of menstruation, the aging woman could focus more time and attention on herself. In August 1852, thirty-four-year-old Sallie Holley (1818-1893) wrote to her friend, Caroline F. Putnam (1826-1917), about a visit to an elderly woman who seemed to be enjoying the freedom of age. "The mother made her appearance," wrote Holley, "a lady eighty years old, but, in spirit and conversation and manners more like eighteen than eighty. Indeed she proved to be a most charming old lady. I was quite captivated with her, so fresh, so youthful, so beautiful. She seems to have read almost everything." ${ }^{, 84}$

While some women found more time to read as they aged, others turned to needlework to fill their time. In 1834, fifty-six-year-old Margaret Bayard Smith (17781844) of Washington, D.C., described a pleasant domestic scene in a letter to her sister. "How comfortable we looked and how industrious," she wrote, "Virginia and Anna doing their canvas work in frames; Ann and I doing ours on our hands, each with a little table before us, covered with worsteds of every shade and colour. Mrs. Barret and Julia working muslin, all circled round a blazing fire, while without doors it was cold and

\footnotetext{
${ }^{83}$ E.J. Tilt, On the Preservation of the Health of Women at the Critical Periods of Life (New York: John Wiley, 1851), 122.

${ }^{84}$ John White Chadwick, ed., A Life for Liberty: Anti-Slavery and Other Letters of Sallie Holley (New York: G.P. Putnam's Sons, 1899), 87. Sallie Holley was born in 1818 in Canandaigua, New York, to Myron Holley and Sally House. In the early 1840s, she became a teacher, but entered Oberlin College in 1847 , graduating in 1851 . Holley became an abolitionist, but did not achieve high visibility within the movement. After the war, she taught for a time at a school in Virginia for former slaves, but eventually returned North. She died in New York City in 1893. William H. Pease and Jane H. Pease, "Holley, Sallie," http://www.anb.org.silk.library.umass.edu:2048/articles/15/15-00900.html, American National Biography Online Feb. 2000; accessed November 21, 2009.
} 
lowering." 85 Smith's biographer, Fredrika J. Teute, has noted that in her letters Smith

"made careful distinctions between different social settings." Smith commented that she

preferred discussions with the men who gathered in her home during the evening more

than the "endless rounds of morning visits among women." 86 Yet, in this 1834 letter,

Smith's words express a sense of enjoyment and satisfaction in working together with

multiple generations of her family.

Margaret Bayard married her second cousin, Samuel Harrison Smith (1772-1845),

in 1800 when she was twenty-two. Her husband was editor of the Daily National

Intelligencer and Washington Advertiser in Washington, D.C., and the couple moved in

well-connected circles, fostering a friendship with then-President Thomas Jefferson

(1743-1826). Between 1801 and 1811, Margaret Bayard Smith gave birth to the couple's

\footnotetext{
${ }^{85}$ Letter from Margaret Bayard Smith, Washington, D.C., to her sister, Maria Kirkpatrick, February 10, 1834, as quoted in Gaillard Hunt, The First Forty Years of Washington Society in the Family Letters of Margaret Bayard Smith (New York: Frederick Ungar Publishing, 1906), 346. Margaret Bayard was born in 1778 and lost her mother, Margaret Hodge (1740-1780), when she was two years old. Her father, Revolutionary War Colonel John Bubenheim Bayard (1738-1807), remarried but young Margaret's stepmother passed away when she was ten. Without a mother figure in her life, Margaret spent the next three years at a Moravian boarding school in Bethlehem, Pennsylvania, where she undoubtedly learned the sewing skills that continued to serve her in 1834. A group of Protestant Reformers who traveled to Philadelphia from Germany in the early eighteenth century, Moravians believed that "everyone ought to receive a universal education." The Moravian Seminary found a permanent home in Bethlehem, Pennsylvania in 1749 and opened to non-Moravian students in 1785, in time for Margaret Bayard to enter in 1788. Instruction in fine needlework was offered for an extra charge and by the 1790s, the school was known for its elegant silk needlework pictures. Ring, Girlhood Embroidery, 434, 436; Edward T. James, ed., Notable American Women 1607-1950: A Biographical Dictionary (Cambridge: The Belknap Press of Harvard University Press, 1971), 371; Donald B. Cole, "Smith, Margaret Bayard," http://www.anb.org.silk.library.umass.edu:2048/articles/20/20-0961.html, American National Biography Online February 2000, accessed July 24, 2008.

${ }^{86}$ Fredrika J. Teute, "Roman Matron on the Banks of Tiber Creek: Margaret Bayard Smith and the Politicization of Spheres in the Nation's Capital," in A Republic for the Ages: The United States Capitol and the Political Culture of the Early Republic, Donald R. Kennon, ed. (Charlottesville: The University Press of Virginia, 1999), 105. For more on Margaret Bayard Smith, see Fredrika J. Teute, "In 'the gloom of evening': Margaret Bayard Smith's View in Black and White of Early Washington Society," The Proceedings of the American Antiquarian Society 106 (1996): 37-58.
} 
four children, two of whom are mentioned in her 1834 letter: Julia Harrison Smith (b.

1801) and Anna Maria Harrison Smith (b. 1811). ${ }^{87}$

Smith's initial description found her houseguest Virginia Southard (circa 1815-

1860) and her daughter Anna stitching canvas work in frames. ${ }^{88}$ This type of work was a common pastime for women during the first half of the nineteenth century, employing colored wool threads on a woven fabric. Smith and an unidentified woman, Ann, were also doing canvas work, but used their hands to provide the proper amount of tension for the cloth, rather than the frames preferred by Virginia and Anna. Applying tension to the fabric was necessary to keep the piece smooth, without puckers or creases, and also helped with making uniform stitches. A more experienced stitcher can better monitor the appropriate amount of tension and stitch neatly, while a less experienced stitcher would find the use of a frame helpful. Later in the letter, Smith wrote that "Virginia, Ann and Anna are all working ottomans for Mrs. Clay and I am doing her lamp and shades.”89

\footnotetext{
${ }^{87}$ James, Notable American Women, 317-318; Cole, "Smith, Margaret Bayard." During the 1810s and 1820s, Samuel Harrison Smith sold his newspaper and moved into a financial career, becoming President of the Bank of Washington, D.C., in 1809. In 1828, he was selected as President of the Washington branch of the Bank of the United States. In the 1820s, as her children grew up, Margaret began a writing career and published her first novel in 1824, when she was forty-six years old. Her second novel, What is Gentility?: A Moral Tale, mocked the prevailing notion that gentility came in one's familial descent. The novel undoubtedly reflected her own education. Teute, "Roman Matron," 118-119.

${ }^{88}$ Canvas work, which we often call needlepoint today, was stitched on cloth woven with 18 to 52 threads per inch, usually unbleached linen. Often the design was drawn onto the cloth before stitching; the cloth could be purchased pre-marked, or the woman could draw the design herself. In 1804, a printseller in Berlin, Germany devised a method of illustrating canvas work designs on gridded paper, which were then hand-colored. This became known as "Berlin work," and was widely popular between 1830 and 1870; over 14,000 designs were published between 1830 and 1840 alone. See: Susan Burrows Swan, A Winterthur Guide to American Needlework (New York: Crown Publishers, Inc., 1976), 26-63; Judith Reiter Weissman and Wendy Lavitt, Labors of Love: America's Textiles and Needlework, 1650-1930 (New York: Wings Books, 1987), 140; and Miss Lambert, The Hand-Book of Needlework (London: John Murray, 1846), 117, 120, 206.

${ }^{89}$ Hunt, The First Forty Years, 347. "Mrs. Clay" was the wife of statesman Henry Clay (1777-1852), who served as a U.S. Senator for Kentucky, was Speaker of the House, and ran unsuccessfully for President of the U.S. in 1824, 1832, and 1844. Robert V. Remini, "Clay, Henry," http://www.anb.org.silk.library.umass.edu:2048/articles/03/03-00100.html, American National Biography Online, February 2000, accessed July 26, 2008. Unfortunately, the ottomans and lamp shades are now lost; no needlework owned by the family from the 1830s remains at Ashland, the Henry Clay Estate, now a
} 
Canvas work was ideal for these types of items - ottoman covers could be worked with embroidered designs and then attached to a wooden base. Likewise, when Smith referred to "her lamp and shades," she was probably describing shades for the lamp and perhaps a lamp mat (see figure 1.13), also household items that were ideal canvas work projects.

The other members of the circle, guest "Mrs. Barret" and Smith's daughter Julia, were "working muslin," a form of whitework embroidery, employing white thread on white cotton fabric. Muslin work was often used to decorate women's caps, worn indoors over their hair, or their gowns and petticoats. Figure 1.14 shows a detail of this type of work on the edge of a gown embroidered around 1827, while figure 1.15 shows a paper pattern used to mark a muslin work design..$^{90}$ The types of needlework pursued by this group of Washington's elite women were primarily decorative, but the work was undertaken to serve a function. The ottoman covers and the lamp and shades were to be used on household furnishings for another friend, Mrs. Lucretia (Hart) Clay (1781-1864). And, the muslin work stitched by Mrs. Barret and Julia would also be useful - it would adorn caps for themselves or for friends or family members. The practicality at the heart of all of these items mediated their decorative appearance. Smith herself explained that the group was both "comfortable" and "industrious." By virtue of her age, as well as her social position, Smith was free to host her friends and family, demonstrating her own gentility and fostering it in the next generation.

museum, in Lexington, Kentucky. I am indebted to Eric Brooks, Curator at Ashland, for his assistance with my question about the ottomans and lamp shades; email correspondence, May 14, 2009.

${ }^{90}$ This gown is now in the collection of Old Sturbridge Village, Sturbridge, Massachusetts. The gown is attributed to Marion Chandler (1800-1857) of Pomfret, Connecticut, who wore it at her marriage to Dr. Hiram Holt in 1828. Information from the curatorial file at Old Sturbridge Village, Sturbridge, Massachusetts. The embroidery pattern is also in the collection of Old Sturbridge Village, Sturbridge, Massachusetts. It is part of a large collection of embroidery patterns dating from the 1790 to 1830 period and probably from Providence, Rhode Island. 


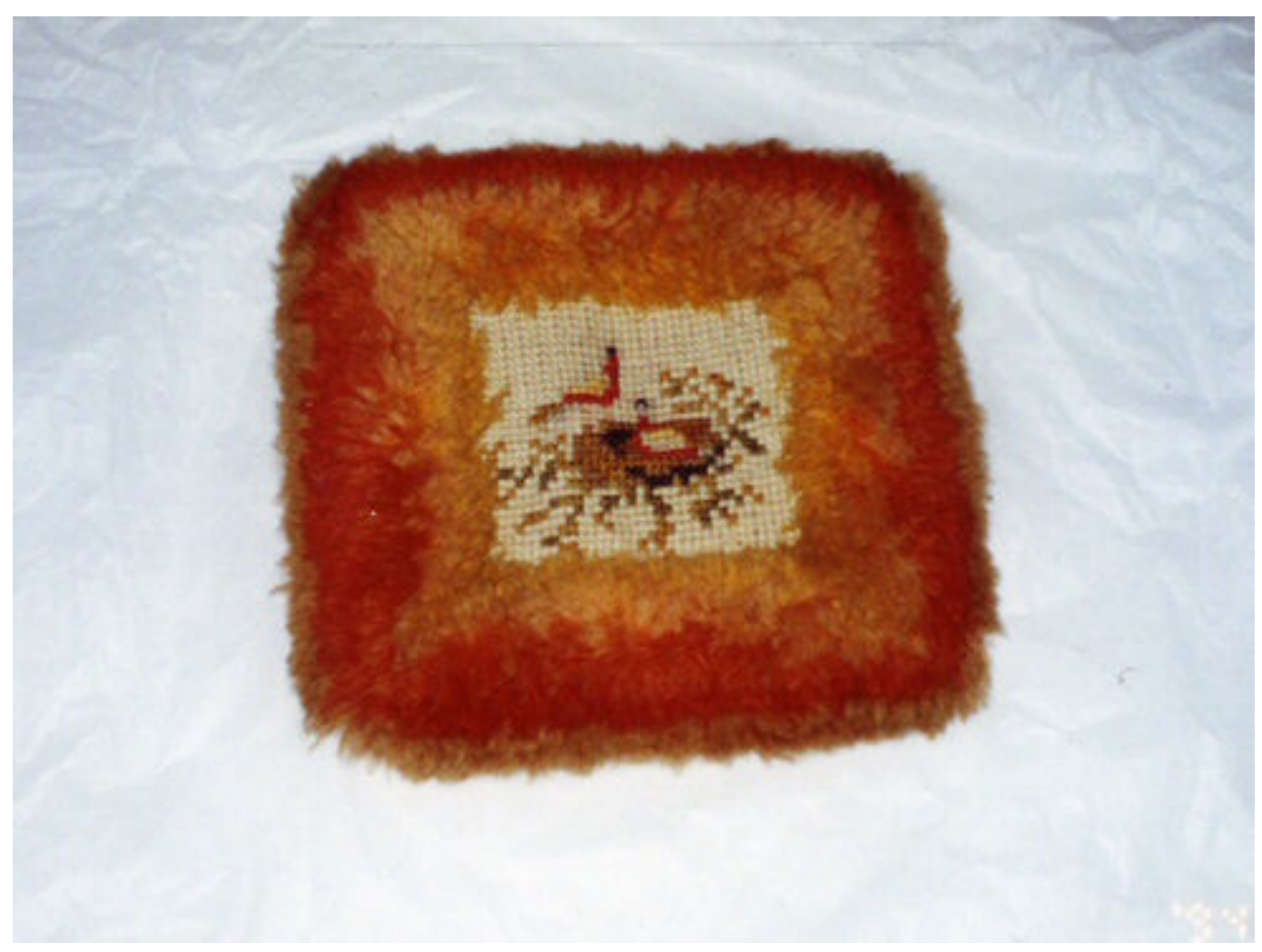

Figure 1.13. Canvas work lamp mat, 1830-1850. Courtesy Peabody Essex Museum, Salem, Massachusetts.

Making a lamp mat like this one allowed antebellum women to express their creativity while keeping themselves occupied in an industrious fashion. This lamp mat is made by stitching with colored thread on a canvas ground. 


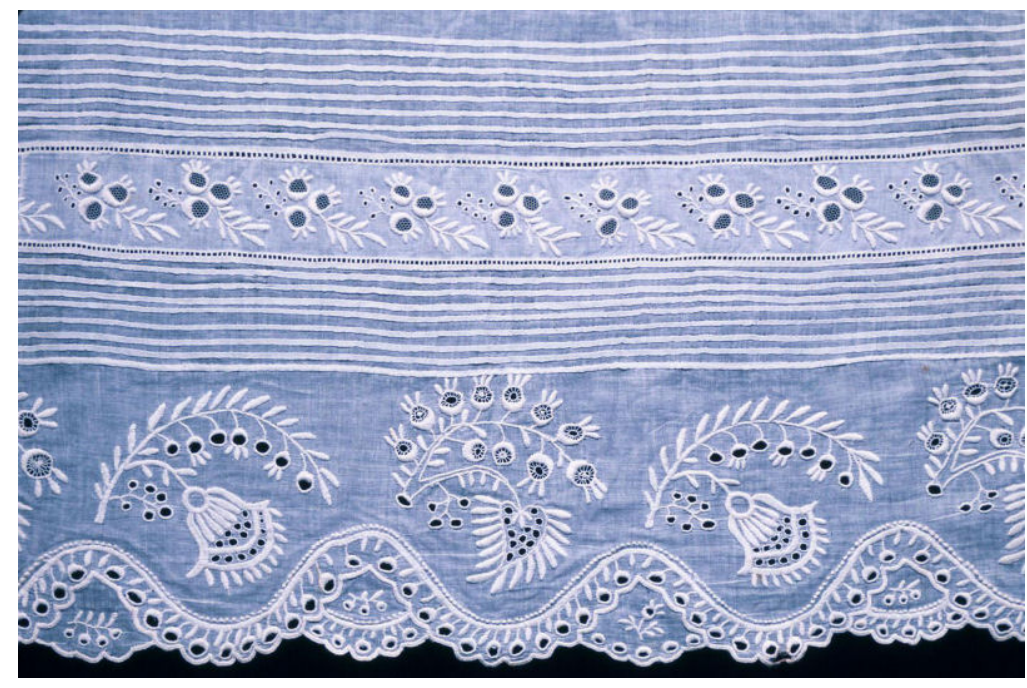

Figure 1.14. Muslin work detail from gown by Marion Chandler (1800-1857), 1828, Pomfret, Connecticut. Courtesy of Old Sturbridge Village, Sturbridge, Massachusetts, 26.33.195. Photograph by Henry Peach.

Muslin work is a form of whitework - embroidering white fabric with white thread - that was popular during the early nineteenth century. This technique was frequently used to decorate women's clothing, such as gowns, caps and petticoats.

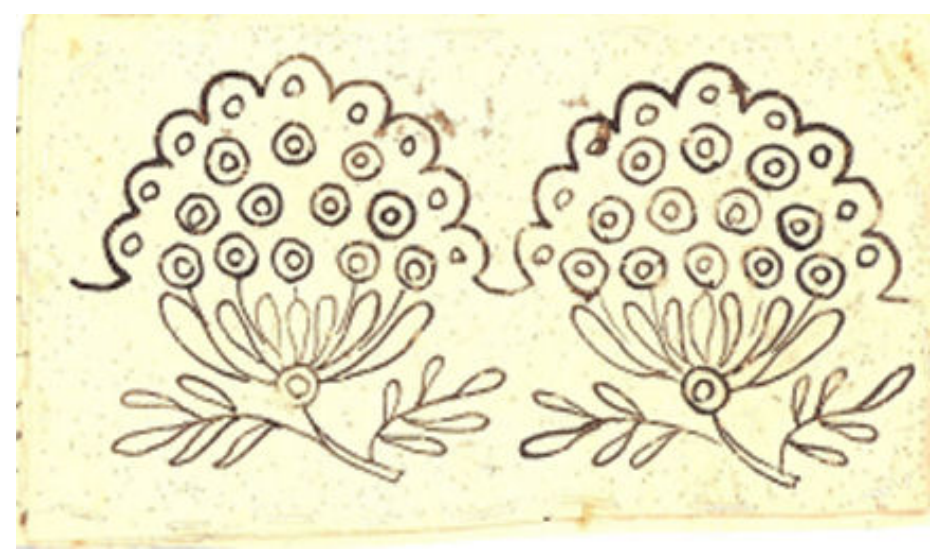

Figure 1.15. Embroidery pattern, 1790-1830, probably Providence, Rhode Island. Courtesy of Old Sturbridge Village, Sturbridge, Massachusetts, 22.12.366.

Paper patterns like this one were used to transfer a muslin work pattern to the ground fabric. Although difficult to see in the image, this pattern has many pin pricks along the lines of the design. It could then be pinned to the ground fabric and, by running a pencil along the lines of the pattern, a mark would be left, through the pin pricks, on the fabric below. This provided the embroiderer with guidelines to follow in order to work her design. 
Several years earlier, in 1827, then-forty-nine-year-old Smith was just starting to explore this new stage in her life when she wrote to her older sister Maria Bayard Boyd:

As Dr. Stevens once said to me, when complaining of nervous affections and restlessness of mind, "You have almost passed the stormy part of life and are entering on a calm and tranquil state, when all there complaints will vanish." His prediction is accomplished and I am often astonished at the contentment and serenity I enjoy. Not that I can possibly imagine this arising entirely from physical causes... I wish you would read Cicero's essay on Old Age, -- every person advanced in life would I think derive advantage from it. ${ }^{91}$

Smith referred to the essay that Cicero wrote in 44 BC when he was sixty-two. Printed by Benjamin Franklin (1706-1790) in 1778, and subsequently reprinted numerous times in the United States, Cicero provided a more positive view of aging than much of the religious and popular literature of the mid-nineteenth century. ${ }^{92}$ Written in the form of an answer to questions from two younger men, Cicero described principles to assist with the aging process. He acknowledged four ways in which old age was difficult: the withdrawal from active pursuits; a weakening body; the deprivation of physical pleasures; and the prospect of death drawing near. To counter these issues, Cicero explained that the quality of one's old age depended on the investments made in earlier years - cultivating healthy habits and friendships as well as identifying activities that provided pleasure. ${ }^{93}$ For aging women, needlework could be one of these pleasurable activities.

While women like Sarah L. Art and Lucretia Buttrick manipulated their needlework to appear younger, or at least ageless, fifty-two-year-old Mary Berry True (1788-1858) seems to have embraced the changes of age by filling some of the time

\footnotetext{
${ }^{91}$ Letter to Maria Boyd, January 12, 1827, as quoted in Hunt, The First Forty Years, 205-206.

${ }^{92}$ Paula A. Scott, Growing Old in the Early Republic: Spiritual, Social and Economic Issues, 1790-1830 (New York: Garland Publishing Inc., 1997), 50.

${ }_{93}$ Marcus Tullius Cicero and Andrew P. Peabody, Cicero De Amicitia To Which Is Added Scipio's Dream and Cicero De Senectute (Boston: Little, Brown, and Company, 1884), 12, 25-26, 28-29, 31.
} 
previously devoted to raising her children with stitching a fashionable table cover.

Worked in 1840, True's cover was made to fit a round tilt-top table made around the same time by her husband, fifty-five-year-old Joseph True (1785-1873) (figure 1.16). ${ }^{94}$

Seeing these two objects in use conjures images of a husband and wife enjoying the freedoms of age by working together to create a symbol of their union that also represents the comfort of growing old as a couple.

Mary Berry True prominently marked her table cover on one side with her initials, "M.T.” and the year, "1840." This mark shows a relationship to those practiced on schoolgirl samplers and employed on countless household textiles from the eighteenth and nineteenth centuries (see figure 1.17), leaving no doubt as to its maker and owner. Mary probably took inspiration from a published pattern to compose the floral design at top center and along the edge. ${ }^{95}$ Mary's table cover demonstrates the technique known as canvas work, and could be termed "Berlin work," a type of needlework fashionable during the 1830 s and 1840 s. Floral patterns were particularly popular. Mary's work echoes the advice provided by one period needlework guide, which advocated, "Groups

\footnotetext{
${ }^{94}$ Both the table and the table cover are now in the collection of the Peabody Essex Museum, Salem, Massachusetts. I am indebted to Paula Bradstreet Richter, Curator of Textiles and Costumes, for showing the table cover to me and sharing her thoughts about it. Technically, the table is attributed to Joseph True; it does not bear any identifying maker's marks. Joseph True was born in Chichester, New Hampshire, in 1785 and moved to Salem, Massachusetts by 1809 when he married Mary (Polly) Berry. Margaret Burke Clunie, "Joseph True and the Piecework System in Salem," The Magazine Antiques 111 (May 1977): 1007. An 1847 letter described True as a master carver, "Joseph True...self taught has real talent, has the best work, is now carving Gothic ornament of a very beautiful kind for the North Church..." 1847 letter from George Phippen to Rev. Joseph B. Felt of Boston, quoted in Clunie, "Joseph True and the Piecework System in Salem," 1009.

95 Discussion with Paula Bradstreet Richter, curator of textiles and costumes at the Peabody Essex Museum, Salem, Massachusetts, during site visit on May 8, 2006.
} 


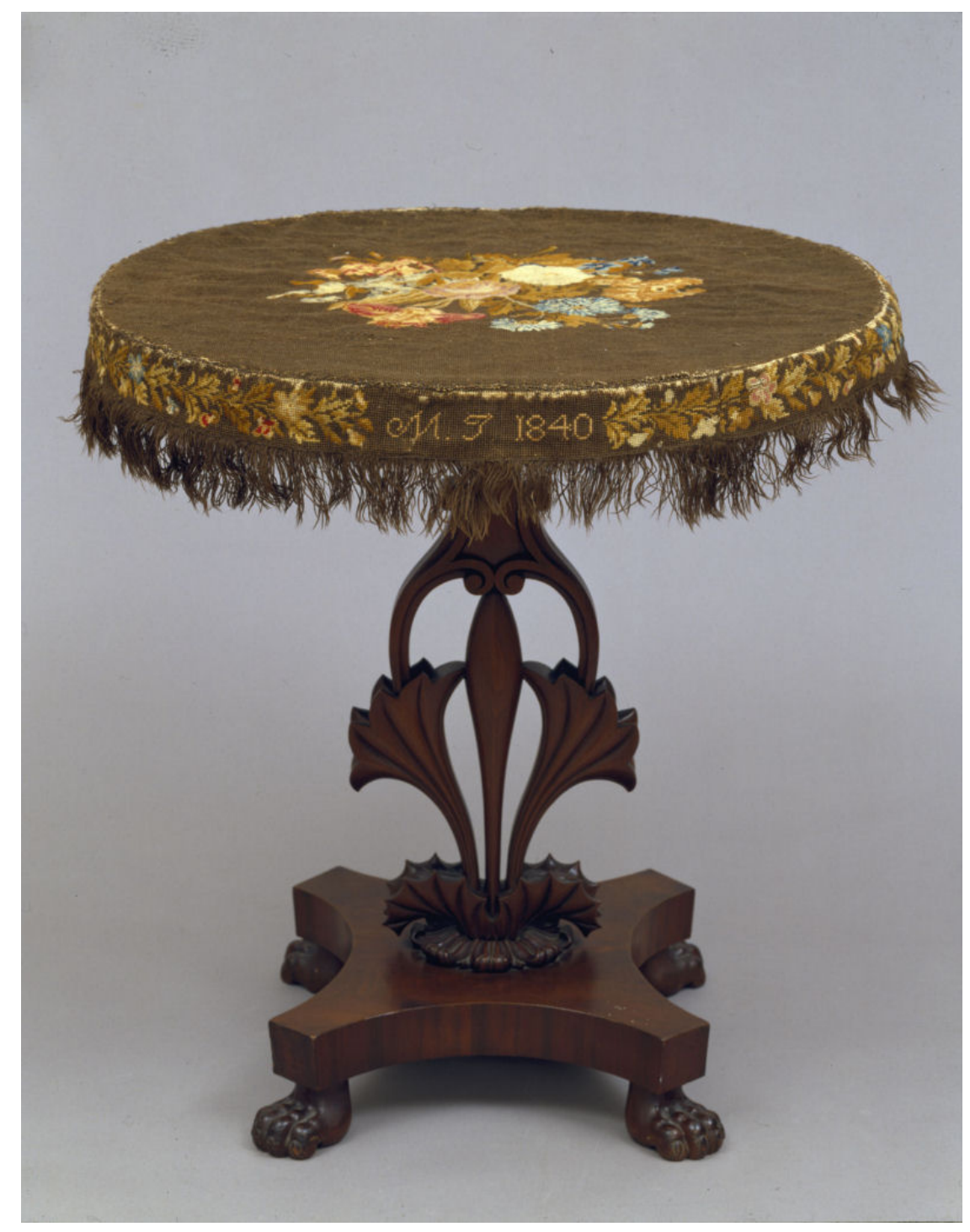

Figure 1.16. Table by Joseph True (1785-1873); table cover by Mary Berry True (17881858), 1840, Salem, Massachusetts. Courtesy of the Peabody Essex Museum, Salem, Massachusetts.

Husband and wife Joseph and Mary True worked together to create this elegant piece of furniture. Joseph carved the table while Mary stitched the cover, marking it with her initials and the date. 


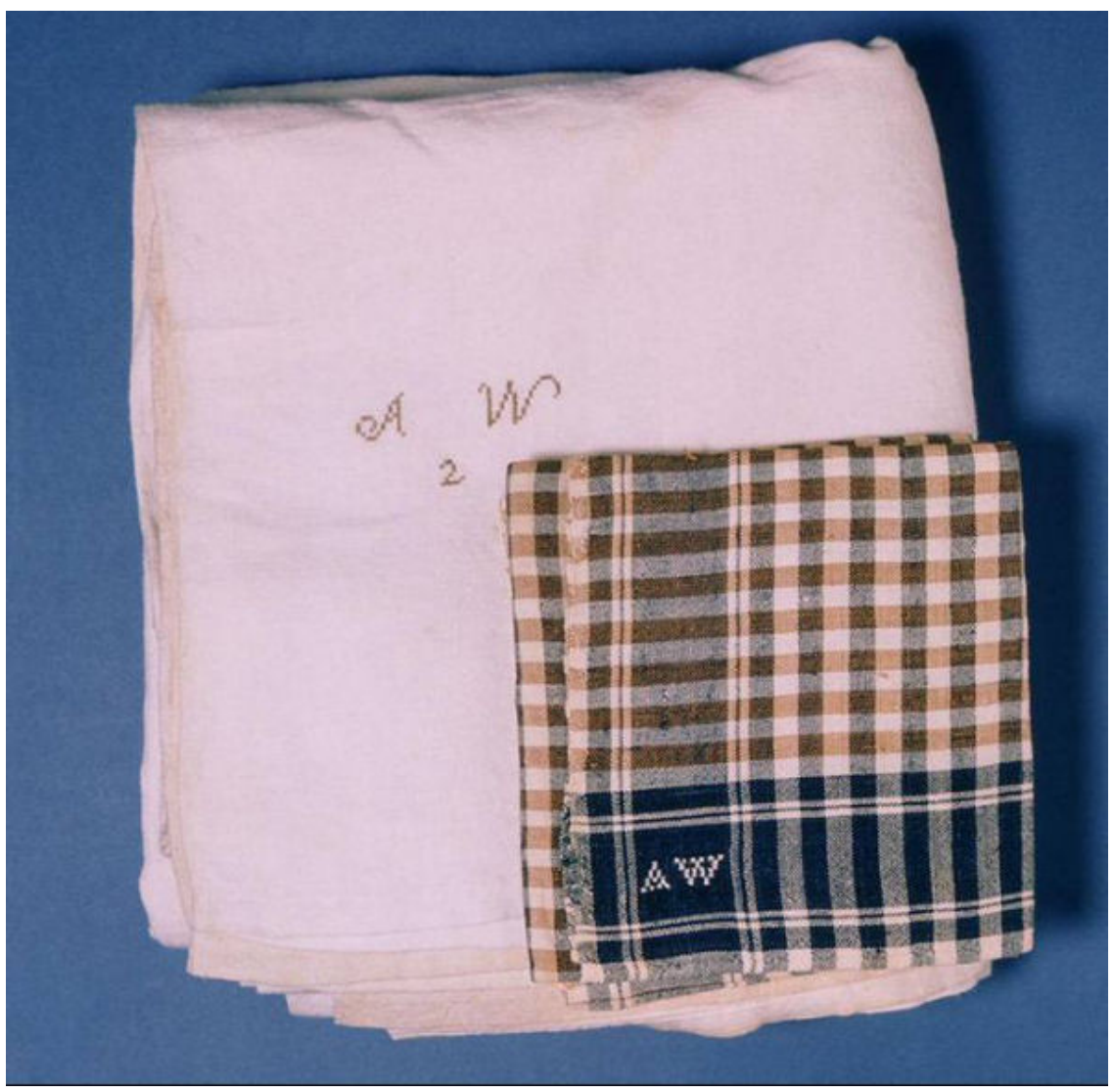

Figure 1.17. Marked textiles from the Wilber family, 1830-1850, Swansea, Massachusetts. Courtesy of Old Sturbridge Village, Sturbridge, Massachusetts, 26.15.300 and 26.21.189.

The initials that Mary Berry True stitched on her table cover resemble the marks that women stitched on innumerable household textiles (including sheets, towels and table linens). These marks are also what young girls practiced by making a sampler. Marking one's household textiles with initials helped to keep track of them and to rotate them evenly. 
of flowers...should always have one or more parts comprised of the hue of the ground...on dark grounds, the brightest colours should occupy the centre..."96 The color scheme also helps to verify the date stitched on the cover. Known as "drab," the brown fabric and the greens that she chose were popular at the time, since they blended well with bright colors. A few years later, one needlework guide would explain that "almost all the class of drab and fawn... are good with blue...the deep rich brown tones of drab are beautiful with yellow.",97

Mary's husband, Joseph, established a woodworking shop in Salem, Massachusetts, where, over several decades, he alternately worked as a carver, turner, cabinetmaker, furniture repairer, painter and varnisher. ${ }^{98}$ A close study of Joseph True's extant account book shows that he spent most of his time working for others in the trade, supplying small carved parts for larger furniture pieces, or carving finish elements on furniture. ${ }^{99}$ The tilt-top table, which he made for personal use, was an opportunity for him to work on something larger. Made out of mahogany, the table has a round tilt-top that could be folded up to make storage easy, or flipped down to serve as work or dining space in the couple's home. The table has carved claw feet and carved lilies for its pedestal, supporting the round top. Although his carving skills were excellent, Joseph, like his wife, relied on printed sources for design inspiration. The lilies on the table are similar to designs printed in contemporary pattern books. ${ }^{100}$

\footnotetext{
${ }^{96}$ Miss Lambert, The Hand-Book of Needlework, 214-215.

${ }^{97}$ Miss Lambert, The Hand-Book of Needlework, 121-122.

${ }^{98}$ Clunie, "Joseph True and the Piecework System in Salem," 1007.

${ }^{99}$ Henry Wycoff Belknap, "Joseph True, Wood Carver of Salem, and His Account Book," Essex Institute Historical Collections 78 (1942): 121, 128.

${ }^{100}$ Belknap, "Joseph True, Wood Carver," 121; Richter, Painted with Thread, 90.
} 
The house where the couple originally used the table was owned by Mary at the time of their marriage in 1809 , having been bequeathed to her while she was still a minor. ${ }^{101}$ In 1840 , when they made the table and its cover, Mary and Joseph had been married for thirty-one years. Their four children were grown and the couple, in their fifties, had the time and the means to make a decorative centerpiece for their parlor. The table and the cover were cherished by their children. After Mary died in 1858, Joseph left Salem to live with his son in Peoria, Illinois. When Joseph died there in 1873, the family continued to use the table until the 1930s; it was donated to the Peabody Essex Museum by one of the couple's descendants in $1974 .^{102}$

Historian Janet Roebuck has suggested that the definition of "old" depended more on appearance and ability than on mere chronological age. ${ }^{103}$ When Elizabeth Lindsay Lomax (b. 1796) turned fifty-nine in September 1855, she assessed her physical condition and concluded that despite her age, she did "not feel old - Have no aches and pains, no gray hairs, no wrinkles." ${ }^{104}$ Nineteenth-century physician and author Frederick Hollick wrote of menopause that "the cessation of the menses is as natural as their first appearance, and the constitutional disturbance resulting from it is also as likely to be beneficial as injurious. In fact, many females when they fully get over it, seem to

\footnotetext{
${ }^{101}$ Belknap, "Joseph True," 122.

${ }^{102}$ Richter, Painted with Thread, 90.

${ }^{103}$ Janet Roebuck, "Grandma as Revolutionary: Elderly Women and Some Modern Patterns of Social Change," International Journal of Aging and Human Development 17 (1983): 253; Janet Roebuck, "When Does 'Old Age' Begin?: The Evolution of the English Definition," Journal of Social History (2001): 417418.

${ }^{104}$ Lindsay Lomax Wood, Leaves from an Old Washington Diary (New York: Books, Inc., 1943), 44. Elizabeth Lindsay was born in Virginia in 1796, the daughter of Colonel William Lindsay (1743-1797) and Martha Fox (ca. 1772-ca. 1806). In 1820, she married Mann Page Lomax (1787-1842), an officer in the U.S. Army, and the couple had seven children. After her husband died in 1842 from injuries sustained in the 1835-1838 war against the Seminole Indians in Florida, Elizabeth supported her family with the government pension she received and by copying documents for the War Department. Biographical information from the North American Women's Letters and Diaries database, http://solomon.nwld.alexanderstreet.com.silk.library.umass.edu:2048/bios/A315BIO.html, accessed August 15,2009
} 
become much younger and more healthy. They... actually appear more juvenile at fifty than they did at thirty-five or forty!"105 This kind of feeling may have motivated women to pick out the dates on their samplers. ${ }^{106}$ They did not feel old or look old, so they acted to destroy the evidence that they were aging.

\section{"a wonderful beauty even in growing old"107: The Cultural Ideal of the Aging Woman}

Medical guides, prescriptive literature, fictional stories about grandmothers, and portraits of aging women all presented a social and cultural ideal of what aging women in antebellum America should look like and how they were to act. Modest, demure, quiet and sweet, antebellum women of a certain age were to resign themselves to their eventual passing, seek a place in heaven, and serve as a role model for the rising generation. One 1852 book painted a picture in words of the model older woman asking "Where could we get another grandmamma for the warm corner? Dear old lady, with her well-starched laces, her spotless white satin cap-riband, her shining black silk gown and shawl, her knitting, and her foot-stove." 108 However, this description, while employing a sense of love and cherished memory, also suggests a darker undertone: the black gown with "well-

\footnotetext{
${ }^{105}$ Frederick Hollick, M.D., The Diseases of Woman, (New York: T.W. Strong, 1849), 234.

${ }^{106}$ The desire to appear younger was not limited to being played out on women's samplers. An image titled "Old Women Ground Young" appears on at least one piece of eighteenth-century creamware. The scene shows elderly women climbing a ladder to the top of a grain-milling machine and young women coming out of the bottom. See Jeanne Schinto, "Old Women Ground Young," Maine Antiques Digest (May 2009), 29C.

${ }^{107}$ L. Maria Child, Looking Toward Sunset (Boston: Ticknor and Fields, 1867), 325.

${ }^{108}$ Caroline M. Kirkland, The Evening Book: Or, Fireside Talk (New York: Charles Scribner, 1852), 14. Caroline M. Stansbury was born in 1801 in New York City, the daughter of Samuel Stansbury and Eliza Alexander. She became a teacher as a young woman. In 1828, she married William Kirkland and they founded a girls' school in Geneva, New York. In 1835, the couple and their four children moved to Michigan Territory. Kirkland began writing novels soon after. In 1843, Caroline and her husband moved their family back to New York City and opened another school, while both continued to write. Caroline died in New York City in 1864. Julie A. Thomas, "Kirkland, Caroline Matilda,"
} 
starched" and "spotless" linens could be interpreted to symbolize a woman set in her ways who eschewed the march of progress. She retained her style of dress and mode of work, pursuing the industry and gentility she was taught as a girl without, presumably, adapting or embracing new ideas.

While religious texts and social pressure defined the ideal for aging women - to age gracefully, remain productive and instruct their children and grandchildren in appropriate values - the existence of antebellum prescriptive literature suggests that not all women were doing so. One author wrote quite plainly that she intended to provide instruction on how to "grow old gracefully," because some of "those who have passed through that stage [youth] are not quite willing enough to retire and leave a clear field for others." 109 These writers tried to persuade women to look upon aging as something positive. As Lydia Maria Child (1802-1880) explained, "If women could only believe it, there is a wonderful beauty even in growing old."110 Eliza Leslie (1787-1858) equated age with beauty and acknowledged that around "middle age" a woman would lose either face or figure. But, this was not without a trade-off, for "a woman with a good mind, a good heart, and a good temper, can never at any age grow ugly - for an intelligent and pleasant expression is in itself beauty, and the best sort of beauty.",111

Many portraits from the antebellum era show that most women followed these guidelines, at least while they were being painted for posterity. In 1849, Jane Anthony Davis (1821-1855) painted a double portrait of Widow Phebe Hunt (b. 1781) (figure

http://www.anb.org.silk.library.umass.edu:2048/articles/16/16-00924.html, American National Biography Online Feb. 2000; accessed November 21, 2009.

${ }^{109}$ Kirkland, The Evening Book, 250.

${ }^{110}$ Child, Looking Toward Sunset, 325.

${ }^{111}$ Leslie, The Behaviour Book, 334. 
1.18). ${ }^{112}$ Both have a handwritten inscription by the artist identifying the sitter and documenting that she was "Aged 68 years" at the time. In both portraits, the widow Hunt wears clothing that her society deemed appropriate to her age: a dark dress with cape collar and a white cap. She is seated with her hands folded in front. One image shows an open book in front of her; her eyeglasses just to the side, suggesting that her eyesight had deteriorated, affecting her reading - and whatever needlework or other close work she might have pursued. Hunt's portrait represents a cultural ideal. She presented all of the hallmarks of aging femininity and at the same time reinforced her society's definition of growing old gracefully, setting an example for younger generations.

Deborah Norris Logan (1761-1839) carefully tread the line between her vanity and her desire for posterity when she had her portrait painted in 1822 at the age of sixtyfour (figure 1.19). ${ }^{113}$ Logan noted that she was not pleased with the final result, writing in her diary that, "tho' like me, it is so ugly, that I feel no inclination to let Posterity think me quite so disagreeable, as they unquestionably will from this picture." "114 Fifty-nineyear-old Elizabeth Lindsay Lomax reacted similarly when she was visited by a "young French artist" in 1855. Surprised that he wished to paint her instead of one of her

\footnotetext{
112 The painting is currently in a private collection. It is pictured in an advertisement for Joan R. Brownstein American Folk Paintings, which appeared in Antiques and the Arts Weekly, March 2, 2007.

${ }^{113}$ The portrait is now in the collection of the National Society of the Colonial Dames of America in the Commonwealth of Pennsylvania at Stenton, Philadelphia. It is a copy of the original portrait painted by Charles Willson Peale in 1822. The original was burned by a relative in 1934. Susan M. Stabile, Memory's Daughters: The Material Culture of Remembrance in Eighteenth-Century America (Ithaca: Cornell University Press, 2004), 130. Deborah Norris was born in 1761 in Philadelphia, Pennsylvania, the daughter of Charles Norris (1712-1766) and Mary Parker (d. 1799). In 1781, she married Quaker doctor George Logan (1753-1821) and they had three sons. Deborah Norris Logan died in 1839. Biographical information from the North American Women's Letters and Diaries database, http://solomon.nwld.alexanderstreet.com.silk.library.umass.edu:2048/bios/A160BIO.html, accessed August $15,2009$.

${ }^{114}$ Logan's diary as quoted in Stabile, Memory's Daughters, 129.
} 

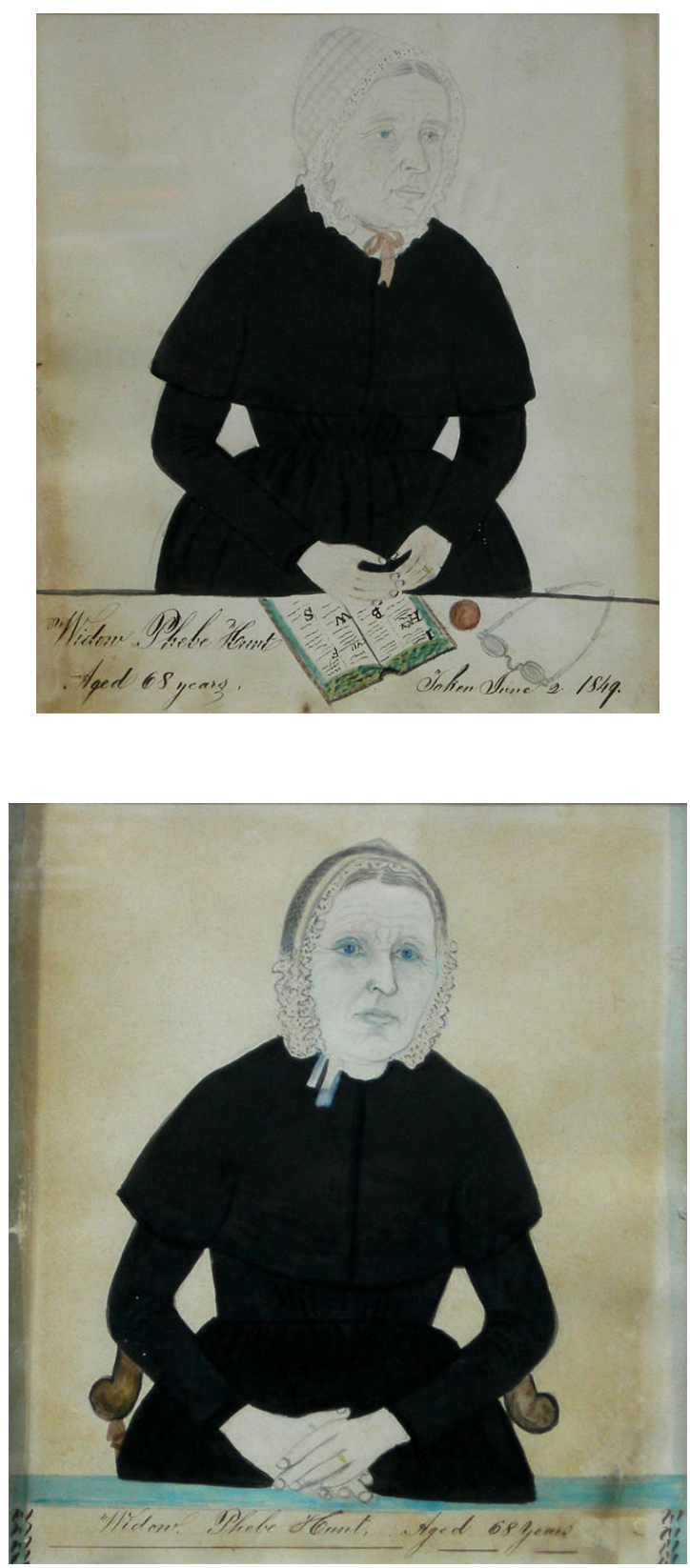

Figure 1.18. Two portraits, Widow Phebe Hunt aged 68 years, by J.A. Davis (18211855), 1849. Courtesy of Joan R. Brownstein American Folk Paintings.

Antebellum portraits of aging women show a similar mode of dress - dark dress with white cap. Sixty-eight-year-old Phebe Hunt presented what was understood as a respectable appearance for her age in these portraits. 


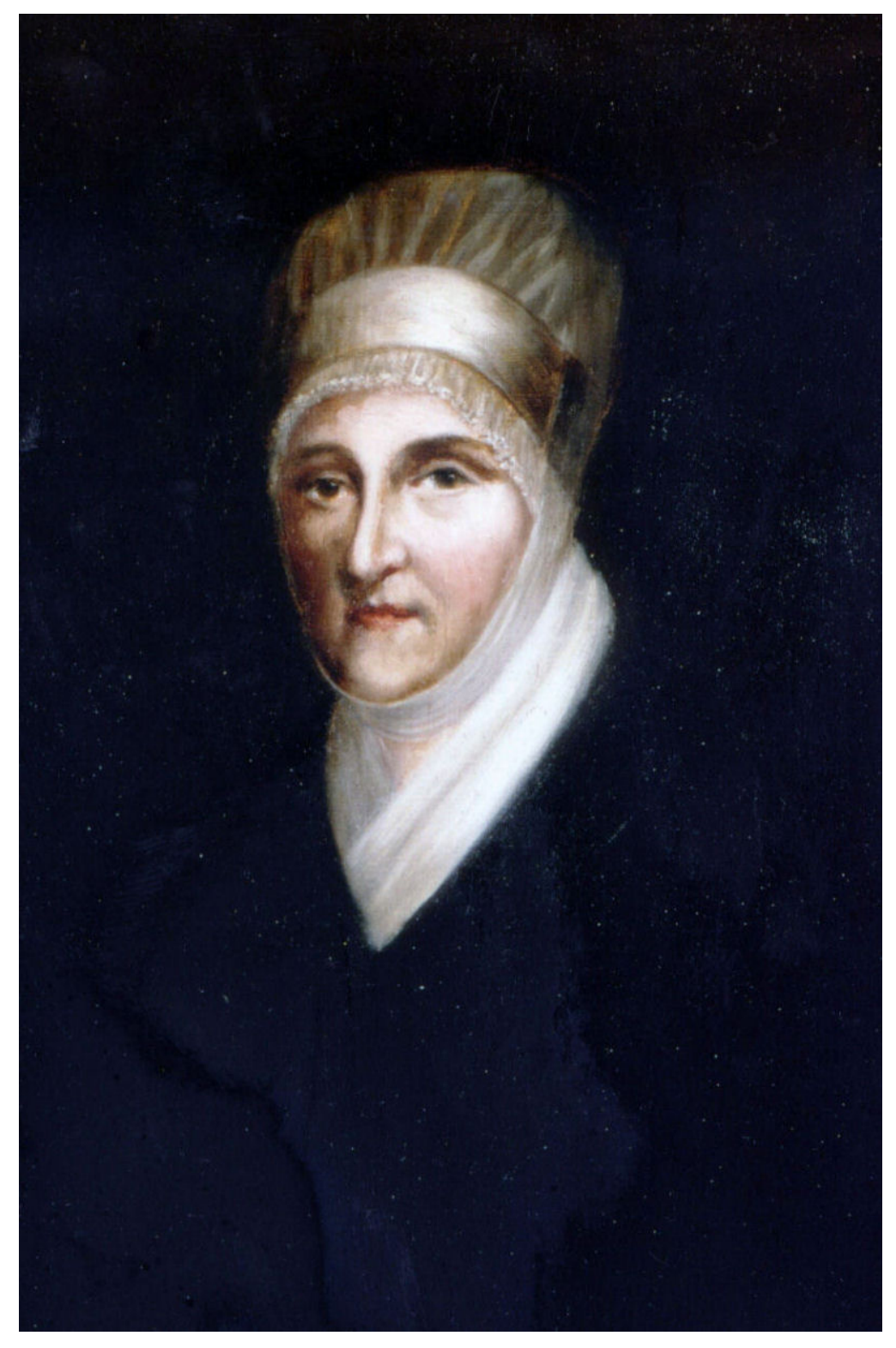

Figure 1.19. Post-1934 reproduction of portrait of Deborah Norris Logan (1761-1839) by Charles Willson Peale (1741-1827), 1822, Philadelphia, Pennsylvania. Courtesy of the National Society of the Colonial Dames of America in the Commonwealth of Pennsylvania at Stenton, Philadelphia.

Deborah Norris Logan did not like this portrait of herself and one of her descendants destroyed the original in 1934. This copy shows an appropriately-dressed older woman wearing modest clothing. 
daughters, Lomax declined his offer. "I was once quite pretty," Lomax explained, "And I am too vain to be handed down to posterity pictured in the autumn of my life."

Contemporary prescriptive literature encouraged aging women to remain productive. According to Lydia Maria Child, "the value of occupation is threefold to elderly people, if usefulness is combined with exercise, for in that way the machinery of body, mind and heart may all be kept from rusting."116 A second author concurred. "The gentler sex have a great resource in age," she wrote, "from their varieties of interesting domestic employment, and especially the uses of the needle." ${ }^{\prime 17}$ A portrait of forty-oneyear-old Allethenia Fisk Holt (1792-1838) of Vermont, painted around 1833, underscores this advice; it depicts her with a pair of scissors on a chain attached to her waistband (figure 1.20). ${ }^{118}$

Despite the age-related eye problems and stiffening joints of its makers, needlework appeared in many pictures and descriptions of demure grandmothers growing old gracefully. A symbol of proper womanhood, as well as of industriousness, knitting or sewing set a proper example for younger generations and was thought to fulfill a woman's natural role as the gentler sex, particularly as hand spinning declined. ${ }^{119}$ An 1849 story about one grandmother explained that she "passed her useful and blameless

\footnotetext{
${ }^{115}$ Wood, Leaves from an Old Washington Diary, 45-46.

${ }^{116}$ Child, Looking Toward Sunset, 175.

117 Sigourney, Past Meridian, 248.

118 The portrait is in the collection of Historic New England, Boston, Massachusetts. Fisk was the daughter of Reverend Abel Fisk and Anna Spaulding of Wilton, New Hampshire; she married Asa Holt. The painting is attributed to Asahel Powers (1813-1843). Illustrated in Mary C. Beaudry, Findings: The Material Culture of Needlework and Sewing (New Haven: Yale University Press, 2006), 132. Genealogical information from email correspondence between the author and Adrienne Sage, Collection Manager at Historic New England; Frederick Clifton Pierce, Fiske and Fisk Family (Chicago, 1896), 253.

${ }^{119}$ Laurel Thatcher Ulrich, The Age of Homespun: Objects and Stories in the Creation of an American Myth (New York: Alfred A. Knopf, 2001), 376. An 1812 portrait of Mrs. Ammi Ruhamah Robbins, which pre-dates the period under consideration here, makes Ulrich's point visually, showing its subject with a book in one hand and her knitting on the table next to her. The painting, by artist Reuben Moulthrop, is now in the collection of the Detroit Art Institute. Ulrich, The Age of Homespun, 376.
} 


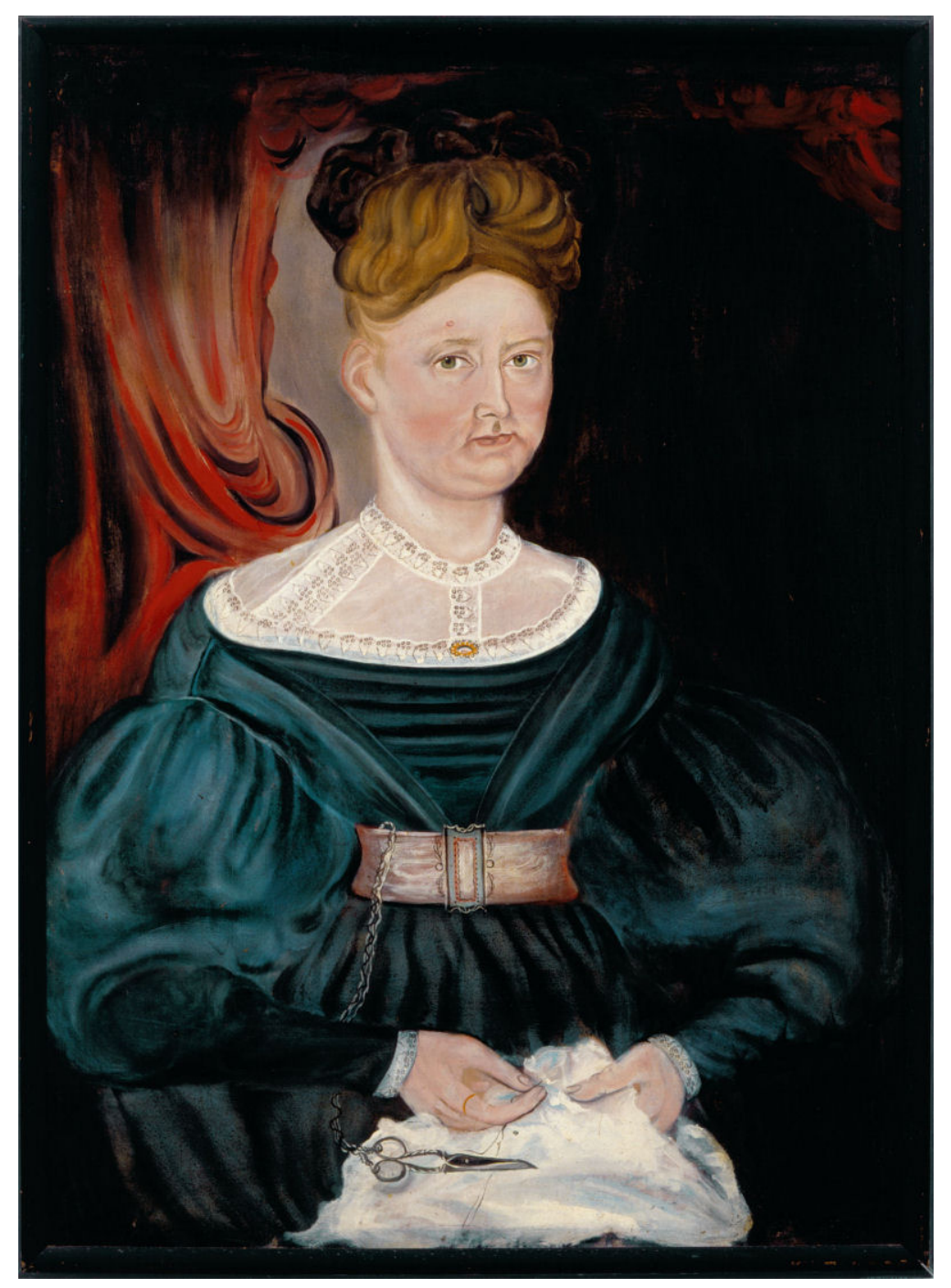

Figure 1.20. Allethenia Fisk Holt (1792-1838) attributed to Asahel Powers (1813-1843), circa 1833, Vermont. Courtesy of Historic New England, Boston, MA.

Just as some aging women chose to be painted in their spectacles, other antebellum women were depicted with their sewing tools. Allethenia Fisk Holt is pictured with her scissors, stitching what looks like a piece of whitework embroidery. 
life. When too old to perform any other labor, she managed to knit stockings for all the family...At threescore years and ten, she quietly passed into the world of spirits; leaving the precious influence of her example to bless her children and her children's children." ${ }^{120}$ Likewise, in March 1835, forty-four-year-old Sarah Ayer (1791-1835) recorded in her diary, "My time has been occupied as usual, in sewing for myself, children, and friends; reading, and visiting the sisterhood." ${ }^{121}$ Ayer's brief entry suggests how ingrained her role was. In this one sentence, we learn that she spent a regular amount of time sewing, that her needlework was often done for others, and that she also passed time reading and visiting her family and neighbors. In short, as an aging woman, Ayer pursued prescribed activities to convey her gentility and moral values to her community.

As women struggled with the physical changes of aging, as well as with how they wished to be remembered, they turned to needlework as a constant in their lives and as a well-understood cultural symbol. Family history remembers that Patty Sessions (17951892) (whose sampler will be explored in chapter 2) insisted on knitting almost until she died at age ninety-four. Despite failing sight and fingers, which dropped stitches and made other errors, Sessions continued to knit each day. Her family took to unraveling her work each night so she could start fresh each day. ${ }^{122}$ While this story initially suggests a certain kind of torture for poor Patty, further reflection suggests that her family

\footnotetext{
${ }^{120}$ The Youth's Sketch Book (Boston: Benjamin B. Mussey and Company, 1849), 22.

${ }^{121}$ Sarah Newman Connell Ayer, Diary of Sarah Connell Ayer (Portland, Maine: Lefavor-Tower Co., 1910), 369. Sarah Newman Connell was born in 1791 in Philadelphia, Pennsylvania, the daughter of Captain George Connell and Mary Greenleaf. In 1810, she married Samuel Ayer and the couple had seven children, although four died in infancy. The family lived in Portland, and later, Eastport, Maine. Sarah Connell Ayer died in 1835. Biographical information from the North American Women's Letters and Diaries database, http://solomon.nwld.alexanderstreet.com.silk.library.umass.edu:2048/bios/A209BIO.html; accessed November 21, 2009.

${ }^{122}$ Ulrich, Age of Homespun, 407.
} 
respected her work and were trying to preserve the pleasure it brought her in old age, rather than leaving a lot of mistakes that would impede her progress and frustrate her work. This story underscores the importance that needlework held for women as they aged. The needlework and the woman were intimately intertwined and connected. In reality, most aging middle-class women did achieve the acceptance preached by etiquette guides and Sunday sermons. In her survey of the letters and diaries of aging American women between 1785 and 1835, Terri L. Premo found that most women were unconcerned with appearing younger than their years. ${ }^{123}$ For example, diarist Joanna Graham Bethune (1770-1860) wrote of her resignation and acceptance of growing older in many entries, including one on her seventieth birthday in February 1840:

My birthday, and which completes my threescore and ten years. I can now say with my mother, "I have turned the last point, and am now waiting a favorable breeze to shoot into port." I have, on my knees, reviewed my past life from childhood to old age... When I review my past life, I am amazed at the goodness and mercy which has followed me from the cradle, and which I trust shall follow me to the grave. ${ }^{124}$

Yet for every Joanna Bethune who worked to "grow old gracefully," there was also an Ann Maria Foltz Kline (b. 1820), presumably so determined to hide her age that she picked out the digits of the year she made her girlhood sampler (see figure 1.21). ${ }^{125}$

Foltz's pictorial sampler has a large flowering vine border around an unusual central motif of a three-quarter view of a house, with its accompanying wellhouse and a pine tree. These motifs suggest that the sampler was worked in Lancaster County,

\footnotetext{
${ }^{123}$ Terri L. Premo, Winter Friends: Women Growing Old in the New Republic, 1785-1835 (Urbana: University of Illinois Press, 1990), 113.

${ }^{124}$ George Washington Bethune, comp., Memoirs of Mrs. Joanna Bethune (New York: Harper and Brothers, 1863), 213-214.

${ }^{125}$ The sampler is now in a private collection. Ann Maria Foltz was the daughter of Jonathon and Elisabeth Foltz of Lancaster County, Pennsylvania. She married Edmund M. Kline in 1851. M. Finkel and Daughter, Samplings 5 (1994): 10.
} 


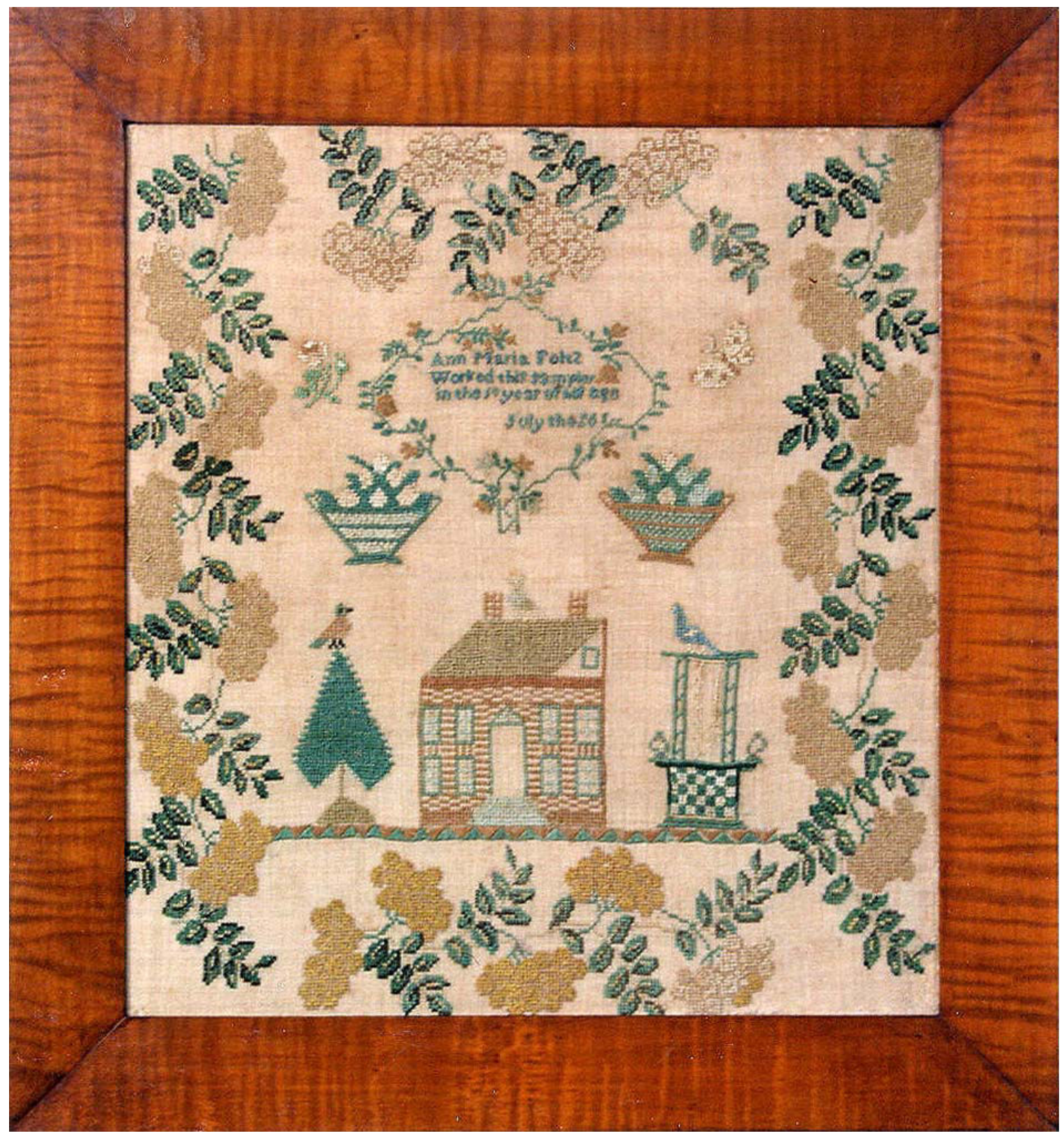

Figure 1.21. Sampler by Ann Maria Foltz (b. 1820), circa 1830, Pennsylvania. Courtesy of M. Finkel and Daughter, Philadelphia, Pennsylvania.

While many antebellum women aged gracefully, wearing clothes that suited their age and donning spectacles, other women fought the aging process. At some point, the year was removed from this sampler made by Ann Maria Foltz. 
Pennsylvania. ${ }^{126}$ More typical fruit baskets also have a central location on the sampler, just below a viny cartouche that reads, "Ann Maria Foltz worked this sampler in the 10 year of her age July the 26." The fabric threads around the end of the inscription show signs that she originally stitched the year she made the sampler, in addition to the month and day, but that those numbers were removed at a later time. Samplers like this one ceased to be an educational exercise and instead provided the agency for mature women to mediate the divide between their reality and antebellum cultural ideals.

Further adding to women's ambivalence about aging were established cultural stereotypes surrounding elderly women. From the seventeenth century on, examples of the aging woman as crone or witch, and of the independent woman as unsexed, abounded. The Salem Witch Trials are perhaps the most well-known and dangerous example of this stereotyping. Recent scholarship has examined the trials as a societal means of controlling women who went against cultural ideals. ${ }^{127}$ In addition to the witchcraft trials, some scholars have explored the use of gossip as a control mechanism in the eighteenth and nineteenth centuries - both amongst women and against women. ${ }^{128}$

While examples of these stereotypes can be found throughout history - even to the present day - at least one study of antebellum magazine fiction suggests that they were not as prevalent as they had perhaps been a century earlier. A study of a random sample of the stories in Littell's Living Age from 1845 to 1882 found that elderly

\footnotetext{
${ }^{126}$ M. Finkel and Daughter, Samplings 5 (1994): 10.

${ }^{127}$ See Carol F. Karlsen, The Devil in the Shape of a Woman: Witchcraft in Colonial New England (New York: W.W. Norton and Company, 1998); Mary Beth Norton, In the Devil's Snare: The Salem Witchcraft Crisis of 1692 (New York: Alfred A. Knopf, 2002).

${ }^{128}$ For example, see Laurel Thatcher Ulrich, Good Wives: Image and Reality in the Lives of Women in Northern New England 1650-1750 (New York: Alfred A. Knopf, 1987), 54-60. For an exploration of female stereotypes in the southern United States during the colonial era, see Kathleen M. Brown, Good Wives, Nasty Wenches, and Anxious Patriarchs: Gender, Race and Power in Colonial Virginia (Chapel Hill: University of North Carolina Press, 1996).
} 
characters appeared in almost half of the 293 stories sampled (47.8\%). And, the majority of these characters $-70.7 \%$ - were depicted as having no health problems, which might also encompass the depiction of an elderly woman as a crone. $84.5 \%$ of these elderly characters were clearly described in the stories as being sane and alert. ${ }^{129}$ The authors concluded that "for the most part, the elderly were portrayed as being treated with affection, reverence, respect or deference." But, they acknowledge that these depictions do not necessarily "reflect the reality of the period." ${ }^{30}$ Another scholar has suggested that the rise of the "separate spheres" ideology offered a more effective controlling impulse for antebellum women than stereotyping them based on age or appearance. ${ }^{131}$ Regardless, the long-standing use of unflattering stereotypes like the crone and the witch undoubtedly influenced some women to pursue appearing younger in whatever way they could.

\section{Mediating the Ideal and the Real}

Prescriptive literature of the antebellum era minced no words in offering an ideal view of how aging women should look and act. Suitable dress for women over forty required "grave colors" without "flounces or feathers," a cap and spectacles. Older women were to sit erect and keep busy by sewing or reading. ${ }^{132}$ Yet, to counter the physical effects of age, some women turned to more youthful forms of dress. One author offered a detailed description of inappropriate female dress:

\footnotetext{
${ }^{129}$ Jane Range and Maris A. Vinovskis, "Images of the Elderly in Popular Magazines: A Content Analysis of Littell's Living Age, 1845-1882," Social Science History 5 (Spring 1981): 130, 132.

${ }^{130}$ Range and Vinovskis, "Images of the Elderly," 156.

${ }^{131}$ Karlsen, The Devil in the Shape of a Woman, 255-257.

${ }^{132}$ Virginia Cary, Letters on Female Character, Addressed to a Young Lady on the Death of Her Mother (Richmond, VA: Ariel Works, 1830), 142.
} 
I was one day walking the streets of a city, when I perceived just before me an exceedingly juvenile figure enveloped in a cloud of rose-coloured drapery, with towering plumes in her wide spread bonnet... when she suddenly turned and disclosed to me, not the bloom and dimples of fifteen as I had anticipated, but a face that I well know had reckoned more than fifty winters. A quantity of artificial curls and rich lace softened the effect of age considerably in her face, but there were distinct traces of the heavy footsteps of time...Had I seen this lady suitably dressed, in grave colours, without flounces and feathers, with a matronly cap surmounted honestly by a pair of spectacles, I should have felt much more respect for her character... ${ }^{133}$

Most prescriptive authors counseled against "deception with regard to age," suggesting that "when elderly people are accused of undue youthfulness of dress or manner, it is usually accompanied with some suggestion of a design upon the other sex," something that was considered altogether inappropriate by mainstream antebellum society. ${ }^{134}$

But, while the aging woman herself was encouraged to act her age and accept growing older, younger readers were also advised not to ask elders about their age. "The slightest jest on the personal defects of those you are conversing with, is an enormity of rudeness and vulgarity," Eliza Leslie warned, "Still worse, to rally any person (especially a woman) on her age, or to ask indirect questions with a view of discovering what her age really is. If we continue to live, we must continue to grow old. We must either advance in age, or we must die. Where then is the shame of surviving our youth?"135 This directive seems to suggest a mixed message - women should aspire to grow old gracefully, but they could expect to be protected from revealing their age.

Recounting a visit to Montpelier to see sixty-year-old Dolley Payne Todd Madison (1768-1849), fifty-year-old Margaret Bayard Smith (1778-1844) embraced the opportunity to reminisce, talking "of scenes long past and of persons far away or dead."

\footnotetext{
${ }^{133}$ Cary, Letters on Female Character, 142.

${ }^{134}$ Kirkland, The Evening Book, 254.

${ }^{135}$ Leslie, The Behaviour Book, 334.
} 
Smith was impressed by her friend's appearance. "She looks young and says she feels so. I can believe her, nor do I think she will ever look or feel like an old woman," Smith mused. ${ }^{136}$ Smith's words resonate with the advice offered by the published advice books of the time. Yet, she did pay attention to her friend's looks and described her youthful bearing as something desirable, demonstrating that advice to "grow old gracefully" was a mixed message in reality. Women were to look their age, but they also knew that looking young was valued. Smith went on to recount a meeting on the same day with "old Mrs. Madison” - her friend's mother-in-law, Eleanor Rose Conway Madison (1731-1829), who, at the time, "lack[ed] but 3 years of being a hundred years old." When Smith asked her how old she was, the lady replied, "I have been a blest woman...blest all my life, and blest in this my old age. I have no sickness, no pain; excepting my hearing my senses are but little impaired. I pass my time in reading and knitting." Smith wrote that she "felt much affected by the sight of this venerable woman. Her face is not as much wrinkled as her son's who is only 77 years old." ${ }^{137}$ While young people were strongly counseled against asking their elders about their age, Smith's words suggest that mature women were freed from this prohibition.

The experience recounted by Smith adds a layer to the "rules of aging" provided by the etiquette guides. While growing older was met with a great deal of ambivalence by women in their forties, fifties and even sixties, once these same women reached their seventies, eighties and beyond, they seem to have adopted a sense of pride in their longevity. Lydia Sigourney drew attention to the value of the needlework made by aging women, implying that the items themselves held added value because of the age of their

\footnotetext{
${ }^{136}$ Hunt, The First Forty Years, 234-235.

${ }^{137}$ Hunt, The First Forty Years, 236. The woman referred to as "old Mrs. Madison" in the letter was the mother of President James Madison (1751-1836).
} 
makers. She described an eighty-four-year-old woman of her acquaintance who "found great pleasure from these unostentatious pursuits." In one year, Sigourney reported, this lady completed forty-eight pairs of stockings and two large bed quilts, one consisting of over 3,000 pieces. ${ }^{138}$ Production at a great age was both an achievement and an example. $^{139}$

Plying needle and thread could be a means for mature women to recapture their youth, each stitch reminding them of their younger years as they stitched a sampler, made a quilt, or knit a stocking. The physical effects of aging could affect the skill level and appearance of the needlework of middle-aged and older women, but the quilts, samplers and other objects that remain demonstrate that those who wanted to stitch did so. For example, in 1837, thirty-six-year-old Emma P. Forbes (b. 1801) of Milton, Massachusetts, included a rather whimsical comment on her sampler. "We all have our hobbies..." she stitched, referring directly to the recreational nature of her work. ${ }^{140}$ And, in April 1860, sixty-seven-year-old Mary Avery Upham (1790-1872) noted in her diary, "I do not know what I should do without my knitting work." ${ }^{141}$ Despite commenting almost thirty years apart, these two women suggest that needlework, whether embroidery, quilting or knitting, was a valued and necessary means of expression for antebellum women from their thirties to their sixties and beyond. But, needlework was no mere

\footnotetext{
${ }^{138}$ Sigourney, Past Meridian, 248. Sigourney may also have been thinking of the productivity of many New England women as they increased their activism, making small items to sell at anti-slavery fairs and other events. For more on the rise of antebellum female activism, see Anne M. Boylan, The Origins of Women's Activism: New York and Boston, 1797-1840 (Chapel Hill: University of North Carolina Press, 2002); and Debra Gold Hansen, Strained Sisterhood: Gender and Class in the Boston Female Anti-Slavery Society (Amherst: The University of Massachusetts Press, 1993), 158, 162-164.

${ }^{139}$ Ulrich, The Age of Homespun, 381-382. See chapter 3 for a discussion of aging women's entries in local agricultural fairs, where advanced age was often highlighted in newspaper accounts of the premiums awarded.

${ }^{140}$ This sampler is now in a private collection, but is pictured in M. Finkel and Daughter, Samplings 6 (1994): 19. Life dates from www.ancestry.com, accessed May 19, 2006.

${ }^{141}$ Diary of Mary Avery Upham, April 23, 1860, Massachusetts Historical Society, Boston, Massachusetts.
} 
hobby; the choice that these women made - to stitch or not to stitch - moved the products of their needle well beyond the functional, as the following example demonstrates.

Upon first glance, the bed covering in figure 1.22 is a veritable sea of triangles.

The unordered use of so many different colors draws the eye around it. Gradually, focus shifts to the center - more triangles and five intricate round blocks with bright yellow, red and green pinwheels. Each triangle measures just under three inches along its widest edge and the spread includes more than 3,600 of them. The maker of this particular bedcover was in her fifties when she stitched it together. While we do not know for sure whether she had good eyesight and limber joints, we can read the object for clues about its maker and consider the choices she made while stitching it. Mary Tayloe (Lloyd) Key (1784-1859) of Maryland made the bedcover in the late 1830 s or early 1840 s, when she was in her fifties. ${ }^{142}$ She had borne her last child in 1827 , when she was forty-one, and lived a comfortable life, allowing her the time to stitch this elaborate item. ${ }^{143}$ Her bedcover represents hours of careful work.

The bedcover takes on different meanings when we consider whether it was made before her husband's death in 1843 or after. Mary Lloyd Key used a fabric with a Greek

\footnotetext{
${ }^{142}$ The quilt is currently in the collection of the Daughters of the American Revolution Museum in Washington, D.C. I am indebted to Alden O'Brien, Curator of Costume and Textiles, for allowing me access to the quilt and its records during site visits in June 2006 and June 2009. Mary Tayloe Lloyd was the daughter of Edward Lloyd (1744-1796) and Elizabeth Gwynn Tayloe (1750-1825). Her grandfather was the royal governor of Maryland and one of her brothers also served as governor of the state. Mary Lloyd married Francis Scott Key (1779-1843) in 1802. The couple had eleven children, five girls and six boys. Family information from www.ancestry.com, accessed May 30, 2008; entry for Francis Scott Key, Maryland Online Encyclopedia, www.mdoe.org/keyFS.html, accessed May 30, 2008; Victor Weybright, Spangled Banner: The Story of Francis Scott Key (New York: Farrar and Rinehart Inc., 1935), 35-36, 40, 226-227. A second quilt attributed to Mary Tayloe Lloyd Key is now in the collection of the San Jose Museum of Quilts and Textiles, San Jose, California. This quilt is paper-pieced in hexagons. The quilt was never finished and the paper templates are still visible on the back, showing that they are recycled letters. Family history suggests that this quilt was made for Key's daughter, Mary Alicia Lloyd Nevins Key (18231886) (known as Alice), around 1840. Unfortunately, details about why the quilt was made are unknown. Phone conversation with staff at the San Jose Museum of Quilts and Textiles, April 10, 2009.

${ }^{143}$ Weybright, Spangled Banner, 227, 275.
} 


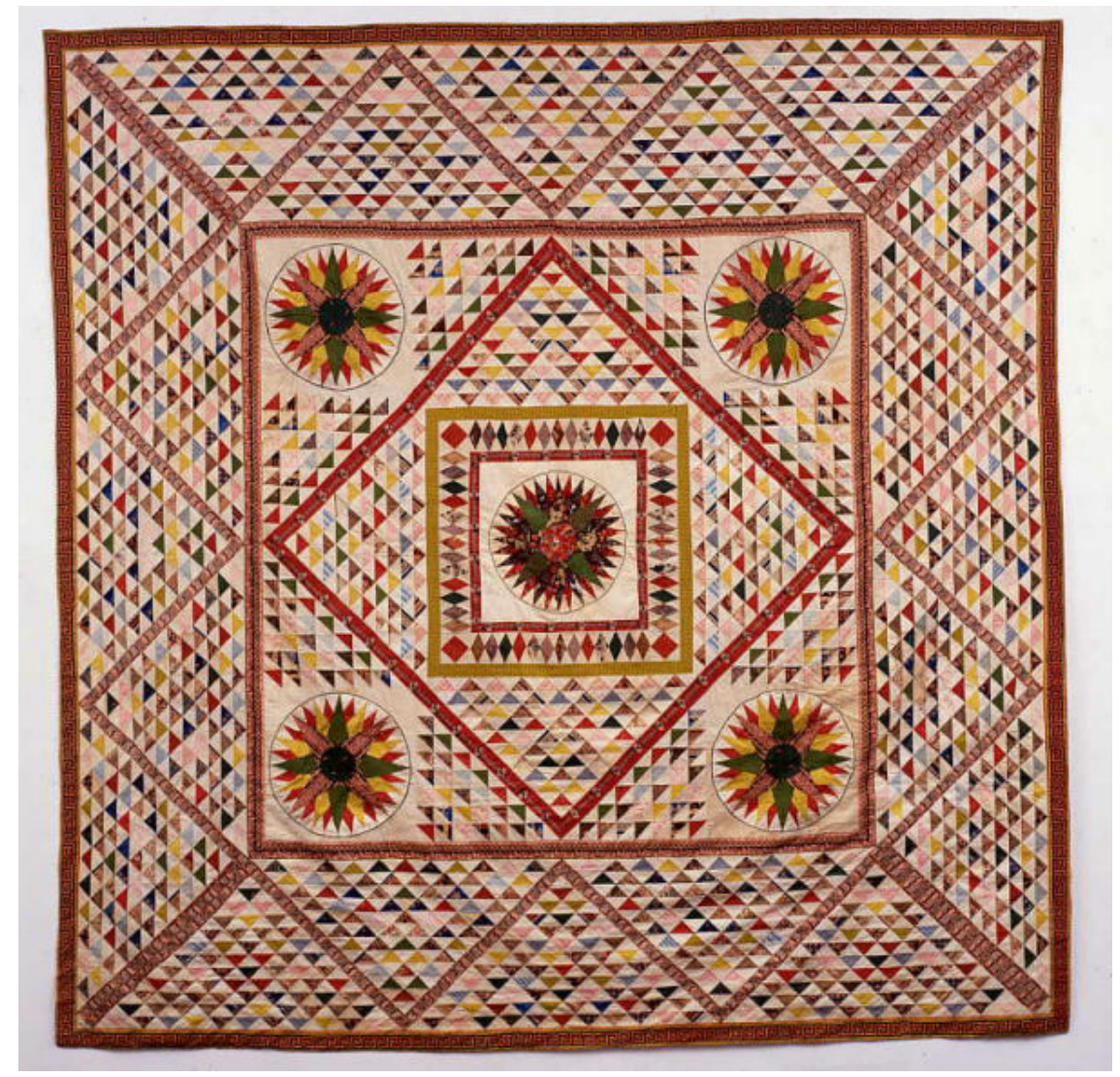

Figure 1.22. Counterpane by Mary Tayloe Lloyd Key (1786-1859), circa 1840, Georgetown, Maryland. Collection of the Daughters of the American Revolution Museum, Washington, D.C.

Mary Lloyd Key created this pieced counterpane using over 3,600 triangles, along with the challenging Mariner's Compass block. The outermost border fabric shows a Greek key motif, which may have been a purposeful choice on the quiltmaker's part to symbolize her family. 
key motif for one of her borders and she carefully cut the fabric into a $2 \frac{1}{4} \mathrm{inch}$ band to show that motif. ${ }^{144}$ At least one scholar has suggested that this was done quite purposefully as a link to the family's name. ${ }^{145}$ If the spread was made prior to her husband's death in 1843, it may suggest pride in the family's accomplishments. Mary's husband, Francis Scott Key (1779-1843), was the famed writer of a poem that would become the American national anthem, "The Star Spangled Banner." Her inclusion of the fabric with the key motif suggests identification with her married name, having left her birth family and become part of a new family. But Mary Key was also described as being somewhat haughty and aware of her social position, having grown up in a wealthy family. ${ }^{146}$ Her family owned a mansion house near Annapolis known as Wye House and the family "spent a fortune on silver knobs, marble stairways and exquisite moldings" for the house. ${ }^{147}$ Built between 1781 and 1784, just before Mary's birth, the house embraced the federal style and may have incorporated the Greek key motif into its design and furnishings. ${ }^{148}$ It is possible that Mary employed the fabric with the Greek key design as a memory of her own past, using it to bring together her girlhood with her married life.

\footnotetext{
${ }^{144}$ Also known as a fret or a meander, the Greek key motif was a popular running ornament in ancient Greece and Rome and was used frequently on American architecture and decorative arts during the federal era. See Harold Koda, "The Greek Key and Divine Attributes in Modern Dress," in Timeline of Art History (New York: The Metropolitan Museum of Art, 2000-), http://www.metmuseum.org/toah/hd/god5/hd_god5.htm (October 2003); www.buffaloah.com/a/DCTNRY/f/fret.html. A similar fabric is employed as a border in a quilt made in 1846 by Mary Rooker Norris (1785-1868) of Maryland (also now in the collection of the Daughters of the American Revolution Museum); see chapter 2 for a discussion of that quilt.

${ }^{145}$ Gloria Seaman Allen, Old Line Traditions: Maryland Women and Their Quilts (Washington, DC: The DAR Museum, 1985), 27.

${ }^{146}$ Weybright, Spangled Banner, 41.

${ }^{147}$ Weybright, Spangled Banner, 41.

${ }^{148}$ Weybright, Spangled Banner, 41; National Register Listings in Maryland, www.marylandhistoricaltrust.net, accessed July 5, 2008; Swepson Earle and Percy G. Skirven, Maryland's Colonial Eastern Shore: Historical Sketches of Counties and of Some Notable Structures (Baltimore: Munder-Thomsen Press, 1916), 29-30.
} 
Alternatively, Mary could have made the piece later in the 1840s, after Francis's death; the fabrics in the bed covering can only limit its origin to the 1835 to 1850 period, not more precisely, and it is undated. If constructed between 1843 and 1850, the bedcover may have taken on another dimension - a memorial to her husband with whom, by all accounts, she shared a caring and happy marriage. ${ }^{149}$ In this case, the inclusion of the key motif fabric could have been Mary's way of keeping her husband nearby. The bedcover includes a variety of fabrics - reds, greens, browns, pinks, yellows and blues many of which may have been left over from family clothing. ${ }^{150}$ By stitching these scraps into her piece, Key could retain memories of those closest to her, even though her children were starting their own families.

Some of the other choices that Mary Key made as she stitched this piece add to an understanding of her life. Perhaps most noticeably, the bed cover is unfinished. It does not have a middle layer of batting and is not quilted. ${ }^{151}$ This difference in construction technically classifies the piece as a counterpane or summer coverlet rather than a quilt. Unquilted bed coverings like this one were not uncommon, particularly in the southern states where warm weather rendered thick quilts unnecessary for most months of the year. In addition, Key's choice to piece over 3,600 triangles together would have created more than 1,800 seams on the back making the quilting more difficult, because there would be more layers to quilt through.

\footnotetext{
${ }^{149}$ Weybright, Spangled Banner, 40-41, 275-277.

${ }^{150}$ Email correspondence between the author and Alden O'Brien, curator of costume and textiles at the Daughters of the American Revolution Museum, July 7, 2008.

${ }^{151}$ Allen, Old Line Traditions, 27. Currently, the quilt has a replacement backing, which is only basted on and does not cover the entire back of the quilt. Email correspondence between the author and Alden O'Brien, curator of costume and textiles at the Daughters of the American Revolution Museum, Washington, DC, July 7, 2008; site visit on June 23, 2009.
} 
While sewing triangles together is one of the simplest quiltmaking tasks, requiring only a straight seam, which was one of the first lessons taught to a young girl, Key juxtaposed the much more complicated Mariner's Compass block in the center of her piece. In addition to being one of the oldest patchwork patterns, the Mariner's Compass required a quilter to be extremely precise in order to make the circle of radiating points match up in the center. The maker also needed a basic understanding of geometry to draft the pattern herself; otherwise, she would need to rely on someone with that knowledge to make the pattern for her. ${ }^{152}$ And, while sewing two triangles together is fairly easy, precisely matching the corners of over 3,600 is a challenge. Key's work is well done, with most points matching closely. ${ }^{153}$

Taken together, the bits of evidence provided by the bedcover itself start to suggest a larger interpretation. Mary Tayloe Lloyd Key, in her fifties, chose to make something that showed off her needlework skill. She used fabrics that were personally meaningful, demonstrating her love of family and perhaps her identification with her married name. Although it was not finished, the spread was tightly associated with its maker, even long after her death. Its good condition is due, in part, to the fact that it was stored out of sight from 1858 until 1925. A note written in 1925 by Key's granddaughter, Mary Tayloe Key McBlair (b. 1855), and given to the Daughters of the American Revolution Museum with the piece reads, "This quilt was made by my grandmother Mary

\footnotetext{
${ }^{152}$ Brackman, Clues in the Calico, 167; Lynne Z. Bassett and Jack Larkin, Northern Comfort: New England's Early Quilts 1780-1850 (Nashville: Rutledge Hill Press, 1998), 61, 99; Judy Mathieson, "Some Published Sources of Design Inspiration for the Quilt Pattern Mariner's Compass $-17^{\text {th }}$ to $20^{\text {th }}$ Century," Uncoverings 2 (1981): 11-18. Brackman suggests that this quilt block may be inspired by the depictions of compass roses on sea charts, or by representations of the sun. The Key family called the pattern "Five Blazing Stars." Curatorial file for the bedcover, Daughters of the American Revolution Museum, Washington, D.C.

${ }^{153} \mathrm{I}$ am indebted to Alden O’Brien and Virginia Vis, who examined the quilt with me on June 23, 2009.
} 
Tayloe Key... [it] was left to her daughter, Mrs. Ellen Key Blunt, who left it to her daughter Miss Alice Key Blunt.",154

Sewing a sampler or stitching a quilt offered a sense of purpose to aging women who had completed their childbearing and childraising duties. In a letter to her son in November 1823, fifty-five-year-old Hannah Robbins Gilman (1768-1837) wrote, "When absent from our children, we feel like useless beings." ${ }^{155}$ Women of an advanced age could still find usefulness through the needle. Lydia H. Sigourney explained that she

had the honor of being acquainted with ladies, who after the age of eighty, excelled in the various uses of the needle, executing embroidery by the evening lamp, and sitting so erect, that younger persons, more addicted to languid positions, asserted that "it made their shoulders ache to look at them." I am in possession of various articles, both useful and ornamental, wrought by the hands of such venerable friends, and doubly precious for their sakes. ${ }^{156}$

While asserting the value of this needlework, Sigourney's words also suggest a disapproval of the young people in the next generations who were not living up to the example set by their elders. This intergenerational tension surrounding needlework will be explored in chapters 3 and 4 .

Needlework was a constant for antebellum women from girlhood to old age. Their parents passed away, their children grew up and moved out, and their husbands died, but needlework remained, even after its maker died. And, as a woman's role changed from daughter to wife to mother to grandmother, so did her needlework,

\footnotetext{
${ }^{154}$ Curatorial file on the quilt, Daughters of the American Revolution Museum, Washington, DC. Mary Tayloe Key McBlair in turn gave the quilt top to her best friend, Maud W. Lipscomb Greenawalt and it was bequeathed to the Daughters of the American Revolution Museum in 1942 by Maud's husband, Frank F. Greenawalt in his wife's memory.

${ }^{155}$ Letter from Hannah Robbins Gilman to Chandler Robbins Gilman, November 15, 1823, in A Family History in Letters and Documents (St. Paul, Minnesota: privately published, 1919), 596. In a letter to her daughter, Elizabeth Hale Gilman Hoffman, two weeks earlier on October 30, 1823, Gilman wrote, "When parents are growing into years...there is a void in their hearts, which nothing but the society of their children can fill. In their absence, they feel like useless beings..." A Family History, 596.

${ }^{156}$ Sigourney, Past Meridian, 116.
} 
evolving in appearance and in function, serving as a productive contribution to the household, but also as a pastime, a means of expression, a gift and a symbol of love. Some of the physical changes of aging - failing eyesight and the aches and pains of arthritis - may have necessitated alterations in how women used their needles, but growing older also had its benefits. As they saw the changes in their own bodies, and in their families, the women in these pages turned to their needlework, adapting it to fulfill new needs and functions. 


\section{CHAPTER 2}

\section{BIOGRAPHICAL NEEDLEWORK: TELLING A LIFE STORY}

In 1853, fifty-eight-year-old Esther Banister Richards (1795-1864) of Sturbridge,

Massachusetts, made a sampler that spells out the facts of her life: her birth, her marriage, and her children (figure 2.1). ${ }^{1}$ It includes a Biblical verse from what is sometimes called the "Prayer of an Old Man for Deliverance" because it is thought to have been written by the aging King David. ${ }^{2}$ The stitched verse reads, "Cast me not off in the time of my old age, Forsake me not when my strength faileth, Now also when I am old and grayheaded, O God forsake me not." ${ }^{3}$ A previous study of family record samplers, needlework samplers stitched with the birth, marriage and death dates of family members, dismissed the value this type of needlework had for its maker, stating that "mature women, who were probably instructors, worked a few family records as examples for their students or for their own relatives." ${ }^{4}$ While in some cases this may be true - that the sampler was merely a teaching exercise - the sampler made by Esther Banister Richards suggests the personal meaning this needlework had for some makers as a memorial and as a means to demonstrate both personal and familial achievements, as we shall see.

Anthropologists have described items like the Richards sampler and the other

pieces considered here as "biographical objects" - personally meaningful possessions that

\footnotetext{
${ }^{1}$ The sampler is now in the collection of Old Sturbridge Village, Sturbridge, Massachusetts. The sampler documents that Esther Banister was born April 19, 1795 and that she married Hollis Richards (1798-1872) on October 7, 1819; according to the sampler, Reverend E[liakim] Phelps (b. 1790) of West Brookfield performed the ceremony. The couple had four children, two of whom died prior to the year when Esther made her sampler. Esther's husband, Hollis Richards, was a carpenter. The 1840 tax records for Sturbridge place the couple in the bottom two-fifths of the town's residents. Esther died in 1864 at the age of sixty-nine from consumption. 1840 town tax records and 1850 U.S. Census, research files, Old Sturbridge Village, Sturbridge, Massachusetts.

${ }^{2}$ See http://bible.cc/psalms/71-9.htm and www.wallbuilders.com/LIBprinterfriendly.asp?id=75, accessed March 5, 2008.

${ }^{3}$ King James Bible, Psalm 71, verses 9 and 18.

${ }^{4}$ Gloria Seaman Allen, Family Record: Genealogical Watercolors and Needlework (Washington, DC: DAR Museum, 1989), 32.
} 


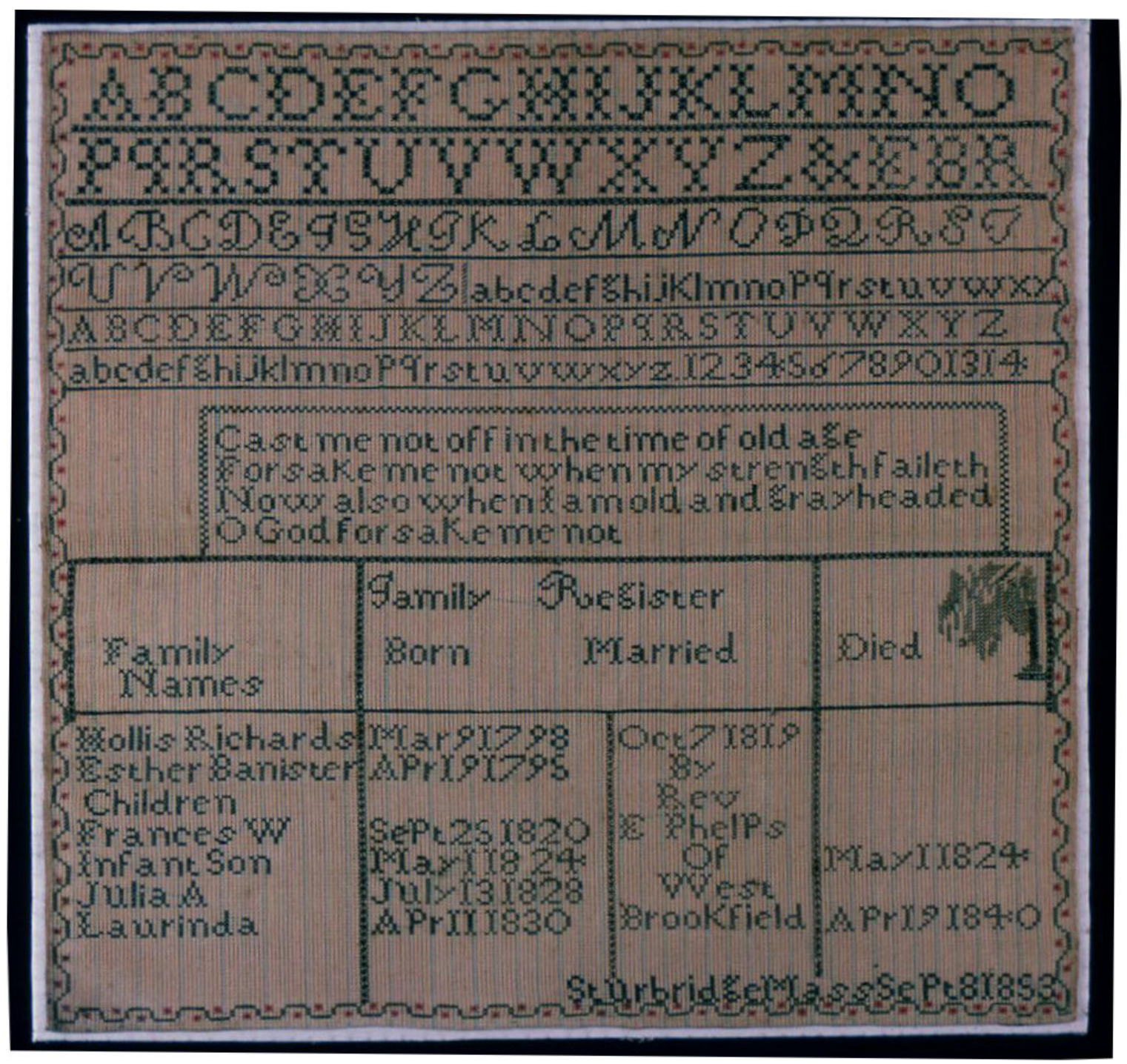

Figure 2.1. Sampler by Esther Banister Richards (1795-1864), 1853, Sturbridge, Massachusetts. Courtesy of Old Sturbridge Village, Sturbridge, Massachusetts, 64.1.116. Photograph by Thomas Neill.

Verse: Cast me not off in the time of old age, Forsake me not when by strength faileth, Now also when I am old and gray headed, O God forsake me not.

Fifty-eight-year-old Esther Banister Richards chose a meaningful verse for her sampler. From the biblical book of Psalms, the verse reflects some of the worries of growing older. Her sampler is stitched on what was then a newer type of canvas, with regular woven blue lines to assist with counting. Richards positioned her fabric so that these lines run in a vertical direction. 
take on lives of their own. ${ }^{5}$ These objects gain value as they are kept by the maker's family, passed from owner to heir. In time, after the family has preserved and revered one of these objects, it can come to define the family, acting as "a vehicle for bringing past time into the present, so that the histories of ancestors... become an intimate part of a person's present identity."6 Anthropologists explain that in many different cultures "people and the things they valued were so complexly intertwined they could not be disentangled."7 The memories that these objects evoke become more important than their function or physicality. ${ }^{8}$ Terming them "mnemonic objects," Susan Stabile suggests that they were especially important as women aged, merging with the maker's self "to renew a unified identity and a continuous narrative of the past in old age."9

Extending the anthropological idea of the biographical object to the samplers and quilts made by aging women offers a new category for needlework that has previously been dichotomized as practical/functional on one hand, or as decorative/ornamental on the other. Defining certain needlework artifacts as "biographical needlework" allows us

\footnotetext{
${ }^{5}$ Janet Hoskins, Biographical Objects: How Things Tell the Stories of People's Lives (New York: Routledge, 1998), 11; Annette B. Weiner, Inalienable Possessions: The Paradox of Keeping-While-Giving (Berkeley: University of California Press, 1992). These sources, along with Nicholas Thomas, Entangled Objects: Exchange, Material Culture and Colonialism in the Pacific (Cambridge: Harvard University Press, 1991), 4, 30, and Arjun Appadurai, ed., The Social Life of Things: Commodities in Cultural Perspective (New York: Cambridge University Press, 1986), focus on non-Western societies, but these scholars generally suggest that the idea has relevance for Western societies. In addition, there are western studies that suggest that certain objects became "biographical" without using the term. For example, in her study of Pennsylvania weaving, Adrienne Hood writes that "spinning wheels were simultaneously a means of support and an emblem of womanly skill and industry," a description that could be interpreted to mean that these objects served as "biographical artifacts." See Adrienne D. Hood, The Weaver's Craft: Cloth, Commerce and Industry in Early Pennsylvania (Philadelphia: University of Pennsylvania Press, 2003), 76.

${ }^{6}$ Annette B. Weiner, "Inalienable Wealth," American Ethnologist 12 (May 1985): 210. Presumably, Esther Richards' sampler was passed down in her family, but that trail is now lost. Old Sturbridge Village acquired the sampler from an antiques dealer who did not have information on the sampler's chain of ownership.

${ }^{7}$ Hoskins, Biographical Objects, 2.

${ }^{8}$ Mihaly Csikszentmihalyi and Eugene Rochberg-Halton, The Meaning of Things: Domestic Symbols and the Self (New York: Cambridge University Press, 1981), 97.

${ }^{9}$ Susan M. Stabile, Memory's Daughters: The Material Culture of Remembrance in Eighteenth-Century America (Ithaca: Cornell University Press, 2004), 135, 189.
} 
to better understand them as objects of their time, building personal, social and cultural contexts. It also helps us to learn more about their makers. As they aged, many women continued to use their needles - not to learn or to provide for their families - but to express themselves. These objects function in a much more complex way than as a household tool or an ornament: they document specific events, they present testimony about a woman's life, they represent the life story of their maker's family, and they serve as memorials to their makers. The quilts and samplers explored in this chapter offered their aging makers a voice for lasting words. Each object described here is both biographical - conveying a life story - and epistolary - employing words on the object, whether written, stitched or applied, to tell that story.

At first glance, Esther Banister Richards' sampler seems to follow the traditional style of any number of family record samplers made by schoolgirls. It has neat columns headed "born," "married," and "died." And like innumerable schoolgirl family register samplers, the columns are not completely filled in. Next to the heading "Died" Richards stitched a weeping willow tree, which provides one of the sampler's small bits of color. A symbol associated with death and the afterlife commonly found on late-eighteenth and early-nineteenth century gravestones, willow trees were a common sampler motif, where they represented death and mourning. Willows were particularly symbolic because of their regenerative power to grow again after being cut. ${ }^{10}$ While the names and dates are neatly stitched in a monochromatic shade of brown, the tree has green leaves that hang over its brown trunk. The willow draws the eye sideways, lingering on the death column, reminding the viewer of the natural cycle of life.

\footnotetext{
${ }^{10}$ Anita Schorsch, Mourning Becomes America: Mourning Art in the New Nation (Clinton, New Jersey: The Main Street Press, 1976), n.p.
} 
The verse above the family record reads, "Cast me not off in the time of my old age, Forsake me not when my strength faileth, Now also when I am old and grayheaded, O God forsake me not." Having spent her life being encouraged to pursue Christian virtues, Richards stitched a verse asking her God for help as she aged; it distinguishes her sampler from the many made by girls and young women. Richards sought God's assistance even when her "strength faileth." She was not the only mature woman to seek solace in this Psalm. Almost ten years earlier, in October 1844, seventy-five-year-old Joanna Graham Bethune (1770-1860) repeated the same phrases in her diary, seeking God's help not only in accepting her own aging process, but also in serving as a model for the younger generation, by showing them the strength of her character and faith, "when I am old and gray-headed, O God, forsake me not, until I have showed Thy strength unto this generation."11

Both women may also have been drawing on the sermons this psalm inspired. In 1805, seventy-four-year-old Springfield clergyman Joseph Lathrop (1731-1820) preached “The Infirmities and Comforts of Old Age: A Sermon to Aged People," beginning with Psalm 71:9 and quickly leaping to 71:18, just as Esther Richards did on her sampler. ${ }^{12}$ In his sermon, Lathrop urged his listeners to recognize that the effects of age were inevitable, to ask God for grace to deal with the weakening body, and to serve as a

\footnotetext{
${ }^{11}$ George Washington Bethune, comp., Memoirs of Mrs. Joanna Bethune (New York: Harper and Brothers, 1863), 227. Bethune reflected on this same Psalm in at least one other diary entry - that for February 1, 1845 - after lamenting the loss of many of her close friends. Bethune sought strength in the Lord, she explained, because of her age. She needed help to continue the work of her local orphan asylum, "Lord, look on this Institution, which thine own hand planted, and which has been a blessing to many, and forsake us not when we are old and gray-headed." See Bethune, Memoirs, 234.

${ }^{12}$ Information about Joseph Lathrop, as well as the text of his 1805 sermon is available at www.wallbuilders.com/LIBprinterfriendly.asp?id=75, accessed March 5, 2008. This sermon was published, see Joseph Lathrop, The Infirmities and Comforts of Old Age: A Sermon to Aged People (Springfield, Massachusetts: Henry Brewer, 1805). Lathrop's sermon, "Old Age Improved," from 1811, was also published. See Joseph Lathrop, Old Age Improved (Springfield, MA: T. Dickman, 1811).
} 
positive testimony of faith before others. Through her sampler, Esther Richards fulfilled Lathrop's last suggestion. Richards probably hung her sampler on the wall of her home where it could remind her to ask God for grace as she aged. In this way, it would also demonstrate to her family and friends that she was remaining positive and seeking the virtues that rewarded a Christian life. This verse reflects its aging maker, just as those stitched on schoolgirl samplers offered prescriptive lessons appropriate for girls and young women in their respective life stages.

Richards's stitched words offered a way to communicate her experience with aging as well as her sorrow over the early deaths of two of her children - an unnamed "infant son" in 1824 and a ten-year-old daughter, Laurinda, in 1840. A popular story, "The Patchwork Quilt," originally published in 1845 in The Lowell Offering, suggests that the individual objects described here were not the lonely aberrations of a handful of women but a representation of societal and cultural morés. In the story, the author, probably Harriet Farley or Rebecca C. Thompson, both Lowell mill girls, described the quilt as more than the functional sum of its parts. As the story's narrator explained, "to me it is a precious reliquary of past treasures; a storehouse of valuables, almost destitute of intrinsic worth... a bound volume of hieroglyphics... which is a key to some painful or pleasant remembrance...but, oh, I am poetizing and spiritualizing over my "patchwork quilt."',13 The quilt represented bonds and connections between family members. It also marked the passage of time and brought together the different stages of her life. Far from being a simple covering to warm someone's bed, this quilt had a story to tell.

\footnotetext{
${ }^{13}$ Harriet Farley or Rebecca C. Thompson, "The Patchwork Quilt," The Lowell Offering 5 (1845) reprinted in Cuesta Ray Benberry and Carol Pinney Crabb, comps., A Patchwork of Pieces: An Anthology of Early Quilt Stories 1845-1940 (Paducah, Kentucky: American Quilter's Society, 1993), 18-23.
} 
Identifying and studying biographical needlework extends previous scholarship on women's diaries. It enlarges the pool of sources and widens the number of women who can be studied beyond those who had the time, education and means to keep a diary. ${ }^{14}$ While historians often place documentary and material sources at divergent ends of the evidentiary spectrum, paper and fabric actually have an intertwined relationship of their own that was understood during the antebellum period. Not only was paper made from fabric, but antebellum indelible inks allowed women to write on fabric itself with words that would last as long as the textile. In effect, women who left their stories in stitches were not that different from the women who kept traditional diaries. Susan Stabile contends that "just as memory repeats our sensory impressions, so writing repeats or copies these sensations on paper." 15 And, just like the act of writing, the act of sewing required its maker to use her needle repetitively to create something - stitches in a sampler or quilt versus words on the page.

There were several reasons for a woman to choose stitching over writing as a way of leaving her mark. Some women never learned to write, or received only a rudimentary education. Others simply had no time or inclination to keep a written diary. However, sewing was an essential skill for these same women - virtually all antebellum women knew how to sew and had to make time for it amidst their daily activities. In addition, their culture placed a high value on industry, as well as on caring and doing for others; for women, these values were privileged over the self-reflection offered by diarykeeping. Expressing oneself through needlework offered means, method, social

\footnotetext{
${ }^{14}$ See Laurel Thatcher Ulrich, "Of Pens and Needles: Sources in Early American Women's History," The Journal of American History 77 (June 1990): 200-207, where she calls for a new methodology to research the lives of everyday women using a combination of traditional and material sources.

${ }^{15}$ Stabile, Memory's Daughters, 81.
} 
acceptance and cultural validation. As women aged, the connection between textiles and expression grew stronger, becoming ingrained in their lives.

An important distinction between biographical needlework and written diaries is that needlework was often more widely accessible to others. In contrast to diaries kept during the eighteenth century, which were usually spiritual and held the expectation of a reader, by the antebellum decades, many women who kept diaries considered them to be extremely personal and went to great lengths to hide them from others. ${ }^{16}$ If they did think the diary would be read, or intended it to be read, they would often edit it first. Similarly, women often asked their correspondents to destroy their letters after receiving them, so they would not be judged later for the content, style and appearance of the letters. ${ }^{17}$

Biographical needlework, on the other hand, was generally made with the express purpose that others would see it. Makers stitched messages that they wanted to leave behind, to make their mark, reminding others of who they were, memorializing themselves or others near and dear, and expressing their opinions on any number of subjects. They gave these objects as gifts, hung them on the wall, displayed them in the home and bequeathed them to children and relatives. Adding women's stitched expressions to the historical context broadens our understanding of their experiences,

\footnotetext{
${ }^{16}$ On eighteenth-century diaries and the evolution of the diary in the nineteenth-century see: Margo Culley, A Day at a Time: The Diary Literature of American Women from 1764 to the Present (New York: Feminist Press at CUNY, 1985); Elizabeth Pendergast Carlisle, Earthbound and Heavenbent: Elizabeth Porter Phelps and Life at Forty Acres 1747-1817 (New York: Scribner, 2004); Nancy F. Cott, The Bonds of Womanhood: “Women's Sphere” in New England, 1780-1835 (New Haven: Yale University Press, 1977); Joanna Bowen Gillespie, “"The Clear Leadings of Providence": Pious Memoirs and the Problems of SelfRealization for Women in the Early Nineteenth Century," Journal of the Early Republic 5 (Summer 1985): 197-221; Mechal Sobel, Teach Me Dreams: The Search for Self in the Revolutionary Era (Princeton: Princeton University Press, 2000); and Laurel Thatcher Ulrich, A Midwife's Tale: The Life of Martha Ballard, Based on her Diary, 1785-1812 (New York: Alfred A. Knopf, 1990).

${ }^{17}$ Martha Saxton, Being Good: Women's Moral Values in Early America (New York: Hill and Wang, 2003), 221; Cott, The Bonds of Womanhood, 16-17. For more on women and their letters, see Marilyn Ferris Motz, True Sisterhood: Michigan Women and Their Kin 1820-1920 (Albany: State University of New York Press, 1983).
} 
offering greater insight about the messages that aging women sent to future generations.

For the female stitcher, her fabric "page" offered a means of expression, and for her

"reader," her work modeled industry and virtue. Aging women used their needlework to

document the continuum of their lives, from a single event or achievement to entire life

stories and family histories.

At one end of this spectrum are the numerous women who documented their needlework by stitching their names or the date into completed projects. ${ }^{18}$ For example, 68-year-old Margaret Steeley Kelley (1784-1865) made a quilt documenting her work with a quilted inscription on a corner block reading, "Pieced 1852 Quilted 1857" (figures 2.2 and 2.3). ${ }^{19}$ Like countless diaries kept by antebellum women, carefully tracking their work - babies birthed, skeins wound, yards woven and clothing made - Kelley's quilt documents her work. ${ }^{20}$ Her stitched words also preserve the quilt's history. Margaret

\footnotetext{
${ }^{18}$ This study identified 167 needlework objects that fit its basic criteria, that is made between 1820 and 1860 by women who were forty and over. Leaving aside the twenty-eight picked-out or altered samplers and the twelve filled-in family records, 127 objects made by women aged forty and over between 1820 and 1860 remain. Out of these 127 objects, about 60\% (76) have no identification information inscribed at all. Forty include the name or initials of the maker, while forty-one have the year or date made inscribed. Of these, fifteen include both the maker's name or initials and the year or date that the object was made, while thirteen include the maker's name, her age and the date or year that the object was made. Alternately, only fourteen include the maker's age, while an additional eight objects include her birthdate. In addition to Margaret Kelley's quilt, see the samplers by Amy Fiske, Elcey Patterson, Patty Sessions and Ruth Croswell and the quilts by Maria Hubbard, Mary Kemp, Amelia Lauck and Emily Snyder discussed in these pages. Another example is the applique album quilt with a stuffed work inscription, "1860. Done by Mrs. C. Bartlett in the 63 year of her age," which is illustrated in Cyril I. Nelson and Carter Houck, Treasury of American Quilts (New York: Greenwich House, 1982), 75.

${ }^{19}$ The quilt is now in the collection of the Erie Historical Museum, Erie, Pennsylvania. Margaret Steeley was born in Lewistown, Pennsylvania in 1784. After she married John Kelley, the couple traveled west to settle in Erie County, Pennsylvania. They had eleven children. See Marianne Berger Woods, ed., Threads of Tradition: Northwest Pennsylvania Quilts (Meadville, Pennsylvania: Crawford County Historical Society, 1997), 32 and History of Erie County, Pennsylvania (Chicago: Warner, Beers and Company, 1884), 60.

${ }^{20}$ See Ulrich, A Midwife's Tale, for an excellent method on extracting the information that diaries can provide.
} 


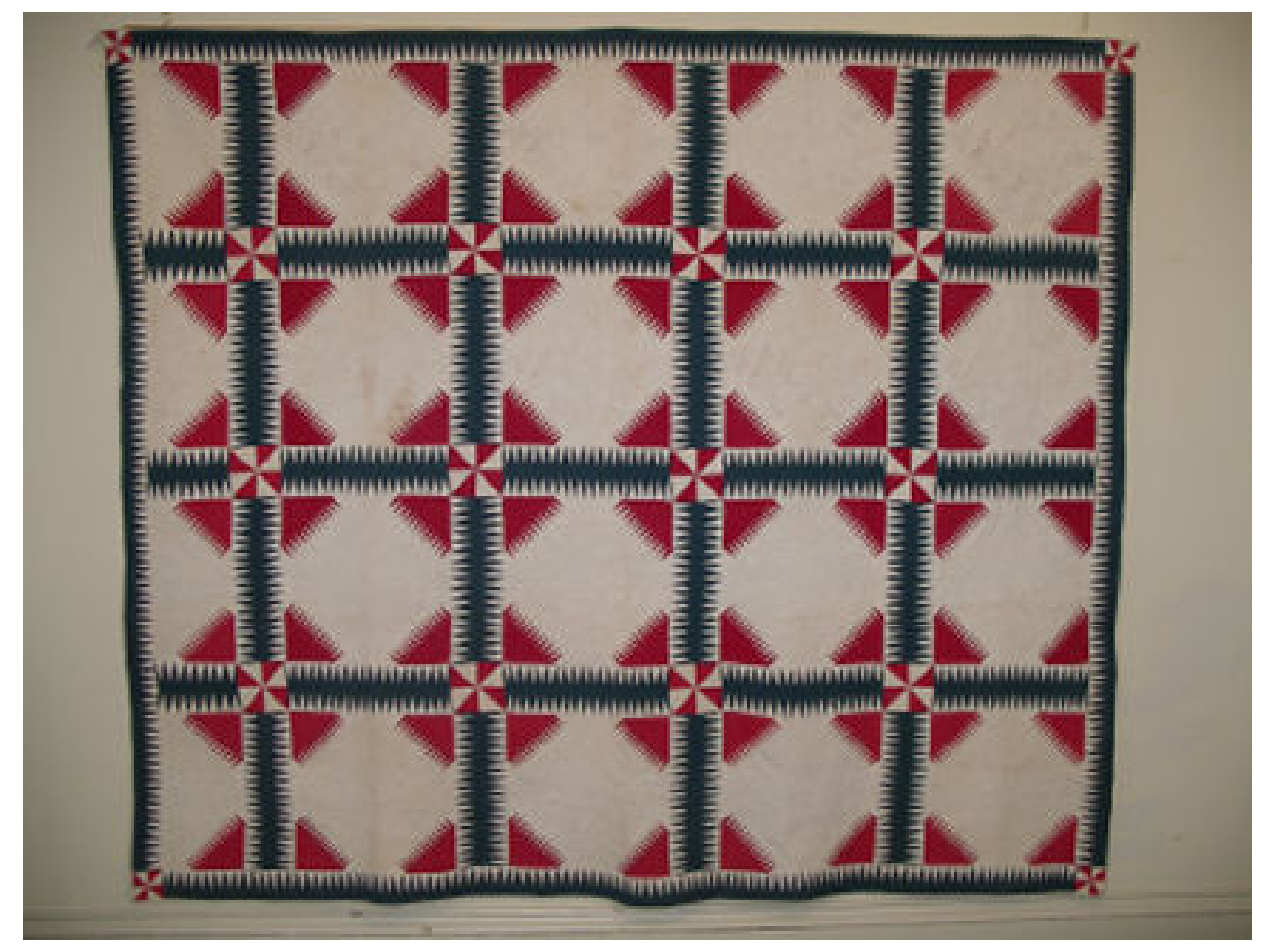

Figure 2.2. Quilt by Margaret Steeley Kelley (1784-1865), pieced 1852, quilted 1857, Pennsylvania. Courtesy of the Erie County Historical Society, Erie, Pennsylvania.

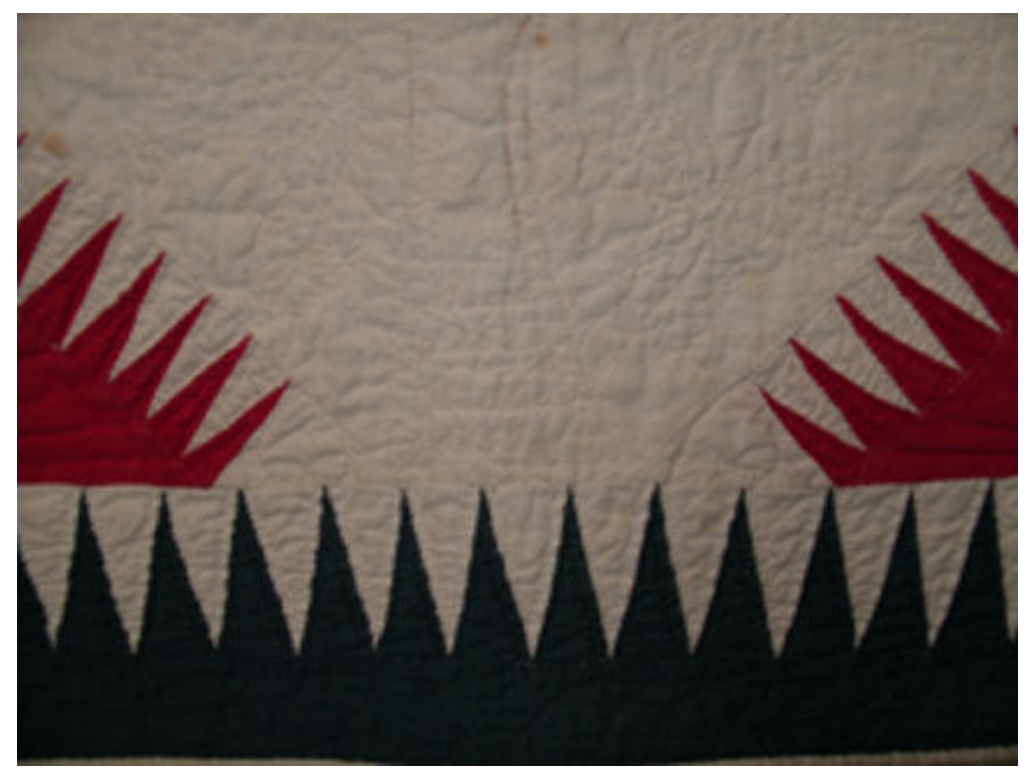

Figure 2.3. Detail of signature on Kelley quilt.

Margaret Kelley pieced this quilt in 1852 and five years later it was quilted by Janet Amanda Coates. These details of its construction are noted on the quilt, which bears the quilted inscription, "Pieced 1852 Quilted 1857," in one corner. 
pieced the quilt in 1852 when she was sixty-eight. But the quilting was done in 1857 by Janet Amanda Coates. ${ }^{21}$ By that time, Margaret was seventy-three years old and may have found quilting difficult due to failing eyesight or another physical problem.

Analysis of period needlework manuals suggests women's motivations to pick up their needles. ${ }^{22}$ As one book explained, "No one can look upon THE NEEDLE, without emotion; it is a constant companion throughout the pilgrimage of life." ${ }^{23}$ These manuals provided basic instruction in sewing, knitting, crochet, quilting and other types of needlework. Period needlework manuals and medical guides suggest that needlework was an ideal activity for women of all ages. The Young Lady's Friend, published in 1837, explained that "there is a soothing and sedative effect in needlework; it composes the nerves, and furnishes a corrective for many of the little irritations of domestic life." ${ }^{24}$ Mid- and late-nineteenth century medical guides, in turn, like Frederick Hollick's in 1849 , counseled menopausal women to "avoid all intense mental application, or strong emotions... and accustom herself, in every particular, to a regular and calm mode of life,"

\footnotetext{
${ }^{21}$ Woods, ed., Threads of Tradition, 32. Unfortunately, evidence documenting the connection between Coates and Kelley remains unlocated, along with any evidence about Coates's life and other quilting activities. The attribution that Coates did the quilting comes from information provided by the donor when the quilt was given in 1926. Letter to the author from Becky Weiser, Curator, Erie County Historical Society, Erie, Pennsylvania, February 2009.

${ }^{22}$ Needlework manuals consulted include: The American Ladies' Memorial (Boston, 1850); Lydia Maria Child, The Girls' Own Book (New York: Clark Austin and Company, 1833); Florence Hartley, The Ladies' Handbook of Fancy and Ornamental Work (Philadelphia: G.G. Evans, 1859); The Ladies' Hand-Book of Fancy Needlework, and Embroidery (New York: J.S. Redfield, 1844); The Ladies' Handbook of Knitting, Netting and Crochet (New York: J. Redfield, 1844); The Ladies' Work-Table Book (New York: J. Winchester, 1844); The Lady's Work-Box Companion (New York: Burgess, Stringer and Company, 1844); Miss Lambert, The Hand-Book of Needlework (New York: Wiley and Putnam, 1842); Miss Lambert, The Hand-Book of Needlework (London: John Murray, 1846); The Seamstress (New York: J.S. Redfield, 1848); Mrs. Ann S. Stephens, The Ladies' Complete Guide to Crochet, Fancy Knitting and Needlework (New York: Garrett and Company, 1854); and The Workwoman's Guide (London: Simpkin, Marshall, 1838).

${ }^{23}$ The Ladies' Work-Table Book, vi.

${ }^{24}$ Quoted in Susan Burrows Swan, Plain and Fancy: American Women and Their Needlework, 1650-1850 (Austin, Texas: Curious Works Press, 1995), 41.
} 
echoing the benefits that needlework manuals ascribed to the act of stitching. ${ }^{25}$ One physician even compared the menopausal woman to a preadolescent, writing that menopause was "the transition of the (sexual) system from an active ovarian state to the quiet condition of a non-ovulating girl."26

Antebellum needlework manuals championed the mainstream cultural values that were the hallmark of virtuous antebellum women. Yet, underneath this, perhaps even in spite of this, these manuals acknowledged that needlework was a means for women to express themselves, within the bounds of what their society deemed acceptable behavior. Documenting the events of one's life, in thread or in ink, offered a woman, particularly an aging woman, a way to achieve some control over her life and to create a lasting memento. An 1854 guide explained that needlework had served this purpose for centuries, "Before women began to read, and when they considered writing as a mystery only to be undertaken by men of nobler parts, Needlework became a sort of medium by which women attempted to express their ideas and embody those affectionate thoughts that must have some expression to keep the full heart from overflowing.",27

A quilt made by Nancy Ward Butler (1779-1863) when she was in her sixties fulfilled this purpose (figure 2.4). ${ }^{28}$ Made in the wake of the death of Butler's infant

\footnotetext{
${ }^{25}$ Frederick Hollick, M.D., The Diseases of Woman (New York: T.W. Strong, 1849), 236-237; Carroll Smith-Rosenberg, Disorderly Conduct: Visions of Gender in Victorian America (New York: Oxford University Press, 1985), 185, 193.

${ }^{26}$ A.M. Longshore-Potts, Discourses to Women on Medical Subjects (San Diego, CA: author, 1890), 32, 94 quoted in Smith-Rosenberg, Disorderly Conduct, 185.

27 Stephens, The Ladies' Complete Guide, 5.

${ }^{28}$ The quilt is currently in the collection of the Smithsonian Institution, Washington, DC. Nancy Ward was born around 1779 in Buckland, Massachusetts. She married James Butler (1779-1854) in 1802 when she was about twenty-three. At some point the couple moved to Chautauqua, New York, where they raised their family. They had at least two children. See family records at www.ancestry.com, accessed November 25, 2007; Doris M. Bowman, American Quilts: The Smithsonian Treasury (Washington, DC: Smithsonian Institution Press, 1991), 37; Sandi Fox, Small Endearments: Nineteenth-Century Quilts for Children and Dolls (Nashville: Rutledge Hill Press, 1980), 7; and Jacqueline M. Atkins and Phyllis A. Tepper, New York Beauties: Quilts from the Empire State (New York: Dutton Studio Books, 1992), 70.
} 


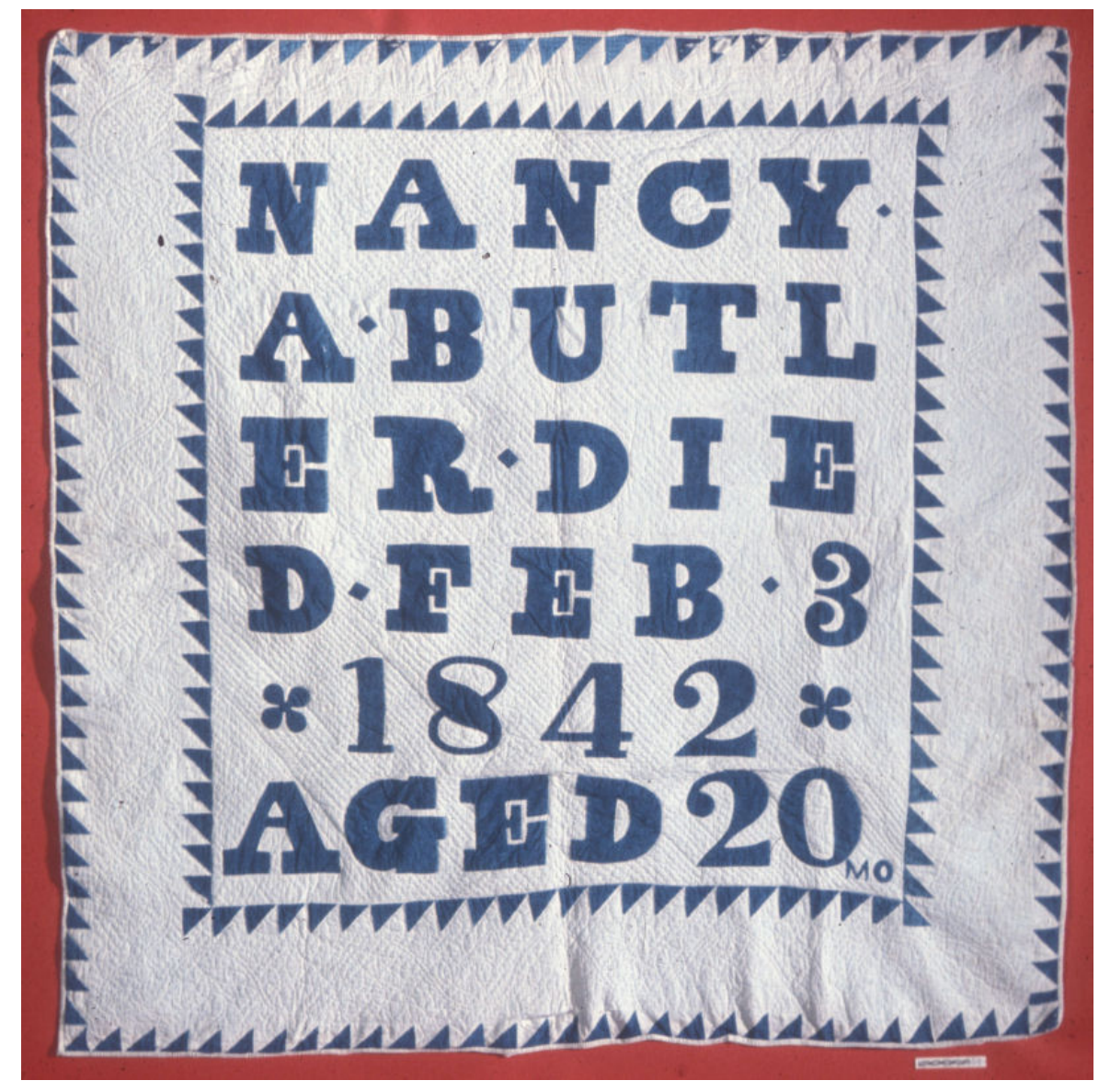

Figure 2.4. Quilt by Nancy Ward Butler (1779-1863), 1842, New York. Courtesy of the National Museum of American History, Smithsonian Institution, Washington, D.C.

One look at Nancy Ward Butler's quilt conveys the magnitude of the grief she felt at the loss of her granddaughter. Three years later she would make a similar quilt mourning the deaths of one of her sons and another granddaughter, who passed away in 1844 and 1845, respectively. 
granddaughter, the quilt commemorated a loved one, expressed the maker's sorrow at a painful loss and allowed her to tell a family story with an object that would survive her and live to tell its story to later generations of that family. Butler appliquéd a bold message across her quilt in large letters (approximately seven inches tall): "Nancy A Butler Died Feb 31842 Aged 20 mo.” There is little additional ornament. The quilt mourns the beloved granddaughter, serving no other aesthetic purpose. That the maker had a "full heart" that was "overflowing" from sorrow is evident from the quilt's enormous lettering, arranged so as to resemble a tombstone.

The lettering on the quilt resembles what has been termed "plain style" lettering on gravestones - rows of letters spelling out simple inscriptions. While "plain style" gravestones were predominant from 1640 to 1710 in New England, well before this quilt was made, the style never fell completely out of use. Stones from the early nineteenth century in Ithaca, New York, show the "plain style," suggesting that it was still known there when Butler was stitching her quilt. This style has been interpreted to represent an attitude of resignation in the face of death. ${ }^{29}$ While Butler's quilt seems to suggest it was created out of anything but resignation, perhaps she sought that resignation and peace by making her quilt, deliberately tracing each letter onto her blue cotton fabric and carefully stitching those letters onto the quilt, one by one.

The central lettering is surrounded by an elaborately quilted border with a floral vine motif. Butler may have chosen a vine for her border because of its well-known symbolism of fertility and of the family (the leaves represent family members attached to the larger vine). In addition, the vine was an important religious symbol, representing the

\footnotetext{
${ }^{29}$ James A. Hijiya, “American Gravestones and Attitudes Toward Death: A Brief History," Proceedings of the American Philosophical Society 127 (October 1983): 341.
} 
relationship between God and man. According to the Bible's Gospel of John, Christ told his disciples: "I am the true vine, and my Father is the husbandman; Every branch in me that beareth not fruit he taketh away; and every branch that beareth fruit, he purgeth it, that it may bring forth more fruit...I am the vine, ye are the branches. He that abideth in me, and I in him, the same bringeth forth much fruit; for without me ye can do nothing." ${ }^{30}$ In addition to being introduced to vine symbolism in the Bible, women were familiar with vines as a common symbol on gravestones. ${ }^{31}$ Butler's use of the vine motif on her quilt may have served two purposes: it continued her stylistic analogy to a tombstone and it provided comfort through the idea that her grandchild was resting with God. The quilt is in good condition, suggesting its primary use as a touchstone and memory holder, rather than as a bed covering.

During the early nineteenth century, patterns of mourning were changing. Many Americans took solace in the idea that as long as one's memory was "kept alive by someone else's grief, one was not entirely dead." ${ }^{, 32}$ This project gave Nancy Ward Butler a way to visually express the full extent of her sorrow, far more than writing a letter or dressing in mourning clothes could possibly achieve. By making a quilt she could make letters large enough to represent the enormity of her grief, leaving no doubt that her

\footnotetext{
${ }^{30}$ Douglas Kiester, Stories In Stone: A Field Guide to Cemetery Symbolism and Iconography (Salt Lake City: Gibbs Smith, 2004), 59. John 15 is quoted on 59-60. Vines were also understood to be connected to grapes and wine; the wine of communion was pressed from the mystical vine. Many New England gravestones depict a vine entwined with effigies of the soul; see Allan I. Ludwig, Graven Images: New England Stonecarving and Its Symbols 1650-1815 (Middletown, CT: Wesleyan University Press, 1966), $168,175,180$.

${ }^{31}$ In her comparison of samplers and gravestone art, scholar Laurel K. Gabel points out that "needlework and gravestones, and almost all other forms of decorative art, drew inspiration from a common vocabulary of popular motifs and themes circulating at the time...these patterns were not unique to needlework or gravestones, but were part of a standard vocabulary of motifs in general use at the time." See Laurel K. Gabel, "A Common Thread: Needlework Samplers and American Gravestones," Markers 19 (2002): 19, 42.

${ }^{32}$ Hijiya, “American Gravestones and Attitudes Toward Death,” 354.
} 
grandchild's memory was being kept alive. ${ }^{33}$ Indeed, when Butler's son, James (18241844), died in May 1844 at age twenty, followed by her granddaughter, Cynthia M. Sage (1822-1845), in 1845 at age twenty-three, she made a second quilt in the same style with the same enormous letters. $^{34}$

While Nancy Ward Butler made a quilt to tell the story of other family members, the quilt that forty-two-year-old Betsey M. Seely Sears (1813-1901) made tells her own story (figures 2.5 and 2.6). ${ }^{35}$ The flowers on the quilt were carefully chosen and can be identified as wildflowers native to her adopted state of Wisconsin. ${ }^{36}$ According to a family story, Betsey would take apart actual plants to be sure she was reproducing them accurately on her quilt. ${ }^{37}$ Her colorful appliquéd bedcover has a central cartouche formed by undulating vines, often used, as we have seen on the Butler quilt, to symbolize family and religious relationships, as well as continuity in life and death. In the middle is an embroidered signature, "By Mrs. Betsey M. Sears Aged 42 Years 1855." The prominence of this signature, with her first and last names, as well as her age, suggests

\footnotetext{
${ }^{33}$ I am indebted to Marla R. Miller for her suggestions on how to interpret the large size of these letters. Genealogical records for Nancy Ward Butler are not complete at www.ancestry.com, or in the books that have previously illustrated this quilt, so it is difficult to know whether this was the first death of a child or grandchild that she experienced. However, young Nancy Adelaide Butler was the oldest daughter of Nancy Ward Butler's son, Calvin Butler, and may have been her first namesake. Family records from www.ancestry.com, accessed November 25, 2007.

${ }^{34}$ This second quilt attributed to Nancy Ward Butler is now in the collection of the Chautauqua County Historical Society, New York. "The Unfinished Story of the Twin Quilts," County History Newsletter (February 1992): 1-2.

${ }^{35}$ The quilt is now in the collection of Heritage City Park, Santa Fe Springs, California. Betsey Mahala Seely was born August 31, 1813 in Westmoreland, New York, the daughter of Daniel Seely and Betsey E. Doolittle. In 1831, when she was eighteen, Betsey married Silas Sears (1806-1859) of Rome, New York. The couple had five children together, four in New York state and their youngest, George M. Sears (18461868), in Wisconsin. By the time of the 1860 U.S. Census, she owned $\$ 1,200$ worth of real estate and had a personal estate valued at $\$ 150$. Her sons George and Lowell, along with Lowell's family, lived with her. Lowell was a farmer with real estate of his own worth $\$ 600$. Betsey Seely Sears lived a long life, passing away in 1901 at the age of eighty-seven. Ellen Kort, Wisconsin Quilts (Charlottesville, Virginia: Howell Press, 2001), 21; curatorial files, Heritage City Park, Santa Fe Springs, California; Census information from www.ancestry.com, accessed November 25, 2007.

${ }^{36}$ Kort, Wisconsin Quilts, 23.

${ }^{37}$ Kort, Wisconsin Quilts, 22.
} 


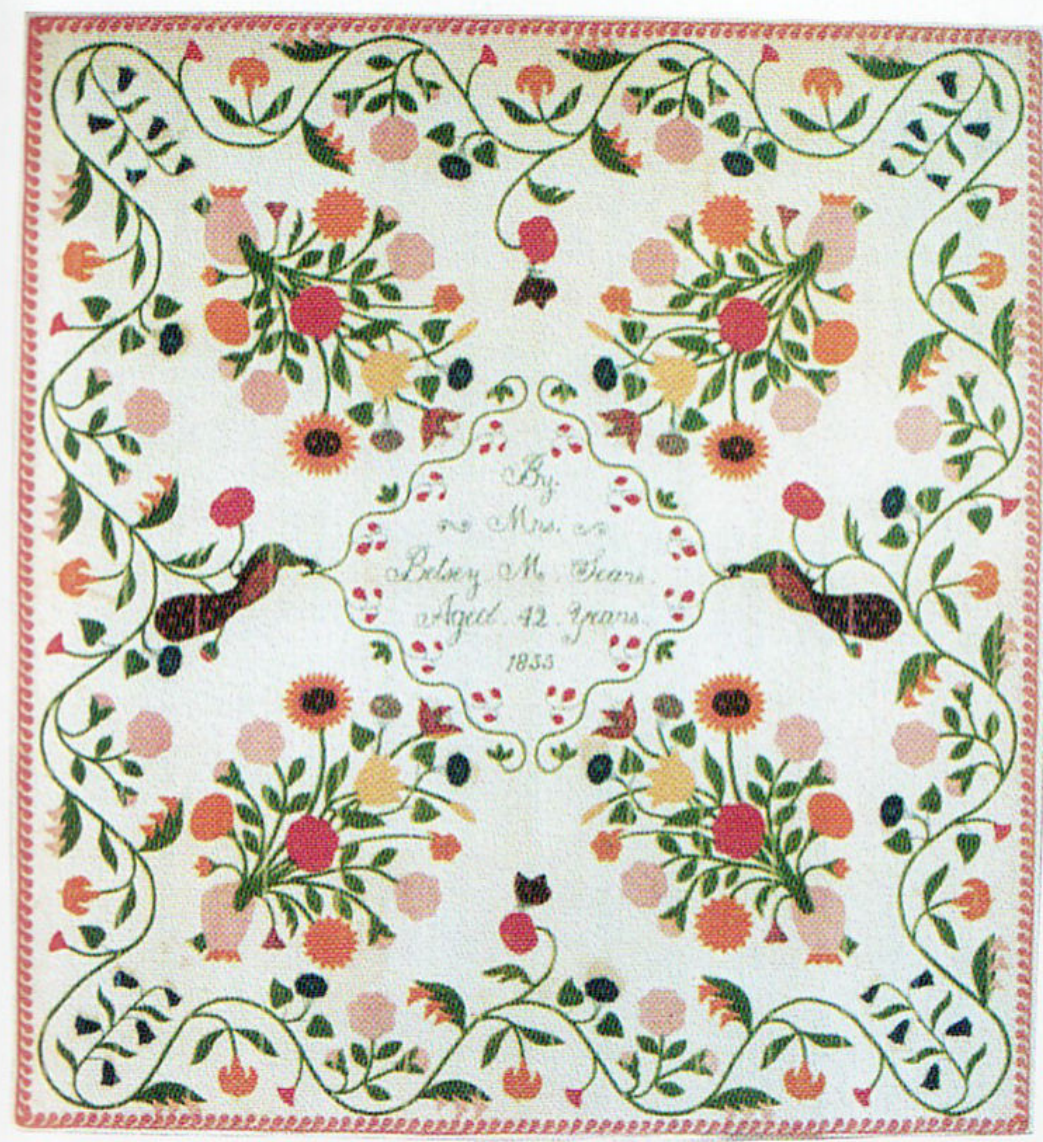

Figure 2.5. Quilt by Betsey M. Seely Sears (1813-1901), 1855, Wisconsin. From Wisconsin Quilts ( 2008 by Ellen Kort. Used with the kind permission of Krause Publications, an imprint of F+W Media, Inc. All rights reserved.

Betsey M. Seely Sears prominently signed her quilt with her name, age and the year. According to family history, she closely examined local wildflowers in order to correctly reproduce them on her quilt. 


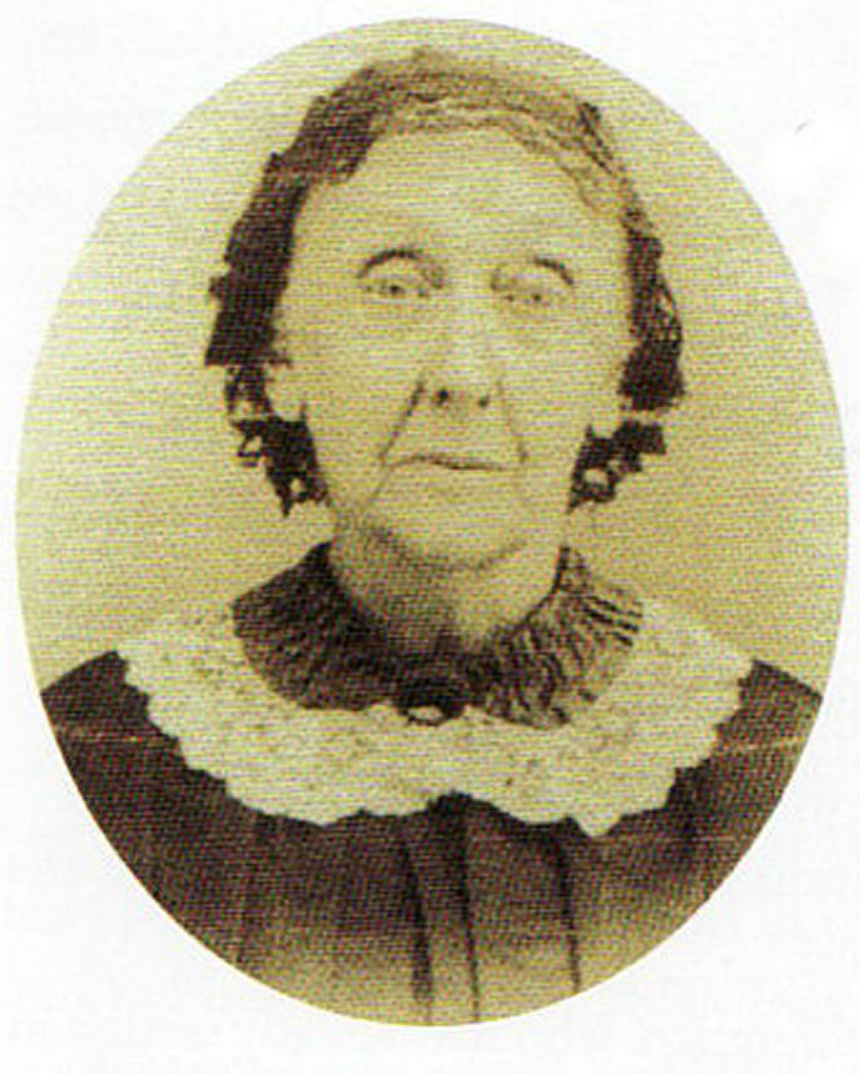

Figure 2.6. Betsey M. Seely Sears (1813-1901), late 1890s, Wisconsin. From Wisconsin Quilts (C) 2008 by Ellen Kort. Used with the kind permission of Krause Publications, an imprint of $\mathrm{F}+\mathrm{W}$ Media, Inc. All rights reserved. 
that a sense of pride and achievement accompanied her work. Unlike the women discussed elsewhere in these pages who hid their age by altering their childhood samplers, Sears proudly stated her age; in effect, her quilt staked a claim to life. Out of the 167 needlework objects located for this study, only twenty-two include the maker's age or birthdate on the object, suggesting that those who made the choice to include this information did so consciously. In contrast, almost twice as many (40) include the maker's name or initials.

While the signature documents the "event" of completing this single quilt, it may also attest to the maker's story of survival in moving west over a decade earlier. At age thirty, Betsey, her husband, Silas (1806-1859), and four small children moved west from New York to Wisconsin in 1843. Their journey was difficult; they ran low on money and then lost two of their children to smallpox. Betsey was also infected but recovered. ${ }^{38}$ She kept a diary and recorded her thoughts about the loss of her children. "It had always seemed to me that if I should ever lose a child, I could never let it out of my arms;" she mused, "but now two of my loves were dead...But God strengthened my almost exhausted endurance, and I became resigned to my fate." 39

Betsey was a seamstress and her skill is evident from her 1855 quilt. Throughout her marriage she sold her needlework products to help with the family finances. In 1848, when Betsey was thirty-five, her husband built an inn, named "Live and Let Live," in Rome, Wisconsin. For seven years, they lived at the inn, but in 1855, Silas built a house for them on the outskirts of town. ${ }^{40}$ At this same time, Betsey made her quilt and signed

\footnotetext{
${ }^{38}$ Kort, Wisconsin Quilts, 21.

${ }^{39}$ Quoted from diary kept by Betsey Seelye Sears (now in a private collection) in Kort, Wisconsin Quilts, 21.

${ }^{40}$ Kort, Wisconsin Quilts, 21.
} 
it. While she did not leave behind an explanation of her work, it is tempting to speculate that she was, in part, celebrating the move to her new home.

Sadly, Silas died in 1859 , only four years after the couple moved into the house he built. ${ }^{41}$ Betsey continued to make quilts in her widowhood, and she also wrote poetry. According to family tradition, she made fourteen quilts after the age of seventy-five. ${ }^{42}$ One other quilt from the 1850s is now in the collection of the Fort Atkinson Historical Society in Wisconsin, having been donated by one of Betsey's descendants (figure 2.7). ${ }^{43}$ Like the quilt seen here, it is made in a floral appliqué pattern that bears a striking resemblance to the floral bouquets on the 1855 quilt, but without the central signature.

After examining hundreds of diaries kept by aging women, Terri Premo pointed out that literacy provided them with tools for self-expression, which they relied on "to expand their daily world, to participate in active and meaningful intercourse with others, and to leave a permanent record of themselves, which could be passed down to later generations. ${ }^{\not 4}$ Biographical needlework functioned the same way. It offered a means of expression, often in a public, tangible way.

\section{$\underline{\text { Epistolary Needlework: Telling Stories and Bearing Witness }}$}

Epistolary needlework, a subset of biographical needlework made up of quilts, samplers and other textiles that have words or a story spelled out across their face in fabric, thread, ink or paint, provided not only a means of recording one's name and

${ }^{41}$ Kort, Wisconsin Quilts, 22; curatorial files, Heritage City Park, Santa Fe Springs, California.

${ }^{42}$ Curatorial files, Heritage City Park, Santa Fe Sprints, California. In later years, Betsey learned to set type to support herself as a job printer in Rome. Kort, Wisconsin Quilts, 22.

${ }^{43}$ Kort, Wisconsin Quilts, 23.

${ }^{44}$ Terri L. Premo, Winter Friends: Women Growing Old in the New Republic, 1785-1835 (Urbana: University of Illinois Press, 1990), 116. 


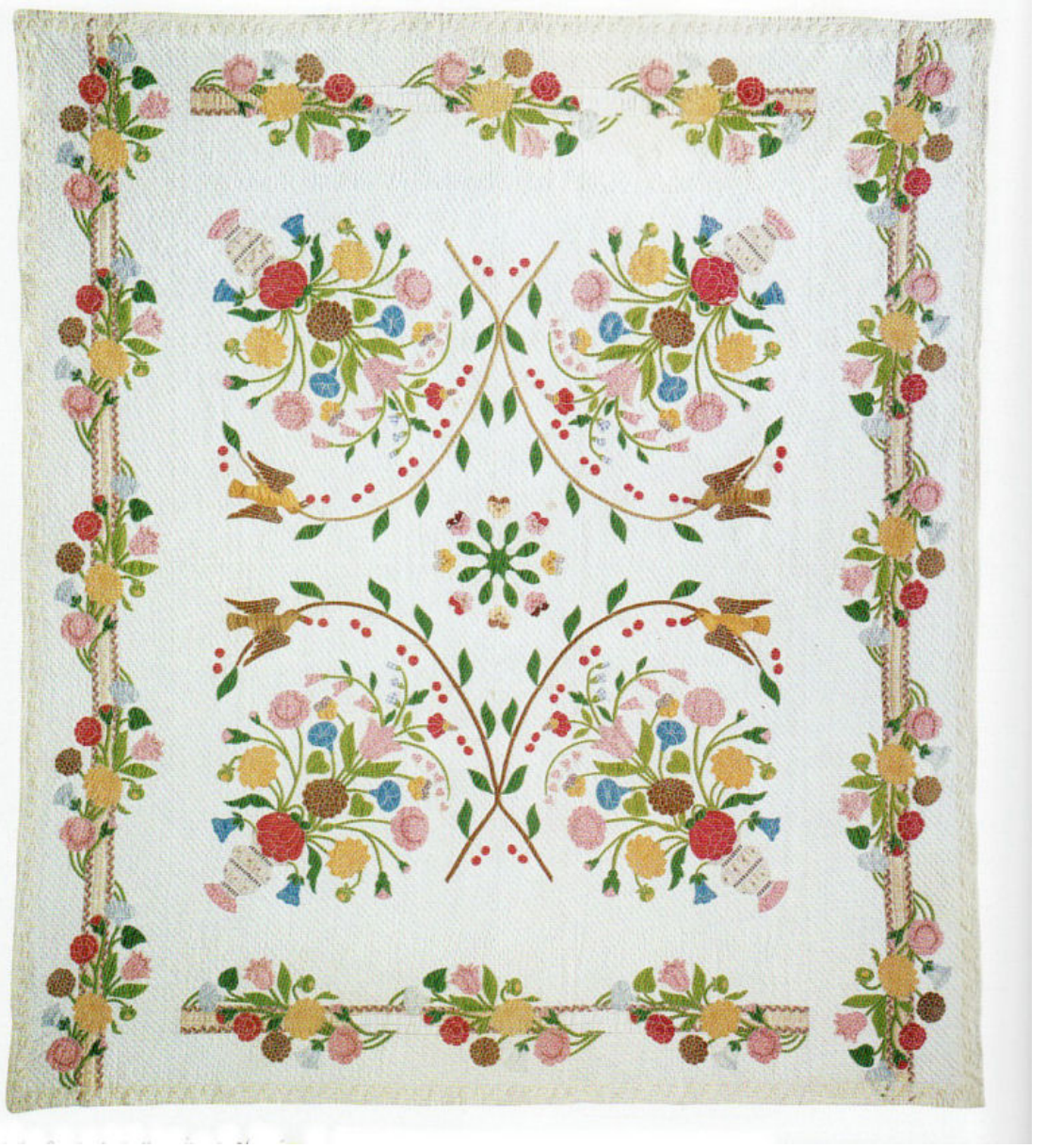

Figure 2.7. Quilt by Betsey M. Seely Sears (1813-1901), circa 1855, Wisconsin. From Wisconsin Quilts (C 2008 by Ellen Kort. Used with the kind permission of Krause Publications, an imprint of $\mathrm{F}+\mathrm{W}$ Media, Inc. All rights reserved.

This undated quilt was also made by Betsey Seely Sears during the 1850 s. She used a similar layout and floral motifs as on the quilt that she signed. 
achievements, but also additional information ranging from family history to religious sentiments or prescriptive advice. ${ }^{45}$ In some cases, these objects served as testimony defined as proof, affirmation and evidence of a fact - that was, upon occasion, legally accepted by the government to document family relationships and past marriages. Partly inspired by the popularity of epistolary novels during the late eighteenth century, epistolary quilts and samplers also drew from their makers' schoolgirl needlework lessons: they incorporated lettering learned by making a sampler. ${ }^{46}$ This lettering was $^{2}$ directly reproduced on the samplers of aging women, or pieced on quilts. One textile scholar has pointed out that "in a society in which a woman had few legal rights, her name was nonetheless often prominently displayed within the household over which she presided." ${ }^{47}$ While Marsha Van Valin has theorized that women made epistolary samplers because they did not know how to write, ${ }^{48}$ by the antebellum period it seems more likely that writing with needle and thread was simply another, and in some cases, a more comfortable way for some women to express themselves.

An 1848 quilt by seventy-nine-year-old Maria Cadman Hubbard (b. 1769) makes this point in a striking fashion (figure 2.8). ${ }^{49}$ Pieced in red and white in a variation of the

\footnotetext{
${ }^{45}$ For more on epistolary textiles, see: Winifred Reddall, "Pieced Lettering on Seven Quilts Dating from 1833 to 1891," Uncoverings 1 (1980): 56-63; Stacy C. Hollander, "Talking Quilts," Folk Art 29 (Spring/Summer 2004): 32-41; Marsha Van Valin, "Epistolary Samplers: When Needles were Pens" in Common Thread, Common Ground: A Collection of Essays on Early Samplers and Historic Needlework, Marsha Van Valin, ed. (Sullivan, Wisconsin: The Scarlet Letter, 2001), 50-55.

${ }^{46}$ Van Valin, "Epistolary Samplers," 50.

${ }^{47}$ Hollander, "Talking Quilts," 38.

${ }^{48}$ Van Valin, "Epistolary Samplers," 50-52.

${ }^{49}$ The quilt is now in the collection of the American Folk Art Museum, New York, New York. Little is known about quiltmaker Maria Cadman Hubbard's life and the attribution of the quilt to New York is not definite. See: Stacy C. Hollander and Brooke Davis Anderson, American Anthem: Masterworks from the American Folk Art Museum (New York: Harry N. Abrams, Inc., 2001), 337; Atkins and Tepper, New York Beauties, 91; Robert Bishop, New Discoveries in American Quilts (New York: E.P. Dutton and Company, Inc., 1975), 32; Elizabeth V. Warren and Sharon L. Eisenstat, Glorious American Quilts: The Quilt Collection of the Museum of American Folk Art (New York: Penguin Studio, 1996), 53-55; and C. Kurt
} 


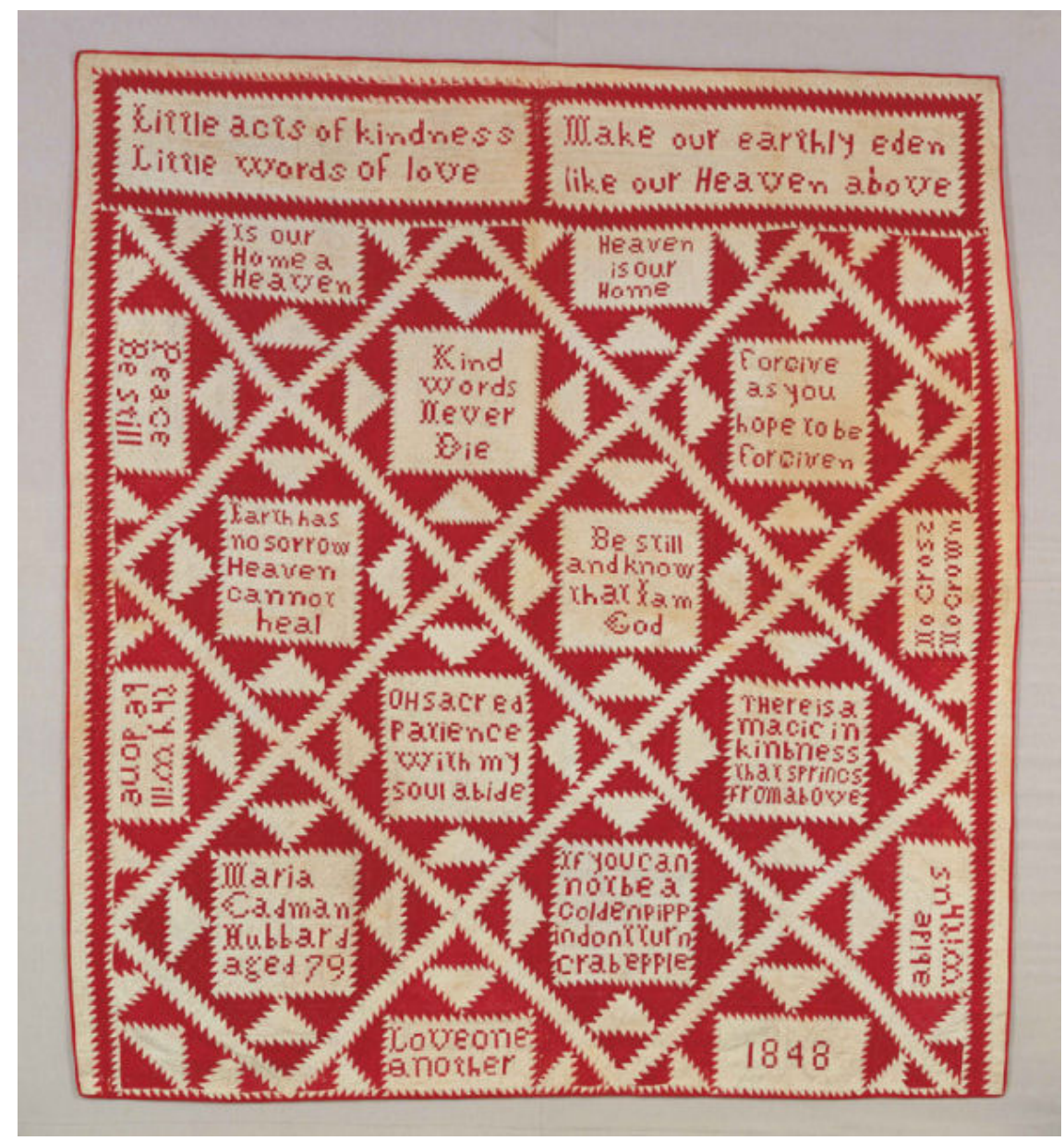

Figure 2.8. Quilt by Maria Cadman Hubbard (b. 1769), 1848, New York. Courtesy of the American Folk Art Museum, New York, New York.

Maria Cadman Hubbard used her quilt to bring together fifteen verses that undoubtedly had meaning for her. The quilt draws on magazines, books, the Bible and hymns to offer a moral guide for all who view it.

Dewhurst, Betty Macdowell, and Marsha Macdowell, Religious Folk Art in America: Reflections of Faith (New York: E.P. Dutton, Inc., 1983), 60. 
Delectable Mountains pattern, Hubbard not only signed her work with her name, age and the date, but she used the white spaces to include fifteen pieced inscriptions of her choosing. The white squares and diagonal lines of the quilt top make a strong visual statement, almost forming a checkerboard of advice. Considered together, the quilt offers Hubbard's personal manifesto - her guide to appropriate conduct.

In a sense, Hubbard created a quilt that served a purpose similar to eighteenthand early-nineteenth-century commonplace books. ${ }^{50}$ These books were created by their owners by bringing together favorite verses, ideas, and essays, usually from printed sources. Just as Hubbard did when making her quilt, the writers of commonplace books pursued a number of distinct actions and choices, identifying verses and texts that resonated with them, choosing to recreate them, and accumulating and organizing them in a new format. Susan Stabile suggests that these books became "memory as a lived practice." ${ }^{, 1}$ The pages took ideas and memories and made them real for their keepers, providing instruction and rules to live by. In addition, by collecting ideas and verses from many places and bringing them to one new location, the owner was taking some control of the material, keeping it close, where it could be easily referenced, and shared with others. Hubbard's quilt holds a relationship to these books. Like those works, she

\footnotetext{
${ }^{50}$ On commonplace books see: Stabile, Memory's Daughters, 9-16, 133; Catherine La Courreye Blecki and Karin A. Wulf, eds., Milcah Martha Moore's Book: A Commonplace Book from Revolutionary America (University Park, Pennsylvania: The Pennsylvania State University Press, 1997); Susan Miller, Assuming the Positions: Cultural Pedagogy and the Politics of Commonplace Writing (Pittsburgh: University of Pittsburgh Press, 1998); and Lucia Dacome, "Noting the Mind: Commonplace Books and the Pursuit of the Self in Eighteenth-Century Britain," Journal of the History of Ideas 65 (October 2004): 603-625. In addition, the following articles, on nineteenth-century scrapbooks, gift books and photo albums, offer additional perspectives on Hubbard's choice to collect verses on her quilt: Patricia P. Buckler and C. Kay Leeper, “An Antebellum Woman's Scrapbook As Autobiographical Composition," Journal of American Culture 14 (1991): 1-8; Cindy Dickinson, "Creating a World of Books, Friends, and Flowers: Gift Books and Inscriptions, 1825-60," Winterthur Portfolio 31 (1996): 53-66; Marilyn F. Motz, "Visual Autobiography: Photograph Albums of Turn-of-the-Century Midwestern Women," American Quarterly 41 (March 1989): 63-92.

${ }^{51}$ Stabile, Memory's Daughters, 16.
} 
chose verses from a number of sources and brought them together in one place. The quilt, like the books, served as a reminder to its maker, and as an inspiration to all who read its words.

In addition to its resonance with commonplace books, the quilt also suggests a relationship to the embroidered perforated paper mottoes that would become popular during the mid- and late-nineteenth century. Perforated paper first became available in the 1840s, around the time Hubbard made her quilt. Initially, it was used for small projects - bookmarks and pictures or mottoes that were twelve inches square or smaller. Eventually, larger sheets of the paper were used to stitch mottoes, which were then framed to hang on the wall of the parlor. In addition to needlework versions, mottoes could be found on buildings, on title pages and at the beginnings of book chapters, carved into furniture, and printed on decorative engravings and lithographs. One study of over 150 embroidered mottoes made between 1860 and 1890 found that $60 \%$ presented a Christian-themed motto, much like the Hubbard quilt, and that the sentiments were drawn from the Bible, hymns and sermons. ${ }^{52}$

Hubbard's quilt may also have been inspired by the evangelical religious movements taking place during the early nineteenth century. Indeed, New York State, where Hubbard is thought to have stitched her quilt, was a focal point for the start of the Second Great Awakening, and may have inspired her to pick up needle and thread. ${ }^{53}$

\footnotetext{
${ }^{52}$ Kenneth L. Ames, Death in the Dining Room and Other Tales of Victorian Culture (Philadelphia: Temple University Press, 1992), 117.

${ }^{53}$ For an overview of the revivals that swept New York's "burned over district," see Whitney R. Cross, The Burned-over District: The Social and Intellectual History of Enthusiastic Religion in Western New York, 1800-1850 (Ithaca: Cornell University Press, 1950); Paul E. Johnson, A Shopkeeper's Millennium: Society and Revivals in Rochester, New York, 1815-1837 (New York: Hill and Wang, 1978); Nancy A. Hewitt, Women's Activism and Social Change: Rochester, New York 1822-1872 (Ithaca: Cornell University Press, 1984); and Nathan O. Hatch, The Democratization of American Christianity (New Haven: Yale University Press, 1989). Unfortunately, Hubbard's specific religious beliefs are unknown.
} 
Known in recent years as the "Pieties Quilt," Hubbard's bed covering includes sayings selected from the Bible, as well as poems and at least one hymn. ${ }^{54}$

The most prominent verse is pieced along the top of the quilt, in two sections, so that when it was put onto the bed, these words would fall along the pillows. This verse reads, "Little acts of kindness / Little words of love / Make our earthly eden / like our Heaven above." The verse is slightly paraphrased from a poem, known as "Little Things," written in 1845 by Julia Fletcher Carney (1823-1908). The poem was quickly published in a Christian periodical that year and apparently struck a chord with American readers: it was subsequently reprinted in many magazines and anthologies, as well as in some children's readers. ${ }^{55}$

Several of the sayings stitched on the quilt are recognizable tenets from the Bible. At the bottom is "love one another," which is found in John 13:34-35. Along the right side of the quilt is "abide with us," which appears in the gospel of Luke when the apostles asked Jesus to remain with them after his resurrection. Another verse on the quilt comes from the book of Psalms, "Be still and know that I am God." The shorter verses on the left side of the quilt are also easily identifiable. "Thy will be done" comes from the Lord's Prayer, second nature to all church members and found in the gospels of Matthew (6:10-14) and Luke (11:2-4). "Peace be still" comes from the New Testament's gospel of Mark, which reads, "Then He arose and rebuked the wind, and said to the sea, 'Peace, be

\footnotetext{
${ }^{54}$ Hollander, "Talking Quilts," 38. The title, "The Pieties Quilt," seems to have been applied in the 1980s, shortly before it was given to the American Folk Art Museum in 1984. Correspondence between the author and Stacy C. Hollander, Senior Curator, American Folk Art Museum, New York, NY, February 19, 2009. ${ }^{55}$ Charles S. Nutter and Wilbur F. Tillett, The Hymns and Hymn Writers of the Church (New York: Eaton \& Mains, 1911), 363; Martin Gardner, Famous Poems from Bygone Days (New York: Dover Publications, 1995), 35.
} 
still!' And the wind ceased and there was a great calm." ${ }^{, 56}$ As distilled purely from the Biblical story, these words convey the power of God. But, did they also carry additional meanings through their use on a woman's quilt? The phrase encourages rest and sleep each night as the quilt's owners crawled under it. Perhaps Hubbard was summoning some of the same power harnessed in the Bible story to exert control over her own life, or the quilt's subsequent owners.

Two verses on the quilt come from hymns. "Heaven is our home" appears in a hymn written by the English Congregational minister Thomas Rawson Taylor (18071835) shortly before his death in 1835 . It was published the following year in his memoirs as part of a selection of hymns. ${ }^{57}$ A hymn known as "Come, Ye Disconsolate," written around 1816 by Thomas Moore (1779-1852), is the source for the quilt's verse, "Earth has no sorrow heaven cannot heal."58 This verse was also popular on gravestones throughout the nineteenth century, offering comfort to mourners.

A shorter verse on the right side of the quilt reads, "No Cross, No Crown," a popular motto during the eighteenth and nineteenth centuries. Referring to the crucifixion and subsequent resurrection of Jesus Christ, the verse reminds the faithful that reward and achievement do not come without pain, suffering and difficulty first. In turn, it also reminded those who sought the rewards of Heaven that they must bear the crosses in their lives, remaining true to their faith and following the rules of the church. Popular for mid- and late-nineteenth century embroidered mottoes, this verse was also the title of

\footnotetext{
${ }^{56}$ This phrase was also the subject of a sermon delivered by Quaker preacher Elias Hicks and subsequently published in The Quaker 1 (1827): 105-143.

${ }^{57}$ Charles Seymour Robinson, Annotations Upon Popular Hymns (New York: Hunt \& Eaton, 1893), 293 -

294. The phrase also appears in the novel, The Black Tulip, by Alexandre Dumas, first published in 1850.

${ }^{58}$ www.cyberhymnal.org/htm/c/y/cydiscon.htm, accessed February 16, 2009.
} 
an early work by Quaker leader William Penn (1644-1718), written in 1668 while he was held prisoner in England for blasphemy. ${ }^{59}$

Hubbard brought together verses and ideas from a multitude of sources and sometimes it is difficult to identify the exact source for a passage she quoted because it circulated so widely in the culture. For example, the verse, "Forgive as you hope to be forgiven" turns up in many sermons and stories from the mid- and late-nineteenth century such as when it concludes the story, "The Broken Vow," published in an issue of The Lowell Offering and Magazine from $1843 .^{60}$ A few of the verses she selected can be found in post-1848 books and magazines, often unsigned, suggesting that they were reprinted multiple times. For example, an unsigned poem in The Soul's Welfare; A Magazine for the People, published in London in 1851, is titled "Forgive and Forget" and begins with a verse that is included on the quilt, "There's a magic in kindness, That springs from above."61 And, the phrase "kind words never die," which appears on the quilt near the top center, would become the chorus for a hymn written in 1855 and made popular by the Hutchinson Family Singers, a traveling family singing group of evangelists. ${ }^{62}$ Prior to 1848 , a slightly different version of this motto, "kind words can

\footnotetext{
${ }^{59}$ For more on William Penn's No Cross, No Crown, see www.bartleby.com/218/0406.html, accessed March 7, 2008. This phrase is used on many embroidered mottoes during the late nineteenth century, see Ames, Death in the Dining Room, 144. A poem titled "No Cross, No Crown" by Rev. T.F.R. Mercein appeared in The Christian Parlor Magazine 6 (1849): 306. For a nineteenth-century explanation of this verse, see Rev. William Holmes, Religious Emblems and Allegories (London: William Tegg, 1868), 151155.

${ }^{60}$ Ione, "Stories from the Linn-Side. No. VIII. The Broken Vow," The Lowell Offering and Magazine (Lowell: William Schouler, 1843), 253.

${ }^{61}$ The Soul's Welfare; A Magazine for the People (London: Houlston and Stoneman, 1851), 70. I have been unable to locate a source of this verse published prior to 1848 .

${ }^{62}$ Frances E. Willard and Mary A. Livermore, eds., American Women: Fifteen Hundred Biographies, volume II (New York: Mast, Crowell \& Kirkpatrick, 1897), 561; Andy Logan, Brendan Gill and Gordon Cotler, “The Talk of the Town: Never Die," The New Yorker (May 12, 1951): 24.
} 
never die," was published as part of a poem titled, "My Philosophy," in The Rover: Weekly Magazine of Tales, Poetry, and Engravings. ${ }^{63}$

The sources for three of the verses Hubbard inscribed on her quilt are not known. ${ }^{64}$ At the top, one block reads, "Is our Home a Heaven," an apparent reversal of the companion block to its right, which reads, "Heaven is our Home." Another block reads, "Oh sacred Patience with my soul abide," which may come from an unidentified hymn, sermon or story. ${ }^{65}$ And, the third unidentified verse is also one of the most charming: "If you can not be a golden pippin, don't turn crab apple." A pippin was any one of several varieties of sweet apples, contrasting it with the sour crabapple. ${ }^{66}$

Whether reminders or aspirations, the "pieties" on Hubbard's quilt offered validation of her past and inspiration for her family's future. The fifteen verses on the quilt include one question, five imperatives and nine observations or statements of advice. Reading through all fifteen provides encouragement to be kind to others, to

\footnotetext{
${ }^{63}$ Seba Smith, ed., The Rover: Weekly Magazine of Tales, Poetry, and Engravings (New York: S.B. Dean \& Co., 1844), 32. Signed only with the initials, "C.H.H.," The Rover explained that this poem had been found in the pages of London's The Illuminated Magazine. It was reprinted again in 1846 in Voices of the True-Hearted (Philadelphia: Merrihew \& Thompson, 1846), 4.

${ }^{64}$ A sampler historian has suggested that "the changes that appear [in sampler verses], the misspellings, the freedom with which phrases or lines are pulled apart and recombined, the length of time over which some verses persistently appear, suggest that some sampler inscriptions... were not copied from books and were indeed passed along via the sampler medium itself." Hubbard's quilt may also be an example of this phenomenon, or she may have taken some of her verses from needlework samplers that she knew. See Toni Flores Fratto, "Remember Me: The Sources of American Sampler Verses," New York Folklore 2 (Winter 1976): 212.

${ }^{65}$ I have been unable to find a pre-1848 source for this saying. However, I am indebted to Marla R. Miller for pointing out a similar phrase in a story called "The Refiner" by "Clement" in The Local Preachers' Magazine and Christian Family Record (London: Aylott and Company, 1857), 240-241.

${ }^{66}$ Hubbard was probably familiar with the grafting experiments that were performed with golden pippin apples and crab apples during the early nineteenth century. These experiments were discussed in a number of agricultural manuals and reports from the 1830s through the 1850s. For example, see Peter Mark Roget, M.D., Animal and Vegetable Physiology Considered with Reference to Natural Theology (London: William Pickering, 1834), 594-595. And, The Golden Pippin was also the title of a play written by English playwright Kane O'Hara in 1772, although there is no evidence about whether Hubbard was familiar with this work. A version of this saying appears in Mrs. Herbert A. Barker and Miss Helen S. Whitney, eds., Boylston Congregational Church Home Department Cook Book (Jamaica Plain, Massachusetts: J. Allen Crosby, 1906), 45.
} 
forgive, and to seek the peace of resignation. In addition, several of the verses remind the viewer to place their faith in God - "thy will be done" and "oh sacred patience with my soul abide" - in order to achieve eternal reward. Terri Premo's study of the diaries of aging women between 1785 and 1835 found that "older women began to fear the prospect of a future void of moral and spiritual substance." ${ }^{67}$ Stitching a quilt or sampler as a physical manifestation of moral and spiritual values could have been one way to cope with this fear.

While Hubbard's quilt, like most of the others discussed here, was primarily intended for family use, some antebellum textiles quite unexpectedly extended their reach, moving beyond the domestic sphere to the most public sphere of all - the courts. The sampler made by ten-year-old Mary Hearn (b. 1782) of Nantucket, Massachusetts, in 1793, traveled from Massachusetts to Rhode Island to upstate New York and ultimately to Washington, D.C., where it served as legal evidence of the marriage of its maker's parents, qualifying Hearn's mother for a military pension (figure 2.9). ${ }^{68}$ Mary Hearn was born in Dutchess County, New York, on December 12, 1782, the daughter of Daniel Hearn (d. 1783) and Elizabeth Ray (1755-1849). Her father served as a wagon conductor during the Revolutionary War but died in July 1783 when Mary was an infant. Elizabeth Hearn took her baby to Nantucket, where she had family. ${ }^{69}$ Mary's sampler includes a row of the motif known as the "Nantucket tree" along the bottom. Given its similarities

\footnotetext{
${ }^{67}$ Premo, Winter Friends, 5.

${ }^{68}$ The sampler is now in the collection of the National Archives and Records Administration, Washington, DC.

${ }^{69}$ Pension file of Daniel Hearn, Massachusetts, W17064, National Archives and Records Administration; Jennifer Davis Heaps, "Remember Me: Six Samplers in the National Archives," Prologue 34 (Fall 2002): 189-190.
} 


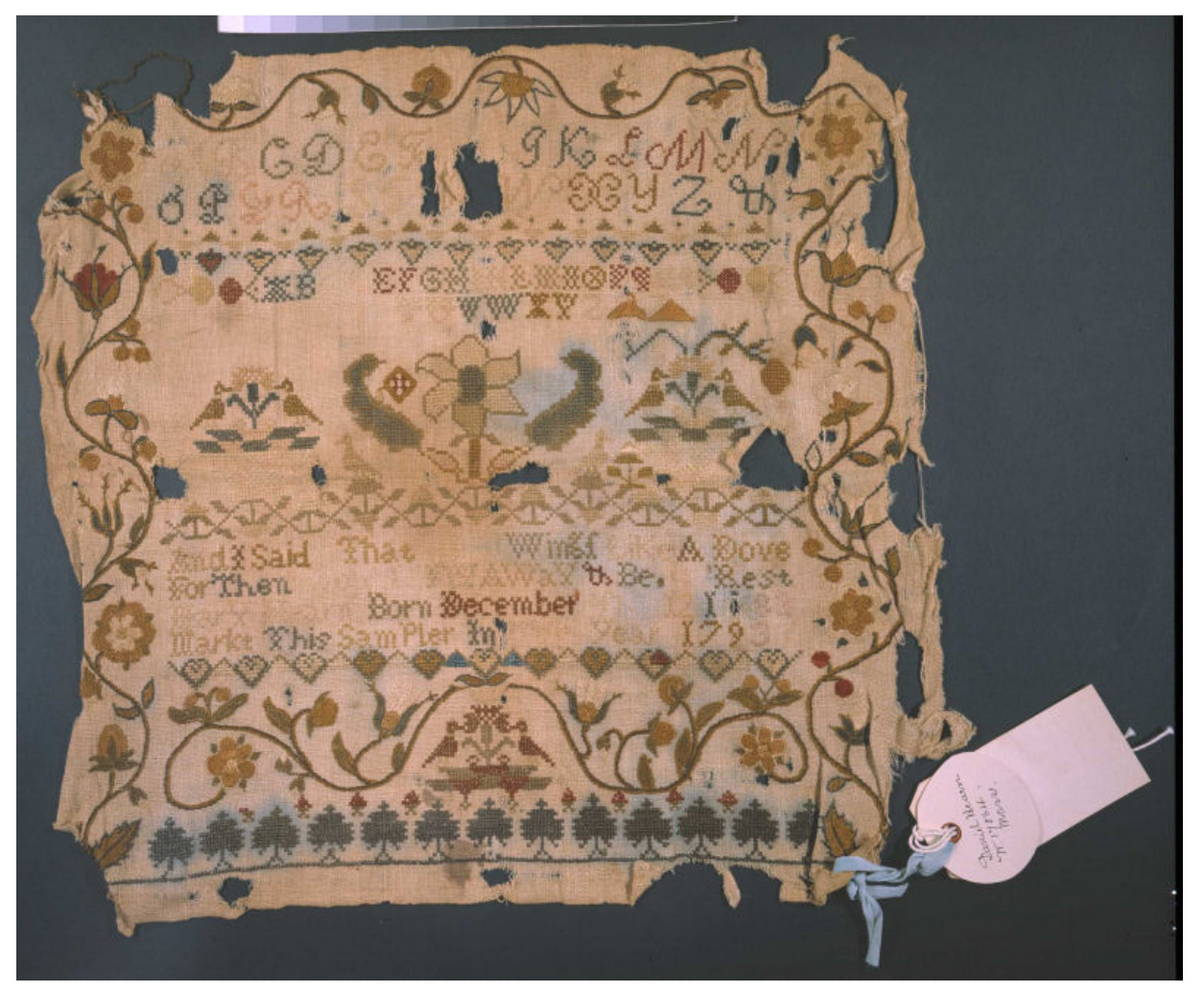

Figure 2.9. Sampler by Mary Hearn (b. 1782), 1793, Nantucket, Massachusetts. Courtesy of the National Archives, Record Group 15, Records of the Department of Veterans Affairs, Entry A1-2A, Case Files of Pension and Bounty-Land Warrant Applications Based on Revolutionary War Service.

Verse: And I said Oh that I had wings like a dove, For then would I fly away \& be at rest. Mary Hearn born December 12, 1782, Markt this sampler in the year 1793.

Mary Hearn Fralick used her girlhood sampler as evidence to prove the marriage of her parents so her mother could qualify for a government pension as the widow of a Revolutionary War soldier. While Mary and her mother were ultimately successful, there were questions about the date the sampler was made since it appeared that the digits in the year had been picked out and later restitched. 
to other known Nantucket samplers, it seems fairly certain that Mary made her sampler on the island under the instruction of a local teacher. ${ }^{70}$

Mary Hearn left Nantucket with her mother, and her sampler, before the War of 1812, settling in Rhode Island, where she taught school. A few years later, Mary and her mother moved to New York state, taking up residence in the town of Marathon where Mary Hearn married Peter Fralick (b. 1783) in $1818 .^{71}$ Many years later, Peter Fralick would recall that his wife had the sampler when they wed, as he testified before the court, "the needle work spoken of by my wife was in her possession when I married her."72

Beginning in 1818, the same year that Mary Hearn married Peter Fralick, the federal government enacted its first legislation regarding pensions for military service. ${ }^{73}$ The files compiled during the early and mid-nineteenth century are full not only of documentary evidence, providing fascinating details about the lives of Revolutionary-era soldiers, as well as their widows and children, but also the odd artifact, including six samplers, sent in to prove various family dates (marriage, births, etc.) in order to secure a pension (see Table 2.1). ${ }^{74}$ These samplers are noteworthy not just because the applicants sent them in but because the federal government accepted them as evidence. They were not rejected as mere ornamental trifles, nor were they discarded by the pension office.

\footnotetext{
${ }^{70}$ The samplers by Polly Coffin and Anna Gardner, which are now in the collection of the Nantucket Historical Association, Nantucket, Massachusetts, show several similarities to the Mary Hearn sampler and were made in the late 1790s. All three share a similar layout, style and motifs. Susan R. Boardman and Aimee E. Newell, "Nantucket Needlework: Samplers from Quaker Schools," Fine Lines 7 (Fall 2002): 8. ${ }^{71}$ Heaps, "Remember Me," 189. Nantucket genealogical records suggest that Mary Hearn married Joseph Elkins and that the couple had a daughter, Phebe, in 1803. Elkins was killed at sea in 1820. Since Mary Hearn married Peter Fralick in New York in 1818, these records seem to be in error or to reference a different Mary Hearn. See the Eliza Barney Genealogical Records at the Nantucket Historical Association; these records are cited in Heaps, "Remember Me," 189.

${ }^{72}$ Deposition by Peter Fralick, April 4, 1846, pension file of Daniel Hearn, National Archives and Records Administration, Washington, D.C.

${ }^{73}$ Heaps, "Remember Me," 186.

${ }^{74}$ Heaps, "Remember Me," 186-187.
} 
Table 2.1. Samplers Submitted to the Pension Office ${ }^{75}$

\begin{tabular}{|l|l|l|l|l|l|l|}
\hline Maker & $\begin{array}{l}\text { Life } \\
\text { Dates }\end{array}$ & $\begin{array}{l}\text { Date of } \\
\text { Sampler }\end{array}$ & $\begin{array}{l}\text { Age of } \\
\text { Maker } \\
\text { when } \\
\text { Sampler } \\
\text { Made }\end{array}$ & $\begin{array}{l}\text { Year } \\
\text { Submitted } \\
\text { to Pension } \\
\text { Office }\end{array}$ & $\begin{array}{l}\text { Age when } \\
\text { Sampler } \\
\text { Submitted }\end{array}$ & $\begin{array}{l}\text { Who was } \\
\text { pension } \\
\text { for? }\end{array}$ \\
\hline $\begin{array}{l}\text { Martha } \\
\text { Earl }\end{array}$ & b. 1781 & 1787 & 6 & 1842 & 61 & $\begin{array}{l}\text { Her } \\
\text { Mother }\end{array}$ \\
\hline $\begin{array}{l}\text { Patsey } \\
\text { Bonner }\end{array}$ & b. 1775 & 1792 & 17 & 1843 & 68 & Herself \\
\hline $\begin{array}{l}\text { Mary } \\
\text { Hearn }\end{array}$ & b. 1782 & 1793 & 11 & 1846 & 64 & $\begin{array}{l}\text { Her } \\
\text { Mother }\end{array}$ \\
\hline $\begin{array}{l}\text { Harriet } \\
\text { Bacon }\end{array}$ & b. 1794 & $\begin{array}{l}\text { ca. } 1804- \\
1805\end{array}$ & 10 or 11 & 1844 & 50 & $\begin{array}{l}\text { Her } \\
\text { Mother }\end{array}$ \\
\hline $\begin{array}{l}\text { Laura } \\
\text { Goodale }\end{array}$ & b. 1793 & ca. 1809 & About 17 & 1840 & 47 & $\begin{array}{l}\text { Her } \\
\text { Mother }\end{array}$ \\
\hline $\begin{array}{l}\text { Huldah } \\
\text { Booth }\end{array}$ & b. 1789 & ca. 1818 & 29 & 1848 & 59 & $\begin{array}{l}\text { Her } \\
\text { siblings }\end{array}$ \\
\hline
\end{tabular}

\footnotetext{
${ }^{75}$ All six samplers are currently in the collection of the National Archives and Records Administration, Washington, D.C. All information in the table comes from Heaps, "Remember Me," 185-195.
} 
Instead the samplers were closely examined and used to make decisions about whether the family should receive a military pension, then kept as part of the official file.

Widows received the right to apply for a pension beginning in 1836. To qualify, the woman had to prove that her late husband had served in the conflict and that they were married at the time. ${ }^{76}$ Absent a marriage license, Mary's mother, Elizabeth Hearn, as well as Mary and Peter Fralick, offered sworn statements to a local judge in Marathon, New York. The statements track Daniel Hearn's service, as well as the subsequent movements of his widow and daughter. ${ }^{77}$ Initially the sampler was used as evidence to prove the connections between the Revolutionary veteran Daniel Hearn, his widow, Elizabeth, and his daughter, Mary. When Mary and her mother compiled their pension application in the spring of 1846, Mary's statement explained that:

she has no record of her age Exsept what is contained in a piece of needle work in her possession made by herself as many as 53 years ago [1793] which needle work is in the words and figures to wit "And I said O that I had wings like a Dove, for then I would fly away and be at rest - Mary Hearn Born December $12^{\text {th }}$ 1782 marked this sampler in the year 1793" which would make me 64 years old Dec next...she made said record in needlework, the recollection she had of her age from her earliest childhood, as her age was told her by her mother... ${ }^{78}$

Accompanying Mary's statement was a supporting statement by Walton

Swetland, a local judge, who examined the sampler and "believe[d] the said Marys age to be therein truly stated...I have carefully examined the same and believe it to be what it purports to be an ancient memorandum or memento of the age and needle work by

\footnotetext{
${ }^{76}$ Heaps, "Remember Me," 186.

${ }^{77}$ Pension file for Daniel Hearn, National Archives and Records Administration.

${ }^{78}$ Deposition of Mary Fralick, April 4, 1846, pension file of Daniel Hearn, National Archives and Records Administration.
} 
Mary Fralick...,79 These statements were important because they established Mary Hearn's date of birth, helping to prove the marriage of her parents and qualifying her mother for a pension.

While the value of the sampler as appropriate legal evidence of Daniel and Elizabeth Hearn's marriage was not disputed, the accuracy of this particular sampler came into question during the pension application process. Although Swetland was convinced that it offered the requisite information, the pension office did not initially agree. The sampler was sent to Washington and examined. In the eyes of the pension office, the sampler appeared to be altered. And, it still shows evidence of having some of the numbers in the signature picked out, like those discussed in chapter 1. At some point after initially making the sampler in 1793 , but before it was sent to the pension office in 1846, Mary Hearn Fralick picked out her age and one of the digits of her birth year. After the pension office questioned this, Mary made another statement explaining that "at the time she mailed said sampler...the figures which appear altered appeared somewhat obliterated and Deponent caused said figures to be reworked and that said figures are the same they were originally except the stile of the work and the color of the silk."

Did Mary Fralick pick out these numbers to hide her age at some time before she and her mother started their pension application? Or did she do it because the sampler was difficult to read by the mid-1840s and she wanted the pension office to be able to easily read the information? Or, was she trying to change the dates to assist with the pension application? We cannot know for sure, but it seems most likely that Mary altered

\footnotetext{
${ }^{79}$ Deposition of Walton Swetland, April 4, 1846, pension file of Daniel Hearn, National Archives and Records Administration.

${ }^{80}$ Deposition by Mary Fralick, April 5, 1847, pension file of Daniel Hearn, National Archives and Records Administration.
} 
her sampler at some point to hide her age. Then, when she needed it for the pension claim, she tried to restitch those numbers so that the sampler would be readable.

Apparently, Mary Fralick's explanation of the alterations on her sampler was acceptable to the pension office; the office awarded her mother, Elizabeth Hearn, a pension of $\$ 276.66$ per year, which was paid until her death in December $1847 .^{81}$

Like Mary Hearn Fralick's sampler, four of the other five samplers found in the pension files were used as evidence to secure pensions for women (either the maker or her mother). ${ }^{82}$ It is significant that these "female" items, by virtue of being needlework, were used to help secure support for another female family member. The use of these samplers in this manner fits into the established patterns of female inheritance, which will be discussed in chapter 4. Where land and currency were passed down from father to son, women received moveable goods for their dowry, representing their share in their father's estate. ${ }^{83}$ Furthermore, these samplers do not simply fill in the historical record for the twenty-first-century scholar, who is used to seeing how public records and manuscript collections omit women. The samplers had to fill a gap at the time, for the women who made them, or for a female relative in need of financial support.

And, these examples show that women understood their textiles and needlework as their property. In the cultures she studied, anthropologist Annette Weiner suggested

\footnotetext{
${ }^{81}$ Heaps, "Remember Me," 190; pension file of Daniel Hearn, National Archives and Records Administration.

${ }^{82}$ The sixth sampler, made Huldah Booth (b. 1789) around 1818, was submitted by the maker and her siblings to try and collect a pension for their father's service. While their mother did receive a pension between 1836 and 1838, the request by the children in 1848 was denied. See Heaps, "Remember Me," 192.

${ }^{83}$ Barbara McLean Ward, "Women's Property and Family Continuity in Eighteenth-Century Connecticut" in Early American Probate Inventories, Peter Benes, ed. (Boston: Boston University Press, 1987), 83-85; Laurel Thatcher Ulrich, "Furniture as Social History: Gender, Property, and Memory in the Decorative Arts," in American Furniture, ed. by Luke Beckerdite (Milwaukee: Chipstone Foundation, 1995), 39-68; Laurel Thatcher Ulrich, "Hannah Barnard's Cupboard: Female Property and Identity in $18^{\text {th }}$-Century New England" in Through a Glass Darkly: Reflections on Personal Identity in Early America, ed. by Ronald Hoffman, Mechal Sobel and Fredrika J. Teute (Durham: University of North Carolina Press, 1997), 238273.
} 
that "all personal possessions invoke an intimate connection with their owners,

symbolizing personal experience that...adds value to the person's social identity." 84

Likewise, using their needles offered antebellum women a way to both tell and control

their story. For the women discussed here, their needles were always accessible, offering

not only comfort and warmth for their families, but a means of expression and a source of identity - and not merely symbolically - for themselves.

\section{$\underline{\text { Autobiographical Needlework }}$}

In the early 1830 s, decades after making her schoolgirl sampler, forty-year-old Caroline Gilman (1794-1888) reflected on her family's changing perception of the sampler. "This sampler was a matter of curiosity, and sometimes of ridicule, to my children," she wrote, "but now that they perceive my gray hairs and increasing infirmities, I find the sampler neatly folded and laid aside, and sometimes a conscious look reveals to me that they think I may soon be folded to rest in the grave." ${ }^{85}$ For Gilman and her children, the sampler became intertwined with the threads of her life as it progressed. And, its meaning changed over those years, evolving from a young girl's school lesson to a quaint outmoded household decoration to a family touchstone, cherished for its association with a beloved mother. Although not specifically using the words, Gilman suggests that "family chauvinism" - a belief in the superiority of one's

\footnotetext{
${ }^{84}$ Weiner, Inalienable Possessions, 36.

${ }^{85}$ Mrs. Caroline Gilman, Recollections of a Housekeeper (New York: Harper and Brothers, 1834), 10-11. Caroline Howard was born in Boston, Massachusetts, in 1794, the daughter of Samuel Howard and Anna Lillie. After the early deaths of her parents, Caroline lived with relatives. In 1819, she married Reverend Samuel Gilman, a Unitarian minister. The couple moved to Charleston, South Carolina, where they had seven children, although three died in infancy. In the 1830s, she began to publish a children's weekly, Rose-Bud, and later wrote a number of novels. She died in 1888 in Washington, D.C. Diane Prenatt, "Gilman, Caroline Howard," http://www.anb.org.silk.library.umass.edu:2048/articles/16/16-00624.html, American National Biography Online Feb. 2000; accessed November 21, 2009.
} 
own family - may have been at work. ${ }^{86}$ The sampler took on a connotation of far more than a school lesson; it was proof of the family's past and a demonstration of their familiarity with genteel standards. Autobiographical needlework suggests that the maker was proud of her skill, making it by definition somewhat narcissistic. Even when Gilman was "folded to rest in the grave," she knew her sampler would remain behind to tell her story.

When forty-two-year-old Elcey Patterson (1803-1862) stitched her sampler in 1846, she left no doubt as to the motivation behind her work (figure 2.10). ${ }^{87}$ The bottom section reads, "Elcey Pattersons Sampler August 231846 / When this you see remember me my old companions / Look at this and learn of me my Young fiends [sic] / Elcey Patterson is my name you see." While this verse is not original, or individual, instead drawn from autograph albums, gravestones and other samplers of the nineteenth century, the layout of the sampler reflects choices made by its stitcher and can be read as an autobiography of its maker.

The top section presents the maker's early history. After the traditional alphabets and numbers, which she would have learned as a young girl, the maker stitched, "Elce Patterson was Born in the state of Ohio Butler County Lemon Township April $171803 . "$ Patterson was three years old when her family became members of the United Society of

\footnotetext{
${ }^{86}$ Although the following do not use the words "family chauvinism," each author does suggest that objects were, in part, understood to show family pride and even superiority: Margaretta L. Lovell, Art in a Season of Revolution: Painters, Artisans, and Patrons in Early America, (Philadelphia: University of Pennsylvania Press, 2005); D. Brenton Simons and Peter Benes, eds., The Art of Family: Genealogical Artifacts in New England (Boston: New England Historic Genealogical Society, 2002); Laurel Thatcher Ulrich, The Age of Homespun: Objects and Stories in the Creation of an American Myth (New York: Alfred A. Knopf, 2001); and Laurel Horton, Mary Black's Family Quilts: Memory and Meaning in Everyday Life (Columbia: University of South Carolina Press, 2005). And, for a comparison of English "family chauvinism," see Leonore Davidoff and Catherine Hall, Family Fortunes: Men and Women of the English Middle Class, 1780-1850 (London: Hutchinson, 1987).

${ }^{87}$ The sampler is now in a private collection. It is illustrated in Sue Studebaker, Ohio Is My Dwelling

Place: Schoolgirl Embroideries 1800-1850 (Athens: Ohio University Press, 2002), 36.
} 


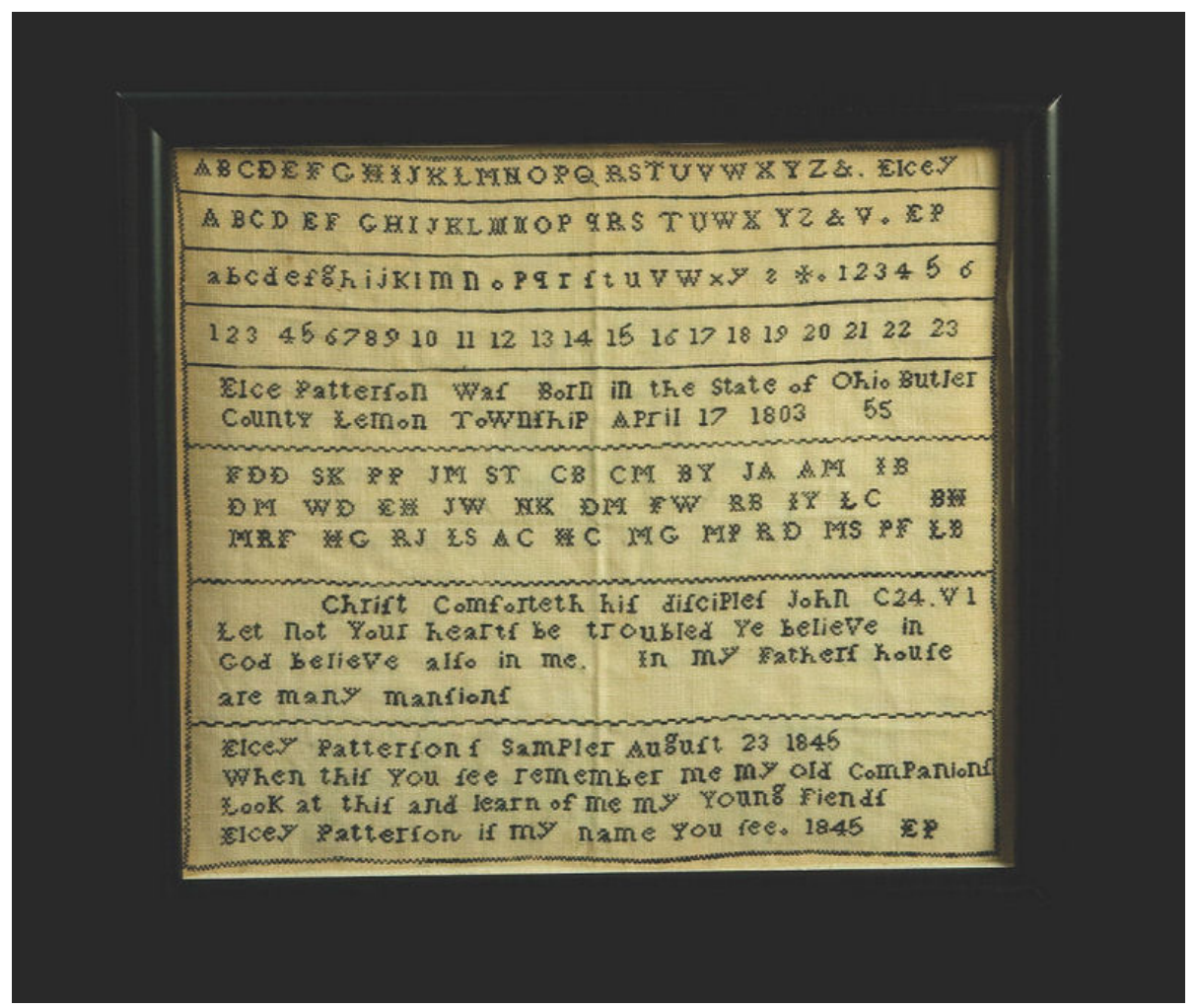

Figure 2.10. Sampler by Elcey Patterson (1803-1862), 1845, Union Village, Ohio. Courtesy of Northeast Auctions, New Hampshire.

Verses:

Christ comforteth his disciples John C.24 V1. Let not your hearts be troubled, Ye believe in God believe also in me. In my fathers house are many mansions.

Elcey Pattersons sampler August 23 1846. When this you see remember me my old companions. Look at this and learn of me my young friends. Elcey Patterson is my name you see. 1845.

Forty-two-year-old Elcey Patterson used her sampler to tell her life story. She included the basic facts of her life and also chose verses that held meaning for her. 
Believers, a Shaker community in Warren County, Ohio. Patterson's Shaker community grew from the first group of dissident Quakers who came to America in 1774 with leader Mother Ann Lee (1736-1784). At the movement's peak in the 1850s there were nineteen Shaker communities in the United States with around 6,000 members. Patterson's community, Union Village, near Lebanon, Ohio, was initially organized in 1805, a year before Patterson and her parents arrived, and became the largest Shaker community west of the Allegheny mountains. ${ }^{88}$

Shakers chose to separate themselves from the world, practicing cooperation, harmony and simplicity, as well as equality between the sexes. Shakers valued function over appearance, which is reflected in Patterson's sampler. Shaker girls and women did not display their samplers the way that many schoolgirls did, nor were the Shaker samplers decorated with the floral borders, small animals and other spot motifs common on American samplers. These samplers instead followed the style of functional marking samplers since the Shakers' communal wash houses made marks essential for distinguishing the inhabitants' clothing. ${ }^{89}$ Yet, even as Patterson's sampler fits the Shaker functional style and was probably used as a teaching exercise, it still carries personal messages by and about its maker.

While the top section tells the story of Patterson's childhood, the middle section reflects the story of her adulthood. There is a band with a series of marks made up of two or three initials each. A closer study of this series of initials, and the knowledge that Patterson was part of a Shaker community, reveal that the initials are those of founding

\footnotetext{
${ }^{88}$ Studebaker, Ohio Is My Dwelling Place, 35.

${ }^{89}$ Mary Jaene Edmonds, Samplers and Samplermakers: An American Schoolgirl Art 1700-1850 (London: Rizzoli, 1991), 155; Studebaker, Ohio Is My Dwelling Place, 35.
} 
Shaker elders and eldresses. ${ }^{90}$ While these names would have been influential on Patterson in her youth, as she aged they would have continued to serve as role models for her. In addition, as a Shaker, who did not believe in procreation, she would not marry and have children, so the usual type of family record needlework, tracking marriage and children, would never be available to her. Perhaps the initials of the eldresses on the sampler filled that role; she considered them to be part of her family and including their initials provided a sense of tradition and continuity. There were no children to pass the sampler to, who had other motives to remember her, hence the need for the instruction or plea. Whether the eldresses represented on the sampler were still alive or not, Patterson may have started to see them as peers by the time she made the sampler as an adult, rather than as the teachers of her youth. The bottom two sections of the sampler, with a verse and Patterson's statement of purpose, quoted above, bring her life story to a close. When she made this sampler, Patterson was one of the community's teachers, instructing the girls in needlework as well as other subjects. ${ }^{91}$

Her sampler was at once a documentation of her life and a lesson for those to come. Patterson selected a religious verse for her sampler, "Christ comforteth his disciples / Let not your hearts be troubled ye believe in / God believe also in me. In my fathers house / are many mansions." But, while Patterson provided a biblical citation for her verse on the sampler, "John C. 24. V 1," it is not quite correct. The verse actually comes from John chapter 14, verses one and two. ${ }^{92}$ Her error may have been a result of including verse one and verse two, or simply a thoughtless mistake. Patterson's sampler ends with the request to "remember me." Undoubtedly, the words of the biblical passage

\footnotetext{
${ }^{90}$ Studebaker, Ohio Is My Dwelling Place, 37.

${ }^{91}$ Studebaker, Ohio Is My Dwelling Place, 37.

${ }^{92}$ I thank Marla R. Miller for bringing this discrepancy to my attention.
} 
provided comfort to an aging woman who was starting to think about the end of her life she may have been cheered to remember that "in my father's house are many mansions." Like Caroline Gilman's sampler, Elcey Patterson left behind an object upon which she made her mark, and one that symbolized her entire life story.

A sampler made by Patty Bartlett Sessions (1795-1892), made in two distinct stages thirty-seven years apart, experienced an evolution from school project to biographical object (figure 2.11). ${ }^{93}$ Patty Bartlett started the sampler in 1811 when she was a young woman of sixteen in Maine but she did not finish it until she was fifty-four and living in Utah. Stitched as it was, in girlhood and in maturity, almost forty years apart, the sampler shows text, design and skill that are different from top to bottom, while telling her life story like Patterson's sampler does.

Patty Bartlett was born in Maine in 1795, to Enoch Bartlett (1742-1825) and his second wife, Martha Ann Hall (1742-1828). When she started the sampler she was attending a local school. However, she married the next year, when she was seventeen, which probably explains why she did not finish her sampler at the time. She wed David Sessions (1790-1850) against her parents' wishes, and they had their first child in $1814 .^{94}$ Patty became a midwife as a young woman, eventually delivering almost 4,000 babies over the course of her life. She also used her needlework skills to earn money to help with the family's expenses. ${ }^{95}$

\footnotetext{
${ }^{93}$ The sampler is in a private collection. It has been analyzed in Ulrich, The Age of Homespun, 404-407 and is also illustrated in Donna Toland Smart, ed., Mormon Midwife: The 1846-1888 Diaries of Patty Bartlett Sessions (Logan, Utah: Utah State University Press, 1997), 4.

${ }^{94}$ Smart, ed., Mormon Midwife, 6, 12. For additional biographical information on Patty Bartlett Sessions, see Susan Sessions Rugh, "Patty B. Sessions" in Sister Saints, Vicky Burgess-Olson (Provo, UT: Brigham Young University Press, 1978), 305-322 and Kenneth L. Holmes, ed., Covered Wagon Women: Diaries and Letters from the Western Trails 1840-1890 (Glendale, CA: The Arthur H. Clark Company, 1983), 157187.

${ }^{95}$ Smart, ed., Mormon Midwife, 8, 10.
} 


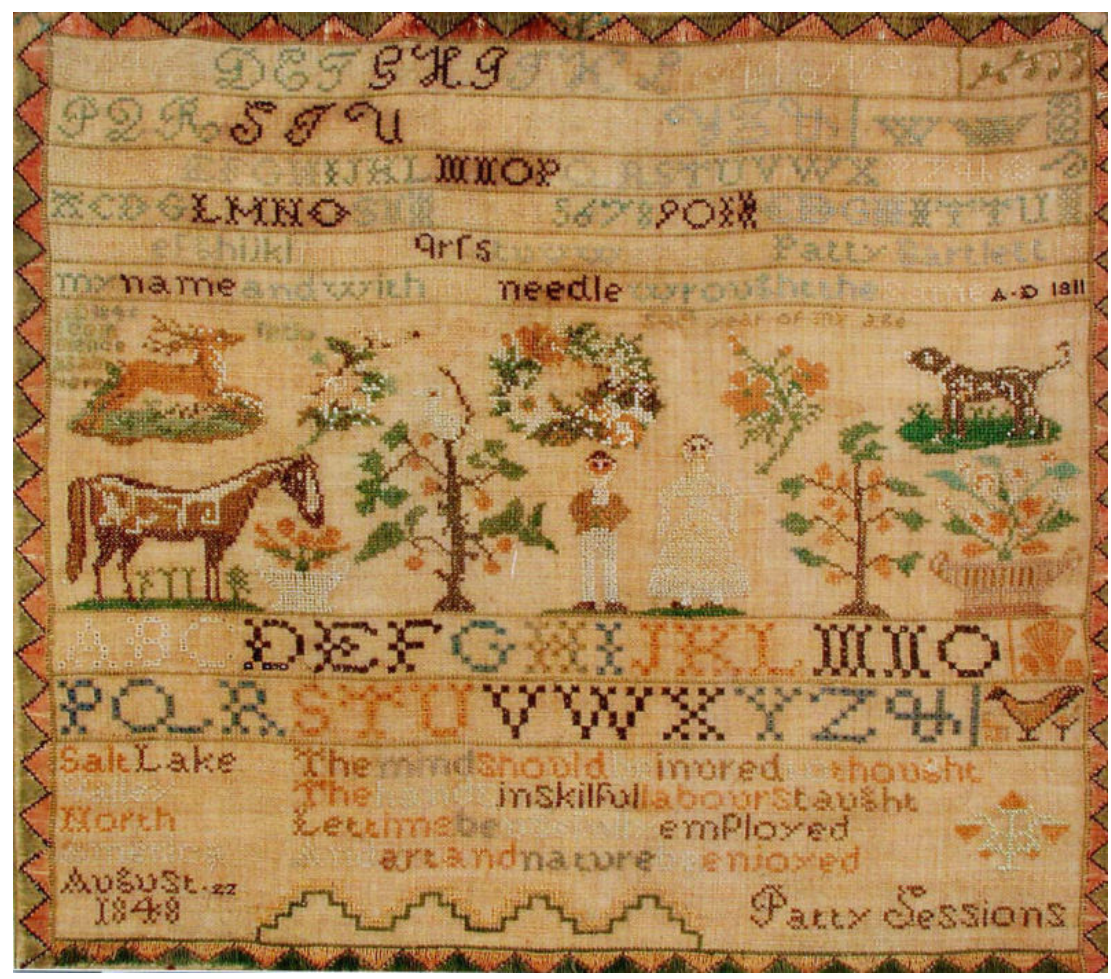

Figure 2.11. Sampler by Patty Bartlett Sessions (1795-1892), 1848, Utah. Private Collection, courtesy of Suzanne B. Anderson.

Verses:

Patty Bartlett is my name and with my needle wrought the same.

The mind should be inured to thought / the hand in skilful labours taught / Let time be usefully employed / And art and nature be enjoyed.

AD 1848 I commence again here in the $54^{\text {th }}$ year of my age. Patty Sessions Salt Lake Valley North America August 221848.

In Utah, at age fifty-four, Patty Bartlett Sessions completed the sampler she started as a young woman of sixteen in Maine. A convert to Mormonism, Sessions took her unfinished sampler with her across the country from Maine. The top and bottom of the sampler document the two stages of life that she experienced as she stitched. 
A close look at the sampler shows that in 1811 she stitched the top and side borders, along with the top section containing alphabets, her name, the year and a short verse found on countless New England samplers: "Patty Bartlett is my name and with my needle wrought the same." In 1848, she finished the bottom section with animals, flowers, signature, and the bottom border. The bottom section also has a verse, "The mind should be inured to thought / the hand in skilful labours taught / Let time be usefully employed / And art and nature be enjoyed." Taken separately the two parts of the sampler represent the two ages of the woman as she stitched. At the top she signed her birth name, "Patty Bartlett," and stitched the rather common, rote schoolgirl verse. The bottom is signed with her married name and makes no mistake about the time and her age, “AD 1848 I commence again here in the $54^{\text {th }}$ year of my age." Below this she completed the sampler with "Patty Sessions Salt Lake Valley North America August 22 1848." 96 The animals included in this section may have been modeled on those on her farm in contrast to the flowers or standard motifs designed by a teacher for use on a young girl's sampler. The verse in this section seems to reflect her older stage of life, cherishing the value of industry and counseling an appreciation of work, art and nature.

When Patty was thirty-nine, she converted to Mormonism. Missionaries came to her town in Maine in 1833. Patty was the first of her family to believe in their message, but held off her baptism in the faith for a year, until 1834, to give her family more time to explore the religion. As she entered her forties, Patty and her family started a new life

\footnotetext{
96 The reference on her sampler to "Salt Lake Valley North America," rather than "United States" reflects the fact that Utah was not a state at the time, but a territory. Although the Mormons petitioned for statehood in 1849-1850 (asking to admit a large area from the Colorado Rockies to the Sierra Nevada Mountains as the state Deseret), Utah did not become a state until 1896. Edward Leo Lyman, "Statehood for Utah," www.media.utah.edu/UHE/s/STATEHOOD.html, accessed July 5, 2009.
} 
with the Mormons. They moved west to Missouri in 1837, when Patty was forty-two, subsequently moving to Illinois in 1839 , when Patty was forty-four. Over the course of her marriage to David Sessions, the couple had eight children, although four died during childhood. $^{97}$

In 1846, when she was fifty-one, Patty began to keep a diary. Her sampler makes its appearance in entries from the spring and summer of 1848 when she was fifty-four. She had packed the sampler away, unfinished, with her silk threads, and carried it west during the 1830s. Her diary entries about the sampler are frustratingly mundane, such as her first notation about picking up the sampler after almost forty years, "Commenced to finish my sampler that I began when I was a girl and went to school."98 She noted working on the sampler in March, May, and June 1848. On August 22, 1848, she recorded, "finished my sampler that I commenced when I was young.",99

However, by reading the other diary entries from these months, her terse comments can be interpreted, suggesting a theory about her motivation in picking up the sampler again. First, in late March 1848, about ten days after she recorded working on her sampler, there was a large leak in her house during a torrential rainstorm and many of her things were damaged. About a month later, Patty noted that she had obtained her first floor since moving to her current home. "I helped Mr Sessions lay down a floor," she wrote, "the first floor that I could set my foot upon as my own for more than two years I have lived on the ground all that time." ${ }^{100}$ Without stating it directly, her words convey a sense of past impatience and dissatisfaction, now at least somewhat allayed. Feeling

\footnotetext{
${ }^{97}$ Smart, ed., Mormon Midwife, 14, 16-19; Ulrich, The Age of Homespun, 405.

${ }^{9}$ Smart, ed., Mormon Midwife, 110.

${ }^{99}$ Smart, ed., Mormon Midwife, 110, 113, 115, 117.

${ }^{100}$ Smart, ed., Mormon Midwife, 111-112.
} 
settled at last, Patty Sessions may have picked up her sampler with an eye toward framing it and hanging it on her wall, demonstrating her own gentility and also staking a claim to the house as hers.

Despite her religious faith, and even though she herself was "sealed" to Joseph Smith (1805-1844) in 1842, Patty found it difficult when her husband David took a plural wife in 1845 . For Patty, her own plural marriage to Joseph Smith seems to have been a spiritual one, intertwined with her faith in Mormon beliefs. ${ }^{101}$ In contrast, David's plural wife lived nearby and Patty had to assist with caring for that woman and her children, as well as working in her own household. Several of her diary entries from 1848 record difficulties with her husband, who was traveling between the homes of his two wives. Patty felt neglected and had to do much hard work alone at her own home during the months that she worked on her sampler. Her own children were grown and out on their own, so she did not have their assistance. On May 12, 1848, during the same season she was working to complete the sampler, she noted, "much to do got very tired" and on July 1, 1848, she wrote, "finished watering the garden Mr Sessions came home just as I got it done."102

Given these events and her own feelings of unhappiness, as well as uncertainty, Patty's decision to pick up her sampler may suggest that it afforded her a sense of agency and a way to gain some control over her surroundings. It also may have allowed her a means of expression for her womanly skills in contrast to those of her husband's younger, less-experienced wife. Indeed, reflecting on her diary entries adds resonance to her choice of verse on the bottom half of her sampler, "The mind should be inured to thought

\footnotetext{
${ }^{101}$ Smart, ed., Mormon Midwife, 19-20, 24, 34.

${ }^{102}$ Smart, ed., Mormon Midwife, 25. When Patty was fifty-five, in 1850, David Sessions died. A year later, at age fifty-six, Patty remarried to John Parry (1789-1868). Smart, ed., Mormon Midwife, 25.
} 
/ the hand in skilful labours taught / Let time be usefully employed..." Perhaps she sought to be inured to jealous thoughts about her husband's second wife, and to protect herself from these thoughts. And, by stitching her sampler, she was "usefully employed." Indeed, Laurel Thatcher Ulrich has suggested that a need for a diversion may have contributed to Patty's actions. ${ }^{103}$

Many of the samplers and quilts described here, such as the one by Patty Sessions, can be considered as "life reviews." Psychiatrists have found that the life review is a naturally-occurring universal process in western societies as aging people remember past experiences and unresolved conflicts, attempting to complete them before they die. ${ }^{104}$ This is not just a modern-day phenomenon; historians of aging have been able to identify the same process in the writings of eighteenth and nineteenth century men and women. Susan Stabile's study of a group of aging Philadelphia female friends in the late eighteenth and early nineteenth century found that these women each engaged in "gather[ing], sort[ing] and integrat[ing] the moments of their lives." And, as they did so, they created and preserved objects, like commonplace books, that embodied memories that "might otherwise remain dormant or forgotten."105 Likewise, a study of published life narratives from the eighteenth and nineteenth centuries suggests that "writing a life narrative aided in the reframing of the past, expanded the consciousness of self, and prepared the individual for a new future." ${ }^{106}$ Stitching an autobiographical or epistolary sampler or quilt, which required similar repetitive motions to writing, and offered the

\footnotetext{
${ }^{103}$ Ulrich, Age of Homespun, 405.

${ }^{104}$ Robert N. Butler, "The Life Review: An Interpretation of Reminiscence in the Aged," Psychiatry 26 (February 1963): 65-66. Butler found allusions to the life review process all the way back to Aristotle. See also Thomas R. Cole, The Journey of Life: A Cultural History of Aging in America (Cambridge: Cambridge University Press, 1992), 38; Alfred F. Young, The Shoemaker and the Tea Party: Memory and the American Revolution (Boston: Beacon Press, 1999), 12.

${ }^{105}$ Stabile, Memory's Daughters, 133-134.

${ }^{106}$ Sobel, Tell Me Dreams, 4.
} 
chance to reflect on the words as they were stitched, provided aging women the same outlet.

In contrast to Patty Sessions, who picked up a half-finished sampler, Ruth Pierce Croswell (1765-1862) started a fresh sampler in 1827 when she was sixty-three (figure 2.12). ${ }^{107}$ Stitched in two shades of blue thread on a bleached piece of linen fabric, Croswell began her sampler with four traditional sampler alphabets. The bottom half of the sampler provides some rather untraditional commentary. "Ruth Croswell Marked this in the 63 year of her age 1827," it begins, as “A Present for Elisabeth L. Wey and may she like Elisabeth of old walk in all the commandments and ordinances of the Lord blameless." A second inscription reads "While prudence guards the lovely fair / From mans deceptive flattering snare / May modesty in outward mien / Bespeak the virtuous mind within." The sampler continues with numbers one through ten, and then carries this genealogical information: "Ruth Pierce born February 22, 1765 was married to Thomas Croswell July 18 1791." The sampler concludes with three rows of stitching that were added well after Croswell stitched the sampler in 1827 - indeed, at least one of the rows was stitched after her death in 1862 since it documents that date. These rows read, "Dr C Died Jan 161844 aged 76. Elisabeth L. Wey Died Feb 10 1845. Ruth Croswell Died January 7 1862."

Ruth Pierce was born on February 22, 1765, in Litchfield, Connecticut. ${ }^{108}$ During her childhood Litchfield was a busy town, located at a transportation hub and known for

\footnotetext{
${ }^{107}$ The sampler is now in the collection of the Litchfield Historical Society, Litchfield, Connecticut. I would like to thank the Historical Society's former curator of collections, Jeannie A. Ingram, for assisting me with access to the sampler and its curatorial file in July 2005.

${ }^{108}$ Catherine Keene Fields and Lisa C. Kightlinger, eds., To Ornament Their Minds: Sarah Pierce's Litchfield Female Academy 1792-1833 (Litchfield, Connecticut: The Litchfield Historical Society, 1993), 21. Ruth was the daughter of John Pierce (d. 1783) and Mary Paterson (d. 1770). John Pierce was a farmer
} 


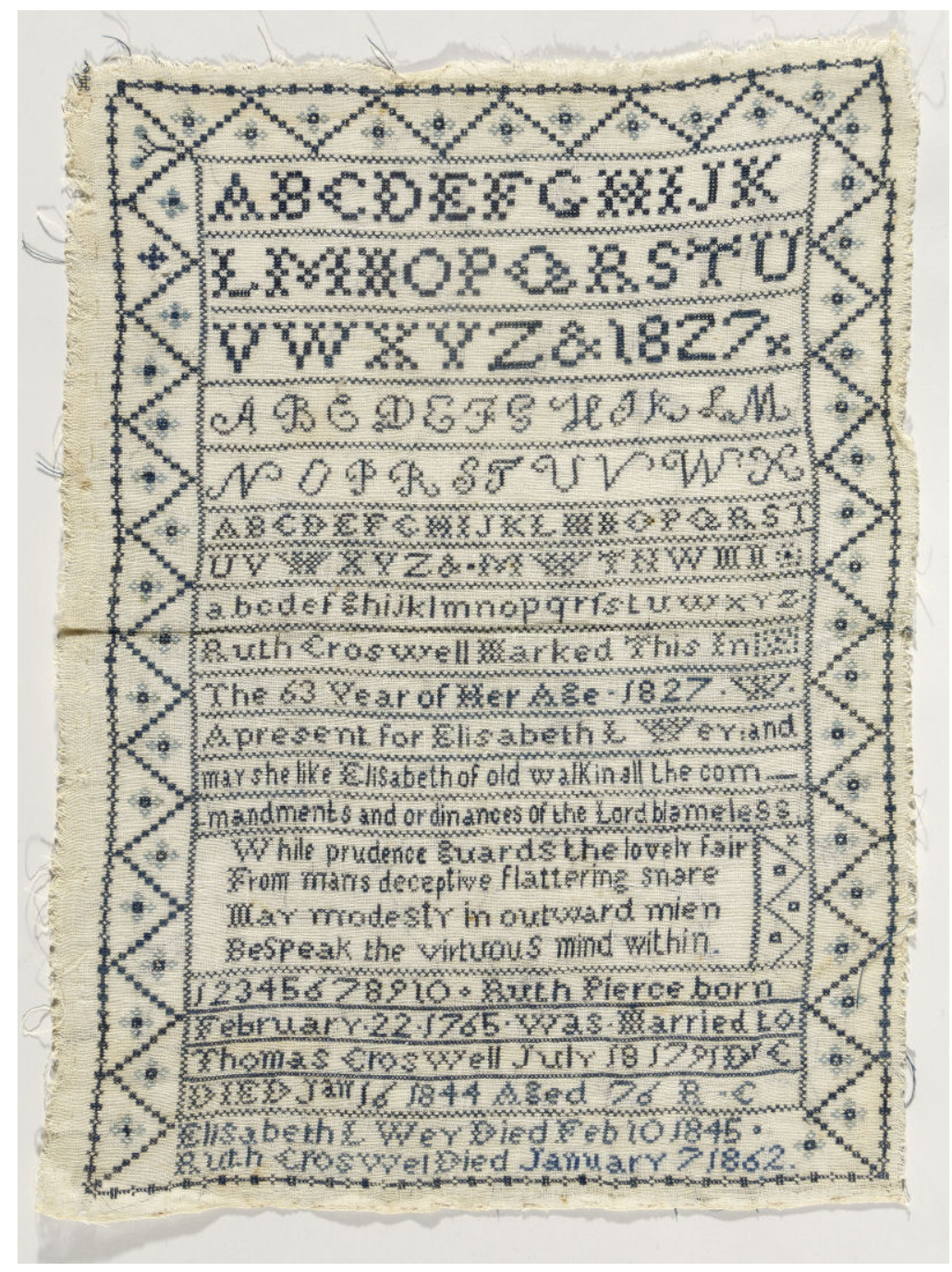

Figure 2.12. Sampler by Ruth Pierce Croswell (1765-1862), 1827, Catskill, New York. Collection of the Litchfield Historical Society, Litchfield, Connecticut.

Verses:

Ruth Croswell marked this in the 63 year of her age. 1827 A present for Elisabeth L. Wey and may she like Elisabeth of old walk in all the commandments and ordinances of the Lord blameless.

While prudence guards the lovely fair, From mans deceptive flattering snare, May modesty in outward mien, Bespeak the virtuous mind within.

Sixty-three-year-old Ruth Pierce Croswell stitched this sampler as a gift for her young granddaughter. Unfortunately, Ruth's granddaughter, Elisabeth Wey, died in 1845 at age twenty-one. Croswell kept the sampler and another family member eventually added the date of Ruth's death along the bottom.

and a potter. In 1770, when Ruth was five, her mother died. Two years later, in 1772, her father married a second time to Mary Goodman. Fields and Kightlinger, eds., To Ornament Their Minds, 21. 
its cultured and educated residents. ${ }^{109}$ Ruth's younger sister, Sarah (1767-1852), would grow up to found the Litchfield Female Academy, which provided a well-rounded education for hundreds of girls and young women during the early decades of the nineteenth century. Sarah Pierce privileged academic accomplishments over the ornamental but realized that she had to provide instruction in needlework and other fancy arts in order to attract students. However, she insisted that needlework be accompanied by reading aloud or serious conversation. One of Pierce's students wrote to her sister in 1802 that Pierce did "not allow anyone to embroider without they attend to some study for she says she wished to ornament their minds when they are with her.",110

Although Ruth did not become a teacher like Sarah, she seems to have shared Sarah's belief in combining needlework with intellectual and moral purposes. One obituary attests to Ruth's quiltmaking skills, describing a particularly special quilt that she made as "the crown of her industry." According to this source, "she called it "The Valley of the Mississippi.' The river, with its winding courses, was of white cotton cloth and ran through the middle of the covering. On either side the region which could be called Christian was represented by blocks of bleached muslin; the region just opening to

\footnotetext{
${ }^{109}$ Fields and Kightlinger, To Ornament Their Minds, 20. In addition, the town was home to Tapping Reeve's Litchfield Law School, the first formal school of law in the United States, established in 1784. In 1776 and 1777, when Ruth was twelve, she attended a school held by Ashbel Baldwin, a graduate of Yale and later an Episcopal minister in Litchfield. While New England girls often had the opportunity to attend school, suggested by the high literacy rates in the region for men and women alike, few had the kind of education offered in this setting. Ruth was able to attend school with boys from the community and take classes in the sciences, beyond basic reading and writing, as well as the ornamental subjects, offered at most female schools and academies at this time. Fields and Kightlinger, To Ornament Their Minds, 22.

${ }^{110}$ Letter from Nancy Hale to Hannah Hale, September 1802, quoted in Fields and Kightlinger, To Ornament Their Minds, 52.
} 
the Gospel by blocks of gray muslin; and the region still in heathen darkness by blocks of black cambric." 111 The religious symbolism that Croswell planned into her quilt suggests that she did not use only her sampler to express her opinions and ideals.

She also valued her connection to American history. Ruth's brother, John Pierce (1752-1788), served as the Army's paymaster during the American Revolution and developed a friendship with George Washington (1732-1799). In addition, John's wife's father was a physician who treated Washington in New York City, strengthening the social bonds between the families. During a 1789 visit to her brother's in-laws, Ruth was able to attend the inauguration festivities for Washington and, on another visit, she took tea with the Washington family. Reportedly, Ruth "remembered vividly to her last days the majestic form of [Washington] on whom so many and such vast hopes then centered, as he stepped forth upon the balcony of the old federal hall in New York... and...took the solemn oath to faithfully administer the constitution and the laws of these United States." 112 Family reminiscences suggest that Ruth Croswell held these memories dear throughout her life, retelling them from time to time to her friends and family. ${ }^{113} \mathrm{Her}$

\footnotetext{
${ }^{111}$ Frazer F. Hilder, "The Croswells of Catskill," unpublished typescript, 22, Vedder Research Library, Greene County Historical Society, Coxsackie, New York. Unfortunately, the current location of this quilt is unknown.

${ }^{112}$ Emily Noyes Vanderpoel, Chronicles of a Pioneer School From 1792-1833 (Cambridge: The University Press, 1903), 327; Hilder, "The Croswells of Catskill," 21. In 1783, when Ruth was eighteen, her father died. Her older brother, John, who was thirty-one years old at the time, took responsibility for his siblings. John Pierce entered the continental army in 1775 and rose through the ranks, achieving the rank of Colonel along with the job of paymaster general in January 1781. On July 18, 1791, Ruth Pierce married Thomas O'Hara Croswell (1767-1844) in Litchfield, Connecticut. Thomas was born on November 6, 1767 to Caleb Croswell (1733-1806) and Hannah Kellogg (d. 1829), probably in West Hartford, Connecticut. Thomas was a physician and after their first year of marriage, the couple moved to Catskill, New York where Thomas eventually became known as the community's beloved "Uncle Doctor." James D. Pinckney, Reminiscences of Catskill (Catskill: J.B. Hall, 1868), 19; Vanderpoel, Chronicles, 328; Hilder, "The Croswells of Catskill," 14, 16.

${ }^{113}$ Vanderpoel, Chronicles, 326; Hilder, "The Croswells of Catskill," 20. Ruth and Thomas Croswell did not have any children of their own. However, they adopted one daughter, Caroline Stanley (1796-1881). She was born in Fort Montgomery, New York in 1796, the daughter of Rufus Stanley (1767-1801) and Lydia Collins (1772-1801). Lydia Collins Stanley was born in 1772 in Litchfield, seven years after Ruth was born in 1765, so it is possible that Ruth Croswell knew Lydia and her family during her girlhood in
} 
sampler and the story of her attendance at Washington's inauguration help us to

understand Ruth Pierce Croswell as a woman who was proud of her family and her own achievements and suggest her desire to be remembered as a model by her children and grandchildren.

Ruth Pierce Croswell stitched a message to her three-year-old granddaughter, Elisabeth Wey (1824-1845), in the 1827 sampler, literally spelling out virtues she hoped Elisabeth would cultivate, as well as a prescription for her actions. "May she like Elisabeth of old walk in all the commandments and ordinances of the Lord blameless," Ruth hoped. "Elisabeth of old" refers to the biblical story of the mother of John the Baptist. After suffering barrenness for years, she found herself with child, because she "walked in all the commandments of the Lord blameless."114 This biblical reference was often included in nineteenth-century obituaries, serving as a high form of praise for those who lived Christian lives and were considered to be virtuous by their neighbors. Women also used the phrase in their diaries and letters to encourage themselves, as well as friends and relatives, to live up to the model provided by the biblical story. ${ }^{115}$ The story, and

Connecticut. Caroline Stanley's parents died within weeks of each other in 1801 and Caroline was adopted by the Croswells. Caroline Stanley married William Wey (d. 1856) in 1815. Wey was a druggist and, after he married Caroline Stanley, he took over running the pharmacy that Thomas Croswell started in the mid1790s. Among the couple's ten children was a daughter named Ruth Croswell Wey (b. 1820) and a son named Thomas Croswell Wey (b. 1822). In addition, the couple were parents to Elisabeth L. Wey, who is prominently referenced on Ruth Croswell's sampler and was Ruth's granddaughter. She was born on October 2, 1824, and was just three years old when the sampler was made. J.V.V. Vedder, Historic Catskill (Catskill, 1922), 66-67; Hilder, "The Croswells of Catskill," 16; www.ancestry.com, accessed July 9, August 5 and October 22, 2007.

${ }^{114}$ Luke 1:6 (King James Bible).

${ }^{115}$ See the letter from Elizabeth Emma Sullivan Stuart (1792-1866) to her daughter, Mary Elizabeth Baker, on December 28, 1858, "to all give a kiss with my hearts fondest love and wishes, and sincere hope that you will all be as happy as "walking in all the commandments of the Lord blameless" can make you," in Helen Stuart Mackay-Smith Marlatt, Stuart Letters of Robert and Elizabeth Sullivan Stuart and Their Children 1819-1864 (New York: privately printed, 1961), 894. See also the diary of Hannah Hobbie for April 13, 1828, where she wrote, "I am often led to cry to God in the language of David, 'Cleanse thou me from secret faults.' O for grace and strength to crucify sin! O that I might walk in all the statutes and ordinances of the Lord blameless," in Robert G. Armstrong, Memoir of Hannah Hobbie, or, Christian Activity, and Triumph in Suffering (New York: American Tract Society, 1837), 72. 
these phrases, offered a goal for women to work toward, but also conveyed accomplishment when they died.

Croswell's sampler included a second verse. "While prudence guards the lovely fair / From mans deceptive flattering snare / May modesty in outward mien / Bespeak the virtuous mind within" is an unattributed verse found on other New England samplers. ${ }^{116}$ However, in Croswell's case, it seems to follow her sister Sarah's ideas about educating girls, encouraging the development of the mind. Croswell may have been providing her granddaughter with additional lessons to learn and goals to reach for as she grew into womanhood.

While many of Ruth Pierce Croswell's generation considered themselves blessed to live to the ripe old age of sixty, she was only beginning her old age when she stitched this sampler at sixty-three in 1827 . On January 16,1844 , when she was seventy-eight, her husband died. Sadly, just over a year later, her granddaughter - and the recipient of her sampler - Elisabeth Wey died on February 10, 1845, when she was twenty-one years old. After her husband's death, Ruth moved into her daughter Caroline's household. ${ }^{117}$ Ruth Croswell died on January 7, 1862 at the extreme old age of ninety-seven. The esteem in which she was held by her community is evident from her obituaries; they report that during her funeral services all places of business were closed in town and that the bells of all of the local churches tolled as her body traveled to the cemetery. ${ }^{118}$

Croswell's sampler, like Elcey Patterson's and Patty Sessions' (and unlike schoolgirl samplers, planned out by a teacher and rigidly stitched with alphabets,

\footnotetext{
${ }^{116}$ Part of this verse is listed in Ethel Stanwood Bolton and Eva Johnston Coe, American Samplers (New York: Dover Publications, 1973), 354.

${ }^{117}$ U.S. Census data for Catskill, New York, 1850, www.ancestry.com, accessed October 2007.

${ }^{118}$ Vedder, Historic Catskill, 66.
} 
approved verses, motifs and floral border) shows the intent of its maker. She chose to present her story, she decided how to tell it and what to say. Her needle gave her the agency to tell her own story and to represent her life as she saw fit. ${ }^{119}$ The sampler also recorded evidence of her life - of her existence - to remind others once she passed that she had lived. Although young Elisabeth did not outlive her grandmother, the sampler continued its own life. Decades after it was initially stitched in 1827 the death dates of its recipient, its maker's husband and its maker were included along the bottom by an anonymous hand. The sampler was passed down in the extended family until 1949 when it was given to the Litchfield Historical Society. ${ }^{120}$

\section{Memorial Needlework: Keeping the Family Alive}

Perhaps the largest sub-type of biographical needlework is memorial - objects made to remember a loved one, or to venerate their maker. Family record samplers, like the one by Esther Banister Richards that opened this chapter, may be the most common example of this genre of needlework. These samplers are a type of decorative needlework that became popular during the early republic period, roughly from 1785 to 1840. They were inspired by some of the social changes taking place for American families. The size and composition of the family was decreasing, as the nuclear family started to become the standard unit. Families also began to experience increasing levels of privacy as domestic space allowed more room for individuals and as home life became separate from public life. In time, the family, rather than the community, served as the

\footnotetext{
${ }^{119}$ Maureen Daly Goggin, “One English Woman's Story in Silken Ink: Filling in the Missing Strands in Elizabeth Parker's Circa 1830 Sampler,” Sampler and Antique Needlework Quarterly 8 (Winter 2002): 47. ${ }^{120}$ Curatorial file, Litchfield Historical Society, Litchfield, Connecticut.
} 
center of emotional and economic support. These changes led to an increased interest in genealogy and in creating and displaying family records. ${ }^{121}$

Needlework family records were often made by schoolgirls; hundreds have been published in catalogs of schoolgirl needlework. One study found that the majority were made by the oldest or youngest daughter in the family. ${ }^{122}$ Many are a snapshot in time partially filled in with birth, marriage and death dates at the time the sampler was initially stitched. However, others were filled in more completely over subsequent decades. These examples fit the category of biographical needlework since they acted as "vehicles for bringing past time into the present."123 They show that families had an interest in maintaining a visible record of their history, enhancing their function as biographical objects. $^{124}$

Dorothy Knight (1803-1854) of Phillipston, Massachusetts, was fourteen in 1817 when she initially stitched her family record sampler (figure 2.13). ${ }^{125}$ It has a classic floral border and includes a house along the bottom along with stylized drapery at the top. Dorothy stitched "Family Record" at the top and divided the body of the sampler into columns headed "Names," "Births," and "Deaths." The lives of her parents and siblings are neatly represented. In 1817 she stitched their names and birth dates. At a later time, the death date for each family member was added, including that of Dorothy herself who passed away at the age of fifty on September 8, 1854. Indeed, even after Dorothy's death, additional dates were added to the sampler: her brother Rufus's death in 1855;

\footnotetext{
${ }^{121}$ Allen, Family Record, 1-3. See also Peter Benes, "Decorated New England Family Registers," in The Art of Family, ed. Simons and Benes, 13-59; and Georgia Brady Barnhill, "'Keep Sacred the Memory of Your Ancestors': Family Registers and Memorial Prints," in The Art of Family, ed. Simons and Benes, 6074.

122 Allen, Family Record, 4.

${ }^{123}$ Weiner, "Inalienable Wealth," 210.

${ }^{124}$ Allen, Family Record, 7.

${ }^{125}$ The sampler is now in the collection of Old Sturbridge Village, Sturbridge, Massachusetts.
} 


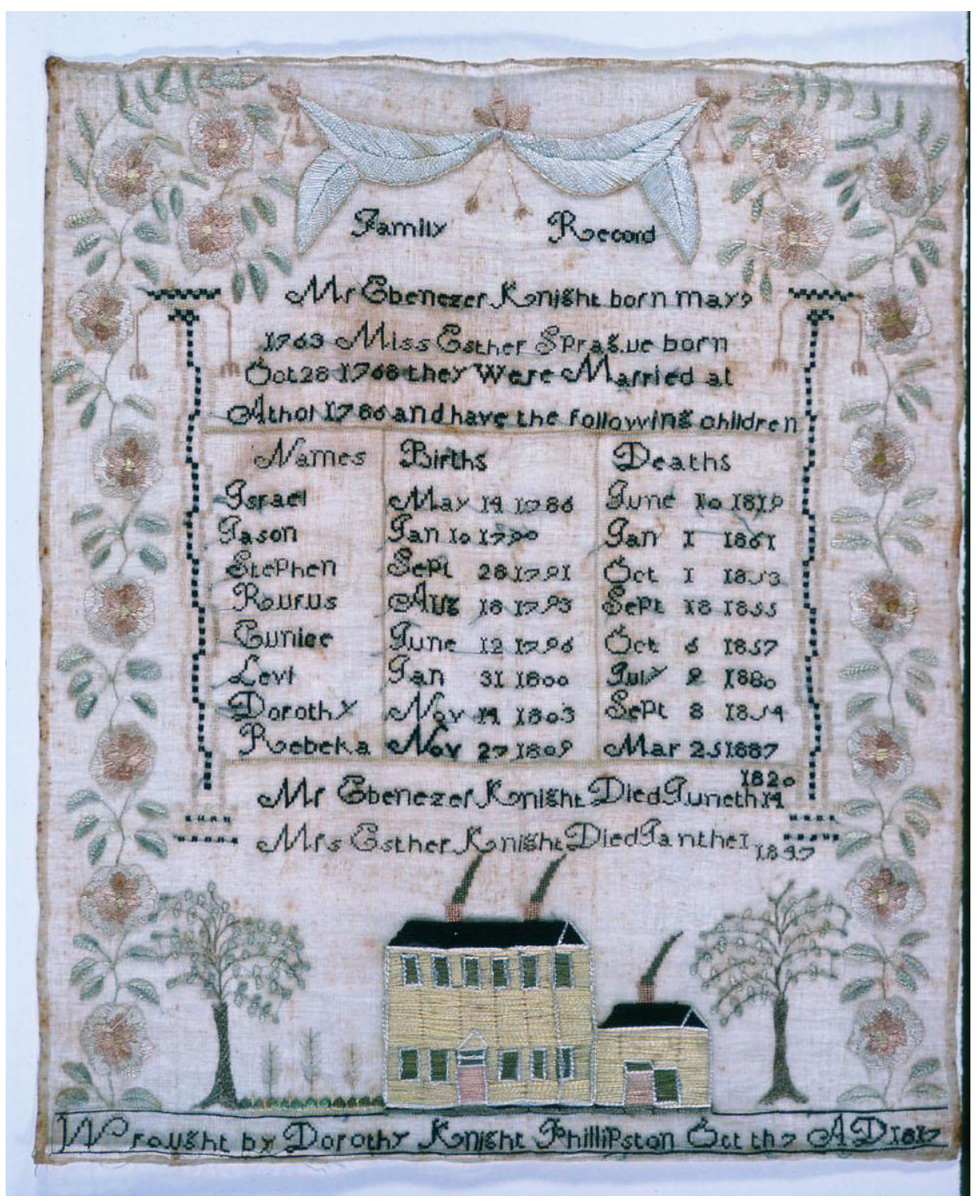

Figure 2.13. Family Record Sampler by Dorothy Knight (1803-1854), 1817, Phillipston, Massachusetts. Courtesy of Old Sturbridge Village, Sturbridge, Massachusetts, 64.1.108. Photograph by Henry Peach.

Dorothy Knight initially stitched her family record sampler in 1817 when she was fourteen. Over the next several decades, Dorothy, or another family member, added to the sampler, recording the death dates of her siblings, and even of Dorothy herself. 
sister Eunice's death in 1857; brothers Jason and Levi in 1861 and 1880, respectively; and, finally, sister Rebekah's passing in 1887 was recorded, seventy years after the sampler was initially stitched. By looking closely at the sampler, it appears that these later dates were added at two points in time, if not more; the color and density of the thread for these entries is visibly different.

Knight's sampler, like the others discussed here, is the result of intergenerational collaboration. She created a document that (by the work's definition) she knew she could not finish. At least one person from a later generation was implicit in the creation of this sampler, if only to add the creator's death date. ${ }^{126}$ Margaretta Lovell proposes that, in eighteenth-century America, portraits were "deeply embedded in issues of memory, history and family context," that even while the canvas was still wet, the portrait was "an object intended for insertion within a three-generation ensemble of eloquent similar objects." ${ }^{, 27}$ Lovell was writing specifically about a circa 1770 portrait of Joshua Henshaw (1703-1777) by John Singleton Copley (1738-1815), which she saw as a bridge from his father-in-law's generation to Henshaw and then to the Henshaw children, all memorialized in paint on canvas. But, the needlework artifacts examined here could be said to fulfill the same functions for the antebellum women who stitched them. Chapter 4 explores gift needlework, which often reminded the recipients of their responsibility to carry forward the memories and achievements of past generations, but the family record samplers discussed here took this responsibility a step further. They do not simply

\footnotetext{
${ }^{126}$ I am indebted to Marla R. Miller for sharing her thoughts about this action - and its meaning - with me.

${ }^{127}$ Lovell, Art in a Season of Revolution, 117. See also Robert B. St. George, Conversing By Signs: Poetics of Implication in Colonial New England Culture (Chapel Hill: University of North Carolina Press, 1998), 11, 326-335, 364-371, 376-377.
} 
transmit family information, they enlist the next generation in completing them, requiring physical action to bring the memories forward.

Although aging women were counseled by their church and their society to seek resignation about the passage of time, in light of the prospect of eternal happiness after death, they still tried to exert some control over it. In her study of letters and diaries kept by aging American women between 1785 and 1835, historian Terri Premo proposed that women recorded family data as one way of coping with growing older. ${ }^{128}$ Keeping family records enabled women to have some agency in the aging process. Tracking family records was considered a woman's task, perhaps as a reflection of her role as a life-giver, so it is not surprising that so many women turned to needlework as one means by which to accomplish that work. ${ }^{129}$ Putting these records on paper or cloth provided a sense of permanence for the women by allowing them to mark their own place in time. ${ }^{130}$ Deborah Logan (1761-1839) noted her motivation to observe the "anniversaries of Births and Deaths of those I love... They seem like watch words to awaken long trains of ideas and call up tender feelings and affections." ${ }^{131}$ Perhaps the most obvious example of how "family chauvinism" could motivate, family records offered a decorative way to show the family's history for all to see, centrally located on the wall of the parlor. These objects provided the added value of not only demonstrating the maker's skill, but the family's very existence. $^{132}$

\footnotetext{
${ }^{128}$ Premo, Winter Friends, 138.

${ }^{129}$ Aafke E. Komter, Social Solidarity and the Gift (New York: Cambridge University Press, 2005), 87-88; Lovell, Art in a Season of Revolution, 134; Allen, Family Record, 32; Laurel Thatcher Ulrich, "Creating Lineages," in The Art of Family, eds. Simons and Benes, 9-11; Thomas, Entangled Objects, 30.

${ }^{130}$ Ulrich, The Age of Homespun, 117.

${ }^{131}$ Logan's diary, vol. 12, p. 109, quoted in Stabile, Memory's Daughters, 133.

${ }^{132}$ In addition to family record samplers, embroidered family coats-of-arms, popular during the late eighteenth century and early nineteenth century, were also ideal for the expression of "family chauvinism." Coats-of-arms originated in England to signify those families that were part of the aristocracy. They were
} 
The urge to keep track of family births and deaths seems to have driven some families to add this information to samplers that were not initially stitched in the family record format. A sampler made by Sarah Holmes (1793-1842) includes the year she completed it - 1801 (figure 2.14). ${ }^{133}$ Along the bottom, above the original signature, an unidentified person supplemented the sampler after Holmes's death by stitching "Died 1842." Over to the left, along the same row, the same hand stitched Holmes's birth year, "Born 1793," so that we know she originally made it when she was eight (figure 2.15). This sampler retained value for the family. It was passed down and given to the NewYork Historical Society in 1968 by the maker's great-granddaughter. ${ }^{134}$

While there are many extant family record samplers to study - both completed and incomplete - only a few "family record quilts" have been found. Making a quilt and giving it to her granddaughter in 1846 offered sixty-one-year-old Mary Rooker Norris (1785-1868) a way to receive recognition for her skill and accomplishments and to embed cherished values in the object (figure 2.16). ${ }^{135}$ She was also leaving a piece of herself behind. She created her family in fabric, piecing together her relations in the top of her quilt, which includes a record of her family's births, marriages and deaths

embraced in the colonies and often used whether the family was entitled to them or not. For more on coatsof-arms, see Betty Ring, Girlhood Embroidery: American Samplers and Pictorial Needlework 1650-1850 (New York: Alfred A. Knopf, 1993), 60-61; Swan, Plain and Fancy, 184; and Betty Ring, "New England Heraldic Needlework of the Neoclassical Period," The Magazine Antiques 144 (October 1993): 484-493.

${ }^{133}$ The sampler is now in the collection of the New-York Historical Society, New York, NY. I am indebted to Collections Manager David Burnhauser for facilitating my visit in August 2005 to see the sampler and for sharing the file on the sampler. Sarah Holmes was born in New Jersey and married Ralph Mead (17891866) in October 1813. The couple had six children, four daughters and two sons. Curatorial file, NewYork Historical Society, New York, NY; additional genealogical information from www.ancestry.com, accessed November 25, 2007.

${ }^{134}$ Curatorial file, New-York Historical Society, New York, New York.

${ }^{135}$ The quilt is now in the collection of the Daughters of the American Revolution Museum, Washington, D.C. I am indebted to Alden O'Brien, curator of costume and textiles for sharing the curatorial file on this quilt during site visits in June 2006 and June 2009. The quilt is made with block- and roller-printed fabrics. It is bound with green and white woven tape. 


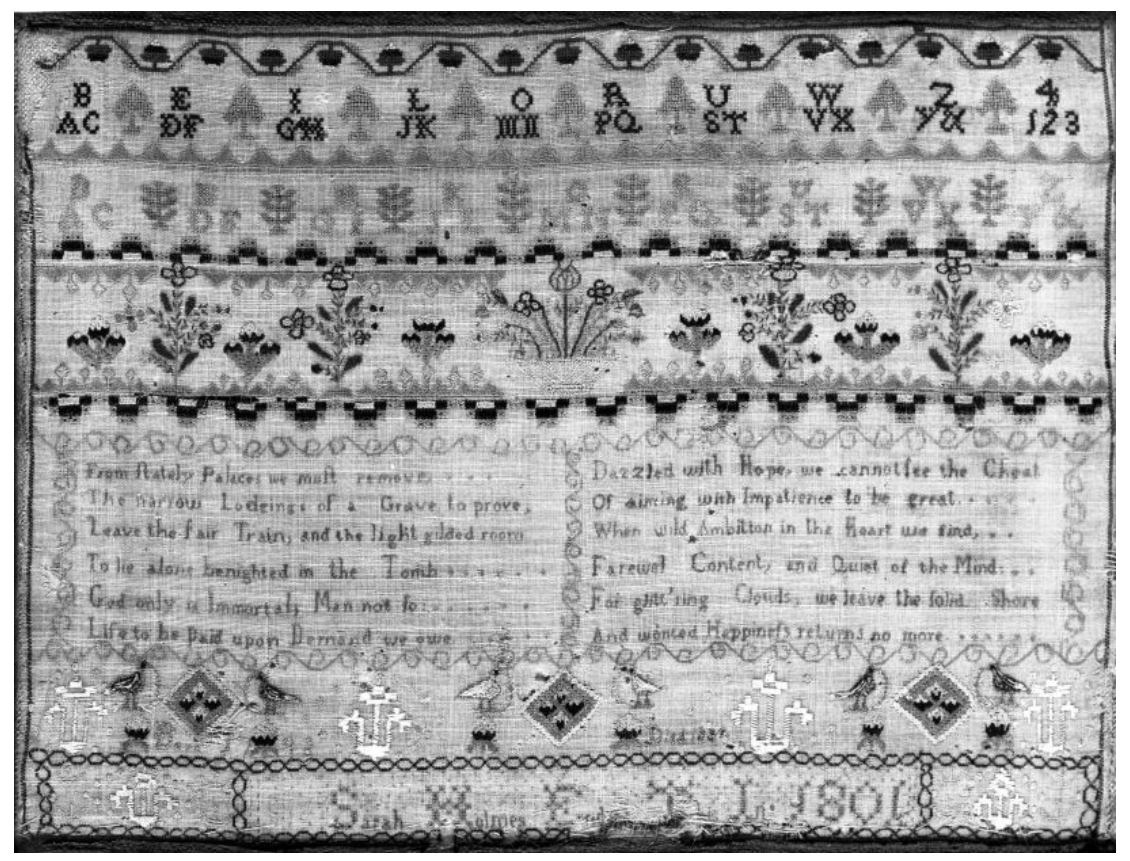

Figure 2.14. Sampler by Sarah Holmes (1793-1842), 1801, New Jersey. Collection of the New-York Historical Society, 1968.45.

\section{Verses:}

From stately palaces we must remove, The narrow lodgings of a grave to prove, Leave the fair train and the light gilded room, To lie alone benighted in the tomb, God only is immortal, Man not so, Life to be paid upon demand we owe.

Dazzled with hope, we cannot see the cheat, of aiming with impatience to be great, When wild ambition in the heart we find, Farewel content, and quiet of the mind, For glitt'ring clouds, we leave the solid shore, And wonted, happiness returns no more.

Although difficult to see, someone altered the sampler made by eight-year-old Sarah Holmes. After Sarah's death in 1842, her birth year and death year were stitched above her signature, one year on the left and one on the right.

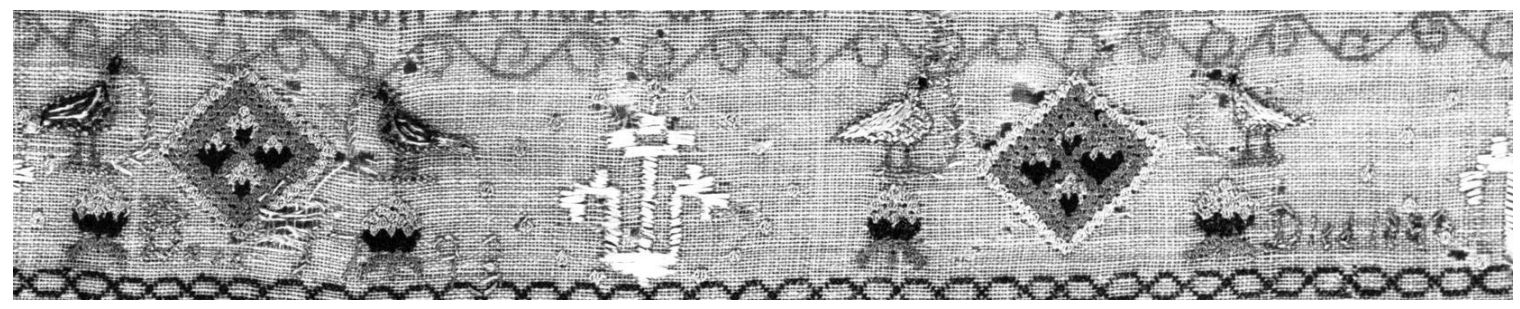

Figure 2.15. Detail of dates added to sampler by Sarah Holmes. 
in the center. Then, just as her family tree had grown, branch by branch, Norris attached a series of rectangular border strips to the sides of her quilt, building it out and making it larger.

The quilt was a gift to the maker's granddaughter, Mary Norris (b. 1845), the daughter of her oldest son, John Saurin Norris (1813-1882). Young Mary was both the first granddaughter and her grandmother's namesake. All three of the elder Mary's children had their first daughters in 1845 and all three were named Mary, presumably in honor of their grandmother. ${ }^{136}$

Mary's quilt provides a wealth of family records. Made in the style known as a medallion quilt, the central medallion section includes Norris's inked family records. Four sections read as follows:

John Saurin Norris / son of / John and Mary Norris / born / Baltimore City / March 251813 / J.S. Norris / and H.T. Tyson / married / in / Philadelphia / June 7 / 1838 / Mary Norris / a memento of / affection / from her Grandmother / Mary Norris Hagerstown, Md. / February 12, 1846 / Isaac T. Norris / born 24 March 1842 / John Olney Norris / born / 11 November 1843 / Mary Norris / born / 4 April 1845 / Henrietta Norris / born / Henrietta T. Norris / daughter of / Isaac and Elizabeth Tyson / born / Baltimore City / Nov. 121809.

These records list the quilt recipient's father and mother by name with their birth dates and marriage date, as well as the names of her maternal grandparents. Her two older brothers are also documented with their birth dates. Her younger sister's name, Henrietta, was added at some point, although her birth date is left blank. Last, but not least, the maker documented herself, inscribing, "Mary Norris a memento of affection from her Grandmother Mary Norris Hagerstown, Md February 12, 1846.”

\footnotetext{
${ }^{136}$ Allen, Family Record, 93. Family information from www.ancestry.com, accessed November 2007.
} 


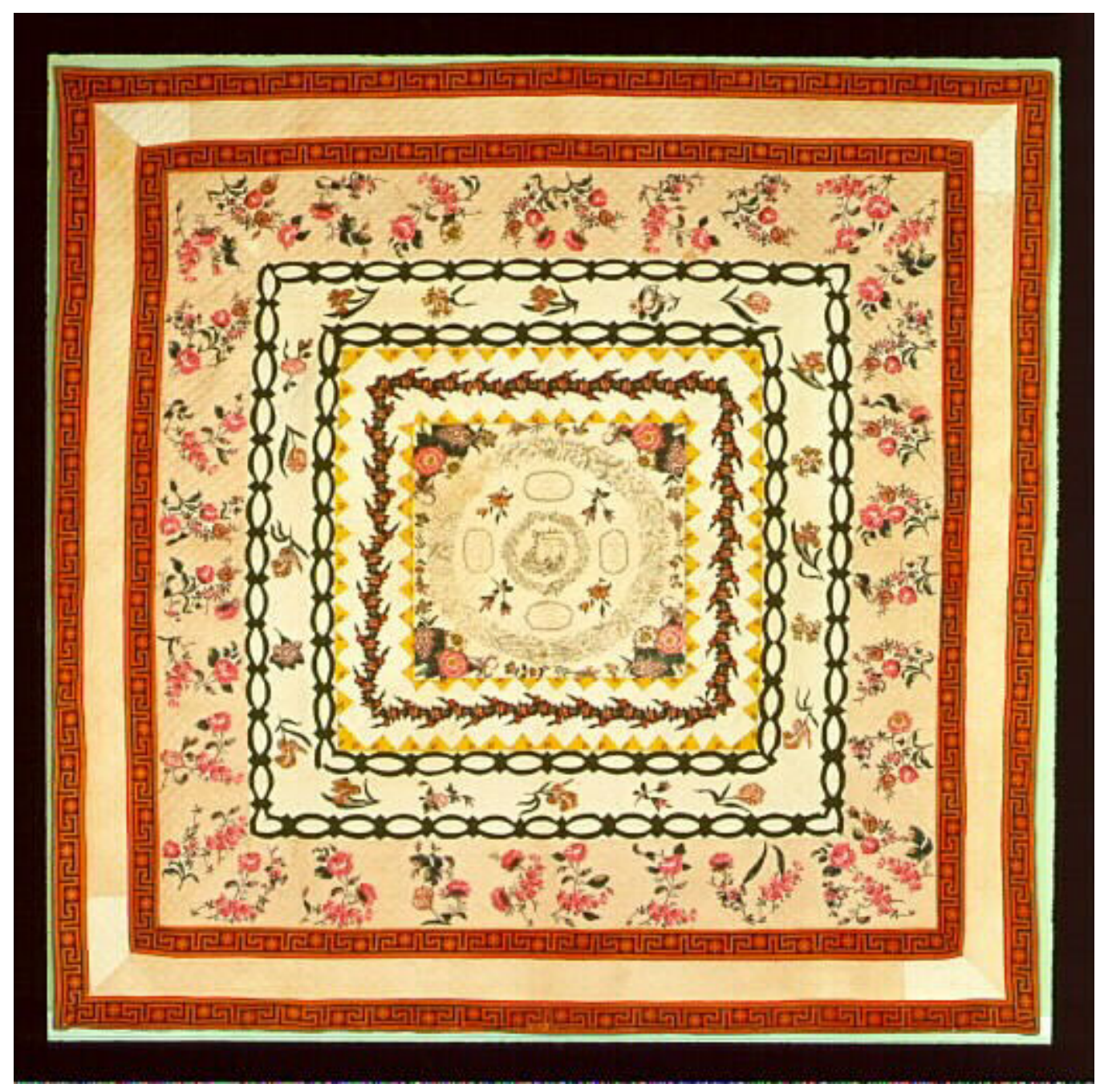

Figure 2.16. Quilt by Mary Rooker Norris (1785-1868), 1846, Hagerstown, Maryland. Courtesy of the Daughters of the American Revolution Museum, Washington, DC.

While family record samplers were quite common during the early nineteenth century, family record quilts are rare. In this example, Mary Rooker Norris inked the birth and marriage dates of her children in the center block and gave the quilt to her granddaughter as a gift. 
Mary Rooker was born in England in 1785, one of twenty-one children of Reverend James Rooker (1756-1828) and Mary Berry (1762-1814). ${ }^{137}$ Being part of such a large family may have influenced her choice to make a family record quilt. She had many family dates to keep track of and had to find her own identity among so many brothers and sisters.

After her husband died in 1829, Mary taught at a seminary for young ladies run by two of her sisters. In 1830, they advertised that "Mrs. Norris, whose talents as a Teacher will be remembered by many, has returned to the city, and will resume her station in the Institution." Given the skill and artistry of the inscriptions inked on her quilt sixteen years later, it seems likely that this was one of the skills she taught at the ladies' seminary. ${ }^{138}$ When she made this quilt, Mary was living in Hagerstown, Maryland, with her daughter Sarah (1822-1878) and son-in-law Thomas Myers (18131894), a Methodist itinerant preacher. ${ }^{139}$

The medallion style and chintz appliqué technique seen in Norris's quilt are representative of neo-classical style, first made popular after the American Revolution and lasting into the era of the early republic, but dated by $1846 .{ }^{140}$ Classical style does

\footnotetext{
${ }^{137}$ Rooker came to Baltimore in 1807 when she was twenty-two. Four years later, in 1811, when she was twenty-six, she married Baltimore native John Norris (1774-1829), a miller. They had five children between 1813 and 1822; three would survive to adulthood. In 1860, when Mary was seventy-five, she was living with her daughter and son-in-law, Sarah and Thomas Myers, in Baltimore. She had a personal estate valued at $\$ 10,000$, while Thomas owned real estate valued at $\$ 5,800$. Allen, Family Record, 93; Gloria Seaman Allen and Nancy Gibson Tuckhorn, A Maryland Album: Quiltmaking Traditions 1634-1934 (Nashville: Rutledge Hill Press, 1995), 108; Thomas M. Myers, The Norris Family of Maryland (New York: W.M. Clemens, 1916), 33; U.S. Census information from www.ancestry.com, accessed September 16, 2007.

${ }^{138}$ Baltimore American and Commercial Daily Advertiser, January 2, 1830, quoted in Allen and Tuckhorn, A Maryland Album, 108.

${ }^{139}$ Allen and Tuckhorn, A Maryland Album, 108.

${ }^{140}$ Barbara Brackman, Clues in the Calico: A Guide to Identifying and Dating Antique Quilts (McLean, VA: EPM Publications, Inc., 1989), 123, 136; Allen and Tuckhorn, A Maryland Album, 15.
} 
seem to have remained popular in Maryland longer than in some regions. ${ }^{141}$ But, like the gift quilts made by Catherine Marion Palmer and Rachel Smith that will be discussed in chapter 4, this quilt may have employed a dated style in order to underscore its purpose as a family touchstone. The medallion style with borders, particularly when made with English chintz fabrics, like this quilt, may reflect Norris's English roots and could have offered her a certain comfort level. ${ }^{142}$

One of the necessary components on all of these examples of family record samplers and quilts was the column headed "Died." Previous studies have documented the changes in mourning practices that took place during the late-eighteenth and earlynineteenth centuries. In reaction to larger social and cultural trends, mourning ceased to be a community activity and became a personal and familial tradition. ${ }^{143}$ In addition, the soul of the deceased was celebrated with a rising set of romantic sensibilities and activities. New types of mourning objects, like jewelry, prints, ceramics, and posthumous portraits became common as the bereaved tried to recapture what they had lost. ${ }^{144}$ One examination of such objects suggests that "material articles become specially

\footnotetext{
${ }^{141}$ Allen and Tuckhorn, A Maryland Album, 41. The quilt made by Mary Lloyd Key, also in the collection of the Daughters of the American Revolution Museum and discussed in chapter 1, employs a very similar border fabric with a Greek key motif, but dates from an unknown point in the late 1830s or early 1840s.

${ }_{142}$ Allen and Tuckhorn, A Maryland Album, 13.

${ }^{143}$ Ann Douglas, "Heaven Our Home: Consolation Literature in the Northern United States, 1830-1880," in Death in America, ed. David E. Stannard (Philadelphia: University of Pennsylvania Press, 1975), 54-55; Ann Douglas, The Feminization of American Culture (New York: The Noonday Press, 1998), 203, 209210; Kenneth L. Ames, "Ideologies in Stone: Meanings in Victorian Gravestones," Journal of Popular Culture 14 (1981): 641-656; James J. Farrell, Inventing the American Way of Death, 1830-1920 (Philadelphia: Temple University Press, 1980), 4-7.

${ }^{144}$ Martha V. Pike and Janice Gray Armstrong, A Time to Mourn: Expressions of Grief in Nineteenth Century America (Stony Brook, NY: The Museums of Stony Brook, 1980), 26, 40, 43, 71, 81; Stannard, ed., Death In America, passim; Martha Pike, "In Memory of: Artifacts Relating to Mourning in Nineteenth Century America," in Rituals and Ceremonies in Popular Culture, ed. Ray B. Browne (Bowling Green, Ohio: Bowling Green University Popular Press, 1980), 296-306; Blanche Linden Ward, "Strange but Genteel Pleasure Grounds: Tourist and Leisure Uses of Nineteenth-Century Rural Cemeteries," in Cemeteries and Gravemarkers: Voices of American Culture, ed. Richard E. Meyer (Ann Arbor, Michigan: UMI Research Press, 1989), 295, 298.
} 
imbued with the emotions of the people who come into contact with them through mere association or through the process of production and exchange."145

When she was ten, Mary W. Evans (1814-1888) stitched a family record at Miss Balch's School in Providence, Rhode Island (figure 2.17). ${ }^{146}$ Like Dorothy Knight's sampler, the Evans piece employs floral elements and columns. At the top she stitched "A Family Record," and then produced neat columns for the names, births and deaths. Mary was the only surviving daughter in her family, as well as the youngest at the time, which probably contributed to her role as family recordkeeper.

Like the Knight sampler, death dates are meticulously included, including Mary's own in 1888 , over sixty years after she first stitched those columns. When Mary stitched the sampler in 1824 at the age of ten she included all of the birth dates for her family, along with death dates for her father, two sisters and one brother. The sampler may have been a sentimental object for Mary when she made it since her father had died two years earlier while working as a carpenter on board the ship Constellation in Valparaiso, Chile. ${ }^{147}$ Over the next sixty-four years, death dates were added to the sampler for Mary's mother, who died in 1864; her brothers, Albert and Elisha, who died in 1880 and 1886, respectively; and for Mary herself, who passed away on November 7, 1888, at the

\footnotetext{
${ }^{145}$ Mary Louise Kete, Sentimental Collaborations: Mourning and Middle-Class Identity in NineteenthCentury America (Durham: Duke University Press, 2000), 53.

${ }^{146}$ The sampler is now in the collection of Winterthur Museum and Country Estate, Delaware. I am indebted to Linda Eaton, Curator of Textiles at Winterthur, for showing me this sampler and for sharing its curatorial file. The Balch School is one of the best-known New England needlework schools from the late eighteenth and early nineteenth centuries. Mary Balch (1762-1831) founded her school in Providence in the early 1780s and taught generations of young women until her death in 1831. The best-known samplers from the Balch school depict identifiable public buildings in Providence and have elaborate floral borders. See Glee Krueger, New England Samplers to 1840 (Sturbridge: Old Sturbridge Village, 1978), 21; Ring, Girlhood Embroidery, 179.

${ }^{147}$ Vital Record of Rhode, Island, 1636-1850. (Online database: NewEnglandAncestors.org, New England Historic Genealogical Society, 2002), (Orig. Pub. Narragansett Historical Publishing Company Providence, RI. James N. Arnold, Vital records of Rhode Island 1636-1850: First Series: births, marriages and deaths: a family register for the people, 21 vols., 1891).
} 


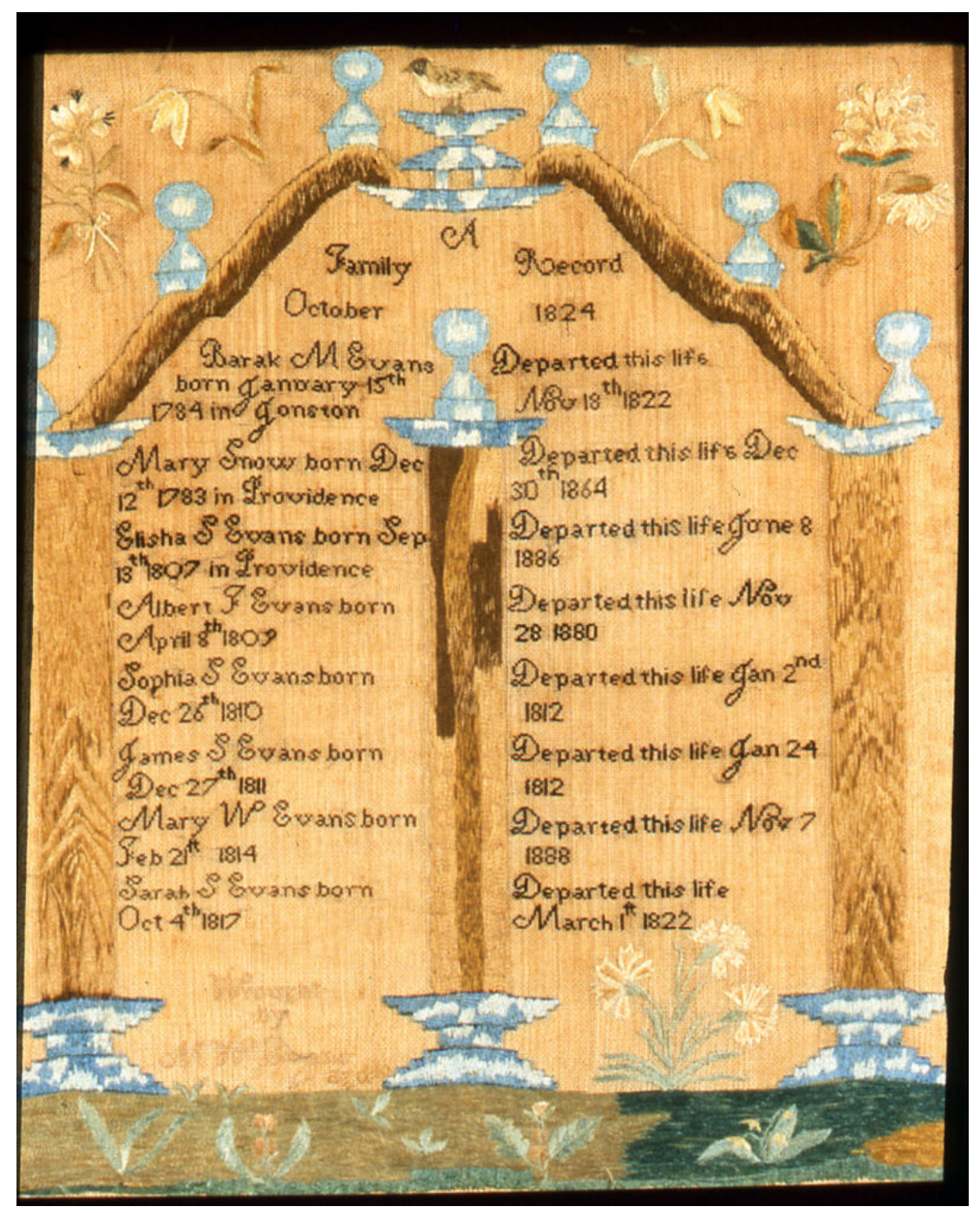

Figure 2.17. Family Record Sampler by Mary W. Evans (1814-1888), 1824, Providence, Rhode Island. Collection of Winterthur Museum and Country Estate, Delaware.

Like Dorothy Knight, Mary W. Evans initially stitched her family record sampler as a young girl. Over the next sixty-five years, Evans, or another relative, continued to update the sampler, adding the death dates of Mary's siblings, and eventually, of Mary herself. The sampler was passed down in Mary's family until 1988, when it was donated to Winterthur Museum and Country Estate. 
age of seventy-four. These additions are discernible because of the thread used to stitch them, which is a different color. ${ }^{148}$

While the line of descent for the Knight family record has been lost, the Evans family record sampler traveled through four generations of the family until it was donated to Winterthur Museum and Country Estate in 1988. Mary W. Evans married Benjamin Cornell (b. circa 1812) around 1833 when she was nineteen. The sampler passed to Mary’s youngest daughter, Laura Cornell (b. circa 1851), after Mary's death. Laura Cornell married Henry S. Easton (b. circa 1846), and they had a son, Walter (b. 1878). The sampler eventually passed to Mary's great-granddaughter, Walter's daughter and namesake for his mother, Laura Easton (b. circa 1906). She presented the sampler to the museum, a century after its maker's death. ${ }^{149}$

The Evans and Knight family record samplers are particularly interesting because they were made by young girls who then kept them close for the rest of their lives and updated them, demonstrating that they fulfilled functions of identity and expression for their makers for decades. Other completed family records were filled in decades after the maker passed away, showing the value they held for the maker's family as a memorial. The maker died, but the sampler lived on.

For example, a family record initially made by Frances Fales (1794-1824) when she was thirteen in 1807 was filled in for decades after she died at the age of thirty in

\footnotetext{
${ }^{148}$ Although it is difficult to tell for sure, it appears that the death date for Mary's mother was added in 1864, possibly by Mary herself, and then the death dates for Mary and her two brothers, all in the 1880s, were added together after her death in 1888 by a different family member. The 1864 date is stitched with a slightly different color thread than the dates from the 1880s, which are stitched in the same color.

${ }^{149}$ Like Mary's father, her husband, Benjamin Cornell, worked as a ship carpenter and, later, as a roofer. The couple had six children. Information on the sampler's family descent comes from the curatorial file, Registrar's Office, Winterthur Museum and Country Estate; the family information is compiled from U.S. Census Records available on www.ancestry.com, accessed October 2007.
} 
1824 (figure 2.18). ${ }^{150}$ When Frances made the sampler in 1807 , she filled in birth dates for her parents and all eleven of her older siblings. She also included her father's death in 1806 and the death dates for four of her siblings who died prior to 1807 . One date from the period between the sampler's initial stitching in 1807 and Frances's death in 1824 was added; the death of Frances's older sister, Harriot, on August 19, 1817. While it is possible that this date was added after Frances died, the thread does not match other dates added later, so it is possible that Frances herself updated the sampler as she grew. Frances died in 1824 and her death date is recorded in the proper column, while death dates for her mother and three additional siblings - in 1845, 1853, 1854, and 1857 - were also recorded long after Frances's death. These four entries are stitched in thread that is a different color from the earlier dates but identical to one another suggesting that they may have been added together.

Filling in the family record sampler over many decades offered one way to sustain a prolonged connection with its maker. This act was also a way to teach the rising generation about relatives who had passed on, encouraging them to cultivate an understanding of family history. It may have offered tangible support for the extended family, reassuring its members of their ancestry and reminding them of their place in history and in their community. In her study of eighteenth-century American portraiture, Margaretta Lovell suggests that family portraits served as "active visual admonishments." They were not simply a form of wallpaper in the family home, but engaged subsequent generations, drawing them backward to memories and their family history, as well as forward to their destiny as more than just individuals, rather as part of a long family

\footnotetext{
${ }^{150}$ The sampler is in a private collection. See M. Finkel and Daughter, Samplings 2 (1992): 10 for an illustration.
} 


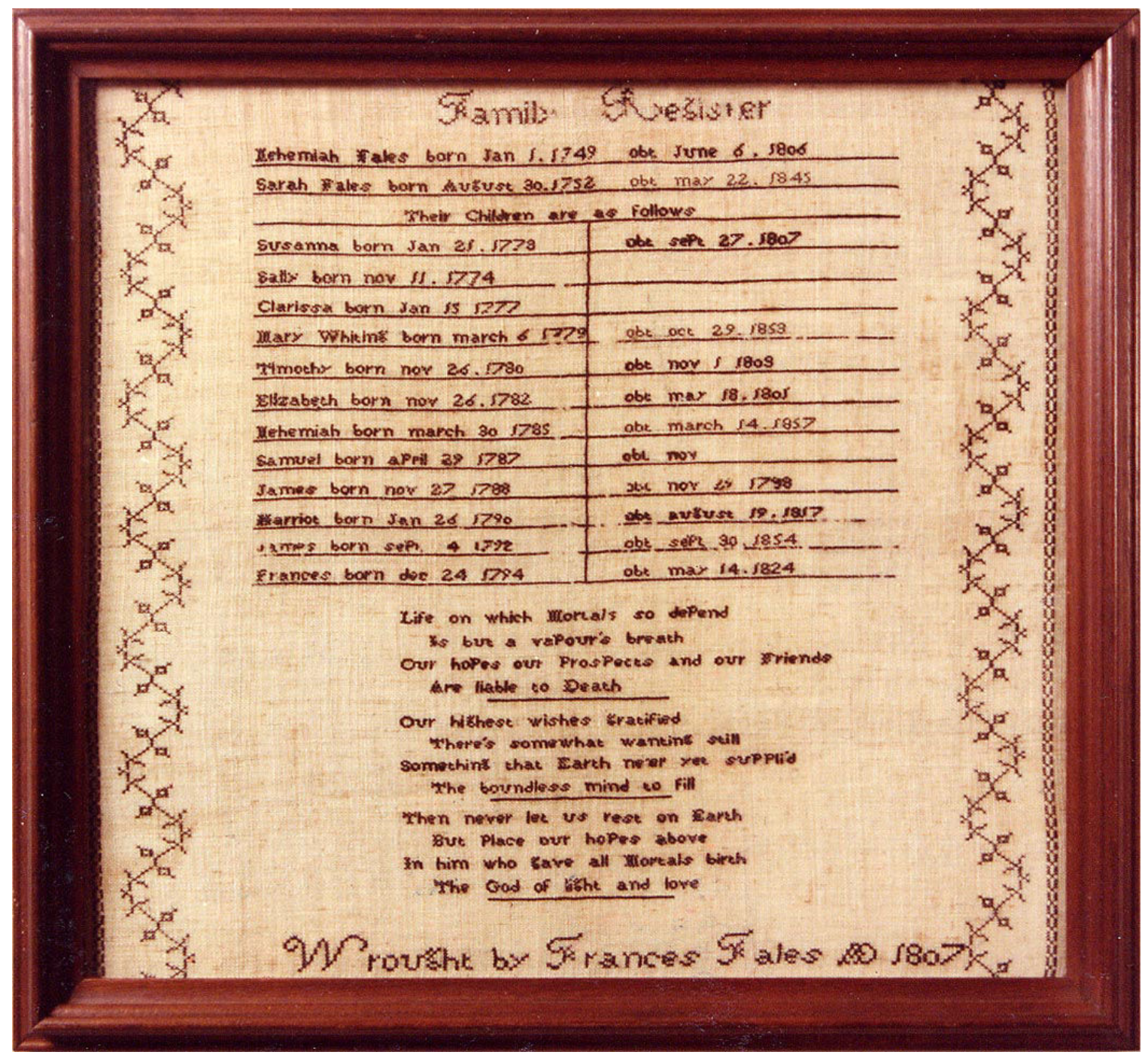

Figure 2.18. Family Record Sampler by Frances Fales (1794-1824), 1807. Courtesy of M. Finkel and Daughter, Philadelphia, Pennsylvania.

Verse: Life on which mortals so depend, is but a vapour's breath, Our hopes our prospects and our friends, are liable to Death. Our highest wishes gratified, There's somewhat wanting still, Something that Earth ne'er yet suppli'd, the boundless mind to fill. Then never let us rest on Earth, but place our hopes above, In him who gave all mortals birth, the God of light and love.

Originally stitched by thirteen-year-old Frances Fales in 1807, this family record sampler shows death dates that were added over several subsequent decades, even after Frances' death at the age of thirty. 
line. ${ }^{151}$ These needlework family records acted the same way, perhaps even more so, since they required actual physical maintenance on top of the necessary intellectual exercise.

Quilts also lent themselves to this type of association since they could be stitched simultaneously by multiple people, and then put on different beds on different nights, coming into contact with multiple family members and friends. And, even if the quilt was made by one person, it could be passed down from generation to generation, with new layers of history and reminiscences added each time.

A well-known quilt by forty-year-old Elizabeth Roseberry Mitchell (1799-1857) serves as an illuminating example of a memorial object; like the samplers above, it was physically altered long after its original maker's death (figure 2.19). ${ }^{152}$ Known as the “Graveyard Quilt,” Mitchell's quilt is pieced with an eight-point star block repeated around a central square, which is bordered to look like the fence and gate of a cemetery. Inside the central section she quilted several coffin shapes. In addition, Mitchell appliquéd and quilted coffin shapes along the outer edges of the quilt. As beloved family members died, she labeled the coffins with their names and moved them from the border into the central graveyard, allowing her to both memorialize the dead and find an outlet for her grief.

Elizabeth Roseberry married Shadrach Mitchell (1797-1875) in 1817 when she was eighteen. Elizabeth was nineteen when her first child was born and gave birth for the last time when she was forty-one. Two of her sons died before she did, two-year-old

\footnotetext{
${ }^{151}$ Lovell, Art in a Season of Revolution, 132. See also St. George, Conversing by Signs, 298-377.

${ }^{152}$ The quilt is currently in the collection of the Kentucky Historical Society, Frankfort, Kentucky.
} 


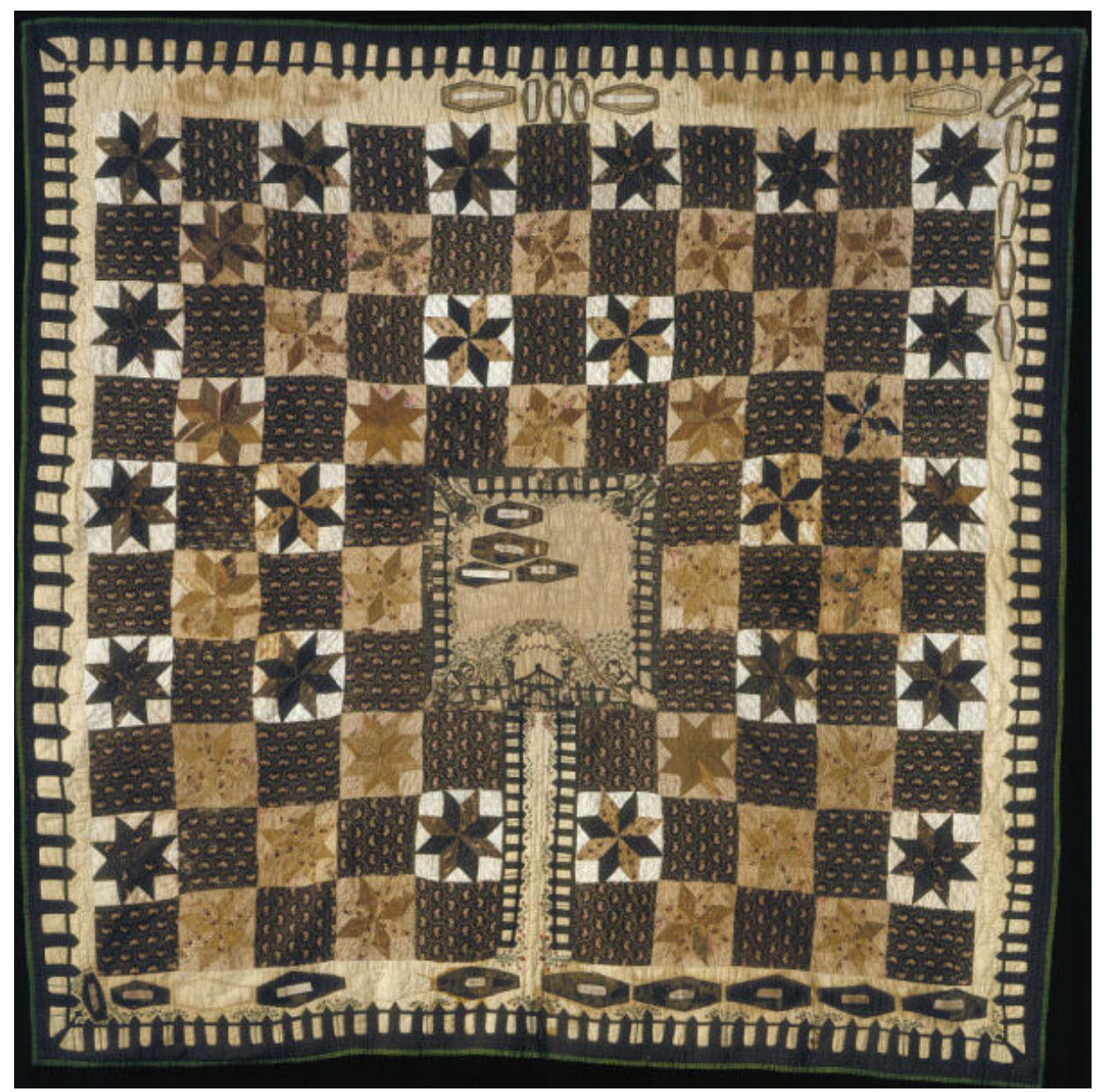

Figure 2.19. Graveyard Quilt by Elizabeth Roseberry Mitchell (1799-1857), circa 1839, Lewis County, Kentucky. Courtesy of the Kentucky Historical Society, Frankfort, Kentucky.

Motivated by her grief over the death of two of her sons, Elizabeth Roseberry Mitchell designed this "graveyard quilt." The coffins along the bottom edge are marked with the names of her children. As family members died, Mitchell - and later her daughter would move the coffins from the border into the graveyard at the center. 
John Vannatta Mitchell in 1836 and twenty-year-old Mathias Mitchell in $1843 .{ }^{153} \mathrm{Her}$ sorrow and grief at these losses seem to have motivated her to begin this quilt in 1843 when she was forty-four. ${ }^{154}$ Elizabeth Mitchell recycled fabric from her children's schoolclothes to piece her quilt. ${ }^{155}$ At least a couple of the fabrics used in the quilt are floral dress fabrics of the type that her daughters would have worn, suggesting that she used scraps from the clothing of all of her children, not just the sons who had passed away.

One of the most striking elements of the quilt is the central depiction of a graveyard. While unusual, Mitchell was not the only quiltmaker to incorporate this motif. A double-sided quilt made by a Cynthia Wells Standish of Wethersfield, Connecticut, and dated 1855, includes a depiction of gravestones at bottom center on one side of the quilt (figure 2.20). ${ }^{156}$ The arrangement of the gravestones on the quilt

${ }^{153}$ Elizabeth Roseberry was born on June 24, 1799, in Pennsylvania, the daughter of Mathias Roseberry (1772-1851) and Sarah Hughes (1779-1858). After she married, Elizabeth moved west with her husband, first to Ohio and then to Kentucky, as their family grew. Shadrach was an innkeeper, eventually expanding his holdings as he purchased more land and built a sawmill, a gristmill and a general store. They had eleven children between 1818 and 1841. Linda Otto Lipsett, Elizabeth Roseberry Mitchell's Graveyard Quilt: An American Pioneer Saga (Dayton, Ohio: Halstead and Meadows Publishing, 1995), 14, 75-96.

${ }^{154}$ The quilt has been published numerous times since it was donated to the Kentucky Historical Society in 1959. See: Ricky Clark, "Fragile Families: Quilts as Kinship Bonds," The Quilt Digest 5 (1987): 11-12; Dennis Duke and Deborah Harding, America's Glorious Quilts (New York: Hugh Lauter Levin Associates, 1987), 74; The Kentucky Quilt Project, Kentucky Quilts 1800-1900 (Louisville: Time Capsules, 1982), plate 42; Roderick Kiracofe, The American Quilt: A History of Cloth and Comfort 1750-1950 (New York: Clarkson Potter, 1993), 170; and Carleton L. Safford and Robert Bishop, America's Quilts and Coverlets (New York: Weathervane Books, 1974), 100. Some of these sources date the quilt to 1839. This may be based on information that the donor gave to the Society when she donated the quilt. At that time, she explained that the quilt was begun as a memorial for Elizabeth's two sons shortly after the donor's father's birth in 1838. However, the second son did not die until January 1843, suggesting that the quilt was started later that year. Adding to the confusion is a second quilt top made by the same maker, which was begun after the first son's death in 1836. According to family tradition, Elizabeth became dissatisfied with this first piece. It had design flaws and did not include the entire family. It became known as a "practice piece" and "pattern" for the second quilt, and was never quilted or finished. See Lipsett, Elizabeth Roseberry Mitchell's Graveyard Quilt, 14-15. The second quilt is now in the collection of the Kentucky Highlands Museum, Ashland, Kentucky.

${ }^{155}$ Lipsett, Elizabeth Roseberry Mitchell's Graveyard Quilt, 96.

${ }^{156}$ The quilt is now in the collection of the Wethersfield Historical Society, Wethersfield, Connecticut. It is illustrated in Quilts and Quiltmakers: Covering Connecticut (Atglen, Pennsylvania: Schiffer Publishing Ltd., 2002), 58-59. Unfortunately, the precise maker of this quilt is unknown. It is signed with the initials, 


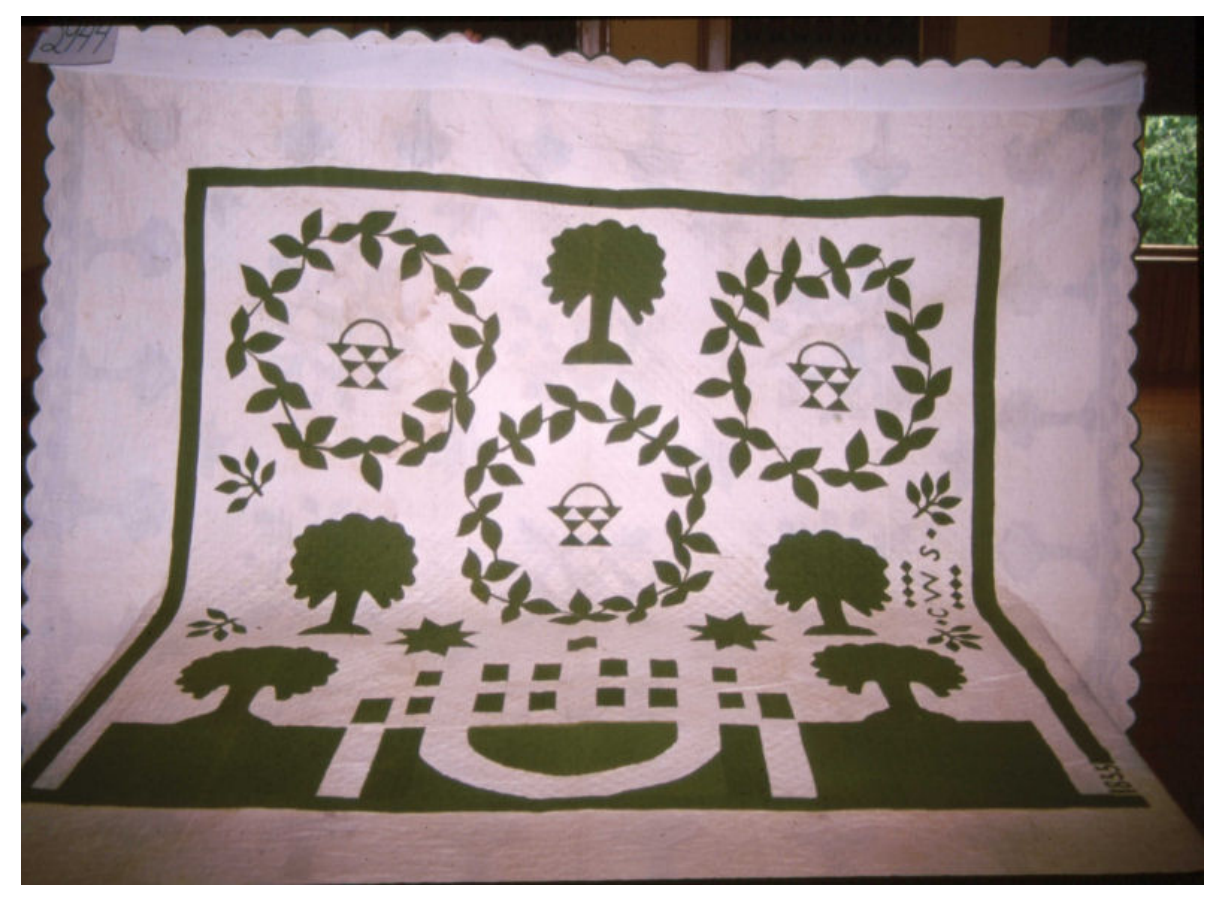

Figure 2.20. Quilt by Cynthia Wells Standish, 1855, Wethersfield, Connecticut. Courtesy of the Connecticut Quilt Search Project.

The initials "CWS" visible at the right side of this quilt stand for Cynthia Wells Standish, who made the quilt. Unfortunately, both mother and daughter had the same initials, so it is unknown which woman made this double-sided quilt. The design at bottom center represents the family's burial plot at the local cemetery.

"CWS," for Cynthia Wells Standish, but this may have been mother Cynthia (1799-1885), who was 56 in 1855, or her daughter, Cynthia (1829-1888), who never married and was 26 in 1855. 
replicates the placement of the stones in the family plot in the Wethersfield cemetery. ${ }^{157}$ The Mitchell quilt also purportedly builds on an Appalachian folk tradition of graveyard quilts, which were made to put over the body at the funeral and then hung over the back of a settee or chair in mourning. ${ }^{158}$

Mitchell's quilt served several purposes. It was a picture of the graveyard and plot where her son, Matthias, was buried, allowing her to maintain a connection to his final resting place. ${ }^{159}$ It also preserved a record of the existence of her two sons, as well as that of her entire family and herself. Like the quilt by Nancy Ward Butler, Mitchell's quilt offered her a way to work out her grief. Her coffins symbolized both the living and the dead, reminding those who looked at the quilt that there was no lasting difference between them. ${ }^{160}$ And, like all of the quilts and samplers discussed here, it enabled Mitchell to leave a legacy of her life and her love and devotion to her family.

The meaning of this quilt was not lost on her family. When Mitchell died in 1857 at age fifty-eight, the quilt passed to her daughter, Sarah (1828-1911), who moved the coffin marked "Mother" from the border into the central graveyard. ${ }^{161}$ When Sarah's husband, Pleasant M. Stallcup (1818-1857) died in 1857, shortly after Elizabeth, she added her husband's name to one of the coffins and stitched it to one of the borders. Later that same year, in what must have seemed an overwhelming chore, Sarah added the

\footnotetext{
${ }^{157}$ Quilts and Quiltmakers, 58.

${ }^{158}$ Lipsett, Elizabeth Roseberry Mitchell's Graveyard Quilt, 18. Lipsett cites an 1810 diary entry by Mrs. John Test near Brookville, Indiana, that describes a hotel that "contained four large feather beds, made up with nice quilts, but something in the form of graves." Lipsett suggests that Mitchell was aware of this Appalachian tradition, but does not provide any direct evidence aside from this diary entry, and an oblique reference to the memories of "old-timers" in the area where Mitchell made the quilt. Lipsett, Elizabeth Roseberry Mitchell's Graveyard Quilt, 18.

${ }^{159}$ The gate resembles that of the Pioneer Cemetery in Woodsfield, Ohio, where Matthias was buried in 1843. Elizabeth's son, John, who died in 1836, may also have been buried in this cemetery. Lipsett, Elizabeth Roseberry Mitchell's Graveyard Quilt, 108.

${ }^{160}$ Clark, "Fragile Familes," 12.

${ }^{161}$ Lipsett, Elizabeth Roseberry Mitchell's Graveyard Quilt, 143.
} 
name of her own young son to a coffin and stitched it along the top to mark his early death. ${ }^{162}$ Over the next thirteen years, nine additional family members were memorialized on the quilt by Sarah: six of her mother's grandchildren; Sarah's sister, Elizabeth (1830-1867); one of her mother's daughters-in-law; and one unidentified relation. Around 1870, when Sarah was forty-seven, she stopped keeping up with the quilt's coffins. When she died in 1911, the quilt passed to her brother, Benjamin Franklin Mitchell (1828-1914), and then to his daughter, Florence (d. 1933). Before Florence passed away in 1933, she gave the quilt to her cousin, another one of Elizabeth Roseberry Mitchell's granddaughters, Nina Mitchell Biggs, the donor of the quilt to the Kentucky Historical Society. ${ }^{163}$

In the maker's mind, her death did not equal the death of the object - quite the contrary, in fact. Mitchell conceived of and produced her quilt so that it would live on after her sons were gone and after she herself had died, like the family record samplers discussed here. These "biographical objects" not only told the story of their maker's family, they also took on a life of their own, a journey which only began after the maker died. The needlework remained, calling the following generations to act by adding to the story that it told and passing it on.

\section{$* * *$}

A story from the March 1846 issue of The Columbian Lady's and Gentleman's Magazine presents the emotional attachment one woman had to her quilt. The narrator made it as a girl, but explained that it was a touchstone for her as an old woman. The quilt was not merely property - it became a sacred object for her as years passed. The

\footnotetext{
${ }^{162}$ Lipsett, Elizabeth Roseberry Mitchell's Graveyard Quilt, 146.

${ }^{163}$ Lipsett, Elizabeth Roseberry Mitchell's Graveyard Quilt, 13, 144, 146, 178, 194-195, 202, 207-208, 214.
} 
author explained quite plainly that the quilt was far from purely functional. It was "not the means of warmth and comfort - [it is] never used as such - [it is a] story-book family legend - illustrated tradition." ${ }^{\prime 64}$ For its maker, the quilt changed over time, and the author acknowledged how common this understanding was. "What woman but can recall some...piece-bag, into which, as a girl, she was permitted to dive when a new doll was to be dressed," she wrote, "and in long after years when the chapter of life is nearly read out, when the eye is dim and the hand tremulous, a fragment of these stuffs...meets the eye and unseals the fountains of emotion."165

Aging women adapted their needlework to fit their changing needs. Rather than serving purely decorative or strictly functional purposes, needlework could also be memorial or biographical. And the purpose it served could overlap or change over time as the maker and owner changed. For girls, needlework was a learning tool. As young wives and mothers, needle and thread were used to contribute to the household and raise their children. In old age, needlework offered a means of agency and expression as well as a legacy for the family. The threads of time stitched by women like Esther Banister Richards, Ruth Pierce Croswell and Mary Rooker Norris are now ours to unravel while their needlework lives on.

\footnotetext{
${ }^{164}$ Miss C.M. Sedgwick, “The Patchwork Quilt," The Columbian Lady's and Gentleman's Magazine 5 (March 1846), reprinted in Benberry and Crabb, A Patchwork of Pieces, 29.

${ }^{165}$ Sedgwick, "The Patchwork Quilt," in Benberry and Crabb, A Patchwork of Pieces, 24-25.
} 


\section{CHAPTER 3}

\section{THE TECHNOLOGICAL RESHAPING OF ANTEBELLUM NEEDLEWORK}

In 1843, fifty-year-old Lucretia Coffin Mott (1793-1880) wrote to her sister, thirty-seven-year-old Martha Coffin Pelham Wright (1806-1875), about her frustration

with their seventy-two-year-old mother, Anna Folger Coffin (1771-1844):

it is so like our mother not to want any "new-fangled" way of doing that which she is in haste to accomplish. Not that she is opposed to improvements and new inventions; not she! when they do not interfere with her desire to make quick work, and finish as she goes. When we were quilting...I wanted a border; but not having another pair of hands (as well as a little ingenuity), I was obliged reluctantly to yield to her importunity, "not to have it forever about;" that "putoffs never accomplish," etc. ${ }^{1}$

Mott's comments suggest the ambivalence that cut across antebellum generations when they were confronted with "new-fangled" products, techniques and styles related to their textiles. Mott's words, and those of others like her, show that the process of adopting "improvements" was not clear-cut. For women, ambivalence and tension about their own lives and the changes taking place in their communities often played out in their needlework - a site of the intersection of proper feminine virtues and new materials. A closer look at the quilts and samplers of mature women, as well as at the words written by and about them, suggests that women were not always ambivalent about the changes themselves, but rather about the marginalization of women's work that was marked by

\footnotetext{
${ }^{1}$ Letter from Lucretia Coffin Mott to Martha Coffin Pelham Wright, September 3, 1843, quoted in Anna Davis Hallowell, James and Lucretia Mott: Life and Letters (Boston: Houghton, Mifflin \& Co., 1884), 260261. Lucretia Coffin, well known abolitionist and women's rights activist, was born on Nantucket Island, Massachusetts, in 1793, the daughter of Thomas Coffin Jr. and Anna Folger, and was raised in the Quaker faith. She attended the Nine Partners school in Dutchess County, New York. At Nine Partners she met James Mott, whom she married in 1811. Lucretia's parents had moved to Philadelphia in 1809, and Lucretia and James moved there after their marriage, as well. The couple had six children, five of whom survived to adulthood. In 1821, Lucretia was recognized as a Quaker minister. Lucretia was active in the abolition and women's rights movements throughout her life. She died in Chelton Hills, Pennsylvania, in 1880. Nancy C. Unger, "Mott, Lucretia Coffin," http://www.anb.org.silk.library.umass.edu:2048/articles/15/15-00494.html, American National Biography Online Feb. 2000; accessed November 21, 2009.
} 
these changes. In addition, these sources show a growing generational tension around women and their needlework.

Women's historians have long pointed out that as the production of cloth and (later) garments moved from looms to factories, saving women time on textile production and clothing manufacture, women's tasks and responsibilities changed in other ways. Most previous studies of the mechanization of textile production have focused on the changes that took place by tracking the rise of the textile factory in New England, exploring the interest in fancywork produced in the home and displayed at fairs, and considering the effect on women's housework. ${ }^{2}$ None of these studies have considered the experience of the women themselves based on their age or the ways in which women received or resisted the transformation of these highly-gendered activities.

Weaving, spinning and sewing have long been intimately associated with women. These activities fulfilled societal and cultural roles far beyond their functional nature. Industry and productivity were woven around the threads of the cloth that countless American women produced. As those chores became mechanized and fabric began to be produced on the factory floor - by younger women and by immigrant women - the cultural roles of textiles and needlework shifted. Women who could afford to purchase machine-made textiles made fewer textiles at home. Some women worked outside the

\footnotetext{
${ }^{2}$ Ruth Schwartz Cowan, More Work for Mother: The Ironies of Household Technology from the Open Hearth to the Microwave (New York: Basic Books, 1983); Thomas Dublin, Transforming Women's Work: New England Lives in the Industrial Revolution (Ithaca: Cornell University Press, 1994); Jonathan Prude, The Coming of Industrial Order: Town and Factory Life in Rural Massachusetts 1810-1860 (Cambridge: Cambridge University Press, 1983); Susan Strasser, Never Done: A History of American Housework (New York: Pantheon Books, 1982); Amy Boyce Osaki, “A “Truly Feminine Employment”: Sewing and the Early Nineteenth-Century Woman." Winterthur Portfolio 23 (Winter 1988): 225-241; Nancy Dunlap Bercaw, "Solid Objects/Mutable Meanings: Fancywork and the Construction of Bourgeois Culture, 18401880," Winterthur Portfolio 26 (1991): 231-248; Beverly Gordon, "Victorian Fancywork in the American Home: Fantasy and Accommodation," in Making the American Home: Middle-Class Women and Domestic Material Culture 1840-1940, Marilyn Ferris Motz and Pat Browne, eds. (Bowling Green, Ohio: Bowling Green State University Popular Press, 1988), 48-68.
} 
home (or inside the home, but for other households) in order to procure the new goods or to make ends meet and had less time to devote to plain or fancy needlework. ${ }^{3}$ As less time was invested in utilitarian tasks, decorative needlework, in particular, became a tool with which women could express opinions, show creativity and demonstrate their familiarity with genteel standards.

Historian Jonathan Prude asserted that ambivalence surrounded the local textile mills he studied in Dudley and Oxford, Massachusetts, but that anti-mill feelings were "neither continuous nor unanimous.", While some feared the change that the mills would bring - citing "moral contagion" brought on by a transient work force as well as a loss of farm workers as hands flocked to industrial labor - others welcomed the benefits of cheaper consumer goods and more jobs. ${ }^{5}$ David Zonderman found similar opinions among the antebellum New England factory workers that he studied. While some welcomed mechanization - and the new types of work it offered, along with opportunities for advancement - others viewed it as a threat that would lead to fewer jobs, monotonous labor and oppressive discipline. ${ }^{6}$ Like most historians of New England's textile mills, Prude and Zonderman approached the subject by focusing on the mills themselves, their owners and their workers. While considering the relationship between the mills, the towns and the workers, neither Prude nor Zonderman considered his argument from the

\footnotetext{
${ }^{3}$ Laurel Thatcher Ulrich, "Wheels, Looms, and the Gender Division of Labor in Eighteenth-Century New England," William and Mary Quarterly 55 (January 1998): 3-38.

${ }^{4}$ Jonathan Prude, "Town-Factory Conflicts in Antebellum Rural Massachusetts," in The Countryside in the Age of Capitalist Transformation: Essays in the Social History of Rural America, Steven Hahn and Jonathan Prude, eds. (Chapel Hill: The University of North Carolina Press, 1985), 73.

${ }^{5}$ Prude, "Town-Factory Conflicts," 76-80. In his study of the Lowell mills, historian Thomas Dublin found that the proportion of the work force employed outside of agriculture increased from $28 \%$ to $41 \%$ between 1820 and 1860. See Thomas Dublin, Women at Work: The Transformation of Work and Community in Lowell, Massachusetts, 1826-1860 (New York: Columbia University Press, 1993), 5.

${ }^{6}$ David A. Zonderman, Aspirations and Anxieties: New England Workers and the Mechanized Factory System 1815-1850 (New York: Oxford University Press, 1992), 6.
} 
perspective of gender or age. But, as Thomas Dublin pointed out in his study of Lowell millworkers, the young women who went to work in the mills were, in part, choosing to reject rural life by doing so. Some "rural spokesmen" felt that it was an example of these young women "rejecting the values of their parents."

In turn, the mothers of these women also reacted to the rise of industrialized textile production. Over the first half of the nineteenth century, textiles - including cloth, needlework and fancywork - became a renewed symbol of and the site of cultural tension. ${ }^{8}$ Conflicts between home and work, city and country, men and women, hand and machine, and, most importantly for this study, between old and young, all played out in woven, stitched and embroidered threads.

The 1832 report of the Committee of Manufactures for the Concord, Massachusetts, Cattle Show acknowledged that there would always be community members "to whom all change is unwelcome." In particular, it singled out the older generation of women who were unhappy about water power being applied to the spinning of cotton in the early nineteenth century. The writer stated that "it was supposed by our respected mothers that the spinning business would be endangered by this novel invention of spinning by water, and they viewed it as an evil omen." Those women who feared this change worried that "the nation would be ruined," and that "little else remains for us and our daughters to do." However, the newspaper reminded readers that it turned out that there were "other channels into which their industry might be profitably

\footnotetext{
${ }^{7}$ Dublin, Women at Work, 55-56.

${ }^{8}$ See Laurel Thatcher Ulrich, The Age of Homespun: Objects and Stories in the Creation of an American Myth (New York: Alfred A. Knopf, 2001), for an examination of the process by which cloth production became romanticized during the nineteenth century.
} 
directed. ${ }^{\prime 9}$ Indeed, given their interest in the sewing machine and their rapid adoption of cylinder-printed fabrics, aging women seem to have been open to technological innovations for their needlework and sewing.

We can look to the needlework of aging antebellum women to learn more about how new sewing tools and materials were received. The items produced by these women, along with their own words in letters and diaries add nuances to our understanding of the industrial revolution. No change takes place without tension and conflict, including the changes in textile production. This chapter uses the rise of the sewing machine, needlework displayed at agricultural fairs, and signature quilts to explore antebellum mechanization and its effects on mature women.

\section{$\underline{\text { Antebellum Needlework Innovations }}$}

Around 1845, newly widowed forty-one-year-old Emily Vandergrift Snyder (b. 1804) made a quilt top as a family keepsake (figure 3.1). ${ }^{10}$ Snyder's quilt employed new materials to stake its place in the present, as well as to remember its maker's past. She left no doubt as to her primary purpose in stitching her quilt. Inked around the center medallion is a family record with the names and birth dates of her children, birth and death information about her husband, and several verses (figure 3.2). The verses acknowledge Emily's grief and piety. One reads, "How many of us, are another year?

\footnotetext{
${ }^{9}$ Report printed in the New England Farmer, November 7, 1832.

${ }^{10}$ The quilt is now in the collection of the Los Angeles County Museum of Art, Los Angeles, California. Snyder's husband, Benjamin Snyder (1794-1845), died in October 1845. The couple married in Philadelphia prior to August 1824 when their first child was born. Eight more children followed, the last in 1842, when Emily was thirty-eight. The source of the verse in the central medallion is unknown, but the other three verses are from the Bible (Psalm 111:10 and Proverbs 14:26 and 27). Sandi Fox, For Purpose and Pleasure: Quilting Together in Nineteenth-Century America (Nashville, Tennessee: Rutledge Hill Press, 1995), 114-117; Gloria Seaman Allen, Family Record: Genealogical Watercolors and Needlework (Washington, DC: DAR Museum, 1989), 94-95; curatorial file from the Los Angeles County Museum of Art, Los Angeles, California.
} 


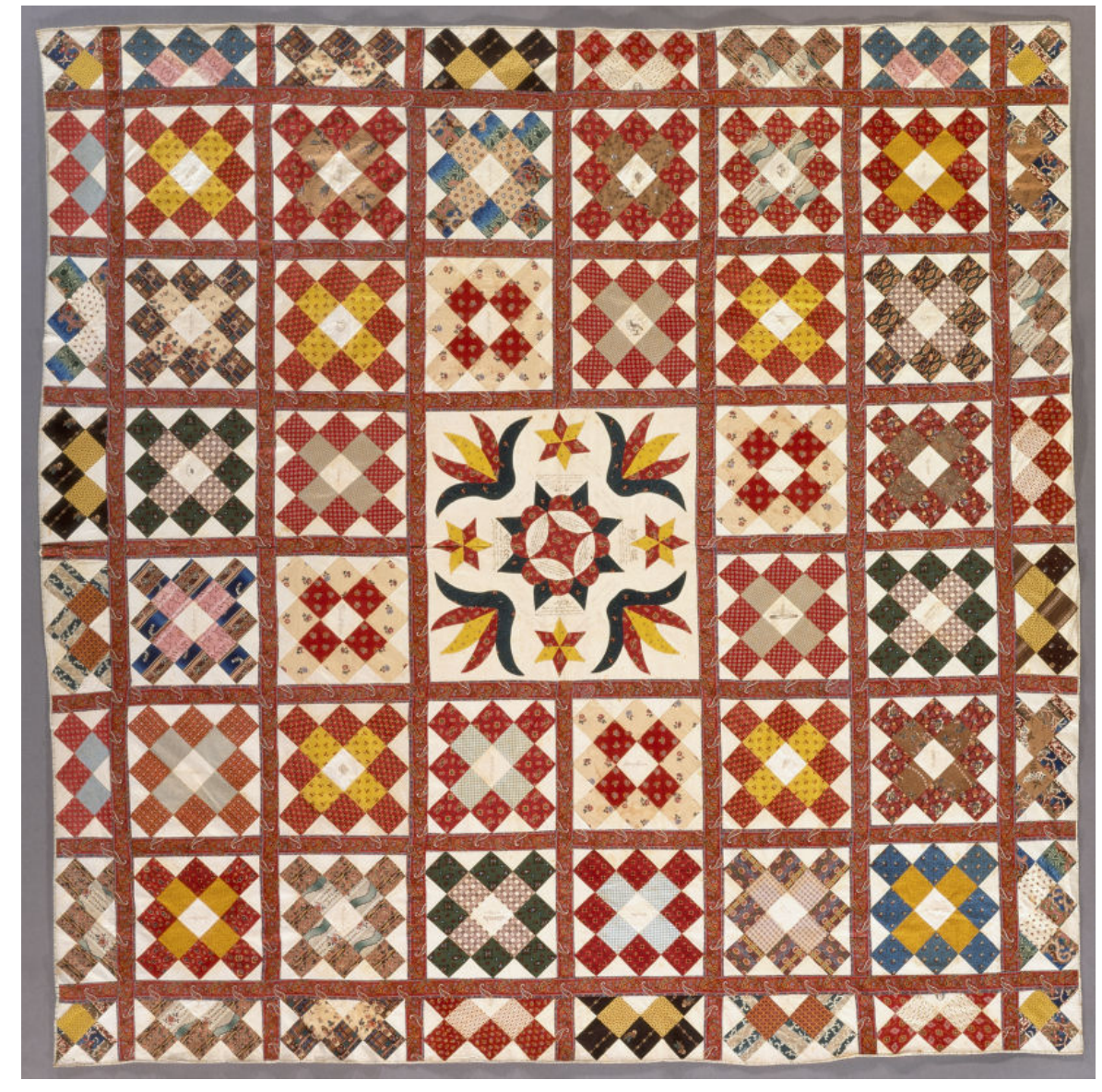

Figure 3.1. Quilt by Emily Vandergrift Snyder (b. 1804), circa 1850, Philadelphia, Pennsylvania. Collection of Los Angeles County Museum of Art, Los Angeles, California, American Quilt Research Center Acquisition Fund (M.87.208). Photo (C) Museum Associates/LACMA.

Emily Vandergrift Snyder's colorful quilt serves as a memorial to her family, tracking family information and meaningful verses. 


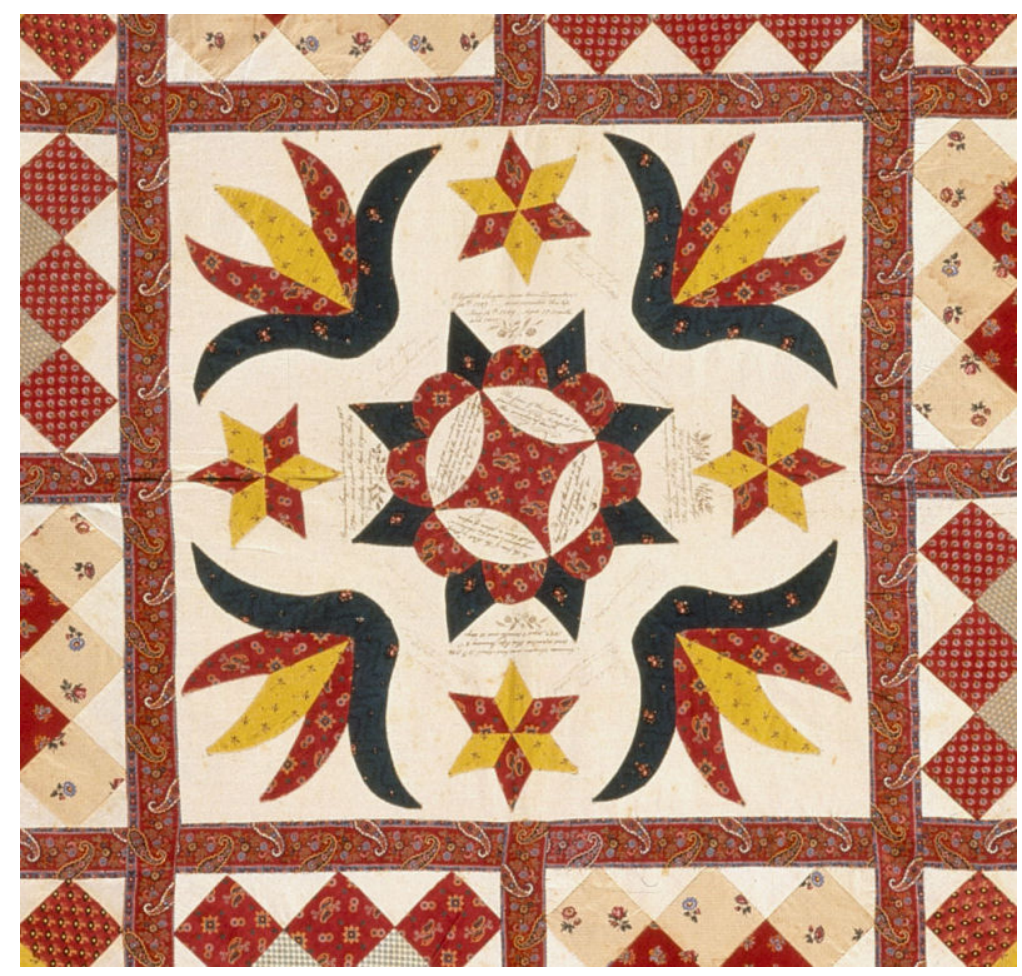

Figure 3.2. Detail of center medallion from quilt by Emily Vandergrift Snyder.

Inscribed verses:

How many of us are another year? May sleep beneath the cold \& silent sod? Then while our lives are in merce lengthed here, Let us in time prepare to meet our God.

The fear of the Lord is a fountain of life, to depart from the snares of death.

The fear of the Lord is the beginning of wisdom: which will lead us to forsake sin.

In the fear of the Lord is strong confidence; and his children shall have a place of refue [sic].

Emily Vandergrift Snyder used indelible ink to record information about her recently deceased husband and their children. 
May sleep beneath the cold and silent sod? Then while our lives, are in merc[y] lengthened here, Let us in time prepare to meet our God." Representing the past, the center medallion of this Pennsylvania quilt shows the influence of the antebellum Pennsylvania-German aesthetic employing colors and motifs that are seen in frakturs from the early nineteenth century. Surrounding blocks were signed by family members and friends. Snyder used bright new cylinder-printed "rainbow" or "ombre" cottons to piece these blocks.

Scotsman Thomas Bell is recognized as the inventor of the first functional cylinder-printing machine in 1783 and French fabric printers were using it by the late 1790s. ${ }^{11}$ The cylinder- or roller-printing machine exponentially increased the supply of these fabrics to meet a demand that had been rising since the early eighteenth century. A single cylinder-printing machine could print as much yardage in four minutes as two people with wood blocks could do in six hours. ${ }^{12}$ This statistic helps to explain the decrease in the cost of printed cotton fabrics during the early nineteenth century, which made them accessible to far more Americans than before. In addition, the details that could be engraved onto the plates wrapped around the rollers were much more precise and crisp. Cylinder printers experimented with inking the rollers in different ways. By gradually shading the colors on the roller, they could get a rainbow effect or different shades of one color for the ground and then have a pattern overlaid. ${ }^{13}$ These colorful

\footnotetext{
${ }^{11}$ Linda Eaton, Quilts in a Material World: Selections from the Winterthur Collection (New York: Abrams, 2007), 122; Margaret T. Ordonez, "Technology Reflected: Printed Textiles in Rhode Island Quilts," in Down by the Old Mill Stream: Quilts in Rhode Island, Linda Welters and Margaret T. Ordonez, eds. (Kent, OH: The Kent State University Press, 2000), 122.

${ }^{12}$ Lynne Z. Bassett and Jack Larkin, Northern Comfort: New England's Early Quilts 1780-1850 (Nashville: Rutledge Hill Press, 1998), 34.

${ }^{13}$ Barbara Brackman, Clues in the Calico: A Guide to Identifying and Dating Antique Quilts (McLean, VA: EPM Publications, Inc., 1989), 86-87. The term "rainbow" to describe this effect was used for wallpaper
} 
printed fabrics were easily purchased at the local store by rural and urban Americans alike.

Antebellum women quickly embraced the bright colors, exuberant patterns and cheaper prices of cylinder-printed fabric. In 1831, forty-four-year-old Emma Willard (1787-1870) noted in her travel diary that she "had long been desirous to see the process of calico printing." 14 A trip to the British Isles allowed her the chance to visit a textile printing factory in Glasgow, Scotland, where she was shown each part of the process from dyeing the cloth to printing and fixing the colors. Willard noted that "after the cloths are dried, measured and packed for market, they are sent to almost every part of the world - many to our own country." ${ }^{15}$ While few first-person sources remain to tell us how antebellum women reacted to these fabrics, the large number of extant quilts that employ them speak volumes. Made all over the country by young, middle-aged, and old women, these quilts, like Snyder's, attest to the popularity of the new fabrics, leaving little doubt that this was one technological innovation that was roundly embraced, rather than shunned or feared.

Snyder's quilt also employed an indelible ink to record the family information she added. New indelible inks, which their makers claimed would not rot fabric, were developed in the mid-1830s, although India ink, imported from China, had been used

(which employed a similar printing process) in 1826. "Rainbow" fabrics were also known as "fondu," French for melt or dissolve, and as "ombre," French for shaded or tinted.

${ }^{14}$ Emma Hart Willard, Journal and Letters from France and Great Britain (Troy, New York: N. Tuttle, 1833), 356. Emma Hart was born in 1787 in Berlin, Connecticut, the daughter of Samuel Hart and Lydia Hinsdale. She began teaching in Berlin, Connecticut, in 1804, and took charge of the Middlebury, Vermont, female academy three years later. In 1809, she married John Willard, a physician and politician. They had a son in 1810. Emma Willard established the Troy Female Seminary in New York in 1821, which became a model for other female institutions. During the 1840 s, she continued as an adviser to the Seminary, but began to focus on writing books. She died in Troy, New York, in 1870. Susan Grigg, "Willard, Emma Hart," http://www.anb.org.silk.library.umass.edu:2048/articles/09/09-00806.html, American National Biography Online Feb. 2000; accessed November 21, 2009.

${ }^{15}$ Willard, Journal and Letters, 357. 
around the world for centuries and worked well for writing on fabric. Despite the availability of India ink, many women made their own ink at home for writing on paper and on fabric. ${ }^{16}$ But, these inks (both homemade and commercial) were colored with iron or tannin - chemicals that caused cloth to deteriorate. During the 1830s and 1840s, several patents were filed in France and in the United States for "indelible writing ink," which used silver nitrate instead of iron. ${ }^{17}$ Payson's Indelible Ink, credited with being the oldest manufactured ink suitable for fabric, came onto the market around $1834 .^{18}$ Advertisements for Payson's Ink directly addressed women who wanted to write on cloth. "This Ink is used without a preparation, and with it," the manufacturer claimed, "you can write in Indelible characters upon cotton and linen cloth, in the same manner that you would write with the common ink on paper. It is warranted not to corrode or injure the finest Cambric; and is so perfectly Indelible as not to be effaced either by time or art." ${ }^{\prime 19}$ Indeed, nineteenth-century literature contains "no reports of damage to paper or cotton fabric from India ink or silver nitrate ink formulations.",20

Indelible inks allowed antebellum women to save time marking their household textiles. They could now write quickly and directly on sheets, towels and other textiles rather than cross-stitching countless initials and numbers. Yet, inks for writing on fabric also offered a more ornamental and meaningful option, as well. From a memorial

\footnotetext{
${ }^{16}$ Lynne Z. Bassett, ed., Massachusetts Quilts: Our Common Wealth (Hanover, New Hampshire: University Press of New England, 2009), 323; Roy Neal, "A Chronological History of Ink," American Ink Maker 38 (September 1960): 38-40; David N. Carvalho, Forty Centuries of Ink (New York: Burt Franklin, 1971), 2, 134-135.

${ }^{17}$ Linda Otto Lipsett, Remember Me: Women and Their Friendship Quilts (San Francisco: The Quilt Digest Press, 1985), 17-18.

${ }^{18}$ Brackman, Clues in the Calico, 118.

${ }^{19}$ Connecticut Courant, November 9, 1835.

${ }^{20}$ Margaret T. Ordonez, "Ink Damage on Nineteenth Century Cotton Signature Quilts," Uncoverings 13 (1992): 157.
} 
viewpoint, a person's handwriting could be preserved, as well as their name, when they signed a quilt block or inscribed a label for their embroidered coverlet.

Quilts were not the only needlework that incorporated new materials. Many antebellum samplers, like Amy Fiske's, which is described in the Introduction, and Esther Banister Richards', which is discussed in chapter 2, were worked on a new type of canvas, a machine-produced fabric, usually with a thread count of thirty-two stitches to the inch or less and woven with a blue weft thread every tenth thread. The popularity of this fabric demonstrates the growing preference for new machine-made goods during the 1820s, 1830s and 1840s. As Miss Lambert explained in her popular 1846 book, The Hand-Book of Needlework: "German cotton canvas...is well adapted for some purposes...it is generally woven with every tenth thread of a different colour, which many persons consider to be of great assistance in counting the stitches." ${ }^{21}$ Having a fabric with the regular blue thread made counting far easier and faster. For older women, the blue guideline could assist them with compensating for failing eyesight as they stitched. For antebellum girls and young women, the blue-line canvas made stitching a sampler easier in light of less rigorous needlework training.

While cylinder printing, indelible ink and "blue line" canvas were all eagerly adopted by antebellum women (young and old), it was the sewing machine that would have the most profound effect on American needlework. In July 1860, sixty-four-yearold Elizabeth Lindsay Lomax (b. 1796) noted in her diary, "Virginia Ellicott called in the

\footnotetext{
${ }^{21}$ Miss Lambert, The Hand-Book of Needlework (London: John Murray, 1846), 111. There is no clear data on when the "blue line" canvas was first produced in this country. An unscientific survey of the samplers in the Old Sturbridge Village collection that use this fabric suggests a date of the early 1840s. Some sampler historians link its use to the rise of Berlin work which filled in the entire ground fabric. See Mary Jaene Edmonds, Samplers and Samplermakers: An American Schoolgirl Art 1700-1850 (London: Rizzoli, 1991), 154.
} 
afternoon. We discussed sewing machines - a very useful invention - I wish that we owned one, I could make shirts in a jiffy for my precious boy."22 Although it was initially patented by Elias Howe (1819-1867) in 1846, the sewing machine did not achieve widespread use in American homes until after the Civil War. ${ }^{23}$ However, antebellum women - of all ages - took notice of this invention during the 1850 s, and Lomax was not alone among aging women in her desire to own one. The time-saving nature of the sewing machine was exclaimed over in diaries, letters and ladies' magazines.

In 1830, Barthelemy Thimmonier (1793-1857), a French tailor, patented the first known machine used in commercial operation. Thimmonier's machine made a chain stitch using a hooked needle moved by a foot treadle. Additional chain stitch machines were developed during the 1830 s. $^{24}$ Shortly after Thimmonier's invention, the lockstitch machine was invented by Walter Hunt (1796-1859) between 1832 and 1834, although he never patented it. ${ }^{25}$ During the next decade, in the 1840 s, patents were registered on many of the elements that make up the sewing machine as we know it: support for the cloth; a needle to carry the thread through the fabric; a combining device to form the stitch; a feeding mechanism to permit one stitch to follow another; tension controls to provide an even delivery of thread; and a mechanism to ensure the precise performance

\footnotetext{
${ }^{22}$ Lindsay Lomax Wood, Leaves from an Old Washington Diary (New York: Books, Inc. 1943), 127.

${ }^{23}$ Suellen Meyer, "Early Influences of the Sewing Machine and Visible Machine Stitching on NineteenthCentury Quilts," Uncoverings 10 (1989): 39-40; Barbara Brackman, Patterns of Progress: Quilts in the Machine Age (Los Angeles: Autry Museum of Western Heritage, 1997), 11, 18; Grace Rogers Cooper, The Invention of the Sewing Machine (Washington, DC: Smithsonian Institution, 1968), 59; Anita B. Loscalzo, "The History of the Sewing Machine and Its Use in Quilting in the United States," Uncoverings 26 (2005): 182.

${ }^{24}$ Loscalzo, "The History of the Sewing Machine," 177.

${ }^{25}$ Brackman, Clues In the Calico, 100.
} 
of each operation in its proper sequence. ${ }^{26}$ In 1846 , Elias Howe patented a sewing machine that was more sophisticated than ever before. And, in the 1850s, Isaac Singer (1811-1875) became active, marketing the sewing machine on a mass scale. ${ }^{27}$

In 1850, forty-two-year-old Frances Swanson Shaw (1808-1876), of West Virginia, presented her son, Samuel (b. 1832), with a red and green appliqué quilt on the occasion of his marriage to Elizabeth Schroyer (1837-1922) (figure 3.3). ${ }^{28}$ Shaw combined hand-sewing with machine sewing to complete her quilt. She appliquéd the central floral motifs by hand, just as her mother and grandmother would have. But, she used her sewing machine to seam the backing fabric together, to apply the long vines in the borders and to add the red binding around the edges. The benefits of the sewing machine were quickly understood by antebellum women, like Shaw, who used her machine to make quick work of sewing long seams and other formerly time-consuming chores.

During the 1840s and 1850s primarily industrial machines were produced, intended for commercial use, although some women purchased these models for home use. The early machines cost about $\$ 100$, a substantial expense for the average farm family with an annual income of $\$ 500 .^{29}$ As forty-eight-year-old Mary Jones (1808-

\footnotetext{
${ }^{26}$ Loscalzo, "The History of the Sewing Machine," 177. See Cooper, The Invention of the Sewing Machine, for a detailed technical history of the sewing machine.

${ }^{27}$ Brackman, Clues in the Calico, 100; Cooper, The Invention of the Sewing Machine, 32, 143.

${ }^{28}$ The quilt descended along a male line and remains in a family collection. It is pictured in Fawn Valentine, West Virginia Quilts and Quiltmakers: Echoes from the Hills (Athens: Ohio University Press, 2000), 109. Frances Swanson Shaw was born in Maryland and married Joseph Shaw (1797-1886) around 1825. The couple moved to West Virginia at some point and eventually had seven children together. See Valentine, West Virginia Quilts, 107-108.

${ }^{29}$ Brackman, Patterns of Progress, 11.
} 


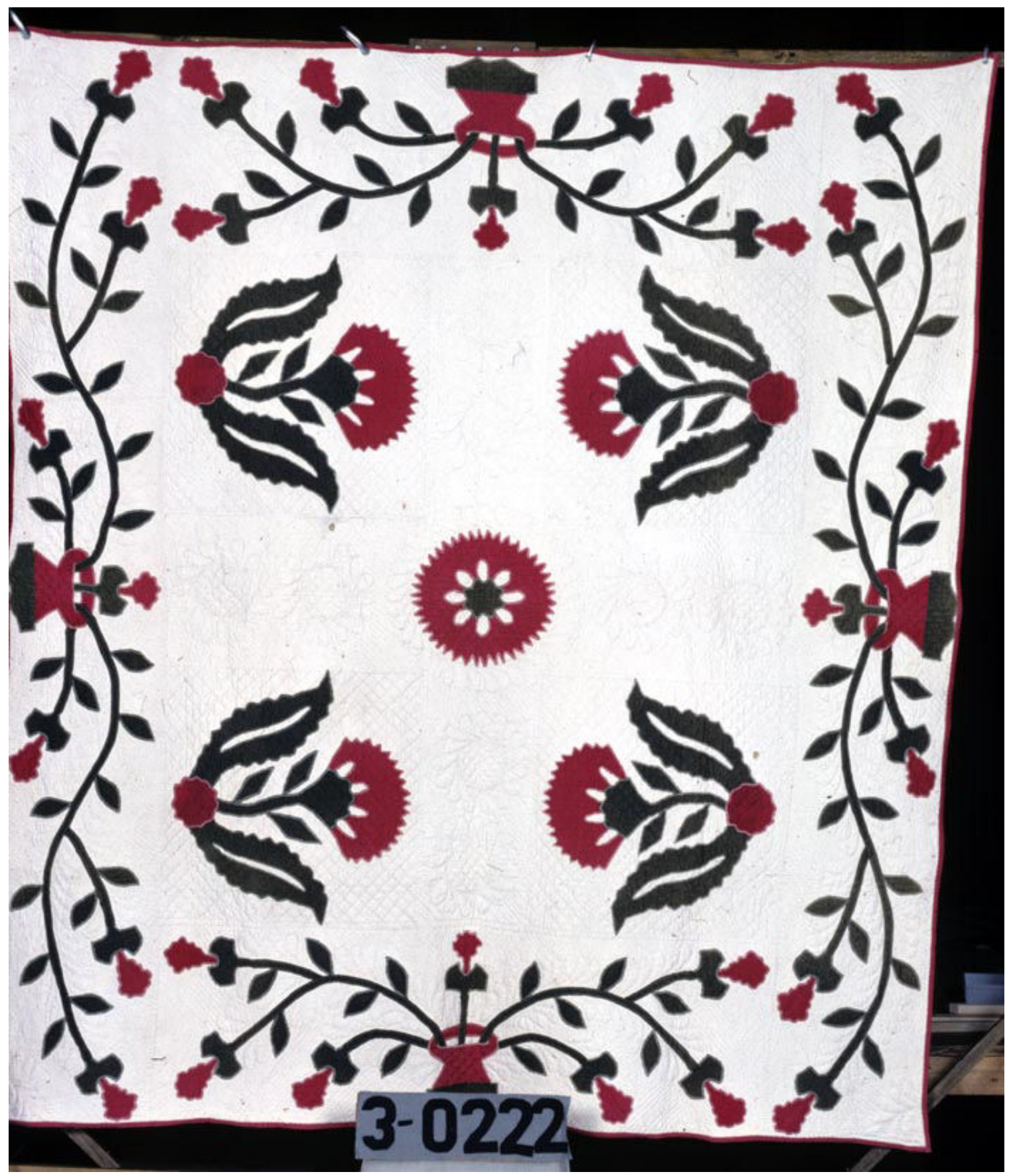

Figure 3.3. Quilt by Frances Swanson Shaw (1808-1876), circa 1850, Hagerstown, Maryland. Courtesy of the West Virginia State Archives, West Virginia Heritage Quilt Project Collection.

Frances Swanson Shaw combined hand sewing with machine sewing to make this quilt on the occasion of her son's wedding. Antebellum women of all ages quickly embraced the sewing machine as a time-saving device. While especially helpful for making clothes and functional household textiles, the machine was also ideal for quickly seaming quilt backs and applying bindings along quilt edges. 
1869) wrote to her daughter in 1856, “A hundred dollars is a great deal to invest in an uncertainty."30 Realizing this, Isaac Singer developed the installment plan, putting the sewing machine within reach of a much wider audience. By 1860, 500,000 sewing machines were in use in the United States (commercial and domestic use combined). ${ }^{31}$ By August 1860, Washington, D.C., resident Elizabeth Lindsay Lomax seemed to be closer to her goal of getting a sewing machine. "The girls have gone down to the city to look at sewing machines," she wrote in her diary, "Wheeler and Wilson's seems to be the best.",32

As these women knew only too well, sewing a man's shirt by hand took over fourteen hours, and a woman's dress could take almost seven hours. ${ }^{33}$ When a sewing machine was used instead of needle in hand, these common garments took only an hour or two. Proponents of women's rights saw the sewing machine as the savior of thousands of women. Reformer Amelia Bloomer (1818-1894) believed that, with the time saved by the sewing machine, female merchants, bookkeepers, shoemakers, cabinetmakers, jewelers, booksellers, typesetters, editors, publishers, farmers, and physicians would become commonplace. As she explained, "Woman has long enough stitched her health and life away, and it is merciful to her that sewing machines have been invented to relieve her of her toilsome, ill-paid labor, and to send her forth into more active and more lucrative pursuits where both body and mind may have the exercise necessary to health and happiness." ${ }^{34}$ Forty-three-year-old Harriette Kidder (1816-1915) of Illinois seconded

\footnotetext{
${ }^{30}$ Robert M. Myers, ed., The Children of Pride: A True Story of Georgia and the Civil War (New Haven: Yale University Press, 1972), 287.

${ }^{31}$ Loscalzo, "The History of the Sewing Machine," 182.

${ }^{32}$ Wood, Leaves from an Old Washington Diary, 127.

${ }^{33}$ Loscalzo, "The History of the Sewing Machine," 177.

${ }^{34}$ D.C. Bloomer, Life and Writings of Amelia Bloomer (New York: Schocken Books, 1975), 168. Amelia Jenks was born in 1818 in Homer, New York, the daughter of Ananias Jenks and Lucy Webb. In 1840, she
} 
Bloomer's appraisal when she wrote in 1859 that her sewing machine was "a very valuable household article. It renders sewing a pleasure rather than a toil." 35

An early champion of the sewing machine, Sarah Josepha Hale (1788-1879), editor of Godey's Lady's Book, trumpeted its benefits for her readers. "By this invention," the seventy-two-year-old Hale exclaimed in 1860, "the needlewoman is enabled to perform her labors in comfort; tasks that used to require the midnight watches by the pale light of a single lamp, and drag through, perhaps, twenty hours, she can now complete in two or three hours. She is thus able to rest at night and have time through the day for family occupations and enjoyments. Is not this a great gain for the good?"36 About a year earlier, forty-eight-year-old Elizabeth Le Breton Stickney Gunn (18111906) called on a friend who had a new sewing machine; it was "a Wheeler \& Wilson, and it has an attachment which will turn down a hem and sew it at the same time. She

married Dexter C. Bloomer, a newspaper editor and a lawyer. Amelia began to write articles for her husband's paper, which was located in Seneca Falls, New York, where they lived. In 1849, she founded a monthly journal, the Lily. Two years later, in 1851, she adopted the style of dress that became associated with her name - a short skirt and full Turkish-style trousers. She was also active throughout the 1840s and 1850 s in the temperance movement. In the 1870s, she began to work for woman suffrage. In 1855, the Bloomers had moved to Iowa where they adopted two children. She died in Council Bluffs, Iowa, in 1894. Kathleen Feeney, "Bloomer, Amelia Jenks," http://www.anb.org.silk.library.umass.edu:2048/articles/15/15-00071.html, American National Biography Online Feb. 2000; accessed November 21, 2009.

${ }^{35}$ Diary entry by Harriette Kidder in 1859, quoted in Pat Ferrero, Elaine Hedges, and Julie Silber, Hearts and Hands: Women, Quilts, and American Society (Nashville: Rutledge Hill Press, 1987), 38. Harriette Smith was a teacher and principal at the Worthington Female Seminary in Ohio. She married Rev. Daniel P. Kidder (1815-1891) in 1842 as his second wife. The couple raised her three children and the two from his first marriage. The family lived in New York City from 1844 to 1846, in Newark, New Jersey from 1846 to 1856, in Evanston, Illinois from 1856 to 1871, in Madison, New Jersey from 1871 to 1881, in New York City from 1882 to 1887, in Evanston, Illinois from 1887 to 1899, and then in Brooklyn and in Ocean Grove, New Jersey. Description of Harriette Smith Kidder papers, Special Collections, Rutgers University Libraries, www.libraries.rutgers.edu/rul/libs/scua/womens fa/wfa h k.shtml, accessed August 27, 2008. ${ }^{36}$ Godey's Lady's Book, July 1860, quoted in Sherbrooke Rogers, Sarah Josepha Hale: A New England Pioneer 1788-1879 (Grantham, New Hampshire: Tompson and Rutter, 1985), 122. Sarah Josepha Buell was born in 1788 in Newport, New Hampshire, the daughter of Gordon Buell and Martha Whittlesey. She taught school from 1806 until 1813, when she married David Hale, a lawyer. When David died in 1822, leaving her to support their five children, she began to write. In 1828, she began editing the Ladies' Magazine, published by a firm in Boston. From 1837 to 1877, she edited Godey's Lady's Book. In 1879, she died in Philadelphia, Pennsylvania. Joyce W. Warren, "Hale, Sarah Josepha Buell," http://www.anb.org.silk.library.umass.edu:2048/articles/16/16-00686.html, American National Biography Online Feb. 2000; accessed November 21, 2009. 
told me she had heard of knitting machines at fifteen dollars that would knit drawers as well as stockings. I really do want one."37

Many female family members seem to have found consensus in their interest in the sewing machine. While all of the aging women quoted here who wrote about sewing machines expressed their positive enthusiasm for the machine, most of them enlisted the help of younger relatives in learning about the options, purchasing the machine and using it. As fifty-one-year-old Mary Jones (1808-1869) wrote to her daughter, on August 16, 1859, "Laura and Sister Susan both use the sewing machine admirably - without basting...Laura says it is the easiest thing in the world. I think it will prove a great comfort.",38

While the sewing machine was quickly adopted for making clothing and seaming household textiles, its use for quiltmaking is harder to document. Quilt historians disagree about the number of quilts made in the late nineteenth century and early twentieth century that employed machine stitching. ${ }^{39}$ The important distinction to be drawn is in identifying how the machine was used in mid-century quilts. Machinequilting and -applique were rare initially. However, the power of the sewing machine with its speed and efficiency in stitching straight seams - was ideal for quickly piecing quilt tops. Recent quilt documentation projects have found many late-nineteenth-century

\footnotetext{
${ }^{37}$ Records of a California Family: Journals and Letters of Lewis C. Gunn and Elizabeth Le Breton Gunn (San Diego: privately published, 1928), 245. Elizabeth LeBreton Stickney married Lewis Carstairs Gunn in 1839, making their home in Philadelphia. Lewis went to California in 1849, and his wife and four children joined him in 1851. The family lived in Sonora, California, where Lewis published a local newspaper and owned a drugstore. In 1861, the family moved to San Francisco. Family information from www.familymarriagerecords.com/db.asp?dbid=3772; accessed November 21, 2009.

${ }^{38}$ Myers, ed., The Children of Pride, 507.

${ }^{39}$ Some quilt historians suggest that only $10 \%$ show machine appliqué or quilting, while others state that 75\% were at least partially machine-stitched if made between 1860 and 1940. Loscalzo, "The History of the Sewing Machine," 186; Roderick Kiracofe, The American Quilt: A History of Cloth and Comfort 17501950 (New York: Clarkson Potter Publishers, 2004), 126.
} 
quilts where the blocks themselves may have been hand-pieced, but were then joined together in long strips by a machine. And, while machine-sewing of any kind is rare in quilts made between 1850 and 1860, it does pop up from time to time, as in the quilts discussed in this chapter. ${ }^{40}$

In the 1850s, Mary Deloach Sneed (1807-1905) showed not only pride in her quiltmaking skill but also in her ability to keep up with new technology (figure 3.4 ). ${ }^{41}$ In her forties at the time, Sneed used her new sewing machine to stitch her fruit basket bedcovering. ${ }^{42}$ According to a note written by one of her descendants, Sneed "made and stuffed the baskets by hand, and stitched the white part on her new sewing machine - one of the first made after it was invented." ${ }^{43}$ Sneed used her machine to appliqué the baskets, quilt the alternating plain blocks and to join the blocks together. She cut out a

\footnotetext{
${ }^{40}$ Other quilts made between 1850 and 1860 with machine-stitching include: two Irish Chain machinepieced quilts from the 1850s (by unknown makers) now in the collection of the International Quilt Study Center; a machine-appliqued Basket Quilt by Delia Birdsey Crocker in the collection of the New England Quilt Museum; a machine-quilted Whig Rose quilt now in the collection of the Art Institute of Chicago; a machine-quilted whitework quilt of unknown origin from about 1860 now in the collection of the Smithsonian Institution; and a machine-pieced Checkerboard Squares quilt now in the collection of the Illinois State Museum. Loscalzo, "The History of the Sewing Machine," 177; Doris M. Bowman, American Quilts: The Smithsonian Treasury (Washington, D.C.: Smithsonian Institution Press, 1991), 6465, 94; The Quilt Index, www.quiltindex.org/fulldisplay.php?pbd=IllinoisISM-a0a0z8-a, accessed January 3, 2009.

${ }^{41}$ The quilt is now in the collection of the Daughters of the American Revolution Museum, Washington, DC. Mary Deloach Sneed was born in Davidson County, Tennessee in 1807. In 1824, she married her first cousin, George Washington Sneed (1799-1851), who was a Methodist minister. The couple had seven children. In 1850, Mary Sneed and her husband moved to Navarro, Texas because of George's declining health. He died in Texas in July 1851. In 1858, Mary moved to Waco, Texas, where she lived until her death in 1905 at age ninety-seven. The quilt was passed down in the family and was given to the Daughters of the American Revolution Museum by the great-great-great-granddaughter of the maker. Curatorial file, Daughters of the American Revolution Museum, Washington DC; www.ancestry.com, accessed January 2, 2009.

${ }^{42}$ The quilt consists of twelve blocks set on point alternating with plain white squares. It has a white cotton backing and front to back binding. The quilt has medium cotton batting and is machine-quilted in a grid and outline pattern. The fruit basket appliqué pattern is an original design, although it shows similarities to other floral basket blocks, see Barbara Brackman, Encyclopedia of Applique: An Illustrated, Numerical Index to Traditional and Modern Patterns (McLean, Virginia: EPM Publications, Inc., 1993), 149; curatorial file, Daughters of the American Revolution Museum, Washington, DC.

${ }^{43}$ Curatorial file, Daughters of the American Revolution Museum, Washington, DC. While it is difficult to document that Sneed's sewing machine was one of the first to make it to Texas, the Austin History Center
} 


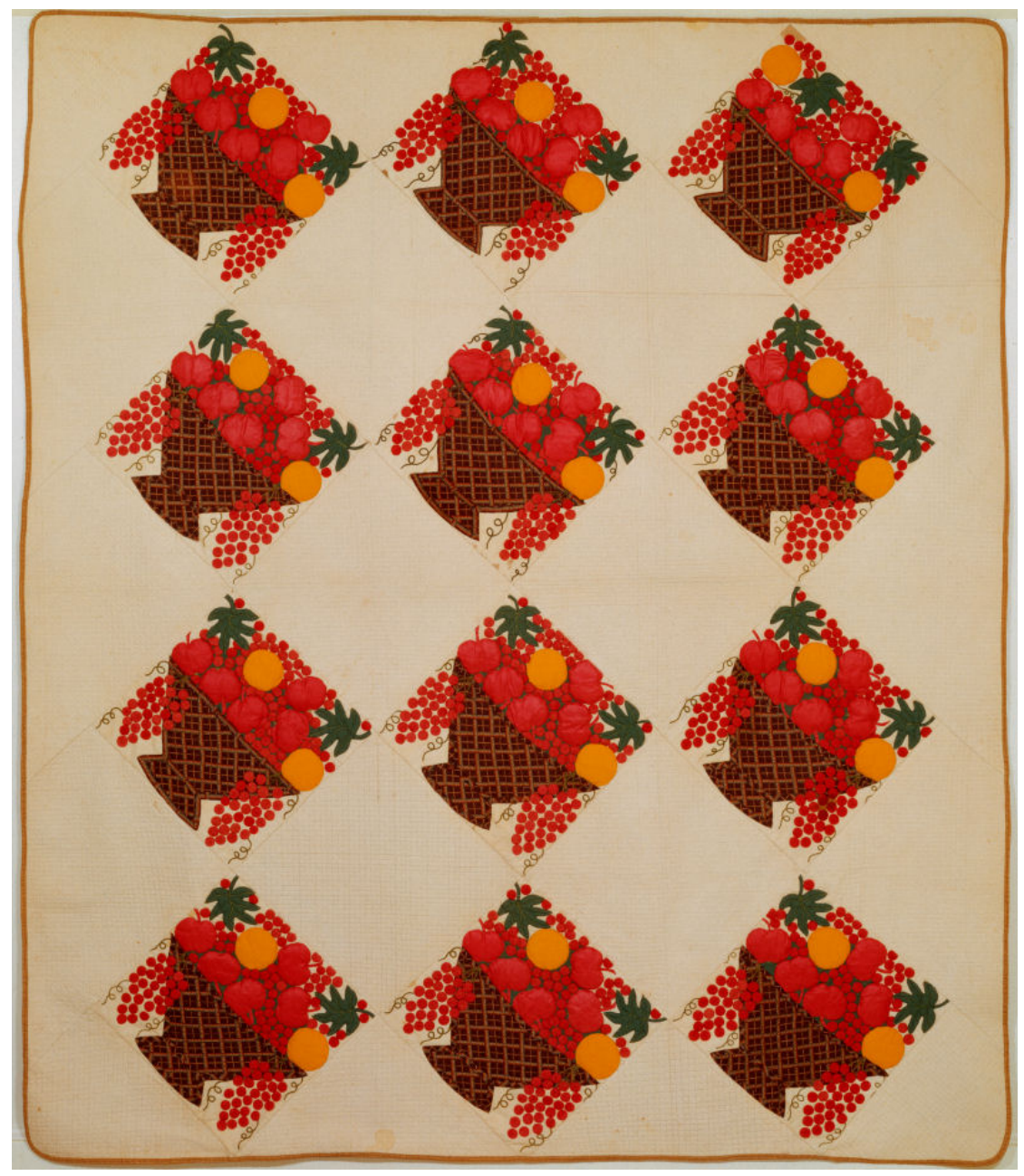

Figure 3.4. Quilt by Mary Deloach Sneed (1807-1905), 1850-1860, Waco, Texas. Courtesy of the Daughters of the American Revolution Museum, Washington, DC.

According to family history, Mary Deloach Sneed's quilt, which includes machine stitching, was made using one of the first sewing machines to come to Texas.

suggests that the first sewing machine in Travis County, Texas, was purchased by Hugh and Helen Mary Tinnin soon after their arrival in 1850, see www.ci.austin.tx.us/library/ahc/begin/lei_amus.htm. 
piece of fabric with a printed basketweave pattern (known as "cheater cloth" ${ }^{\text {" } 44}$ ) and then used rows of machine stitching to give it the appearance of woven strips of fabric rather than the one piece of fabric that it actually is. ${ }^{45}$ The alternating plain blocks are machinequilted in a crosshatched pattern with lines one-half inch apart. A close look at her quilt shows that Sneed made all of the blocks first - both the appliquéd baskets and the quilted squares - and then sewed them together. As a final step, she added a backing and tied it to the front of the quilt to hold it together - the common purpose behind quilting a quilt. ${ }^{46}$ This material evidence of Sneed's construction technique suggests a woman who was excited by the new technology represented by her sewing machine, yet who was still learning how to incorporate it into her quiltmaking process. Combining machine sewing with hand sewing in her quilt may have allowed Sneed to adapt to the changes taking place in her culture and to navigate the new ways that were emerging.

The Shaw quilt, the Sneed quilt, and others from the 1850s show that the sewing machine was not feared by all women - young or old - and, instead, was employed by young and old women alike to make a variety of items. Further research is needed to gain a fuller understanding of how many quilts from the sewing machine's first decade show machine stitching. Quilt scholar Anita Loscalzo persuasively suggests that "many

\footnotetext{
44 "Cheater cloth," also known as "imitation patchwork" and "printed patchwork," is a cotton fabric printed to look like pieced patchwork. Initially produced by English and American printers in the 1840s and 1850s, simulated patchwork fabrics continued to be popular into the early twentieth century. These fabrics reflected the taste of the time - log cabin blocks in the 1850s, employing Centennial motifs in the 1870s and Dresden Plate and Grandmother's Flower Garden patterns in the 1930s. Brackman, Clues in the Calico, 94-95; Bassett and Larkin, Northern Comfort, 78.

${ }^{45}$ Email correspondence from Alden O'Brien, curator of costume and textiles, Daughters of the American Revolution Museum, Washington, D.C., November 10, 2008.

${ }^{46} \mathrm{I}$ am indebted to Alden O'Brien, curator of costume and textiles, and to Virginia Vis, curatorial volunteer, at the Daughters of the American Revolution Museum for their insights during our examination of the Sneed quilt on June 23, 2009.
} 
more were done, but not kept and valued because of changes in taste."47 The rise of the Colonial Revival aesthetic during the late nineteenth and early twentieth centuries led to a revival of handwork and a distaste for machine-made items. As quilts - and other decorative needlework - that showed machine work were rediscovered by descendants, museums and dealers, they do not appear to have been valued or kept by these people to the same degree as entirely hand-made examples.

Yet, while the machine made quick work of formerly time-consuming plain sewing, such as the miles of seams sewn to construct sheets and towels, and the constant making and mending of family clothing, the time that was saved was quickly redirected to the production of more elaborate clothing, and to fancywork. One 1859 sewing guide championed the machine as "the liberator of our sex" but explained that this meant that women would have more time for hand-wrought fancy work. ${ }^{48}$ Likewise, in 1860 , Godey’s Lady’s Book suggested, “The Sewing Machine should be here named as the completement of the art of needle-work. It, the machine, will do all the drudgeries of sewing, thus leaving time for the perfecting of the beautiful in woman's handiwork." 49 Rather than freeing women from household drudgery, some women saw it merely as a machine that made one area of their work faster, thus allowing the time saved to be spent on other domestic chores. Decorative needlework continued to be an emotional issue, with two distinct sides - one that lauded the ability of women to focus more time on the beautiful and one that saw it marginalizing women even more, away from skilled jobs and a decent wage. And, changing views of women's needlework could often be divided along generational lines.

\footnotetext{
${ }^{47}$ Loscalzo, "The History of the Sewing Machine," 187.

${ }^{48}$ Mrs. Pullan, The Lady's Manual of Fancy-Work (New York: Dick \& Fitzgerald, 1859), xiv-xv.

49 “The Sewing Machine,” Godey's Lady's Book 60 (November 1860), 463.
} 


\section{Agricultural Fairs: A Means of Recognition or Marginalization?}

At the end of the 1850s, the New York Tribune predicted that "the needle will soon be consigned to oblivion, like the [spinning] wheel, and the loom, and the knittingneedles... The more work can be done, the cheaper it can be done by means of machines..."50 While an urban northeastern newspaper could be matter-of-fact about this development, boiling it down to a clear-cut statement of economic value, changes in textile and needlework production between 1820 and 1860 actually provoked numerous types of reactions, from fear and reluctance to wholehearted approval. And the conflict between these reactions often played out at agricultural fairs in the northeastern and midwestern United States.

The first American agricultural fair, convened in Pittsfield, Massachusetts, in 1810, was the brainchild of Elkanah Watson (1758-1842). Watson created the Berkshire Agricultural Society to offer a practical means of education for local farmers. ${ }^{51}$ While Watson's aims were pragmatic, he also realized that he needed to have a social element to maintain interest. To increase participation, the 1811 fair was bigger and grander with a parade and awards, or premiums, for the best entries. By 1813, the Berkshire Agricultural Fair included an "Agricultural Ball" and invited women to compete for prizes with their textiles. ${ }^{52}$

The agricultural society movement gained strength during the first half of the nineteenth century. By 1860, there were over 700 county and local agricultural societies

\footnotetext{
${ }^{50}$ Quoted in Claudia B. Kidwell and Margaret C. Christman, Suiting Everyone: The Democratization of Clothing in America (Washington, DC: Smithsonian Institution Press, 1974), 79.

${ }^{51}$ Mark A Mastromarino, "Elkanah Watson and Early Agricultural Fairs, 1790-1860," Historical Journal of Massachusetts 17 (Summer 1989): 106-107.

52 Mastromarino, "Elkanah Watson," 109-110; Catherine Kelly, "The Consummation of Rural Prosperity and Happiness: New England Agricultural Fairs and the Construction of Class and Gender, 1810-1860," American Quarterly 49 (September 1997): 581.
} 
in the north and the west, most modeled on Watson's "Berkshire Plan."53 Local women quickly took a visible role by assisting with decorating the hall and entering needlework and foodstuffs in the competitions.

New England's agricultural fairs employed the rural agrarian tradition to cope with technological changes, an evolving economy and shifting gender roles. The annual reports of the exhibits of "domestic manufactures" are often telling, with the descriptions serving as a locus for the intersection of old traditions and new products, as well as for old gender roles and new economic realities. Historian Catherine E. Kelly found that:

[rural men] attempted to reconcile the domestic manufactures of their mothers with the fancy work that occupied the imaginations of their wives and daughters, simultaneously applauding old-fashioned economy while celebrating the fashionable display that attended middle-class culture even in rural New England. In the process, they elaborated the distinctions between utility and ornament, between farmer's wife and leisured lady, between household economy and middle class domesticity. ${ }^{54}$

Agricultural fairs offered women a socially acceptable means of achieving recognition for their work, allowing them to build self-esteem and make a contribution to their community. As historian Linda Borish observed: "While many farmers criticized and underappreciated farm women's labors at home, when women showed these labors for all to see in public, suddenly, her skills became acclaimed and she held some cultural power." $"$ As mechanized industrialization spread across the country during the mid- and late-nineteenth century, the displays of "domestic manufactures" at the annual agricultural fair offered a touchstone for residents who were anxious about these changes as well as a means for older women to resist their marginalization.

\footnotetext{
${ }^{53}$ Kelly, "The Consummation of Rural Prosperity," 579.

${ }^{54}$ Kelly, "The Consummation of Rural Prosperity," 586-587.

${ }^{55}$ Linda J. Borish, "A Fair, Without the Fair, is No Fair at All': Women at the New England Agricultural Fair in the Mid-Nineteenth Century," Journal of Sport History 24 (1997): 162.
} 
Not only women noticed the changes taking place in textile and needlework production. Connecticut Congregationalist minister Horace Bushnell (1802-1876) commented in 1851 that "this transition from mother and daughter power to water and steam-power is a great one, greater by far than many have as yet begun to conceive." 56 Yet, for every Bushnell who applauded the industrial changes taking place and the impact they had on American women, there was another who was less comfortable with these developments. For example, an 1856 Ohio agricultural society report commented, "We are glad to see from these beautiful specimens, that the spinning wheel and loom are not defunct institutions in American homes...We were greatly pleased, too, with an embroidered cushion, on an elegant chair, the work of a lady sixty years old...Beautiful in itself, it was more still an object of interest from the age of the lady who wrought it."57 These comments, found readily in the accounts and records of local agricultural fairs, touch on two sources of anxiety and ambivalence specific to female adoption of mechanized and industrial developments pertaining to needlework. First, they suggest a generational conflict between young women who could purchase fabric at the local store and sew quick seams on a sewing machine, and their mothers and grandmothers who were raised to equate industry, gentility and femininity with their needles. Second, these comments also point to a gender-based conflict between aging women and their menfolk,

\footnotetext{
${ }^{56}$ Quoted in Ulrich, The Age of Homespun, 21. Horace Bushnell's "The Age of Homespun," published in an anthology of his work, Work and Play (New York: Charles Scribner's Sons, 1881), was originally a speech given on the second day of the Litchfield County [Connecticut] Centennial, August 14, 1851 in Litchfield, CT; see Ulrich, Age of Homespun, 12-25. As a boy, Bushnell worked in his father's textile mill. For biographical information on Bushnell, see E. Brooks Holifield, "Bushnell, Horace," http://www.anb.org.silk.library.umass.edu:2048/articles/08/08-00219.html, American National Biography Online, February 2000, accessed January 3, 2009.

${ }^{57} 11^{\text {th }}$ Annual Report of the Board of Agriculture of the State of Ohio: to the Governor, for the Year1856 (Columbus: Richard Nevins, 1857), 162.
} 
as women were more and more tightly circumscribed in the home. ${ }^{58}$ And, in both cases they suggest how nostalgia for the past could be a motivator for action in the present, influencing the types of needlework aging women made and how they used it.

As one (presumably male) reporter wrote in 1829, "We would restore the good old day of housewifery, when...women knew the use of the distaff, and instead of waltzes, cantatas, and duets, thrummed out by a boarding school miss, upon a discordant piano, the houses of our farmers rang with the cheerful sound of the wheel... and the loom..."59 Disdainful of the shallow achievements of women of his day, this writer bemoaned what he saw as an exchange of productive work spinning thread and weaving cloth for frivolous dances and songs. "[The farmer's daughter] is better educated than her mother, perhaps, and not half so good a housekeeper," explained another commentator, "and so she naturally takes to fashion and light literature, receives calls and returns them, dusts the parlor for her share of the housework, works worsted cats and dogs for intellectual discipline, and wears a stylish bonnet to church by way of morals and religion." 60 Contemporary literature and prints illustrated the dangers of a society where young women were taught to value beauty over industry. For example, the satirical print by Gillray in figure 1.5 shows the airs that one daughter returning from boarding school had taken on. Many writers were concerned about the dangers of consumption to the financial well-being of American families, as well as to maintaining a sense of class difference, at the expense of industry and thrift. ${ }^{61}$

\footnotetext{
${ }^{58}$ Jeanne Boydston, Home and Work: Housework, Wages and the Ideology of Labor in the Early Republic (New York: Oxford University Press, 1990), 156.

${ }^{59}$ The New England Farmer, November 6, 1829.

${ }^{60}$ Henry F. French, "Make Your Girls Independent," New England Farmer, October 1854.

${ }^{61}$ See Catherine E. Kelly, In the New England Fashion: Reshaping Women's Lives in the Nineteenth Century (Ithaca: Cornell University Press, 1999), 214-241.
} 
But, for some, mechanization was a good thing - it freed women to pursue nobler aims as they cultivated their own knowledge and transferred it to their offspring, not unlike the goals of the Republican Motherhood of their grandmothers. In 1857, the Ohio State Board of Agriculture presented a positive view of these changes for women:

What a vast amount of female labor has been superceded by the spinning machine, power loom, knitting and sewing machine. So far as the employment of females in the farmers house is concerned, the wives and daughters of the future farmers of Ohio cannot realize the condition of those who lived during the first half century of its existence in this state. We hope the day is not far distant when the farmer's wife shall be relieved from all drudgery, and can devote her time more to the mental and physical education of her offspring, and the cultivation of science, arts and literature. ${ }^{62}$

According to this report, the women of 1857 were better off than their predecessors.

They could spend less time working and more time caring for their families and pursuing their own interests, including, presumably, decorative needlework.

Previous studies of needlework at agricultural fairs have relied on the printed records of the societies and the fairs. ${ }^{63}$ These studies focused on specific states and used a quantitative methodology to analyze the categories and the premiums awarded. Quilt historian Barbara Brackman's analysis of Kansas agricultural fairs suggests that these displays influenced the spread of quilt patterns and styles. She states that the ribbon winners were held up as worthy of imitation - the women who entered their quilts did so, at least in part, as a point of pride. She concluded that while the prize categories affected aesthetics, the newspaper accounts of the needlework shown created taste. ${ }^{64}$ Virginia Gunn's study of Ohio fairs drew similar conclusions, stating that the agricultural fair

${ }^{62} 12^{\text {th }}$ Annual Report of the Ohio State Board of Agriculture...for the Year 1857 (Columbus: Richard Nevins, 1858), 150.

${ }^{63}$ See Barbara Brackman, "Fairs and Expositions: Their Influence on American Quilts" in Bits and Pieces: Textile Traditions, Jeannette Lasansky, ed. (Lewisburg, PA: Oral Traditions Project, 1991), 91-99; and Virginia Gunn, "Quilts at $1{ }^{\text {th }}$ Century State and County Fairs: An Ohio Study," Uncoverings 9 (1988): 105-128.

${ }^{64}$ Brackman, "Fairs and Expositions," 92-95. 
displays in that state provided inspiration for future needlework and helped shape regional taste and stylistic preferences in quiltmaking. ${ }^{65}$ Winning a prize allowed a woman to gain prestige, feel pride in her work and acquire some material reward. The premiums rewarded evidence of skill, industry, thrift and good taste. ${ }^{66}$ Certainly, aging women found prize recognition to be a useful tool in fighting their marginalization to the hearth. They were able to display their abilities as well as a pursuit of industry and thrift - and thus their continued value to family, home and community, despite the many changes taking place around them.

These studies have also noted that entries by the very old and the very young were often singled out as particularly noteworthy. ${ }^{67}$ Quilt historian Barbara Brackman suggests that this may be due to "the inarticulateness of the male reporters assigned to cover the ladies' exhibits." ${ }^{68}$ For example, the Domestic Hall at an 1858 Ohio fair was described this way:

There were many quilts there, the handiwork of the fair ladies of Ohio - some were really fine, others pretty, and some gaudy... There were a hundred different articles of use or ornament that doubtless skipped our eye among the rest; for we have only an indistinct recollection of a mixed mass of dry goods. Some one of our lady readers will doubtless supply us with a better description of the remarkables in this hall. ${ }^{69}$

Lacking the expertise to comment more specifically on the features of the craftwork displayed, these reporters focused on the "human interest" aspect of the show - youth and age, while implicitly marginalizing women's skill and work, as well as the varied talents and production that they pursued every day in the home and exhibited at the fair.

\footnotetext{
${ }^{65}$ Gunn, "Quilts at $19^{\text {th }}$ Century State and County Fairs," 106.

${ }^{66}$ Borish, "“A Fair, Without the Fair, is No Fair at All'," 163-166.

${ }^{67}$ Brackman, "Fairs and Expositions," 94-95; Gunn, "Quilts at 19 $9^{\text {th }}$ Century State and County Fairs," 117.

${ }^{68}$ Brackman, "Fairs and Expositions," 95.

${ }^{69}$ As quoted from a newspaper account in $13^{\text {th }}$ Annual Report of the Ohio State Board of Agriculture...for the Year 1858 (Columbus: Richard Nevins, 1859), 142-143.
} 
Agricultural fairs offered mature women an arena in which to express their own pride in their work, and also to call the attention of others to that work - and the skill it represented. A report of the 1843 Lake County [Ohio] Agricultural Society fair recounted that part of the parade to the fairgrounds included "about thirty-five ladies engaged in knitting, sewing, spinning, and various other employments, significant of the high and important position which female industry occupies in the great workshop of civilization." ${ }^{70}$ Women's work was not only important for individual ladies, but for society and civilization. The Ohio reporter went on to explain that the agricultural fairs "produce laudable emulation., ${ }^{, 71}$ Indeed, aging women who entered their needlework in the fairs understood this and used the agricultural fair as a way to show their pride in their work and their importance to home, community and nation.

In April 1856 a group of Nantucket island residents gathered to establish the Nantucket Agricultural Society, motivated in large part by a desire to effect significant change on the island, in order to recapture economic viability. ${ }^{72}$ In a sense, the group was taking steps to resist the marginalization of their entire community. Chartered by the state of Massachusetts, the Society was formed "for the encouragement of Agriculture and Mechanic Arts, in the County of Nantucket, by premiums and other means." ${ }^{.73}$ Nantucket Island is well-known for its history as a whaling port. But by the mid-1840s, the whaling industry was in decline and island residents were forced to consider new ways to make a living. Nantucket's population in 1840 was about 10,000 , but as the

\footnotetext{
${ }^{70}$ The Weekly Ohio State Journal, November 1, 1843.

${ }^{71}$ The Weekly Ohio State Journal, November 1, 1843.

${ }^{72}$ For more on the early history of the Nantucket Agricultural Society, see Aimee E. Newell, “"'No Harvest of Oil”: Nantucket's Agricultural Fairs, 1856-1890," in New England Celebrates: Spectacle, Commemoration, and Festivity, Peter Benes, ed. (Boston: Boston University, 2002), 149-165.

${ }^{73}$ Transactions of the Nantucket Agricultural Society for 1856 (New York: Nantucket Agricultural Society, 1857), 6-10. Hereafter, Transactions.
} 
whaling industry waned, thousands of islanders left their homes in pursuit of alternate ways of making a living. By 1870 , the island's population had declined to 4,000 people. $^{74}$

After its founding, the Nantucket Agricultural Society quickly set to work encouraging residents to farm the land in order to offset the loss of the whaling industry. From October 28 to 30, 1856, the Society held its first fair. According to newspaper accounts, attendance at the Fair was overwhelming. Initially scheduled for only one day, its popularity spilled onto a second day when 1,200 people attended, prompting Fair organizers to hold it open for a third consecutive day. ${ }^{75}$

Newspaper accounts reported that the women of the Society decorated the hall and arranged the exhibits of fruits, vegetables, and fancy goods. Women were also active in performing evening programs, writing songs and conducting choirs. And they created a quilt, presumably as a fundraiser for the Society (figure 3.5). Details on why the quilt was made are frustratingly vague in the newspaper reports and Society records. One island newspaper reported only that "an Album Quilt was exhibited by the Society, composed of squares marked with the autograph of the maker, each square made by a different person. ${ }^{, 76}$

Despite this description, physical evidence makes it seem more likely that the quilt was made by a small group of women and then signed by members of the

\footnotetext{
${ }^{74}$ Newell, "No Harvest of Oil," 149.

${ }^{75}$ Nantucket Inquirer, October 31, 1856.

${ }^{76}$ The Weekly Mirror, November 1, 1856. The quilt is now in the collection of the Nantucket Historical Association, Nantucket, Massachusetts. For more information on the quilt, see: Aimee E. Newell, "Agricultural Fairs and Quilts," in Bassett, ed., Massachusetts Quilts, 182-185; and Aimee E. Newell, "Island Pride: The Nantucket Agricultural Society Quilt," PieceWork Magazine 14 (September/October 2006): 28-31.
} 


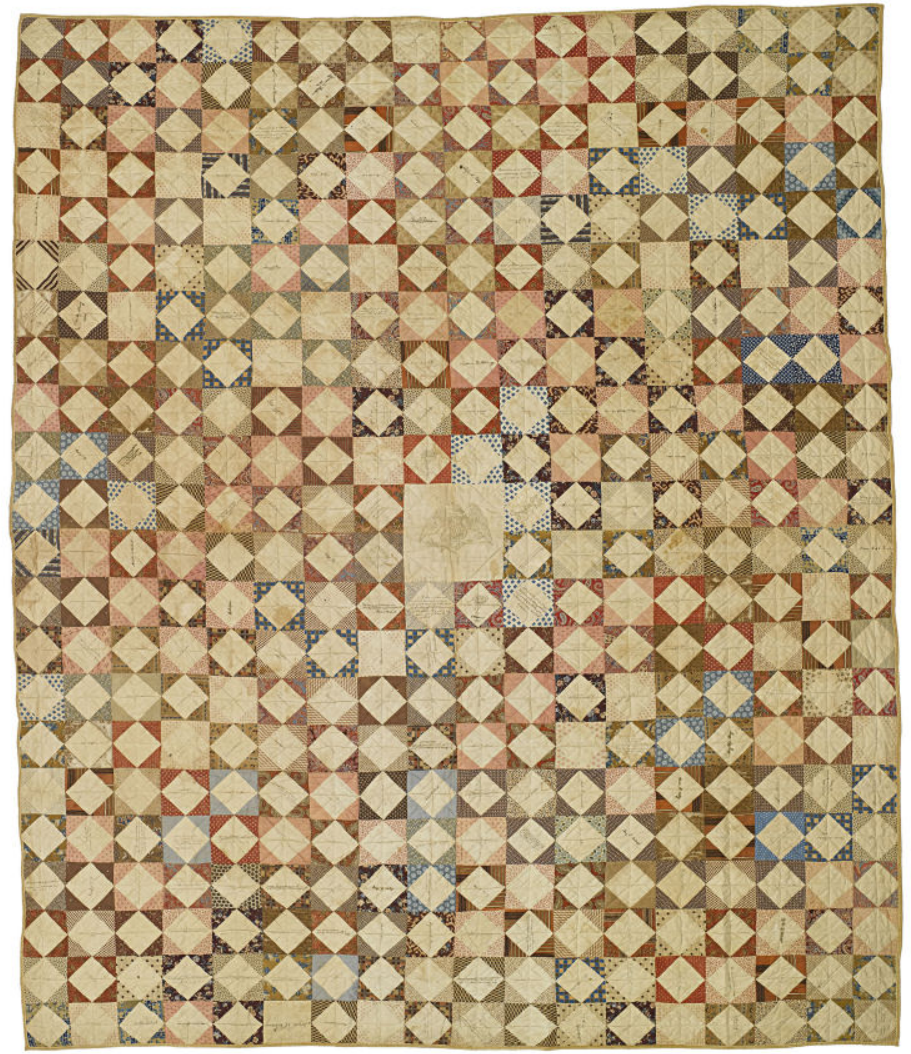

Figure 3.5. Nantucket Agricultural Society Quilt, 1856, Nantucket, Massachusetts. Courtesy of the Nantucket Historical Association, Nantucket, Massachusetts.

This quilt, made for the first Nantucket Agricultural Society fair, seems to have been made under the direction of Lucy Macy Mitchell and Hannah Gardner Fosdick. Each diamond was signed by an islander and the quilt may have been auctioned off to raise money for the Society. 
Society and their families. At least one handwritten signature runs into the pieced triangle at the corner of the block, suggesting that the quilt top was constructed before the blocks were signed (figure 3.6). And, the dates on the signature blocks range from October 15 to October 21, just a week before the fair. The quilt must have been put together long before these dates in order for it to be completed for display on October 28 . The Society's records suggest that the quilt was auctioned off. On the last evening of the Fair, a song by the Glee Club was "followed by the auction bell, calling all to the sale of the remaining articles donated to the fair.",77

The quilt contains about 218 signatures of men, women and children, although some are now too faint to decipher and others have faded completely. In addition to the names, the quilt includes many verses. Some relate directly to agriculture, such as that on the square signed by Nathaniel Barney (1792-1869), who wrote "He that ploweth should plow in hope." Other verses reflect more standard sentiments including, "God is love," and "As the twig is bent the tree is inclined." The quilt is pieced in a simple square block, known alternatively as "Friendship Album Quilt," "Broken Sash," and "Dutch Tile." 78 The center square of the quilt is larger than the pieced blocks and has an inked drawing of an eagle with a faint verse written underneath reading, "Nantucket Agricultural Society, incorporated / in the year one thousand, eight hundred, and / fifty six. / Lucy S. Mitchell" (figure 3.7). These inked inscriptions are a central part of the design plan for the quilt and would not have been possible without the antebellum advances in indelible inks. Community members were able to personalize their block

\footnotetext{
${ }^{77}$ Transactions, 47.

${ }^{78}$ Barbara Brackman, Encyclopedia of Pieced Quilt Patterns (Paducah, Kentucky: American Quilter's Society, 1993), 300. The quilt blocks have muslin centers with triangles of printed cottons at the corners in pink, brown, blue and other colors. It is quilted in a grid pattern combined with an "X" through each block. The quilt is backed with a printed pink cotton fabric and bound with brown striped twill tape.
} 


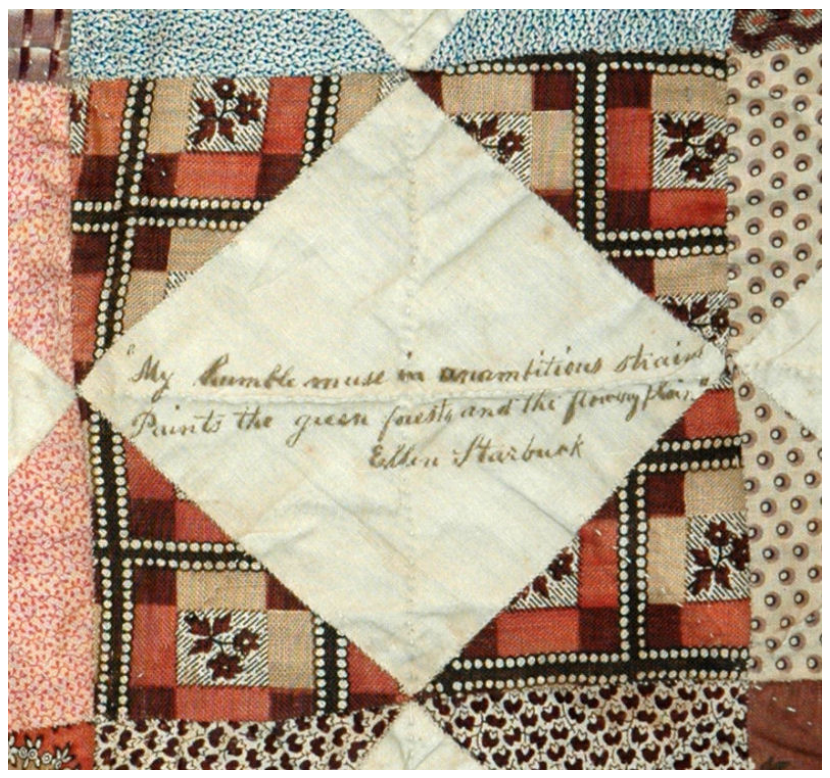

Figure 3.6. Detail of signed block on Nantucket Agricultural Society quilt.

Verse: My humble muse in an ambitious strain, Paints the forest green and the flowing [plain?]. Ellen Starbuck.

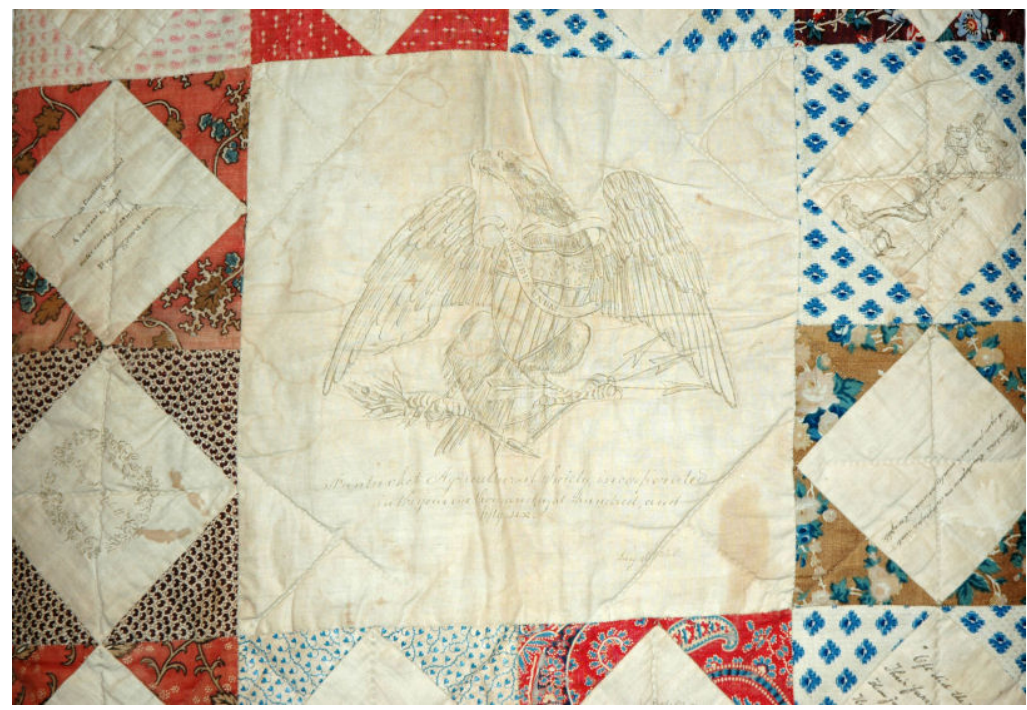

Figure 3.7. Detail of center block on Nantucket Agricultural Society quilt.

Verse: Nantucket Agricultural Society, incorporated/in the year one thousand, eight hundred, and / fifty six. / Lucy S. Mitchell. 
beyond just signing their name. They could be spontaneous by adding a favorite verse or drawing a personal symbol.

Newspaper accounts of the fair reprinted several of the songs performed during the evening activities, including one called "The Agricultural Fair," written by fifteenyear-old Margaret Getchell (1841-1880), who also signed one of the quilt's blocks. One stanza of the song reads, "Here's GARDNER with his plenteous horn, In Album Quilt displayed, With colored squares and stitches fine, That ladies fair have made; With MRS. MITCHELL'S eagle proud, In centre-piece outspread, And MRS. FOSDICK'S model plough, With not a line mislaid., ${ }^{, 79}$ The song verse seems to be describing the signature quilt with its central square showing an inked eagle. There are no Mrs. Mitchells or Mrs Fosdicks listed as premium winners in the quilt category at the Fair, but "Mrs. H. Fosdick" received special mention for "handsome specimens of marking with indelible ink" shown at the Fair. ${ }^{80}$ And "Lucy S. Mitchell" is the name in the central square with the inked eagle, suggesting that she is the Mrs. Mitchell named in the song. Forty-sevenyear-old Hannah M. Gardner Fosdick (1809-1864) and forty-four-year-old Lucy S. Macy Mitchell (1812-1875) also signed multiple blocks in the quilt, underscoring that they were instrumental in creating it. ${ }^{81}$ The centrality of the inked drawings and signatures attracted attention - from the newspaper and from fairgoers.

\footnotetext{
${ }^{79}$ Transactions, 47-48. The "Gardner" in the song probably refers to Edward Gardner (1804-1863), founding President of the Nantucket Agricultural Society.

${ }^{80}$ Transactions, 63.

${ }^{81}$ Hannah M. Gardner was born December 20, 1809, the daughter of Oliver C. Gardner (1784-1860) and Hannah Macy (1788-1867). She was the second wife of Obed Fosdick (1801-1852) and they had two children, John B. M. (b. 1848) and Oliver G. (b. 1849). After her husband died in 1852, Hannah Fosdick ran a dry goods store. One island memoirist described her as "a large woman of peculiar and distinctive characteristics...she was indeed a striking character, was a shrewd business woman, and creditably maintained her home from her store sales." Joseph E. C. Farnham, Brief Historical Data and Memories of My Boyhood Days in Nantucket (Providence: Snow and Farnham, 1915), 77. According to the 1860 U.S. Census, Hannah Fosdick had a personal estate valued at $\$ 3,000$. She died on February 21, 1864. Lucy
} 
The choice made by these Nantucket women to stitch a signature quilt for the island's first Fair was deliberate. Signature quilts initially appeared in the Delaware Valley in the 1840s. From the mid-Atlantic region, the style traveled to New England, Virginia and Ohio by the mid-1840s and enjoyed enormous popularity until the mid$1850 \mathrm{~s} .{ }^{82}$ Given their rapid rise in popularity, their reliance on a set formula and their limited duration, signature quilts fit the definition of a fad. But, they also served a serious purpose - they assisted their makers and owners with adapting to major - and often disruptive - life changes when they were given as wedding presents or as going away gifts to couples or families moving west. ${ }^{83}$ Given the significant economic and social changes taking place on Nantucket - the demise of the whaling industry and the resulting departure of many island residents - it is not surprising that the ladies of the Agricultural Society chose a quilt that symbolically gathered their community together. Signature quilts were a tangible reminder of family and friends - and the social support they provided. Made to preserve and remember events and relationships of the past, they can be understood as an attempt to slow down time and cherish the past.

\footnotetext{
Macy was born on May 19, 1812, the daughter of John W. Macy (1790-1831) and Sally Swain (17901824). In 1834, she married Francis Mitchell (1808-1890) and they had one son, John W. (b. 1836). According to the U.S. Census in 1850 and 1860, Francis was a shoemaker and then a dry goods merchant. Francis was also a founding member of the Nantucket Agricultural Society, initially appointed to the Society's Finance Committee. Lucy is listed as "Lucy S. Mitchell" in both years, although her middle name is not identified in island genealogical records. Lucy S. Macy Mitchell died on December 27, 1875. Her obituary in the island newspaper remembered her as "a woman of rare Christian virtues, social in her nature, ever welcoming one and all to her quiet home, which, in its beautiful surroundings of nature and art, was truly emblematic of that paradise promised above." Nantucket Inquirer and Mirror, December 29, 1875. Genealogical information from the Barney Genealogical Record, Nantucket Historical Association Research Library, Nantucket, Massachusetts; U.S. Census information from www.ancestry.com, accessed January 2, 2009.

${ }^{82}$ Jessica F. Nicoll, Quilted for Friends: Delaware Valley Signature Quilts, 1840-1855 (Winterthur, Delaware: Winterthur Museum and Gardens, 1986), 5, 7; Barbara Brackman, "Signature Quilts: Nineteenth-Century Trends," Uncoverings 10 (1989): 28-33.

${ }^{83}$ Nicoll, Quilted for Friends, 11.
} 
Signature quilts can also serve as symbols of the ambivalence surrounding midnineteenth century mechanization, particularly as it affected textile production. They were a tool by which women could navigate their changing culture. For mature women, making and giving signature quilts could be a reaction to industrialization. As one quilt scholar has explained, these quilts were "a way of countering the disruptive forces that were weakening their networks of social interdependence." ${ }^{84}$ They retained the traditional form of the block-set quilt, while also offering women a way to mediate the newness of roller-printed fabrics and seemingly-magical indelible ink. These quilts could be personalized in new and different ways, offering a freedom of expression to counsel the recipients with a favorite proverb, or to just sign one's name in his or her own unique way.

In the mid-Atlantic region, sixty-year-old Euphemia Righter's (1790-1873) signature quilt, finished in 1850 , is typical of its era (figure 3.8). ${ }^{85}$ She signed the center block, "Mrs. Euphemia Righter / Beaver Meadow / Penna. / February $8^{\text {th }}$, 1850" (figure 3-9). The thirty-two smaller blocks making up the quilt top are signed by relatives and neighbors, which allowed Righter to gather her community around her every time she used the quilt. ${ }^{86}$ Euphemia signed the center block of her quilt, placing herself at the

\footnotetext{
${ }^{84}$ Jessica F. Nicoll, "Signature Quilts and the Quaker Community, 1840-1860," Uncoverings 7 (1986): 36.

${ }^{85}$ The quilt is now in the collection of the State Museum of Pennsylvania, Harrisburg, Pennsylvania. It is pictured in Lucinda Reddington Cawley, Lorraine DeAngelis Ezbiansky, and Denise Rocheleau Nordberg, Saved for the People of Pennsylvania: Quilts from the State Museum of Pennsylvania (Harrisburg, Pennsylvania: Pennsylvania Historical and Museum Commission, 1997), 18-19. The quilt was brought from Pennsylvania to Chicago by members of the Connecticut branch of the Stiles family and then handed down in that family until it was given to the State Museum of Pennsylvania in 1983. The signatures of Nathan D. Stiles and Richard Stiles appear in two of the quilt's blocks. Curatorial file, State Museum of Pennsylvania, Harrisburg, Pennsylvania. I am indebted to curator Beatrice Hulsberg for sharing the file with me.

${ }^{86}$ The quilt's technique shows that one person, presumably Euphemia Righter, made all of the blocks, but that they were signed individually. Cawley, Ezbiansky and Nordberg, Saved for the People of Pennsylvania, 18.
} 


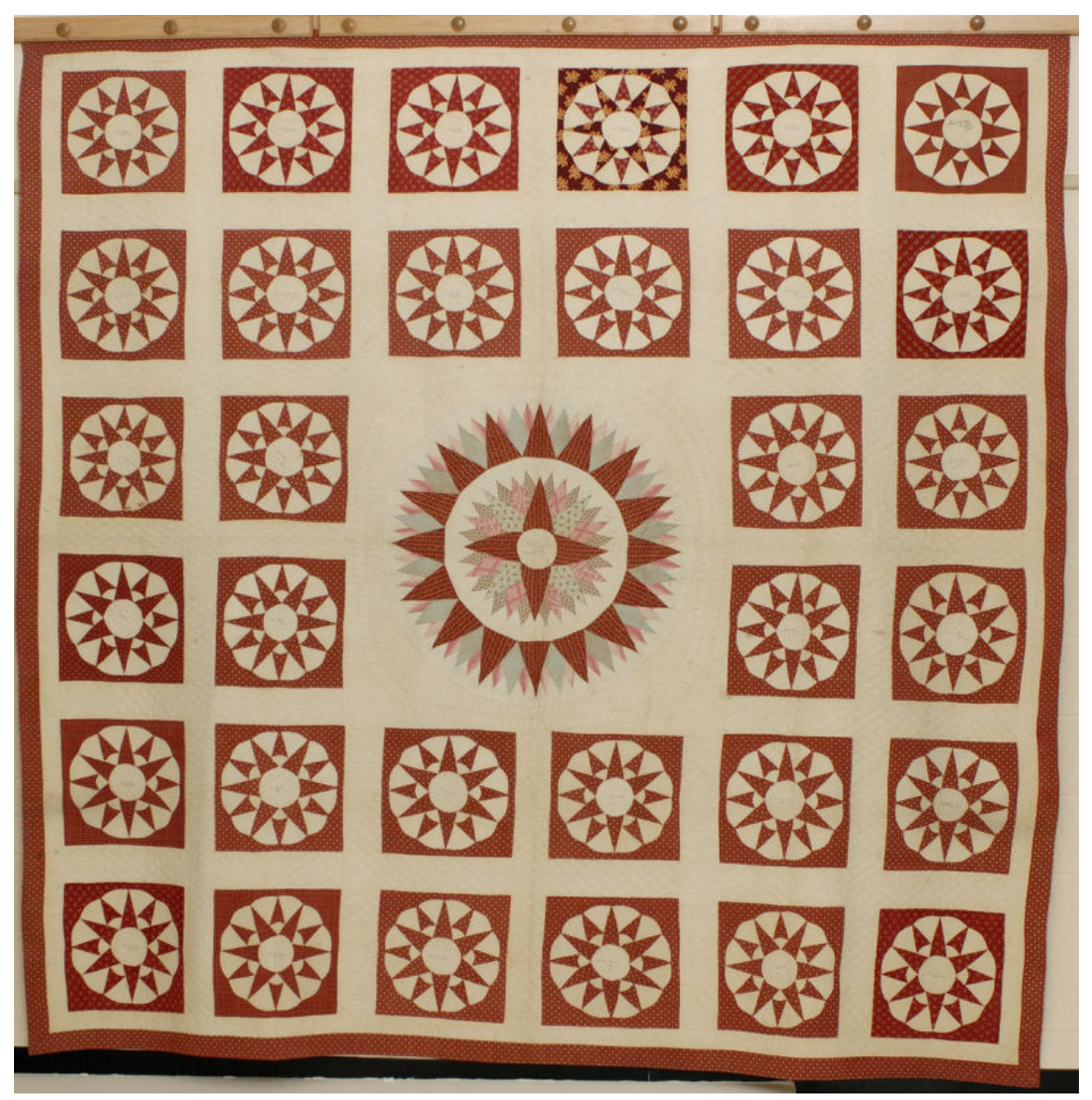

Figure 3.8. Quilt by Euphemia Wilson Righter (1790-1873), 1850, Beaver Meadow, Pennsylvania. Courtesy of the State Museum of Pennsylvania, Harrisburg, Pennsylvania.

Euphemia Wilson Righter had her children and neighbors sign the centers of the blocks on this quilt. She placed herself at the middle. 


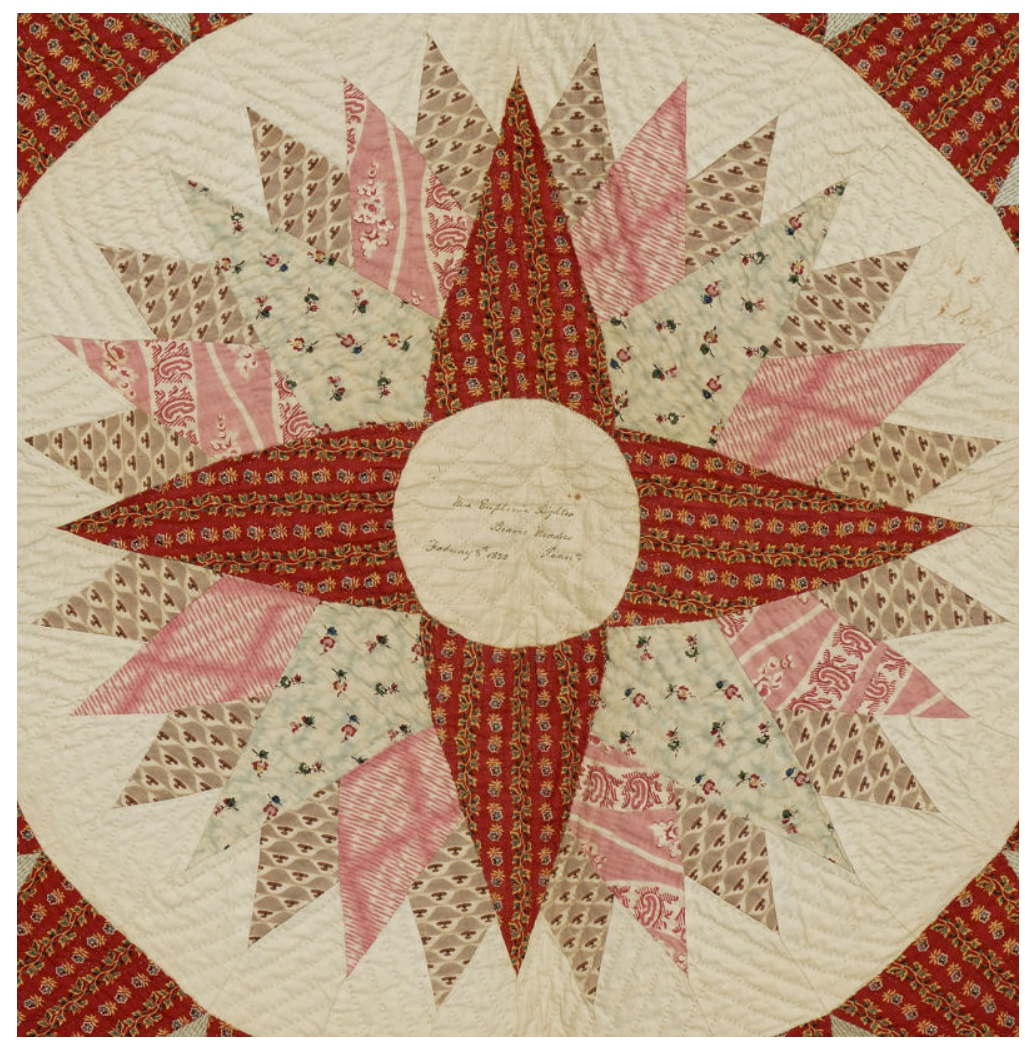

Figure 3.9. Detail of central medallion from quilt by Euphemia Wilson Righter. Inscription: Mrs. Euphemia Righter, Beaver Meadows, June 5, 1849. 
center of her family and community. She grouped the other signed blocks by family names.

Euphemia's daughter, Jane Righter (b. 1816), who had married Dr. Isaiah McKay (1812-1858) around 1837, signed the quilt, as did both of Euphemia's daughters-in-law, but not her sons. ${ }^{87}$ A younger son, John W. Righter (1819-1856), was a mill owner who married Margaretta Woodnutt Hall (b. 1815). ${ }^{88}$ Older son William Wilson Righter (known as W.W.) (1817-1854) married Jane Ferguson McNair (1820-1891) in 1841. They moved to Mauch Chuck, Pennsylvania, in 1850, the same year that Righter completed her quilt. ${ }^{89}$ W.W. Righter was a doctor and several of his patients also signed blocks, suggesting that it may have been intended as a gift for the couple. ${ }^{90}$

The quilt is large, measuring 111 inches by 108 inches. It includes thirty-two thirteen-and-a-half inch square blocks plus the larger and more elaborate center compass block. The earliest dates on the blocks are from 1844, with the latest dates in 1850. This helps to pinpoint when Euphemia started her quilt and also tells us that she worked on it for six years. A woman of Righter's experience and skill could certainly have pieced these blocks in a matter of weeks and then spent several days quilting it, either alone or with friends. The six-year spread of dates on the blocks suggests that she did not put the quilt together until after the last block was signed in 1850 since it would be much easier to sign the blocks before they were joined together and quilted. Why did it take six years for her to gather the signatures? Is this a reflection of the changing times? The demands

\footnotetext{
${ }^{87}$ Cawley, Ezbiansky, and Nordberg, Saved for the People of Pennsylvania, 18; curatorial file, State Museum of Pennsylvania, Harrisburg, Pennsylvania.

${ }^{88}$ Biographical, Genealogical and Descriptive History of the First Congressional District of New Jersey (New York: Lewis Publishing Co., 1900), 1-521.

89 James Birtley McNair, McNair, McNear, and McNeir Genealogies (Chicago: the author, 1923), 259.

${ }^{90}$ Cawley, Ezbiansky, and Nordberg, Saved for the People of Pennsylvania, 18.
} 
of her occupation? Instead of an aging housewife who found herself with more and more leisure time to fill as her children grew up, married and moved out to their own households, Righter had to support herself. She had less help and less time to sew and quilt. Was this also an effect of her age? As she aged, did failing eyesight and growing arthritis impede her progress on her quilt? We have no way to know.

Righter's quilt functions as a clear symbol of her family connections and her role as a mother and a neighbor. Her personal history helps to support our understanding of the quilt as a cherished touchstone. Born in 1790 in Moreland, Pennsylvania, Euphemia Reese Wilson married John Righter Jr. (c. 1791-1820) in November 1814, when she was twenty-four. Sadly, their marriage was cut short by John's death in $1820 .{ }^{91}$ Left a widow with three small children, Euphemia undoubtedly experienced feelings of anxiety and isolation. When she made her quilt thirty years later, she must have taken satisfaction in her achievements, despite her hardships. Indeed, she employed the Mariner's Compass block in her quilt, which was a decided show of skill; it took experience and precision to stitch this block so that all points matched up.

Righter does not seem to have married again. According to the 1850 United States Census, she was head of a Mauch Chunk, Pennsylvania household that included fourteen unrelated people, suggesting that she was running a boardinghouse..$^{92}$ One study of Pennsylvania widows from 1750 to 1850 found that more than $80 \%$ of the women who became widows (half of those who married) never married again. ${ }^{93}$ For these women, keeping their family together trumped cultural ideas of "proper female behavior." In

\footnotetext{
${ }_{91}^{91}$ Cawley, Ezbiansky and Nordberg, Saved for the People of Pennsylvania, 18.

${ }^{92}$ U.S. Census information from www.ancestry.com, accessed December 31, 2008; Cawley, Ezbiansky and Nordberg, Saved for the People of Pennsylvania, 18.

${ }^{93}$ Lisa Wilson, Life After Death: Widows in Pennsylvania 1750-1850 (Philadelphia: Temple University Press, 1992), 1-2.
} 
other words, "When proper femininity stood in the way of providing for herself and her family, cultural prescription was quietly put aside."94 For Euphemia Righter, this meant opening her home to strangers in order to make a living and provide for her children.

By its appearance, Euphemia's quilt fits neatly into the story of signature quilts a story told in several previous quilt studies. ${ }^{95}$ But, when we think about the quilt as a series of choices made by its sixty-year-old maker, consider the six years that it took for her to complete it, and admire the skill with which the challenging blocks are pieced, we can add a nuanced understanding to the quilt as the needlework of an aging antebellum woman. We should interpret the quilt as a memory object, keeping sight of what it says about its present as well as its maker's past. Like some of the other quilts in this chapter, Righter combined new materials with traditional style. The Mariner's Compass is one of the earliest-named quilt blocks; letters written during the first decade of the nineteenth century call it by this name. ${ }^{96}$ The medallion style is also an older component of the quilt, although surrounding it with blocks separated by lattice strips was a newer touch. And, the contemporary printed fabrics and indelible ink used for the signatures were also newer components in this quilt.

Recent quilt scholarship suggests that signature quilts are closely tied to the Romantic Movement, which reached its peak during the antebellum era. ${ }^{97}$ As Protestant churches began to preach that individuals had the power to determine their own religious fate, congregants began to pursue good works and to seek salvation through faith. Looking back to the chivalric knights of the Gothic and Renaissance eras, as well as a

\footnotetext{
${ }^{94}$ Wilson, Life After Death, 5.

${ }^{95}$ For example, see Brackman, "Signature Quilts," 25-37; Nicoll, Quilted for Friends; and Lipsett, Remember Me.

${ }^{96}$ Letter from Eliza Southgate, 1798, quoted in Bassett and Larkin, Northern Comfort, 61.

${ }^{97}$ Bassett, ed., Massachusetts Quilts, 269.
} 
rising interest in the individual, offered models for contemporary Americans and contributed to an increase in sentimentality and nostalgia that is evident in antebellum decorative needlework. Signature quilts seem to have been a perfect tool for provoking nostalgia - both when they were made and, particularly, as they were saved and cherished by subsequent owners.

\section{Navigating Generational Tension with a Needle}

In 1831, The New England Farmer reported that a "gratuity" was awarded to "a carpet made of shreds of cloths by Mrs. Rachael Holmes (b. 1751) of Sterling, Massachusetts, at the age of eighty - affording evidence that the hand of female industry is busy in New England from life's earliest to its declining period, and that the ingenuity of usefulness which brightens its morning cheers the serene evening of its days of good work." ${ }^{98}$ Nine years later, in 1840, ninety-year-old Mrs. Ruth Watson (b. 1750) of Spencer, Massachusetts, entered four woolen work bags in the Worcester Agricultural Society fair. According to the printed account of the fair, these bags "demonstrated to all, that even 90 years have not been sufficient to blot out that skill and dexterity which are required in producing works of ingenuity and taste. May she live a thousand years." ${ }^{.99}$

These articles, and countless others that cite the work of aging women, implied that girls and old women alike should be using their needles to remain industrious and to meet societal expectations. In 1834, the New England Farmer advocated that girls who won premiums at the annual fair deserved special consideration as potential wives. "A wife could not be dowered better," the paper asserted, "and when an agency for the

\footnotetext{
${ }^{98}$ The New England Farmer, November 16, 1831.

${ }^{99}$ The New England Farmer, November 4, 1840.
} 
procurement of marriage contracts shall be established here, the young ladies who have received premiums from this Society, should occasion the largest demands by the broker upon those who may have the good fortune to secure such prizes." ${ }^{100}$ While few agricultural fair reporters went this far - essentially making the women themselves as much a commodity as the goods they were producing - the benefits of the fairs were obvious to the entire community. The show of quilts, textiles and other items produced by women offered inspiration and a model for improvement. And, while fair organizers hoped to involve and inspire community women in direct ways; the evidence also suggests that the women manipulated the fairs to their own ends as well, using the events to focus attention on their skill, to bring attention to favorite social causes, and to hold their families and communities together.

The work of aging women displayed at agricultural fairs was often singled out, described in terms of the industry it represented and the model it set. The praise encouraged the older generation to remain productive, while reminding the younger generation that their elders represented a valued component of society. In 1843, the New England Farmer explained, "No one effect of these annual shows, perhaps, is of more beautiful tendency, than the influence they exert on the young... Of more aspiring ambition, with minds less warped by prejudice, and more susceptible of conviction than the old, the young agriculturists see and hear much at these shows that they will retain..." ${ }^{101}$ Indeed, an account of the 1842 Hartford County [Connecticut] Agricultural Fair reported that "the specimens of household manufacture, which were numerous and highly creditable, [showed] that industry and thrift are still the distinguishing

\footnotetext{
${ }^{100}$ The New England Farmer, November 5, 1834.

${ }^{101}$ New England Farmer, October 25, 1843.
} 
characteristics of our fair countrywomen." 102 Older women themselves used their needlework to send messages to the younger attendees, reminding them of the older generation's values and achievements.

Antebellum girls seem to have paid attention to their elders' example. In 1842, one reporter offered some hope for the rising generation, pointing to the cotton counterpanes submitted by two girls as a counter to fears that "the females of the rising generation" were doomed to "fall behind their granddames." 103 In 1850, the Hampshire Gazette encouraged "every bigoted admirer of grandmothers and despiser of granddaughters" to consider "a wondrous picture in worsted" on display at the local fair due to its "elegant chirography" and "meritorious" labor, which would inspire all - young and old alike. ${ }^{104}$

Forty-six-year-old Submit Gay's (1796-1880) striking Star of Bethlehem quilt, which was entered in the Hartford County Agricultural Society's 1842 fair, offered a breath-taking vista to visitors (figure 3.10). ${ }^{105}$ In addition to the large central star, the quilt incorporates eight Star of LeMoyne blocks and a pieced sawtooth border. It shows elaborate quilting in a variety of motifs, including flowers, pineapples and medallions with suns. Gay won a silver medal for her quilt, signifying that the judges considered it the best in the "bed quilt" category. ${ }^{106}$ While it is unknown how many younger visitors were inspired by this quilt, Gay's own family did value it. Though she did not have

\footnotetext{
${ }^{102}$ Hartford County Agricultural Society report for 1842 fair, quoted in the curatorial file for quilt by Submit Gay, Wadsworth Atheneum, Hartford, Connecticut.

${ }^{103}$ Hampshire Gazette, October 18, 1842, quoted in Kelly, "The Consummation of Rural Prosperity," 587.

${ }^{104}$ Hampshire Gazette, October 22, 1850, quoted in Kelly, "The Consummation of Rural Prosperity," 591.

${ }^{105}$ The quilt is now in the collection of the Wadsworth Atheneum, Hartford, Connecticut.

${ }^{106}$ The Connecticut Courant, October 15, 1842.
} 


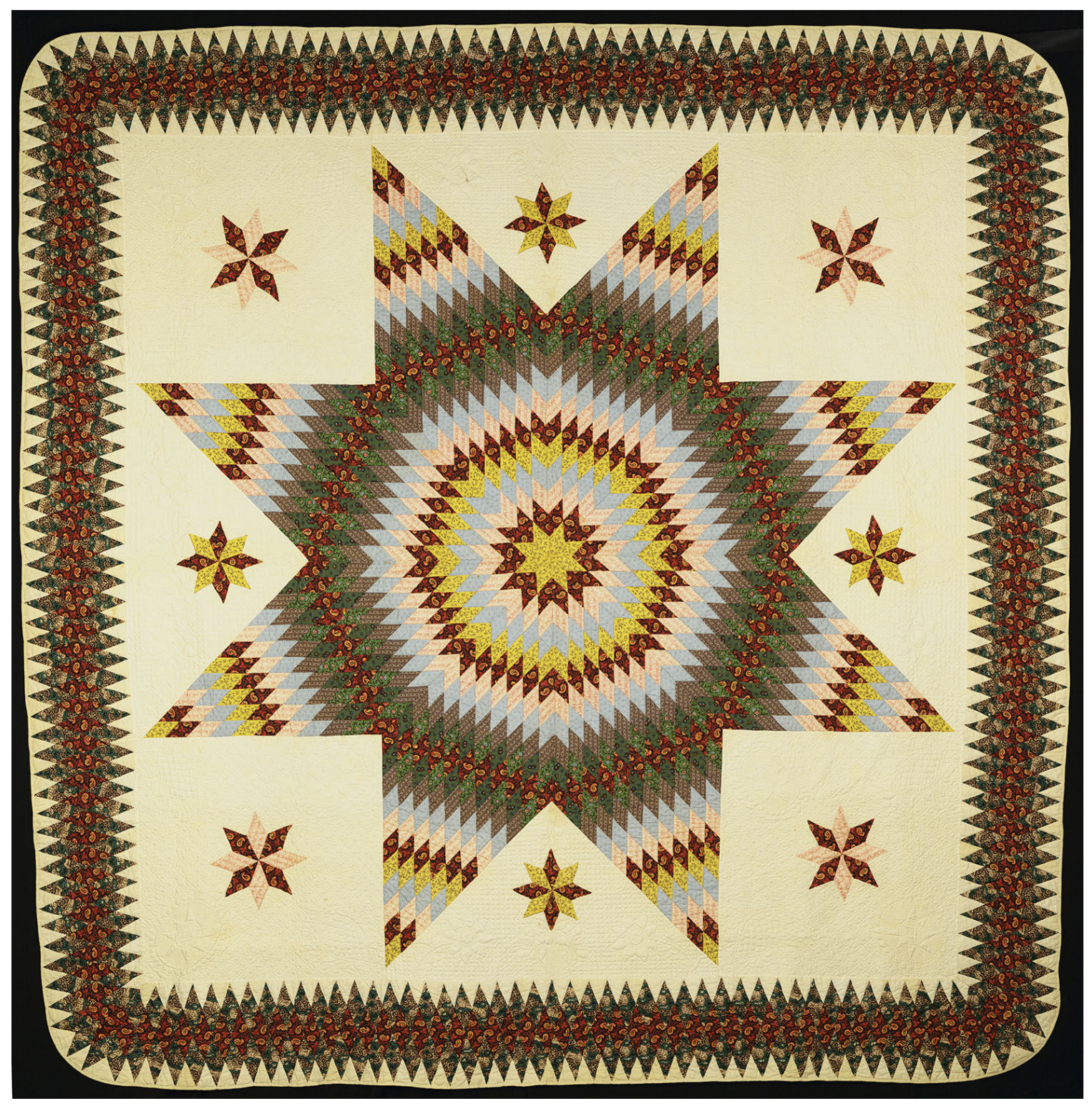

Figure 3.10. Quilt by Submit Gay, 1842, Connecticut. Courtesy of the Wadsworth Atheneum, Hartford, Connecticut.

Submit Gay entered her impressive quilt in the local agricultural fair in 1842 and won a prize for the best "bed quilt." Undoubtedly, her skilled work and the pleasing visual impact of her quilt inspired younger generations of women to follow in her footsteps. 
children to whom the quilt descended, the quilt was passed down in her family until it was donated to the Wadsworth Atheneum by her great-niece in $1926 .^{107}$

A silk hexagon mosaic quilt by forty-one-year-old Marina Jones Gregg (18111899) of Charleston, South Carolina, in 1852 offers a similar example to Gay's quilt, but from the southern United States (figure 3.11). ${ }^{108}$ Like Gay's quilt, Gregg's is also impressive due to the number of small pieces that she cut out and stitched together (figure 3.12). In addition, Gregg's quilt shows exemplary quilting at a remarkable fourteen stitches to the inch. Gregg quilted an echo of each hexagon inside the small pieces and a cable design in the navy blue silk border. ${ }^{109}$ Her work shows a level of skill that would have been understood by all women viewing the quilt, whether young or old. Whether Gregg was showing off, or just taking pride in her work, we will never know. Regardless, like Submit Gay, Gregg was rewarded for her work, winning a silver pitcher inscribed "Southern Central Agricultural Society to Mrs. M. Gregg for Best Quilt.""110 Agricultural fairs were not the only venue open to antebellum needlewomen eager to display their best work. In addition, charitable fairs abounded during the midnineteenth century, allowing women not only to show off their skill, but to also raise

\footnotetext{
${ }^{107}$ Submit Gay was born in Simsbury, Connecticut on March 12, 1796, to Richard Gay and Lucina Granger. She died in Connecticut on March 23, 1880. Genealogical information from www.ancestry.com, accessed January 4, 2009.

${ }^{108}$ The quilt is now in the collection of the Charleston Museum, Charleston, South Carolina. Marina was born in 1811, the daughter of Colonel Mathias Jones (1779-1829) and Clara Penny Jones. She married William Gregg (1800-1867) in 1829 and the couple moved to Columbia, South Carolina. They had seven children. William Gregg was a silversmith and jeweler who became quite wealthy, eventually becoming a textile manufacturer. In 1838, they moved back to Charleston. According to the 1860 U.S. Census, William owned real estate worth $\$ 40,000$ and had a personal estate worth $\$ 250,000$. Marina Jones Gregg died on January 1, 1899 at the age of 87. Mosaic Quilts: Paper Template Piecing in the South Carolina Lowcountry (Greenville, SC: Curious Works Press, 2002), 45; U.S. Census information from www.ancestry.com, accessed June 2009.

${ }^{109}$ Mosaic Quilts, 45.

${ }^{110}$ Mosaic Quilts, 45.
} 


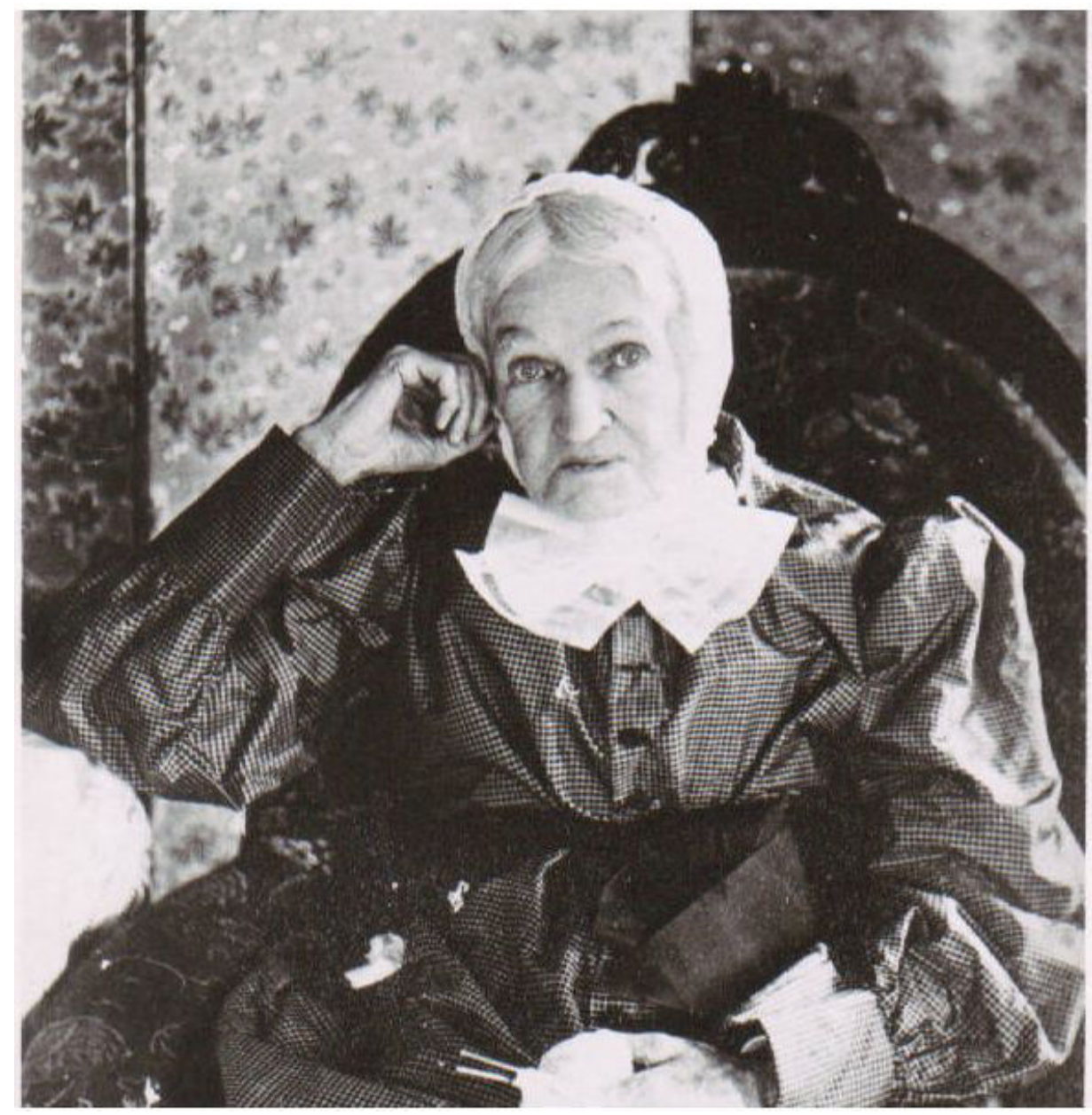

Figure 3.11. Marina Jones Gregg (1811-1899), circa 1890. Courtesy of the GreggGraniteville Library, University of South Carolina - Aiken.

Marina Jones Gregg appears to be holding a knitting project in her photographic portrait. Just as in antebellum painted portraits, the knitting may have been intended to symbolize her industry, as well as her femininity. 


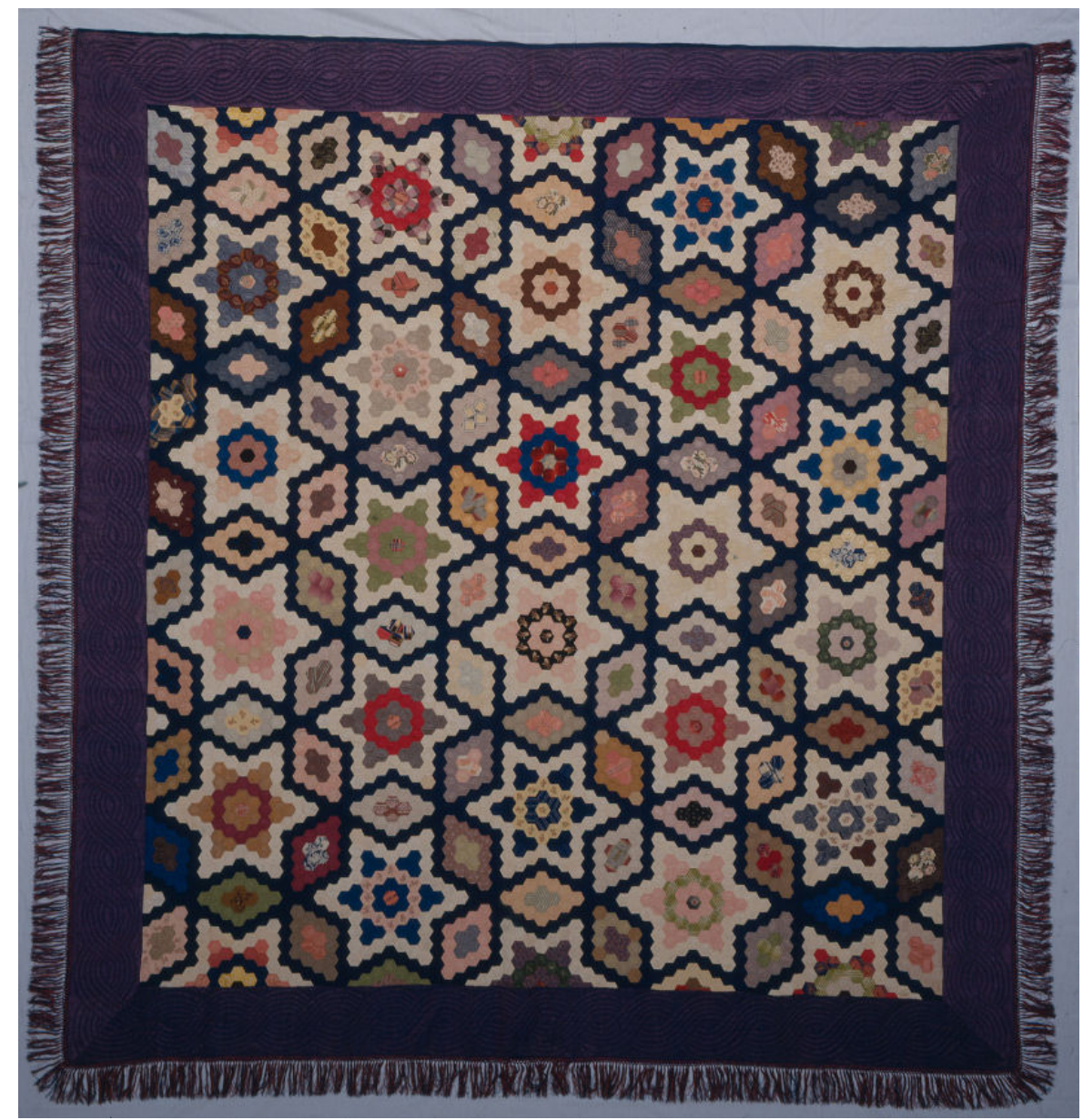

Figure 3.12. Quilt by Marina Jones Gregg (1811-1899), 1852, Charleston, South Carolina. Courtesy of the Charleston Museum, Charleston, South Carolina.

Like Submit Gay, Marina Jones Gregg entered her impressive quilt in a local agricultural fair where it won a prize. The quilts on view at local fairs offered their makers a venue to show off their skill, while also offering inspiration for other local quilters. 
funds for political and social causes that they supported. ${ }^{111}$ Though an atypical example, Lucy Hiller Cleveland (1780-1866) entered vignettes of what she called her "figures of rags" in several antebellum charitable fairs (figure 3.13). ${ }^{112}$ She grouped some of her doll-like figures into visual stories from her own life, while others expressed her feelings about contemporary reform issues. In October 1844 she was awarded a diploma for the best "Specimen of Figures of Rags" by the Mechanics' Literary Association of Rochester, New York. In 1852, she entered a vignette in the Shirtwoman's Union Fair in New York City, which raised $\$ 20$ for the financial relief of women garment workers. ${ }^{113}$

From the 1830 s through the 1860 s, Cleveland made at least eleven vignettes. She created them from a wide variety of materials including silk, cotton, wool, glass, leather, beads, and human hair. Cleveland then embellished them with embroidery, quilting, knitting and paint. ${ }^{114}$ In a letter to the wife of her stepson, in 1847, she recounted, "I have been quite at my old trade since here stuffing + dressing, and "hiking into shape"...it

\footnotetext{
${ }^{111}$ For a comprehensive history of these fairs, see Beverly Gordon, Bazaars and Fair Ladies: The History of the American Fundraising Fair (Knoxville: The University of Tennessee Press, 1998).

${ }^{112}$ Lucy Hiller was born in 1780 in Salem, Massachusetts, the daughter of Joseph Hiller (1748-1814) and Margaret Cleveland (1748-1804). Her father was a clockmaker, silversmith and engraver, perhaps where Lucy got her skill for detail. Married first in 1806 to Captain William Lambert of Roxbury, Massachusetts, he died in 1807. In 1816, she married her deceased sister's husband, her first cousin, William Cleveland (1777-1842). In 1828 and 1829, she accompanied her sea captain husband on a trading voyage aboard the Zephyr including stops in the East Indies, Timor and China. Between 1827 and 1842, Cleveland anonymously wrote and published more than a dozen children's book on topics including abolition, temperance and social benevolence. Lucy Hiller Cleveland died in 1866, aged eighty-six. Paula Bradstreet Richter, "Lucy Cleveland's 'Figures of Rags': Textile Arts and Social Commentary in Early-NineteenthCentury New England," in Textiles in Early New England: Design, Production, and Consumption, Peter Benes, ed. (Boston: Boston University, 1999), 49-50; Paula Bradstreet Richter, "Lucy Cleveland, Folk Artist," The Magazine Antiques 158 (August 2000): 206.

${ }^{113}$ Richter, "Lucy Cleveland, Folk Artist," 204, 206.

${ }^{114}$ In addition to eleven vignettes, the Peabody Essex Museum also owns five additional single figures. A twelfth vignette, now in the collection of the Shelburne Museum, Shelburne, Vermont, has been attributed to Cleveland, but curator Paula Bradstreet Richter disputes this attribution due to differences in style. Email correspondence from Paula Bradstreet Richter, January 6, 2009.
} 


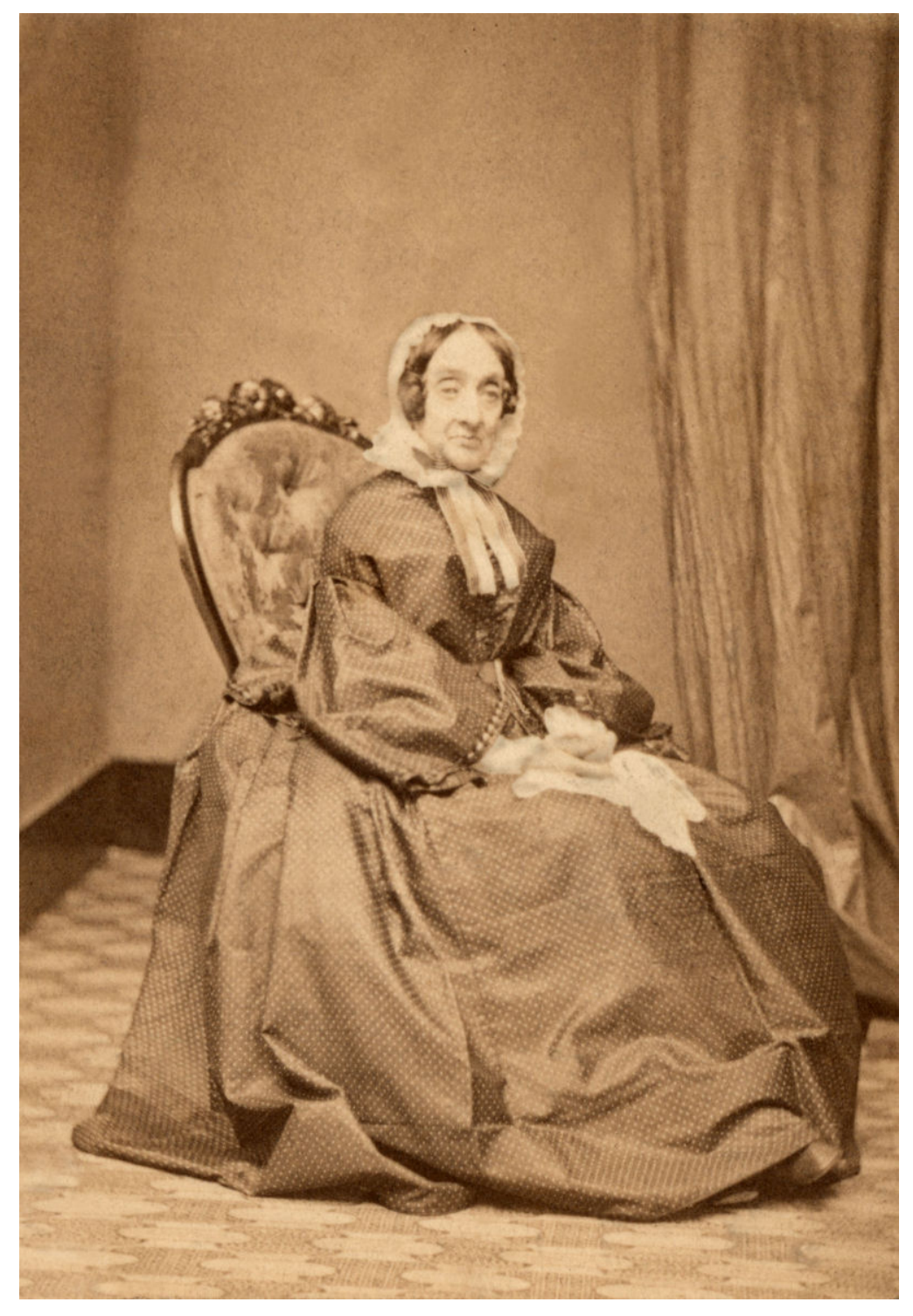

Figure 3.13. Lucy Hiller Cleveland (1780-1866) by D.W. Bowdoin, 1863, Salem, Massachusetts. Courtesy of the Peabody Essex Museum, Salem, Massachusetts. 
gives great satisfaction." 115 Her granddaughter later remembered that "people would come to her \& want her to teach them how to make them. She would tell them it was knowledge, that she couldn't impart to anyone, it was a gift to her."116

One of Cleveland's largest vignettes, "The Sick Chamber," was made for an unspecified fair in 1831 (figure 3.14). ${ }^{117}$ The vignette's composition resembles a wellknown lithograph depicting George Washington (1732-1799) on his death bed. ${ }^{118}$ The scene centers on a sick bed, a four-poster draped with white cotton curtains. There is a Bible open on the bed beside the patient. A male figure dressed in knee breeches and a dressing gown - clothing that was old-fashioned in 1831 - sits in a wing chair next to the bed. On the far side of the bed, a nurse, holding a medicine bottle, and a female friend or relative seem to be having some kind of disagreement about the patient's treatment. At the end of the bed, a black servant peers through the curtains. Cleveland's spare furnishings - the bed and a small table at its foot - are meticulously made and suggest a simple room. Her vignette is in keeping with recommendations for the sick room made by Catharine E. Beecher several decades later, “A sick-room should always be kept very neat and in perfect order...A sick person has nothing to do but look about the room; and when every thing is neat and in order, a feeling of comfort is induced..."119

\footnotetext{
${ }^{115}$ Letter from Lucy Cleveland, Boston, to Mrs. W.S. Cleveland, Salem, Massachusetts, May 23, 1847, Lucy Cleveland Papers, Phillips Library, Peabody Essex Museum, Salem, Massachusetts.

${ }^{116}$ Manuscript written by Susan Cleveland Bristol, December 9, 1918, quoted in Richter, "Lucy Cleveland, Folk Artist," 211.

${ }^{117}$ The vignette is now in the collection of the Peabody Essex Museum, Salem, Massachusetts. Richter, "Lucy Cleveland, Folk Artist," 207.

${ }^{118}$ Richter, "Lucy Cleveland, Folk Artist," 207.

${ }^{119}$ Catharine E. Beecher and Harriet Beecher Stowe, The American Woman's Home: Or, Principles of Domestic Science (New York: J.B. Ford and Company, 1869), 339-340.
} 


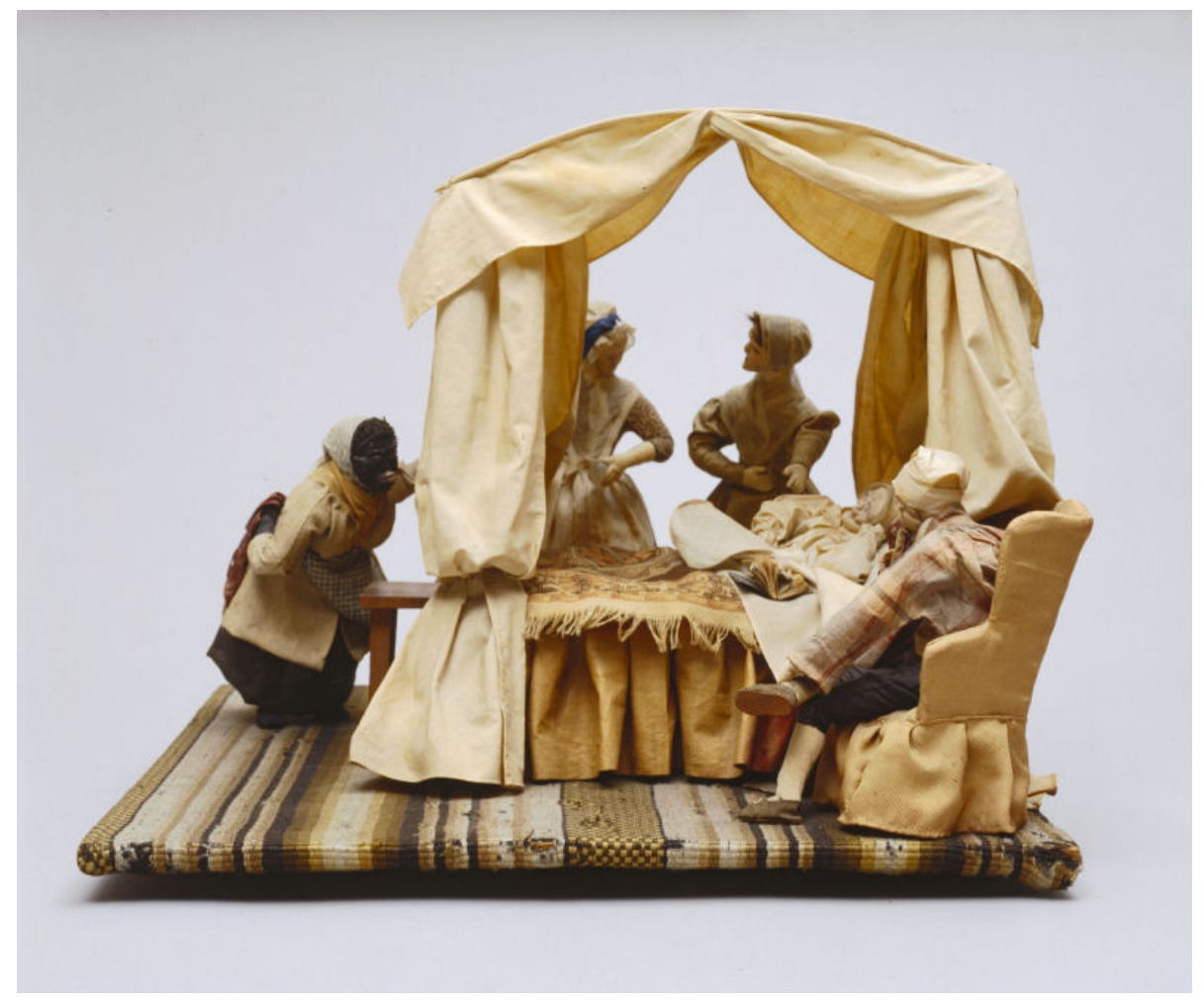

Figure 3.14. “The Sick Chamber” by Lucy Hiller Cleveland (1780-1866), 1831, Salem, Massachusetts. Courtesy of the Peabody Essex Museum, Salem, Massachusetts.

Lucy Hiller Cleveland made at least eleven vignettes. She reproduced exacting details for example, down to the proper bed furnishings - and formed her figures in such a way as to give each one some personality. Each vignette tells a story and may have been drawn from her life experience. 
This was a scene that Cleveland herself knew well. Fifty-one when she made it, Cleveland was undoubtedly confronting her own aging process. Her father had died in 1814, when Cleveland was thirty-four; her sister Mary died the following year. Lucy was the caretaker for both, not surprisingly since she was the younger single woman in the household. ${ }^{120}$ Women were often considered to be natural nurses and were counseled to cultivate "the indispensable qualities in a good nurse...common sense, conscientiousness, and sympathetic benevolence."121 It is tempting to speculate that Cleveland was thinking of the caretaking role she practiced in the 1810s while she made this vignette, but she did not leave explicit evidence of this.

During the later part of her life, Cleveland kept an album where she wrote original poems and verses. ${ }^{122}$ A gift from her stepson in 1837, when she was fifty-seven, Cleveland wrote regularly in the book until she filled it in 1859. She often noted her birthday, as in December 1845 when she wrote a poem called "Birthday Thoughts." It begins, "Three score and five! Are in thy pack, Which once belonged to me, And thou will never give one back, or turn thee from thy onward track, through vast eternity!" Many entries are poems written for family members and friends to mark special occasions, like birthdays, weddings and births. Other entries deal specifically with the passage of time - for example, poems called "Reminiscence" and "The Shadow of Time" - suggesting that her own aging process was on her mind.

Cleveland continued to care for sickly relatives throughout her life. Writing to her stepson in 1842, while in Boston caring for her sister, Cleveland noted "my sister

\footnotetext{
${ }^{120}$ Richter, "Lucy Cleveland's 'Figures of Rags, "' 50.

${ }^{121}$ Beecher and Stowe, The American Woman's Home, 342, 343.

122 The album is now in the Lucy Cleveland collection, Phillips Library, Peabody Essex Museum, Salem, Massachusetts.
} 
has been much better since I came, tho' I do not flatter myself with having the remotest agency in the convalescence." After remarking that thoughts of her own home gave her pleasure while away, Cleveland reminded herself, "I did not come for pleasure - alas! The word seems out of place with me, what have I to do with anything but duty." ${ }^{123}$ Her words give a hint of intergenerational tension, as she balanced her own wants with the duty and responsibility of caring for her family.

In the late 1840 s or early 1850 s, while in her late sixties or early seventies, she made another vignette centered around the aging process. Called "The Foot Bath," it shows an elderly woman and black servant with an elderly man in eighteenth-century costume (figure 3.15). ${ }^{124}$ The woman carries a red flannel bandage and bottle of bay rum (used for medicinal purposes), while the servant holds a wooden tub. The man shows reluctance for the imminent treatment of his bandaged leg.

An 1841 letter from Cleveland to her stepson describes her experience as she cared for yet another family invalid. "I found your poor aunt very - very feeble," she reported, "\& almost blind with inflammation in the eyes, with blisters on the back of her neck." Undoubtedly, Cleveland drew once again on her personal caretaking experience when she formed her figures. In the 1841 letter, she wrote that "the poor invalid sets hour after hour alone, with closed eyes \& such weak \& lame limbs, as render her

\footnotetext{
${ }^{123}$ Letter from Lucy Cleveland, Boston, to William S. Cleveland, Salem, October 2, 1842, Lucy Cleveland papers, Phillips Library, Peabody Essex Museum, Salem, Massachusetts. Cleveland was probably caring for her older sister, Dorcas Cleveland (1773-1850).

${ }^{124}$ This vignette is also known as "The Second Wife." This title appears in a January 1922 article in The Magazine Antiques and seems to originate from that time. Paula Bradstreet Richter notes that some of the vignettes were named according to family tradition, while others were assigned names by the museum staff who cataloged them. At least one of the vignettes in the Peabody Essex Museum collection has its name written on the base in pencil, possibly by Cleveland herself. Email correspondence from Paula Bradstreet Richter, January 6, 2009.
} 


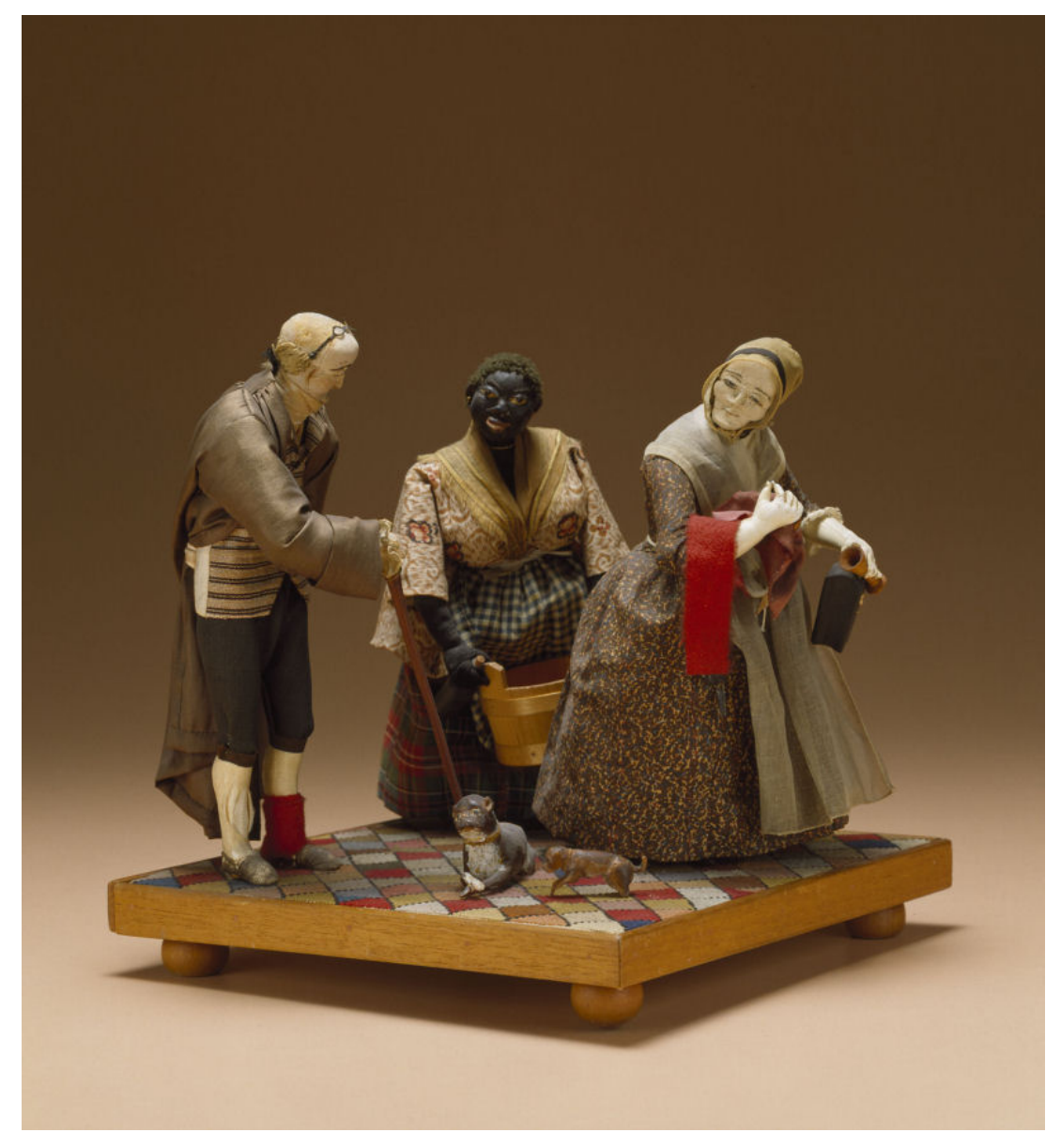

Figure 3.15. "The Foot Bath" by Lucy Hiller Cleveland (1780-1866), 1845-1855, Salem, Massachusetts. Courtesy of the Peabody Essex Museum, Salem, Massachusetts.

Lucy Hiller Cleveland nursed her own father when he was sick. Her personal experience undoubtedly informed the details in this vignette. 
exceedingly helpless - and the blessing of a friend to sit in the room even, \& give her the sound of the human voice with a kind word occasionally, is most truly acceptable" words that also describe her fabric sculpture. ${ }^{125}$ As one 1830s advice guide observed, "The care of the sick, is a science, to which time and attention should be devoted. It is part of the business of our sex. Appointed as we are, to varieties of indisposition, we are the more readily "touched with the infirmities" of others." 126 In addition to her letters and her actions, Cleveland's vignettes helped to show her understanding of her caretaking responsibilities, as well as providing an outlet for her own experiences and aging process.

In 1851, sixty-two-year-old Catharine Maria Sedgwick (1789-1867) wrote to her niece, Katherine Maria Sedgwick Minot (1820-1880):

It is good, as the burdens of age accumulate, to shake them all off; to change old, tiresome ideas for new ones; to take a world of fresh impressions; to fill the storehouse of imagination with new and beautiful images; to gain assurance to uncertain opinions; to verify old fancies; to throw off some of your old social burdens while you extend the social chain. ${ }^{127}$

In the same spirit, aging women often embraced antebellum needlework innovations. They used their needlework to gain agency and to meld old traditions with new technologies. Tensions between the "old way" and the new could be expressed through material objects as they could not be in words. Needlework offered aging antebellum women the opportunity to be a model, to show the younger generation their skill, their achievements and their idea of beauty. In turn, it offered an outlet for the nostalgia that must have bubbled up in these women as their families and communities grew and

\footnotetext{
${ }^{125}$ Letter from Lucy Cleveland to William S. Cleveland, May 16, 1841, quoted in Richter, "Lucy Cleveland's 'Figures of Rags,'” 58.

${ }^{126}$ Lydia Huntley Sigourney, Letters to Mothers (Hartford: Hudson and Skinner, 1838), 221-222.

${ }^{127}$ Letter from Catharine Maria Sedgwick to Katherine Maria Sedgwick Minot in Mary E. Dewey, ed., Life and Letters of Catharine M. Sedgwick (New York: Harper \& Row, 1871), 332.
} 
changed. Through their needlework, mature women maintained a connection to the past while also manipulating their future. 


\title{
CHAPTER 4
}

\section{FAMILY CURRENCY: THE GIFT NEEDLEWORK OF AGING WOMEN}

\author{
In 1823, sixty-two-year-old Amelia Heiskell Lauck (1760-1842) completed what
}

was at least her second quilt in two years as a gift for one of her six surviving children, Rebecca (Lauck) Cunningham (1787-1858) (figure 4.1). ${ }^{1}$ Amidst the quilted designs is a signature reading "Made by Amelia Lauck in the 62 year of her age April $15^{\text {th }} 1823$. " The center, or medallion, of the quilt has a floral design applied using the technique of chintz appliqué (also known today as broderie perse or cut-out chintz). Lauck thoughtfully cut out colorful floral motifs from a chintz fabric and arranged them to suit her own taste on the white ground fabric. She then pieced three borders in a pattern of red and white printed cotton (now often called Delectable Mountains ${ }^{2}$ ) and alternated plain white borders where she could quilt fancy motifs. Lauck's quilting skill was masterful. The quilt shows nine stitches to the inch with elaborate motifs including parallel lines, clamshells, feathers and floral wreaths. She also quilted the initials of the

\footnotetext{
${ }^{1}$ The quilts made for Lauck's daughter, Rebecca, and son, William, are currently in the collection of the Daughters of the American Revolution (DAR) Museum, Washington, DC. I am indebted to Alden O'Brien, curator of costume and textiles, for making these quilts and their curatorial files available to me during site visits in June 2006 and June 2009. The quilt made for Lauck's son, Morgan, along with a fourth that is not signed or labeled (but is attributed to Lauck), are in the collection of Colonial Williamsburg, Williamsburg, Virginia. I am indebted to Linda Baumgarten, curator at Colonial Williamsburg, for sharing descriptions of those quilts with me. Amelia Heiskell was born in 1760 in Winchester, Virginia, the daughter of Christopher Heiskell (1721-1808) and Eve Fitzgerald (1730-1788). Amelia's father was a property owner in Winchester and a member of the Lutheran church. The family would eventually include six children; Amelia was the second born. In 1779, at the age of nineteen, she married Peter Lauck (17531849). Peter Lauck was born in Pennsylvania, but moved to Virginia with his family and served in the militia there during the Revolutionary War. After the War, he became proprietor of the Red Lion Inn in Winchester, Virginia, joined the local church, served as County Constable in 1781, was a commissioner for the Farmers Bank of Virginia, and a founder of the Friendship Fire Company. He was also a Freemason, serving as Master of Hiram Lodge in 1807. See Gloria Seaman Allen, First Flowerings: Early Virginia Quilts (Washington, DC: DAR Museum, 1987), 23; Christie's, Important American Furniture, Folk Art, Silver and Prints Including Property from the Garbisch Collection from the Sky Club (New York: Christie's, 2006), 198; curatorial files at the DAR Museum, Washington, DC.

${ }^{2}$ The "Delectable Mountains" pattern name references John Bunyan's Pilgrim's Progress (1678), describing the point from which the travelers were able to view the wonders of the Celestial City. Christie's, Important American Furniture, 198.
} 


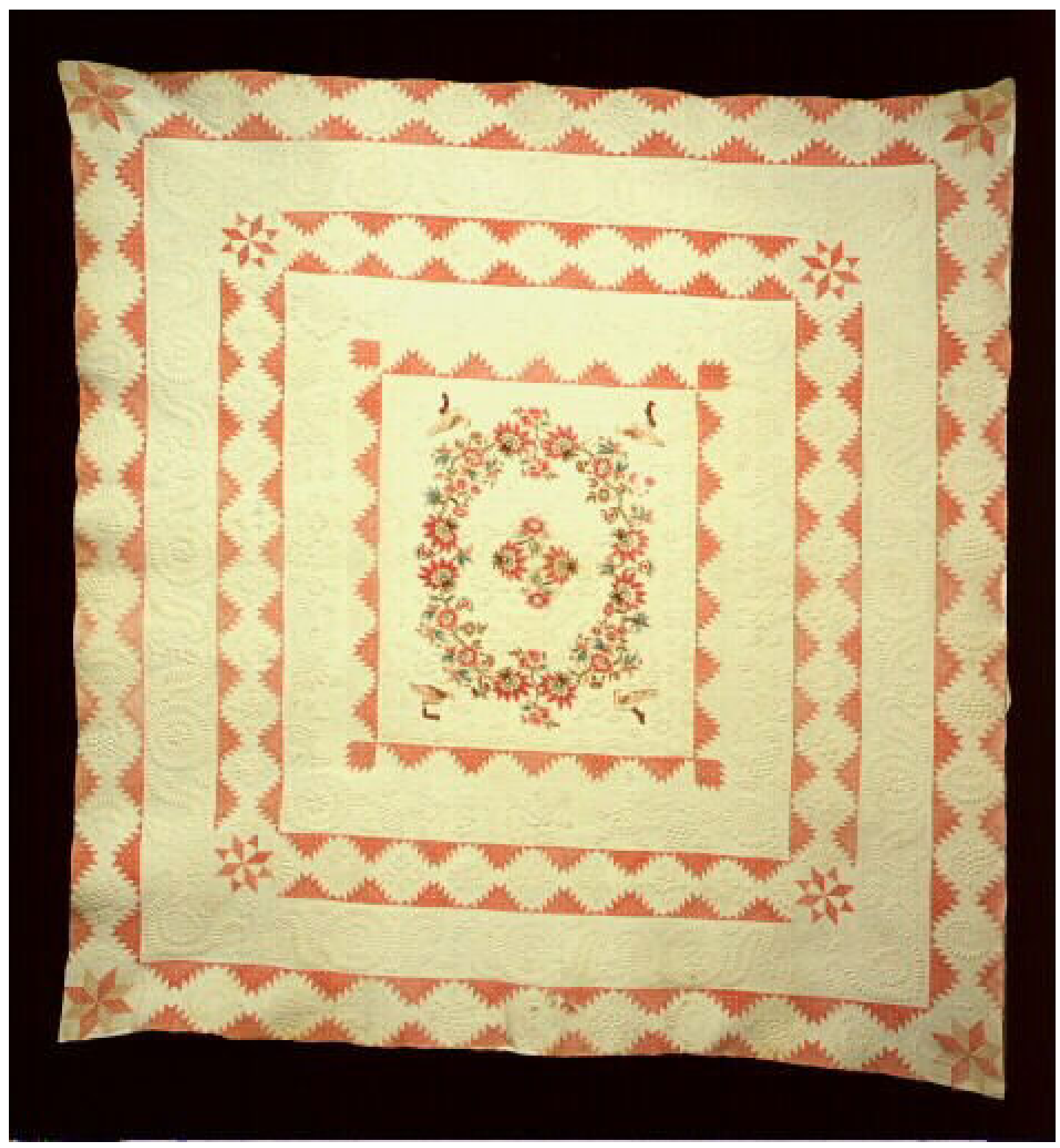

Figure 4.1. Quilt by Amelia Heiskell Lauck (1760-1842), circa 1822, Winchester, Virginia. Courtesy of the Daughters of the American Revolution Museum, Washington, DC.

Amelia Heiskell Lauck made three similar quilts, all of which she signed in the quilting and gave to her children. A fourth unsigned quilt has been attributed to Lauck due to its similarities in pattern and construction. It may also have been a gift to one of her children. 
recipients into the design. The quilt includes areas of stuffed work, a popular antebellum technique where small sections of the quilting were filled with cotton batting or other stuffing, adding dimension to the work. Lauck completed a second quilt around the same time and a third similar quilt by 1830 when she was about seventy, as well as a fourth at an undetermined time. Three of the quilts have a quilted signature documenting Lauck's work, and making clear that these quilts were gifts from Lauck to her children (figure $4.2)$.

Lauck's quilts remind us of one reason that aging women picked up their needles during the antebellum period. She used her needlework as "family currency"3 - giving a small piece of herself to her children so she could continue to have a presence in their lives as they married and started their own families and so they could remember the values she espoused, the skills she possessed, and the love and affection she felt for them. A letter written by forty-three-year-old Ann Gillam Storrow (1784-1856) suggests that gifts could function as a stand-in for their maker when she was unable to be physically present. In an 1827 letter to her friend, historian Jared Sparks (1789-1866), she wrote, "Mementoes are I know rather useless things to those who can remember their friends without, but I shall feel very much pleased if you will put my "persevere" pencil case into your pocket and use it while you are absent. I shall then have the gratification of thinking that I can be associated with something that is useful to you."

\footnotetext{
${ }^{3}$ I use the phrase "family currency" based on my reading of Marla R. Miller, The Needle's Eye: Women and Work in the Age of Revolution (Amherst: University of Massachusetts Press, 2006), 108 and Laurel Horton, Mary Black's Family Quilts: Memory and Meaning in Everyday Life (Columbia: University of South Carolina Press, 2005), 2.

${ }^{4}$ Frances Bradshaw Blanchard, ed., Letters of Ann Gillam Storrow to Jared Sparks (Northampton, Massachusetts: Smith College, Department of Government and History, 1921), 228. Ann Gillam Storrow was born in 1784 in Halifax, Nova Scotia, the daughter of Thomas Storrow and Ann Appleton. The family lived in England and Jamaica before moving to Boston, Massachusetts, where her parents died within a year and a half of each other. Ann never married, living with her sister, Louisa, and Louisa's husband,
} 


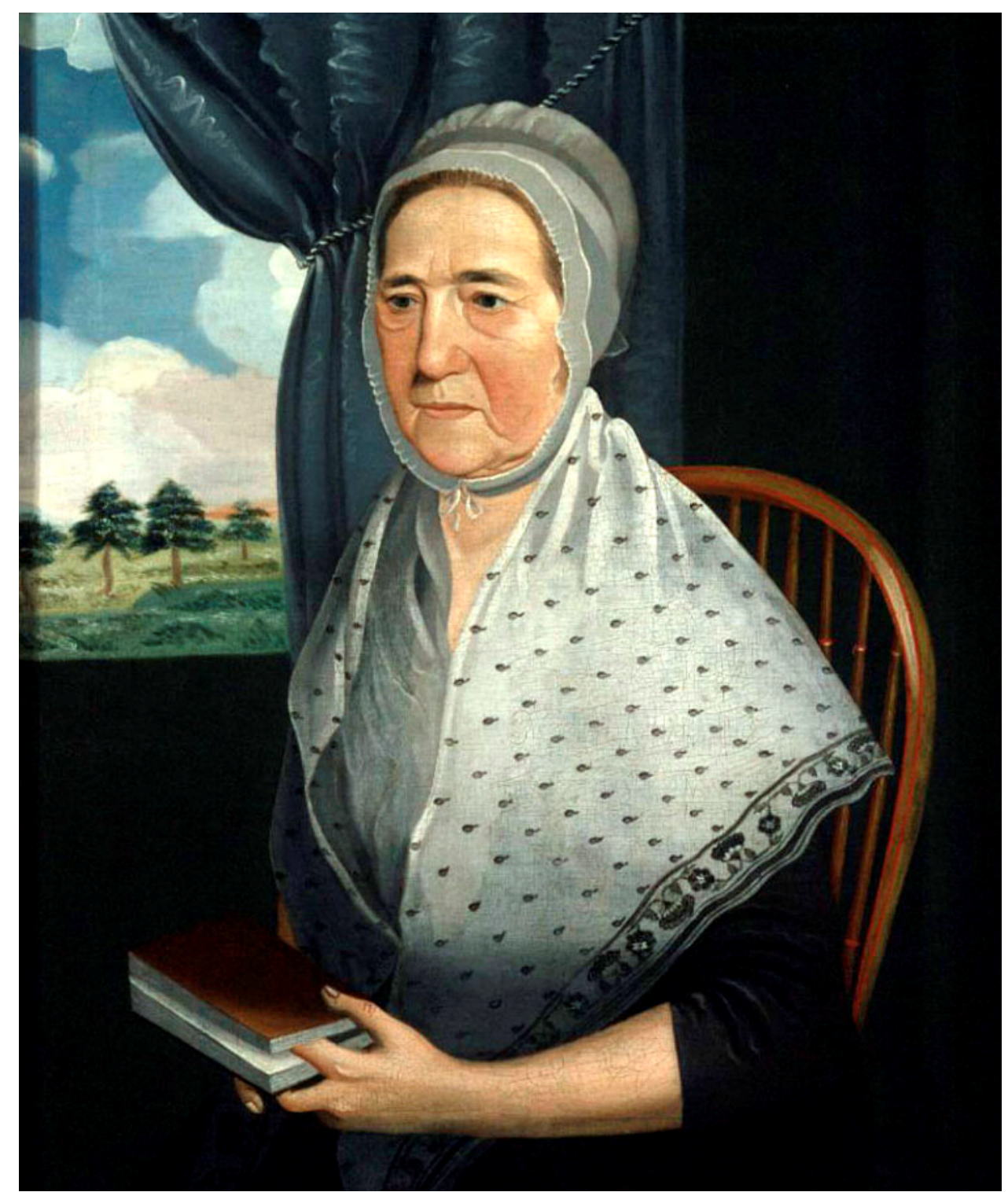

Figure 4.2. Amelia Heiskell Lauck (1760-1842) by Jacob Frymire (1770-1822), 1801, Virginia. Collection of the Museum of Early Southern Decorative Arts (MESDA) at Old Salem.

Stephen Higginson. After Stephen's death, Ann and Louisa moved to Brattleboro, Vermont, to live with Louisa's son. Ann became a friend of historian Jared Sparks and corresponded with him throughout her life. Ann died in 1856 in Brattleboro, Vermont. Biographical information from the North American Women's Letters and Diaries database, http://solomon.nwld.alexanderstreet.com.silk.library.umass.edu:2048/bios/A48BIO.html; accessed November 21, 2009. 
Anthropologists have studied the act of gift-giving and the meaning of the gift for decades, ever since Marcel Mauss's seminal work, The Gift, was first published in $1950 .^{5}$ Mauss led the way by making the point that a gift is more than just an object and that the act of giving is rarely purely altruistic. ${ }^{6}$ Subsequent scholars have expanded this analysis, suggesting that gifts have a particular relationship to and meaning for women. ${ }^{7}$ Micaela Di Leonardo asserted that "kin work" arose with the "cult of domesticity" during the eighteenth and nineteenth centuries, defining it as the:

conception, maintenance and ritual celebration of cross-household kin ties...the organization of holiday gatherings; the creation and maintenance of quasi-kin relations; decisions to neglect or to intensify particular ties; the mental work of reflection about all these activities; and the creation and communication of altering images of family and kin. ${ }^{8}$

Indeed, it seems that giving gifts was a vital part of a woman's life cycle and caretaking duties, only becoming more so as she aged. This is borne out in an 1847 letter, when sixty-eight-year-old Eleanor Parke Custis Lewis (1779-1852) explained that she was "busily engaged in worsted work, a screen...for my granddaughter Caroline. It is very tedious but I shall not leave it until completed." Lewis went on to explain that she never left the house "except to church. See the occupations of a Grandmother."

\footnotetext{
${ }^{5}$ This study employs the following translation: Marcel Mauss, The Gift: The Form and Reason for Exchange in Archaic Societies, trans. W.D. Halls (New York: W.W. Norton, 1990).

${ }^{6}$ Mauss, The Gift, 3-5.

${ }^{7}$ For example, see David Cheal, "'Showing Them You Love Them': Gift Giving and the Dialectic of Intimacy," in The Gift: An Interdisciplinary Perspective, Aafke E. Komter, ed. (Amsterdam: Amsterdam University Press, 1996), 98; Carolyn J. Rosenthal, "Kinkeeping in the Familial Division of Labor," Journal of Marriage and the Family 47 (November 1985): 965-966; David Cheal, The Gift Economy (London: Routledge, 1988), 183; Mark Osteen, ed., The Question of the Gift: Essays Across Disciplines (London: Routledge, 2002), 19; and Aafke E. Komter, Social Solidarity and the Gift (New York: Cambridge University Press, 2005), 80.

${ }^{8}$ Micaela Di Leonardo, "The Female World of Cards and Holidays: Women, Families, and the Work of Kinship,” Signs 12 (Spring 1987): 442-443, 449.

${ }^{9}$ Letter from Eleanor Parke Custis Lewis to Elizabeth Bordley, March 28, 1847 quoted in Patricia Brady, George Washington's Beautiful Nelly: The Letters of Eleanor Parke Custis Lewis to Elizabeth Bordley Gibson, 1794-1851 (Columbia, South Carolina: University of South Carolina Press, 1991), 248. Eleanor Parke Custis was born in 1779, the daughter of John Parke Custis, who was the son of Martha Washington
} 
Anthropologist Aafke E. Komter states that "giving gifts is an act that creates and maintains social ties." She describes women as "kin keepers," socially and culturally expected to maintain the family's social relationships and to remember birthdays, weddings and other important occasions. ${ }^{10}$ According to Di Leonardo, these activities, which brought women together in "kin-centered networks," also served as "sources of women's autonomous power and...sites of emotional fulfillment, and, at times, as the vehicles for actual survival and/or political resistance." 11

Much of the anthropological literature on gifts has centered on non-Western societies, with some recent studies of contemporary Western society. ${ }^{12}$ Few works explore the function of gifts in eighteenth- and nineteenth-century Western societies. ${ }^{13}$ However, the theories and results generated by all of these studies do offer insight into

and her first husband, Daniel Parke Custis. After Eleanor's father died in 1781, she and her brother, George Washington Parke Custis, were adopted by George and Martha Washington. In 1799, she married Lawrence Lewis, George Washington's nephew. The couple had eight children, but only Frances Parke Lewis survived her mother. Eleanor died in 1852. Biographical information from the North American Women's Letters and Diaries database, http://solomon.nwld.alexanderstreet.com.silk.library.umass.edu:2048/bios/A200BIO.html; accessed November 21, 2009.

${ }^{10}$ Komter, Social Solidarity and the Gift, 2, 87-88.

${ }^{11}$ Di Leonardo, "The Female World of Cards and Holidays," 441.

${ }^{12}$ Works that focus on gift giving in non-Western societies include: Mauss, The Gift; Karen Sykes, Arguing with Anthropology: An Introduction to Critical Theories of the Gift (London: Routledge, 2005); Annette B. Weiner, Inalienable Possessions: The Paradox of Keeping-While-Giving (Berkeley: University of California Press, 1992); Marilyn Strathern, The Gender of the Gift (Berkeley: University of California Press, 1988); and James Carrier, "Gifts, Commodities, and Social Relations: A Maussian View of Exchange," Sociological Forum 6 (1991): 119-136. Works that explore gift-giving in contemporary Western society include: Cheal, "Showing Them You Love Them"; Aafke Komter and Wilma Vollebergh, "Gift Giving and the Emotional Significance of Family and Friends," Journal of Marriage and the Family 59 (August 1997): 747-757; David Cheal, "The Ritualization of Family Ties," American Behavioral Scientist 31 (July/August 1988): 632-643; David J. Cheal, "Intergenerational Family Transfers," Journal of Marriage and the Family 45 (November 1983): 805-813; Barry Schwartz, "The Social Psychology of the Gift," The American Journal of Sociology 73 (July 1967): 1-11; and James Carrier, "Gifts in the World of Commodities: The Ideology of the Perfect Gift in American Society," Social Analysis 29 (1990): 19-37.

${ }^{13}$ The recent literature on gifts in eighteenth and nineteenth century Western societies, particularly by historians, includes papers focused on specific types of gifts and those that explore exchanges of goods. For example, see Ellen Hartigan-O'Connor, "Abigail's Accounts: Economy and Affection in the Early Republic," Journal of Women's History 17 (Fall 2005): 35-58; and Cindy Dickinson, "Creating a World of Books, Friends, and Flowers: Gift Books and Inscriptions, 1825-60," Winterthur Portfolio 31 (1996): 5366. In addition, there is a significant literature on early American dowry customs and bequests; several of these works are cited in the following pages. 
antebellum American society. The gifts given by mature women of the antebellum era could be seen as a means of coping with their changing environment. As their society industrialized and urbanized, the family was no longer the basic economic unit and not all family members remained in the same tight geographical area. ${ }^{14}$ They sought to maintain relationships and to stay connected over longer distances. Giving a gift was one way to accomplish this. $^{15}$

Needlework gifts from mature female family members were not unusual during the nineteenth century and they offer an opportunity to explore the motives behind them as well as the social and cultural roles that quilts, samplers, and other needlework played for women during the antebellum decades. For these antebellum women, their needlework products were ideal gifts. As Gail Bakkom has explained, "the intimate connections created by the gift quilt...make the quilt more than a mere material possession by giving it a symbolic dimension, reflecting the event as well as the family spirit." 16 Using needlework as gifts continued a long tradition stretching back to the seventeenth and eighteenth centuries. Museum collections include numerous Irish-stitch pocketbooks, knitted purses, and bead chains that expressed the love and esteem of their

\footnotetext{
${ }^{14}$ For historical literature that considers the changing shape of family life in the early republic and antebellum eras, see: Lynn A. Bonfeld and Mary C. Morrison, Roxana's Children: The Biography of a Nineteenth-Century Vermont Family (Amherst: University of Massachusetts Press, 1995); Christopher Clark, The Roots of Rural Capitalism: Western Massachusetts, 1780-1860 (Ithaca: Cornell University Press, 1994); Carl N. Degler, At Odds: Women and the Family in America from the Revolution to the Present (New York: Oxford University Press, 1980); Thomas Dublin, Transforming Women's Work: New England Lives in the Industrial Revolution (Ithaca: Cornell University Press, 1994); Catherine E. Kelly, In the New England Fashion: Reshaping Women's Lives in the Nineteenth Century (Ithaca: Cornell University Press, 1999); D. Brenton Simons and Peter Benes, eds., The Art of Family: Genealogical Artifacts in New England (Boston: New England Historic Genealogical Society, 2002); and Laurel Thatcher Ulrich, A Midwife's Tale: The Life of Martha Ballard, Based on her Diary, 1785-1812 (New York: Alfred A. Knopf, 1990). For comparative work on the changing shape of family life in England during the same period, see Leonore Davidoff and Catherine Hall, Family Fortunes: Men and Women of the English Middle Class, 1780-1850 (London: Hutchinson, 1987).

${ }^{15}$ Cheal, "The Ritualization of Family Ties," 632-633.

${ }^{16}$ Gail Bakkom, "Connections of Families and Friends," in Minnesota Quilts: Creating Connections with Our Past by Minnesota Quilt Project (Stillwater, Minnesota: Voyageur Press, 2005), 50.
} 
makers, complete with histories that identify them as gifts. ${ }^{17}$ A socially-sanctioned activity, needlework was considered not only appropriate, but proper and uplifting. The gift of needlework set a cultural example for younger generations of women by teaching important skills, reminding them of their history, and preserving moral order during what was often perceived as an unsettled time. In addition, for aging women who felt nostalgic - or yearned for the past - giving needlework that reflected dated styles and techniques could have been a way for them to prolong a connection to their own girlhood.

Although the anthropological literature has advanced our understanding of gift exchange and the gift-giving impulse, historical and material culture analysis of gifts lags behind. Many textile historians make statements about gift needlework as if they were obvious, restating "traditional" ideas without pausing to document their sources. Still other books make broad statements about gift needlework without providing detailed contexts for their sources. These works illustrate the need for a more rigorous examination of gift quilts and their family histories, which will ultimately enlarge our understanding of American quiltmaking, as well as of women's lives and their experiences. As quilt scholar Virginia Gunn asserted almost twenty years ago, "If scholars are not careful, and if they do not recognize myths for what they are, the body of "false beliefs" accepted as valid can color historical analysis and interpretation."18 Undocumented family stories, often the only source about a quilt's history, are useful but must be considered carefully in conjunction with the quilts themselves. Do the fabrics,

\footnotetext{
${ }^{17}$ For examples, see Susan Burrows Swan, Plain and Fancy: American Women and Their Needlework, 1650-1850 (Austin, Texas: Curious Works Press, 1995), 55, 57, 104, 106-107; Glee Krueger, "Mary Wright Alsop 1740-1829 and Her Needlework," The Connecticut Historical Society Bulletin 52 (Summer/Fall 1987): 125-224; Amy Boyce Osaki, "A "Truly Feminine Employment": Sewing and the Early Nineteenth-Century Woman," Winterthur Portfolio 23 (1988): 225; and Lynne Zacek Bassett, "Woven Bead Chains of the 1830s," The Magazine Antiques 148 (December 1995): 798-807.

${ }^{18}$ Virginia Gunn, "From Myth to Maturity: The Evolution of Quilt Scholarship," Uncoverings 13 (1992): 194.
} 
pattern and construction of the quilt correspond with the dates of the people and events of the family story?

Many previous quilt studies give rise to another common misconception: that gift quilts were typically wedding gifts. For example, according to a study of West Virginia quilts, "Gift quilts are most often associated with marriage, given in wedding celebration."19 The romanticism is appealing: this idea intertwines the tradition of quilting with a sense of warmth and maternal instinct. What better gift to give one's child than a soft, warm bed covering - in a sense, allowing the mother's arms to hug her children each night as they sleep despite their removal to a home of their own. But, is this true? Or, is this simply an appealing and tempting explanation, much like the one that swirls around so many heirloom family dresses from the eighteenth and nineteenth centuries, which are assumed to be wedding dresses? The West Virginia study would be more accurate if it explained that in that particular study, gift quilts were most often associated with marriage, if that is the case, and to add information on how many such quilts were located.

Nevertheless, quilts given as gifts - because they tended to be more elaborate than everyday quilts, and because of their sentimental overtones - do seem to survive in disproportionate numbers, at least among museum collections. Among the 167 needlework artifacts located for this study (see Appendix), fifty-five were either inscribed as gifts or have been passed down with specific family stories describing them as gifts (see Table 4.1). Fifty-three of the fifty-five are quilts and they serve as the primary

\footnotetext{
${ }^{19}$ Fawn Valentine, West Virginia Quilts and Quiltmakers: Echoes from the Hills (Athens: Ohio University Press, 2000), 157.
} 
sources for this chapter. ${ }^{20}$ According to the family information preserved with the quilts, all were given by older makers to younger recipients. Almost half of these gift quilts were given by the maker to her daughter (14) or her granddaughter (10). Seven were given to a son; three to a grandson; and the remaining nineteen were spread between nieces, great-granddaughters, great-nieces, a daughter-in-law, a stepdaughter and nonblood relations. The fifty-three quilts were made by thirty-six women. Six of these makers were from New England, four lived in the Mid-west, nine makers were from MidAtlantic states, fifteen makers lived in the southeastern United States, one in the west and one in an unknown state. ${ }^{21}$ This group of artifacts provides a base for a reconsideration of gift quilts.

Of the fifty-three gift quilts located for this study, only fifteen - far fewer than half of them - are identified as wedding gifts. This may reflect the fact that many of the quilts associated with a wedding were made by the bride herself (either alone or in a group), rather than given to her as a gift. For example, an Ohio quilt documentation project found that half of the wedding quilts documented were made entirely by brides, while the other half were made by relatives. ${ }^{22}$ In her study of the pre-1860 diaries of New England quilters, Lynn A. Bonfield noted "the absence of explicit references to

\footnotetext{
${ }^{20}$ Aside from quilts, this study found two other needlework gifts fitting the criteria for date and age of maker: the sampler made by Ruth Pierce Croswell, which is discussed in chapter 2, and an embroidered coverlet by Lucretia Street Hall. Since the overwhelming majority of needlework gifts found were quilts, this chapter focuses primarily on those objects.

${ }^{21}$ The New England makers were from Massachusetts, Vermont, Rhode Island and Connecticut; the MidAtlantic makers from New York, Pennsylvania, and Delaware; the Mid-West quilters were from Illinois, Ohio, and Missouri; the southeastern makers lived in Maryland, Virginia, South Carolina, Tennessee, Georgia and West Virginia; and the western maker lived in Texas.

${ }^{22}$ Ricky Clark, ed., Quilts in Community: Ohio's Traditions (Nashville: Rutledge Hill Press, 1991), 129. A Pennsylvania project found that 264 quilts it documented were identified by their owners as having been made for a specific life event. $60 \%$ of these were "firmly identified" as having been made in preparation for marriage, adding support to the idea that many "wedding quilts" were made by the bride herself, rather than given to her by family or friends. See Patricia J. Keller, "To Go to Housekeeping: Quilts Made for Marriage in Lancaster County," in Bits and Pieces: Textile Traditions, Jeannette Lasansky, ed. (Lewisburg, Pennsylvania: Oral Traditions Project, 1991), 60.
} 
wedding or bridal quilts," explaining that while quilting activity often increased around the time of a wedding, "there does not seem to have been a tradition of describing these quilts in such terms.",23

In the survey herein, several of the quilts were given to commemorate a birth while others have no clear-cut occasion associated with the gift. Some of the latter examples may have been started with a specific occasion in mind, but then were finished much later, without the original intent recorded. And, among this group of gift quilts, only five of the fifteen quilts with a family history of functioning as a marriage gift have strong evidence to support the family story. ${ }^{24}$ The other ten are identified as wedding gifts only through family tradition and/or oral history. This suggests that a quilt given around the time of a wedding was not necessarily a gift for the wedding, but perhaps served another purpose for its maker, passed along to maintain connections and traditions and to preserve memories of the bride's relationship to her birth family. Of the remaining thirty-eight gift quilts identified here, sixteen were gifts at birth, three were bequests, one was for a child's eighth birthday and eighteen were given for unspecified or unidentified events.

In view of these numbers, the quilts made by Amelia Heiskell Lauck for her children can perhaps be analyzed and understood in a new way. Peter and Amelia Lauck had eleven children; six survived to adulthood. Of the four quilts that Amelia made that are extant today, three are marked with information documenting the recipients and the

\footnotetext{
${ }^{23}$ Lynn A. Bonfield, "Diaries of New England Quilters Before 1860," Uncoverings 9 (1988): 181.

${ }^{24}$ That is, five of the quilts were inscribed or labeled with a year by the maker. The other ten quilts have less definite matches between the date of the quilt and the date of the gift-giving occasion, as determined by using the date of the fabric in the quilt to compare to the date of the wedding. Whether the date is inscribed on the quilt or not, quilt dating is never an exact science, but there are methods that can be employed to establish a working date of the object. By analyzing the fabrics in the quilt, and comparing them to catalogs of documented fabrics, a date span for the quilt can be suggested.
} 
maker. Her son Morgan (1796-1828) received his quilt around the time of his marriage to Ann Maria Ott (1804-1872) in 1824; it is marked with the maker's name and age, along with the names of the recipients. ${ }^{25}$ Her daughter Rebecca (1787-1858) and son-inlaw John Cunningham (b. 1764) received theirs in April 1823, more than fifteen years after their marriage ${ }^{26}$ it is marked with the maker's name and age, the date of the gift and the initials of the recipients. Amelia's son William (1805-1875) and his wife, Eliza Jane Sowers (1812-1872), got their quilt at an unspecified time, perhaps when they married in 1830; their quilt's inscription includes their initials and the words, "presented by their mother.",27

Lauck's other three surviving children, sons Samuel (b. 1790), Isaac (1793-1851), and Joseph (b. 1799), also married and it is likely that the fourth quilt, attributed to Amelia Heiskell Lauck but unsigned and unlabeled, was originally given to one of these men. Samuel married in 1816 and Isaac in 1814, while Joseph married in 1825. Joseph's wedding, which was close in time to two of the other three children's marriages, could be the occasion for the gift of the fourth quilt, which employs the same pattern, techniques, and fabric. However, the fact that this quilt does not have an inscription suggests that it could have been the first of the four made by Lauck. It is possible that she did not

\footnotetext{
${ }^{25}$ This quilt is now in the collection of Colonial Williamsburg, Williamsburg, Virginia. Stitched into this quilt is the inscription that it was made in Lauck's " $62^{\text {nd }}$ year." She turned sixty-two in 1823 . In addition, the names of both recipients are also stitched in, but her son Morgan did not marry until 1824 . The information from the quilt itself suggests that Lauck made the quilt before the couple married and then presented it to both at or after the wedding. Family information from www.ancestry.com, accessed January 18, 2009.

${ }^{26}$ Rebecca and John Cunningham seem to have received their quilt long after their marriage. Genealogical sources do not provide the date of the couple's marriage but it was presumably prior to the 1806 birth of their first child, Julia Hannah. See genealogical records for the Lauck and Cunningham families on www.ancestry.com, accessed January 18, 2009; email correspondence with Alden O'Brien, curator of costume and textiles, Daughters of the American Revolution Museum, May 29, 2007, and conversation on June 23, 2009.

${ }^{27}$ This quilt is in the collection of the Daughters of the American Revolution Museum, Washington, D.C. Genealogical information from www.ancestry.com, accessed January 18, 2009.
} 
initially think to sign her work, but as she began to give her quilts to her children, wanted to commemorate the occasion and started signing them. The fourth quilt was found in Winchester, Virginia, and since Samuel Lauck was the only child to remain in that town, it adds evidence that this quilt was initially given to him, perhaps when he married in $1816 .^{28}$ The quilts served a function for the maker and the recipients, those related by marriage as well as by blood. For Lauck, her quilts were a means of expression of her skill and her love. With the quilts she made a tangible connection to her new son- and daughters-in-law, drawing them into her family, while also introducing herself into their lives. For her children, the quilts prolonged her involvement in their lives, providing a stand-in for herself, her influence and her love.

While maternal affection was part of what compelled women to make quilts for their children and grandchildren, gift quilts were not purely altruistic. Quilts, and other needlework, were culturally intertwined with women's moral codes and their place in the household during the first half of the nineteenth century. Needlework was a way for a woman to express her identity, her artistic sensibilities, and her opinions about the changes taking place around her. Women whose children and grandchildren were born and got married between 1820 and 1860 had themselves grown up and been educated during and shortly after the American Revolution. They were encouraged to raise their children to be models of Republican virtue and to represent cherished values of industry, morality and benevolence themselves. ${ }^{29}$

\footnotetext{
${ }^{28}$ The fourth, unsigned, quilt is now in the collection of Colonial Williamsburg, Williamsburg, Virginia. I am indebted to Alden O'Brien, curator of costume and textiles at the Daughters of the American Revolution Museum, for sharing her theory that this quilt was originally given to Samuel since he was the only child to stay in Winchester, Virginia where the quilt was found.

${ }^{29}$ For a thorough explanation of "Republican motherhood" see Linda K. Kerber, Women of the Republic: Intellect and Ideology in Revolutionary America (Chapel Hill: University of North Carolina Press, 1987); Mary Beth Norton, Liberty's Daughters: The Revolutionary Experience of American Women, 1750-1800
} 
Terri Premo's survey of diaries and letters written by aging women between 1785 and 1835 found that older women saw it as their role to serve as living reminders of the moral code. They believed they needed to carry the achievements of the Revolutionary era forward. ${ }^{30}$ Giving gifts was a material extension of this role: older women could pass on an actual physical manifestation of their moral code. They could also pass on important feminine knowledge through sewing and quilting lessons. But, in the 1820s, some of their daughters and granddaughters were starting to follow different paths; for example, some found work outside the home - even working in textile factories. Gifts embedded their recipients in traditions that mitigated the effects of change. Giving a quilt was a way to remind the recipient of woman's true place, as well as of the giver's skill with the needle. The quilt could remind the recipient of a certain style or fashion, considered genteel and appropriate by the giver. These gifts also undoubtedly allowed their makers some sense of self-satisfaction - providing an opportunity to express creativity, try out new colors, materials and patterns, and revel in the joy of creating something pretty.

Quilts and samplers made by women over forty in the years between 1820 and 1860 communicated on personal, social and cultural levels and were understood by men, women and children of the time. Mature women could make and give quilts and other needlework, but they could also give the "gift of learning" by teaching younger

(Boston: Little, Brown and Company, 1980); and Ruth H. Bloch, "American Feminine Ideals in Transition: The Rise of the Moral Mother, 1785-1815," Feminist Studies 4 (June 1978): 100-126.

${ }^{30}$ Terri L. Premo, Winter Friends: Women Growing Old in the New Republic, 1785-1835 (Urbana: University of Illinois Press, 1990), 5. Also see Barry Schwartz, "The Social Context of Commemoration: A Study in Collective Memory," Social Forces 61 (December 1982): 386, where Schwartz asserts that history was divided into two stages in the antebellum mind, "an extraordinary period of creation by the Founding Fathers and an ordinary era or preservation and consolidation." The latter was perceived as "an age of ennui," when the subsequent generation did not match the achievements of its parents and grandparents. 
generations to stitch, and they could bequeath their needlework after they were gone. In each of these ways, they gave a "gift by example," manipulating the memory of the Revolutionary generation and its values to make their own statement in the present.

\section{I give and bequeath this quilt: Needlework as Property}

Gift quilts did not hold solely emotional value. While needlework gifts from a woman to her children or grandchildren were not generally recorded on formal documents like deeds and probate inventories in the same way as land or livestock, they were considered property. The long-held belief that women did not own property in the early nineteenth century has been eroded by scholars such as Laurel Thatcher Ulrich, Barbara McLean Ward, Toby Ditz, Marylynn Salmon and Norma Basch. While married women were legally prohibited from owning most types of property, it is well established that unmarried women (both never-married and widowed) could and did own property; that married women could own some types of property if it was given under certain conditions; and, in the case of moveable goods, that women, married and unmarried alike, were understood to control a great number of items which they, in turn, gave, bequeathed or sold as they saw fit. ${ }^{31}$

\footnotetext{
${ }^{31}$ On colonial and antebellum American women and property, see: Toby L. Ditz, Property and Kinship: Inheritance in Early Connecticut 1750-1820 (Princeton, New Jersey: Princeton University Press, 1986); Marylynn Salmon, Women and the Law of Property in Early America (Chapel Hill: The University of North Carolina Press, 1986); Norma Basch, In the Eyes of the Law: Women, Marriage and Property in Nineteenth-Century New York (Ithaca: Cornell University Press, 1982); Laurel Thatcher Ulrich, The Age of Homespun: Objects and Stories in the Creation of an American Myth (New York: Alfred A. Knopf, 2001); Barbara McLean Ward, "Women's Property and Family Continuity in Eighteenth-Century Connecticut" in Early American Probate Inventories, Peter Benes, ed. (Boston: Boston University Press, 1987), 74-85; and Jeannette Lasansky, "Quilts In the Dowry," in Bits and Pieces, Lasansky, ed., 48-55.
} 
A pair of samplers made in the early 1830s makes this point visually. One was stitched around 1830 and shows Quaker-style lettering. ${ }^{32}$ Rather than a traditional signature with maker's name, date and place, the maker simply stitched, "Mary R. Dearborn's Property" along the bottom (figure 4.3). ${ }^{33}$ A second sampler, stitched in 1835 by Betsey Maria Ayer of St. Johnsbury, Vermont, includes a similar stitched signature reading, "The Property of Betsey Maria Ayer wrought by herself in the $12^{\text {th }}$ year of her age in A.D. 1835" (figure 4.4). ${ }^{34}$ Considering these samplers from a material culture perspective suggests two meanings for their unusual signatures. First, both samplers show the traditional style of a "marking sampler," made to teach a young girl how to stitch the letters of the alphabet so she will be able to mark her household textiles and clothing with her initials once she has a home and family of her own to look after (see figure 1.16). From a practical standpoint, marking initials is about signifying the ownership of property and protecting that ownership. The marks allowed the woman to identify her linens and to keep track of how many items she owned, ensuring their prompt return, particularly when they were sent out for laundering or even just spread to dry on the bushes outside the house.

Second, the explicit use of the word "property" is striking; it is rarely seen on textiles. Markings are never quite so blunt in their appearance on household textiles as they are on these samplers. Instead, they are usually small groupings of the initials of the

\footnotetext{
${ }^{32}$ The Quaker alphabet is made up of Roman-style letters, recognizable by its straight letters formed by bold lines of cross-stitch at the left side of the letters.

${ }^{33}$ Now in a private collection, this sampler is pictured in M. Finkel and Daughter, Samplings 1 (1992): 6. Unfortunately, this sampler does not offer enough information to conclusively identify its maker. The date of its origin is estimated to be about 1830 based on a comparison with other samplers showing a similar style, layout, motifs and materials.

${ }^{34}$ Now in a private collection, this sampler is pictured in M. Finkel and Daughter, Samplings 24 (2003): 7. Despite having the maker's name and her birth year provided by this sampler, conclusive identification of the maker was not possible.
} 


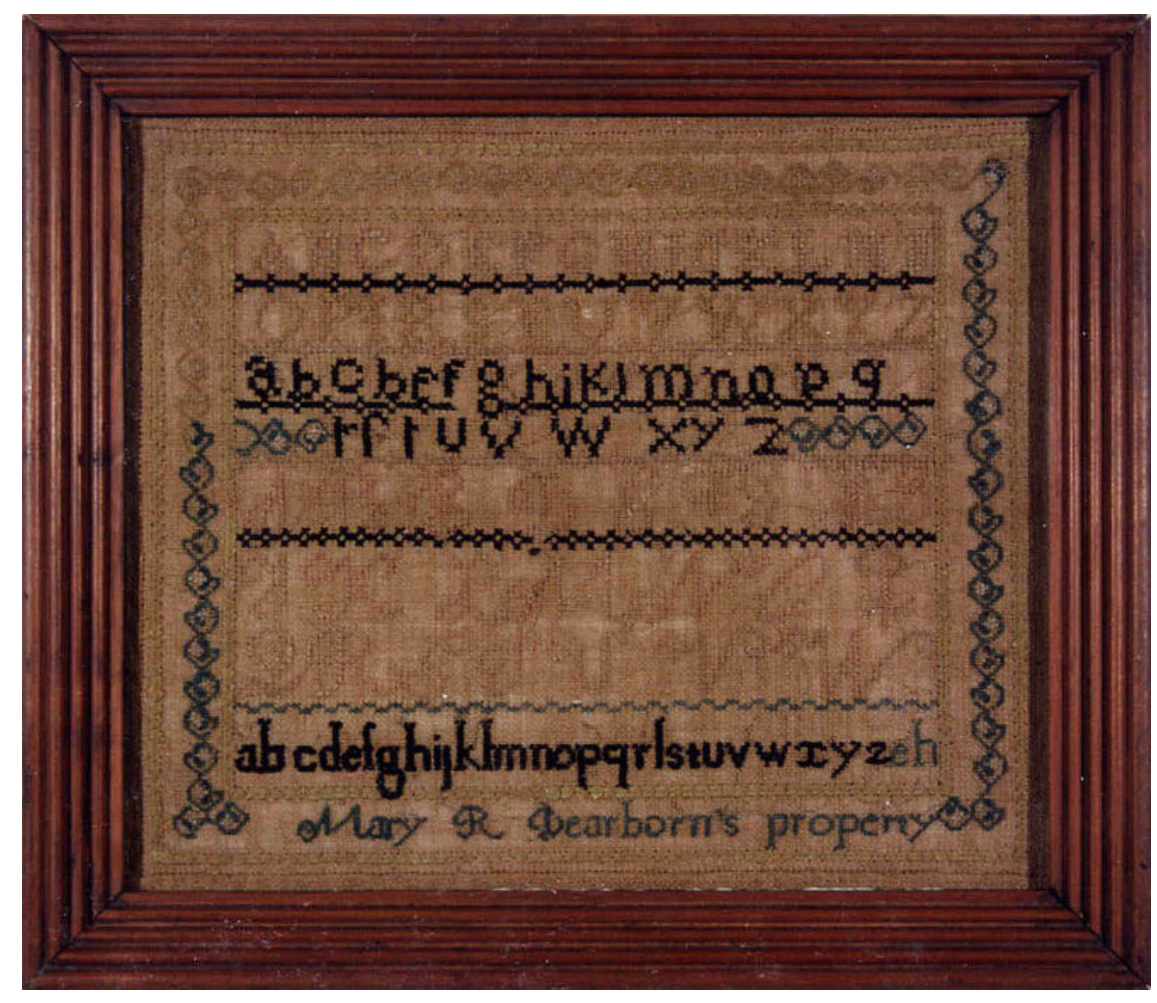

Figure 4.3. Sampler by Mary R. Dearborn, early 1830s. Private collection.

This sampler is unusual because of the signature stitched along the bottom, "Mary R. Dearborn's property." While samplers were almost always signed by their makers, usually with the date or their age, inclusion of the word "property" is rare. 


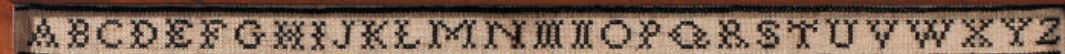

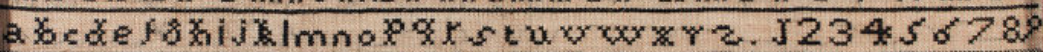

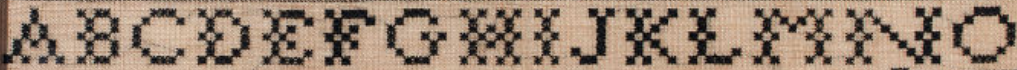

$8<x+5 \times$ y r ry $x<z<x .99$

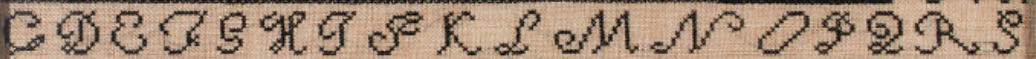

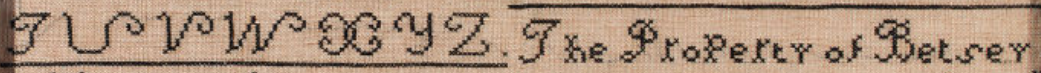

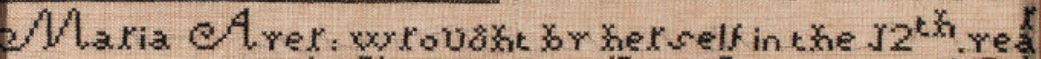

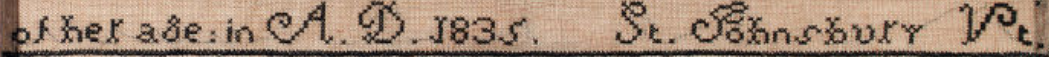

Figure 4.4. Sampler by Betsey Maria Ayer, 1835, St. Johnsbury, Vermont. Private collection.

Inscription: The Property of Betsey Maria Ayer: wrought by herself in the $12^{\text {th }}$ year of her age: in A.D. 1835. St. Johnsbury Vt.

Like Mary Dearborn, Betsey Maria Ayer also used the word "property" when she signed her sampler. She may have been learning that her sampler was hers to do with as she saw fit. Girls made samplers to practice stitching their initials. They would later use these letters to mark their household textiles, signifying them as domestic property. 
woman and her husband, with perhaps the year or a number to keep track of the life of the textile. These two samplers seem to suggest something deeper. Textiles, like these samplers, were part of the female realm. Ostensibly, these girls were being taught that textiles were their responsibility and their property. Implicitly, they were also learning that they could do with their sampler as they pleased.

The use of the word "property" on these samplers may also reflect the growing popular attention directed to proposals for Married Women's Property Acts during the 1830s. During the 1820 s and 1830 s, women and men alike began to campaign for legal changes that would allow married women to retain some rights to property that they brought to the marriage, or that they acquired by gift or bequest while married. ${ }^{35}$ In some states, support for this kind of legislation was a reaction to the banking crisis in the 1830 s in order to protect certain types of property brought to the marriage by the wife from her husband's creditors. ${ }^{36}$ In 1837, Godey's Lady's Book's "Editor's Table" supported passage of a New York bill that would increase the rights of women to own real estate and other forms of property; other newspapers and magazines spoke out on both sides of the issue. ${ }^{37}$ Referring to "property" on a sampler might have offered a means for a local teacher - and her students - to speak out on this issue themselves.

The practical understanding of women's property is further illustrated by a hexagon quilt made by Abigail Reynolds Greene (1794-1889) of Rhode Island. ${ }^{38}$ The quilt is backed with a wool blanket marked with her maiden initials, "A.R." The blanket

\footnotetext{
${ }^{35}$ Basch, In the Eyes of the Law, 16, 27.

${ }^{36}$ Carole Shammas, "Re-Assessing the Married Women's Property Acts," Journal of Women's History 6 (Spring 1994): 11.

${ }^{37}$ Quoted in Basch, In the Eyes of the Law, 119-120.

${ }^{38}$ The quilt is now in a private collection. It is illustrated in Linda Welters and Margaret T. Ordonez, eds., Down by the Old Mill Stream: Quilts in Rhode Island (Kent, OH: The Kent State University Press, 2000), 67.
} 
was probably initially made in preparation for Greene's 1811 wedding. Later, it was recycled into its use as a quilt backing, showing that textile items like this were controlled by the women who made them. While the blanket may have outlived its primary function, when choosing materials for her quilt backing roughly ten years later, Greene salvaged the section with her initials. And those initials were ones she most likely learned to stitch by making a marking sampler like the ones above.

Barbara McLean Ward and Laurel Thatcher Ulrich have shown that women understood the economic system they lived with, particularly as it applied to dowries and bequests within the family. Upon the death of their father, sons generally inherited a share of his home and land. Daughters, on the other hand, usually received their share as part of their dowry upon marriage. This inheritance took the form of "moveable" goods like textiles, silver and furniture. ${ }^{39}$

Ward argues that "a woman's role in society was in part defined by her control over these household goods."40 The objects that the woman brought into the household at marriage underscored the importance of the matrilineal line's contribution to the new household of the married couple. As Ward explains, maintaining this property offered the woman continuity with her birth family and solidified kinship ties, despite the blatant change in her name. ${ }^{41}$ Ulrich points out, too, that the goods given to the woman as her dowry formed the core of the bequest she would leave to her own daughter. Thus,

\footnotetext{
${ }^{39}$ Ward, "Women's Property and Family Continuity," 83-85; Laurel Thatcher Ulrich, "Furniture as Social History: Gender, Property, and Memory in the Decorative Arts," in American Furniture, ed. by Luke Beckerdite (Milwaukee: Chipstone Foundation, 1995), 55; Laurel Thatcher Ulrich, "Hannah Barnard's Cupboard: Female Property and Identity in $18^{\text {th }}$-Century New England" in Through a Glass Darkly: Reflections on Personal Identity in Early America, ed. by Ronald Hoffman, Mechal Sobel and Fredrika J. Teute (Durham: University of North Carolina Press, 1997), 253-255; Ditz, Property and Kinship, 79, 114.

${ }^{40}$ Ward, "Women's Property and Family Continuity," 76.

${ }^{41}$ Ward, "Women's Property and Family Continuity," 76, 85.
} 
"ownership of precious household goods offered the power not only to shape a material environment but to build lineages and alliances over time.",42

Dowry gifts of textiles offer both a context and a model for how women understood textiles and needlework on more than a purely functional level. A note inside the front cover of a memorandum book kept by Reverend Zenas L. Leonard (1773-1841) of Sturbridge, Massachusetts, reads, "List of supplies for beginning housekeeping given each daughter..." The first page is inscribed "For Mary Ann" and is followed by several lines of textile goods, each with a dollar value on the right. For example, Mary Ann Leonard (1803-1889) received four bed quilts, which her father valued at five dollars apiece, along with one coverlet worth seven dollars, and numerous other household textiles totaling $\$ 124.69$ 1/2. Subsequent pages provide similar lists for Leonard's younger daughters, Vernera (1805-1892) and Sarah (1810-1850). The dates on each page correspond to the marriage of each girl. ${ }^{43}$

Dowry items, such as textiles, silver, and furniture, often retained the mark of the woman's maiden, or birth, name, whether functional or decorative. While the items that Reverend Leonard tracked were purely functional, allowing his daughters to start housekeeping, some were also more personal and decorative. A woman's sampler, made when she was a young girl and signed with her birth name, or a quilt given to her on the eve of her marriage and signed by her mother, seem like they would have served the

\footnotetext{
${ }^{42}$ Ulrich, "Hannah Barnard's Cupboard," 257, 273.

${ }^{43}$ Account book kept by Reverend Zenas L.Leonard, 1830-1842, Sturbridge, Massachusetts, Old Sturbridge Village Research Library. Mary Ann Leonard married Reverend Francis W. Emmons on August 31, 1829; Vernera Leonard married Francis E. Corey on April 25, 1831 (after receiving goods totaling \$108.80 in her father's account book), and Sarah Leonard married Thomas Spooner on September 5,1842 (with a total of only $\$ 21.21$ worth of goods in her father's account book). This type of account was not uncommon. Jane Nylander found similar accounts kept a century earlier by Samuel Lane of Stratham, New Hampshire. See Jane C. Nylander, "Provision for Daughters: The Accounts of Samuel Lane," in House and Home, Peter Benes, ed. (Boston: Boston University, 1990), 11-27.
} 
same functions as furniture and silver marked with her name that she brought to her new home. $^{44}$ Elizabeth Range Miller (1777-1843) bequeathed a set of household items to her granddaughter, which may have served the same function as a dowry from the girl's parents. In her will, she left her "grand daughter who now lives with [her], Mary Devault," her "Side Board, Desk, One half of [her] kitchen Furniture or kitchen utensils, one feather and one straw bed, bed stead, and well furnished with suitable bed clothing for same, also [her] quilted quilt of the pattern known and called 'Rose of Sharon.",45 To outsiders, these items demonstrated the family's full web of kin relationships. ${ }^{46}$ For the bride, they allowed her to remember her birth family's history and to preserve her personal identity.

The quilt that forty-seven-year-old Catherine (Penniman) Bradford (1778-1827) made for her daughter, Catherine Ann (b. 1802), when she married in 1825 fulfilled this role (figure 4.5). ${ }^{47}$ Made from hundreds of silk triangles, the quilt has an embroidered central medallion that was brought from England by the bride's father, sea captain

\footnotetext{
${ }^{44}$ A study of Pennsylvania-German dowry records from the nineteenth century found that after furniture, "textiles were the most highly valued and most abundant items in young peoples' 'outfittings." See Jeannette Lasansky, A Good Start: The Aussteier or Dowry (Lewisburg, Pennsylvania: Oral Traditions Project, 1990), 78.

${ }^{45}$ Elizabeth Range Miller's will is quoted in Bets Ramsey and Merikay Waldvogel, The Quilts of Tennessee: Images of Domestic Life Prior to 1930 (Nashville: Rutledge Hill Press, 1986), 9. Elizabeth Range was born in 1777 in Berkeley, Virginia, the daughter of Peter Range and Elizabeth Ronimus. In 1798, she married Jacob Miller (1779-1858) in Washington, Tennessee. The couple had nine children. Mary Devault (1825-1889) was the oldest daughter of Elizabeth's oldest daughter, Mary Miller (17991859), who had married Daniel Devault [or DeWald] (1800-1886) in 1825. Genealogical information from www.ancestry.com, accessed August 10, 2009.

${ }^{46}$ Barbara McLean Ward and Gerald W.R. Ward, "Sterling Memories: Family and Silver in Early New England," in The Art of Family, Simons and Benes, eds., 181-182.

${ }^{47}$ The quilt is now in a private collection. It is illustrated in Ellen Kort, Wisconsin Quilts (Charlottesville, Virginia: Howell Press, 2001), 3. Catherine Ann Penniman, the quiltmaker, was born on November 5, 1778 in Braintree, Massachusetts, the daughter of William Penniman and Rebecca Edmunds. Her father was a well-known shipbuilder. In 1793, when she was fifteen, Catherine married Charles Bradford, a sea captain. The couple had one child in 1802, Catherine Ann Bradford, the quilt recipient. She married Seraphim Masi in November 1825. See Kort, Wisconsin Quilts, 2.
} 


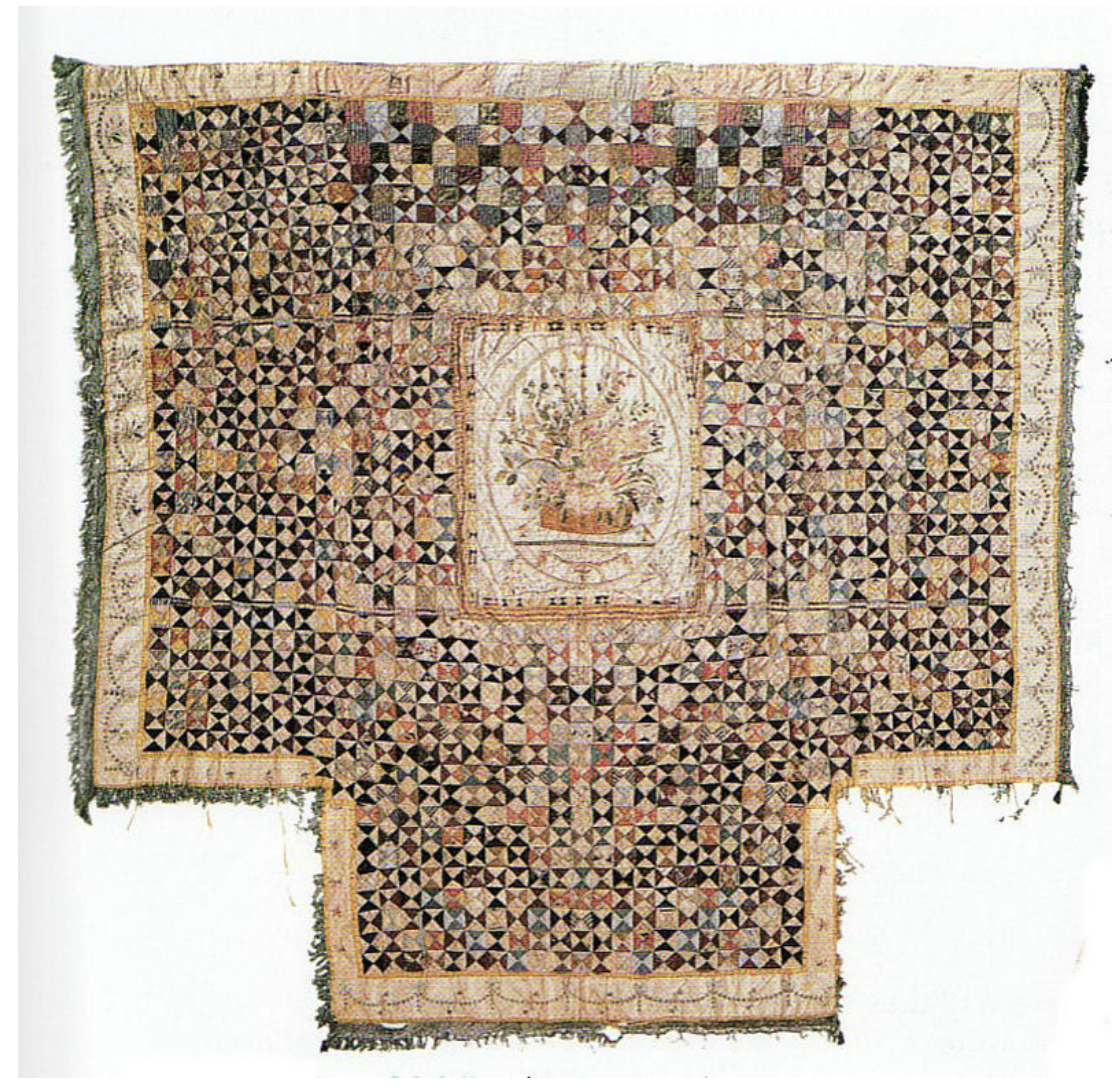

Figure 4.5. Quilt by Catherine Penniman Bradford (1778-1827), 1825, Boston, Massachusetts. From Wisconsin Quilts @ 2008 by Ellen Kort. Used with the kind permission of Krause Publications, an imprint of $\mathrm{F}+\mathrm{W}$ Media, Inc. All rights reserved.

Catherine Penniman Bradford made this quilt for her daughter's marriage in 1825. It quickly became a family heirloom as Catherine's husband, who brought the silk fabric in the center from England, died in 1823. Catherine died soon after her daughter's wedding, in 1827. The quilt has subsequently been passed down through eight generations. 
Charles Bradford (1767-1823). ${ }^{48}$ Since Captain Bradford died two years before his daughter married, and her mother died two years after the wedding, the quilt must have been a precious keepsake for young Catherine, allowing her to keep memories of her mother and her father nearby. Transformed into an heirloom almost immediately, seven Catherines have given the quilt to another since $1825 .{ }^{49}$ Dowry gifts, like Catherine Bradford's silk quilt, provided women with a model for giving gifts as they aged, suggesting the meaning that textiles and other "moveables" could hold, as well as putting the means for creating a gift within their grasp. And, once learned, this lesson carried through the woman's life cycle to any bequests she might make.

Most women of the antebellum period recognized that they were not positioned to be able to pass on significant amounts of land or cash. Even a woman as well off as Eleanor Parke (Custis) Lewis (1779-1852), adopted granddaughter of George Washington (1732-1799), wrote in 1825, when she was forty-six, that she would give her daughter "half of the only property in my power 600 acres of Kenahwa Land - not of much value at this time, if ever." ${ }^{50}$ In addition to this one reference to a gift of land, Lewis frequently wrote about needlework gifts she was making to present to friends and family as tokens of her love. ${ }^{51}$ Her gifts took many forms; in March 1821 she sent a watch bag and a pincushion, partially made from "Grandmama's wedding petticoat when she married the Genl," along with four pairs of "cambrick cuffs," to her lifelong friend Elizabeth Bordley Gibson (1777-1863) and in December 1824 she wrote about painting a

\footnotetext{
${ }^{48}$ Kort, Wisconsin Quilts, 2.

${ }^{49}$ Kort, Wisconsin Quilts, 3.

${ }^{50}$ April 5, 1825 letter to Elizabeth Bordley quoted in Brady, George Washington's Beautiful Nelly, 287.

${ }^{51}$ See letters written by Eleanor Parke Custis Lewis on March 22, 1821, October 25, 1823, November 24, 1824, December 22, 1824, October 2, 1825 and October 7, 1825 in Brady, George Washington's Beautiful Nelly, for additional examples of her hand-made needlework gifts. See also the diary kept by Mary Avery Upham (1790-1872) for the years from 1832 to 1860, where she makes numerous references to needlework gifts that she is working on, Massachusetts Historical Society, Boston, Massachusetts.
} 
pair of firescreens to give to the Marquis de Lafayette (1757-1834). ${ }^{52}$ During the 1840 s

and 1850 s, she set about completing needlework wall hangings or stool or piano covers

so that each of her fourteen grandchildren would have a sample of her needlework after

her death. ${ }^{53}$ "I am at work on a screen for my darling Conrad Lewis, nine years old,"

Lewis reported to Bordley in December 1848: "Every winter I work a large piece for one

of my Grandchildren, I wish I could show them to you."54

Eleanor's older sister, Eliza Parke Custis (1776-1832), seems to have had similar

feelings about her own needlework. In 1815, thirty-nine-year-old Eliza added two

borders to a quilt her adoptive grandmother, Martha Washington (1732-1802), had started

shortly before her death (figure 4.6). ${ }^{55}$ She later inscribed the quilt, "This Quilt was

entirely the work of my grandmother as far as the plain borders. I finished it in 1815 and

leave it to my Rosebud [her daughter, Eliza Law (1797-1822)]. E.P. Custis."56

\footnotetext{
${ }^{52}$ Brady, George Washington's Beautiful Nelly, 104-105, 158.

${ }^{53}$ Heather Ruth Palmer, "Where is Nineteenth-Century Southern Decorative Needlework?," The Southern Quarterly 27 (1988): 65.

${ }^{54}$ Letter from Eleanor Parke Custis Lewis to Elizabeth Bordley, December 17, 1848, quoted in Brady, George Washington's Beautiful Nelly, 251.

55 The quilt is currently on loan to the Smithsonian Institution, Washington, DC. Eliza Parke Custis added two borders of printed fabric. The quilt top, which is not quilted or finished, employs both block-printed fabrics and copperplate-printed fabrics. It shows similarities to two other quilts attributed to Martha Washington: "The Penn Treaty Counterpane" made around 1785 and now owned by Mount Vernon; and an unfinished bed cover dating to the 1790s, also owned by Mount Vernon. Both employ similar colors, fabrics and patterns to this quilt. Curatorial file, Smithsonian Institution, Washington, D.C. Martha Dandridge was born in 1731, the daughter of John and Frances Dandridge. In 1749, she married Daniel Parke Custis. The couple had two children who survived infancy before Daniel died in 1757. In 1759, she married George Washington (1732-1799). Eliza Parke Custis was born in 1776 in Mount Airy, Maryland, the daughter of John Parke Custis (1754-1781) and Eleanor Calvert (1754-1811). In 1796, she married Thomas Law (1756-1834) and the couple had one child, Eliza Law (1797-1822). Eliza later left her husband, divorced him and returned to using her maiden name. Genealogical information from www.ancestry.com, accessed August 12, 2009; Edith Tunis Sale, Old Time Belles and Cavaliers (Philadelphia: J.B. Lippincott, 1912), 232.

${ }^{56}$ Barbara Tricarico, ed., Quilts of Virginia 1607-1899: The Birth of America Through the Eye of a Needle (Atglen, PA: Schiffer Publishing Ltd., 2006), 46; Doris M. Bowman, American Quilts: The Smithsonian Treasury (Washington, DC: Smithsonian Institution Press, 1991), 20.
} 


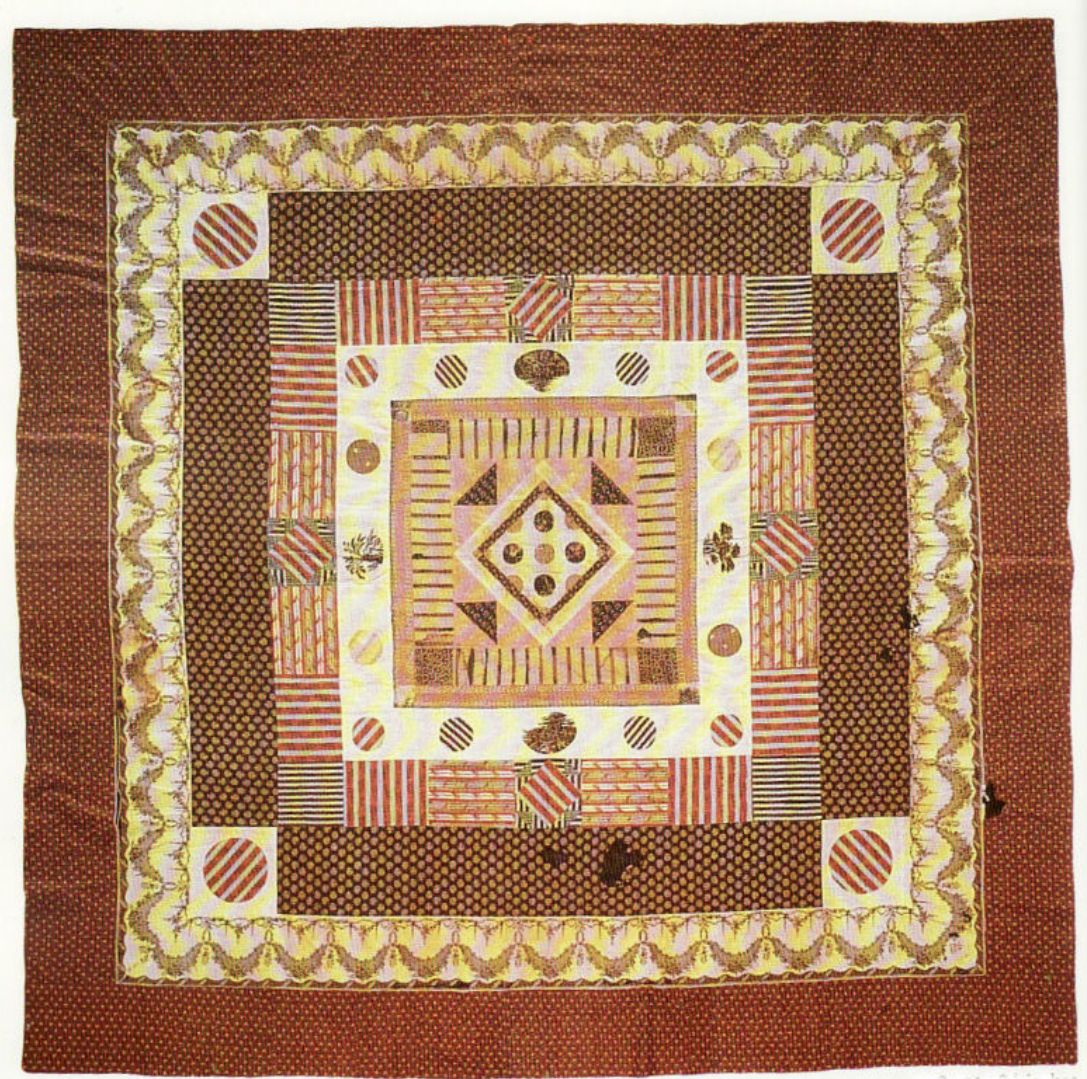

Figure 4.6. Quilt by Martha Washington (1732-1802) and Eliza Parke Custis (17761832), completed in 1815, Virginia. Courtesy of the National Museum of American History, Smithsonian Institution, Washington, DC.

Eliza Parke Custis added borders to this quilt top, which was begun by her grandmother, Martha Washington, in 1815. Custis then attached a note to the quilt stating her intention to leave it to her daughter, Eliza Law. 
Unfortunately, Eliza's words leave little conclusive evidence about her motives. The unfinished quilt top had apparently been laid aside for at least thirteen years (since Martha Washington died in 1802) before Eliza took it up and added the two outer borders. And, while Eliza explained in her note that she "finished it in 1815," she also recorded that she left it to her daughter, presumably at some future time, rather than giving it to her at that time, suggesting that by adding to the quilt, it became hers, rather than solely Martha Washington's. Eliza's daughter was only five when her greatgrandmother died and would have had few memories of the woman, despite her historical stature, yet undoubtedly would have treasured the quilt, which represented her mother's work as well.

What motivated the elder Eliza to add to the top? One of the most notable national events of 1815 was the end of the War of 1812. Perhaps the end of the hostilities led her to pick up the quilt once again. After all, the first stitch extended Martha Washington's needlework across four generations - that which was started by the wife of the first president came to rest with a young woman who celebrated a second American victory over the British. As women, both Eleanor and Eliza Parke Custis used tools and materials available to make gifts that would retain family value and remind their descendants about their lives and achievements, as well as those of their grandmothers and great-grandmothers. ${ }^{57}$

English-born Esther Johnson Parkinson Slater (1778-1859) did the same. When she updated her will in 1857 , she included a number of bequests to family, servants and local organizations. While Slater was unusual in that she had a significant estate of

\footnotetext{
${ }^{57}$ I am indebted to Marla R. Miller for sharing her ideas on the meaning that this quilt top might have held for its makers and owners.
} 
almost $\$ 14,000$, including property and cash, allowing for a $\$ 2,000$ bequest to the Domestic and Foreign Missionary Society of the Protestant Episcopal Church for "the support of Foreign Missions," she included heartfelt gifts of her own needlework as well. One of her stepsons received "three pieces of work that hang in the South Parlor."58 Esther Slater clearly felt a responsibility to care for those around her, financially and emotionally, and used all of the means at her disposal to do so, whether cash, furniture or needlework.

Several of the quilts identified in this study remain extant because they were specifically bequeathed along a female line, like the one passed down through eight generations of Catherines. Mary (Betsy) Totten Polhemus Williams (1781-1861) made a spectacular Rising Sun (or Star of Bethlehem) quilt when she was in her mid-forties or early fifties (figure 4.7). ${ }^{59}$ The center of the quilt is an eight-point star pieced from 648 diamonds. Appliqued flowers and birds fill the spaces between the star's points. Judging from the printed cottons in the quilt, Totten must have made it during the early 1830s,

\footnotetext{
${ }^{58}$ Will, probate inventory and receipts for bequests, Esther Slater (estate) collection, MSS9001S - box 6, Rhode Island Historical Society, Providence, Rhode Island.

${ }^{59}$ The quilt is now in the collection of the Smithsonian Institution, Washington, DC. Born in Staten Island, New York, Totten was the daughter of Gilbert Totten (1741-1819) and Mary Butler (b. 1739). She married twice, first to Joseph Polhemus (b. 1762) in 1821 when she was forty, and then to Matthew Williams (b. 1780) in 1828 when she was 47 . See family trees on www.ancestry.com, accessed December 9, 2007. The Star of Bethlehem pattern was also known as the Lone Star, inspired by the history of Texas. This pattern's appearance in the 1830s slightly predates the fall of the Alamo in 1836. An adaptation of the central medallion format, the pattern requires precision so that all of the pieces will line up crisply. See Stella Rubin, Miller's How to Compare and Value American Quilts (Tenterden: Miller's, 2001), 120; Barbara Brackman, Clues In the Calico: A Guide to Identifying and Dating Antique Quilts (McLean, Virginia: EPM Publications, 1989), 171. At least three other quilts are also attributed to Totten. Two employ the same large Rising Sun pattern and are now in the collection of the Staten Island Historical Society, Staten Island, New York. One of these has an embroidered inscription, "Mary Ann Dubois John Dubois October the 6 1835." Mary Ann Johnson (b. 1807) was Totten's niece and married John Dubois on October 6, 1835; family tradition holds that this quilt was a wedding gift for her. Curatorial file, Staten Island Historical Society, Staten Island, New York. A third quilt, in the Sunburst pattern, is now in the collection of the New York State Historical Association, Cooperstown, New York. I thank John Hart Jr., Assistant Curator of Collections, New York State Historical Association, and Maxine Friedman, Chief Curator, Staten Island Historical Society, for sharing information and images of these quilts with me.
} 


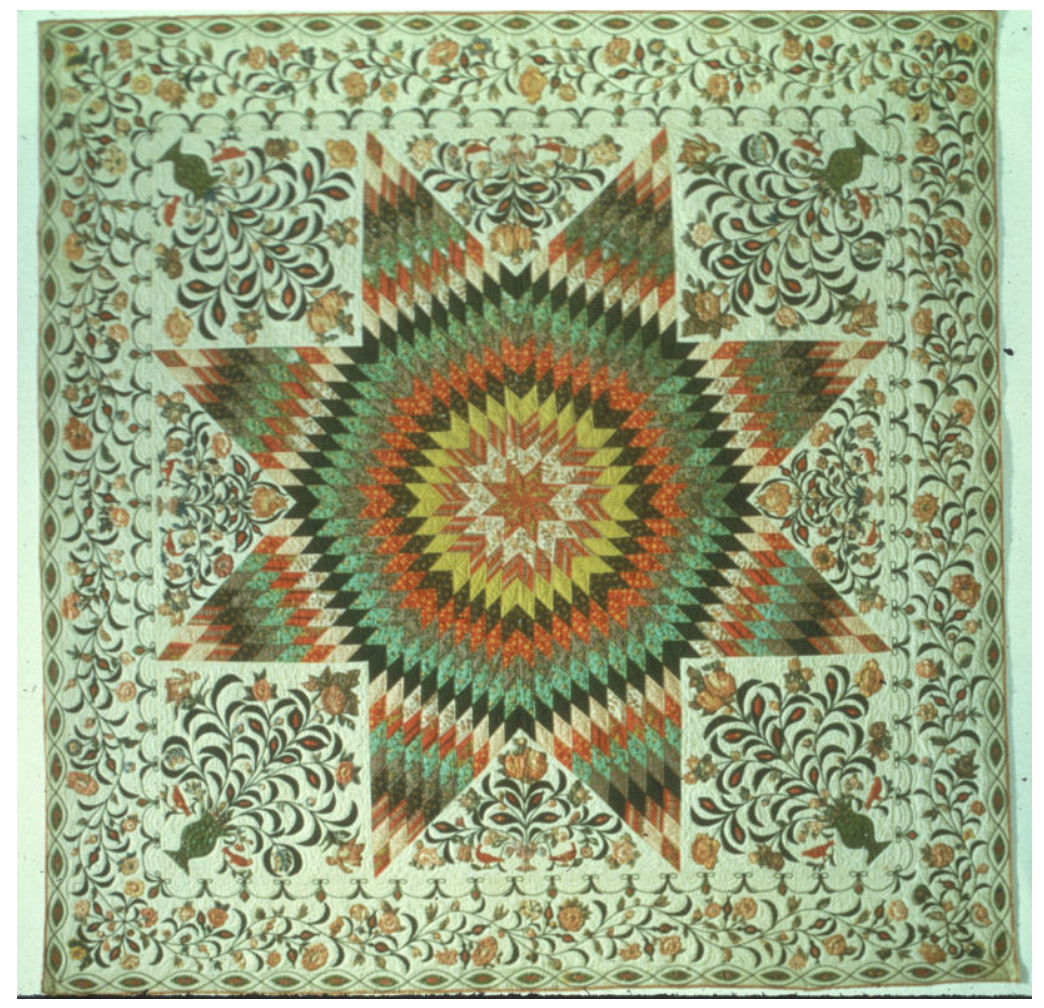

Figure 4.7. Quilt by Mary (Betsey) Totten Polhemus Williams (1781-1861), circa 1830, Staten Island, New York. Courtesy of the National Museum of American History, Smithsonian Institution, Washington, DC.

Mary Totten Polhemus Williams made at least three quilts using the Rising Sun pattern seen here. She willed this one to a grand-niece and gave a second to a niece for her wedding. 
after her second marriage in 1828. Regardless, she signed the quilt on the front at a bottom corner with red cross-stitched initials, "BT." ${ }^{60}$ Although married twice, Betsy (Totten) Polhemus Williams labeled the quilt with the initials of her birth name, an indication of her identification with her own family.

When she died childless at the age of eighty-one, Totten bequeathed the quilt to her sister's granddaughter, Rachel Drake (b. 1833), who was then twenty-eight. In her will, Totten described her quilt as "my large spread called the Rising Sun." It was the first item she mentioned, "after all my lawful debts are paid and discharged." ${ }^{\text {N1 }}$ Not only is the enumeration of a quilt unusual in a will, its placement as the first bequest is also noteworthy. Representing family connections, cultural traditions and her own personal pride, Totten's quilt provides documentation of the role that quilts played when given as gifts by older women to friends and family.

Historian Toby Ditz found that the subjects of her study of inheritance patterns in Connecticut used the patriarchal transfer of land from father to son in an attempt to "anchor each family member to the community through property arrangements that reinforced patriarchal authority within households."62 But, this is just one side of the property equation. Certain types of moveables, including quilts and samplers made and distributed by female family members, provided a comparable structure to maintain family and community ties among women. ${ }^{63}$ These two types of property - land and moveables - had an important relationship to one another based, in part, on their gender

\footnotetext{
${ }^{60}$ Bowman, American Quilts, 29; Jacqueline M. Atkins and Phyllis A. Tepper, New York Beauties: Quilts from the Empire State (New York: Dutton Studio Books, 1992), 48; Patsy and Myron Orlofsky, Quilts In America (New York: Abbeville Press, 1992), 48.

${ }^{61}$ Totten's will is quoted in Bowman, American Quilts, 28.

${ }^{62}$ Ditz, Property and Kinship, 80.

${ }^{63}$ Carroll Smith-Rosenberg, Disorderly Conduct: Visions of Gender in Victorian America (New York: Oxford University Press, 1985), 62-65.
} 
associations. In short, neither was complete without the other. Just as men felt a responsibility to pass on land to their sons to maintain the family name, women seem to have felt the same responsibility to maintain family traditions and history, with an eye toward helping subsequent generations of female relations. Artist Ruth Henshaw Bascom (1772-1848) made her feelings known in her 1841 will, writing "if I leave any property at my decease, it may eventually descend to such of my female relatives, to whom it would be most beneficient - for their own personal use \& under their sole control." ${ }^{64}$ The textiles women received as their dowry, those they made as gifts, as well as those named in female-to-female bequests, became family heirlooms that were used to bind the generations together.

When forty-nine-year-old Sarah (Wadsworth) Mahan (1802-1885) completed a quilt in 1851 (figure 4.8) she attached a written inscription (figure 4.9) to the quilt top, making her wishes for its future ownership clear: "This quilt, commenced by our dear Laura \& finished by me, principally from fragments of her dresses, I give \& bequeath unto her sister Julia M. Woodruff, or in case of her death to her sister Hila M. Hall, if she survives, otherwise to the oldest surviving granddaughter of their father, Artemas Mahan deceased." ${ }^{65}$ Far more than a warm bed covering, this quilt was a legacy intended to join a shattered family together and to be a sentimental object for its maker and her family. Initially started by fourteen-year-old Laura Mahan (1834-1848), the quilt was unfinished

\footnotetext{
${ }^{64}$ A copy of Bascom's will is in the Ruth Henshaw Bascom papers at the American Antiquarian Society, Worcester, Massachusetts. Bascom's will is quoted in Michael R. Payne and Suzanne Rudnick Payne, “A "woman could paint a likeness?,"” The Magazine Antiques 175 (January 2009): 182.

${ }^{65}$ The quilt is currently in the collection of the Allen Memorial Art Museum, Oberlin, Ohio. The bequest is quoted in Ricky Clark, "Fragile Families: Quilts as Kinship Bonds," The Quilt Digest 5 (1987): 5.
} 


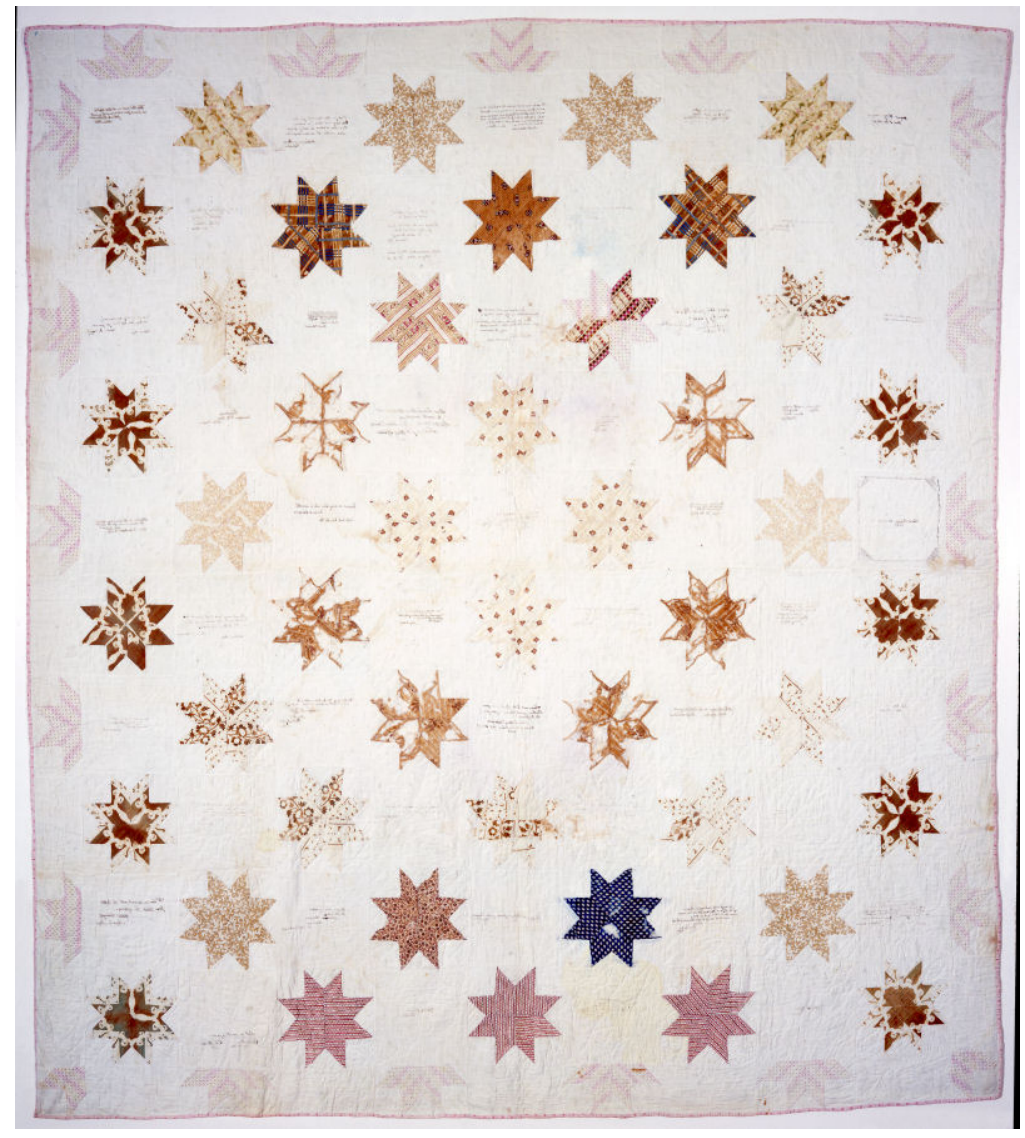

Figure 4.8. Quilt by Sarah Wadsworth Mahan (1802-1885), 1851, Ohio. Allen Memorial Art Museum, Oberlin College, Ohio; Special Acquisitions Fund and Gift of Private Donors, 1985.

Sarah Wadsworth Mahan completed this quilt, which was started by her fourteen-yearold stepdaughter, after the girl's premature death. 


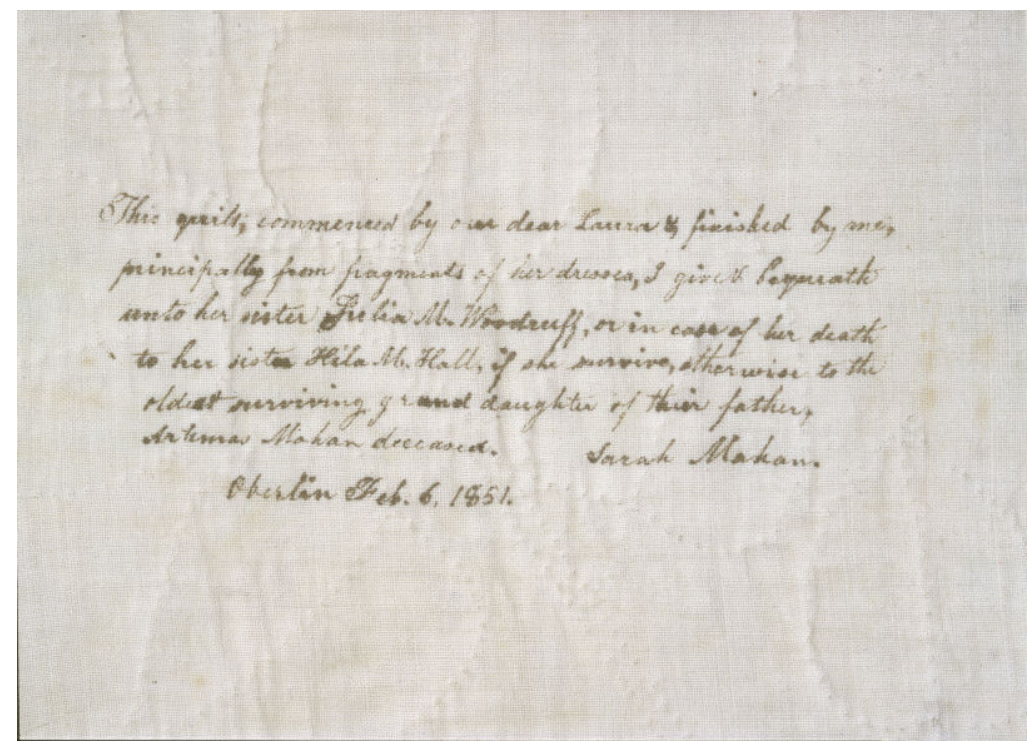

Figure 4.9. Detail of quilt by Sarah Wadsworth Mahan.

Sarah Wadsworth Mahan left explicit instructions about who her quilt should descend to after her death:

"This quilt commenced by our dear Laura \& finished by me; principally from fragments of her dresses, I give and bequeath unto her sister Julia M. Woodruff, or in case of her death to her sister Hila M. Hall, if she survives, otherwise to the oldest surviving grand daughter of their father, Artemas Mahan deceased. Sarah Mahan. Oberlin Feb. 6, 1851." 
when she died in 1848. Laura's stepmother, Sarah Wadsworth, married Laura's father, Artemas Mahan (b. 1790-1800; d. circa 1843), when Laura was a small child. The loss of her step-daughter, just five years after the death of her husband, must have hit Sarah hard. Laura was the last child living at home with Sarah in Oberlin, Ohio; her sisters, Hila (b. 1821) and Julia, had married in 1839 and 1847, respectively. Both Laura and Sarah attended classes at the Oberlin Collegiate Institute, then under the presidency of Artemas's brother, Asa Mahan (1799-1889). ${ }^{66}$

As Sarah explained in the inscription, she used scraps from Laura's dresses to finish the quilt. She then asked forty-four friends and relatives to sign quilt blocks in 1850 and 1851. In 1851, around the time she completed the quilt and made her intentions about its future ownership known, Sarah took a teaching job in Minnesota. The quilt represented numerous important connections for her - and was a valuable keepsake linking her to family and friends both living and dead. ${ }^{67}$ Despite her specific instructions for the future ownership of the quilt, it actually descended through women in her own family. Mahan's inscription sent the quilt to her step-daughters (Laura Mahan's older sisters): Julia Mahan Woodruff and then Hila Mahan Hall, and then to the oldest surviving granddaughter of Sarah's husband and Laura's father, Artemas Mahan. ${ }^{68}$

\footnotetext{
${ }^{66}$ Clark, ed., Quilts in Community, 131; Clark, "Fragile Families," 13-14; Ricky Clark, "Quilt Documentation: A Case Study," in Making the American Home: Middle-Class Women \& Domestic Material Culture 1840-1940, Marilyn Ferris Motz and Pat Browne, eds. (Bowling Green, Ohio: Bowling Green State University Popular Press, 1988), 163-166.

${ }^{67}$ Clark, ed., Quilts in Community, 132; Clark, "Fragile Families," 14; Clark, "Quilt Documentation," 169, 179-186.

${ }^{68}$ Precise genealogical information for Artemas and Sarah Mahan and their family is not available so the reason for the change in descent of the quilt is unknown. A Hila Hall of the correct age does not appear on the 1880 U.S. Census, so she may have passed away by that time. A genealogical record at www.ancestry.com, accessed May 21, 2009, lists a Julia Mahan who was born in 1825, married Francis Woodruff in 1847 and died in 1892 . These dates fit the Mahan family timeline and this may be Laura's sister and Sarah's step-daughter. She was alive in 1885, but her exact whereabouts in 1885 are not known; it is possible that distance between Julia and Sarah made exchange of the quilt impossible. As for the
} 
Instead, the quilt first went to Sarah Judson Wadsworth (1831-1908), the wife of quiltmaker Sarah's nephew Edward Payson Wadsworth (b. 1830). The couple had no children, so the quilt next went to their niece, Sarah Wadsworth Getchell (1855-1939). Finally, the quilt was transferred to Sarah Wadsworth Getchell's granddaughter, Josephine. $^{69}$

Sarah Wadsworth Mahan's circumstances regarding property ownership were somewhat different than those of many of the other women mentioned here. She was a widow when she made the quilt and wrote the bequest, which gave her more control over her belongings than most married women. In addition, Michigan, where Sarah and Artemas Mahan lived before he died, passed a Married Woman's Property Act in 1844, the year after Artemas died. Her husband's estate, predating the property legislation, was in litigation until 1848, giving Sarah a particularly personal understanding of the transfer of property from one person to another. ${ }^{70}$ Her experience with her husband's estate may have encouraged her to write out her intentions for the quilt and to state specifically what should happen if one of her intended beneficiaries should die.

Gifts of needlework - whether part of a dowry, bequest, or celebratory spirit - are particularly salient examples of women's property ownership patterns during the early nineteenth century because textiles were at the heart of women's inheritances from the seventeenth century on. Textiles, including decorative needlework like samplers and quilts, provided a well-understood lexicon for women to express themselves, not only in

oldest granddaughter of Artemas Mahan, genealogical records were not available to conclusively identify this person.

${ }^{69}$ Clark, "Quilt Documentation," 182.

${ }^{70}$ Clark, "Fragile Families," 18. 
terms of their personal beliefs and opinions, but also in terms of their social position, including the material property that they owned.

A group of quilts related to the Scattergood-Savery family of Philadelphia demonstrates how the maternal line used quilts to maintain its own inheritance pattern while also reflecting the social position of their maker. Rebecca Scattergood Savery (1770-1855) was part of two prominent Quaker families in Pennsylvania and New Jersey. Her own family arrived in America during the late 1600s, with many of the Scattergood men subsequently making their living as seafaring merchants. Her husband's father, William Savery (1722-1787), arrived in the colonies around 1740 and became a premier Philadelphia furniture maker. Rebecca Scattergood married Thomas Savery (17511819), a carpenter-builder, in 1791 when she was twenty-one years old. The couple raised five children. ${ }^{71}$

In the 1820s and 1830s, after her husband's death, when Rebecca was in her fifties, she made at least five quilts for her children and grandchildren. ${ }^{72}$ Three of the quilts are in the "Sunburst" pattern created by stitching thousands of small diamond shapes in rows to make a vibrant quilt top. The earliest of the three dates to 1827 , according to family history, and contains a staggering 6,700 pieces. It was made for Rebecca's daughter Elizabeth (1806-1860) when she became engaged to James Cresson (1806-1872) (figure 4.10). ${ }^{73}$ Unfortunately, when a theological dispute divided the Society of Friends around the same time, the Savery and Cresson families took different

\footnotetext{
${ }^{71}$ Mimi Sherman, “A Fabric of One Family: A Saga of Discovery,” The Clarion 14 (Spring 1989): 58.

${ }^{72}$ Two of the quilts are friendship quilts pieced in the same six-point star block pattern and signed by a network of friends and family. One is currently in a private collection while the other is owned by the American Folk Art Museum in New York City. Sherman, "A Fabric of One Family," 58-59.

${ }^{73}$ The quilt is currently in the collection of Winterthur Museum and Country Estate, Delaware. I am indebted to Linda Eaton for generously sharing curatorial information about this quilt during my site visit on February 7, 2006.
} 


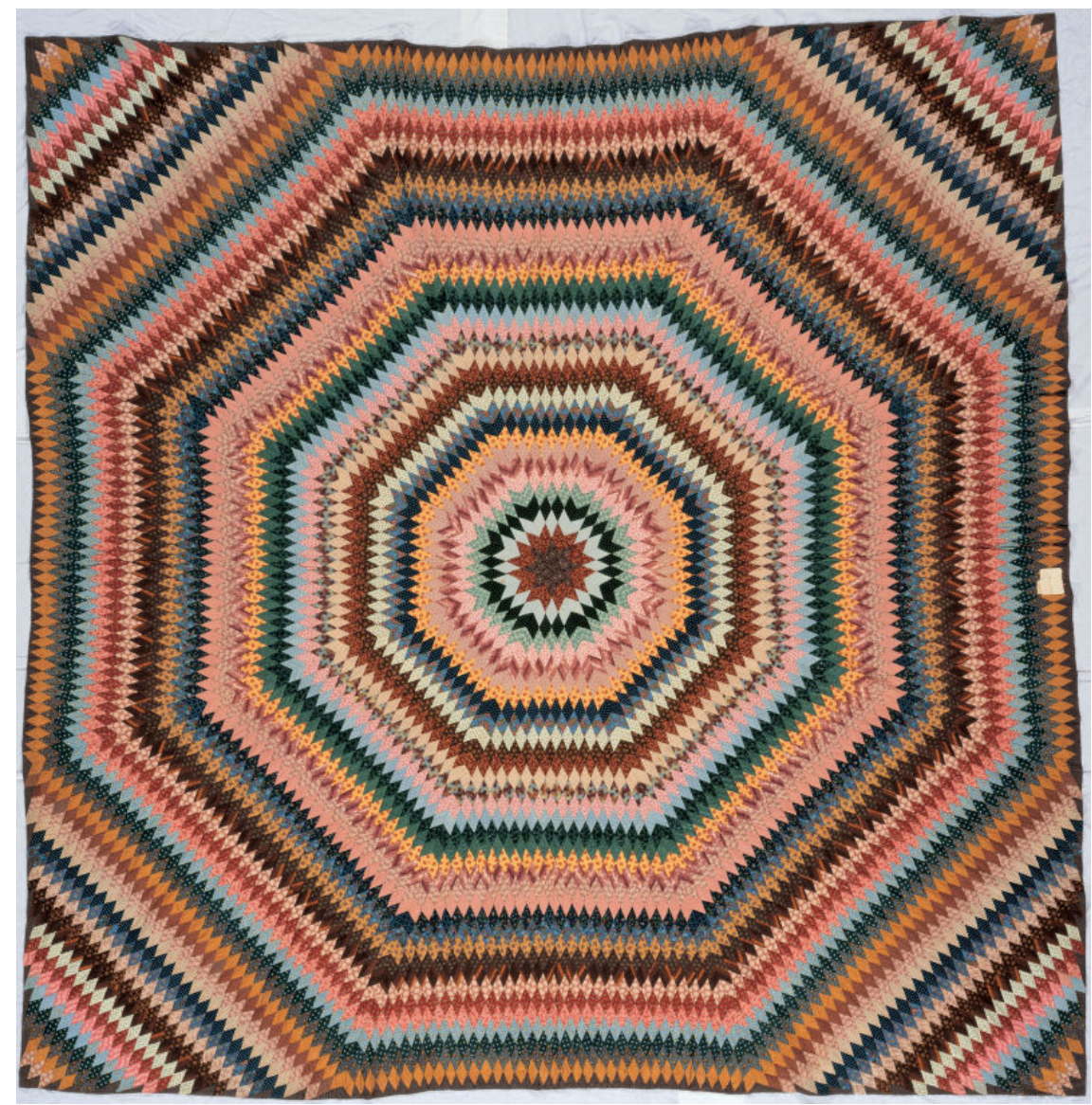

Figure 4.10. Quilt by Rebecca Scattergood Savery (1770-1855), 1827, Philadelphia, Pennsylvania. Courtesy of Winterthur Museum and Country Estate, Delaware.

Rebecca Scattergood Savery made three of these detailed quilts, each one with thousands of small diamonds stitched together. She gave them to family members who subsequently passed them down as family treasures. 
sides, and family history suggests that Elizabeth's family subsequently prohibited her marriage. Elizabeth received the quilt, but she never, in fact, married and later passed the quilt on to her namesake niece, Elizabeth L. Savery (1852-1936). ${ }^{74}$

Rebecca made a second quilt in the late 1830s, when she was in her late fifties, which was handed down in the family of her granddaughter, and namesake, Rebecca Walter Savery (1836-1902), the only daughter of quiltmaker Rebecca's son William (1798-1858). Like the first Sunburst quilt, this one is made from thousands of pieces about 2,900. ${ }^{75}$ These quilts are made using an English piecing technique, often called "Mosaic" or "Honeycomb." The fabric was basted around paper templates and then each diamond was whipstitched to the one next to it. After they were joined, the paper patterns were removed. Thought to be the earliest piecing technique used in American quilts, template piecing allows for smooth, uniform pieces across the entire quilt top. ${ }^{76}$

This older technique experienced a resurgence during the 1830s, yet Rebecca Scattergood Savery undoubtedly learned the technique as a young girl in the 1780 s.

The fabrics in the quilts are good-quality roller-printed cottons, some with a glaze, adding a shine to their finish. ${ }^{77}$ Rebecca Scattergood Savery's quilts not only have a

\footnotetext{
${ }^{74}$ Sherman, "A Fabric of One Family," 59.

${ }^{75}$ This quilt is currently in the collection of the American Folk Art Museum, New York City.

${ }^{76}$ Aimee E. Newell, "Paper-Template Piecing in Early-Nineteenth-Century America," Piecework Magazine 13 (September/October 2005): 41; Lynne Z. Bassett and Jack Larkin, Northern Comfort: New England's Early Quilts 1780-1850 (Nashville: Rutledge Hill Press, 1998), 27-30; Mosaic Quilts: Paper Template Piecing in the South Carolina Lowcountry (Greenville, South Carolina: Curious Works Press, 2002), 7-8, 12-14; Aimee E. Newell, "Sarah Clarke Ellis Ide Quilt," in Massachusetts Quilts: Our Common Wealth, Lynne Zacek Bassett, ed. (Hanover, NH: University Press of New England, 2009), 93-95.

${ }^{77}$ Stacy C. Hollander and Brooke Davis Anderson, eds., American Anthem: Masterworks from the American Folk Art Museum (New York: Harry N. Abrams, Inc., 2001), 325; Linda Eaton, Quilts in a Material World: Selections from the Winterthur Collection (New York: Abrams, 2007), 37. Savery's quilts may seem to be at odds with the "plain style" associated with Quakerism. As many scholars have documented, plain did not mean cheap - members of the Society of Friends often sought out good quality fabrics to make their clothing. In addition, schisms within the faith led some members to interpret the idea of "the best sort but plain" differently. For more on Quaker aesthetics see Eaton, Quilts in a Material World, 36-37; Emma Jones Lapsansky and Anne A. Verplanck, eds., Quaker Aesthetics: Reflections on a
} 
stunning arrangement of color and pattern but are also breathtaking by virtue of the sheer amount of work needed to complete each top. As she assembled hundreds of small pieces of fabric, Rebecca transmitted messages to her children and grandchildren. She showed that she could afford to use stylish fabrics, and demonstrated her fluency with the fashion of the time. As discussed in chapter 3, the explosion of colorful, patterned rollerprinted fabrics in the 1820s inspired a vogue for bright, exuberant quilts pieced with multiple fabrics. ${ }^{78}$ Savery's Sunburst quilts use English, and possibly some American, roller prints from the late 1830 s, suggesting that she bought the most recently available fabrics expressly to make her quilts. ${ }^{79}$ She did not use older fabrics that she already had on hand, or recycle scraps from old clothing and household textiles. Her Sunburst quilts are also very large, measuring nine and ten feet square, requiring much time to cut out thousands of diamond-shaped pieces.

Rebecca's third Sunburst quilt was made in 1839 when she was fifty-nine years old for another granddaughter, Sarah Savery (b. 1839), the daughter of her son Thomas (1802-1860). This quilt, made with over 3,900 pieces, afterwards passed from mother to daughter for five generations. Subsequent owner Hannah Savery Mellor (b. 1872), the daughter of the original recipient, stitched the following note to the back: "This quilt was made for Mother by my great-grandmother, Rebecca Scattergood Savery, 1839.”80 These three quilts reflect inheritance patterns that were maintained for generations and were

Quaker Ethic in American Design and Consumption (Philadelphia: University of Pennsylvania Press, 2003).

${ }^{78}$ Bassett and Larkin, Northern Comfort, 8, 34, 74-75. For a thorough exploration of this aesthetic, see Sumpter T. Priddy, American Fancy: Exuberance in the Arts, 1790-1840 (Milwaukee: Chipstone Foundation, 2004).

${ }^{79}$ Her 1839 and circa 1840 Sunburst quilts employ some of the same fabrics. Sherman, "A Fabric of One Family," 60-61.

${ }^{80}$ Sherman, "A Fabric of One Family," 57-59. This quilt is now in the collection of the Philadelphia Museum of Art, Pennsylvania. 
valued by Rebecca, her daughters and her granddaughters. The quilts passed directly from woman to woman; they were a legacy that Rebecca could provide, just as her husband provided land and cash for his sons.

As Laurel Thatcher Ulrich has argued, women used property to "assert identities, build alliances, and reweave family bonds torn by marriage, death or migration." ${ }^{, 11}$ Quilt scholar Laurel Horton believes that "quilts functioned as a kind of currency in an informal, female-centered economy based on kinship, mutual support, and the transformation of ordinary materials into objects of significance and value." ${ }^{\prime 82}$ Giving a quilt as a gift was an exchange of property, but this was only part of the value that the gift held for giver and recipient. These gifts also held social and cultural value for those involved. Needlework gifts were far more than fabric and thread, and they provided more than just physical and emotional comfort and warmth. These objects created "cultural memory" 83 - allowing their givers to express nostalgia, remember the past and to influence the memories of their descendants.

\section{"the productions of our own industry" $"$ : The Social Nature of Gifts}

While the gifts of needlework discussed here were made by a single person and given to another, they also provided a connection to a larger social matrix of family members and friends and, as such, held meaning and value for that larger community. Society prescribed certain rules around the act of giving gifts, which formed a context for the women who made quilts and then presented them to another person. These

\footnotetext{
${ }^{81}$ Ulrich, Age of Homespun, 133.

${ }^{82}$ Horton, Mary Black's Family Quilts, 2.

${ }^{83}$ Susan M. Stabile, Memory's Daughters: The Material Culture of Remembrance in Eighteenth-Century America (Ithaca: Cornell University Press, 2004), 71-72.

${ }^{84}$ Mme. Celnart, The Gentleman and Lady's Book of Politeness (Boston: Allen and Ticknor, 1833), 152.
} 
needlework gifts provided a means for women to perform one of their most important societal roles - that of maintaining connections between what could be disparate branches of the family tree. For aging women of the antebellum era, this task seems to have increased in importance and urgency as they grew older. Aging women could employ textiles as a badge of their femininity, using them to express their fears, their love and affection, and their opinions.

Scholars have explored the role of letters among families in the antebellum era as children moved west in search of better economic opportunities. ${ }^{85}$ In her study of the correspondence of Michigan women during the nineteenth century, Marilyn Motz argued that each letter took on a life of its own, bringing a bit of the writer's identity and life to the recipient. She found that letters offered a means of power and expression for women, who "without real power to control decisions within the family...learned to manipulate words to persuade without seeming to persuade and to create for themselves an illusion of community out of the reality of their isolation." 86 Careful consideration of the quilts made as gifts suggests that they worked in much the same way, enabling makers to create community, express feelings and opinions, and maintain social connections. They also provided comfort and warmth, as well as a legacy of intangible memories and tangible mementoes.

\footnotetext{
${ }^{85}$ For example, see Marilyn Ferris Motz, True Sisterhood: Michigan Women and Their Kin 1820-1920 (Albany: State University of New York Press, 1983) and Martha Saxton, Being Good: Women's Moral Values in Early America (New York: Hill and Wang, 2003), 109-110, 189-191.

${ }^{86}$ Motz, True Sisterhood, 81.
} 
A group of quilts made by Anna Catharine Hummel Markey Garnhart (17731860) while in her forties and fifties, bound together generations across long distances (figure 4.11). ${ }^{87}$ Eleven of her quilts have been located from Florida to Oklahoma, turning up 150 years later in families who had no knowledge that related quilts had descended through other lines. ${ }^{88}$ Married twice, with three children, Garnhart had eleven grandchildren, suggesting that she made one quilt for each of them. Other quilts may yet reside with families who have lost touch with their extended relations, or may not have survived to the present. All of her extant quilts are appliquéd, many with flower baskets and five with eagles. Her great-granddaughter remembered that Catharine used quality materials to make her quilts: "the lining of the quilt," she recalled, "was 50 ct. a yard, the top was one dollar a yard and the thread she spun herself." ${ }^{\prime 89}$ At the time, in the 1820 s and 1830s, cheap printed cottons were available for as little as four or five cents a yard,

\footnotetext{
${ }^{87}$ Known as Catharine, Garnhart was born on April 27, 1773 in Frederick, Maryland. Her mother, Christiana Catharine Grundler (b. 1747), was German and came to America with her family when she was seven. Christiana married John Hummel (1751-1781) who died in 1781 when Catharine was only eight years old. Christiana later married Johann Fiege (1755-1829), a Hessian soldier who came to the colonies to fight in the Revolutionary War. When the War was over, he stayed in Maryland and purchased a grist mill. Catharine Hummel married John Markey (1771-1820) in 1796 when she was twenty-three. Together they had three children. After Markey died in 1820, Catharine married again, this time to Henry Garnhart (d. 1825), but the marriage does not seem to have been happy. Catharine and Henry lived together only a short time and he died in Charlestown, Virginia in 1825; thirty-five years later, she was buried next to her first husband in Maryland. Catharine amassed a substantial amount of property during her life. She inherited land and moveable goods from her father as his only surviving child and may have inherited from her mother too. See Dorothy Cozart, "An Early Nineteenth Century Quiltmaker and Her Quilts," Uncoverings 7 (1986): 74-76; Gloria Seaman Allen, Old Line Traditions: Maryland Women and Their Quilts (Washington, DC: The DAR Museum, 1985), 14-15.

${ }^{88}$ Seven of Garnhart's quilts are now at the Daughters of the American Revolution Museum in Washington, DC (although five of these are on loan to the Museum from their private owners); an eighth quilt is in the collection of the Plains Indians and Pioneers Museum in Woodward, Oklahoma. Three others remain in private collections; two are pictured in Rubin, Miller's How to Compare and Value American Quilts, 43; the third is illustrated as number 2054 in Clarence P. Hornung, Treasury of American Design (New York: Harry N. Abrams, Inc., 1972). I am indebted to Alden O'Brien, Curator of Costume and Textiles at the Daughters of the American Revolution Museum, for making the Garnhart quilts at the Museum, and their curatorial files, available to me during site visits in June 2006 and June 2009. I also thank Alden O'Brien and Virginia Vis, Curatorial Volunteer at the Daughters of the American Revolution Museum, for their thoughts on the dates of the quilts during my site visit in June 2009.

${ }^{89}$ Cozart, "An Early Nineteenth Century Quiltmaker," 76.
} 


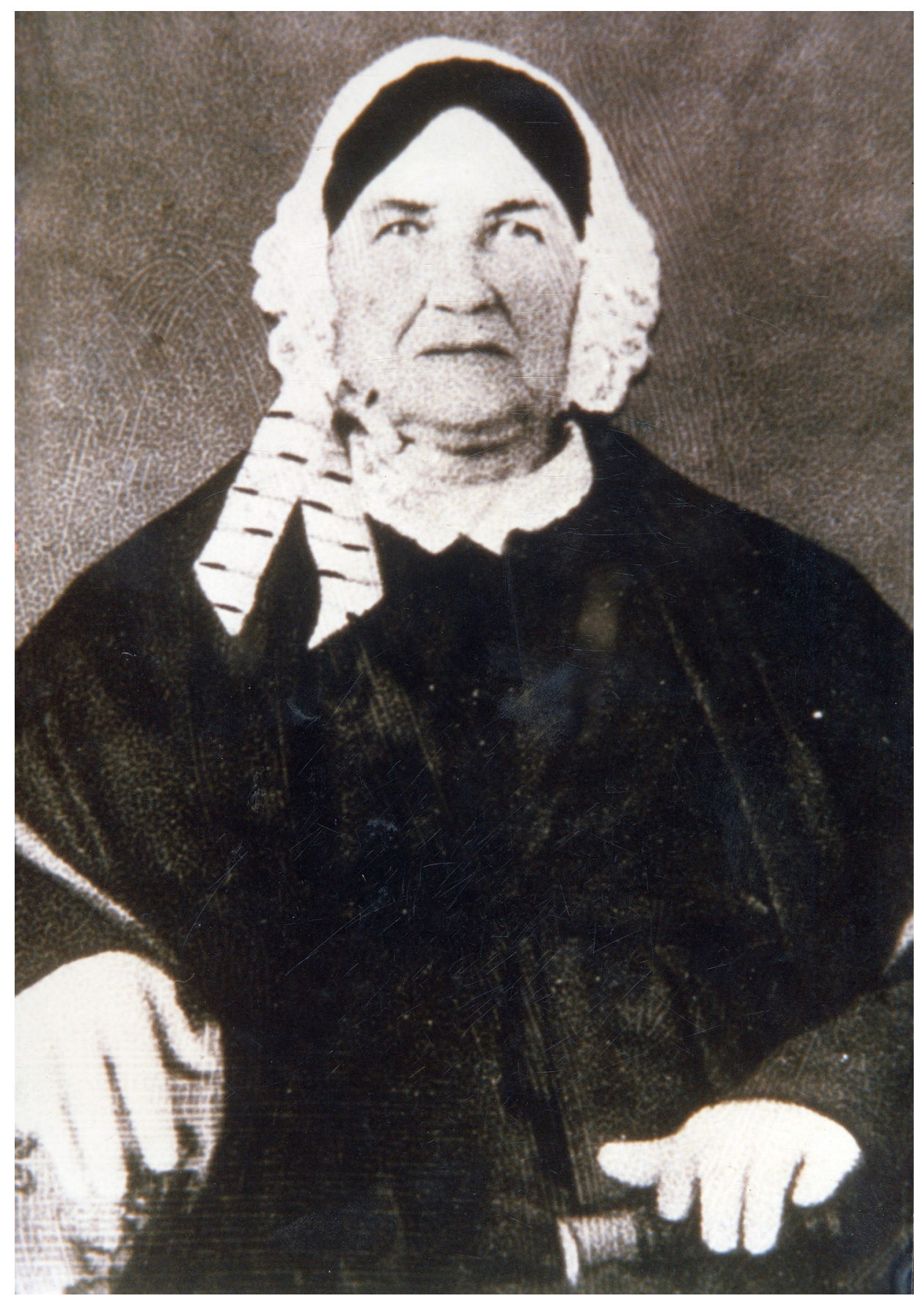

Figure 4.11. Anna Catharine Hummel Markey Garnhart (1773-1860), circa 1850. Courtesy of the Plains Indians and Pioneers Museum, Woodward, Oklahoma. 
while better quality fabrics sold for twenty-five to fifty cents per yard. ${ }^{90}$ Printed cottons priced at one dollar per yard may have been an exaggeration, a conflation of prices the great-granddaughter remembered, or an expression to signify that Garnhart used expensive cottons. Regardless, the quilts are made from good quality fabrics and are still in good condition suggesting that they were not used as bedcoverings very often, if at all. Their primary function was not as utilitarian household objects.

Catharine made one of the quilts for her first grandchild, John David Markey (b. circa 1821), around the time of his birth when she was forty-eight. ${ }^{91}$ In 1852 , as an adult, John David Markey moved west to Iowa, Missouri, Oregon and finally, to Oklahoma, bringing his grandmother's quilt with him each time. ${ }^{92}$ Catharine's second grandchild, Anna Markey (b. 1824) was the recipient of a bed-size quilt with a striking eagle design in the center (figure 4.12). ${ }^{93}$ Although this quilt was given later, around 1824, Markey seems to have made it almost ten years earlier, around 1815, judging by the fabrics she used. In 1846, when the recipient was twenty-two, she reportedly quilted the piece herself. ${ }^{94}$ According to family tradition, Garnhart based her central eagle on a similar

\footnotetext{
${ }^{90}$ Bassett and Larkin, Northern Comfort, 34, 37.

${ }^{91}$ This quilt is now in the collection of the Plains Indians and Pioneers Museum, Woodward, Oklahoma. I am indebted to the museum's former curator Kristin Mravinec for sharing the history of the quilt with me. Email correspondence from Kristin Mravinec, June 5, 2007. This quilt has been illustrated in Jane Amstutz Hamden and Pamela Frazee Woolbright, eds., Oklahoma Heritage Quilts: A Sampling of Quilts Made in or Brought to Oklahoma Before 1940 (Paducah, KY: American Quilter's Society, 1990), 125; Louisa B. James, "The Federal Eagle Quilt," The Quilting Quarterly 24 (Spring 1996): 23-24; Allen, Old Line Traditions, 15.

${ }^{92}$ Cozart, "An Early Nineteenth Century Quiltmaker," 80.

${ }^{93}$ This quilt is now in the collection of the Daughters of the American Revolution Museum, Washington, DC. It was donated to the Museum in 1974 by Garnhart's descendant, Mrs. Stephen J. Buynitzky. Curatorial files, Daughters of the American Revolution Museum, Washington, DC. The quilt is illustrated in Allen, Old Line Traditions, 14.

${ }^{94}$ Cozart, "An Early Nineteenth Century Quiltmaker," 78.
} 


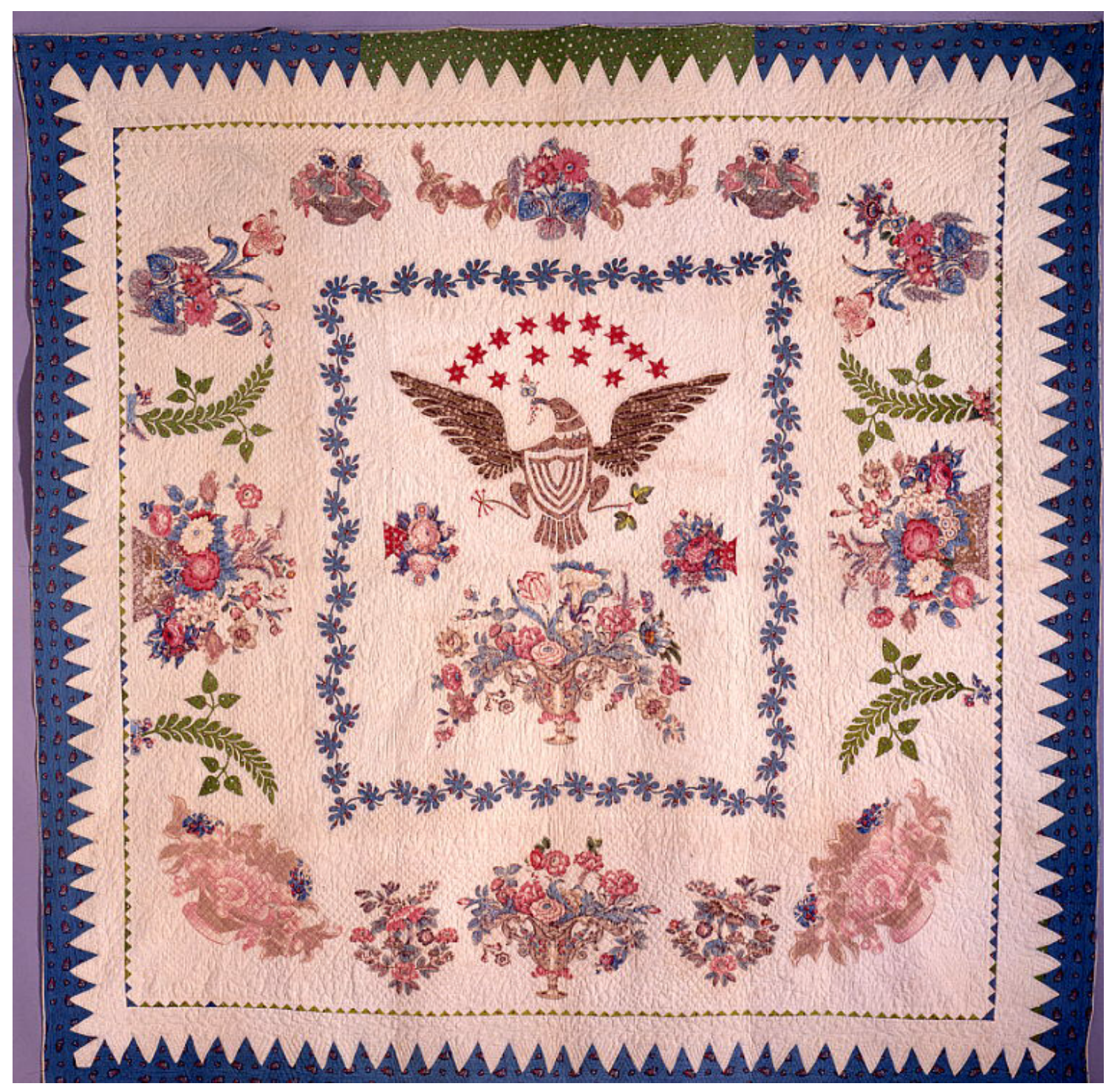

Figure 4.12. Quilt by Anna Catharine Hummel Markey Garnhart (1773-1860), circa 1815, Frederick, Maryland. Courtesy of the Daughters of the American Revolution Museum, Washington, DC.

Anna Catharine Hummel Markey Garnhart made several quilts employing a similar eagle motif. It is thought to have been inspired by an eagle design on a Liverpool jug, which was also handed down in the family. 
motif on a Liverpool pitcher that was also passed down in the family. ${ }^{95}$ None of Garnhart's quilts can be precisely dated; she did not sign any of them. Her choice to make eleven quilts using the same technique (cut-out chintz appliqué) and design motifs (eagles and flower baskets), suggests that she enjoyed it, although she may have had other motivations, as well. It is tempting to speculate the she made quilt after quilt over a period of many years and then gave them to her grandchildren, sometimes years after she first made them, but Garnhart did not leave any documentation about why or when she made each quilt.

A third quilt shows Garnhart's flower basket design (figure 4.13). ${ }^{96}$ This one was given to her grandson, J. Henshaw Markey (1835-1899). While the two quilts described above seem to have been gifts at birth, this quilt dates to about 1850 , when the recipient was fifteen. ${ }^{97}$ The remaining eight quilts that are known today include five full-size quilts and three cradle quilts. Five show Garnhart's flower basket design and three employ her eagle motif. All of these quilts were passed down through multiple generations.

Perhaps part of what motivated women to give textiles as gifts was their participation in multiple families - one as a daughter, one as a wife and, eventually, several as a mother. ${ }^{98}$ Keeping up with their role as "kinkeeper" in these many families required them to maintain connections, as well as their own identity, even though their role changed in each situation. The quilt was a stand-in for the woman, a way to suggest

\footnotetext{
${ }^{95}$ Curatorial files, Daughters of the American Revolution Museum, Washington, DC.

${ }^{96}$ This quilt is in the collection of the Daughters of the American Revolution Museum, Washington, DC. It was donated by a descendant of the recipient in 1991. Curatorial file, Daughters of the American

Revolution Museum, Washington, DC.

${ }^{97}$ Curatorial file, Daughters of the American Revolution Museum, Washington, DC.

${ }^{98}$ Degler, At Odds, 109.
} 


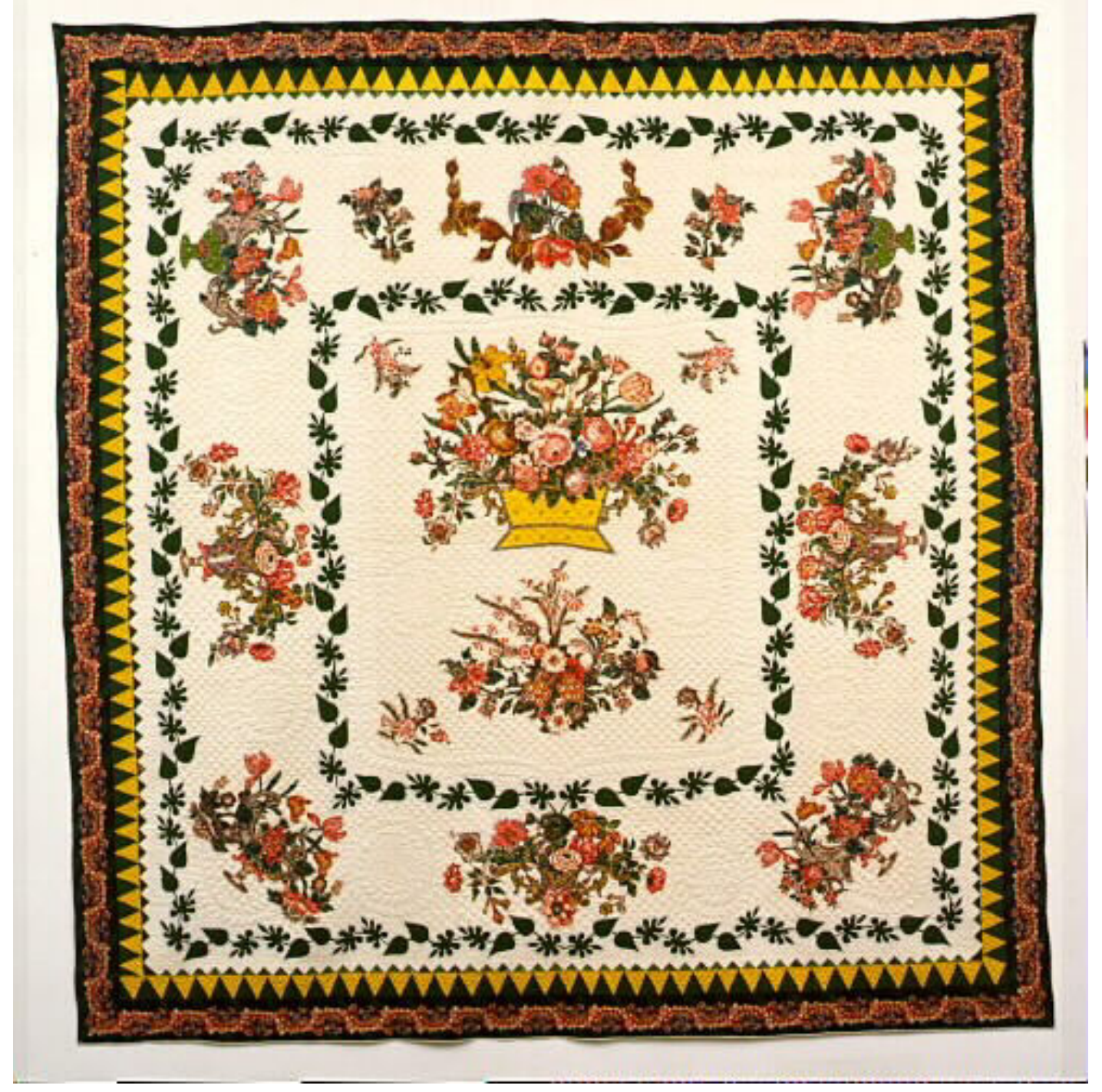

Figure 4.13. Quilt by Anna Catharine Hummel Markey Garnhart (1773-1860), circa 1850, Frederick, Maryland. Courtesy of the Daughters of the American Revolution Museum, Washington, DC.

Eleven quilts made by Anna Catharine Hummel Markey Garnhart are known and it is thought that she gave one to each of her grandchildren. The central flower basket design is common to several of the quilts. Garnhart cut out floral motifs from different fabrics and then created her own basket design on the quilt. 
taste and values without being there in person since, presumably, recipients thought of the maker every time they touched, saw or used the quilt. In turn, the quilt could maintain the "kin-keeping" role of its maker, continuing to fulfill her responsibility to keep family history alive, even after the woman was gone.

These ideas are further illustrated by a group of three quilts associated with the Marion and Palmer families of South Carolina. ${ }^{99}$ They visually represent their use by multiple generations, thus telling their own version of family history. Two of the three quilts recycle sections of older quilts. By reusing older techniques and fabrics, these quilts offered a way for the makers to transmit the values they cherished to the next generation and to remind following generations of family history.

Around 1830, forty-eight-year-old Harriet Kirk Marion (1782-1856) made a quilt by adding a new chintz border to an earlier piece of patchwork (figure 4.14). The center section is composed of pieced squares in an Irish Chain pattern variation made five to fifteen years earlier and shows signs of having been laundered. The chintz border, on the other hand, retains its glaze, suggesting that it was added later and that the quilt was not subsequently washed. A later label on the back of the quilt states that it was made for Harriet's granddaughter and namesake, Harriet Marion Palmer, who was born in November $1830 .^{100}$

The date of 1830 for the quilt is supported by the age of the chintz fabric used in the border, giving credence to the family's statement that the quilt was made to celebrate a birth that year. Genealogical sources confirm that the maker named on the label was

\footnotetext{
${ }^{99}$ All three quilts are now in the collection of the Museum of Early Southern Decorative Arts (MESDA) in Winston-Salem, North Carolina.

${ }^{100}$ Paula W. Locklair, Quilts, Coverlets and Counterpanes: Bedcoverings from the MESDA and Old Salem Collections (Winston-Salem, North Carolina: Old Salem, Inc., 1997), 43. The quilt has no batting; it has a linen backing and is quilted in a simple pattern of diagonal lines.
} 


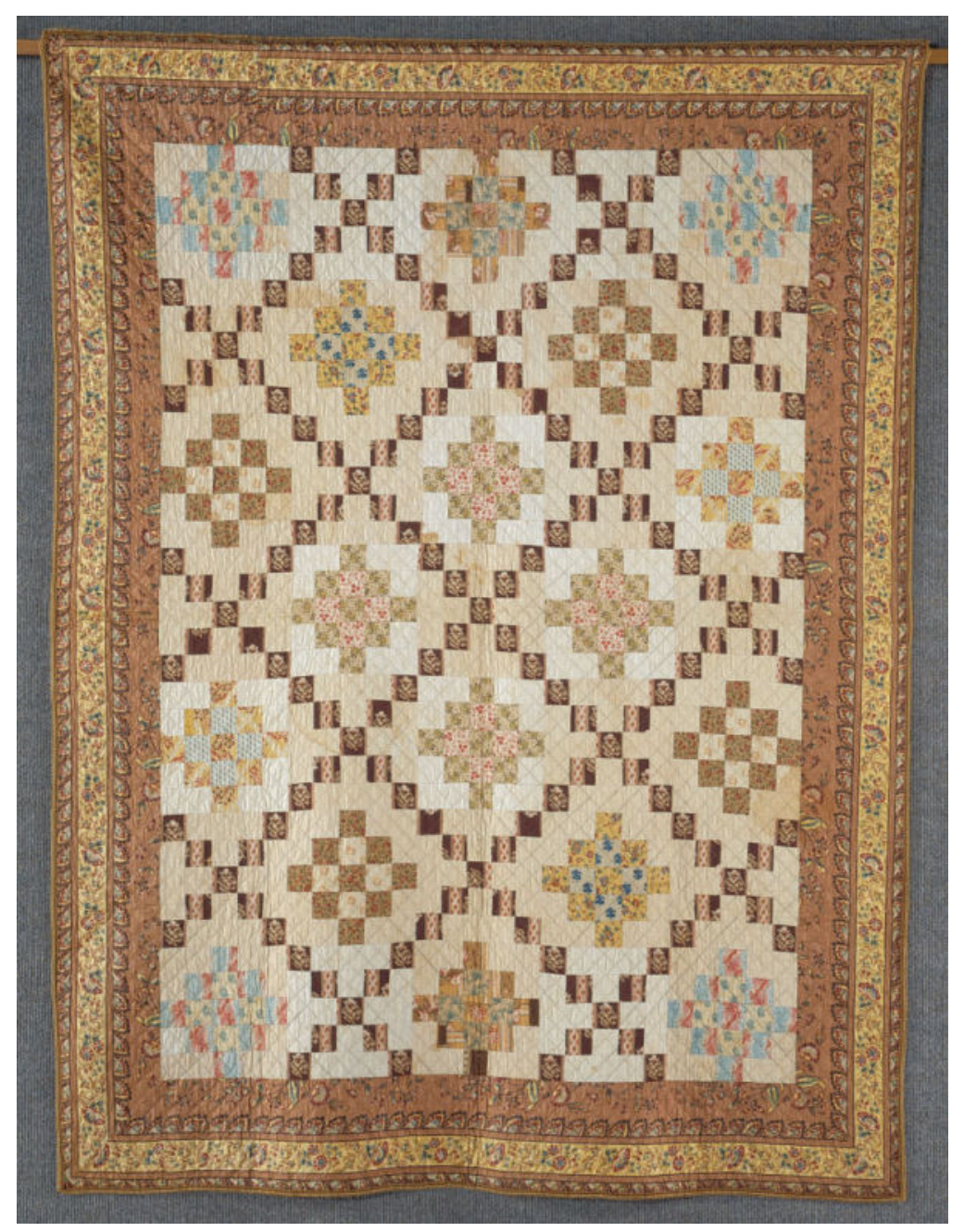

Figure 4.14. Quilt by Harriet Kirk Marion (1782-1850), circa 1830, South Carolina. Collection of the Museum of Early Southern Decorative Arts (MESDA) at Old Salem.

Harriet Kirk Marion recycled the center section of this quilt from an older piece. She freshened up what is one of the oldest named patchwork patterns, Irish Chain, by adding a border of fashionable chintz fabric and gave the quilt to her granddaughter at birth. 
alive at the time and could have made the quilt. ${ }^{101}$ One quilt historian has suggested that the central section must have held value for its giver, enough that adding a fashionable border renewed the quilt's meaning when presented as a gift to the younger generation. ${ }^{102}$ In this way, the quilt was transformed from an everyday bedcover into a family heirloom. The quilt can also be considered symbolically. Just as it brings together an older section and a newer fabric, so the birth of a new generation carried forward the older generation, ensuring it a small piece of immortality. Harriet Marion Palmer was the third grandchild born to Harriet Kirk Marion, but her first namesake. And, her first two grandchildren had died prior to the birth of the third. The first, a grandson, died shortly before his second birthday in 1828, and the second, a granddaughter, died at nine months, just a few weeks before young Harriet was born in late November $1830 .^{103}$ This quilt may have enabled Marion to feel she was watching over her new grandchild and namesake.

The quilt combines one of the oldest named patchwork patterns - Irish Chain with crisp, printed chintz fabric. ${ }^{104}$ Chintz quilts were particularly popular in the southern United States during the early nineteenth century, especially those made by appliquéing these colorful fabrics to a plain ground. Even when block-style quilts became popular during the mid-nineteenth century, chintz borders remained a frequent quilt component in the region. ${ }^{105}$ One quilt scholar has noted that these borders

\footnotetext{
${ }^{101}$ Benjamin W. Dwight, The History of the Descendants of John Dwight of Dedham, Mass. (New York: John F. Trow and Son, 1874), 401-403.

${ }^{102}$ Kathleen Staples, "Tangible Displays of Refinements: Southern Needlework at MESDA," The Magazine Antiques 171 (January 2007): 201.

${ }^{103}$ Dwight, History of the Descendants of John Dwight, 402-403.

${ }^{104}$ Bassett and Larkin, Northern Comfort, 62.

${ }^{105}$ Lacy Folmar Bullard and Betty Jo Shiell, Chintz Quilts: Unfading Glory (Tallahassee, Florida: Serendipity Publishers, 1983), 10, 30, 36; Laurel Horton, "Quiltmaking Traditions in South Carolina," in Social Fabric: South Carolina's Traditional Quilts, Laurel Horton and Lynn Robertson Myers, eds. (Columbia: McKissick Museum, 1986), 12-14; Elizabeth V. Warren and Sharon L. Eisenstat, Glorious American Quilts: The Quilt Collection of the Museum of American Folk Art (New York: Penguin Studio,
} 
represented a "compromise" for South Carolina quiltmakers, "who still associated chintz fabrics with fine quilts... and found a way to adapt these fabrics to the changing styles." 106 As part of a well-to-do family, Harriet Kirk Marion used the fashionable chintz she was familiar with to make this quilt for her grandchild.

A second quilt from this same family was made for the same recipient (figure 4.15). In the late 1840 s, when she was in her early forties, Catherine Marion Palmer (1807-1895) made the quilt for her daughter, seventeen-year-old Harriet MarionPalmer. ${ }^{107}$ This framed-center quilt employs the technique of chintz appliqué. Catherine Palmer cut out motifs from at least five different imported chintz fabrics and rearranged them to her own taste. ${ }^{108}$ This technique has been described as "converting yardage into 'Swiss cheese' remnants" since she would have cut entire printed plant or bird motifs out of her fabric, rather than starting at the edge and cutting regular geometrical shapes like squares or triangles and leaving the motifs to fall where they might. ${ }^{109}$

Catherine's quilt has two inscriptions. Handwritten on the quilt itself is "Harriet M. Palmer from her mother." A later label is also sewn to the back, reading, "Quilt made by Catherine Marion Palmer Dwight St. John Berkeley SC 1847." ${ }^{\prime 10}$ Like the quilt made by Harriet Kirk Marion, this quilt's fabrics support the date on the label, and the people named can be confirmed in genealogical records to have lived at that time. However, the occasion for this gift is unknown. Harriet Palmer did not marry until 1858, ten years after

1996), 14-17; and Jeremy Adamson, Calico and Chintz: Antique Quilts from the Collection of Patricia S. Smith (Washington, DC: Renwick Gallery, 1997), 34-36.

${ }^{106}$ Horton, "Quiltmaking Traditions," 14.

${ }^{107}$ Locklair, Quilts, Coverlets and Counterpanes, 45.

${ }^{108}$ Staples, "Tangible Displays," 202.

${ }^{109}$ Mosaic Quilts, 16. The quilt has batting and is backed with a cotton fabric. The triple border is constructed from two different chintzes with a plain cotton strip in between. It is quilted throughout.

${ }^{110}$ Locklair, Quilts, Coverlets and Counterpanes, 45. 


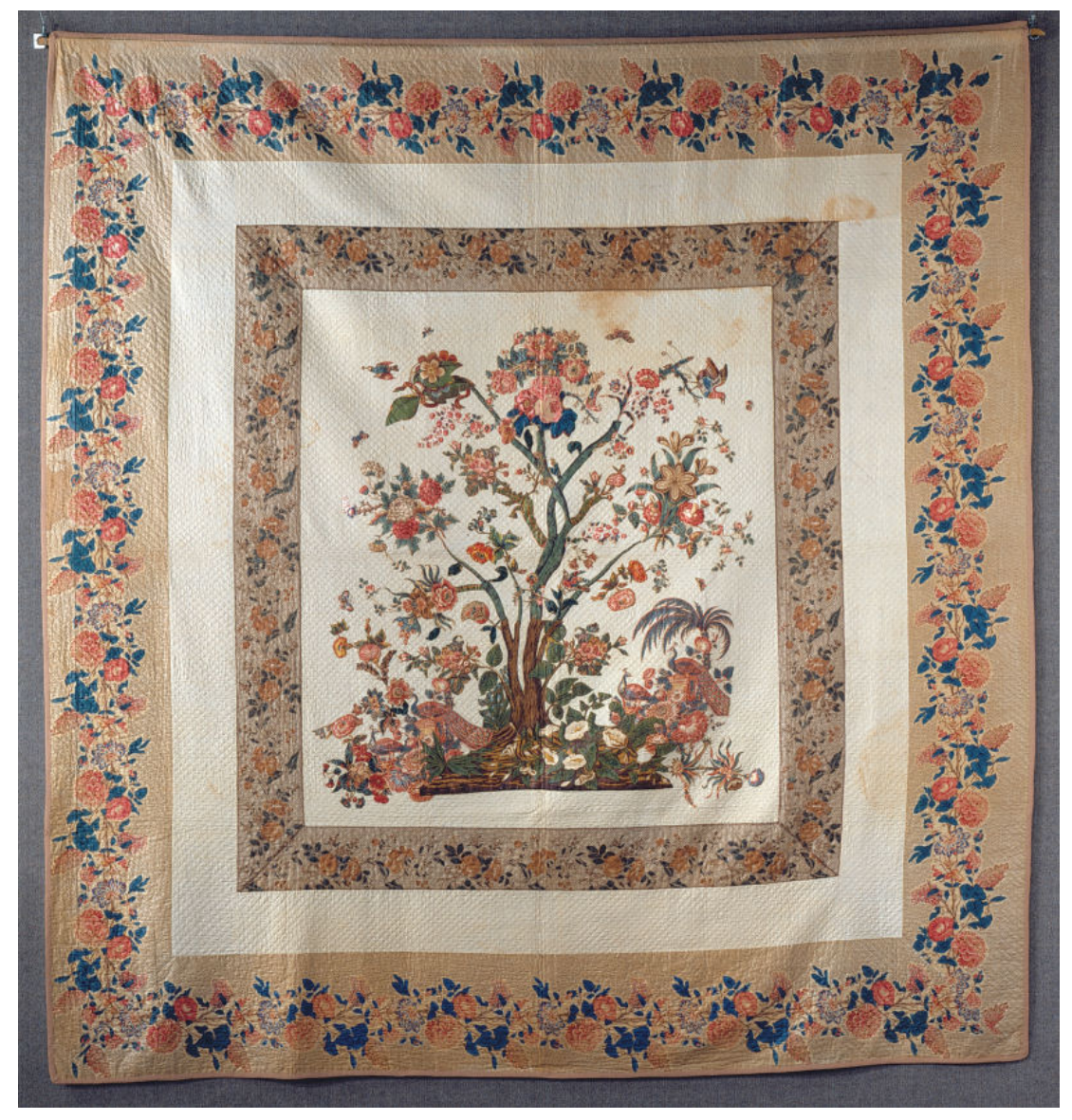

Figure 4.15. Quilt by Catherine Marion Palmer (1807-1895), 1847, South Carolina. Collection of the Museum of Early Southern Decorative Arts (MESDA) at Old Salem.

Catherine Marion Palmer made this quilt for her daughter when the girl was about seventeen. She used the technique of chintz appliqué - cutting out motifs from several different fabrics and rearranging them on her ground fabric - to make the central design. This technique was becoming dated by the late 1840s, so it is possible that Palmer was trying to remind her daughter of what was fashionable when she herself was a young woman. 
the quilt was made. ${ }^{111}$ Since this quilt was given by a mother to her oldest daughter as that daughter reached adulthood, it is possible that Catherine and Harriet Palmer understood this quilt as a coming-of-age gift. The technique used to make the quilt was extravagant in its use of fabric. It could allow the quiltmaker to show her friends and family that she was in a financial position to follow this expensive fashion and that her daughter's dowry prospects were quite good. ${ }^{112}$ However, by 1840 , the popularity of chintz appliqué was starting to wane; Palmer's use of the technique may also be an example of a woman using an older quiltmaking fashion to make a personal point. ${ }^{113}$ And, it might have communicated how dearly this mother loved and valued her daughter as the time approached for her to leave her mother's side and start her own household.

The third quilt from the extended Marion-Palmer family is comprised of templatepieced hexagons in a pattern known today as Stars and Honeycombs, but known during the early and mid-nineteenth century as Honeycomb or Mosaic (figure 4.16). ${ }^{114}$ Interlocking geometric motifs have a long history in architectural decoration. During the late eighteenth century, these mosaic patterns were re-created in patchwork in Europe and America, but did not become common until the nineteenth century. In the 1830 s, the pattern was popular enough to appear in the pages of Godey's Lady's Book when the magazine included an illustration of "Hexagon Patch-Work" complete with detailed instructions. ${ }^{115}$ Like the other two quilts, this one also has a chintz border. The center

\footnotetext{
${ }^{111}$ Dwight, History of the Descendants of John Dwight, 402.

112 Staples, "Tangible Displays," 202.

${ }^{113}$ Bassett and Larkin, Northern Comfort, 30, 32; Brackman, Clues in the Calico, 136-137.

${ }^{114}$ Mosaic Quilts, 36; Bassett and Larkin, Northern Comfort, 62. There is no batting; this quilt is backed with a cotton fabric.

${ }^{115}$ Newell, "Paper Template Piecing," 40-43; Newell, "Sarah Clarke Ellis Ide Quilt," 93-95; Bassett and Larkin, Northern Comfort, 27-30; Mosaic Quilts, 7-8, 12-14.
} 


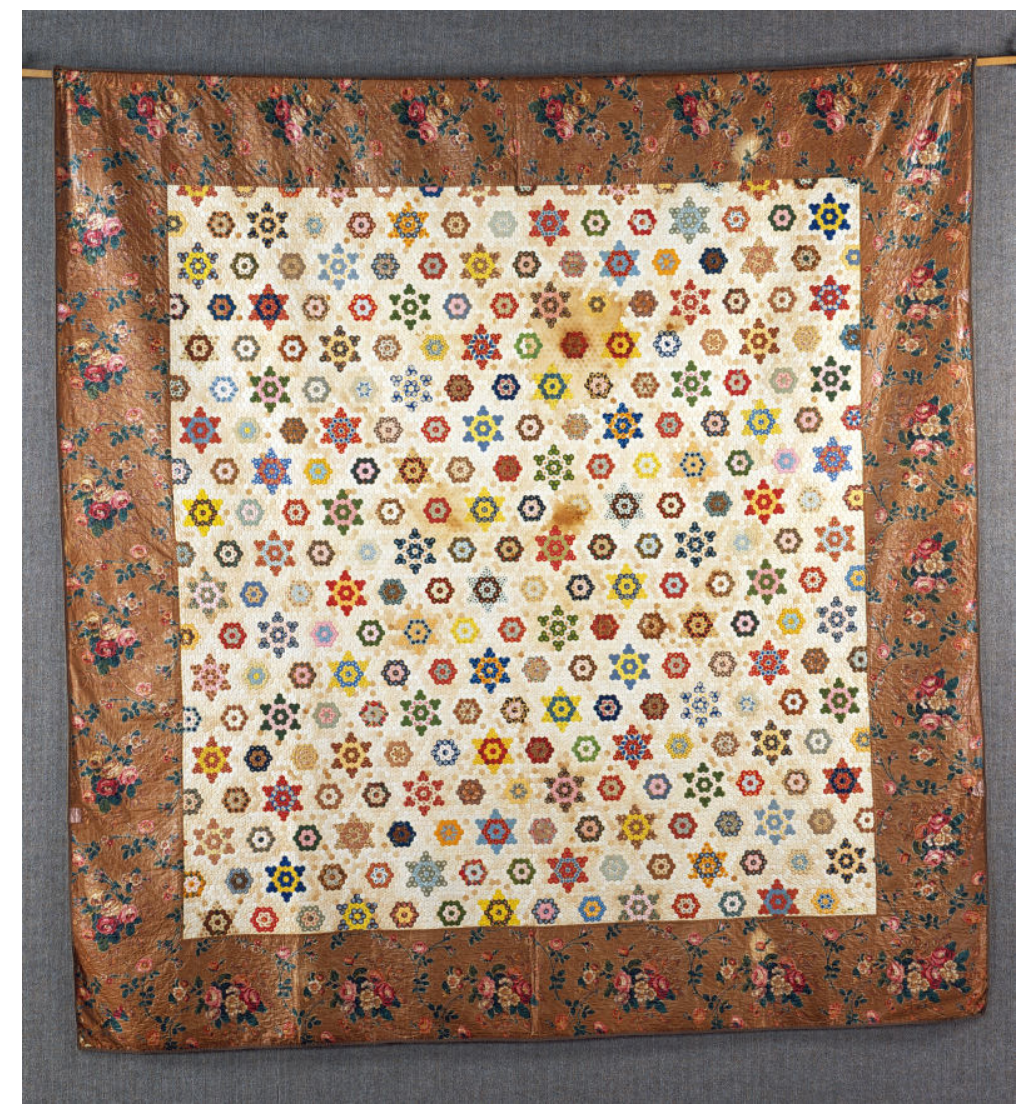

Figure 4.16. Quilt by Harriet Kirk Marion (1782-1850), circa 1840, or by Elizabeth Marion Porcher (1760-1796) and Elizabeth Catherine Porcher Palmer (1781-1841), 1790 and 1830, South Carolina. Collection of the Museum of Early Southern Decorative Arts (MESDA) at Old Salem.

This quilt has a recycled center that has been freshened by adding a border of chintz. The maker of the quilt is unknown; there is evidence that it might have been made around 1840 by Harriet Kirk Marion for her grandson, or in 1790 and 1830 by Elizabeth Marion Porcher and her daughter, Elizabeth Catherine Porcher Palmer, for their grandson and son, respectively. 
section is quilted in a cross-hatched pattern, while the border is marked for the same pattern, but is only quilted in one set of parallel lines. ${ }^{116}$

Various family members labeled the quilt at different times, provoking questions about its history. Written in ink on the quilt itself is "John G Palmer / from his Grandmother / Mother." John Palmer (b. 1807) and Catherine Marion had a son in 1841 and named him after his father. ${ }^{117}$ If the quilt was given to John Jr., the "Grandmother" named in the inscription would be Harriet Kirk Marion and the "Mother" Catherine Marion Palmer. There is a second inscription on a later label sewn to the back that offers similar information, reading, "Quilt made / by Harriet Kirk Marion / of St. Johns Berkeley S.C. / for her grand son / John Gendron Palmer / 1840 / Marked by Kate Palmer Logare / great granddaughter."118 Although the date on this label does not match genealogical records, two published sources have attributed the quilt to Harriet Kirk Marion based on these inscriptions. The unfinished quilting in the border, along with the newer wool braid binding on the quilt, have been interpreted to mean that Kate Palmer Logare worked on the quilt long after her great-grandmother died. ${ }^{119}$

However, an article published in early 2007 offered a different interpretation of the quilt. ${ }^{120}$ Ignoring the later label sewn onto the quilt, the author holds that the quilt was not made by Harriet Kirk Marion. In this interpretation, the inked inscription on the quilt refers to John Gendron Palmer (b. 1807), who married Harriet Kirk Marion's daughter Catherine in 1830, and suggests that the makers were John's grandmother, Elizabeth Marion Porcher (1760-1796), and his mother, Elizabeth Catherine Porcher

\footnotetext{
${ }^{116}$ Locklair, Quilts, Coverlets and Counterpanes, 44.

${ }^{117}$ Dwight, History of the Descendants of John Dwight, 403.

118 Staples, "Tangible Displays," 201.

${ }^{119}$ Locklair, Quilts, Coverlets and Counterpanes, 44; Mosaic Quilts, 36.

${ }^{120}$ Staples, "Tangible Displays," 201.
} 
Palmer (1781-1841). In this case, Elizabeth Marion Porcher would have to have made the central section in the 1790s and Elizabeth Catherine Porcher Palmer would have added the up-to-date chintz border around 1830 when she was in her forties. ${ }^{121}$

The 2007 interpretation is intriguing as it sends the quilt from a maternal line to a son, but questions remain regarding the attribution of the pattern and the fabrics to this early date. ${ }^{122}$ Whether this quilt was made by Harriet Kirk Marion around 1840, or by Elizabeth Porcher and Elizabeth Palmer in 1790 and 1830, it demonstrates how carefully gift quilts must be considered. Family stories often confuse names and dates across generations. Memories lapse, causing family stories to conflate the path by which a quilt traveled from one generation to another. Gift quilts must be closely examined, using the fabrics, patterns, and techniques to help date the quilt and to confirm or contest a beloved family story. And, as in the case of the third Marion-Porcher-Palmer quilt discussed here, sometimes even this method fails, underscoring the importance of careful consideration of all of the available evidence and of allowing for multiple interpretations.

Each of these quilts represents at least two generations of design and use, documenting the multiple families to which each maker and recipient belonged. In her study of diaries and letters written by women during the early Republic, historian Terri Premo found that, for aging women, biological reproduction and the creation of art or literature reassured them that their lives would continue to influence some small part of

\footnotetext{
${ }^{121}$ Staples, "Tangible Displays," 201.

${ }^{122}$ Staples found that the size of the pattern repeats on the hexagon fabrics is in keeping with those from the 1790s as shown in Barbara Johnson and Natalie Rothstein, A Lady of Fashion: Barbara Johnson's Album of Styles and Fabrics (New York: Thames and Hudson, 1987). Some show wear, fading and signs of previous cleaning. Staples did not check the greens on these fabrics; if they are overprinted (yellow over blue), it helps suggest a 1790s date for this part of the quilt since a fast green dye was not available for the first time until the 1820s. Email correspondence from Kathleen A. Staples, March 25, 2009.
} 
the world after they left it. ${ }^{123}$ The quilts of the Marion, Porcher and Palmer families, as well as the others described here, function this way; they were created by women to give to their progeny, which must have made them strong talismans of family tradition. As forty-seven-year-old Eleanor Parke Lewis (1779-1852) explained in an 1826 letter to a friend, “...my Grandchild is the object of my devoted affection. The Child of My Child, it excites even more interest than I should perhaps feel for my own, at its present age...It is certain that the title of Grandmother is most dear to me \& excites the most anxious \& affect[tionat]e feelings." 124

All of the quilts considered in this chapter to this point have been gifts between members of the same family, whether through birth or by marriage. But two of the gift quilts located for this study were gifts between people who were not related by blood or marriage. What motivated those gifts? Did they operate under a different set of circumstances than family gifts? If so, did they represent different things than family gifts? Recent anthropological studies suggest that the relationship between giver and recipient is what makes the gift, not the actual gift itself. "Even an ordinary object becomes unique when it is given as a gift," explains anthropologist James Carrier, "because it is marked by the tie that links the giver and recipient to each other and by the occasion of the gift." ${ }^{25}$ Other anthropologists have found that gifts to friends do differ from gifts for family; that gifts "maintain traditional family structures, but they are

\footnotetext{
${ }^{123}$ Premo, Winter Friends, 162.

${ }^{124}$ Letter from Eleanor Parke Custis Lewis to Elizabeth Bordley, December 24, 1826, quoted in Brady, George Washington's Beautiful Nelly, 185.

${ }^{125}$ Carrier, "Gifts, Commodities," 122, 126.
} 
creative acts that may be used as well to define new forms of relationships and to support emerging possibilities for social action."126

Period etiquette guides offer insight about the rituals of gift-giving. Etiquette books prescribed rules of conduct to assist Americans with learning and showing good manners. And, manners, like gifts, serve social functions: they constitute a subtle but pervasive system of social regulation or control; they generate feelings that help people assume their social roles; they tell us about each other and about our place in the social order. $^{127}$

Etiquette manuals provided a guide to basic good manners regarding gifts: let the giver see that you appreciate the gift; thank the giver both verbally and with a short note; do not give the gift away to another person. The books agree on the common occasions when gifts were given: weddings, christenings and the Christmas and New Year's holidays. ${ }^{128}$ One writer also listed the departure of "intimate friends" from the same town, as well as "upon return from a journey" as appropriate gift-giving occasions. ${ }^{129}$

The etiquette books acknowledged the implicit understanding that the recipient of a gift was obligated to return the action, and at a comparable level. However, all of these books cautioned against giving a gift at a value beyond what the giver could afford; they

\footnotetext{
${ }^{126}$ Cheal, "Ritualization," 642. See also Komter and Vollebergh, "Gift Giving and the Emotional Significance," 756.

${ }^{127}$ C. Dallett Hemphill, Bowing to Necessities: A History of Manners in America, 1620-1860 (New York: Oxford University Press, 1999), 3-4; Smith-Rosenberg, Disorderly Conduct, 63.

${ }^{128}$ Etiquette books consulted for this study include: The Art of Good Behaviour (New York: C.P. Huestis, 1848); Catharine E. Beecher, A Treatise on Domestic Economy (Boston: Marsh, Capen, Lyon and Webb, 1841); Celnart, The Gentleman and Lady's Book of Politeness; Etiquette for Ladies (New York: Burgess, Stringer and Company, 1844); Eliza Farrar, The Young Lady's Friend (Boston: American Stationers Company, 1837); Florence Hartley, The Ladies' Book of Etiquette and Manual of Politeness (Philadelphia: G.G. Evans, 1860); The Ladies' Companion (Worcester: The Spy Office, 1824); Eliza Leslie, The Behaviour Book (Philadelphia: Willis P. Hazard, 1854); Mrs. William Parkes, Domestic Duties (New York: J. \& J. Harper, 1829); and True Politeness: A Hand-Book of Etiquette for Ladies (New York: Leavitt and Allen, 1853).

${ }^{129}$ Celnart, The Gentleman and Lady's Book of Politeness, 151.
} 
called into question extravagant gifts to brides or other acquaintances. This suggests that although none mention needlework specifically, most prescriptive writers would heartily approve of a gift of this kind. Indeed, the author of 1833's The Gentleman and Lady's Book of Politeness claimed "the most delicate presents are the productions of our own industry."130 An 1857 children's story makes the point that "it's the thought that counts" without subtlety. When the girl in the story asked her grandmother what sort of present she might like, the grandmother replied, "I should think a great deal more of the love which induced them to give it to me, than of the present itself."131 The author of a popular mid-century needlework manual asked her readers, "Does not a gift become trebly valuable when the time and thoughts, as well as the mere money of the giver, are represented in it?"132

No less a literary luminary than Ralph Waldo Emerson (1803-1882) concurred with the basic rules and constraints suggested by the etiquette guides. In an 1844 essay on gifts, Emerson reviewed the basic elements of gift-giving etiquette. "The rule for a gift," he wrote, “...is that we might convey to some person that which properly belonged to his character, and was easily associated with him in thought." ${ }^{133}$ Emerson made the point that "the only gift is a portion of thyself" and thus, the giver should give something that is heartfelt and within his or her budget. As Emerson put it, "this is right and pleasing, for it restores society...when a man's biography is conveyed in his gift..."134 Among his list of suggestions when he comes to "the girl" is the gift of needlework, "a

\footnotetext{
${ }^{130}$ Celnart, The Gentleman and Lady's Book of Politeness, 152.

${ }^{131}$ Mrs. Anne E. Guild, Grandmother Lee's Portfolio (Boston: Whittemore, Niles and Hall, 1857$), 7$.

${ }^{132}$ Mrs. Pullan, The Lady's Manual of Fancy-Work (New York: Dick and Fitzgerald, 1858), xiii.

${ }^{133}$ Ralph Waldo Emerson, The Complete Works of Ralph Waldo Emerson: Essays. 2d series [Vol. 3] (Boston: Houghton Mifflin, 1903-1904), 161.

${ }^{134}$ Emerson, The Complete Works, 161.
} 
handkerchief of her own sewing."135 By implication, if "a man's biography is conveyed in his gift," a woman's "biography" is symbolized by her needlework.

Another etiquette book, from 1837, privileged homemade gifts above others: "The least exceptionable presents are those which consist of the work of your own hands." However, the writer goes on to point out that these home-made gifts must represent the latest fashion and materials. ${ }^{136}$ These are interesting points to consider in the context of the quilts and samplers known to have functioned as gifts. Several of the quilts surveyed here were made using techniques that, by the time of the gift, were outdated. Was the etiquette book author being prescriptive based on her own personal experience? Or, were the makers and givers of these quilts and samplers flaunting, or simply unaware, of these etiquette "rules"?

The gift of a quilt fulfilled all of the written and unwritten etiquette rules of the antebellum period. It was made by hand, often from scraps thus belaying the need to spend extra money. It also implied the spending of time, presumably during which the maker contemplated her affection for the intended recipient. And it communicated a woman's feelings toward the recipient, showing compassion and tenderness, appropriate whether the gift was for a family member or not.

Quilts were physical objects that could be saved for decades as a source of memories. Quilts given to very young children at their birth or christening seem to fulfill this function. ${ }^{137}$ In 1851, seventy-three-year-old Esther Slater (1778-1859), widow of

\footnotetext{
${ }^{135}$ Emerson, The Complete Works, 161.

${ }^{136}$ Farrar, The Young Lady's Friend, 277.

${ }^{137}$ In addition to this quilt by Esther Slater, other antebellum quilts made by women aged forty and over for young children that were located as part of this study include: a quilt made by Henrietta Whitney (17861870) for her granddaughter at birth in 1849, now in the collection of the New Haven Colony Historical Society, New Haven, Connecticut; a quilt made by Mary Elizabeth Taylor (1774-1846) for her two-yearold grandson in 1824, now in the collection of the Telfair Museum of Art, Savannah, Georgia; a quilt made
} 
famed textile factory magnate Samuel Slater (1768-1835), made a cradle quilt for Anna Russell Whitney (1851-1940) shortly after her birth on February 8 of that year (figure 4.17). ${ }^{138}$ Unlike most of the other gift quilts discussed here, Slater and Whitney do not appear to have been blood relations or connected through any kind of family relationship. At the time, Slater had been a widow for fifteen years. She did not have any children of her own, but reportedly enjoyed a good relationship with her stepchildren from her husband's first marriage. ${ }^{139}$

The recipient of the quilt, Anna Russell Whitney, was the daughter of Dr. James Orne Whitney (1823-1895) and Elizabeth Slack Miller (1816-1902). ${ }^{140}$ The nature of the relationship between Slater and the Whitney family is unknown. Slater may have been a patient of Dr. Whitney. He had an office on High Street in Pawtucket while she lived at 69 East Avenue in the same city. ${ }^{141}$ Or, she might have known him through church, mutual friends or Dr. Whitney's work at the local historical society.

by Isabelle Pennock (b. 1795) for her three-year-old niece in 1848, now in the collection of the Chester County Historical Society, West Chester, Pennsylvania; a quilt by Margaret Boyce Elliott (1800-1867) for her granddaughter at birth in 1843, now in the collection of the Maryland Historical Society, Baltimore, Maryland; and a quilt by Ann G. Boker (b. ca. 1803) for her three-year-old granddaughter in 1860, now in the collection of Winterthur Museum and Country Estate, Delaware. Quilts and Quiltmakers: Covering Connecticut (Atglen, PA: Schiffer Publishing Ltd., 2002), 42-43; Anita Zaleski Weinraub, ed., Georgia Quilts: Piecing Together a History (Athens: University of Georgia Press, 2006), 49-51; Tandy Hersh, "1842 Primitive Hall Pieced Quilt Top: The Art of Transforming Printed Fabric Designs through Geometry," Uncoverings 7 (1986): 47-59; Nancy E. Davis, The Baltimore Album Quilt Tradition: Maryland Historical Society (Tokyo: Kokusai, 1999), entry \#12; Eaton, Quilts in a Material World, 56-57.

${ }^{138}$ The quilt is now in the collection of the Slater Mill Historic Site, Pawtucket, Rhode Island.

${ }^{139}$ Gail Fowler Mohanty, "Esther Slater and Her Falling Blocks Quilt," in Down by the Old Mill Stream, Welters and Ordonez, eds., 226-231.

${ }^{140}$ Dr. James Orne Whitney was born in Attleboro, Massachusetts in 1823 and married Elizabeth Slack Miller in Rhode Island in 1850. Anna was the couple's first child; they had three more children together, but only the three daughters lived to adulthood. The Whitney family's published history states that Dr. Whitney was "regarded by physicians as an exceptionally acute diagnostician, his judgment in this regard being well nigh infallible. He was one of the founders and the first physician of the Pawtucket dispensary...He has written a number of articles for medical journals throughout the country and has introduced a number of surgical appliances into the profession." Frederick Clifton Pierce, Whitney: The Descendants of John Whitney (Chicago: published by the author, 1895), 554.

${ }^{141}$ Mohanty, "Esther Slater," 230. 


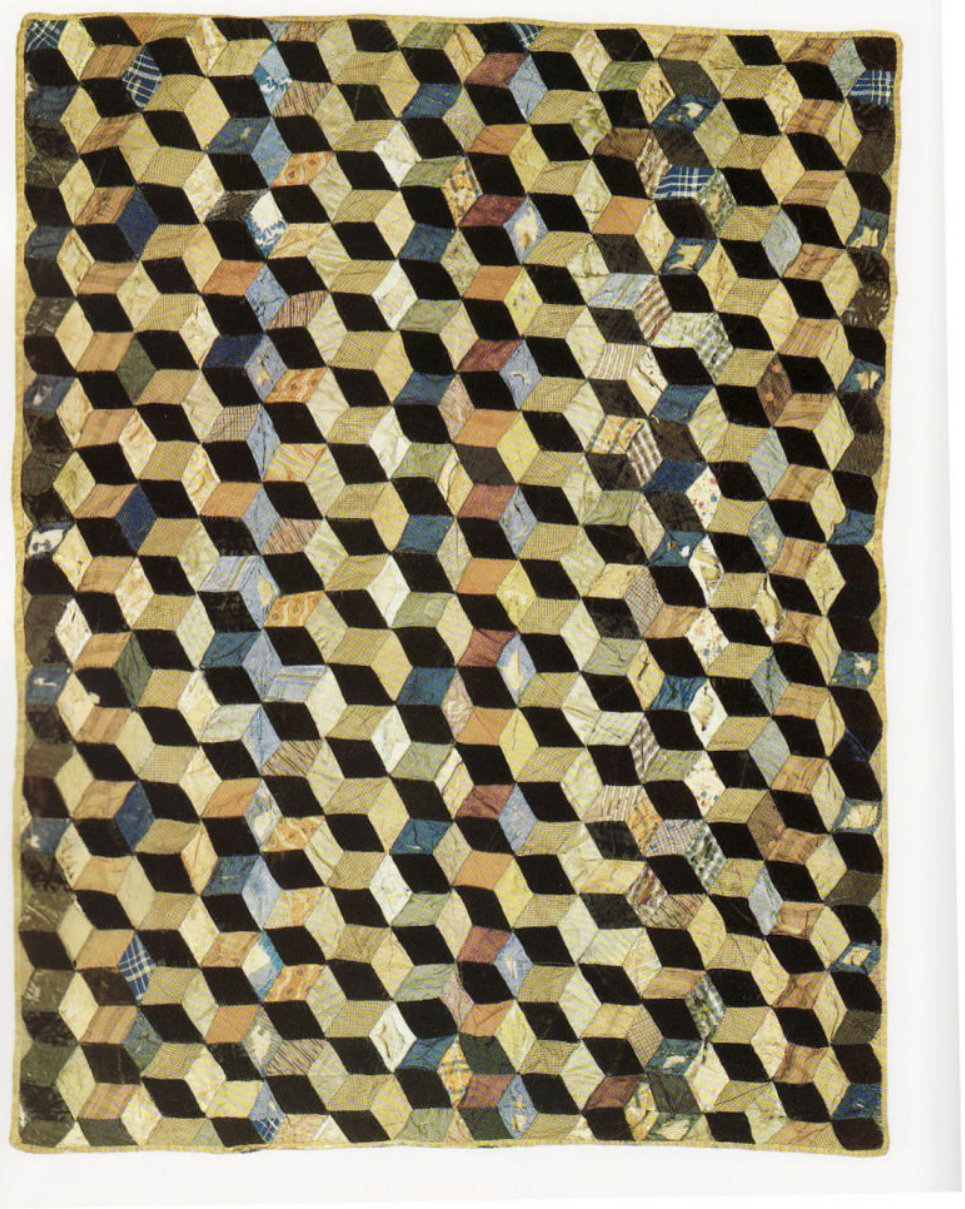

Figure 4.17. Quilt by Esther Johnson Parkinson Slater (1778-1859), 1851, Pawtucket, Rhode Island. Collection of Slater Mill Historic Site; courtesy of the Rhode Island Quilt Documentation Project (RIQDP \#662).

Esther Johnson Parkinson Slater made this crib-size quilt for an unrelated child of her acquaintance. To make it, she combined a piecing technique that she probably learned as a child in England with the luxurious American fabrics she could afford as the widow of textile magnate Samuel Slater. 
In some respects, this quilt offers the potential for a more enlightening

understanding of gift quilts since the motive for the gift cannot be ascribed to simple filial duty or maternal love. Baby Anna Whitney was not Esther's responsibility to care for financially or to teach how to stitch. But, the quilt - in design and construction - reflects the life experiences of its maker in a striking manner.

Esther Slater was born on March 15, 1778, in England. Like almost every girl in England and America at this time, she learned to stitch at a young age. Accompanying her 1851 quilt in the collection of the Slater Mill Historic Site today is a sampler that she made in 1787 at the age of nine (figure 4.18). The sampler is not signed but does have an "E" at the end of one row, helping to verify the maker. ${ }^{142}$ Stitched in silk thread on fine linen fabric, the sampler shows off a skilled variety of embroidery stitches: seed stitch, cross stitch, feather stitch, closed herringbone stitch, trailing stitch and hem stitch. Esther included numbers and the alphabet, along with a floral vine border, a row of double carnations and a central motif of five trees. ${ }^{143}$

Before 1807, Esther married Robert Parkinson (d. 1816) in England and they made a business trip to the United States during the early years of their marriage. The Parkinsons settled in Philadelphia where Robert developed a business relationship with Samuel Slater. ${ }^{144}$ In 1816, Esther's husband, Robert Parkinson, died of "dropsy of the brain." She returned home to England but came back to Philadelphia in 1817 to settle her late husband's estate. Five years earlier, while Esther and Robert were living in

\footnotetext{
${ }^{142}$ The sampler is now in the collection of the Slater Mill Historic Site, Pawtucket, Rhode Island. The attribution of the sampler to Esther Johnson Parkinson Slater is based on a label that was affixed to the frame when it was given to the Slater Mill Historic Site in 1964. The sampler may have been originally signed with Esther's name. The letters may subsequently have disintegrated or have been picked out. It is difficult to tell what caused this and what kind of stitching may have originally been there. I am indebted to Curator Andrian Paquette for his assistance during my site visit on March 20, 2009.

${ }^{143}$ Mohanty, "Esther Slater," 226, 229.

${ }^{144}$ Mohanty, "Esther Slater," 226, 228.
} 


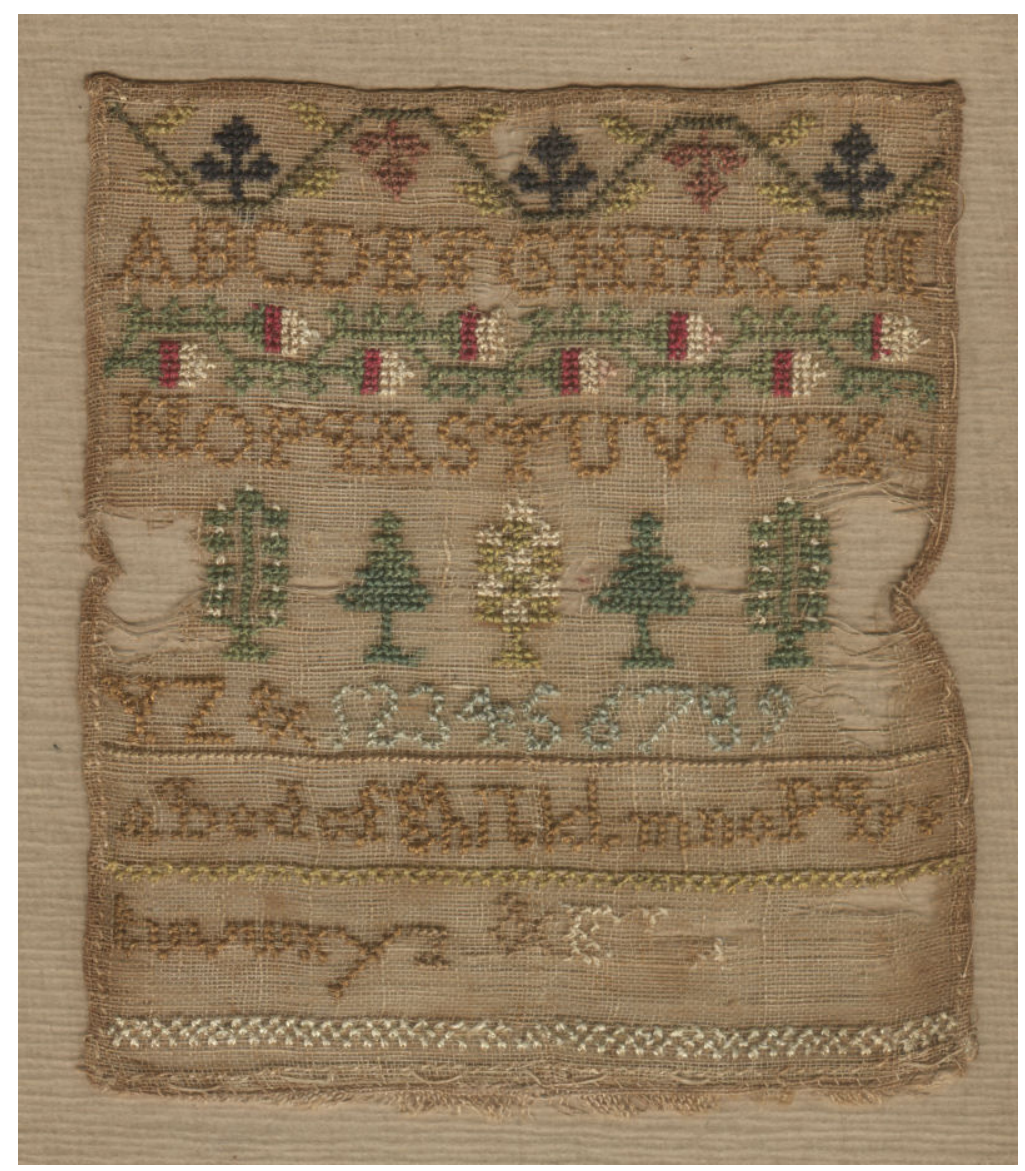

Figure 4.18. Sampler by Esther Johnson, 1787, England. Collection of Slater Mill Historic Site, Pawtucket, Rhode Island.

Esther Johnson Parkinson Slater made this sampler as a child. It shows high technical ability since it is stitched on fine fabric. 
Philadelphia, Samuel Slater's wife, Hannah Wilkinson Slater (1774-1812), gave birth to the couple's youngest child on September 19, 1812. A couple of weeks later, Hannah Slater died due to complications from childbirth. When Esther Parkinson returned to Philadelphia in 1817 to deal with her husband's estate, she and Samuel Slater became close; they married in Philadelphia on November $21,1817 .^{145}$

On April 20, 1835, Samuel Slater died in Webster, Massachusetts. Esther and Samuel had a prenuptial agreement due to his successful mill business and the property each owned as a result of their first marriages. Esther received the interest on $\$ 10,000$ from Slater's estate annually, which amounted to about $\$ 600$. After an 1836 trip to England, she returned to Rhode Island and built her own house at 69 East Avenue in Pawtucket, living there until her death in 1869. Esther maintained her relationship with her stepchildren and, by all accounts, lived comfortably in her own home with an Irish servant. ${ }^{146}$ These were the circumstances of her life when she made this quilt as a gift in 1851.

At thirty-five by twenty-seven inches, the quilt is sized for a small bed or cradle. ${ }^{147}$ Pieced in a pattern known as Falling Blocks or Tumbling Blocks, the quilt is made using the technique known as "template piecing" or "paper piecing," like the Catherine Marion Palmer quilt and the Rebecca Scattergood Savery quilts above. Some remnants of the pattern pieces, which appear to have been recycled from a newspaper, are visible through loose seams on the top of the quilt. Several women's magazines,

\footnotetext{
145 Mohanty, "Esther Slater," 228-229.

${ }^{146}$ Mohanty, "Esther Slater," 229-230.

147 The quilt is backed with brown silk and has an applied binding. It was given to the Slater Mill Historic Site by a Whitney family descendant, Charles Crawford Carter, in 1952, one hundred years after it was reportedly made. Curatorial file, Slater Mill Historic Site, Pawtucket, Rhode Island. The attribution to Slater probably came from a family story passed along by the donor; the quilt is not signed, nor was any label or letter documenting the story given with the quilt.
} 
including Godey's Lady's Book and Peterson's Magazine, included illustrations and descriptions of "box" patterns like this one. This particular pattern is found in an 1851 issue of Godey's Lady's Book. ${ }^{148}$

Esther's background suggests that she might have learned this technique as a child in England and was probably making this quilt in the most comfortable way for her. So the quilt incorporates Esther's English heritage (in the technique) as well as her comfortable economic position and her husband's fame as a textile producer (in the fabrics used). The quilt is made from a colorful variety of silk fabrics, both printed and plain. It is backed with a luxurious silk fabric. This type of quilt was primarily decorative - made by women who had the time to stitch it together and who could afford to use silks and velvets, which could not be laundered. For this reason, it is a somewhat odd choice as a baby gift; but would have been understood as a cherished keepsake, one that represented Esther's English heritage and her Rhode Island life, while also serving as a fashionable memorial after its maker's death.

While providing a general overview of proper gift-giving conduct, most etiquette books from the early- and mid-nineteenth century do not specifically address gift-giving between close family members, such as parent and child or grandparent and grandchild. Gifts between close family members seem to have been understood to be governed by different rules. In 1829, etiquette writer Mrs. Parkes explained, "The little interchanges of presents between the members of a family are always pleasing, and afford a tacit

\footnotetext{
${ }^{148}$ Mohanty, "Esther Slater," 230; Barbara Brackman, Encyclopedia of Pieced Quilt Patterns (Paducah, Kentucky: American Quilter's Society, 1993), 26-27; Virginia Gunn, "Template Quilt Construction and Its Offshoots: From Godey's Lady's Book to Mountain Mist," in Pieced By Mother: Symposium Papers, Jeannette Lasansky, ed. (Lewisburg, Pennsylvania: Oral Traditions Project, 1988), 72-73.
} 
assurance of the unchanged affection of each party." ${ }^{\prime 149}$ There is no mention of the tacit responsibility for the recipient to reciprocate, merely the presumption that gifts between family members signified the love and affection between them. Parkes also stated that marriages and births were "signals for the display of the greatest generosity." the published etiquette guides seem to have been written to navigate the more murky waters between friends, acquaintances and romantic relations. Family gifts were governed far more by tradition, which was assumed and understood rather than documented and written down.

Some of the family gift quilts described here contained a more tangible part of the giver or receiver. ${ }^{151}$ A quilt made by fifty-seven-year-old Susan Kuhns (circa 1787-circa 1865) of Greensburg, Pennsylvania, for her niece, Anna Mariah Kuhns (1817-1868), was made around 1840 from one of her dresses (figure 4.19). ${ }^{152}$ Susan was born about 1787 in Pennsylvania, the daughter of Johan Philip Kuhns (or Kuntz) (1747-1822) and Anna Margaretta Stambach (1754-1816). She never married or had children of her own but must have felt a connection to her nieces and nephews. Anna Mariah was the daughter of Susan's brother, John Kuhns (1783-1868), and his wife, Susanna Welty (1798-1870). Anna Mariah was her parents' first child, born in 1817. She married Asemus Rumbaugh $(1818-1848)$ in July $1840 .{ }^{153}$

\footnotetext{
${ }^{149}$ Parkes, Domestic Duties, 104.

${ }^{150}$ Parkes, Domestic Duties, 104.

${ }^{151}$ See the quilts by Sarah Wadsworth Mahan and by Harriet Kirk Marion discussed in this chapter. Also see the quilt made by Ann G. Boker for her granddaughter in 1860. Eaton, Quilts in a Material World, 5657.

${ }^{152}$ The quilt is currently in the collection of the Daughters of the American Revolution Museum in Washington, DC. I am indebted to Alden O'Brien for allowing me access to the quilt and its curatorial file during a site visit in June 2006. The quilt utilizes the Garden Maze pattern, named for its resemblance to the mazes made out of garden vegetation that were popular in America and Europe for centuries.

${ }^{153}$ See family trees on www.ancestry.com, accessed May 27, 2007.
} 


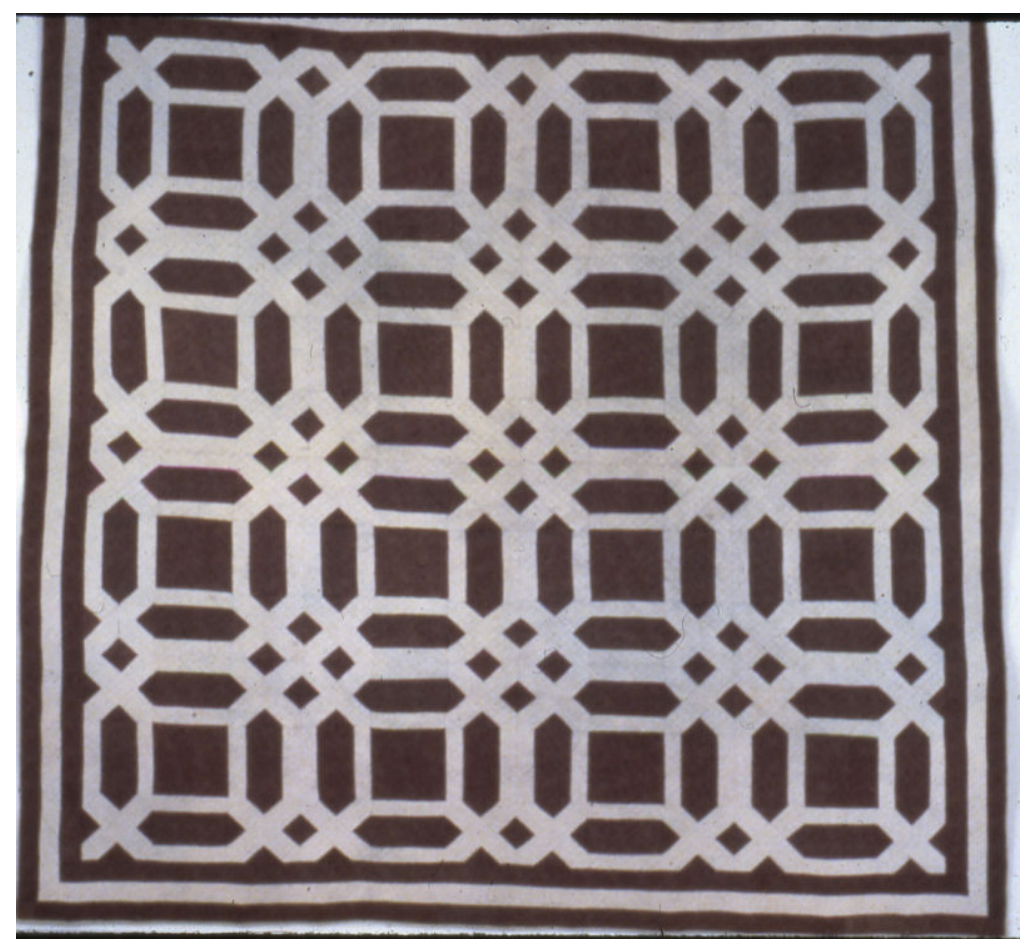

Figure 4.19. Quilt by Susan Kuhns (circa 1787-circa 1865), circa 1830, Greenburg, Pennsylvania. Courtesy of the Daughters of the American Revolution Museum, Washington, DC.

A family story suggests that this quilt was made by Susan Kuhns for her niece, using that woman's "second day dress," or the dress she wore to begin housekeeping after her marriage. Family stories must be considered carefully; in this case the date of the fabric and the date of her niece's wedding do not match up, suggesting that part of the story may have been mixed up by subsequent generations. 
Family tradition suggests that the quilt was made using fabric from Anna Mariah's "second day" dress - the one she wore the day after her wedding to begin housekeeping. ${ }^{154}$ But, the family story and the quilt itself do not support the same history. The color and pattern of the fabrics used suggest that the quilt dates to the 1830s, five to ten years before Anna Mariah married in 1840. Perhaps the quilt was made earlier, in preparation for her marriage. Or, it might have been made a few years after her marriage when her "second day" dress no longer fit or had worn out. This would make the story about the fabric correct - just not the family's date for the origin of the quilt.

As the Kuhns family quilt suggests, gift quilts quite literally preserved family history. Even Lucy Larcom (1824-1893) - who made no secret of her loathing of sewing in her autobiography - found herself drawn to the family scrap bag because of the sentimental associations she formed with the fabrics within. "I liked assorting those little figured bits of cotton cloth," she wrote, "for they were scraps of gowns I had seen worn, and they reminded me of persons who wore them." ${ }^{155}$ Another young woman, writing in 1845 about "The Patchwork Quilt" in The Lowell Offering, detailed the many connections she felt from one glance at her quilt, "Here is the piece intended for the centre...remnants of that bright copperplate cushion which graced my mother's easy chair," she mused, "here is a piece of that radiant cotton gingham dress which was purchased to wear to the dancing school...here is a piece of the first dress I ever saw, cut

\footnotetext{
${ }^{154}$ Curatorial file, The Daughters of the American Revolution Museum, Washington, DC.

${ }^{155}$ Lucy Larcom, A New England Girlhood (Boston: Northeastern University Press, 1986), 122. Lucy Larcom was born in 1824 in Beverly, Massachusetts, the daughter of Benjamin Larcom and Lois Barrett. When she was seven, her father died and her mother moved the family to Lowell, Massachusetts, where she managed a boardinghouse and where Lucy worked in the textile mills. In 1846, Lucy moved west with her sister and taught in Illinois, but returned to Massachusetts in 1852. She taught for nine years in Massachusetts and then became a magazine editor. Later, she worked as a freelance writer. Larcom never married; she died in Boston, Massachusetts, in 1893. Shirley Marchalonis, "Larcom, Lucy," http://www.anb.org.silk.library.umass.edu:2048/articles/16/16-00961.html, American National Biography Online Feb. 2000; accessed November 21, 2009.
} 
with what were called "mutton-leg" sleeves. It was my sister's..."156 The author continued with memories of no less than twelve additional scraps related to several of her family members, as well as some tied to milestones in her own life. ${ }^{157}$

\section{At my grandmother's feet: The Cultural Nature of Gifts}

Mature women gave gifts on many occasions. Sometimes, the giver may have been trying to prolong her influence and to remind others of her existence at the end of her life, or even past her death. Needlework was considered an "appropriate" activity for women; as such, older women, in particular, manipulated their society and culture by using needlework to express opinions, engage in relationships socially and show off pride in their accomplishments. By using specific materials or techniques, sometimes the maker was trying to impose her own values or code of beliefs on the recipient.

In her survey of diaries and letters written by aging women between 1785 and 1835, historian Terri Premo asserts that older women saw it as their role to serve as living reminders of the moral code. It was their role to carry the achievements of the Revolutionary era forward. ${ }^{158}$ Susan Stabile contends that the Philadelphia women she studied understood they were responsible for transmitting the memory of their generation. ${ }^{159}$ Giving gifts was a material extension of this role - older women could pass on an actual physical manifestation of their moral code, or do the same by passing on knowledge through sewing lessons.

\footnotetext{
${ }^{156}$ Harriet Farley or Rebecca C. Thompson, "The Patchwork Quilt" in A Patchwork of Pieces: An Anthology of Early Quilt Stories 1845-1940, Cuesta Ray Benberry and Carol Pinney Crabb, comps. (Paducah, Kentucky: American Quilter's Society, 1993), 20-21.

${ }^{157}$ Farley or Thompson, "The Patchwork Quilt," 21-22.

${ }^{158}$ Premo, Winter Friends, 5.

${ }^{159}$ Stabile, Memory's Daughters, 131.
} 
Enhancing the feelings and activities of some of these antebellum grandmothers were larger cultural events. Many of these women were born during or just after the Revolutionary War and felt the responsibilities of that event heavily. In the 1820s, as the Revolutionary generation aged, there was a resurgence of interest in the events of the late eighteenth century. In part, the younger generation wanted to learn what they could from the older generation before it was gone. At the same time, the older people were starting to undertake a "life review," looking back on events and experiences of their lives. ${ }^{160}$ In essence, supply and demand for Revolutionary memory came together in the 1820s and $1830 \mathrm{~s}$ - the younger generation sought an understandable narrative of their history and the older generation was nostalgically looking back to those formative events of young adulthood. ${ }^{161}$ And, for women, this meant communicating memories and traditions the best way they knew - through textiles.

Historian Len Travers found evidence of a generational divide as children of the post-Revolution generations felt they could never live up to their parents and grandparents who survived the Revolution. He suggests that the "rising generation" suffered from an inferiority complex that may have been unfairly placed on their shoulders by their elders. ${ }^{162}$ The women of the antebellum period who employed older techniques to make quilts may have provoked similar feelings in the next generation. For those born during and shortly after the Revolutionary War, practicing the needlework traditions of their youth, like whitework and chintz appliqué, allowed them to

\footnotetext{
${ }^{160}$ Alfred F. Young, The Shoemaker and the Tea Party: Memory and the American Revolution (Boston: Beacon Press, 1999), 12; Stabile, Memory's Daughters, 133-134; Robert N. Butler, "The Life Review: An Interpretation of Reminiscence in the Aged," Psychiatry 26 (February 1963): 65-76.

${ }^{161}$ Young, The Shoemaker and the Tea Party, xiii, 89.

${ }^{162}$ Len Travers, Celebrating the Fourth: Independence Day and the Rites of Nationalism in the Early Republic (Amherst: University of Massachusetts Press, 1997), 216; Schwartz, "The Social Context of Commemoration," 386.
} 
demonstrate their skills and their facility with "appropriate" aesthetics and activities. This also challenged the younger generations to carry forward the memories and traditions that seemed to be disappearing. Having been raised to believe that they were responsible for carrying on the noble Revolutionary memory, women like Rebecca Scattergood Savery and Susan Kuhns tried to instill the same sense of responsibility in their younger relatives.

Older women seem to have been aware that their needlework preferences were becoming dated. In April 1858, sixty-eight-year-old Mary Avery Upham (1790-1872) noted in her diary, "I began some of my old-fashioned trimming for one of my bed spreads."163 Upham's words suggest some self-consciousness about her preference, which may have defined her stage of life. Indeed, an 1859 needlework guide helps put Upham's words into a larger context. "We own to a liking for Patchwork," the author confessed, "genuine old-fashioned patchwork, such as our grandmothers made, and such as some dear old maiden aunt, with imperfect sight, is making for fairs and charities, and whiling away otherwise tedious hours." ${ }^{\prime 164}$ In the eyes of this author, the type of needlework a woman stitched marked her as old, as much as her "imperfect sight" did.

This idea is demonstrated by two quilts made late in life by Rachel Smith (b. circa 1795) of Derby, Connecticut. The first quilt was made by the sixty-four-year-old Smith for her great-niece Isabel Eagle (dates unknown), around the time of the younger woman's marriage in 1859. When she was about seventy-seven, Smith made the

\footnotetext{
${ }^{163}$ Mary Avery Upham diary, April 13, 1858, Massachusetts Historical Society, Boston, Massachusetts. Emphasis added.

${ }^{164}$ Florence Hartley, The Ladies' Hand Book of Fancy and Ornamental Work (Philadelphia: John E. Potter and Company, 1859), 189.
} 
second quilt while visiting another great-niece, Mary Elizabeth (Faitoute) Morris (b.

1845), in Newark, New Jersey, near the time of that young woman's marriage in 1872

(figure 4.20). ${ }^{165}$ Smith employed a quilt style - whitework - that had been in vogue

when she was a young woman learning to quilt in the early decades of the nineteenth

century, but that had waned in popularity by mid-century. ${ }^{166}$ Whitework is a type of

needlework employing white thread on white fabric to embroider or quilt decorative

designs.

Whitework quilts are a type of wholecloth quilt made using large pieces of plain

white fabric for front and back. Often the quality of the quilting on these bedcoverings

showed skill above that seen on pieced quilts, since the quilting was the focal point and

sole design element. It seems likely that Rachel Smith made these gift quilts using the

most elegant technique that she knew, befitting the situation as she understood it. ${ }^{167}$

\footnotetext{
${ }^{165}$ The 1859 quilt is now in the collection of the New-York Historical Society in New York City; the 1870s quilt is in the collection of the Newark Museum in Newark, New Jersey. Genealogical information from www.ancestry.com, accessed May 2, 2006 and December 19, 2006; curatorial file, Newark Museum, Newark, New Jersey; curatorial file, New-York Historical Society. I am indebted to Ulysses Grant Dietz, Curator of Decorative Arts at the Newark Museum for sharing information from the quilt's file with me. I also thank David Burnhauser of the New-York Historical Society for facilitating my site visit in August 2005. The 1870s quilt is illustrated in Sandi Fox, Small Endearments: Nineteenth-Century Quilts for Children and Dolls (Nashville, TN: Rutledge Hill Press, 1980), 41.

${ }^{166}$ Textile historians come to no strict agreement about when whitework passed out of fashion, but most state that it was becoming unfashionable by the 1850s and 1860s. See Jacqueline M. Atkins, "From Lap to Loom: Marseilles Quilts, Marseilles-Style Spreads, and Their White Work Offspring," Proceedings of the Textile History Forum (2000): 21; Bassett and Larkin, Northern Comfort, 83-86; Brackman, Clues in the Calico, 133-134; Kathy Epstein, "Padded, Stuffed and Corded: White-on-White Quilts," Piecework Magazine 5 (November/December 1997): 36; Jean Taylor Federico, "White Work Classification System," Uncoverings 1 (1980): 68; Yolanda Van De Krol, "Candlewicking," Piecework Magazine 5 (November/December 1997): 27; Kimberly Wulfert, "The Journey of a Whitework Wedding Quilt," Piecework Magazine 14 (May/June 2006): 32; Merikay Waldvogel, Childhood Treasures: Doll Quilts By and For Children (Intercourse, Pennsylvania: Good Books, 2008), 29; and Lynne Z. Bassett, Telltale Textiles: Quilts from the Historic Deerfield Collection (Deerfield, Massachusetts: Historic Deerfield, Inc., 2003), 26-29.

${ }^{167}$ Another factor that may have had an effect on Rachel's needlework, and who she gave it to, was her status as a single woman. Rachel never married, instead making quilts for the children of her siblings and their children. While motherhood was a constant for many American women during these decades of great social and cultural change, Rachel Smith did not have that role to fall back on. Instead, she may have embraced her needle as evidence of her femininity and proper place.
} 


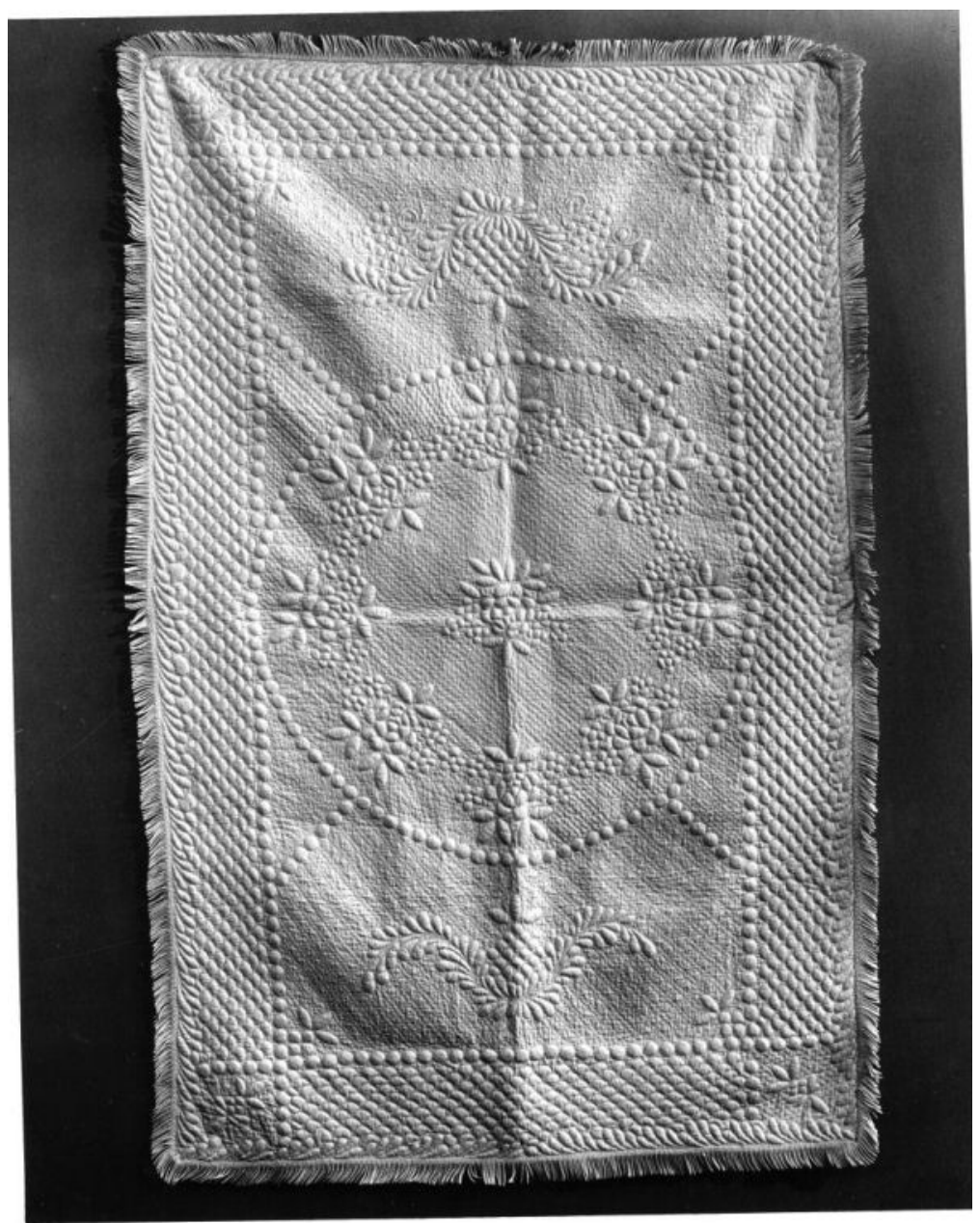

Figure 4.20. Quilt by Rachel Smith (b. 1795), 1870s, New Jersey. Gift of Miss Mary Elizabeth Morris and John B. Morris Jr., 1935, Collection of the Newark Museum, 35.252 .

Rachel Smith made this quilt and another whitework quilt as gifts for two of her greatnieces. The other quilt was made in 1859 , also well after the peak of popularity for this style. Smith may have been trying to teach her great-nieces about what was fashionable when she was a young woman. 
Championed by urban tastemakers from the 1810s to 1830 s, when Rachel was in her teens and twenties, whitework was the height of fashion at that time. As a New England resident, Rachel could have seen whitework quilts at local or regional agricultural fairs, where they were often awarded prizes. The style was influenced by the neoclassical ideals of purity and simplicity, taking inspiration from the ancient Greek and Roman temples that were becoming symbols of democracy to Americans. ${ }^{168}$ Partly, this judgment by tastemakers was used to set urban and upper-class needlework and values apart from those of the middling and provincial classes. At that time, colorful printed cottons were affordable for a wider section of the population, so women of means needed a different type of needlework to set themselves apart. ${ }^{169}$ In the mid- and late-nineteenth century, Rachel Smith's choice may have been a reaction to a change of fashion; she may have chosen this older technique to express discontent with contemporary styles while also passing on a record of her own history and talent to her younger relatives. As Victorian-era Americans started to furnish their homes with elaborately carved furniture, knick-knack shelves and etageres, to show off souvenirs collected while traveling, women like Rachel Smith may have yearned for a return to the simple aesthetic of their youth. ${ }^{170}$ Returning to a whitework quilt may have been Smith's personal response to changes around her.

\footnotetext{
168 Bassett, Telltale Textiles, 26.

169 There is some evidence that whitework quilts were understood to be more valuable than pieced quilts; probate inventory evidence in New England values whitework quilts at four or five times the value of calico quilts. See Bassett and Larkin, Northern Comfort, 86.

${ }^{170}$ For more on the Victorian aesthetic, see Katherine C. Grier, Culture \& Comfort: People, Parlors, and Upholstery 1850-1930 (Rochester, New York: The Strong Museum, 1988); Kenneth L. Ames, Death in the Dining Room and Other Tales of Victorian Culture (Philadelphia: Temple University Press, 1992); William Seale, The Tasteful Interlude: American Interiors through the Camera's Eye, 1860-1917 (New York: Praeger, 1975); and Harvey Green, The Light of the Home: An Intimate View of the Lives of Women in Victorian America (New York: Pantheon Books, 1983), 93-111.
} 
In some quarters, it was not the type of needlework that defined whether one was fashionable, but picking up the needle at all. During the second quarter of the nineteenth century, needlework started (in some small circles) to be derided as a wasteful, vain or even degrading activity, particularly by proponents of the women's rights movement. ${ }^{171}$ Suffragist Abigail Duniway (1834-1915) claimed that quilts were "primary symbols of woman's unpaid subjection." ${ }^{172}$ And, Elizabeth Cady Stanton (1815-1902) sought to rescue young women from "the maelstrom of embroidery" by showing them "the unspeakable folly of giving [the] optic nerves to such base uses, when they were designed by the Creator to explore the planetary world, with chart and compass to guide mighty ships across the sea, to lead the sons of Adam with divinest love from earth to heaven." 173 As several women's historians have noted, during the early nineteenth century women's role within the household began to change, due in part to changes in cultural values. ${ }^{174}$ Over time a genteel class emerged, championing a refined lifestyle and the importance of the home as the family's moral center. In light of these changes, all sorts of housework, including needlework, cooking and laundry, suffered in the court of social opinion, part

\footnotetext{
${ }^{171}$ Rozsika Parker, The Subversive Stitch: Embroidery and the Making of the Feminine (New York: Routledge, 1984), 14.

${ }^{172}$ Quoted in Pat Ferrero, Elaine Hedges, and Julie Silber, Hearts and Hands: Women, Quilts and American Society (Nashville: Rutledge Hill Press, 1987), 91, 94.

${ }^{173}$ Theodore Stanton and Harriot Stanton Blatch, eds., Elizabeth Cady Stanton, As Revealed in Her Letters, Diary, and Reminiscences, vol. 1 (New York: Harper and Row, 1922), 336. Elizabeth Cady was born in 1815 in Johnstown, New York, the daughter of Daniel Cady and Margaret Livingston. She attended Emma Willard's Troy Female Seminary. She married abolitionist Henry Stanton in 1840. The couple had seven children. She died in New York City in 1902. Ann D. Gordon, "Stanton, Elizabeth Cady," http://www.anb.org.silk.library.umass.edu:2048/articles/15/15-00640.html, American National Biography Online Feb. 2000; accessed November 21, 2009.

${ }^{174}$ See Jeanne Boydston, Home and Work: Housework, Wages and the Ideology of Labor in the Early Republic (New York: Oxford University Press, 1990); Ruth Schwartz Cowan, More Work for Mother: The Ironies of Household Technology from the Open Hearth to the Microwave (New York: Basic Books, 1983); Kelly, In the New England Fashion; Susan Strasser, Never Done: A History of American Housework (New York: Henry Holt and Company, 2000).
} 
of a process of devaluation. One agricultural newspaper stated bluntly in 1833 that "housework is going out of fashion.",175

An 1852 story, My Thimbles, illustrates the effects of the changes taking place in how needlework was viewed by Americans. The story begins as the narrator reflects on the place of needlework during her girlhood, implying that things were different in 1852 . She recalled that when she was a girl, presumably in the 1820 s or 1830 s, "the grown-up people thought it of great importance that a woman should be mistress of the needle: indeed they never thought of anything else. It never entered the heads of my mother, grandmothers and aunts, that ignorance of needlework could be any thing but disgraceful..."176 Yet, by 1852, not only suffragists expressed hostility toward fancy needlework. The popular press had also started to make derisive judgments. As demonstrated in the previous chapter, agricultural fairs became a site of conflict regarding the value of fancywork. Many women embraced this kind of needlework, even using it to raise money to support social causes; yet some were also critical, suggesting that it merely diverted women from pursuing a formal political voice. ${ }^{177}$

Giving a quilt endowed the maker with a sense of empowerment in response to changing societal perceptions of needlework. In addition, making something to give to another protected the stitcher from the censure of those critics who blasted needlework as

\footnotetext{
${ }^{175}$ New England Farmer, October 16, 1833 quoted in Holly V. Izard, “The Ward Family and Their 'Helps': Domestic Work, Workers, and Relationships on a New England Farm, 1787-1866," The Proceedings of the American Antiquarian Society 103 (1993): 76.

${ }^{176}$ Mrs. E.B. Hall, My Thimbles (Boston: Crosby, Nichols and Company, 1852), 3. Emphasis added.

${ }^{177}$ Beverly Gordon, "Victorian Fancywork in the American Home: Fantasy and Accommodation," in Making the American Home, Motz and Browne, eds., 48-68; Nancy Dunlap Bercaw, "Solid Objects/Mutable Meanings: Fancywork and the Construction of Bourgeois Culture, 1840-1880," Winterthur Portfolio 26 (1991): 231-248; Pat Crothers, "Gender Misapprehensions" The "Separate Spheres” Ideology, Quilters, and Role Adaptation, 1850-1890," Uncoverings 14 (1993): 55; Parker, The Subversive Stitch, 169-170.
} 
unnecessary and diversionary from more important pursuits. ${ }^{178}$ Women of Rachel Smith's generation also used their needles to pass on the skills required to make quilts, samplers and other needlework. As Terri Premo explains, grandmothers gave the "gift of education" by teaching the younger generation. ${ }^{179}$ Susan Stabile has called this "a feminine genealogy of learning." 180 Teaching their granddaughters to stitch was part of a cultural legacy, not a whim or a leisure pastime. One period author explained, "Old age has, at least, sufficient strength remaining to train the rising generation, and instruct them in the duties to which they may hereafter be called; and certainly there cannot be a more important or a more honorable occupation." 181

A doll quilt made by seven-year-old Ella Mygatt Whittlesey (b. 1845) demonstrates this point well (figure 4.21). ${ }^{182}$ Pieced in the Chimney Sweep pattern, the quilt has an inked inscription on the back, "Ella Mygatt Whittlesey / Aged seven. Her Stint / taught by her Grandmother Elinor Stuart. / 1852." The inscription identifies the quiltmaker, her teacher, and the date; it also includes the phrase "her stint," offering some insight into the purpose of this quilt as well as the process of teaching needlework. From the Old English meaning "to blunt," and Middle English meaning "to cease," a "stint" is defined by its end - it is a quantitative amount of time spent on a specific task. The use of this phrase conveys the sense that learning to stitch and completing this quilt were part of young Ella's education, a rite of passage for many girls. The phrase has the

\footnotetext{
${ }^{178}$ Parker, The Subversive Stitch, 14, 153-154.

${ }^{179}$ Premo, Winter Friends, 84-85.

${ }^{180}$ Stabile, Memory's Daughters, 12.

${ }^{181}$ Lydia Maria Child, Looking Toward Sunset (Boston: Ticknor and Fields, 1867), 89-90.

182 The quilt is now in the collection of the Metropolitan Museum of Art, New York, New York. Fox, Small Endearments, 159; Deborah E. Kraak and Barbara C. Adams, "Reflections on Little Girls and Their Sewing for Dolls," Piecework Magazine 11 (January/February 2003): 60, 63; Amelia Peck, American Quilts \& Coverlets in the Metropolitan Museum of Art (New York: The Metropolitan Museum of Art, 2007), 116, 249.
} 


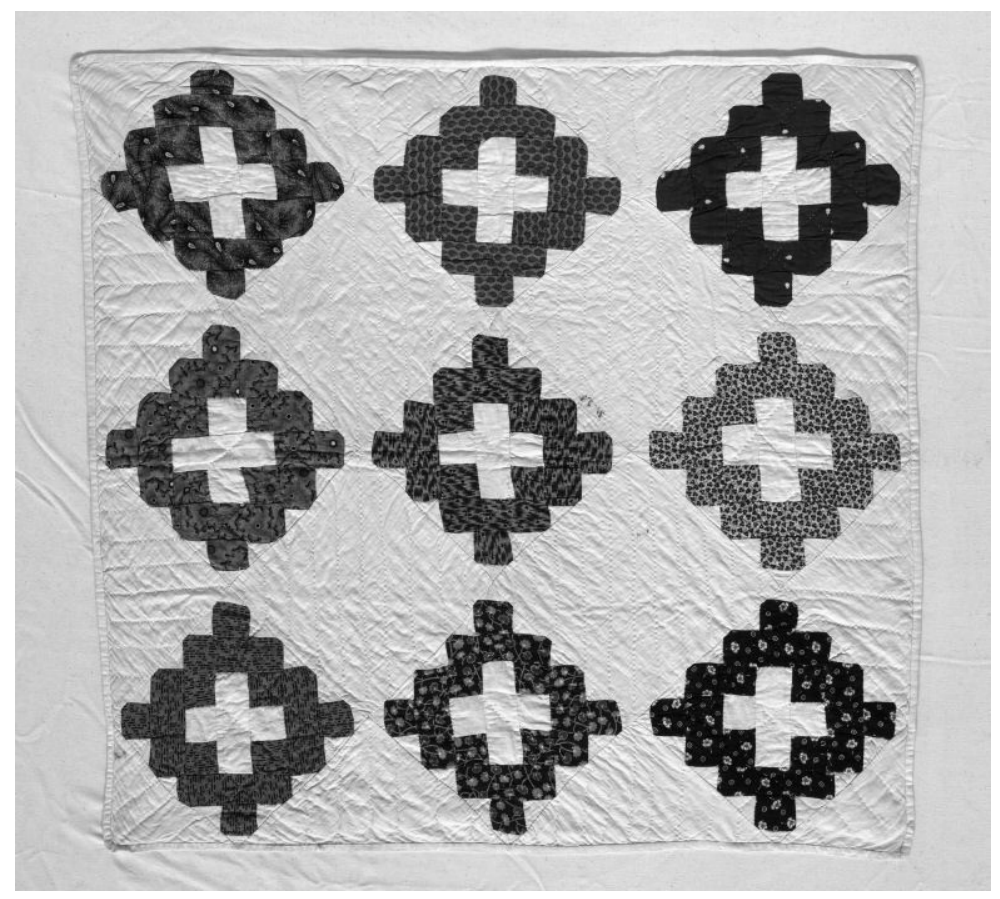

Figure 4.21. Doll quilt by Ella Mygatt Whittlesey (b. 1845), 1852. The Metropolitan Museum of Art, Gift, Mrs. Roger Brunschwig Fund, 1988 (1988.213), Image (C) The Metropolitan Museum of Art.

Inscription: Ella Mygatt Whittlesey Aged seven. Her Stint taught by her Grandmother Elinor Stuart. 1852.

Many young girls, like Ella Mygatt Whittlesey, were taught to sew by their grandmothers. Passing on this knowledge was a different type of gift for aging antebellum women to give. 
connotation of a requirement; Ella had to learn to sew, just like her mother and grandmother before her. At the time, a "stint" was defined as a specific amount of work to be done each day. This method, rather than working for an arbitrary amount of time, was favored by many nineteenth-century women as a greater enticement to accomplishment and as encouraging a sense of achievement. In addition, the girl could achieve a certain amount of control through the "stint" method; she could decide when to do the work. ${ }^{183}$ Twelve-year-old Caroline Cowles Clark (1842-1913) recorded in an 1854 diary entry, "I am sewing a sheet over and over for Grandmother and she puts a pin in to show me my stint, before I can go out to play. I am always glad when I get to it."184 Like Ella Whittlesey and Caroline Cowles Clark, Sarah Levis Miller (1803-1890) learned to sew from her grandmother. She looked back on the experience fondly: "I remember sitting on a stool at my Grand Mother Levis feet," she later recalled, "\& sewing Patchwork when I could not have been more than four years, or than five years..." 185 The motor activity of learning to stitch, the style of what was stitched, and the means to make it, were all part of a cultural transfer from one generation to another. Through the teaching of these practical skills, older women passed on a set of values associated with the "republican motherhood" that their mothers and grandmothers ostensibly held dear.

\footnotetext{
${ }^{183}$ Ferrero, Hedges, and Silber, Hearts and Hands, 18.

${ }^{184}$ Village Life in America 1852-1872 including the Period of the American Civil War as Told in the Diary of a School-Girl (New York: Henry Holt and Company, 1913), 39-40. Caroline Cowles Richards was born in 1842 and raised in Canandaigua, New York, by her grandmother. In 1866, she married Edmund Clarke. Caroline died in 1913. Biographical information from the North American Women's Letters and Diaries database, http://solomon.nwld.alexanderstreet.com.silk.library.umass.edu:2048/bios/A300BIO.html; accessed November 21, 2009.

${ }^{185}$ Patricia J. Keller, “Quaker Quilts from Delaware River Valley 1760-1890,” The Magazine Antiques 156 (August 1999): 185. Miller wrote her "Early Recollections" in 1889; this manuscript is in a private collection, but is quoted in Keller's article.
} 
In turn, teaching their daughters and granddaughters provided a productive role for mature women during an unsettling time in their lives as the values they had been raised to cherish were being questioned and revised. ${ }^{186}$ While older women had been teaching the next generation to stitch since the seventeenth century - and even before during the antebellum period this activity took on new meaning since the rise of spinning, weaving and sewing machines radically altered the types of fabrics available and the way that household textiles and clothing were made. Eleanor Parke Custis Lewis took great pride in the needlework skill of her granddaughter, sending an example of the work - a bag - to a friend and explaining: "She is only 10 years old \& the work (except the balls \& the making up which her Mother did) it is entirely her work, \& you will acknowledge that she is a very neat needle woman."187

Interacting with one's granddaughter offered a sense of continuity amidst change on personal, family and societal levels. Aging women had to adjust to their own changing bodies, as well as to their evolving families and communities. This older generation of women looked to the younger generations with hope for the future and a sense of responsibility to the past. As they used their own skills to teach the next generation, these aging women were undoubtedly reminded of their own lessons as girls, forming a bond that was reinforced through the act of stitching. ${ }^{188}$ And, this is supported by myriad diaries, reminiscences and autobiographies written during the nineteenth

\footnotetext{
${ }^{186}$ Premo, Winter Friends, 84.

${ }^{187}$ Letter from Eleanor Parke Custis Lewis to Elizabeth Bordley, December 10, 1844 quoted in Brady, George Washington's Beautiful Nelly, 243-244.

${ }^{188}$ Parker, The Subversive Stitch, 130-131. While most of the textiles described here spring from a relationship with the grandmother as giver and the granddaughter as receiver, at least one object shows that grandmothers were also the recipient of the bounty of sewing lessons, whether inside the home or out. A New England sampler made around 1815 by Sarah Salter has a stitched inscription, "Sarah Salter worked this / in the $8^{\text {th }}$ year of her age / A present for Grandmother." M. Finkel and Daughter, Samplings 6 (1994): 12
} 
century; almost all recount a sewing lesson with an older female relative. ${ }^{189}$ For example, Lucy Larcom remembered threading needles and learning to tie knots at the knee of her elderly aunts. ${ }^{190}$ Visual images of the very old and very young side-by-side were also common in the nineteenth century. As Kenneth Ames has asserted, these images suggested that the activity was traditional and venerable, as represented by the older person, while the presence of the younger person was "an assurance that the lore and learning of the past will be carried on to future generations," and that some things will remain the same even as time passes. ${ }^{191}$

In turn, grandmothers gifted their quilts to the younger generations. Mary Laman Kemp's (1758-1845) quilt, which is inscribed "This quilt was pieced in the year 1840 by Mrs. Mary Kemp in her eighty-second year for her great grand daughter Mary Jane Elizabeth Doub when she was eight years old," was one such gift (figures 4.22 and 4.23). ${ }^{192}$ This quilt, pieced in the Feathered Star pattern, and composed of many small triangles, demonstrated the importance of sewing straight seams and matching corners

\footnotetext{
${ }^{189}$ Elaine Hedges, "The Nineteenth-Century Diarist and Her Quilts," Feminist Studies 8 (Summer 1982): 295. See the documentary and material examples cited in this dissertation: the Whittlesey quilt and Bracket sampler, as well as the Sarah Levis and Caroline Cowles Clark sources.

${ }^{190}$ Larcom, A New England Girlhood, 28-29.

${ }^{191}$ Ames, Death In the Dining Room, 169, 173.

192 This quilt is now in a private collection. It is pictured in Gloria Seaman Allen and Nancy Gibson Tuckhorn, A Maryland Album: Quiltmaking Traditions 1634-1934 (Nashville: Rutledge Hill Press, 1995), 98-99. Mary Laman was born in Maryland in 1758, the daughter of Adam Laman (1732-1823) and Anna Margaretha Steltz (1729-1818). She married Peter Kemp (1749-1811) in 1779 and they had ten children. At her father's death in 1823, Mary was not only the executor of his estate, but its sole beneficiary. Her father willed her the entire estate "for the many favors of services received from her." The recipient of the quilt, Mary Jane Elizabeth Doub, was the granddaughter of Mary (Laman) Kemp's fourth child, Esther (1785-1866) who married Valentine Doub (1777-1844) in 1804. Mary's grandson, Joshua Doub (dates unknown), was Mary Jane's father and raised her with his wife while he worked as a merchant. Mary Jane would go on to have six children of her own and passed the quilt to the next generation. The quilt's inscription, signed by an "L.L. Coleman" whose relationship to the family is unknown, suggests that the quilt's function as a family touchstone was well-known enough within, and perhaps outside of, the family that the inscription was made by a third party rather than by the giver or the recipient. Allen and Tuckhorn, A Maryland Album, 99.
} 


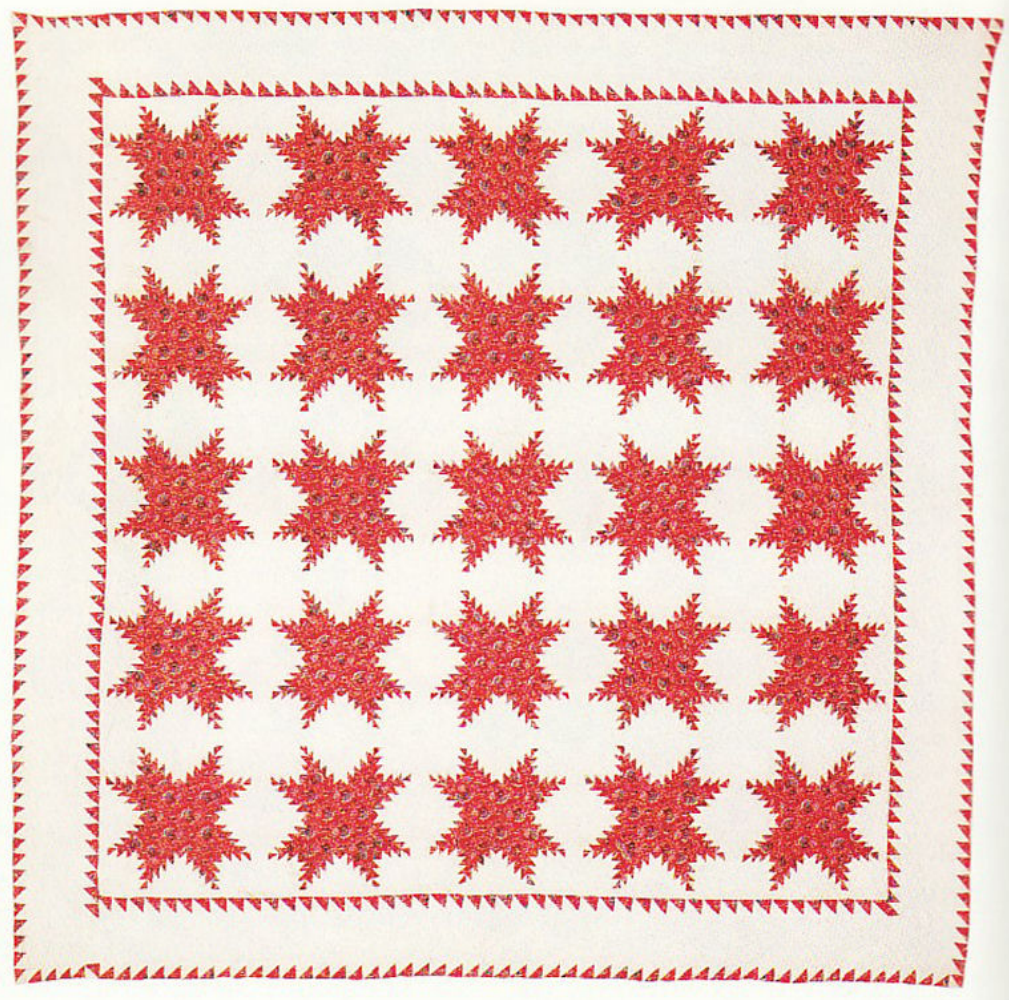

Figure 4.22. Quilt by Mary Laman Kemp (1758-1845), 1840, Rocky Springs, Maryland. Private Collection. Reprinted by permission. A Maryland Album: Quiltmaking Traditions 1634-1934, Gloria Seaman Allen and Nancy Gibson Tuckhorn, 1995, Thomas Nelson Inc. Nashville, Tennessee. All Rights Reserved.

Mary Laman Kemp made this quilt for her great-granddaughter's eighth birthday. It would have been a lasting memorial of her love as the girl grew up. 


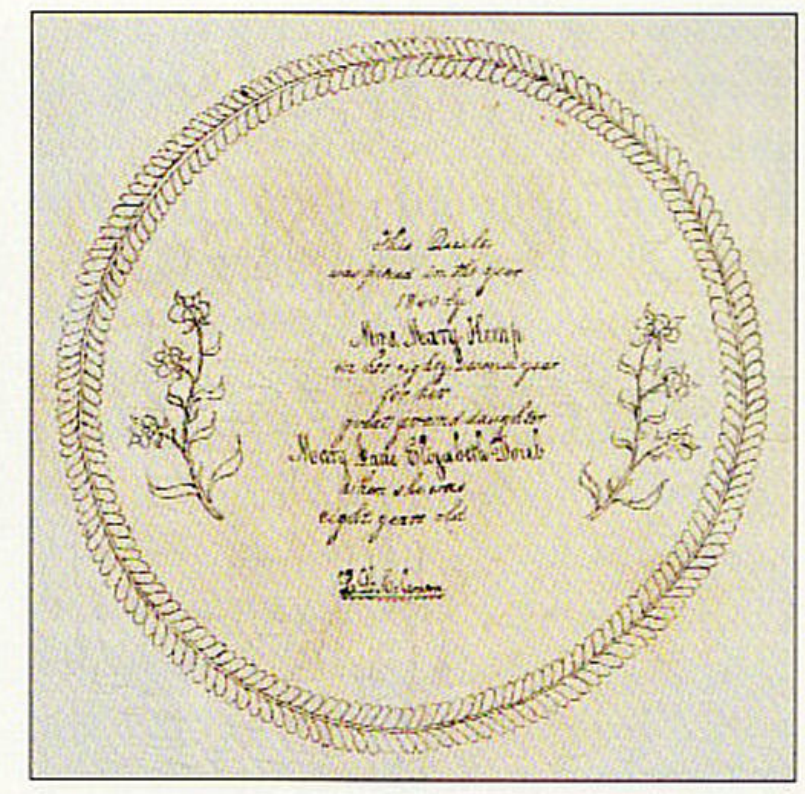

Figure 4.23. Detail of inscription on quilt by Mary Laman Kemp. Reprinted by permission. A Maryland Album: Quiltmaking Traditions 1634-1934, Gloria Seaman Allen and Nancy Gibson Tuckhorn, 1995, Thomas Nelson Inc. Nashville, Tennessee. All Rights Reserved.

Inscription: This quilt was pieced in the year 1840 by Mrs. Mary Kemp in her eightysecond year for her great grand daughter Mary Jane Elizabeth Doub when she was eight years old. L.L. Coleman. 
and patterns. The quilt could function as a model of womanly skills, even when Kemp could not. These quilts were not intended as practical household items; instead they were special, deliberately made to become lasting family heirlooms. In a study of the Revolutionary War in American memory, historian Sarah Purcell explained that “monuments served as powerful physical reminders of what the 'best' American men had sacrificed for their country, and patriots hoped they would serve to further bind the nation together." 193 For women of that same generation, gift needlework could serve as their own personal monuments, arranged around the home and within arm's length to provoke frequent memories and reminders. Hanging a sampler on the wall or placing a quilt on the bed may have been a type of monument to its maker, serving as a personal reminder to her family.

The group of Philadelphia women that Susan Stabile studied created their own network of memories using spaces and artifacts. Bringing objects that once belonged to their deceased mothers and husbands close to them helped them feel that those people were still nearby. Stabile calls these "mnemonic objects" and suggests that these objects merged with the self "to renew a unified identity and a continuous narrative of the past in old age." 194 By exploring the memories and material culture of a small group of aging women in late-eighteenth century Philadelphia, Stabile determined that aging women believed themselves to be "responsible for the transmitting of memory from one generation to another."195 Did aging women of the antebellum period see their role as "memory transmitters" any differently?

\footnotetext{
${ }^{193}$ Sarah J. Purcell, Sealed with Blood: War, Sacrifice and Memory in Revolutionary America (Philadelphia: University of Pennsylvania Press, 2002), 103.

${ }^{194}$ Stabile, Memory's Daughters, 135, 189.

195 Stabile, Memory's Daughters, 131.
} 
A quilt made by Abigail Reynolds Greene (1794-1889) suggests not (figure 4.24). ${ }^{196}$ She, like many other women of her generation, could have been inspired to stitch as part of her role as a "kin-keeper" - to maintain connections between family members, and to remind her family of its personal history. In 1860, when she was sixtysix years old, Abigail inscribed a quilt “AG 1860 to Abby G. Fry” and gave it to her granddaughter, Abby Fry (1842-1860). Born in 1842, Abby Fry was the first granddaughter named for her grandmother (although others would follow - three grandchildren and one niece would ultimately share her name). ${ }^{197}$ While naming a child after her grandmother was not uncommon, it does seem significant that so many of Abigail Greene's children offered her namesakes. This suggests respect for their mother, as well as close-knit family ties and may be read as a sign of Abigail's success in her role as kin keeper. Sadly, young Abby died of appendicitis on May 14, 1860 at the age of seventeen. $^{198}$

Like many of the other quilts described here, this one offers physical evidence that can be interpreted multiple ways. One scholar - noticing features more consistent with quilts of the 1830 s and 1840 s than with 1860 - has suggested that the quilt was made at an earlier time and only inscribed in 1860. The one-patch block set on point without borders is consistent with Rhode Island quilts made before 1850. The flowers, hearts and birds resemble those seen on other types of textiles and folk art from the 1830s and 1840s. And, fiber analysis suggests that the wool used for the back came from an

\footnotetext{
196 The quilt is now in a private collection; it is pictured in Welters and Ordonez, eds., Down by the Old Mill Stream, 237.

${ }^{197}$ Family genealogical information from www.ancestry.com, accessed March 14, 2007.

${ }^{198}$ Linda Welters, "Homespun Folk Art" in Down by the Old Mill Stream, Welters and Ordonez, eds., 236237.
} 


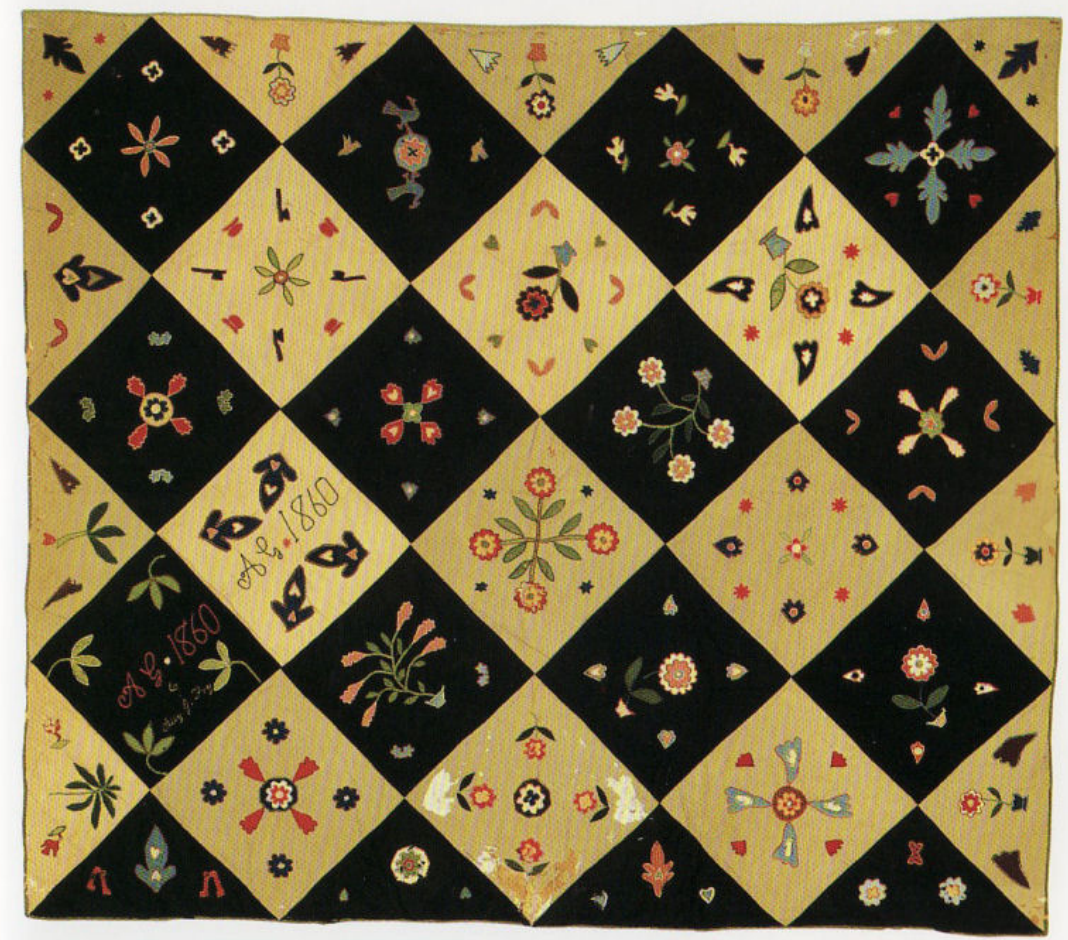

Figure 4.24. Quilt by Abigail Reynolds Greene (1794-1889), 1860, East Greenwich, Rhode Island. Private Collection; courtesy of the Rhode Island Quilt Documentation Project (RIQDP \#562).

Abigail Reynolds Greene gave this quilt to her namesake, her granddaughter Abigail Fry, shortly before the girl died in 1860 at the young age of seventeen. 
early breed of sheep. ${ }^{199}$ All of these things suggest an earlier date of origin for the quilt. However, the embroidery thread used for the inscription resembles that used to appliqué the various motifs on the quilt top, which would indicate that the top and the inscription were completed at the same time. ${ }^{200}$ The physical evidence presented by the quilt is ambiguous, offering multiple interpretations as to how it was made and used.

One possible way to reconcile this seemingly contradictory evidence is that Abigail Greene may have made the quilt for her granddaughter as a sewing lesson. It is made from older materials and shows an older style. There are also some poor quilting stitches visible in the quilt; perhaps young Abby was working on it with her grandmother when she became ill.

Another way that the quilt's conflicting material evidence can be reconciled is if Abigail Greene took it out when Abby became ill and added the inscription, giving it to her while she was sick to keep her warm and symbolically covered with her grandmother's love and protection. Several of Abigail's close family members died prior to 1860 when the quilt was made and/or given, including six of her children and her husband. ${ }^{201}$ This quilt, intended for a granddaughter who also died as a young woman, may have been a means for Abigail to cope with her grief, or to symbolically ward off the danger of illness from a beloved grandchild.

\footnotetext{
${ }^{199}$ Welters, "Homespun Folk Art," 236. It is plausible that the Greenes, who lived in rural Rhode Island, owned sheep. Unfortunately, extant tax records for East Greenwich, Rhode Island, at the Rhode Island Historical Society and at the East Greenwich Town Hall do not include a level of detail that would reveal what kind of livestock Abigail and her husband owned. Phone conversations with the Rhode Island Historical Society, Providence, Rhode Island, on September 3, 2009, and with the Town Clerk's Office, East Greenwich Town Hall, Rhode Island on September 4, 2009.

${ }^{200}$ Welters, "Homespun Folk Art," 236.

${ }^{201}$ See family trees, www.ancestry.com, accessed March 14, 2007.
} 
Needlework gifts from women to friends and family were far more than customary tokens of esteem, particularly for women as they aged. A final example has a particularly poignant associated history. Around 1845 or 1846, Catherine Crast Sloat (1798-1873) gave her daughter, Sarah Sloat Burr (1821-1910), a quilt that she made (figure 4.25). ${ }^{202}$ The front of this reversible quilt is pieced in strips, forming a pattern known as Flying Geese. The quilt incorporates many different fabrics, including some that may have been recycled from clothing and household textiles, perhaps representing family stories and memories. The quilt is backed with an older quilt, pieced in the Irish Chain pattern, and faded, suggesting that it was previously used and, thus, making it physically representative of the family's history.

In 1843, twenty-two-year-old New York native Sarah Sloat married Charles Clark Burr (1817-1903). Three years later, the couple moved west with his parents and his brother, traveling to California with a group of fellow Mormons. At some point between Sarah's marriage and her departure, her mother, forty-seven-year-old Catherine Crast Sloat gave her this quilt. ${ }^{203}$ According to family history, Sarah took the quilt on this trip. During the long ocean voyage, Sarah Sloat Burr gave birth to one child and lost another to dysentery. ${ }^{204}$

Throughout the long, difficult trip, the quilt may have served Sarah as a stand-in for her mother's love and comfort, and as a reminder of her birth family. Sarah was the

\footnotetext{
${ }^{202}$ The quilt remains in a private collection but is pictured in Sandi Fox, Quilts: California Bound, California Made 1840-1940 (Los Angeles: FIDM Museum and Library, Inc., 2002), 32-37. Catherine Crast, sometimes referred to as "Caty," was born in Albany, New York in 1798 and married John Lounsbury Sloat (1799-1884) in 1818 when she was twenty years old. John and Catherine Sloat had eleven children, all born in New York. According to U.S. Census data, John Sloat was a cooper. In 1850, the Census indicates that he owned real estate worth $\$ 350$, placing the family securely at the middle to lower end of the economic scale. Fox, Quilts: California Bound, 34; U.S. Census information from www.ancestry.com, accessed May 27, 2007.

${ }^{203}$ The story of the quilt is known through family history, see Fox, Quilts: California Bound, 34.

${ }^{204}$ Fox, Quilts: California Bound, 34.
} 


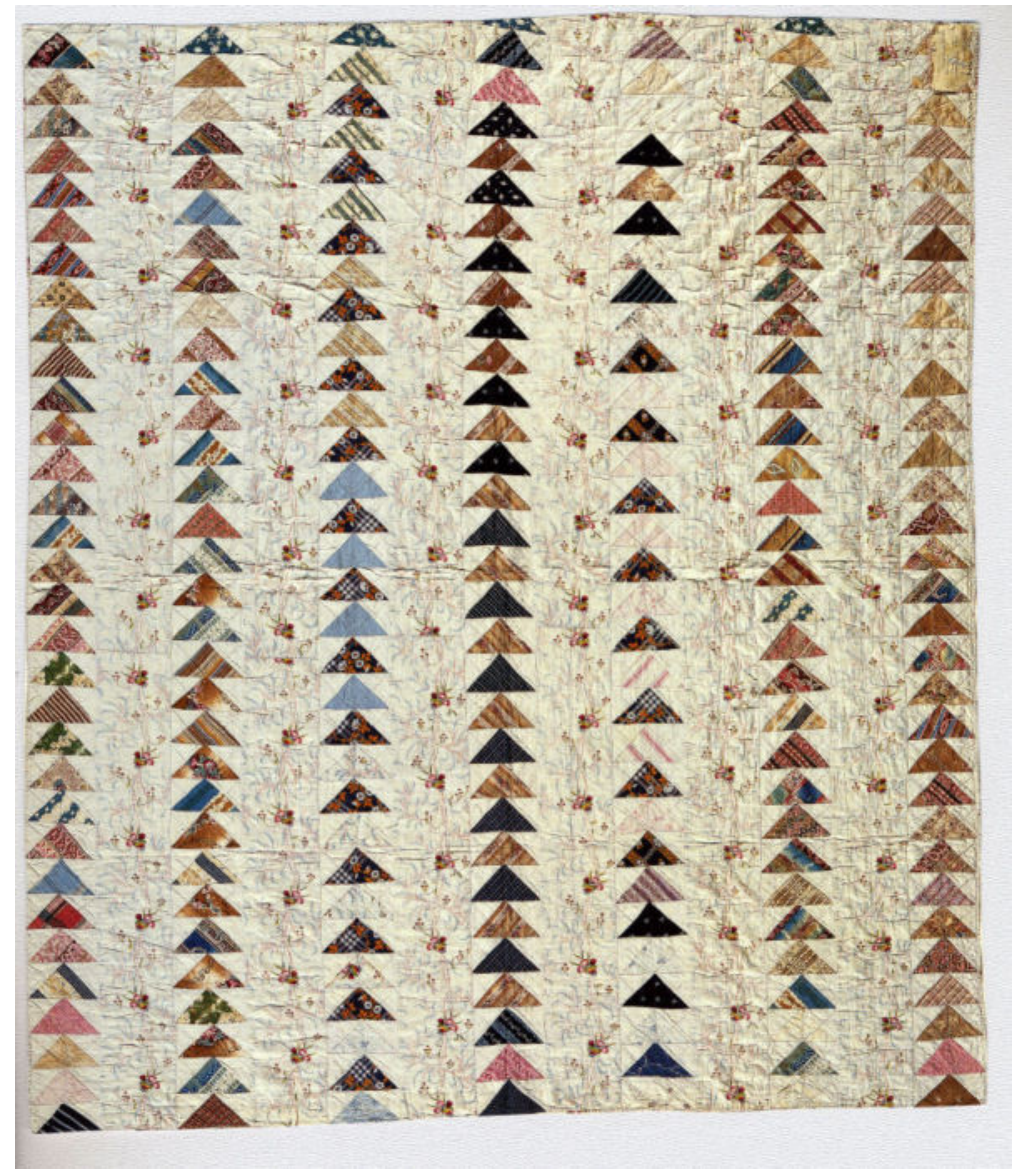

Figure 4.25. Quilt by Catherine Crast Sloat (1798-1873), circa 1845, New York. Private Collection.

Catherine Crast Sloat recycled a second quilt as the backing for this one. Before her daughter left New York for California with her husband and his family, Sloat gave her this quilt. Sloat could not read or write and may have intended this quilt to be a stand-in for her presence while her daughter was far away. 
only child of John and Catherine Sloat to leave New York, so the family must have felt the separation keenly. Catherine Sloat could not read or write, making the quilt an important means of maintaining a connection to her absent daughter. ${ }^{205}$

For the aging women described here, a needlework gift was more than the sum of its parts; it was understood to embody the person who made it. In turn, these women used their needlework to influence their families, society and culture; to cope with change; and to express their identity and values. Terri Premo has asserted that "old women in the new republic often believed their generation experienced and understood the past differently."206 Far from being merely a functional bed covering, each quilt discussed here was an extension of its maker's identity. These objects were intended by their givers to be passed down for generations reminding their progeny of their ancestors' existence, talents and skills, to remind them of where they came from, and to carry forward the same values and traditions.

\footnotetext{
${ }^{205}$ Fox, Quilts: California Bound, 35.

${ }^{206}$ Premo, Winter Friends, 115.
} 
Table 4.1. Antebellum Needlework Given as Gifts by Aging Women

\begin{tabular}{|l|l|l|l|l|l|}
\hline $\begin{array}{l}\text { Maker's Name and } \\
\text { Life Dates }\end{array}$ & $\begin{array}{l}\text { Artifact Type, Date; } \\
\text { Age of Maker }\end{array}$ & Town and State & $\begin{array}{l}\text { Recipient Name and } \\
\text { Life Dates }\end{array}$ & $\begin{array}{l}\text { Relationship to } \\
\text { Maker }\end{array}$ & $\begin{array}{l}\text { Occasion for } \\
\text { Gift }\end{array}$ \\
\hline $\begin{array}{l}\text { Deborah Barnes (b. } \\
\text { 1790) }\end{array}$ & Quilt, 1851; 61 & Baltimore, MD & Dr. Leese & Unknown \\
\hline $\begin{array}{l}\text { Nancy (Miller) } \\
\text { Benson (1809- } \\
1879)^{2}\end{array}$ & $\begin{array}{l}\text { Quilt, circa 1850; } \\
\text { about 41 }\end{array}$ & Spartanburg, SC & $\begin{array}{l}\text { Rosa Benson } \\
\text { (b. 1826) }\end{array}$ & Daughter \\
\hline $\begin{array}{l}\text { Ann G. (Hitchcock) } \\
\text { Boker (b. circa } \\
1803)^{3}\end{array}$ & Quilt, 1860; about 57 & $\begin{array}{l}\text { Lower } \\
\text { Chichester, PA }\end{array}$ & $\begin{array}{l}\text { Amanda Boker Bunn } \\
\text { (b. 1857) }\end{array}$ & Granddaughter & Unspecified \\
\hline $\begin{array}{l}\text { Catharine Ann } \\
\text { Penniman) Bradford } \\
(1778-1827)^{4}\end{array}$ & Quilt, 1825; 47 & Boston, MA & $\begin{array}{l}\text { Catherine Ann } \\
\text { Bradford (b. 1802) }\end{array}$ & Daughter & Marriage \\
\hline $\begin{array}{l}\text { Julia (Stevens) } \\
\text { Crosby (1798-1879) }\end{array}$ & $\begin{array}{l}\text { Quilt, circa 1860; } \\
\text { about 62 }\end{array}$ & $\begin{array}{l}\text { East Hardwick, } \\
\text { VT }\end{array}$ & $\begin{array}{l}\text { Calvin Stevens } \\
\text { Crosby and Lucy } \\
\text { Brook }\end{array}$ & $\begin{array}{l}\text { Son and daughter- } \\
\text { in-law }\end{array}$ & Unspecified \\
\hline $\begin{array}{l}\text { Julia (Stevens) } \\
\text { Crosby (1798-1879) }\end{array}$ & $\begin{array}{l}\text { Quilt, circa 1860; } \\
\text { about 62 }\end{array}$ & $\begin{array}{l}\text { East Hardwick, } \\
\text { VT }\end{array}$ & $\begin{array}{l}\text { Seraphine Crosby } \\
\text { and Sherburne } \\
\text { Leonard Wiswell }\end{array}$ & $\begin{array}{l}\text { Daughter and son- } \\
\text { in-law }\end{array}$ & Unspecified \\
\hline Ruth (Pierce) & Sampler, 1827; 63 & Catskill, NY & Elisabeth L. Wey (d. & Granddaughter & Unspecified \\
\hline
\end{tabular}

\footnotetext{
${ }^{1}$ In the collection of the Herbert F. Johnson Museum of Art, Cornell University, Ithaca, New York. The quilt is illustrated in Cathy Rosa Klimaszewski, Made to Remember: American Commemorative Quilts (Ithaca: Cornell University Press, 1991), 24.

${ }^{2}$ Collection of the Mary Black Foundation. Illustrated in Horton, Mary Black's Family Quilts, 31.

${ }^{3}$ Now in the collection of Winterthur Museum and Country Estate, Delaware, this quilt is pictured in Eaton, Quilts in a Material World, 57.

${ }^{4}$ Now in a private collection, the quilt is illustrated in Kort, Wisconsin Quilts, 3.

${ }^{5}$ In a private collection; discussed in Linda Otto Lipsett, Remember Me: Women and Their Friendship Quilts (San Francisco: The Quilt Digest Press, 1985), 109.

${ }^{6}$ This quilt is in a private collection and is pictured in Lipsett, Remember $M e, 100$.
} 


\begin{tabular}{|c|c|c|c|c|c|}
\hline $\begin{array}{l}\text { Croswell (1765- } \\
1862)^{7}\end{array}$ & & & 1845) & & \\
\hline $\begin{array}{l}\text { Margaret Boyce } \\
\text { Elliott }(1800-1867)^{8}\end{array}$ & $\begin{array}{l}\text { Quilt, circa 1843; } \\
\text { about } 43\end{array}$ & $\mathrm{MD}$ or $\mathrm{DE}$ & $\begin{array}{l}\text { Margaret Jane } \\
\text { Collins (b. 1843) }\end{array}$ & Granddaughter & Birth \\
\hline $\begin{array}{l}\text { Hannah Warner } \\
\text { Forwood (1811- } \\
1886)^{9}\end{array}$ & Quilt, 1854; 43 & $\begin{array}{l}\text { Prob. Kennett } \\
\text { Square, PA }\end{array}$ & $\begin{array}{l}\text { Sallie A. Forwood } \\
(1834-1905)\end{array}$ & Daughter & Marriage \\
\hline $\begin{array}{l}\text { Anna Catherine } \\
\text { (Hummel) Markey } \\
\text { Garnhart (1773- } \\
1860)^{10}\end{array}$ & $\begin{array}{l}\text { Quilt, circa 1822; } \\
\text { about } 49\end{array}$ & Frederick, MD & $\begin{array}{l}\text { John David Markey } \\
\text { (b. 1822) }\end{array}$ & Grandson & Birth \\
\hline $\begin{array}{l}\text { Anna Catherine } \\
\text { (Hummel) Markey } \\
\text { Garnhart (1773- } \\
1860)^{11}\end{array}$ & $\begin{array}{l}\text { Quilt, 1830-1845; } \\
\text { about 57-72 }\end{array}$ & Frederick, MD & Unidentified & $\begin{array}{l}\text { Probably } \\
\text { Grandchild }\end{array}$ & Probably Birth \\
\hline $\begin{array}{l}\text { Anna Catherine } \\
\text { (Hummel) Markey } \\
\text { Garnhart (1773- } \\
1860)^{12}\end{array}$ & $\begin{array}{l}\text { Quilt, circa 1815; } \\
\text { about } 42\end{array}$ & Frederick, MD & $\begin{array}{l}\text { Anna Markey (b. } \\
\text { 1824) }\end{array}$ & Granddaughter & Birth \\
\hline $\begin{array}{l}\text { Anna Catherine } \\
\text { (Hummel) Markey } \\
\text { Garnhart (1773- } \\
1860)^{13}\end{array}$ & $\begin{array}{l}\text { Quilt, circa } 1820- \\
1840 ; \text { about } 47-67\end{array}$ & Frederick, MD & $\begin{array}{l}\text { Mary Ellen Markey } \\
\text { (b. 1833) }\end{array}$ & Granddaughter & Birth \\
\hline Anna Catherine & Quilt, circa 1850; & Frederick, MD & John Hanshaw & Grandson & Unspecified \\
\hline
\end{tabular}

\footnotetext{
${ }^{7}$ In the collection of the Litchfield Historical Society, Litchfield, Connecticut.

${ }^{8}$ Collection of the Maryland Historical Society, Baltimore, Maryland. Illustrated in Davis, The Baltimore Album Quilt Tradition, entry 12.

${ }^{9}$ Collection of the Chester County Historical Society, West Chester, Pennsylvania.

${ }^{10}$ Collection of the Plains Indians and Pioneers Museum, Woodward, Oklahoma.

${ }^{11}$ In a private collection, currently on loan to the Daughters of the American Revolution Museum, Washington, DC.

${ }^{12}$ Collection of the Daughters of the American Revolution Museum, Washington, DC.

${ }^{13}$ In a private collection, but currently on loan to the Daughters of the American Revolution Museum, Washington, DC.
} 


\begin{tabular}{|c|c|c|c|c|c|}
\hline $\begin{array}{l}\text { (Hummel) Markey } \\
\text { Garnhart (1773- } \\
1860)^{14}\end{array}$ & about 77 & & Markey (b. 1835) & & \\
\hline $\begin{array}{l}\text { Anna Catherine } \\
\text { (Hummel) Markey } \\
\text { Garnhart (1773- } \\
1860)^{15}\end{array}$ & $\begin{array}{l}\text { Quilt, 1835-1855; } \\
\text { about } 62-82\end{array}$ & Frederick, MD & Unidentified & $\begin{array}{l}\text { Probably } \\
\text { Grandchild }\end{array}$ & Probably Birth \\
\hline $\begin{array}{l}\text { Anna Catherine } \\
\text { (Hummel) Markey } \\
\text { Garnhart (1773- } \\
1860)^{16}\end{array}$ & $\begin{array}{l}\text { Quilt, } 1835-1845 ; \\
\text { about } 62-72\end{array}$ & Frederick, MD & Unidentified & $\begin{array}{l}\text { Probably } \\
\text { Grandchild }\end{array}$ & Probably Birth \\
\hline $\begin{array}{l}\text { Anna Catherine } \\
\text { (Hummel) Markey } \\
\text { Garnhart (1773- } \\
1860)^{17}\end{array}$ & $\begin{array}{l}\text { Quilt, 1820-1835; } \\
\text { about 47-62 }\end{array}$ & Frederick, MD & Unidentified & $\begin{array}{l}\text { Probably } \\
\text { Grandchild }\end{array}$ & Probably Birth \\
\hline $\begin{array}{l}\text { Anna Catherine } \\
\text { (Hummel) Markey } \\
\text { Garnhart (1773- } \\
1860)^{18}\end{array}$ & $\begin{array}{l}\text { Quilt, ca. 1840; about } \\
67\end{array}$ & Frederick, MD & Unidentified & $\begin{array}{l}\text { Probably } \\
\text { Grandchild }\end{array}$ & Probably Birth \\
\hline $\begin{array}{l}\text { Anna Catherine } \\
\text { (Hummel) Markey } \\
\text { Garnhart (1773- } \\
1860)^{19}\end{array}$ & $\begin{array}{l}\text { Quilt, 1820-1840; } \\
\text { about 47-67 }\end{array}$ & Frederick, MD & Unidentified & $\begin{array}{l}\text { Probably } \\
\text { Grandchild }\end{array}$ & Probably Birth \\
\hline $\begin{array}{l}\text { Anna Catherine } \\
\text { (Hummel) Markey }\end{array}$ & $\begin{array}{l}\text { Quilt, 1825-1840; } \\
\text { about 52-67 }\end{array}$ & Frederick, MD & Unidentified & $\begin{array}{l}\text { Probably } \\
\text { Grandchild }\end{array}$ & Probably Birth \\
\hline
\end{tabular}

\footnotetext{
${ }^{14}$ Collection of the Daughters of the American Revolution Museum, Washington, DC.

${ }^{15}$ In a private collection, currently on loan to the Daughters of the American Revolution Museum, Washington, DC.

${ }^{16}$ In a private collection, currently on loan to the Daughters of the American Revolution Museum, Washington, DC.

${ }^{17}$ In a private collection, currently on loan to the Daughters of the American Revolution Museum, Washington, DC.

${ }^{18}$ In a private collection.

${ }^{19}$ In a private collection.
} 


\begin{tabular}{|l|l|l|l|l|l|}
\hline $\begin{array}{l}\text { Garnhart (1773- } \\
1860)^{20}\end{array}$ & & & \\
\hline $\begin{array}{l}\text { Abigail (Reynolds) } \\
\text { Greene }(1794- \\
1889)^{21}\end{array}$ & Quilt, 1860; 66 & $\begin{array}{l}\text { East Greenwich, } \\
\text { RI }\end{array}$ & $\begin{array}{l}\text { Abby G. Fry (1842- } \\
1860)\end{array}$ & Granddaughter & Unspecified \\
\hline $\begin{array}{l}\text { Lucretia (Street) Hall } \\
(1773-1851)^{22}\end{array}$ & $\begin{array}{l}\text { Embroidered } \\
\text { Coverlet, 1828; 55 }\end{array}$ & $\begin{array}{l}\text { Charlemont, } \\
\text { MA }\end{array}$ & $\begin{array}{l}\text { Catherine Hall } \\
(1808-1890)\end{array}$ & Daughter & Marriage \\
\hline $\begin{array}{l}\text { Louvica (Creek) } \\
\text { Houchins (1788- } \\
\text { after 1850) }\end{array}$ & $\begin{array}{l}\text { Quilt, circa 1839; } \\
\text { about 51 }\end{array}$ & IL & $\begin{array}{l}\text { Louvica Barr (1827- } \\
1916)\end{array}$ & Granddaughter & Unspecified \\
\hline $\begin{array}{l}\text { Mary (Duncan) } \\
\text { Kelly (1814-1898) }\end{array}$ & Quilt, 1858; 44 & $\begin{array}{l}\text { St. Clairsville, } \\
\text { OH }\end{array}$ & $\begin{array}{l}\text { Martha Jane Kelly } \\
(1841-1922)\end{array}$ & Daughter \\
\hline $\begin{array}{l}\text { Mary Laman Kemp } \\
(1758-1845)^{25}\end{array}$ & Quilt, 1840; 82 & Rocky Springs, & $\begin{array}{l}\text { Mary Jane Elizabeth } \\
\text { Doub (1832-1908) }\end{array}$ & $\begin{array}{l}\text { Great- } \\
\text { granddaughter }\end{array}$ & Marriage \\
\hline $\begin{array}{l}\text { Mary Tayloe (Lloyd) } \\
\text { Key (1786-1859) }\end{array}$ & $\begin{array}{l}\text { Quilt top, ca. 1840; } \\
\text { about 54 }\end{array}$ & $\begin{array}{l}\text { Georgetown, } \\
\text { MD }\end{array}$ & $\begin{array}{l}\text { Mary Alicia Lloyd } \\
\text { Nevins Key (1823- } \\
1886)\end{array}$ & Daughter & Unspecified \\
\hline $\begin{array}{l}\text { Susan Kuhns (ca. } \\
1787-c a .1865)^{27}\end{array}$ & $\begin{array}{l}\text { Quilt, circa 1840; } \\
\text { about 53 }\end{array}$ & Greenburg, PA & $\begin{array}{l}\text { Anna Maria Kuhns } \\
(1817-1868)\end{array}$ & Niece & Marriage \\
\hline $\begin{array}{l}\text { Amelia (Heiskell) } \\
\text { Lauck (1760-1842) }\end{array}$ & $\begin{array}{l}\text { Quilt, circa 1822; } \\
\text { about 62 }\end{array}$ & Winchester, VA & $\begin{array}{l}\text { Morgan (1796-1828) } \\
\text { and Ann Maria }\end{array}$ & $\begin{array}{l}\text { Son and daughter- } \\
\text { in-law }\end{array}$ & Marriage \\
\hline
\end{tabular}

\footnotetext{
${ }^{20}$ In a private collection.

${ }^{21}$ In a private collection. Illustrated in Welters and Ordonez, eds., Down by the Old Mill Stream, 236-237.

${ }^{22}$ Collection of Historic Deerfield, Deerfield, Massachusetts. Illustrated in Judith Reiter Weissman and Wendy Lavitt, Labors of Love: America's Textiles and Needlework, 1650-1930 (New York: Wings Books, 1987), 24.

${ }^{23}$ Collection of the Daughters of the American Revolution Museum, Washington, DC.

${ }^{24}$ Collection of the Ohio Historical Society, Columbus, Ohio. Illustrated in Ricky Clark, ed., Quilts in Community, 129.

${ }^{25}$ In a private collection. Illustrated in Allen and Tuckhorn, A Maryland Album, 98-99.

${ }^{26}$ Collection of the San Jose Museum of Quilts and Textiles, San Jose, California.

${ }^{27}$ Collection of the Daughters of the American Revolution Museum, Washington, DC.

${ }^{28}$ Collection of Colonial Williamsburg, Williamsburg, Virginia.
} 


\begin{tabular}{|l|l|l|l|l|l|}
\hline & & & Lauck (1804-1872) & \\
\hline $\begin{array}{l}\text { Amelia (Heiskell) } \\
\text { Lauck (1760-1842) }\end{array}$ & Quilt, 1823; 63 & Winchester, VA & $\begin{array}{l}\text { John (b. 1764) and } \\
\text { Rebecca (Lauck) (b. } \\
\text { 1787) Cunningham }\end{array}$ & $\begin{array}{l}\text { Daughter and son- } \\
\text { in-law }\end{array}$ & Unspecified \\
\hline $\begin{array}{l}\text { Amelia (Heiskell) } \\
\text { Lauck (1760-1842) }\end{array}$ & $\begin{array}{l}\text { Quilt, circa 1822; } \\
\text { about 62 }\end{array}$ & Winchester, VA & $\begin{array}{l}\text { William (1805-1875) } \\
\text { and Eleanor (Sowers) } \\
\text { (b. 1812) Lauck }\end{array}$ & $\begin{array}{l}\text { Son and daughter- } \\
\text { in-law }\end{array}$ & Unspecified \\
\hline $\begin{array}{l}\text { Amelia (Heiskell) } \\
\text { Lauck (1760-1842) }\end{array}$ & $\begin{array}{l}\text { Quilt, 1820-1830; 60- } \\
70\end{array}$ & $\begin{array}{l}\text { Probably } \\
\text { Winchester, VA }\end{array}$ & Unknown & Probably son & Unspecified \\
\hline $\begin{array}{l}\text { Mary M. Leggett (b. } \\
\text { 1786) }\end{array}$ & Quilt, 1852; 66 & $\begin{array}{l}\text { Valley Forge, } \\
\text { PA }\end{array}$ & Anna M. Leggett & Daughter & Unspecified \\
\hline $\begin{array}{l}\text { Sarah Wadsworth } \\
\text { Mahan (1802- } \\
1885)^{33}\end{array}$ & Quilt, 1851; 49 & Oberlin, OH & Julia M. Woodruff & Stepdaughter & Bequest \\
\hline $\begin{array}{l}\text { Harriet (Kirk) } \\
\text { Marion (1782- } \\
1856)^{34}\end{array}$ & $\begin{array}{l}\text { Quilt, circa 1830; } \\
\text { about 48 }\end{array}$ & $\begin{array}{l}\text { St. Stephen's } \\
\text { Parish, SC }\end{array}$ & $\begin{array}{l}\text { Harriet Marion } \\
\text { Palmer (b. 1830) }\end{array}$ & Granddaughter & Birth \\
\hline $\begin{array}{l}\text { Dorothea (Dolly) } \\
\text { (1802-1892) McClanahan }\end{array}$ & $\begin{array}{l}\text { Quilt, circa 1860; } \\
\text { about 58 }\end{array}$ & $\begin{array}{l}\text { String Prairie, } \\
\text { TX }\end{array}$ & $\begin{array}{l}\text { Nancy McClanahan } \\
\text { (b. 1837) }\end{array}$ & Daughter & Marriage \\
\hline $\begin{array}{l}\text { Elizabeth } \\
\text { McClintock (b. }\end{array}$ & Quilt, 1849; 69 & $\begin{array}{l}\text { Sara Jane } \\
\text { McClintock }\end{array}$ & Daughter & Unspecified \\
\hline
\end{tabular}

\footnotetext{
${ }^{29}$ Collection of the Daughters of the American Revolution Museum, Washington, DC.

${ }^{30}$ Collection of the Daughters of the American Revolution Museum, Washington, DC.

${ }^{31}$ Collection of Colonial Williamsburg, Williamsburg, VA.

${ }^{32}$ In a private collection, the quilt was documented as part of the Quilts of Tennessee documentation project. An image of the quilt is accessible online at the Quilt Index, http://www.quiltindex.org/fulldisplay.php?pbd=TennesseeTSLA-a0a4r0-a, accessed on August 3, 2008.

${ }_{33}^{33}$ Collection of the Allen Memorial Art Museum, Oberlin, Ohio. Illustrated in Ricky Clark, "Fragile Families," 5-6.

${ }^{34}$ Collection of MESDA, Winston-Salem, North Carolina. Illustrated in Locklair, Quilts, Coverlets and Counterpanes, 43-44.

${ }^{35}$ In a private collection, the quilt is pictured in Karoline Patterson Bresenhan and Nancy O'Bryant Puentes, Lone Stars: A Legacy of Texas Quilts 1836-1936 (Austin: University of Texas Press, 1986), 48.
} 


\begin{tabular}{|c|c|c|c|c|c|}
\hline 1780$)^{36}$ & & & & & \\
\hline $\begin{array}{l}\text { Johanna Penelope } \\
\text { Elizabeth Cushing } \\
\text { Montell (1784- } \\
\text { 1857) }\end{array}$ & $\begin{array}{l}\text { Quilt, circa 1840; } \\
\text { about } 56\end{array}$ & Baltimore, MD & Francis T. Montell & Son & Marriage \\
\hline $\begin{array}{l}\text { Mary Rooker Norris } \\
(1785-1868)^{38}\end{array}$ & Quilt, 1846; 61 & $\begin{array}{l}\text { Hagerstown, } \\
\text { MD }\end{array}$ & $\begin{array}{l}\text { Mary Norris (b. } \\
1845)\end{array}$ & Granddaughter & Birth \\
\hline $\begin{array}{l}\text { Catherine Couturier } \\
\text { (Marion) Palmer } \\
(1807-1895)^{39}\end{array}$ & $\begin{array}{l}\text { Quilt, 1847-1848; 40- } \\
41\end{array}$ & St. John's, SC & $\begin{array}{l}\text { Harriet M. Palmer (b. } \\
\text { 1830) }\end{array}$ & Daughter & Unspecified \\
\hline $\begin{array}{l}\text { Unidentified: Harriet } \\
\text { (Kirk) Marion } \\
\text { (1782-1856) OR } \\
\text { Elizabeth (Marion) } \\
\text { Porcher (1760-1796) } \\
\text { and Elizabeth } \\
\text { Catherine (Porcher) } \\
\text { Palmer (1781- } \\
1841)^{40}\end{array}$ & $\begin{array}{l}\text { Quilt, circa } 1841 \text { OR } \\
\text { circa } 1790 \text { and circa } \\
1830 ; \text { about } 48 \text { OR } \\
\text { about } 30 \text { and } 49\end{array}$ & $\mathrm{SC}$ & $\begin{array}{l}\text { John Gendron } \\
\text { Palmer (b. 1841) OR } \\
\text { John Gendron } \\
\text { Palmer (b. 1807) }\end{array}$ & $\begin{array}{l}\text { Grandson OR } \\
\text { Grandson/Son }\end{array}$ & $\begin{array}{l}\text { Birth OR } \\
\text { Marriage }\end{array}$ \\
\hline $\begin{array}{l}\text { Isabelle (Liddon) } \\
\text { Pennock (b. 1795) }\end{array}$ & $\begin{array}{l}\text { Quilt, 1842-1843; 47- } \\
48\end{array}$ & $\begin{array}{l}\text { Marlborough } \\
\text { Township, PA }\end{array}$ & $\begin{array}{l}\text { Sarah Wistar } \\
\text { Pennock (b. 1840) }\end{array}$ & Niece & Unspecified \\
\hline $\begin{array}{l}\text { Elizabeth Daniel } \\
\text { Poindexter (circa } \\
\text { 1807-circa 1858) }\end{array}$ & $\begin{array}{l}\text { Quilt, circa 1852; } \\
\text { about } 45\end{array}$ & $\begin{array}{l}\text { Cooper County, } \\
\text { MO }\end{array}$ & $\begin{array}{l}\text { Mary Ann } \\
\text { Poindexter (b. circa } \\
\text { 1827) }\end{array}$ & Daughter & Marriage \\
\hline
\end{tabular}

\footnotetext{
${ }^{36}$ Collection of the Grout Museum, Waterloo, IA.

${ }^{37}$ Collection of the Maryland Historical Society, Baltimore, MD. Illustrated in Allen, Old Line Traditions, 16.

${ }^{38}$ Collection of the Daughters of the American Revolution Museum, Washington, DC.

${ }^{39}$ Collection of MESDA, Winston-Salem, NC. Illustrated in Locklair, Quilts, Coverlets and Counterpanes, 45.

${ }^{40}$ Collection of MESDA, Winston-Salem, NC. Illustrated in Mosaic Quilts, 35.

${ }^{41}$ Collection of the Chester County Historical Society, West Chester, Pennsylvania.

${ }^{42}$ Collection of the Daughters of the American Revolution Museum, Washington, DC.
} 


\begin{tabular}{|l|l|l|l|l|l|}
\hline $\begin{array}{l}\text { Jemima Kassel } \\
\text { Reger (1815-1902) }\end{array}$ & $\begin{array}{l}\text { Quilt, circa 1859; } \\
\text { about 44 }\end{array}$ & $\begin{array}{l}\text { Buckhannon, } \\
\text { WV }\end{array}$ & $\begin{array}{l}\text { Montreville Reger } \\
(1834-1887) \text { and } \\
\text { Elizabeth Carper } \\
(1834-1926)\end{array}$ & $\begin{array}{l}\text { Son and daughter- } \\
\text { in-law }\end{array}$ & Marriage \\
\hline $\begin{array}{l}\text { Rebecca Scattergood } \\
\text { Savery (1770- } \\
1855)^{44}\end{array}$ & Quilt, 1839; 69 & Philadelphia, PA & $\begin{array}{l}\text { Sarah Savery (b. } \\
1839)\end{array}$ & Granddaughter & Birth \\
\hline $\begin{array}{l}\text { Rebecca Scattergood } \\
\text { Savery (1770- } \\
1855)^{45}\end{array}$ & $\begin{array}{l}\text { Quilt, 1835-1840; 65- } \\
70\end{array}$ & Philadelphia, PA & $\begin{array}{l}\text { William Savery } \\
(1798-1858) \text { or } \\
\text { Rebecca Walter } \\
\text { Savery (1836-1902) }\end{array}$ & $\begin{array}{l}\text { Son or } \\
\text { granddaughter }\end{array}$ & Unspecified \\
\hline $\begin{array}{l}\text { Rebecca Scattergood } \\
\text { Savery (1770- } \\
1855)^{46}\end{array}$ & Quilt, 1827; 57 & Philadelphia, PA & $\begin{array}{l}\text { Elizabeth Savery } \\
(1806-1860)\end{array}$ & Daughter & Marriage \\
\hline $\begin{array}{l}\text { Frances Shaw (1808- } \\
1876)^{47}\end{array}$ & $\begin{array}{l}\text { Quilt, circa 1850; } \\
\text { about 42 }\end{array}$ & $\begin{array}{l}\text { Hagerstown, } \\
\text { MD }\end{array}$ & $\begin{array}{l}\text { Samuel Shaw (b. } \\
1832)\end{array}$ & Son & Marriage \\
\hline $\begin{array}{l}\text { Esther (Johnson) } \\
\text { Parkinson Slater } \\
(1778-1859)\end{array}$ & Quilt, 1851; 73 & Pawtucket, RI & $\begin{array}{l}\text { Anna Russell } \\
\text { Whitney (1851-1940) }\end{array}$ & Unknown & Birth \\
\hline $\begin{array}{l}\text { Catherine (Crast) } \\
\text { Sloat (1798-1873) }\end{array}$ & $\begin{array}{l}\text { Quilt, circa 1845; } \\
\text { about 47 }\end{array}$ & Quilt, circa 1840; \\
\hline $\begin{array}{l}\text { Mary (Polly) } \\
\text { (Hutchings) Small } \\
\text { (1775-1846) }\end{array}$ & about 65 & $\begin{array}{l}\text { Pleasant } \\
\text { Exchange, TN }\end{array}$ & $\begin{array}{l}\text { Phoeba (Wilson) } \\
\text { Small (1811-1864) } \\
(1821-1910)\end{array}$ & Daughter-in-law & $\begin{array}{l}\text { Before-death } \\
\text { bequest }\end{array}$ \\
\hline
\end{tabular}

\footnotetext{
${ }^{43}$ Illustrated in Valentine, West Virginia Quilts and Quiltmakers, 82-83.

${ }^{44}$ Collection of the Philadelphia Museum of Art, Philadelphia, PA.

${ }^{45}$ Collection of the American Folk Art Museum, New York, NY.

${ }^{46}$ Collection of Winterthur Museum and Country Estate, Winterthur, Delaware.

${ }^{47}$ Illustrated in Valentine, West Virginia Quilts and Quiltmakers, 109.

${ }^{48}$ Collection of Slater Mill Historic Site, Pawtucket, Rhode Island. Illustrated in Welters and Ordonez, eds., Down by the Old Mill Stream, $226-231$.

${ }^{49}$ In a private collection. Illustrated in Fox, Quilts: California Bound, California Made, 32-37.
} 


\begin{tabular}{|c|c|c|c|c|c|}
\hline $\begin{array}{l}\text { Rachel Smith (b. } \\
\text { circa 1795) }\end{array}$ & Quilt, 1859; about 64 & Derby, CT & Isabel C. Eagle & Great-niece & Marriage \\
\hline $\begin{array}{l}\text { Mary Elizabeth } \\
\text { Clayton (Miller) } \\
\text { Taylor (1774- } \\
1846)^{52}\end{array}$ & Quilt, 1824; 50 & Savannah, GA & $\begin{array}{l}\text { William Taylor (b. } \\
\text { 1822) }\end{array}$ & Grandson & Unspecified \\
\hline $\begin{array}{l}\text { Mary (Betsy) Totten } \\
\text { Polhemus Williams } \\
(1781-1861)^{53}\end{array}$ & $\begin{array}{l}\text { Quilt, circa 1830; } \\
\text { about } 49\end{array}$ & $\begin{array}{l}\text { Staten Island, } \\
\text { NY }\end{array}$ & $\begin{array}{l}\text { Rachel Mary Drake } \\
\text { (b. 1833) }\end{array}$ & Great-niece & Bequest \\
\hline $\begin{array}{l}\text { Mary (Betsy) Totten } \\
\text { Polhemus Williams } \\
(1781-1861)^{54}\end{array}$ & Quilt, 1835; 54 & $\begin{array}{l}\text { Staten Island, } \\
\text { NY }\end{array}$ & $\begin{array}{l}\text { Mary Ann Johnson } \\
\text { Dubois (b. 1807) }\end{array}$ & Niece & Marriage \\
\hline $\begin{array}{l}\text { Henrietta Frances } \\
\text { (Edwards) Whitney } \\
(1786-1870)^{55}\end{array}$ & Quilt, 1849; 63 & New Haven, CT & $\begin{array}{l}\text { Susan Huntington } \\
\text { Whitney (b. 1849) }\end{array}$ & Granddaughter & Birth \\
\hline
\end{tabular}

\footnotetext{
${ }^{50}$ The quilt is now in a private collection; it is illustrated in Bets Ramsey and Merikay Waldvogel, Southern Quilts: Surviving Relics of the Civil War (Nashville: Rutledge Hill Press, 1998), 59.

${ }^{51}$ Collection of the New-York Historical Society, New York, New York.

${ }^{52}$ Now in the collection of the Telfair Museum of Art; the quilt is illustrated in Weinraub, ed., Georgia Quilts, 50.

${ }^{53}$ Collection of the Smithsonian Institution, Washington, DC. Illustrated in Bowman, American Quilts, 28.

${ }^{54}$ Collection of the Staten Island Historical Society, Staten Island, New York.

${ }^{55}$ Collection of the New Haven Colony Historical Society, New Haven, Connecticut. Illustrated in Quilts and Quiltmakers: Covering Connecticut, 43.
} 


\section{CONCLUSION}

\section{A STITCH IN TIME}

Around 1855, seventy-one-year-old Rhoda Warner of Painesville, Ohio, stitched an elaborate quilt, which she titled Heroes of the Revolution (figure C.1). ${ }^{1}$ Born around 1784, just as the Revolutionary War came to an end, Warner later used her needle to make a number of historical references on her quilt, pulling together her eighteenthcentury girlhood with her mid-nineteenth-century old age. The central section includes thirteen circles, each around a thirteen-point star, symbolizing the original thirteen colonies. At the top, there is the American symbol of an eagle. Forming a border around the central group of thirteen stars is a chain of embroidered names. Each signer of the Declaration of Independence is included in this chain. A cloth hand pinned to the quilt points to "J. Witherspoon" and "R. Stockton" in the circle of Declaration signers (figure C.2). ${ }^{2}$

Like Amy Fiske and many of the women discussed in these pages, Warner used her needlework to serve multiple purposes: to comment on the events of her life, to provide a reminder of herself for generations to come, to show pride in her work, to express and reflect nostalgia for the past, and to adapt to the changes taking place around her by using a medium that was comfortable for her. Exploring this last example of needlework by an aging antebellum American woman provides a review of the themes

\footnotetext{
${ }^{1}$ The quilt is now in the collection of the Buffalo and Erie County Historical Society, Buffalo, New York. ${ }^{2}$ Lynn T. Hoffman, Patterns In Time: Quilts of Western New York (Buffalo, NY: Buffalo and Erie County Historical Society, 1990), 23. Quilt historian Ricky Clark points out that newspapers of the time used similar hands to draw readers' attention to items of particular interest. Pin holes in the hand fabric suggest that it has been moved and may have had an educational purpose with the flexibility to point to sayings or signers as appropriate. Ricky Clark, ed., Quilts In Community: Ohio's Traditions (Nashville: Rutledge Hill Press, 1991), 142.
} 


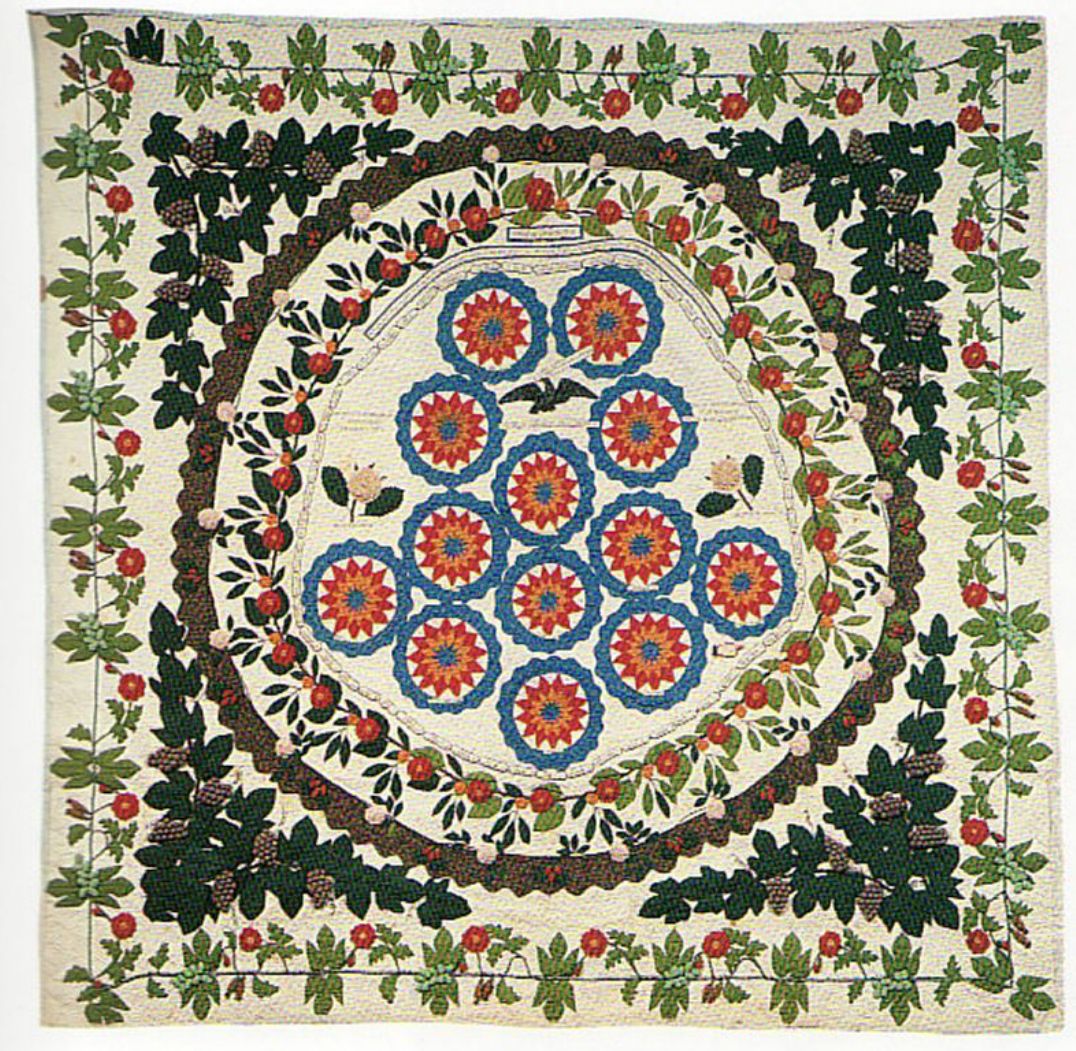

Figure C.1. Heroes of the Revolution quilt by Rhoda Warner (b. 1784), 1855, Painesville, Ohio. Courtesy of the Buffalo and Erie County Historical Society, Buffalo, New York.

Just like Amy Fiske's sampler, discussed in the Introduction, Rhoda Warner created a quilt that told a story about herself. Born just after the Revolutionary War, Warner experienced the development of the new nation. And, as she made her quilt, she witnessed the growing tensions between North and South. In addition to the political content in her quilt, Warner showed off her needlework skill, employing six different techniques, instead of just two or three. 


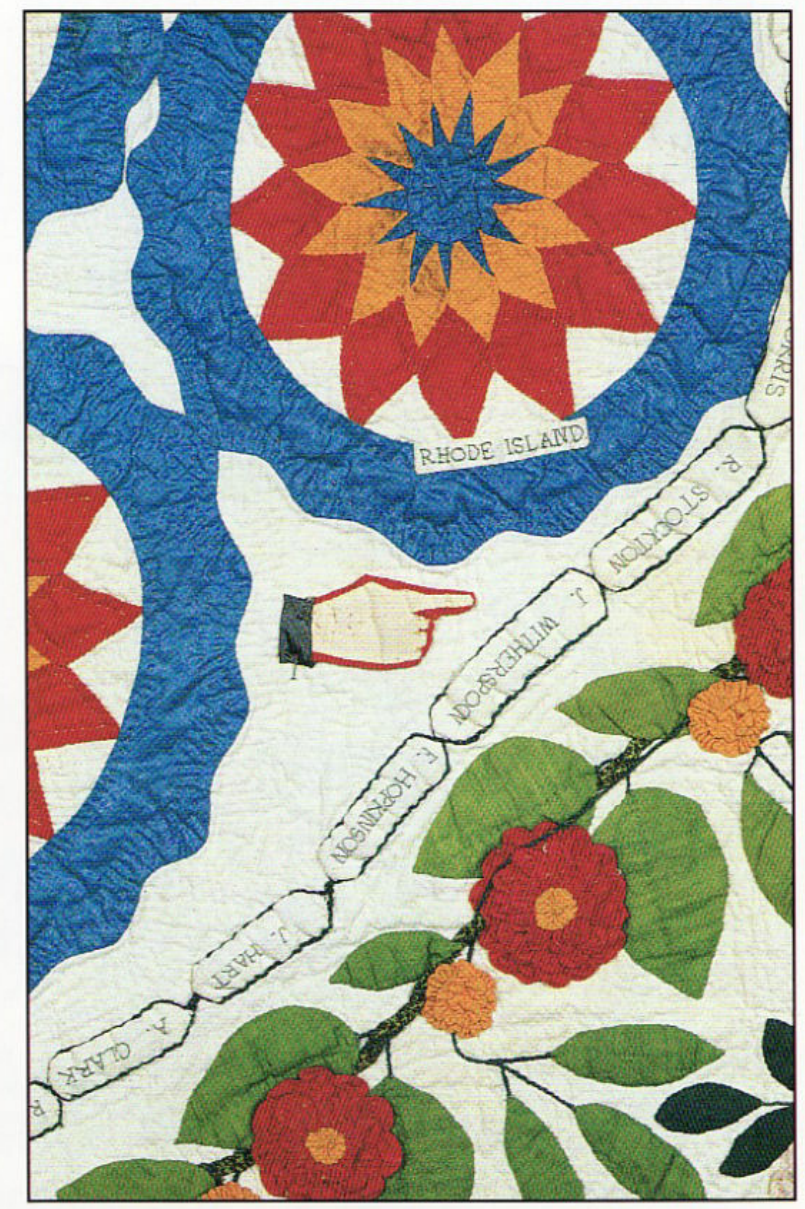

Figure C.2. Detail from Heroes of the Revolution quilt by Rhoda Warner. 
covered in these pages, while also reinforcing the value that needlework made by mature women holds for historians.

An 1844 needlework guide offered a lofty view of why its readers should pick up their needles:

We have a higher end in view than promoting the acquisition of accomplishments, however elegant and pleasing. We wish to direct the minds of those we are thus endeavoring to interest and instruct, to the immortal beauties of moral excellence. These works may be made conducive...to the development of family affection, and the promotion... of the purposes of genuine charity, benevolence and friendship. But there is yet a higher kind of use to which we would apply them... [the lady's] work, and the power and skill to plan and execute it, are emanations of the immortal mind. ${ }^{3}$

The benefits of needlework for women of all ages were constantly being transmitted, socially and culturally, through books, magazines, sermons and the needlework itself. And, as many of the examples illustrated here demonstrate, women continued to pursue values of industry, skill, hard work and motherly affection as they aged, often despite failing eyesight or achy joints. But these same objects were not made in cookie-cutter fashion - or made as an end in themselves - in order to keep aging fingers occupied. Example after example in the preceding chapters offered a way for their makers to express themselves, serving as a means to many different ends.

Indeed, aging women stitched for many of the same reasons that younger women did - to show their skill and to express themselves or to be creative. But, the context for the work of younger women was inherently different, offering potential for a future comparative study. Aging women had their own experiences that affected their work: changes in their bodies and minds; an increasing nostalgia for the past; memories to reflect on and remember, which were portrayed in their quilts and samplers. An older

\footnotetext{
${ }^{3}$ The Ladies' Hand-Book of Knitting, Netting, and Crochet (New York: J. Redfield, 1844), 56.
} 
woman, in her fifties or sixties, often had more time to devote to her needlework because her child-rearing duties were over and because she had built up more skill over the decades, affecting the kind of work she could do.

As discussed in chapter 1, needlework was considered an ideal activity for aging women - socially sanctioned, morally uplifting, and enjoyable. As women reached their forties and fifties, coinciding with the arrival of menopause, many found themselves happy to be freed from the cycles of menstruation and childbirth. Antebellum sources suggest that although women were considered "old" as they reached menopause, the women themselves often embraced this part of their lives by pursuing new and old hobbies, while doting on grandchildren and expressing their creativity with their needles. A close look at the quilt made by Rhoda Warner in 1855 helps to illustrate the conscious choices that many aging women made as they put needle to cloth. Warner's quilt shows that she was capable of incredibly detailed and skilled needlework, suggests that she took pride in her work, and that she used her needle to express her opinions and earn some money. A handwritten label that was once attached to the quilt tells its story: “This revolutionary Quilt containes 2404 Pieces / 57 names, 80 words, 1063 Letters of needlework / By Mrs. Rhoda Warner Aged 71 Years of Painesville Ohio / Sept. 1. 1855 This Quilt for Sale."4

Women like Amy Fiske and Rhoda Warner did not leave diaries or collections of letters that tell us about their lives. Instead, their needlework tells their life story. Both women, along with several others in these pages, stitched objects that trace the stages of their lives. As discussed in chapter 2, biographical and epistolary needlework offers a new category for items previously locked into a binary equation - decorative versus

\footnotetext{
${ }^{4}$ Clark, ed., Quilts In Community, 142.
} 
functional. The biographical objects shown here serve both purposes and more. They were meant to be ornamental, but they also served an important function for their makers - and continue to be useful today.

Warner's quilt is biographical, telling her own story, as well as the story of her nation. While employing a layout typical of the 1850s, Warner used eighteenth-century content to give her design meaning, thus bringing together her youth with her old age in one quilt. The stars in the center represent the original thirteen colonies, each one has an embroidered label stitched at the bottom with the name of a state. ${ }^{5}$ Likewise, as mentioned above, the names of the signers of the Declaration form a border around the center. An American eagle holds a prominent place at top center and has a banner in its beak reading, "O Washington Live Forever." As a fifteen-year-old girl in 1799, Warner would have had lasting memories of the public mourning of the first President's death. This phrase was used in at least one eulogy for Washington, which was delivered on February 22, 1800, before the New York State Society of the Cincinnati, and was later published. ${ }^{6}$ Still another verse, "The British King Lost States Thirteen," appeared in a primer that went through 450 editions by $1830 .^{7}$ It is possible that Warner had known this verse for more than sixty years before incorporating it into her quilt.

Another eighteenth-century element of Warner's quilt is evident from the wide variety of techniques she employed to put it together, all skills that she would have learned as a girl in the 1780s and 1790s, as she prepared to manage a household of her

\footnotetext{
${ }^{5}$ Clark, ed., Quilts In Community, 142.

${ }^{6}$ Eulogy delivered February 22, 1800 by Hon. Jeremiah Smith for the New York State Society of the Cincinnati. See Eulogies and Orations on the Life and Death of General George Washington, First President of the United States of America (Boston: printed by Manning and Loring, 1800), 168.

${ }^{7}$ Samuel J. Smith, "New England Primer," http://digitalcommons.liberty.edu/educ fac pubs/100; accessed October 19, 2008.
} 
own after marriage. While many quilts show two or three skills at most, for example, piecing and quilting or appliqué and quilting, Warner's quilt includes six: piecing, appliqué, quilting, embroidery, ruching, and stuffed work. The data provided on the quilt's label - the numbers of pieces, words, names, and letters - suggests the pride that Warner took in her work. She was the one who would have kept track of these numbers and decided to include them on the label.

Indeed, the existence of the label suggests that the quilt was on public display around September 1855. Warner, like the women discussed in chapter 3, undoubtedly enjoyed the attention her work received at the local agricultural fair. The displays of needlework at American fairs offered inspiration to the female community, while also setting the style and defining local fashions. For aging antebellum women, who were watching textile tasks become increasingly industrialized, and the work of the home become devalued, agricultural fairs offered recognition of their skill. These venues provided not only an outlet for their pride in their work, but also a place where they could offer a model to the younger generations and show their mastery of technological innovations, such as cylinder-printed fabrics, indelible inks and the sewing machine.

Records of a local agricultural fair demonstrate that Warner was no stranger to submitting her work for public judgment. In 1854, she exhibited a quilt at her local county fair. The newspaper described that quilt as "the most accomplished piece of ladies' work on exhibition." " Two years later, in 1856, Warner exhibited her Heroes of the Revolution quilt at the county fair, where a reporter described it:

A "revolutionary quilt" hung nearby, the name of which awakened inquiry. Its workmanship was not remarkable. But it was made by a lady seventy years old,

\footnotetext{
${ }^{8}$ Quoted in Clark, ed., Quilts In Community, 143. Details about this quilt, such as the style and pattern, are unknown.
} 
and embraced the names of nearly all the lovers of Independence, and Revolutionary times. It was made up of 2,404 pieces. The patriotic feelings and patient industry of which it is the result, are worthy of praise. ${ }^{9}$

While the presumably male reporter considered the workmanship "not remarkable," the judges saw otherwise, awarding Warner a diploma and a $\$ 3$ premium for the best "worked quilt."10 The reporter pointed to "patriotic feelings and patient industry" as being worthy of praise. His comments suggest the cultural backdrop that aging antebellum women stitched against. Their culture encouraged them to show proper virtues of industry and patriotism and to serve as an example for the young. Women like Warner could do this with their needles, while also manipulating their stitches to their own ends without attracting negative attention.

Although Warner did not leave any written evidence about her motivation to make her quilt, its subject matter does suggest a political viewpoint, which can be understood by looking at national issues in 1855. Throughout the 1840s and 1850s, the abolition movement gained strength, particularly in Warner's home state of Ohio. On May 30, 1854, the Kansas-Nebraska Act was signed into law, repealing the Missouri Compromise of 1820 and reopening the question of slavery in the West. For the next two

\footnotetext{
${ }^{9}$ Newspaper account quoted in $11^{\text {th }}$ Annual Report of the Board of Agriculture of the State of Ohio: To the Governor for the Year 1856 (Columbus: Richard Nevins, 1857), 163. The quilt was sold in 1856 to Dr. Charles Lewis Stockton (1816-1874), a descendant of Richard Stockton (1730-1781) who signed the Declaration of Independence and whose name appears on the quilt. Dr. Stockton's grandson and granddaughter-in-law donated the quilt to the Buffalo and Erie County Historical Society in 1924. Hoffman, Patterns In Time, 22-23.

${ }^{10} 11^{\text {th }}$ Annual Report of the Board of Agriculture of the State of Ohio, 121. Warner's quilt seems to have offered inspiration to other local quiltmakers. A quilt, known as the "Garden of Eden" quilt, and attributed to Olive Batchelor Wells (1822-1873) of Painesville, Ohio, shows strong similarities to Warner's quilt. Wells's quilt was also exhibited at the 1856 Lake County Fair. Like Warner's quilt it depicts realisticlooking fruit and flowers that are stuffed and ruched; it employs the same type of embroidered labels; it uses the same "type-face" for the embroidery; and it has the same type of hand pointing to text on the quilt. In addition to the fact that both women showed their work at the local agricultural fair, they seem to have had a personal relationship. According to the 1860 U.S. Census, Rhoda Warner lived with a relative of Olive Wells's husband. See Clark, ed., Quilts In Community, 143. The Wells quilt is now in the collection of the Spencer Museum of Art at the University of Kansas, Lawrence, Kansas.
} 
years, guerilla warfare continued between pro-slavery and anti-slavery settlers in Kansas as they fought over whether Kansas would be a slave state or not. ${ }^{11}$

The southern states saw parallels between their situation in 1855 and that of the original thirteen colonies in the 1760 s and 1770s. One of the embroidered mottos included on Warner's quilt reads, “The British King Lost States Thirteen.” More than simply a historical statement or a verse drawn from her schoolgirl days, this may be a reference to the threatened loss of the slave states during the 1850s.

For Warner, raised with the model of George Washington ever-present, President Franklin Pierce (1804-1869) may have seemed a weak statesman, unable to resolve the growing national divide over the question of slavery. ${ }^{12}$ One of Warner's verses in the quilt can be read as a critique of Pierce and 1855 politics: "May our political horizons glow with truth and the nation learn righteousness." 13 With this verse, Warner seems to be advocating for the abolition of slavery.

By gathering together the names of the heroes of the Revolution, Warner may have been trying, in her own way, to hold on to the union before it crumbled. "Our fathers fought and bled and died for our liberty," she stitched, "How dear how sweet." The first part of this phrase appeared in the Congressional Record in 1837, referring to gains that had been made with the Revolution. And, the records of the Continental Congress, which had been published complete with confidential sections in 1821, include the following from September 1774: "it is an indispensable duty which we owe to God, our country, ourselves and posterity, by all lawful ways and means in our power to

\footnotetext{
11 "Key Events in the Presidency of Franklin Pierce," http://millercenter.org/academic/americanpresident/keyevents/pierce; accessed March 20, 2009.

12 "Franklin Pierce," http://millercenter.org/academic/americanpresident/pierce/essays/biography; accessed March 20, 2009.

${ }^{13}$ I have been unable to track down any pre-1855 sources for this verse.
} 
maintain, defend and preserve those civil rights and religious rights and liberties, for which many of our fathers fought, bled and died, and to hand them down entire to future generations."14 Unfortunately, the records documenting this quilt - its label and the agricultural fair records - refer only to Warner's married name and we are unable to trace whether her father fought in the Revolutionary War, which would add yet another layer of resonance to the words she stitched into her quilt as she grew older.

Regardless of her personal attachments to the Revolutionary War and its soldiers, Warner's choice of this verse suggests a desire to remember the heroes and values of the past. She wanted others to remember what the founders fought for, just as she had remembered. Her choice to include the list of the signers of the Declaration of Independence is symbolic. While interest in the Declaration had last peaked in 1826, its fiftieth anniversary, she may also have seen newspaper stories about the death of the last signer in $1832 .{ }^{15}$ During the 1820 s, commemorative versions of the Declaration were produced and sold to be framed and hung in parlors. While Warner's source for her list of signers is unknown, she would have had access to these prints and to books of American history, which included the names of the signers. By the 1850s, the Declaration was once again attracting notice as both the North and the South used it for propaganda to support their political views. ${ }^{16}$

\footnotetext{
${ }^{14}$ Journals of the Continental Congress, volume 1, September 1774, accessed at http://memory.loc.gov on June 18, 2009. See also “The Gallery of a Misanthrope," The American Monthly Magazine 5 (1835): 338, which includes the sentence, "'Twas for Liberty our fathers fought, and bled, and died."

${ }^{15}$ Michael Kammen, A Season of Youth: The American Revolution and the Historical Imagination (Ithaca: Cornell University Press, 1988), 46, 49. Charles Carroll (1737-1832) of Maryland was the last surviving signer of the Declaration of Independence. He died in Baltimore on November 14, 1832. See http://bioguide.congress.gov/scripts/biodisplay.pl?index $=\mathrm{C} 000185$, accessed November 21, 2009. The news of Carroll's death appeared in the Columbus, Ohio newspaper, the Ohio State Journal, on December 1, 1832. Presumably, it also appeared in other Ohio newspapers around the same time.

${ }^{16}$ Kammen, A Season of Youth, 55-58; Pauline Maier, American Scripture: Making the Declaration of Independence (New York: Alfred A. Knopf, 1997), 175-180, 189-201.
} 
Rhoda Warner's quilt, Amy Fiske's sampler, and the other objects featured here eloquently express the importance of the study of material culture. Scholar Sherry Turkle would call them "evocative objects," objects that serve as "companions to our emotional lives or as provocations to thought." ${ }^{17}$ She also believes that "objects have life roles that are multiple and fluid." ${ }^{18}$ Indeed, this is why the consideration of age as a category of analysis is important. As the bodies, minds and lifestyles of aging antebellum women changed, so did their needlework, reflecting their experiences new and old, their wisdom learned, and even the effects of their aching fingers or blurring vision. Rhoda Warner's quilt is a fitting closing example of all of these points and it represents the themes discussed in each chapter. Her descriptive label, which includes her age, demonstrates that many antebellum women were conscious of their age, whether they embraced it and grew old gracefully, or worked to hide it.

Like the biographical needlework in chapter 2, Warner's quilt brings together the years of her childhood with those of her maturity. Her quilt commemorates the new country just being formed when she was born and comments on the growing pains of the nation as the question of slavery took center stage. As with several examples in chapter 3, Warner entered her quilt in a local agricultural fair, demonstrating her skill, expressing her pride and perhaps exhorting the younger generations not to forget those who came before. While she did not make her quilt a gift, like those described in chapter 4 , she still used it to leave a lasting mark. Warner's quilt is a gift to us today, as are all of the objects examined here - allowing us to admire their workmanship, creativity and skill, to

\footnotetext{
${ }^{17}$ Sherry Turkle, ed., Evocative Objects: Things We Think With (Cambridge, Massachusetts: The MIT Press, 2007), 5.

${ }^{18}$ Turkle, Evocative Objects, 6.
} 
remember the past, and to learn more about the comparisons and contrasts between then and now.

Just because a woman married, gave birth, or reached menopause, her needlework did not remain static ever after. The types of items that she stitched, how they looked and how she intended them to be used continued to change and evolve. The study of women's needlework must also continue to evolve. Concerted efforts to fully identify the makers of the thousands of quilts, samplers and other decorative needlework in museum collections across the country are needed. With the rise of the internet, the sources to verify family stories are virtually at the fingertips of historians, researchers and museum curators. This will be slow work, but the rewards are worth it. And, this is not only true for needlework made during the antebellum decades. As American society changed after the Civil War and into the twentieth century, the ways that women used their needles also changed. Additional study of this later time period would offer a fruitful comparison.

In 1854, Eliza Leslie offered a hopeful goal to all aging antebellum women. "As long as she lives and retains her faculties," Leslie wrote, the antebellum woman "will endeavour to improve, and to become still a wiser and a better woman; never excusing herself by indolently and obstinately averring that "she is too old to learn," or that she cannot give up her old-fashioned habits... No one with a mind unimpaired, and a heart still fresh, is too old to learn."19 The women described here followed this advice - and left their needlework behind to continue the cycle. Every time we look at their quilts and samplers, we are learning again, improving our own lives and carrying the threads of time forward.

\footnotetext{
${ }^{19}$ Eliza Leslie, The Behaviour Book: A Manual for Ladies (Philadelphia: Willis P. Hazard, 1854), 336.
} 


\section{APPENDIX}

\section{METHODOLOGICAL NOTE DECORATIVE NEEDLEWORK MADE BY WOMEN FORTY AND OVER BETWEEN 1820 AND 1860}

- Initially I made several choices to define the needlework that would be appropriate for this study. The objects in the appendix fit the following criteria:

○ They are "decorative" rather than primarily functional household textiles or clothing

- They are attributed to a single maker (or were initially made by one person, but may have been subsequently altered by someone else)

- They have an identified female maker and at least a rough origin date

- The maker can be determined to have been forty or older when the object was made; or the object was altered at some later point (i.e., samplers with the date picked out, family records with death dates added)

- The origin date for the object is between 1820 and 1860

- The object is of American origin, but no regional or local geographical constraints were applied

- Once I defined the types of objects I was looking for, I sent an initial query to 212 American museums asking for information on their holdings that fit the above criteria. I received responses from 124 institutions. Twenty-five had no useful objects while ninety-nine sent me information on their needlework holdings. I followed up on all of these responses after reviewing the material sent, focusing on objects that would fit my criteria.

- I made site visits to sixteen museums/historical societies, all of which had items that are listed in the appendix. During these visits, I physically examined as many appropriate objects as possible, making notes and doing research on site. The sites I visited were:

- Old Sturbridge Village, Sturbridge, Massachusetts

- Historic New England, Haverhill, Massachusetts

○ Litchfield Historical Society, Litchfield, Connecticut

- American Folk Art Museum, New York, New York

○ New-York Historical Society, New York, New York

○ Cooper Hewitt, New York, New York

- Metropolitan Museum, New York, New York

- Nantucket Historical Association, Nantucket, Massachusetts

- Daughters of the American Revolution Museum, Washington, DC

- Winterthur Museum and Country Estate, Winterthur, Delaware

- Chester County Historical Society, West Chester, Pennsylvania

○ Concord Museum, Concord, Massachusetts

- Peabody Essex Museum, Salem, Massachusetts

- Slater Mill Historic Site, Pawtucket, Rhode Island

- Historic Deerfield, Deerfield, Massachusetts

- Wadsworth Atheneum, Hartford, Connecticut 
- National Museum of American History, Smithsonian Institution, Washington, DC

- During a trip to Winterthur Museum and Country Estate, I also spent two days in their Library looking at their holdings of needlework catalogs (primarily quilt and sampler catalogs, since the most work has been done on these types of objects). I made notes about all of the items I found in the catalogs that fit my criteria many of these items are listed in the appendix.

- Over the course of the project, I reviewed major auction catalogs and the antiques trade newspapers (Art and Antiques Weekly; Maine Antique Digest) regularly, making notes of any appropriate objects. I have also been sent references from colleagues in the museum and antiques trades.

- As I found objects that looked promising, I did genealogical and historical research to verify the maker's life dates and to build context about the maker and her family. Objects with strong supporting evidence, that told an interesting story and offered analytical potential were integrated into the thematic chapters.

- The Appendix lists 167 objects made by 144 makers.

- Age Breakdown:

- Objects made by woman in her forties: 42

- Objects made by woman in her fifties: 31

- Objects made by woman in her sixties: 29

- Objects made by woman in her seventies: 4

- Objects made by woman in her eighties: 2

- Objects made by woman of unknown specific age: 59

- Origin Location Breakdown:

- Objects made in New England: 42

- Objects made in the Mid-Atlantic: 40

- Objects made in the South: 47

- Objects made in the Mid-West: 20

- Objects made in the West: 2

- Unknown Origin Location: 16

○ Date of Origin Breakdown:

- Objects made in the 1820s: 23

- Objects made in the 1830s: 26

- Objects made in the 1840s: 31

- Objects made in the 1850s: 47

- Objects with no specific date or started pre-1820: 40 


\section{APPENDIX. Decorative Needlework Made by Women Forty and Over between 1820 and 1860}

\begin{tabular}{|c|c|c|c|c|c|c|}
\hline Name (Life Dates) & $\begin{array}{l}\text { Artifact } \\
\text { Type }\end{array}$ & $\begin{array}{l}\text { Artifact } \\
\text { Date }\end{array}$ & Place Made & $\begin{array}{l}\text { Age When } \\
\text { Made }\end{array}$ & $\begin{array}{l}\text { Reason for } \\
\text { Inclusion }\end{array}$ & Current Owner \\
\hline $\begin{array}{l}\text { Susanna Jaquith } \\
\text { Abbott (1797-1896) }\end{array}$ & Quilt & Circa 1846 & Bedford, MA & Circa 49 & $\begin{array}{l}\text { Made by woman } 40 \\
\text { and over }\end{array}$ & $\begin{array}{l}\text { Historic New } \\
\text { England }\end{array}$ \\
\hline $\begin{array}{l}\text { Lura Clapp Allen (b. } \\
\text { 1791) }\end{array}$ & Quilt & 1851 & North Hero, VT & 60 & $\begin{array}{l}\text { Made by woman } 40 \\
\text { and over }\end{array}$ & Private Collection \\
\hline $\begin{array}{l}\text { Sarah L. Art (1793- } \\
\text { 1875) }\end{array}$ & Sampler & 1806 & Lewes, DE & 13 & Picked out sampler & Winterthur \\
\hline Martha Jane Avery & Sampler & & & & Picked out sampler & $\begin{array}{l}\text { Historic New } \\
\text { England }\end{array}$ \\
\hline $\begin{array}{l}\text { Elizabeth Benton } \\
\text { Boyles Bagley (b. } \\
1815 \text { ) }\end{array}$ & Quilt & 1860 & Fayetteville, TN & 45 & $\begin{array}{l}\text { Made by woman } 40 \\
\text { and over }\end{array}$ & Private Collection \\
\hline $\begin{array}{l}\text { Abigail Barnard } \\
(1806-1886)\end{array}$ & Sampler & 1833 & Pittsfield, MA & 27 & $\begin{array}{l}\text { Filled in family } \\
\text { record }\end{array}$ & $\begin{array}{l}\text { Cooper-Hewitt } \\
\text { Museum }\end{array}$ \\
\hline $\begin{array}{l}\text { Maria Barnard } \\
(1803-1864)\end{array}$ & Sampler & Circa 1830 & Pittsfield, MA & Circa 27 & $\begin{array}{l}\text { Filled in family } \\
\text { record }\end{array}$ & Private Collection \\
\hline $\begin{array}{l}\text { Deborah Barnes (b. } \\
1790)\end{array}$ & Quilt & 1851 & Baltimore, MD & 61 & $\begin{array}{l}\text { Made by woman } 40 \\
\text { and over }\end{array}$ & $\begin{array}{l}\text { Herbert F. Johnson } \\
\text { Museum of Art }\end{array}$ \\
\hline $\begin{array}{l}\text { Eliza Macy Howland } \\
\text { Barney (1783-1867) }\end{array}$ & Quilt & Circa 1830 & $\begin{array}{l}\text { New Bedford, } \\
\text { MA }\end{array}$ & Circa 47 & $\begin{array}{l}\text { Made by woman } 40 \\
\text { and over }\end{array}$ & Historic Deerfield \\
\hline $\begin{array}{l}\text { Mrs. C. Bartlett (b. } \\
\text { 1797) }\end{array}$ & Quilt & 1860 & & 63 & $\begin{array}{l}\text { Made by woman } 40 \\
\text { and over }\end{array}$ & Private Collection \\
\hline $\begin{array}{l}\text { Nancy Miller } \\
\text { Benson (1809-1879) }\end{array}$ & Quilt & Circa 1850 & Spartanburg, SC & Circa 41 & $\begin{array}{l}\text { Made by woman } 40 \\
\text { and over }\end{array}$ & $\begin{array}{l}\text { Mary Black } \\
\text { Foundation }\end{array}$ \\
\hline Sarah Berry & Sampler & Circa 1820 & & 13 & Picked out sampler & Private Collection \\
\hline $\begin{array}{l}\text { Charlotte Jackson } \\
\text { Blackman (b. 1790) }\end{array}$ & Sampler & 1831 & $\begin{array}{l}\text { Washington } \\
\text { County, IN }\end{array}$ & 41 & $\begin{array}{l}\text { Made by woman } 40 \\
\text { and over }\end{array}$ & DAR Museum \\
\hline
\end{tabular}




\begin{tabular}{|c|c|c|c|c|c|c|}
\hline $\begin{array}{l}\text { Harriet Woodward } \\
\text { Dorsey Blunt (1794- } \\
1862)\end{array}$ & Quilt & 1852 & Woodborne, MD & 58 & $\begin{array}{l}\text { Made by woman } 40 \\
\text { and over }\end{array}$ & $\begin{array}{l}\text { Montgomery } \\
\text { County Historical } \\
\text { Society }\end{array}$ \\
\hline $\begin{array}{l}\text { Ann G. Hitchcock } \\
\text { Boker (b. ca. 1803) }\end{array}$ & Quilt & 1860 & $\begin{array}{l}\text { Lower } \\
\text { Chichester, PA }\end{array}$ & Circa 57 & $\begin{array}{l}\text { Made by woman } 40 \\
\text { and over }\end{array}$ & Winterthur \\
\hline $\begin{array}{l}\text { Eveline Borden (b. } \\
\text { 1816) }\end{array}$ & Sampler & $182 ?$ & Tiverton, MA & & Picked out sampler & Private Collection \\
\hline $\begin{array}{l}\text { Catharine Ann } \\
\text { Penniman Bradford } \\
(1778-1827)\end{array}$ & Quilt & 1825 & Boston, MA & 47 & $\begin{array}{l}\text { Made by woman } 40 \\
\text { and over }\end{array}$ & Private Collection \\
\hline Henrietta Bradford & Sampler & $18 ? 3$ & MA & & Picked out sampler & Unknown \\
\hline $\begin{array}{l}\text { Sarah M. Bradford } \\
(1813-1848)\end{array}$ & Sampler & 1832 & Cornwall, CT & 19 & $\begin{array}{l}\text { Filled in family } \\
\text { record }\end{array}$ & $\begin{array}{l}\text { Old Sturbridge } \\
\text { Village }\end{array}$ \\
\hline $\begin{array}{l}\text { Susanna Brewer } \\
(1764-1855)\end{array}$ & Quilt & Circa 1830 & MA & Circa 66 & $\begin{array}{l}\text { Made by woman } 40 \\
\text { and over }\end{array}$ & Private Collection \\
\hline Sarah Stanley Brown & Sampler & $\begin{array}{l}\text { Circa 1820- } \\
1830\end{array}$ & Honeybrook, PA & & Picked out sampler & Private Collection \\
\hline $\begin{array}{l}\text { Nancy Ward Butler } \\
(1779-1863)\end{array}$ & Quilt & 1842 & Jamestown, NY & 63 & $\begin{array}{l}\text { Made by woman } 40 \\
\text { and over }\end{array}$ & $\begin{array}{l}\text { Smithsonian } \\
\text { Institution }\end{array}$ \\
\hline $\begin{array}{l}\text { Nancy Ward Butler } \\
(1779-1863)\end{array}$ & Quilt & 1845 & NY & 66 & $\begin{array}{l}\text { Made by woman } 40 \\
\text { and over }\end{array}$ & McClurg Museum \\
\hline $\begin{array}{l}\text { Lucretia Buttrick } \\
(1801-1892)\end{array}$ & Sampler & & Concord, MA & & Picked out sampler & Concord Museum \\
\hline $\begin{array}{l}\text { Azubah G. Capen } \\
(1814-1837)\end{array}$ & Sampler & 1824-1837 & Stoughton, MA & $10-23$ & $\begin{array}{l}\text { Filled in family } \\
\text { record }\end{array}$ & $\begin{array}{l}\text { Old Sturbridge } \\
\text { Village }\end{array}$ \\
\hline $\begin{array}{l}\text { Mary McElwain } \\
\text { Chenoweth (1815- } \\
\text { 1897) }\end{array}$ & Quilt & 1860 & $\begin{array}{l}\text { Webster County, } \\
\text { MO }\end{array}$ & 45 & $\begin{array}{l}\text { Made by woman } 40 \\
\text { and over }\end{array}$ & Private Collection \\
\hline $\begin{array}{l}\text { Adeline Eliza Clark } \\
\text { (b. 1818) }\end{array}$ & Sampler & Circa 1830 & Schenectady, NY & Circa 12 & Picked out sampler & Private Collection \\
\hline
\end{tabular}




\begin{tabular}{|c|c|c|c|c|c|c|}
\hline $\begin{array}{l}\text { Elizabeth Van Horne } \\
\text { Clarkson (1771- } \\
\text { 1852) }\end{array}$ & Quilt & Circa 1830 & New York, NY & Circa 59 & $\begin{array}{l}\text { Made by woman } 40 \\
\text { and over }\end{array}$ & $\begin{array}{l}\text { Metropolitan } \\
\text { Museum }\end{array}$ \\
\hline $\begin{array}{l}\text { Lucy Hiller } \\
\text { Cleveland (1780- } \\
1866)\end{array}$ & $\begin{array}{l}\text { Fabric } \\
\text { Sculptures }\end{array}$ & $1831-1866$ & Salem, MA & $51-86$ & $\begin{array}{l}\text { Made by woman } 40 \\
\text { and over }\end{array}$ & $\begin{array}{l}\text { Peabody Essex } \\
\text { Museum }\end{array}$ \\
\hline $\begin{array}{l}\text { Mary Conger (1808- } \\
1888)\end{array}$ & Quilt & 1858 & Casey, IL & 50 & $\begin{array}{l}\text { Made by woman } 40 \\
\text { and over }\end{array}$ & Private Collection \\
\hline $\begin{array}{l}\text { Julia Stevens Crosby } \\
(1798-1879)\end{array}$ & Quilt & Circa 1860 & $\begin{array}{l}\text { East Hardwick, } \\
\text { VT }\end{array}$ & Circa 62 & $\begin{array}{l}\text { Made by woman } 40 \\
\text { and over }\end{array}$ & Private Collection \\
\hline $\begin{array}{l}\text { Julia Stevens Crosby } \\
(1798-1879)\end{array}$ & Quilt & Circa 1860 & $\begin{array}{l}\text { East Hardwick, } \\
\text { VT }\end{array}$ & Circa 62 & $\begin{array}{l}\text { Made by woman } 40 \\
\text { and over }\end{array}$ & Private Collection \\
\hline $\begin{array}{l}\text { Ruth Pierce } \\
\text { Croswell (1765- } \\
1862)\end{array}$ & Sampler & 1827 & Catskill, NY & 63 & $\begin{array}{l}\text { Made by woman } 40 \\
\text { and over }\end{array}$ & $\begin{array}{l}\text { Litchfield } \\
\text { Historical Society }\end{array}$ \\
\hline $\begin{array}{l}\text { Margaret Boyce } \\
\text { Elliott (1800-1867) }\end{array}$ & Quilt & Circa 1843 & $\mathrm{MD}$ or $\mathrm{DE}$ & Circa 43 & $\begin{array}{l}\text { Made by woman } 40 \\
\text { and over }\end{array}$ & $\begin{array}{l}\text { Maryland } \\
\text { Historical Society }\end{array}$ \\
\hline $\begin{array}{l}\text { Mary W. Evans } \\
(1814-1888)\end{array}$ & Sampler & 1824 & Providence, RI & 10 & $\begin{array}{l}\text { Filled in family } \\
\text { record }\end{array}$ & Winterthur \\
\hline $\begin{array}{l}\text { Sarah Evans (1799- } \\
\text { 1871) }\end{array}$ & Quilt & 1854 & $\begin{array}{l}\text { Sugar Creek } \\
\text { Township, OH }\end{array}$ & 55 & $\begin{array}{l}\text { Made by woman } 40 \\
\text { and over }\end{array}$ & Private Collection \\
\hline $\begin{array}{l}\text { Tamson C. Evans } \\
\text { (poss. b. 1796) }\end{array}$ & Sampler & & Possibly VT & 11 & Picked out sampler & $\begin{array}{l}\text { Old Sturbridge } \\
\text { Village }\end{array}$ \\
\hline $\begin{array}{l}\text { Rebecca Fairchild } \\
\text { (b. 1773) }\end{array}$ & $\begin{array}{l}\text { Mourning } \\
\text { Picture }\end{array}$ & 1830 & New Milford, PA & 57 & $\begin{array}{l}\text { Made by woman } 40 \\
\text { and over }\end{array}$ & Private Collection \\
\hline $\begin{array}{l}\text { Frances Fales (1794- } \\
\text { 1824) }\end{array}$ & Sampler & 1807 & & 13 & $\begin{array}{l}\text { Filled in family } \\
\text { record }\end{array}$ & Private Collection \\
\hline $\begin{array}{l}\text { Amy Fiske (1785- } \\
1859)\end{array}$ & Sampler & 1852 & Sturbridge, MA & 66 & $\begin{array}{l}\text { Made by woman } 40 \\
\text { and over }\end{array}$ & $\begin{array}{l}\text { Old Sturbridge } \\
\text { Village }\end{array}$ \\
\hline Matilda Fiske (1784- & Quilt & $1825-1835$ & Sturbridge, MA & $41-51$ & Made by woman 40 & Old Sturbridge \\
\hline
\end{tabular}




\begin{tabular}{|c|c|c|c|c|c|c|}
\hline 1880) & & & & & and over & Village \\
\hline $\begin{array}{l}\text { Sarah A. Fitch } \\
(1800-1869)\end{array}$ & Quilt & Circa 1840 & Norwalk, CT & Circa 40 & $\begin{array}{l}\text { Made by woman } 40 \\
\text { and over }\end{array}$ & $\begin{array}{l}\text { Old Sturbridge } \\
\text { Village }\end{array}$ \\
\hline $\begin{array}{l}\text { Ann Maria Foltz (b. } \\
1820 \text { ) }\end{array}$ & Sampler & Circa 1830 & PA & Circa 10 & Picked out sampler & Private Collection \\
\hline $\begin{array}{l}\text { Hannah Warner } \\
\text { Forwood (1811- } \\
\text { 1886) }\end{array}$ & Quilt & 1854 & $\begin{array}{l}\text { Probably Kennett } \\
\text { Square, PA }\end{array}$ & 43 & $\begin{array}{l}\text { Made by woman } 40 \\
\text { and over }\end{array}$ & $\begin{array}{l}\text { Chester County } \\
\text { Historical Society }\end{array}$ \\
\hline $\begin{array}{l}\text { Anna Catherine } \\
\text { Hummel Markey } \\
\text { Garnhart (1773- } \\
1860 \text { ) }\end{array}$ & Quilt & Circa 1822 & Frederick, MD & Circa 49 & $\begin{array}{l}\text { Made by woman } 40 \\
\text { and over }\end{array}$ & $\begin{array}{l}\text { Plains Indians and } \\
\text { Pioneer Museum }\end{array}$ \\
\hline $\begin{array}{l}\text { Anna Catherine } \\
\text { Hummel Markey } \\
\text { Garnhart (1773- } \\
\text { 1860) }\end{array}$ & Quilt & Circa 1850 & Frederick, MD & Circa 77 & $\begin{array}{l}\text { Made by woman } 40 \\
\text { and over }\end{array}$ & DAR Museum \\
\hline $\begin{array}{l}\text { Anna Catherine } \\
\text { Hummel Markey } \\
\text { Garnhart (1773- } \\
1860 \text { ) }\end{array}$ & Quilt & Circa 1815 & Frederick, MD & Circa 42 & $\begin{array}{l}\text { Made by woman } 40 \\
\text { and over }\end{array}$ & DAR Museum \\
\hline $\begin{array}{l}\text { Anna Catherine } \\
\text { Hummel Markey } \\
\text { Garnhart (1773- } \\
\text { 1860) }\end{array}$ & Quilt & $1830-1845$ & Frederick, MD & $57-72$ & $\begin{array}{l}\text { Made by woman } 40 \\
\text { and over }\end{array}$ & Private Collection \\
\hline $\begin{array}{l}\text { Anna Catherine } \\
\text { Hummel Markey } \\
\text { Garnhart (1773- } \\
\text { 1860) }\end{array}$ & Quilt & $1835-1855$ & Frederick, MD & $62-82$ & $\begin{array}{l}\text { Made by woman } 40 \\
\text { and over }\end{array}$ & Private Collection \\
\hline $\begin{array}{l}\text { Anna Catherine } \\
\text { Hummel Markey }\end{array}$ & Quilt & $1835-1845$ & Frederick, MD & $62-72$ & $\begin{array}{l}\text { Made by woman } 40 \\
\text { and over }\end{array}$ & Private Collection \\
\hline
\end{tabular}




\begin{tabular}{|c|c|c|c|c|c|c|}
\hline $\begin{array}{l}\text { Garnhart (1773- } \\
\text { 1860) }\end{array}$ & & & & & & \\
\hline $\begin{array}{l}\text { Anna Catherine } \\
\text { Hummel Markey } \\
\text { Garnhart (1773- } \\
\text { 1860) }\end{array}$ & Quilt & $1820-1835$ & Frederick, MD & $47-62$ & $\begin{array}{l}\text { Made by woman } 40 \\
\text { and over }\end{array}$ & Private Collection \\
\hline $\begin{array}{l}\text { Anna Catherine } \\
\text { Hummel Markey } \\
\text { Garnhart (1773- } \\
1860 \text { ) }\end{array}$ & Quilt & Circa 1840 & Frederick, MD & Circa 67 & $\begin{array}{l}\text { Made by woman } 40 \\
\text { and over }\end{array}$ & Private Collection \\
\hline $\begin{array}{l}\text { Anna Catherine } \\
\text { Hummel Markey } \\
\text { Garnhart (1773- } \\
1860 \text { ) }\end{array}$ & Quilt & $1820-1840$ & Frederick, MD & $47-67$ & $\begin{array}{l}\text { Made by woman } 40 \\
\text { and over }\end{array}$ & Private Collection \\
\hline $\begin{array}{l}\text { Anna Catherine } \\
\text { Hummel Markey } \\
\text { Garnhart (1773- } \\
\text { 1860) }\end{array}$ & Quilt & $1820-1840$ & Frederick, MD & $47-67$ & $\begin{array}{l}\text { Made by woman } 40 \\
\text { and over }\end{array}$ & Private Collection \\
\hline $\begin{array}{l}\text { Anna Catherine } \\
\text { Hummel Markey } \\
\text { Garnhart (1773- } \\
1860 \text { ) }\end{array}$ & Quilt & $1825-1840$ & Frederick, MD & $52-67$ & $\begin{array}{l}\text { Made by woman } 40 \\
\text { and over }\end{array}$ & Private Collection \\
\hline $\begin{array}{l}\text { Submit Gay (1796- } \\
\text { 1880) }\end{array}$ & Quilt & 1842 & Simsbury, CT & 46 & $\begin{array}{l}\text { Made by woman } 40 \\
\text { and over }\end{array}$ & $\begin{array}{l}\text { Wadsworth } \\
\text { Atheneum }\end{array}$ \\
\hline $\begin{array}{l}\text { Rebecca Gladstone } \\
\text { (b. 1795) }\end{array}$ & Quilt & Circa 1841 & Baltimore, MD & Circa 46 & $\begin{array}{l}\text { Made by woman } 40 \\
\text { and over }\end{array}$ & DAR Museum \\
\hline Eliza Goddard & Sampler & $\begin{array}{l}\text { Possibly } \\
1813\end{array}$ & $\begin{array}{l}\text { Possibly Athol, } \\
\text { MA }\end{array}$ & 8 & Picked out sampler & $\begin{array}{l}\text { Old Sturbridge } \\
\text { Village }\end{array}$ \\
\hline $\begin{array}{l}\text { Sarah W. Gooch } \\
(1797-1856)\end{array}$ & Sampler & $1822-1849$ & $\mathrm{TN}$ & $25-52$ & $\begin{array}{l}\text { Filled in family } \\
\text { record }\end{array}$ & Private Collection \\
\hline
\end{tabular}




\begin{tabular}{|c|c|c|c|c|c|c|}
\hline $\begin{array}{l}\text { Abigail Reynolds } \\
\text { Greene (1794-1889) }\end{array}$ & Quilt & 1860 & $\begin{array}{l}\text { East Greenwich, } \\
\text { RI }\end{array}$ & 66 & $\begin{array}{l}\text { Made by woman } 40 \\
\text { and over }\end{array}$ & Private Collection \\
\hline $\begin{array}{l}\text { Marina Jones Gregg } \\
(1811-1899)\end{array}$ & Quilt & 1852 & Charleston, SC & 41 & $\begin{array}{l}\text { Made by woman } 40 \\
\text { and over }\end{array}$ & $\begin{array}{l}\text { Charleston } \\
\text { Museum }\end{array}$ \\
\hline $\begin{array}{l}\text { Catherine Babson } \\
\text { Griffin (1805-1834) }\end{array}$ & Sampler & 1818 & Gloucester, MA & 13 & $\begin{array}{l}\text { Filled in family } \\
\text { record }\end{array}$ & Private Collection \\
\hline Agnes Grubb & Sampler & 1825 & Mid-Atlantic & & Picked out sampler & Private Collection \\
\hline Hetty Rosalia Gruet & Sampler & Circa 1820 & Probably PA & 12 & Picked out sampler & Private Collection \\
\hline Mary Halfline & Sampler & Circa 1780 & Probably PA & 11 & Picked out sampler & Private Collection \\
\hline $\begin{array}{l}\text { Lucretia Street Hall } \\
(1773-1851)\end{array}$ & $\begin{array}{l}\text { Embroidered } \\
\text { Coverlet }\end{array}$ & 1828 & Charlemont, MA & 55 & $\begin{array}{l}\text { Made by woman } 40 \\
\text { and over }\end{array}$ & Historic Deerfield \\
\hline $\begin{array}{l}\text { Mary Hopkins } \\
\text { Hayne (1776-1856) }\end{array}$ & Quilt & Circa 1825 & $\mathrm{NC}$ or $\mathrm{SC}$ & Circa 49 & $\begin{array}{l}\text { Made by woman } 40 \\
\text { and over }\end{array}$ & Private Collection \\
\hline $\begin{array}{l}\text { Mary Hearn (b. } \\
\text { 1782) }\end{array}$ & Sampler & 1793 & Nantucket, MA & 10 & Picked out sampler & National Archives \\
\hline $\begin{array}{l}\text { Mary Dyer Herbert } \\
(1781-1852)\end{array}$ & Quilt & Circa 1839 & Bolair, WV & Circa 58 & $\begin{array}{l}\text { Made by woman } 40 \\
\text { and over }\end{array}$ & Private Collection \\
\hline $\begin{array}{l}\text { Martha Hewitt (b. } \\
\text { ca. 1799) }\end{array}$ & Quilt & 1855 & MI & 56 & $\begin{array}{l}\text { Made by woman } 40 \\
\text { and over }\end{array}$ & Private Collection \\
\hline $\begin{array}{l}\text { Sarah Holmes } \\
(1793-1842)\end{array}$ & Sampler & 1801 & NJ & 8 & Altered sampler & $\begin{array}{l}\text { New-York } \\
\text { Historical Society }\end{array}$ \\
\hline $\begin{array}{l}\text { Louvica Creek } \\
\text { Houchins (1788- } \\
\text { after 1850) }\end{array}$ & Quilt & Circa 1839 & IL & Circa 51 & $\begin{array}{l}\text { Made by woman } 40 \\
\text { and over }\end{array}$ & DAR Museum \\
\hline $\begin{array}{l}\text { Maria Cadman } \\
\text { Hubbard (b. 1769) }\end{array}$ & Quilt & 1848 & NY & 79 & $\begin{array}{l}\text { Made by woman } 40 \\
\text { and over }\end{array}$ & $\begin{array}{l}\text { American Folk Art } \\
\text { Museum }\end{array}$ \\
\hline $\begin{array}{l}\text { Eleanor Yates Keady } \\
(1808-1881)\end{array}$ & Quilt & 1855 & Dunlap, IL & 47 & $\begin{array}{l}\text { Made by woman } 40 \\
\text { and over }\end{array}$ & Private Collection \\
\hline $\begin{array}{l}\text { Margaret Steeley } \\
\text { Kelley (1784-1865) }\end{array}$ & Quilt & $1852 / 1857$ & PA & $68 / 73$ & $\begin{array}{l}\text { Made by woman } 40 \\
\text { and over }\end{array}$ & $\begin{array}{l}\text { Erie County } \\
\text { Historical Society }\end{array}$ \\
\hline
\end{tabular}




\begin{tabular}{|c|c|c|c|c|c|c|}
\hline $\begin{array}{l}\text { Mary Duncan Kelly } \\
(1814-1898)\end{array}$ & Quilt & 1858 & $\begin{array}{l}\text { St. Clairsville, } \\
\text { OH }\end{array}$ & 44 & $\begin{array}{l}\text { Made by woman } 40 \\
\text { and over }\end{array}$ & $\begin{array}{l}\text { Ohio Historical } \\
\text { Society }\end{array}$ \\
\hline $\begin{array}{l}\text { Mary Laman Kemp } \\
(1758-1845)\end{array}$ & Quilt & 1840 & $\begin{array}{l}\text { Rocky Springs, } \\
\text { MD }\end{array}$ & 82 & $\begin{array}{l}\text { Made by woman } 40 \\
\text { and over }\end{array}$ & Private Collection \\
\hline $\begin{array}{l}\text { Mary Tayloe Lloyd } \\
\text { Key (1786-1859) }\end{array}$ & Quilt top & Circa 1840 & Georgetown, MD & Circa 54 & $\begin{array}{l}\text { Made by woman } 40 \\
\text { and over }\end{array}$ & DAR Museum \\
\hline $\begin{array}{l}\text { Mary Tayloe Lloyd } \\
\text { Key (1786-1859) }\end{array}$ & Quilt top & Circa 1840 & Georgetown, MD & Circa 54 & $\begin{array}{l}\text { Made by woman } 40 \\
\text { and over }\end{array}$ & $\begin{array}{l}\text { San Jose Museum } \\
\text { of Quilts and } \\
\text { Textiles }\end{array}$ \\
\hline $\begin{array}{l}\text { Dorothy Knight } \\
(1803-1854)\end{array}$ & Sampler & 1817 & Phillipston, MA & 14 & $\begin{array}{l}\text { Filled in family } \\
\text { record }\end{array}$ & $\begin{array}{l}\text { Old Sturbridge } \\
\text { Village }\end{array}$ \\
\hline $\begin{array}{l}\text { Susan Kuhns (ca. } \\
\text { 1787-ca. 1865) }\end{array}$ & Quilt & Circa 1840 & Greenburg, PA & Circa 53 & $\begin{array}{l}\text { Made by woman } 40 \\
\text { and over }\end{array}$ & DAR Museum \\
\hline Margaret Larkum & Sampler & 1799 & Philadelphia, PA & & Picked out sampler & Private Collection \\
\hline $\begin{array}{l}\text { Amelia Heiskell } \\
\text { Lauck (1760-1842) }\end{array}$ & Quilt & Circa 1822 & Winchester, VA & Circa 62 & $\begin{array}{l}\text { Made by woman } 40 \\
\text { and over }\end{array}$ & DAR Museum \\
\hline $\begin{array}{l}\text { Amelia Heiskell } \\
\text { Lauck (1760-1842) }\end{array}$ & Quilt & 1823 & Winchester, VA & 63 & $\begin{array}{l}\text { Made by woman } 40 \\
\text { and over }\end{array}$ & DAR Museum \\
\hline $\begin{array}{l}\text { Amelia Heiskell } \\
\text { Lauck (1760-1842) }\end{array}$ & Quilt & Circa 1822 & Winchester, VA & 62 & $\begin{array}{l}\text { Made by woman } 40 \\
\text { and over }\end{array}$ & $\begin{array}{l}\text { Colonial } \\
\text { Williamsburg }\end{array}$ \\
\hline $\begin{array}{l}\text { Amelia Heiskell } \\
\text { Lauck (1760-1842) }\end{array}$ & Quilt & $1820-1830$ & Winchester, VA & $59-69$ & $\begin{array}{l}\text { Made by woman } 40 \\
\text { and over }\end{array}$ & $\begin{array}{l}\text { Colonial } \\
\text { Williamsburg }\end{array}$ \\
\hline $\begin{array}{l}\text { Mary M. Leggett (b. } \\
\text { 1786) }\end{array}$ & Quilt & 1852 & Valley Forge, PA & 66 & $\begin{array}{l}\text { Made by woman } 40 \\
\text { and over }\end{array}$ & Private Collection \\
\hline $\begin{array}{l}\text { Sarah Wadsworth } \\
\text { Mahan (1802-1885) }\end{array}$ & Quilt & 1851 & Oberlin, $\mathrm{OH}$ & 49 & $\begin{array}{l}\text { Made by woman } 40 \\
\text { and over }\end{array}$ & $\begin{array}{l}\text { Allen Memorial } \\
\text { Art Museum }\end{array}$ \\
\hline $\begin{array}{l}\text { Eleanor Caroline } \\
\text { Malone (1828-1894) }\end{array}$ & Sampler & 1836 & Boston, MA & 8 & Picked out sampler & Private Collection \\
\hline $\begin{array}{l}\text { Susan Bishop } \\
\text { Marble (1807-1821) }\end{array}$ & Sampler & 1817 & New Haven, CT & 10 & $\begin{array}{l}\text { Filled in family } \\
\text { record }\end{array}$ & DAR Museum \\
\hline
\end{tabular}




\begin{tabular}{|c|c|c|c|c|c|c|}
\hline $\begin{array}{l}\text { Harriet Kirk Marion } \\
(1782-1856)\end{array}$ & Quilt & Circa 1830 & $\begin{array}{l}\text { St. Stephen's } \\
\text { Parish, SC }\end{array}$ & Circa 48 & $\begin{array}{l}\text { Made by woman } 40 \\
\text { and over }\end{array}$ & MESDA \\
\hline $\begin{array}{l}\text { Harriet Kirk Marion } \\
\text { (1782-1856) or } \\
\text { Elizabeth Marion } \\
\text { Porcher (1760-1796) } \\
\text { and Elizabeth } \\
\text { Catherine Porcher } \\
\text { Palmer (1781-1841) }\end{array}$ & Quilt & $\begin{array}{l}\text { Circa } 1841 \text { or } \\
\text { circa } \\
1790 / 1830\end{array}$ & $\mathrm{SC}$ & $\begin{array}{l}\text { Circa } 48 \text { or } \\
\text { circa } 30 \text { and } \\
49\end{array}$ & $\begin{array}{l}\text { Made by woman } 40 \\
\text { and over }\end{array}$ & MESDA \\
\hline $\begin{array}{l}\text { Dorothea "Dolly" } \\
\text { Keyes McClanahan } \\
(1802-1892)\end{array}$ & Quilt & Circa 1860 & String Prairie, TX & Circa 58 & $\begin{array}{l}\text { Made by woman } 40 \\
\text { and over }\end{array}$ & Private Collection \\
\hline $\begin{array}{l}\text { Margaret Cabell } \\
\text { McClelland (1785- } \\
\text { 1863) }\end{array}$ & Quilt & Circa 1850 & VA & Circa 65 & $\begin{array}{l}\text { Made by woman } 40 \\
\text { and over }\end{array}$ & DAR Museum \\
\hline $\begin{array}{l}\text { Elizabeth } \\
\text { McClintock (b. } \\
\text { 1780) }\end{array}$ & Quilt & 1849 & & 69 & $\begin{array}{l}\text { Made by woman } 40 \\
\text { and over }\end{array}$ & Grout Museum \\
\hline $\begin{array}{l}\text { Susan Miller (1793- } \\
\text { 1861) }\end{array}$ & Quilt & Circa 1840 & $\begin{array}{l}\text { Rockingham } \\
\text { County, VA }\end{array}$ & Circa 47 & $\begin{array}{l}\text { Made by woman } 40 \\
\text { and over }\end{array}$ & $\begin{array}{l}\text { Harrisonburg- } \\
\text { Rockingham } \\
\text { Historical Society }\end{array}$ \\
\hline $\begin{array}{l}\text { Catharine Mitchell } \\
(1775-1847)\end{array}$ & Quilt & $1830-1840$ & $\begin{array}{l}\text { Dorchester } \\
\text { County, MD }\end{array}$ & $55-65$ & $\begin{array}{l}\text { Made by woman } 40 \\
\text { and over }\end{array}$ & $\begin{array}{l}\text { Maryland } \\
\text { Historical Society }\end{array}$ \\
\hline $\begin{array}{l}\text { Elizabeth Roseberry } \\
\text { Mitchell (1799- } \\
\text { 1857) }\end{array}$ & Quilt & Circa 1839 & $\begin{array}{l}\text { Lewis County, } \\
\mathrm{KY}\end{array}$ & 40 & $\begin{array}{l}\text { Made by woman } 40 \\
\text { and over }\end{array}$ & $\begin{array}{l}\text { Kentucky } \\
\text { Historical Society }\end{array}$ \\
\hline $\begin{array}{l}\text { Johanna Penelope } \\
\text { Elizabeth Cushing } \\
\text { Montell (1784-1857) }\end{array}$ & Quilt & Circa 1840 & Baltimore, MD & Circa 56 & $\begin{array}{l}\text { Made by woman } 40 \\
\text { and over }\end{array}$ & $\begin{array}{l}\text { Maryland } \\
\text { Historical Society }\end{array}$ \\
\hline Nancy Ely Moore (b. & Sampler & 1859 & Warren County, & 52 & Made by woman 40 & Western Reserve \\
\hline
\end{tabular}




\begin{tabular}{|c|c|c|c|c|c|c|}
\hline 1807) & & & KY & & and over & Historical Society \\
\hline Lucretia Mulford & Sampler & 1785 & $\mathrm{CT}$ & & Picked out sampler & Private Collection \\
\hline $\begin{array}{l}\text { Betsy Rice Nims } \\
(1751-1842)\end{array}$ & Quilt & Circa 1840 & Buckland, MA & Circa 89 & $\begin{array}{l}\text { Made by woman } 40 \\
\text { and over }\end{array}$ & $\begin{array}{l}\text { Pocumtuck Valley } \\
\text { Memorial } \\
\text { Association }\end{array}$ \\
\hline $\begin{array}{l}\text { Mary Rooker Norris } \\
(1785-1868)\end{array}$ & Quilt & 1846 & Hagerstown, MD & 61 & $\begin{array}{l}\text { Made by woman } 40 \\
\text { and over }\end{array}$ & DAR Museum \\
\hline $\begin{array}{l}\text { Catherine Couturier } \\
\text { Marion Palmer } \\
(1807-1895)\end{array}$ & Quilt & $1847-1848$ & St. John's, SC & $40-41$ & $\begin{array}{l}\text { Made by woman } 40 \\
\text { and over }\end{array}$ & MESDA \\
\hline $\begin{array}{l}\text { Elcey Patterson } \\
(1803-1862)\end{array}$ & Sampler & 1845 & $\begin{array}{l}\text { Union Village, } \\
\mathrm{OH}\end{array}$ & 42 & $\begin{array}{l}\text { Made by woman } 40 \\
\text { and over }\end{array}$ & Private Collection \\
\hline $\begin{array}{l}\text { Isabelle Liddon } \\
\text { Pennock (b. 1795) }\end{array}$ & Quilt & $1842-1843$ & $\begin{array}{l}\text { Marlborough } \\
\text { Township, PA }\end{array}$ & $47-48$ & $\begin{array}{l}\text { Made by woman } 40 \\
\text { and over }\end{array}$ & $\begin{array}{l}\text { Chester County } \\
\text { Historical Society }\end{array}$ \\
\hline $\begin{array}{l}\text { Elizabeth Daniel } \\
\text { Poindexter (ca. } \\
\text { 1807-ca. 1858) }\end{array}$ & Quilt & Circa 1852 & $\begin{array}{l}\text { Cooper County, } \\
\text { MO }\end{array}$ & Circa 45 & $\begin{array}{l}\text { Made by woman } 40 \\
\text { and over }\end{array}$ & DAR Museum \\
\hline $\begin{array}{l}\text { Mary Ann Post (b. } \\
\text { 1813) }\end{array}$ & Sampler & 1827 & Chatham, CT & 14 & $\begin{array}{l}\text { Filled in family } \\
\text { record }\end{array}$ & Private Collection \\
\hline $\begin{array}{l}\text { Sylvia Punderson } \\
(1769-1826)\end{array}$ & $\begin{array}{l}\text { Mourning } \\
\text { Picture }\end{array}$ & $1822-1826$ & Groton, CT & $53-57$ & $\begin{array}{l}\text { Made by woman } 40 \\
\text { and over }\end{array}$ & $\begin{array}{l}\text { Connecticut } \\
\text { Historical Society }\end{array}$ \\
\hline Emily C. Rawlings & Sampler & Circa 1820 & $\begin{array}{l}\text { Probably } \\
\text { Baltimore, MD }\end{array}$ & 10 & Picked out sampler & DAR Museum \\
\hline $\begin{array}{l}\text { Katurah Reeve } \\
(1775-1852)\end{array}$ & $\begin{array}{l}\text { Whitework } \\
\text { Coverlet }\end{array}$ & 1820 & NY & 45 & $\begin{array}{l}\text { Made by woman } 40 \\
\text { and over }\end{array}$ & Winterthur \\
\hline $\begin{array}{l}\text { Jemima Kassel } \\
\text { Reger }(1815-1902)\end{array}$ & Quilt & Circa 1859 & Buckhannon, WV & Circa 44 & $\begin{array}{l}\text { Made by woman } 40 \\
\text { and over }\end{array}$ & Private Collection \\
\hline $\begin{array}{l}\text { Elizabeth Abrams } \\
\text { Renwick (1782- } \\
1863)\end{array}$ & Quilt & Circa 1840 & $\begin{array}{l}\text { Newberry } \\
\text { County, SC }\end{array}$ & Circa 58 & $\begin{array}{l}\text { Made by woman } 40 \\
\text { and over }\end{array}$ & MESDA \\
\hline
\end{tabular}




\begin{tabular}{|c|c|c|c|c|c|c|}
\hline $\begin{array}{l}\text { Esther Banister } \\
\text { Richards (1795- } \\
1864)\end{array}$ & Sampler & 1853 & Sturbridge, MA & 58 & $\begin{array}{l}\text { Made by woman } 40 \\
\text { and over }\end{array}$ & $\begin{array}{l}\text { Old Sturbridge } \\
\text { Village }\end{array}$ \\
\hline $\begin{array}{l}\text { Euphemia Reese } \\
\text { Wilson Righter } \\
(1790-1873)\end{array}$ & Quilt & 1850 & $\begin{array}{l}\text { Beaver Meadow, } \\
\text { PA }\end{array}$ & 60 & $\begin{array}{l}\text { Made by woman } 40 \\
\text { and over }\end{array}$ & $\begin{array}{l}\text { State Museum of } \\
\text { Pennsylvania }\end{array}$ \\
\hline Candace Russell & Sampler & & & 52 & $\begin{array}{l}\text { Made by woman } 40 \\
\text { and over }\end{array}$ & $\begin{array}{l}\text { Western Reserve } \\
\text { Historical Society }\end{array}$ \\
\hline $\begin{array}{l}\text { Jane Richards } \\
\text { Russell (1802-1889) }\end{array}$ & Quilt & Circa 1855 & Jerseyville, IL & Circa 53 & $\begin{array}{l}\text { Made by woman } 40 \\
\text { and over }\end{array}$ & $\begin{array}{l}\text { Illinois State } \\
\text { Museum }\end{array}$ \\
\hline $\begin{array}{l}\text { Rachel Engard } \\
\text { Saulnier (1776- } \\
1866)\end{array}$ & Quilt & Circa 1835 & Philadelphia, PA & Circa 59 & $\begin{array}{l}\text { Made by woman } 40 \\
\text { and over }\end{array}$ & Private Collection \\
\hline $\begin{array}{l}\text { Rebecca Scattergood } \\
\text { Savery }(1770-1855)\end{array}$ & Quilt & 1827 & Philadelphia, PA & 57 & $\begin{array}{l}\text { Made by woman } 40 \\
\text { and over }\end{array}$ & Winterthur \\
\hline $\begin{array}{l}\text { Rebecca Scattergood } \\
\text { Savery }(1770-1855)\end{array}$ & Quilt & $1835-1840$ & Philadelphia, PA & $65-70$ & $\begin{array}{l}\text { Made by woman } 40 \\
\text { and over }\end{array}$ & $\begin{array}{l}\text { American Folk Art } \\
\text { Museum }\end{array}$ \\
\hline $\begin{array}{l}\text { Rebecca Scattergood } \\
\text { Savery }(1770-1855)\end{array}$ & Quilt & 1839 & Philadelphia, PA & 69 & $\begin{array}{l}\text { Made by woman } 40 \\
\text { and over }\end{array}$ & $\begin{array}{l}\text { Philadelphia } \\
\text { Museum of Art }\end{array}$ \\
\hline $\begin{array}{l}\text { Maria Boyd Schulz } \\
\text { (b. 1806) }\end{array}$ & Quilt & Mid-1850s & Charleston, SC & Circa 50 & $\begin{array}{l}\text { Made by woman } 40 \\
\text { and over }\end{array}$ & $\begin{array}{l}\text { Charleston } \\
\text { Museum }\end{array}$ \\
\hline $\begin{array}{l}\text { Betsey Sears (1813- } \\
\text { 1901) }\end{array}$ & Quilt & 1855 & $\begin{array}{l}\text { Jefferson County, } \\
\text { WI }\end{array}$ & 42 & $\begin{array}{l}\text { Made by woman } 40 \\
\text { and over }\end{array}$ & $\begin{array}{l}\text { Heritage Park, City } \\
\text { of Santa Fe } \\
\text { Springs, CA }\end{array}$ \\
\hline $\begin{array}{l}\text { Betsey Sears (1813- } \\
\text { 1901) }\end{array}$ & Quilt & $1850-1860$ & $\begin{array}{l}\text { Jefferson County, } \\
\text { WI }\end{array}$ & $37-47$ & $\begin{array}{l}\text { Made by woman } 40 \\
\text { and over }\end{array}$ & $\begin{array}{l}\text { Fort Atkinson } \\
\text { Historical Society }\end{array}$ \\
\hline $\begin{array}{l}\text { Patty Sessions } \\
(1795-1892)\end{array}$ & Sampler & $1811 / 1848$ & ME and UT & $16 / 53$ & $\begin{array}{l}\text { Made by woman } 40 \\
\text { and over }\end{array}$ & Private Collection \\
\hline $\begin{array}{l}\text { Deborah Ellis Shaw } \\
(1796-1859)\end{array}$ & Quilt & $1850-1859$ & Palmer, MA & $54-63$ & $\begin{array}{l}\text { Made by woman } 40 \\
\text { and over }\end{array}$ & Historic Deerfield \\
\hline
\end{tabular}




\begin{tabular}{|c|c|c|c|c|c|c|}
\hline $\begin{array}{l}\text { Frances Shaw (1808- } \\
1876)\end{array}$ & Quilt & Circa 1850 & Hagerstown, MD & Circa 42 & $\begin{array}{l}\text { Made by woman } 40 \\
\text { and over }\end{array}$ & Private Collection \\
\hline Eliza Sibbett & Sampler & Circa 1830 & $\begin{array}{l}\text { Probably } \\
\text { Philadelphia, PA }\end{array}$ & Probably 18 & Picked out sampler & Private Collection \\
\hline $\begin{array}{l}\text { Esther Johnson } \\
\text { Parkinson Slater } \\
(1778-1859)\end{array}$ & Quilt & 1851 & Pawtucket, RI & 73 & $\begin{array}{l}\text { Made by woman } 40 \\
\text { and over }\end{array}$ & $\begin{array}{l}\text { Slater Mill Historic } \\
\text { Site }\end{array}$ \\
\hline $\begin{array}{l}\text { Elizabeth Deardorf } \\
\text { Slingluff (1775- } \\
\text { 1852) }\end{array}$ & Quilt & $1825-1830$ & $\begin{array}{l}\text { New Windsor, } \\
\text { MD }\end{array}$ & $50-55$ & $\begin{array}{l}\text { Made by woman } 40 \\
\text { and over }\end{array}$ & Private Collection \\
\hline $\begin{array}{l}\text { Catherine Crast } \\
\text { Sloat (1798-1873) }\end{array}$ & Quilt & Circa 1845 & NY & Circa 47 & $\begin{array}{l}\text { Made by woman } 40 \\
\text { and over }\end{array}$ & Private Collection \\
\hline $\begin{array}{l}\text { Mary C. Slocum (b. } \\
\text { ca. 1817) }\end{array}$ & Quilt & Circa 1858 & Rock County, WI & Circa 41 & $\begin{array}{l}\text { Made by woman } 40 \\
\text { and over }\end{array}$ & $\begin{array}{l}\text { State Historical } \\
\text { Society of } \\
\text { Wisconsin }\end{array}$ \\
\hline $\begin{array}{l}\text { Mary "Polly" } \\
\text { Hutchings Small } \\
(1775-1846)\end{array}$ & Quilt & Circa 1840 & $\begin{array}{l}\text { Pleasant } \\
\text { Exchange, TN }\end{array}$ & Circa 65 & $\begin{array}{l}\text { Made by woman } 40 \\
\text { and over }\end{array}$ & Private Collection \\
\hline $\begin{array}{l}\text { Rachel Smith (b. } \\
\text { circa 1795) }\end{array}$ & Quilt & 1859 & Derby, CT & Circa 64 & $\begin{array}{l}\text { Made by woman } 40 \\
\text { and over }\end{array}$ & $\begin{array}{l}\text { New-York } \\
\text { Historical Society }\end{array}$ \\
\hline $\begin{array}{l}\text { Rebecca Smith } \\
\text { Smith (1807-1875) }\end{array}$ & Quilt & Circa 1860 & Decatur, IL & Circa 53 & $\begin{array}{l}\text { Made by woman } 40 \\
\text { and over }\end{array}$ & Private Collection \\
\hline $\begin{array}{l}\text { Mary Deloach Sneed } \\
(1807-1905)\end{array}$ & Quilt & $1850-1860$ & Waco, TX & $43-53$ & $\begin{array}{l}\text { Made by woman } 40 \\
\text { and over }\end{array}$ & DAR Museum \\
\hline $\begin{array}{l}\text { Emily Snyder (b. } \\
\text { 1804) }\end{array}$ & Quilt top & $1845-1850$ & Philadelphia, PA & $41-46$ & $\begin{array}{l}\text { Made by woman } 40 \\
\text { and over }\end{array}$ & $\begin{array}{l}\text { Los Angeles } \\
\text { County Museum of } \\
\text { Art }\end{array}$ \\
\hline $\begin{array}{l}\text { Eliza Sockman } \\
(1807-1887)\end{array}$ & Sampler & 1821 & Wheeling, WV & 14 & Picked out sampler & $\begin{array}{l}\text { Ohio Historical } \\
\text { Society }\end{array}$ \\
\hline Hannah Stockton & Quilt & Circa 1830 & Philadelphia, PA & Circa 40 & Made by woman 40 & Fenimore Art \\
\hline
\end{tabular}




\begin{tabular}{|c|c|c|c|c|c|c|}
\hline Stiles (1790-1864) & & & & & and over & Museum, NYSHA \\
\hline $\begin{array}{l}\text { Sally Bowen Story } \\
(1789-1872)\end{array}$ & Sampler & Circa 1800 & Marblehead, MA & Circa 11 & Picked out sampler & $\begin{array}{l}\text { Peabody Essex } \\
\text { Museum }\end{array}$ \\
\hline $\begin{array}{l}\text { Sarah Summers (ca. } \\
1820-1900 \text { ) }\end{array}$ & Quilt & Circa 1860 & $\begin{array}{l}\text { Jones County, } \\
\text { GA }\end{array}$ & Circa 40 & $\begin{array}{l}\text { Made by woman } 40 \\
\text { and over }\end{array}$ & Private Collection \\
\hline $\begin{array}{l}\text { Eliza Sumner (1802- } \\
1856)\end{array}$ & Quilt & 1848 & Spencer, MA & 46 & $\begin{array}{l}\text { Made by woman } 40 \\
\text { and over }\end{array}$ & Private Collection \\
\hline $\begin{array}{l}\text { Mary Elizabeth } \\
\text { Clayton Miller } \\
\text { Taylor (1774-1846) }\end{array}$ & Quilt & 1824 & Savannah, GA & 50 & $\begin{array}{l}\text { Made by woman } 40 \\
\text { and over }\end{array}$ & $\begin{array}{l}\text { Telfair Museum of } \\
\text { Art }\end{array}$ \\
\hline $\begin{array}{l}\text { Susanna Bradford } \\
\text { Tillson (1807-1835) }\end{array}$ & Sampler & 1817 & Plymouth, MA & 10 & Picked out sampler & Private Collection \\
\hline $\begin{array}{l}\text { Ann Titus (1811- } \\
\text { 1886) }\end{array}$ & Sampler & 1823 & NY & 12 & Picked out sampler & Private Collection \\
\hline $\begin{array}{l}\text { Mary "Betsey" } \\
\text { Totten Polhemus } \\
\text { Williams (1781- } \\
\text { 1861) }\end{array}$ & Quilt & Circa 1830 & Staten Island, NY & Circa 49 & $\begin{array}{l}\text { Made by woman } 40 \\
\text { and over }\end{array}$ & $\begin{array}{l}\text { Smithsonian } \\
\text { Institution }\end{array}$ \\
\hline $\begin{array}{l}\text { Mary "Betsey" } \\
\text { Totten Polhemus } \\
\text { Williams (1781- } \\
\text { 1861) }\end{array}$ & Quilt & Circa 1825 & Staten Island, NY & Circa 44 & $\begin{array}{l}\text { Made by woman } 40 \\
\text { and over }\end{array}$ & $\begin{array}{l}\text { New York State } \\
\text { Historical } \\
\text { Association }\end{array}$ \\
\hline $\begin{array}{l}\text { Mary "Betsey" } \\
\text { Totten Polhemus } \\
\text { Williams (1781- } \\
\text { 1861) }\end{array}$ & Quilt & Circa 1830 & Staten Island, NY & Circa 49 & $\begin{array}{l}\text { Made by woman } 40 \\
\text { and over }\end{array}$ & $\begin{array}{l}\text { Staten Island } \\
\text { Historical Society }\end{array}$ \\
\hline $\begin{array}{l}\text { Mary "Betsey" } \\
\text { Totten Polhemus } \\
\text { Williams (1781- } \\
\text { 1861) }\end{array}$ & Quilt & 1835 & Staten Island, NY & 54 & $\begin{array}{l}\text { Made by woman } 40 \\
\text { and over }\end{array}$ & $\begin{array}{l}\text { Staten Island } \\
\text { Historical Society }\end{array}$ \\
\hline
\end{tabular}




\begin{tabular}{|c|c|c|c|c|c|c|}
\hline Chloe Trask & Sampler & Circa 1820 & MA & & Picked out sampler & Private Collection \\
\hline $\begin{array}{l}\text { Mary Berry True } \\
(1788-1858)\end{array}$ & Table Cover & 1840 & Salem, MA & 52 & $\begin{array}{l}\text { Made by woman } 40 \\
\text { and over }\end{array}$ & $\begin{array}{l}\text { Peabody Essex } \\
\text { Museum }\end{array}$ \\
\hline $\begin{array}{l}\text { Elizabeth Trodge } \\
\text { Turley (1792-1881) }\end{array}$ & Quilt & Circa 1860 & Waverly, IL & Circa 68 & $\begin{array}{l}\text { Made by woman } 40 \\
\text { and over }\end{array}$ & $\begin{array}{l}\text { Illinois State } \\
\text { Museum }\end{array}$ \\
\hline $\begin{array}{l}\text { Mary Van Voorhis } \\
\text { (b. ca. 1788) }\end{array}$ & Quilt & Circa 1850 & PA & Circa 62 & $\begin{array}{l}\text { Made by woman } 40 \\
\text { and over }\end{array}$ & The Witte Museum \\
\hline $\begin{array}{l}\text { Lucy Walton (1799- } \\
1870)\end{array}$ & Sampler & 1847 & Enfield, NH & 48 & $\begin{array}{l}\text { Made by woman } 40 \\
\text { and over }\end{array}$ & Private Collection \\
\hline $\begin{array}{l}\text { Catherine Ann } \\
\text { Waring (1787-1867) }\end{array}$ & Quilt & $1840-1850$ & TX or MD & $57-67$ & $\begin{array}{l}\text { Made by woman } 40 \\
\text { and over }\end{array}$ & Private Collection \\
\hline $\begin{array}{l}\text { Rhoda Warner (b. } \\
\text { 1784) }\end{array}$ & Quilt & 1855 & Painesville, $\mathrm{OH}$ & 71 & $\begin{array}{l}\text { Made by woman } 40 \\
\text { and over }\end{array}$ & $\begin{array}{l}\text { Buffalo and Erie } \\
\text { County Historical } \\
\text { Society }\end{array}$ \\
\hline $\begin{array}{l}\text { Sara Boyd Waugh } \\
(1774-1863)\end{array}$ & Quilt & Circa 1830 & PA & Circa 56 & $\begin{array}{l}\text { Made by woman } 40 \\
\text { and over }\end{array}$ & Private Collection \\
\hline $\begin{array}{l}\text { Jane Smith Phillips } \\
\text { Wells (1794-1874) }\end{array}$ & Quilt & Circa 1850 & Peconic, NY & Circa 56 & $\begin{array}{l}\text { Made by woman } 40 \\
\text { and over }\end{array}$ & Private Collection \\
\hline C.A. Wetmore & Sampler & & NY & & Picked out sampler & $\begin{array}{l}\text { Litchfield } \\
\text { Historical Society }\end{array}$ \\
\hline $\begin{array}{l}\text { Margaret Wetmore } \\
(1810-1843)\end{array}$ & Sampler & 1823 & $\mathrm{OH}$ & 13 & Picked out sampler & $\begin{array}{l}\text { Western Reserve } \\
\text { Historical Society }\end{array}$ \\
\hline S.E. Wheeler & Sampler & 1840 & $\mathrm{OH}$ & & Picked out sampler & Private Collection \\
\hline $\begin{array}{l}\text { Polly Wheelock (b. } \\
1785 \text { ) }\end{array}$ & Quilt & Circa 1850 & NY or IL & Circa 65 & $\begin{array}{l}\text { Made by woman } 40 \\
\text { and over }\end{array}$ & $\begin{array}{l}\text { LaSalle County } \\
\text { Historical Society }\end{array}$ \\
\hline $\begin{array}{l}\text { Henrietta Frances } \\
\text { Edwards Whitney } \\
(1786-1870)\end{array}$ & Quilt & 1849 & New Haven, CT & 63 & $\begin{array}{l}\text { Made by woman } 40 \\
\text { and over }\end{array}$ & $\begin{array}{l}\text { New Haven } \\
\text { Colony Historical } \\
\text { Society }\end{array}$ \\
\hline $\begin{array}{l}\text { Rebecca Garretson } \\
\text { Wickersham (1791- }\end{array}$ & Quilt & Circa 1854 & $\begin{array}{l}\text { Newberry } \\
\text { Township, PA }\end{array}$ & Circa 63 & $\begin{array}{l}\text { Made by woman } 40 \\
\text { and over }\end{array}$ & $\begin{array}{l}\text { State Museum of } \\
\text { Pennsylvania }\end{array}$ \\
\hline
\end{tabular}




\begin{tabular}{|c|c|c|c|c|c|c|}
\hline 1873) & & & & & & \\
\hline $\begin{array}{l}\text { Elizabeth Wilder } \\
\text { (1811-1873) }\end{array}$ & Sampler & & Sterling, MA & & $\begin{array}{l}\text { Filled-in family } \\
\text { record }\end{array}$ & Private Collection \\
\hline $\begin{array}{l}\text { Eliza Lucas } \\
\text { Williams (1773- } \\
1844)\end{array}$ & Rug & Circa 1825 & Deerfield, MA & Circa 52 & $\begin{array}{l}\text { Made by woman } 40 \\
\text { and over }\end{array}$ & Historic Deerfield \\
\hline $\begin{array}{l}\text { Catharine Woolsey } \\
\text { (ca. 1775-1856) }\end{array}$ & Coverlet & 1822 & $\begin{array}{l}\text { Dutchess County, } \\
\text { NY }\end{array}$ & Circa 47 & $\begin{array}{l}\text { Made by woman } 40 \\
\text { and over }\end{array}$ & $\begin{array}{l}\text { Metropolitan } \\
\text { Museum }\end{array}$ \\
\hline
\end{tabular}




\section{BIBLIOGRAPHY}

\section{Unpublished Primary Sources}

Anonymous Woman, Montague, Massachusetts. Diary. Old Sturbridge Village Research Library, Sturbridge, Massachusetts.

Clapp Family Letters. American Antiquarian Society, Worcester, Massachusetts.

Cleveland, Lucy. Papers. Phillips Library, Peabody Essex Museum, Salem, Massachusetts.

Dorr, Elizabeth. Diaries. Massachusetts Historical Society, Boston, Massachusetts.

Flint, Catherine Dean. Diary. Flint Family Papers. American Antiquarian Society, Worcester, Massachusetts.

Leonard Family Papers. Old Sturbridge Village Research Library, Sturbridge, Massachusetts.

Salisbury, Elizabeth Tuckerman. Diary. Salisbury Family Papers. American Antiquarian Society, Worcester, Massachusetts.

Slater, Esther. S Miscellaneous Manuscripts (Mss 9001). Rhode Island Historical Society, Providence, Rhode Island.

Upham, Mary Avery. Diaries. Massachusetts Historical Society, Boston, Massachusetts.

\section{Published Primary Sources}

Alcott, William. The Young Woman's Book of Health. Boston: Tappan, Whittemore and Mason, 1850.

Alden, Joseph. The Aged Pilgrim. Boston: Massachusetts Sabbath School Society, 1846.

Allen, Elizabeth Waterhouse, ed. Memorial of Joseph and Lucy Clark Allen. Boston: G.H. Ellis, 1891.

The American Ladies' Memorial. Boston, 1850.

Ames, Blanche Butler, comp. Chronicles from the Nineteenth Century: Family Letters of Blanche Butler and Adelbert Ames Married July 21 ${ }^{\text {st }}$, 1870, vol. 1. Clinton, MA: privately printed, 1957.

Armstrong, Robert G. Memoir of Hannah Hobbie, or, Christian Activity, and Triumph in Suffering. New York: American Tract Society, 1837. 
The Art of Good Behaviour. New York: C.P. Huestis, 1848.

Ayer, Sarah Connell. Diary of Sarah Connell Ayer. Andover, MA: Lefavor-Towner Company, 1910.

Barber, John Warner. Historical Collections...of Every Town in Massachusetts. Worcester: Dorr, Howland and Company, 1840.

Bard, Samuel. A Compendium of the Theory and Practice of Midwifery. New York: Collins and Company, 1819.

Bates, Samuel P. History of Greene County, Pennsylvania. Chicago: Nelson, Rishforth, 1888.

Bedford, Gunning. Lecture Introductory to a Course on Obstetrics and Diseases of Women and Children. New York: Jennings, 1847.

Beecher, Catharine E. A Treatise on Domestic Economy. Boston: Marsh, Capen, Lyon and Webb, 1841.

Beecher, Catharine E. and Harriet Beecher Stowe. The American Woman's Home: Or, Principles of Domestic Science. New York: J.B. Ford and Company, 1869.

Benberry, Cuesta Ray and Carol Pinney Crabb, comps. A Patchwork of Pieces: An Anthology of Early Quilt Stories 1845-1940. Paducah, Kentucky: American Quilter's Society, 1993.

Bethune, George Washington, comp. Memoirs of Mrs. Joanna Bethune. New York: Harper \& Brothers, 1863.

Blanchard, Frances Bradshaw, ed. Letters of Ann Gillam Storrow to Jared Sparks. Northampton, MA: Smith College, Department of Government and History, 1921.

Bloomer, D.C. Life and Writings of Amelia Bloomer. New York: Schocken Books, 1975.

Botta, Vincenzo, ed. Memoirs of Anne C.L. Botta Written by Her Friends: with Selections from Her Correspondence and from Her Writings in Prose and Poetry. New York: J. Selwin Tait and Sons, 1893.

Brady, Patricia. George Washington's Beautiful Nelly: The Letters of Eleanor Parke Custis Lewis to Elizabeth Bordley Gibson, 1794-1851. Columbia, SC: University of South Carolina Press, 1991. 
Brevitt, Joseph. The Female Medical Repository. Baltimore: Hunter and Robinson, 1810.

Buchan, William. Domestic Medicine Adapted to the Climate and Diseases of America. Philadelphia: R. Folwell, 1801.

Bushnell, Horace. Work and Play. London: Strahan, 1864.

Butler, Charles. The American Lady. Philadelphia: Hogan and Thompson, 1839.

Carpenter, William. Principles of Human Physiology. Philadelphia: Lea and Blanchard, 1850.

Cary, Virginia. Letters on Female Character, Addressed to a Young Lady on the Death of Her Mother. Richmond, VA: Ariel Works, 1830.

Celnart, Mme. The Gentleman and Lady's Book of Politeness. Boston: Allen and Ticknor, 1833.

Chadwick, John White, ed. A Life for Liberty: Anti-Slavery and Other Letters of Sallie Holley. New York: G.P. Putnam's Sons, 1899.

Child, Lydia Maria. The American Frugal Housewife. 1844. Reprint, Mineola, NY: Dover Publications, Inc., 1999.

—. The Family Nurse. Boston: Charles J. Hendee, 1837.

—. The Girls’ Own Book. New York: Clark Austin and Company, 1833.

—. Looking Toward Sunset. Boston: Ticknor and Fields, 1867.

The Child's Picture Gallery. Boston: Otis, Broaders and Company, 1842.

Cicero, Marcus Tullius and Andrew P. Peabody. Cicero De Amicitia To Which Is Added Scipio's Dream and Cicero De Senectute. Boston: Little, Brown, and Company, 1884.

Clark, Allen C. Life and Letters of Dolly Madison. Washington, DC: Press of W.R. Roberts Co., 1914.

Clark, M.D., J. Henry. Sight and Hearing, How Preserved, and How Lost. New York: C. Scribner, 1856.

Clark, Joseph S. An Historical Sketch of Sturbridge, Mass. From Its Settlement to the Present Time. Brookfield, MA: E. and L. Merriam, 1838. 
Coale, William-Edward. Hints on Health. Boston: Phillips, Sampson and Company, 1852.

Coffin, Albert Isaiah. A Treatise on Midwifery. London: W.B. Ford, 1849.

Cooper, Susan Fenimore. Journal of a Naturalist in the United States. London: Richard Bentley \& Son, 1855.

Crane, Elaine Forman, ed. The Diary of Elizabeth Drinker: The Life Cycle of an Eighteenth-Century Woman. Boston: Northeastern University Press, 1994.

Curtis, John Harrison. Observations on the Preservation of Sight. Worcester: C. Harris, 1839.

Cutter, Calvin. The Female Guide. West Brookfield, MA: Charles A. Mirick, 1844.

Davis, George. A Historical Sketch of Sturbridge and Southbridge. West Brookfield, MA: Power Press of O.S. Cooke and Co., 1856.

Dewees, William P. A Treatise on the Diseases of Females. Philadelphia: H.C. Carey and J. Lea, 1826.

Dewey, Mary E., ed. Life and Letters of Catherine M. Sedgwick. New York: Harper and Row, 1871.

DeWitt, Francis. Statistical Information Relating to Certain Branches of Industry in Massachusetts. Boston: William White, 1856.

Dixon, Edward H. Woman and Her Diseases. New York: Charles H. Ring, 1846.

Dow, George Francis. The Holyoke Diaries, 1709-1865. Salem, MA: Essex Institute, 1911.

Drury, Clifford M. Elkanah and Mary Walker: Pioneers Among the Spokanes. Caldwell, ID: Caxton Printers, 1940.

$11^{\text {th }}$ Annual Report of the Board of Agriculture of the State of Ohio: To the Governor for the Year 1856. Columbus, OH: Richard Nevins, 1857.

Emerson, Ralph Waldo. The Complete Works of Ralph Waldo Emerson: Essays. $2 d$ Series [Vol. 3]. Boston: Houghton Mifflin, 1903-1904.

Emerson, Sarah Hopper, ed. Life of Abby Hooper Gibbons: Told Chiefly through Her Correspondence, vol.1. New York: G.P. Putnam's Sons, 1897.

Emery, Sarah Anna. My Generation. Newburyport, MA: M.H. Sargent, 1893. 
- Reminiscences of a Nonagenarian. Newburyport, MA: W.H. Huse and Company, 1879.

Etiquette for Ladies. Philadelphia: Carey, Lea and Blanchard, 1838.

Etiquette for Ladies. New York: Burgess, Stringer and Company, 1844.

Eulogies and Orations on the Life and Death of General George Washington, First President of the United States of America. Boston: printed by Manning and Loring, 1800.

Extracts from the Memorandums of Jane Bettle, with a Short Memoir Respecting Her, $2^{\text {nd }}$ ed. Philadelphia: J. and W. Kite, 1843.

A Family History in Letters and Documents. St. Paul, MN: privately printed, 1919.

Farnham, Eliza W. Woman and Her Era. New York: A.J. Davis and Company, 1864.

Farrar, Eliza. The Young Lady’s Friend. Boston: American Stationers Company, 1837.

Fisher, George. The Instructor: or, American Young Man's Best Companion. Walpole, New Hampshire: Isaiah Thomas and David Carlisle, 1744.

Fisk, Fidelia. Recollections of Mary Lyon. Boston: American Tract Society, 1866.

Gilman, Mrs. Caroline. Recollections of a Housekeeper. New York: Harper and Brothers, 1834.

Gordon, Donald. The Diary of Ellen Birdseye Wheaton. Boston: privately printed, 1923.

Gove, Mary S. Lectures to Women on Anatomy and Physiology. New York: Harper Brothers, 1846.

Guild, Mrs. Anne E. Grandmother Lee’s Portfolio. Boston: Whittemore, Niles and Hall, 1857.

Hall, A.G. The Mother's Own Book and Practical Guide to Health. Rochester, NY, 1843.

Hall, Mrs. E.B. My Thimbles. Boston: Crosby, Nichols and Company, 1852.

Hallowell, Anna Davis. James and Lucretia Mott: Life and Letters. Boston: Houghton, Mifflin \& Co., 1884. 
Hamilton, Alexander. A Treatise on the Management of Female Complaints. New York: Samuel Campbell, 1792.

Hand, William M. The House Surgeon. New Haven: Silas Andrus, 1820.

Hard, M.K. Woman's Medical Guide. Mt. Vernon, OH: W.H. Cochran, 1848.

Hartley, Florence. The Ladies' Book of Etiquette and Manual of Politeness.

Philadelphia: G.G. Evans, 1860.

—. The Ladies' Handbook of Fancy and Ornamental Work. Philadelphia: G.G.

Evans, 1859.

Hollick, M.D., Frederick. The Diseases of Woman. New York: T.W. Strong, 1849.

—. The Marriage Guide, or Natural History of Generation. New York: T.W. Strong, circa 1860.

Hopkins, Samuel, ed. Memoirs of the Life of Mrs. Sarah Osborn (1714-1796).

Worcester: Leonard Worcester, 1799.

Howe, M.A. DeWolfe, ed. The Articulate Sisters. Cambridge, MA: Harvard University Press, 1946.

Hunt, Gaillard. The First Forty Years of Washington Society in the Family Letters of Margaret Bayard Smith. New York: Frederick Ungar Publishing, 1906.

Hurd, D. Hamilton, comp. History of Worcester County, Massachusetts. Philadelphia: J.W. Lewis and Company, 1889.

The Improved American Family Physician. New York, 1833.

Jones, Alice Johnson. In Dover on the Charles. Newport, RI: The Milne Printery, 1906.

King, Caroline Howard. When I Lived in Salem, 1822-1866. Brattleboro, VT: Stephen Daye Press, 1937.

Kirkland, Caroline M. The Evening Book: Or, Fireside Talk. New York: Charles Scribner, 1852.

The Ladies' Companion. Worcester: The Spy Office, 1824.

The Ladies’ Guide in Needlework. Philadelphia: J. \& J.L. Gihon, 1850.

The Ladies' Hand-Book of Fancy Needlework, and Embroidery. New York: J.S. Redfield, 1844. 
The Ladies' Handbook of Knitting, Netting and Crochet. New York: J. Redfield, 1844.

Ladies’ Indispensable Assistant. New York, 1851.

The Ladies' Work-Table Book. New York: J. Winchester, 1844.

The Lady's Work-Box Companion. New York: Burgess, Stringer and Company, 1844.

Lambert, Miss. The Hand-Book of Needlework. New York: Wiley and Putnam, 1842.

—. The Hand-Book of Needlework. London: John Murray, 1846.

Larcom, Lucy. A New England Girlhood. Boston: Northeastern University Press, 1986.

Leslie, Eliza. The Behaviour Book. Philadelphia: Willis P. Hazard, 1854.

Letters of Lydia Maria Child. Boston: Houghton, Mifflin and Company, 1883.

Life and Letters of Miss Mary C. Greenleaf, Missionary to the Chickasaw Indians.

Boston: Massachusetts Sabbath School Society, 1858.

Lyman, Arthur T. Arthur Theodore Lyman and Ella Lyman: Letters and Journals, vol. 1. Menasha, WI: George Banta Publishing Company, 1932.

MacDonald, Edgar E. The Education of the Heart: The Correspondence of Rachel Mordecai Lazarus and Maria Edgeworth. Chapel Hill: University of North Carolina Press, 1977.

Marcus, Jacob R., comp. The American Jewish Woman: A Documentary History. New York: Ktav Publishing House, 1981.

Mariotti, Eva. The Diary of Mary Poor of Indian Hill Farm. Boston: Warren F. Kellogg, 1895.

Marlatt, Helen Stuart Mackay-Smith. Stuart Letters of Robert and Elizabeth Sullivan Stuart and Their Children 1819-1864. New York: privately printed, 1961.

Marvin, Abijah P. History of Worcester County, Massachusetts. Boston: C.F. Jewett and Company, 1879.

Mauriceau, Dr. A.M. The Married Woman's Private Medical Companion. New York, 1847.

Memorial of Sarah Pugh: A Tribute of Respect from Her Cousins. Philadelphia: J.B. Lippincott \& Co., 1888. 
Morrill, Charles. The Physiology of Woman. Boston: Bela Marsh, 1848.

Morse, Frances Rollins, ed. Henry and Mary Lee: Letters and Journals...1802-1860. Boston: Thomas Todd Company, 1926.

Myers, Robert M., ed., The Children of Pride: A True Story of Georgia and the Civil War. New Haven: Yale University Press, 1972.

Paine, Harriet E. Old People. Boston: Houghton Mifflin, 1910.

Pancoast, Samuel. The Ladies' Medical Guide. Philadelphia: John E. Potter, circa 1859.

Parkes, Mrs. William. Domestic Duties: or, Instructions to Young Married Ladies. New York: J \& J Harper, 1829.

Philipson, David. Letters of Rebecca Gratz. Philadelphia: Jewish Publication Society of America, 1929.

Pinckney, James D. Reminiscences of Catskill. Catskill, NY: J.B. Hall, 1868.

Porter, Dr. Book of Men, Women and Babies. New York: DeWitt and Davenport, 1855.

Pullan, Mrs. The Lady's Manual of Fancy-Work. New York: Dick and Fitzgerald, 1858.

Ralph, Joseph. A Domestic Guide to Medicine. New York, 1835.

Records of a California Family: Journals and Letters of Lewis C. Gunn and Elizabeth Le Breton Gunn. San Diego: privately printed, 1928.

Roget, M.D., Peter Mark. Animal and Vegetable Physiology Considered with Reference to Natural Theology. London: William Pickering, 1834.

Rollins, Mrs. Ellen Chapman. New England Bygones. Philadelphia: J.B. Lippincott and Company, 1883.

Root, Grace Cogswell, ed. Father and Daughter: A Collection of Cogswell Family

Letters and Diaries. West Hartford: American School for the Deaf, 1924.

Rowe, George Robert. On Some of the Most Important Disorders of Women. London: John Churchill, 1844.

The Seamstress. New York: J.S. Redfield, 1848.

See, John. A Guide to Mother and Nurses. New York, 1833. 
Sherwood, Mrs. The Red Book and Mary Anne. New York: Peter Hill, 1833.

—. The Rose Buds. New York: T. Mason and G. Lane, 1837.

—. What Could I Do Without Grandmother. Providence: Weeden and Peek, [1848$1850]$.

Sigourney, Lydia H. Letters to Mothers. Hartford: Hudson and Skinner, 1838.

—. Looking Toward Sunset. Boston: Ticknor and Fields, 1866.

—. Past Meridian. Hartford: F.A. Brown, 1856.

Skinner, H.B. The Female Medical Guide and Married Woman's Advisor. Boston: Skinner's Publication Rooms, 1849.

Smart, Donna Toland, ed. Mormon Midwife: The 1846-1888 Diaries of Patty Bartlett Sessions. Logan: Utah State University Press, 1997.

Smith, Ethan, ed. Memoirs of Mrs. Abigail Bailey (1746-1815). New York: Arno Press, 1980.

Smith, Seba, ed. The Rover: Weekly Magazine of Tales, Poetry, and Engravings. New York: S.B. Dean \& Co., 1844.

The Soul's Welfare: A Magazine for the People. London: Houlston and Stoneman, 1851.

Stanford, John. The Aged Christian's Companion. New York: Stanford and Swords, 1849.

Stanton, Theodore and Harriot Stanton Blatch, eds. Elizabeth Cady Stanton, As Revealed in Her Letters, Diary, and Remembrances, vol. 1. New York: Harper and Row, 1922.

Stephens, Mrs. Ann S. The Ladies' Complete Guide to Crochet, Fancy Knitting and Needlework. New York: Garrett and Company, 1854.

Sturtevant, Sarah Maria. Winter Scenes in the Denham Family. Bangor: D. Bugbee, 1847.

$13^{\text {th }}$ Annual Report of the Ohio State Board of Agriculture...for the Year 1858.

Columbus, OH: Richard Nevins, 1859.

Through Some Eventful Years. Macon, Georgia: Press of the J.W. Burke Co., 1926.

Ticknor, Caleb. Philosophy of Living. New York: Harper and Brothers, 1836. 
Tilt, E.J. On the Preservation of the Health of Women at the Critical Periods of Life. New York: John Wiley, 1851.

Tolman, George. Concord, Massachusetts: Births, Marriages and Deaths, 1635-1850. Boston: T. Todd, printer, 1895.

Transactions of the Nantucket Agricultural Society for 1856. New York: Nantucket Agricultural Society, 1857.

True Politeness: A Hand-Book of Etiquette for Ladies. New York: Leavitt and Allen, 1853.

Tupper, Frederick and Helen Tyler Brown, eds. Grandmother Tyler's Book: The Recollections of Mary Palmer Tyler. New York: G.P. Putnam's Sons, 1925.

$12^{\text {th }}$ Annual Report of the Ohio State Board of Agriculture...for the Year 1857. Columbus, OH: Richard Nevins, 1858.

Village Life in America 1852-1872 Including the Period of the American Civil War as Told in the Diary of a School-Girl. New York: Henry Holt and Company, 1913.

Vital Records of Sturbridge, Massachusetts to the Year 1850. Boston: New England Historic Genealogical Society, 1906.

Willard, Emma Hart. Journal and Letters from France and Great Britain. Troy, NY: N. Tuttle, 1833.

Wilson, W. Emerson. Phoebe George Bradford Diaries. Wilmington, DE: Historical Society of Delaware, 1975.

Wisner, Benjamin Blydenburg. Memoirs of the Late Mrs. Susan Huntington. Boston: Crocker and Brewster, 1826.

Wood, Lindsay Lomax. Leaves from an Old Washington Diary. New York: Books, Inc., 1943.

The Workwoman's Guide. London: Simpkin, Marshall, 1838.

The Young Lady's Friend. Boston: American Stationers' Company, 1837.

The Young Lady's Own Book. Philadelphia: Thomas, Cowperthwait and Company, 1838.

The Youth's Sketch Book. Boston: Benjamin B. Mussey and Company, 1849. 


\section{Secondary Sources}

Achenbaum, W. Andrew. "Further Perspectives on Modernization and Aging: A (P)review of the Historical Literature." Social Science History 6 (Summer 1982): 347368.

- Old Age in the New Land: The American Experience Since 1790. Baltimore: Johns Hopkins University Press, 1978.

Adamson, Jeremy. Calico and Chintz: Antique Quilts from the Collection of Patricia S. Smith. Washington, DC: Renwick Gallery, 1987.

Allen, Gloria Seaman. Family Record: Genealogical Watercolors and Needlework. Washington, DC: DAR Museum, 1989.

—. First Flowerings: Early Virginia Quilts. Washington, DC: The DAR Museum, 1987.

- A Maryland Sampling: Girlhood Embroidery 1738-1860. Baltimore: Maryland Historical Society, 2008.

—. Old Line Traditions: Maryland Women and Their Quilts. Washington, DC: The DAR Museum, 1985.

Allen, Gloria Seaman and Nancy Gibson Tuckhorn. A Maryland Album: Quiltmaking Traditions 1634-1934. Nashville: Rutledge Hill Press, 1995.

Ames, Kenneth L. Death in the Dining Room and Other Tales of Victorian Culture. Philadelphia: Temple University Press, 1992.

- "Ideologies in Stone: Meanings in Victorian Gravestones." Journal of Popular Culture 14 (1981): 641-656.

Appadurai, Arjun, ed. The Social Life of Things: Commodities in Cultural Perspective. New York: Cambridge University Press, 1986.

Appleby, Joyce. Inheriting the Revolution: The First Generation of Americans. Cambridge, MA: Belknap Press, 2000.

Arch, Stephen Carl. After Franklin: The Emergence of Autobiography in PostRevolutionary America 1780-1830. Hanover: University of New Hampshire, 2001.

Atkins, Jacqueline M. "From Lap to Loom: Marseilles Quilts, Marseilles-Style Spreads, and Their White Work Offspring." Proceedings of the Textile History Forum, 2000, 1326. 
—. Shared Threads: Quilting Together Past and Present. New York: Viking Studio Books, 1994.

Atkins, Jacqueline M. and Phyllis A. Tepper. New York Beauties: Quilts from the Empire State. New York: Dutton Studio Books, 1992.

Ayers, Edward L., Patricia Nelson Limerick, Stephen Nissenbaum and Peter S. Onuf. All Over the Map: Rethinking American Regions. Baltimore: The Johns Hopkins University Press, 1996.

Banner, Lois W. American Beauty. Chicago: The University of Chicago Press, 1983.

- In Full Flower: Aging Women, Power and Sexuality, New York: Vintage Books, 1993.

Basch, Norma. In the Eyes of the Law: Women, Marriage and Property in NineteenthCentury New York. Ithaca: Cornell University Press, 1982.

Bassett, Lynne Z. Telltale Textiles: Quilts from the Historic Deerfield Collection. Deerfield, MA: Historic Deerfield, Inc., 2005.

- "Virtuous Habits of Perseverance: Quilting and the Education of Girls in Nineteenth-Century America." Piecework Magazine 7 (March/April 1999): 46-49.

—. "Woven Bead Chains of the 1830s." The Magazine Antiques 148 (December 1995): 798-807.

Bassett, Lynne Z., ed. Massachusetts Quilts: Our Common Wealth. Hanover, NH: University Press of New England, 2009.

- What's New England about New England Quilts? Sturbridge, MA: Old Sturbridge Village, 1999.

Bassett, Lynne Z. and Jack Larkin. Northern Comfort: New England's Early Quilts 1780-1850. Nashville: Rutledge Hill Press, 1998.

Baym, Nina. Woman's Fiction: A Guide to Novels by and about Women in America 1820-70. Urbana: University of Illinois Press, 1993.

- "Women and the Republic: Emma Willard's Rhetoric of History." American Quarterly 43 (March 1991): 1-23.

Beaudry, Mary C. Findings: The Material Culture of Needlework and Sewing. New Haven: Yale University Press, 2006. 
Belknap, Henry Wycoff. "Joseph True, Wood Carver of Salem, and His Account Book." Essex Institute Historical Collections 78 (1942): 116-157.

Benes, Peter, ed. Textiles in Early New England: Design, Production, and Consumption. Boston: Boston University, 1999.

- Textiles in New England II: Four Centuries of Material Life. Boston: Boston University, 2001.

Bennett, Eileen. The Evolution of Samplers - Embroidery and Sampler Time Line - A 400 Year History of Sampler Making. Jenison, MI: The Sampler House, 2001.

Bercaw, Nancy Dunlap. "Solid Objects/Mutable Meanings: Fancywork and the Construction of Bourgeois Culture, 1840-1880." Winterthur Portfolio 26 (1991): 231248.

Berkin, Carol. First Generations: Women in Colonial America. New York: Hill and Wang, 1996.

- Revolutionary Mothers: Women in the Struggle for America's Independence. New York: Alfred A. Knopf, 2005.

Berlo, Janet Catherine and Patricia Cox Crews. Wild By Design: Two Hundred Years of Innovation and Artistry in American Quilts. Lincoln, NE: International Quilt Study Center, 2003.

Biographical, Genealogical and Descriptive History of the First Congressional District of New Jersey. New York: Lewis Publishing Co., 1900.

Bishop, Robert. New Discoveries in American Quilts. New York: E.P. Dutton and Company, Inc., 1975.

Blecki, Catherine La Courreye and Karin A. Wulf, eds. Milcah Martha Moore's Book: A Commonplace Book from Revolutionary America. University Park, PA: The Pennsylvania State University Press, 1997.

Bloch, Ruth H. "American Feminine Ideals in Transition: The Rise of the Moral Mother, 1785-1815.” Feminist Studies 4 (June 1978): 100-126.

—. "Inside and Outside the Public Sphere." The William and Mary Quarterly 62 (January 2005): 99-106.

Boardman, Michelle. "Picturing the Past: Studying Clothing Through Portraits." Unpub. paper, Old Sturbridge Village, Sturbridge, MA, 1990. 
Boardman, Susan R. and Aimee E. Newell. "Nantucket Needlework: Samplers from Quaker Schools.” Fine Lines 7 (Fall 2002): 7-9.

Bodnar, John. "Generational Memory in an American Town." The Journal of Interdisciplinary History 26 (Spring 1996): 619-637.

Bolton, Ethel Stanwood and Eva Johnston Coe. American Samplers. Reprint, 1921; New York: Dover Publications, Inc., 1987.

Bonfield, Lynn A. "The Production of Cloth, Clothing and Quilts in $19^{\text {th }}$ Century New England Homes." Uncoverings 2 (1981): 77-96.

—_. "Diaries of New England Quilters Before 1860." Uncoverings 9 (1988): 171-197.

Bonfield, Lynn A. and Mary C. Morrison. Roxana's Children: The Biography of a Nineteenth-Century Vermont Family. Amherst: University of Massachusetts Press, 1995.

Borish, Linda J. "“A Fair, Without the Fair, is no Fair At All': Women at the New England Agricultural Fair in the Mid-Nineteenth Century." Journal of Sport History 24 (1997): 155-176.

Bowman, Doris M. American Quilts: The Smithsonian Treasury. Washington, DC: Smithsonian Institution Press, 1991.

Boydston, Jeanne. "Gender as a Question of Historical Analysis." Gender and History 20 (November 2008): 558-583.

- Home and Work: Housework, Wages and the Ideology of Labor in the Early Republic. New York: Oxford University Press, 1990.

Boylan, Anne M. The Origins of Women's Activism: New York and Boston, 1797-1840. Chapel Hill: University of North Carolina Press, 2002.

—. "Timid Girls, Venerable Widows and Dignified Matrons: Life Cycle Patterns Among Organized Women in New York and Boston, 1797-1840." American Quarterly 38 (Winter 1986): 779-797.

Brackman, Barbara. Clues in the Calico: A Guide to Identifying and Dating Antique Quilts. McLean, VA: EPM Publications, Inc., 1989.

- Encyclopedia of Applique: An Illustrated, Numerical Index to Traditional and Modern Patterns. McLean, Virginia: EPM Publications, Inc., 1993.

—. Encyclopedia of Pieced Quilt Patterns. Paducah, KY: American Quilter's Society, 1993. 
- Patterns of Progress: Quilts in the Machine Age. Los Angeles: Autry Museum of Western Heritage, 1997.

—_. "Signature Quilts: Nineteenth-Century Trends." Uncoverings 10 (1989): 25-37.

Bresenhan, Karoline Patterson and Nancy O'Bryant Puentes. Lone Stars: A Legacy of Texas Quilts 1836-1936. Austin: University of Texas Press, 1986.

Brown, Gillian. Domestic Individualism: Imagining Self in Nineteenth-Century America. Berkeley: University of California Press, 1990.

Brown, Kathleen M. Good Wives, Nasty Wenches, and Anxious Patriarchs: Gender, Race and Power in Colonial Virginia. Chapel Hill: University of North Carolina Press, 1996.

Bruner, Jerome. "Life as Narrative." Social Research 71 (Fall 2004): 691-710.

Buckler, Patricia P. and C. Kay Leeper. “An Antebellum Woman's Scrapbook As Autobiographical Composition." Journal of American Culture 14 (1991): 1-8.

Bullard, Lacy Folmar and Betty Jo Schiell. Chintz Quilts: Unfading Glory. Tallahassee, FL: Serendipity Publishers, 1983.

Burdick, Nancilu. Legacy: The Story of Talula Gilbert Bottoms and Her Quilts. Nashville: Rutledge Hill Press, 1988.

Burgess-Olson, Vicky. Sister Saints. Provo, UT: Brigham Young University Press, 1978.

Burman, Barbara, ed. The Culture of Sewing: Gender, Consumption and Home Dressmaking. Oxford: Berg, 1999.

Burstein, Andrew. America's Jubilee: How in 1826 a Generation Remembered Fifty Years of Independence. New York: Alfred A. Knopf, 2001.

Burstyn, Joan N. "Catharine Beecher and the Education of American Women." The New England Quarterly 47 (September 1974): 386-403.

Bushman, Richard L. The Refinement of America: Persons, Houses, Cities. New York: Vintage Books, 1992.

Butler, Robert N. "The Life Review: An Interpretation of Reminiscence in the Aged." Psychiatry 26 (February 1963): 65-76.

Carlisle, Elizabeth Pendergast. Earthbound and Heavenbent: Elizabeth Porter Phelps and Life at Forty Acres 1747-1817. New York: Scribner, 2004. 
Carrier, James. "Gifts, Commodities, and Social Relations: A Maussian View of Exchange." Sociological Forum 6 (1991): 119-136.

- "Gifts in a World of Commodities: The Ideology of the Perfect Gift in American Society." Social Analysis 29 (1990): 19-37.

Carson, Cary. "Doing History with Material Culture." In Material Culture and the Study of American Life, edited by Ian M.G. Quimby, 41-64. New York: W.W. Norton and Company, 1978.

Carvalho, David N. Forty Centuries of Ink. New York: Burt Franklin, 1971.

Carvalho III, Joseph. "Rural Medical Practice in Early $19^{\text {th }}$ Century New England." Historical Journal of Western Massachusetts 4 (Spring 1975): 1-15.

Cawley, Lucinda Reddington, Lorraine DeAngelis Ezbiansky, and Denise Rocheleau Nordberg. Saved for the People of Pennsylvania: Quilts from the State Museum of Pennsylvania. Harrisburg: Pennsylvania Historical and Museum Commission, 1997.

Cerny, Catherine A. "Quilt Ownership and Sentimental Attachments: The Structure of Memory." Uncoverings 18 (1997): 95-119.

Chace, Elizabeth Buffum. Two Quaker Sisters. New York: Liveright Publishing Corp., 1987.

Chambers-Schiller, Lee Virginia. Liberty, A Better Husband: Single Women in America, the Generations of 1780-1840. New Haven: Yale University Press, 1984.

Cheal, David. "Intergenerational Family Transfers." Journal of Marriage and the Family 45 (November 1983): 805-813.

—. "The Ritualization of Family Ties." American Behavioral Scientist 31 (July/August 1988): 632-643.

—. "The Social Dimensions of Gift Behaviour." Journal of Social and Personal Relationships 3 (1986): 423-439.

Chodorow, Nancy. The Reproduction of Mothering: Psychoanalysis and the Sociology of Gender. Berkeley: The University of California Press, 1978.

Chudacoff, Howard P. How Old Are You? Age Consciousness in American Culture. Princeton: Princeton University Press, 1989. 
Chudacoff, Howard P. and Tamara K. Hareven. "From the Empty Nest to Family Dissolution: Life Course Transitions into Old Age." Journal of Family History 4 (Spring 1979): 69-83.

Clark, Christopher. The Roots of Rural Capitalism: Western Massachusetts, 1780-1860. Ithaca: Cornell University Press, 1994.

Clark, Ricky. "Fragile Families: Quilts as Kinship Bonds." The Quilt Digest 5 (1987): 519.

- Quilted Gardens: Floral Quilts of the Nineteenth Century. Nashville: Rutledge Hill Press, 1994.

Clark, Ricky, ed. Quilts in Community: Ohio's Traditions. Nashville: Rutledge Hill Press, 1991.

Cleveland, Richard L. and Donna Bister. Plain and Fancy: Vermont's People and Their Quilts as a Reflection of America. San Francisco: The Quilt Digest Press, 1991.

Clunie, Margaret Burke. "Joseph True and the Piecework System in Salem." The Magazine Antiques 111 (May 1977): 1006-1013.

Cole, Thomas R. The Journey of Life: A Cultural History of Aging in America, Cambridge: Cambridge University Press, 1992.

Conforti, Joseph. Imagining New England: Explorations of Regional Identity from the Pilgrims to the Mid-20 ${ }^{\text {th }}$ Century. Chapel Hill: University of North Carolina Press, 2001.

Cooper, Grace Rogers. The Copp Family Textiles. Washington, DC: Smithsonian Institution Press, 1971.

- The Invention of the Sewing Machine. Washington, DC: Smithsonian Institution, 1968.

Cott, Nancy F. The Bonds of Womanhood: “Women's Sphere” in New England, 17801835. New Haven: Yale University Press, 1977.

Cott, Nancy, et al. "Considering the State of US Women's History." Journal of Women's History 15 (2003): 145-163.

Cowan, Ruth Schwartz. More Work for Mother: The Ironies of Household Technology from the Open Hearth to the Microwave. New York: Basic Books, 1983.

Cozart, Dorothy. "An Early Nineteenth Century Quiltmaker and Her Quilts." Uncoverings 7 (1986): 73-82. 
Crews, Patricia Cox and Ronald C. Naugle, eds. Nebraska Quilts and Quiltmakers. Lincoln: University of Nebraska Press, 1991.

Cross, Whitney R. The Burned-over District: The Social and Intellectual History of Enthusiastic Religion in Western New York, 1800-1850. Ithaca: Cornell University Press, 1950.

Crothers, Pat. "Gender Misapprehensions: The "Separate Spheres” Ideology, Quilters, and Role Adaptation, 1850-1890." Uncoverings 14 (1993): 41-61.

Csikszentmihalyi, Mihaly and Eugene Rochberg-Halton. The Meaning of Things:

Domestic Symbols and the Self. New York: Cambridge University Press, 1981.

Culley, Margo. A Day at a Time: The Diary Literature of American Women from 1764 to the Present. New York: Feminist Press at CUNY, 1985.

Curry, David Park. Stitches In Time: Samplers in the Museum's Collection. Lawrence: University of Kansas, Museum of Art, 1975.

Cutter, William Richard. Historic Homes and Places and Genealogical and Personal Memoirs Relating to the Families of Middlesex County, Massachusetts. New York: Lewis Historical Pub. Co., 1908.

Dacome, Lucia. "Noting the Mind: Commonplace Books and the Pursuit of the Self in Eighteenth-Century Britain." Journal of the History of Ideas 65 (October 2004): 603625.

D'Ambrosio, Paul S. and Charlotte M. Emans. Folk Art's Many Faces: Portraits in the New York State Historical Association. Cooperstown, NY: New York State Historical Association, 1987.

Davidoff, Leonore and Catherine Hall. Family Fortunes: Men and Women of the English Middle Class, 1780-1850. London: Hutchinson, 1987.

Davidson, Mary M. Plimoth Colony Samplers. Marion, MA: The Channings, 1975.

Davis, Carolyn O'Bagy. Pioneer Quiltmaker: The Story of Dorinda Moody Slade 18081895. Tucson: Sanpete Publications, 1990.

—. Quilted All Day: The Prairie Journals of Ida Chambers Melugin. Tucson: Sanpete, 1993.

Davis, Gayle R. "Women in the Quilt Culture: An Analysis of Social Boundaries and Role Satisfaction.” Kansas History 13 (Spring 1990): 5-12. 
Davis, Nancy E. The Baltimore Album Quilt Tradition: Maryland Historical Society. Tokyo: Kokusai, 1999.

Davis, Natalie Zemon. The Gift in Sixteenth-Century France. Madison: The University of Wisconsin Press, 2000.

Deetz, James. In Small Things Forgotten: The Archaeology of Early American Life. New York: Doubleday, 1977.

Degler, Carl N. At Odds: Women and the Family in America from the Revolution to the Present. New York: Oxford University Press, 1980.

Delaplaine, Edward S. Francis Scott Key: Life and Times. New York: Biography Press, 1937.

Demos, John. Circles and Lines: The Shape of Life in Early America. Cambridge, MA: Harvard University Press, 2004.

Demos, John and Sarane Spence Bocock, eds. Turning Points: Historical and Sociological Essays on the Family. Chicago: The University of Chicago Press, 1978.

Deutsch, Davida Tenenbaum. "Needlework Patterns and Their Use in America." The Magazine Antiques 139 (February 1991): 368-381.

Dewhurst, C. Kurt, Betty Macdowell, and Marsha Macdowell. Religious Folk Art In America: Reflections of Faith. New York: E.P. Dutton, Inc., 1983.

Dickinson, Cindy. "Creating a World of Books, Friends, and Flowers: Gift Books and Inscriptions, 1825-60." Winterthur Portfolio 31 (1996): 53-66.

Di Leonardo, Micaela. "The Female World of Cards and Holidays: Women, Families, and the Work of Kinship." Signs 12 (Spring 1987): 440-453.

Ditz, Toby L. Property and Kinship: Inheritance and Early Connecticut 1750-1820.

Princeton, NJ: Princeton University Press, 1986.

Dodge, Joseph Thompson. Genealogy of the Dodge Family of Essex County, Mass., 1629-1894. Madison, Wisconsin: Democrat Printing Company, 1898.

Douglas, Ann. The Feminization of American Culture. New York: Alfred A. Knopf, 1979.

Douglas, Diane M. "The Machine in the Parlor: A Dialectical Analysis of the Sewing Machine." Journal of American Culture 5 (Spring 1982): 20-29. 
Douglas, Mary and Baron C. Isherwood. The World of Goods. New York: Basic Books, Inc., 1979.

Dublin, Thomas. Transforming Women's Work: New England Lives in the Industrial Revolution. Ithaca: Cornell University Press, 1994.

- Women at Work: The Transformation of Work and Community in Lowell, Massachusetts, 1826-1860. New York: Columbia University Press, 1993.

Dublin, Thomas, ed. Farm to Factory: Women's Letters, 1830-1860. New York: Columbia University Press, 1993.

Duke, Dennis and Deborah Harding, eds. America's Glorious Quilts. New York: Hugh Lauter Levin Associates, Inc., 1987.

Dwight, Benjamin W. The History of the Descendants of John Dwight of Dedham, Mass. New York: John F. Trow and Son, 1874.

Earle, Swepson and Percy G. Skirven. Maryland's Colonial Eastern Shore: Historical Sketches of Counties and of Some Notable Structures. Baltimore: Munder-Thomsen Press, 1916.

Eaton, Linda. Quilts in a Material World: Selections from the Winterthur Collection. New York: Abrams, 2007.

Edmonds, Mary Jaene. Samplers and Samplermakers: An American Schoolgirl Art 17001850. London: Rizzoli, 1991.

Elbert, E. Duane and Rachel Kamm Elbert. History from the Heart: Quilt Paths Across Illinois. Nashville: Rutledge Hill Press, 1993.

Embroidered Samplers in the Collection of the Cooper-Hewitt Museum. Washington, DC: The Smithsonian Institution, 1984.

Epstein, Kathy. "Padded, Stuffed and Corded: White-on-White Quilts." Piecework Magazine 5 (November/December 1997): 33-37.

Farnam, Anne. "Essex County Furniture Carving: The Continuance of a Tradition." Essex Institute Historical Collections 116 (July 1980): 145-155.

Farnham, Joseph E.C. Brief Historical Data and Memories of My Boyhood Days in Nantucket. Providence: Snow and Farnham, 1915.

Farrell, James J. Inventing the American Way of Death, 1830-1920. Philadelphia: Temple University Press, 1980. 
Federico, Jean Taylor. "White Work Classification System." Uncoverings 1 (1980): 6871.

Feinson, Marjorie Chary, "Where are the Women in the History of Aging?" Social Science History 9 (Autumn 1985): 429-452.

Ferrero, Pat, Elaine Hedges and Julie Silber. Hearts and Hands: Women, Quilts and American Society. Nashville: Rutledge Hill Press, 1987.

Field, Corinne T. “““Are Women...All Minors?”: Woman's Rights and the Politics of Aging in the Antebellum United States." Journal of Women's History 12 (Winter 2001): 113-137.

Fields, Catherine Keene and Lisa C. Kightlinger, eds. To Ornament Their Minds: Sarah Pierce's Litchfield Female Academy 1792-1833. Litchfield, CT: The Litchfield Historical Society, 1993.

Finkel \& Daughter, M. Samplings 1-35 (1992-2009).

Fischer, David Hackett. Growing Old in America. New York: Oxford University Press, 1977.

Fleming, E. McClung. “Artifact Study: A Proposed Model.” Winterthur Portfolio 9 (1974): 153-173.

Fox, Sandi. For Purpose and Pleasure: Quilting Together in Nineteenth-Century America. Nashville: Rutledge Hill Press, 1995.

—. Quilts: California Bound, California Made 1840-1940. Los Angeles: FIDM Museum and Library, Inc., 2002.

- Small Endearments: Nineteenth-Century Quilts for Children and Dolls. Nashville: Rutledge Hill Press, 1980.

- Wrapped in Glory: Figurative Quilts and Bedcovers 1700-1900. Los Angeles: Thames and Hudson and Los Angeles County Museum of Art, 1990.

Frank, Robin Jaffee. Love and Loss: American Portrait and Mourning Miniatures. New Haven: Yale University Art Gallery, 2000.

Fratto, Toni Flores. “'Remember Me': The Sources of American Sampler Verses," New York Folklore 2 (Winter 1976): 205-222.

Fuhrer, Mary Babson, ed. Letters from the "Old Home Place": Anxieties and Aspirations in Rural New England, 1836-1843. Boylston, MA: Old Pot Publications, 1997. 
Furgason, Mary Jane and Patricia Cox Crews. "Prizes from the Plains: Nebraska State Fair Award-Winning Quilts and Quiltmakers." Uncoverings 14 (1993): 188-220.

Gabel, Laurel K. "A Common Thread: Needlework Samplers and American Gravestones." Markers 19 (2002): 18-49.

Gardner, Martin. Famous Poems from Bygone Days. New York: Dover Publications, 1995.

Gilbert, Jennifer. The New England Quilt Museum Quilts. Concord, CA: C\&T Publishing, 1999.

Gillespie, Joanna Bowen. “"“The Clear Leadings of Providence”: Pious Memoirs and the Problems of Self-Realization for Women in the Early Nineteenth Century." Journal of the Early Republic 5 (Summer 1985): 197-221.

Glassie, Henry. Material Culture. Bloomington: Indiana University Press, 1999.

Goggin, Maureen Daly. “One English Woman's Story in Silken Ink: Filling in the Missing Strands in Elizabeth Parker's Circa 1830 Sampler." Sampler and Antique Needlework Quarterly 8 (Winter 2002): 38-49.

Goody, Jack. "Inheritance, Property and Women: Some Comparative Considerations." In Family and Inheritance: Rural Society in Western Europe, 1200-1800, edited by Jack Goody, Joan Thirsk and E.P. Thompson, 10-36. Cambridge: Cambridge University Press, 1976.

Goody, Nancy H. "Fiskdale: 1816-1850." Unpub. paper, Old Sturbridge Village Research Library, Sturbridge, MA, 1977.

Gordon, Beverly. Bazaars and Fair Ladies: The History of the American Fundraising Fair. Knoxville: The University of Tennessee Press, 1998.

—_. Shaker Textile Arts, Hanover, NH: University Press of New England, 1980.

—. "Victorian Fancy Goods: Another Reappraisal of Shaker Material Culture." Winterthur Portfolio 25 (Summer/Autumn 1990): 111-129.

Gouldner, Alvin W. "The Norm of Reciprocity: A Preliminary Statement." American Sociological Review 25 (April 1960): 161-178.

Graffam, Olive Blair. Youth Is the Time for Progress: The Importance of American Schoolgirl Art 1780-1860. Washington, DC: The DAR Museum, 1998. 
The Great River: Art and Society of the Connecticut Valley, 1635-1820. Hartford: Wadsworth Atheneum, 1985.

Green, Harvey. The Light of the Home: An Intimate View of the Lives of Women in Victorian America. New York: Pantheon Books, 1983.

Grier, Katherine C. Culture and Comfort: People, Parlors and Upholstery, 1850-1930. Rochester, NY: Strong Museum, 1988.

Gross, Robert. The Minutemen and Their World. New York: Hill and Wang, 1976.

Gunn, Virginia. "From Myth to Maturity: The Evolution of Quilt Scholarship." Uncoverings 13 (1992): 192-205.

- "Quilts at Nineteenth-Century State and County Fairs: An Ohio Study." Uncoverings 9 (1988): 105-128.

Haber, Carole. Beyond Sixty-Five: The Dilemma of Old Age in America's Past. Cambridge: Cambridge University Press, 1983.

Haber, Carole and Brian Gratton. "Aging in America: The Perspective of History." In Handbook of the Humanities and Aging, edited by Thomas R. Cole, David D. Van Tassel, and Robert Kastenbaum, 352-370. New York: Springer Publishing Company, 1992.

—. Old Age and the Search for Security: An American Social History. Bloomington: Indiana University Press, 1994.

Hahn, Steven and Jonathan Prude, eds. The Countryside in the Age of Capitalist Transformation: Essays in the Social History of Rural America. Chapel Hill: The University of North Carolina Press, 1985.

Hall, Ruth Gardiner. Descendants of Governor William Bradford (through the first seven generations). 1951.

Halttunen, Karen. Confidence Men and Painted Women: A Study of Middle-Class Culture in America, 1830-1870. New Haven: Yale University Press, 1982.

Hamden, Jane Amstutz and Pamela Frazee Woolbright, eds. Oklahoma Heritage Quilts: A Sampling of Quilts Made In or Brought to Oklahoma Before 1940. Paducah, KY: American Quilter's Society, 1990.

The Hands that Made Them: Quilts of Adams County, Pennsylvania. Camp Hill, PA: Adams County Quilt Project Committee, 1993. 
Hansen, Debra Gold. Strained Sisterhood: Gender and Class in the Boston Female AntiSlavery Society. Amherst: University of Massachusetts Press, 1993.

Hansen, Karen V. A Very Social Time: Crafting Community in Antebellum New England. Berkeley: University of California Press, 1994.

Harbeson, Georgiana Brown. American Needlework. New York: Bonanza Books, 1938.

Hareven, Tamara K. "The Last Stage: Historical Adulthood and Old Age." Daedalus 105 (Fall 1976): 13-27.

Hartigan-O'Connor, Ellen. "Abigail's Accounts: Economy and Affection in the Early Republic.” Journal of Women's History 17 (Fall 2005): 37-58.

Hatch, Nathan O. The Democratization of American Christianity. New Haven: Yale University Press, 1989.

Heaps, Jennifer Davis. "Remember Me: Six Samplers in the National Archives." Prologue 34 (Fall 2002): 185-195.

Hedges, Elaine. “The Nineteenth-Century Diarist and Her Quilts." Feminist Studies 8 (Summer 1982): 293-299.

Hemphill, C. Dallett. Bowing to Necessities: A History of Manners in America, 16201860. New York: Oxford University Press, 1999.

Hersh, Tandy. "1842 Primitive Hall Pieced Quilt Top: The Art of Transforming Printed Fabric Designs through Geometry." Uncoverings 7 (1986): 47-59.

Hewitt, Nancy A. Women's Activism and Social Change: Rochester, New York 18221872. Ithaca: Cornell University Press, 1984.

Hiester, Jan and Kathleen Staples. This Have I Done: Samplers and Embroideries from Charleston and the Lowcountry. Charleston, SC: Curious Works Press and The Charleston Museum, 2001.

Hijiya, James A. "American Gravestones and Attitudes Toward Death: A Brief History." Proceedings of the American Philosophical Society 127 (October 1983): 339-363.

Hoffert, Sylvia D. "Female Self-Making in Mid-Nineteenth-Century America." Journal of Women's History 20 (Fall 2008): 34-59.

Hoffman, Lynn T. Patterns In Time: Quilts of Western New York. Buffalo, NY: Buffalo and Erie County Historical Society, 1990. 
Hollander, Stacy C. American Radiance: The Ralph Esmerian Gift to the American Folk Art Museum. New York: Harry N. Abrams, 2001.

—. “Talking Quilts.” Folk Art 29 (Spring/Summer 2004): 32-41.

—. "White on White and a Little Gray." Folk Art 31 (Spring/Summer 2006): 32-41.

Hollander, Stacy C. and Brooke Davis Anderson. American Anthem: Masterworks from the American Folk Art Museum. New York: Harry N. Abrams, Inc., 2001.

Holmes, Kenneth L., ed. Covered Wagon Women: Diaries and Letters from the Western Trails 1840-1890. Glendale, CA: The Arthur H. Clark Company, 1983.

Holmes, Rev. William. Religious Emblems and Allegories. London: William Tegg, 1868.

Hood, Adrienne D. The Weaver's Craft: Cloth, Commerce and Industry in Early Pennsylvania. Philadelphia: University of Pennsylvania Press, 2003.

Hornung, Clarence P. Treasury of American Design. New York: Harry N. Abrams, Inc., 1972.

Horton, Laurel. Mary Black's Family Quilts: Memory and Meaning in Everyday Life. Columbia: University of South Carolina Press, 2005.

Horton, Laurel and Lynn Robertson Myers. Social Fabric: South Carolina's Traditional Quilts. Columbia, SC: McKissick Museum, 1986.

Hoskins, Janet. Biographical Objects: How Things Tell the Stories of People's Lives. New York: Routledge, 1998.

Howe, Henry. Historical Collections of Ohio. Columbus: Henry Howe \& Son, 1891.

Huber, Stephen and Carol. Samplers: How to Compare and Value. London: Mitchell Beazley, 2002.

Huish, Marcus. Samplers and Tapestry Embroideries. New York: Dover Publications, Inc., 1970.

Hume, Janice. Obituaries in American Culture. Jackson: University Press of Mississippi, 2000.

—. "Press, Published History, and Regional Lore: Shaping the Public Memory of a Revolutionary War Heroine.” Journalism History 30 (Winter 2005): 200-209. 
Hyde, Lewis. The Gift: Imagination and the Erotic Life of Property. New York: Random House, 1983.

Ivey, Kimberly Smith. In the Neatest Manner: The Making of the Virginia Sampler Tradition. Austin, TX: Curious Works Press, 1997.

Izard, Holly V. "The Ward Family and Their 'Helps': Domestic Work, Workers, and Relationships on a New England Farm, 1787-1866." Proceedings of the American Antiquarian Society 103 (1993): 61-90.

James, Edward T., ed. Notable American Women 1607-1950: A Biographical Dictionary. Cambridge: The Belknap Press of Harvard University Press, 1971.

James, Louise B. “The Federal Eagle Quilt.” The Quilting Quarterly 24 (Spring 1996): 23-24.

Jeffrey, Julie Roy. The Great Silent Army of Abolitionism: Ordinary Women in the Antislavery Movement. Chapel Hill: University of North Carolina Press, 1998.

Jehle, Michael A., ed. Picturing Nantucket: An Art History of the Island with Paintings from the Collection of the Nantucket Historical Association. Nantucket: Nantucket Historical Association, 2000.

Jensen, Joan M. Loosening the Bonds: Mid-Atlantic Farm Women, 1750-1850. New Haven: Yale University Press, 1988.

Johnson, Barbara and Natalie Rothstein. A Lady of Fashion: Barbara Johnson's Album of Styles and Fabrics. New York: Thames and Hudson, 1987.

Johnson, Paul E. A Shopkeeper's Millennium: Society and Revivals in Rochester, New York, 1815-1837. New York: Hill and Wang, 1978.

Jones, Michael Owen. "How Can We Apply Event Analysis to "Material Behavior," and Why Should We?” Western Folklore 56 (Summer/Fall 1997): 199-214.

Kammen, Michael. "Changing Perceptions of the Life Cycle in American Thought and Culture." Proceedings of the Massachusetts Historical Society 91 (1979): 35-66.

- Mystic Chords of Memory: The Transformation of Tradition in American Culture. New York: Alfred A. Knopf, 1991.

- A Season of Youth: The American Revolution and the Historical Imagination. Ithaca: Cornell University Press, 1988.

Karlsen, Carol F. The Devil in the Shape of a Woman: Witchcraft in Colonial New England. New York: W.W. Norton and Company, 1998. 
Kasson, John F. Rudeness \& Civility: Manners in Nineteenth-Century Urban America. New York: Hill and Wang, 1990.

Keister, Douglas. Stories In Stone: A Field Guide to Cemetery Symbolism and Iconography. Salt Lake City: Gibbs Smith, 2004.

Keller, Patricia J. "Quaker Quilts from the Delaware River Valley 1760-1890.” The Magazine Antiques 156 (August 1999): 184-193.

Kelley, Mary. Learning to Stand and Speak: Women, Education, and Public Life in America's Republic. Chapel Hill: University of North Carolina Press, 2006.

—. "Reading Women/Women Reading: The Making of Learned Women in Antebellum America." The Journal of American History 83 (September 1996): 401-424.

—. "A Woman Alone: Catharine Maria Sedgwick's Spinsterhood in NineteenthCentury America." The New England Quarterly 51 (June 1978): 209-225.

Kelly, Catherine E. "The Consummation of Rural Prosperity and Happiness: New England Agricultural Fairs and the Construction of Class and Gender, 1810-1860." American Quarterly 49 (September 1997): 574-603.

—. In the New England Fashion: Reshaping Women's Lives in the Nineteenth Century. Ithaca: Cornell University Press, 1999.

—. "“"Well Bred Country People": Sociability, Social Networks, and the Creation of a Provincial Middle Class, 1820-1860." Journal of the Early Republic 19 (Fall 1999): 451479.

Kentucky Quilts 1800-1900. Louisville: The Kentucky Quilt Project, 1982.

Kerber, Linda K. "Separate Spheres, Female Worlds, Woman's Place: The Rhetoric of Women's History." Journal of American History 75 (1988): 9-39.

- Women of the Republic: Intellect and Ideology in Revolutionary America. Chapel Hill: University of North Carolina Press, 1987.

Kete, Mary Louise. Sentimental Collaborations: Mourning and Middle-Class Identity in Nineteenth-Century America. Durham: Duke University Press, 2000.

Kidwell, Claudia B. and Margaret C. Christman. Suiting Everyone: The Democratization of Clothing in America. Washington, DC: Smithsonian Institution Press, 1974.

Kiracofe, Roderick. The American Quilt: A History of Cloth and Comfort 1750-1950. New York: Clarkson Potter Publishers, 2004. 
Kleinberg, S.J. "The History of Old Age.” Convergence in Aging 1 (1982): 24-37.

Klimaszewski, Cathy Rose. Made to Remember: American Commemorative Quilts. Ithaca: Cornell University Press, 1991.

Komter, Aafke E. Social Solidarity and the Gift. Cambridge: Cambridge University Press, 2005.

Komter, Aafke E., ed. The Gift: An Interdisciplinary Perspective. Amsterdam: Amsterdam University Press, 1996.

Komter, Aafke and Wilma Vollebergh. "Gift Giving and the Emotional Significance of Family and Friends." Journal of Marriage and the Family 59 (August 1997): 747-757.

Kort, Ellen. Wisconsin Quilts. Charlottesville, VA: Howell Press, 2001.

Kraak, Deborah E. and Barbara C. Adams. "Reflections on Little Girls and Their Sewing for Dolls." Piecework Magazine 11 (January/February 2003): 59-64.

Krueger, Glee. A Gallery of American Samplers: The Theodore H. Kapnek Collection. New York: Bonanza Books, 1984.

—. "Mary Wright Alsop 1740-1829 and Her Needlework." The Connecticut Historical Society Bulletin 52 (Summer/Fall 1987): 125-224.

—. New England Samplers to 1840. Sturbridge, MA: Old Sturbridge Village, 1978.

LaBranche, John F. and Rita F. Conant. In Female Worth and Elegance: Sampler and Needlework Students and Teachers in Portsmouth, New Hampshire 1741-1840.

Portsmouth: The Portsmouth Marine Society, 1996.

Lane, Janie Warren Hollingsworth. Key and Allied Families. Macon, GA: Press of the J.W. Burke Co., 1931.

Lane, Rose Wilder. Woman's Day Book of American Needlework. New York: Simon and Schuster, 1963.

Lapsansky, Emma Jones and Anne A. Verplanck, eds. Quaker Aesthetics: Reflections on a Quaker Ethic in American Design and Consumption. Philadelphia: University of Pennsylvania Press, 2003.

Lasansky, Jeannette. A Good Start: The Aussteier or Dowry. Lewisburg, PA: Oral Traditions Project, 1990. 
Lasansky, Jeannette, ed. Bits and Pieces: Textile Traditions. Lewisburg, PA: Oral Traditions Project, 1991.

- In the Heart of Pennsylvania: Symposium Papers. Lewisburg, PA: Oral Traditions Project, 1986.

- On the Cutting Edge: Textile Collectors, Collections, and Traditions. Lewisburg, PA: Oral Traditions Project, 1994.

—. Pieced by Mother: Symposium Papers. Lewisburg, PA: Oral Traditions Project, 1988.

Lebsock, Suzanne. The Free Women of Petersburg: Status and Culture in a Southern Town, 1784-1860. New York: W.W. Norton and Company, 1985.

Lenz, Heather. "Learning to Quilt with Grandma Mary Sibley: Gift Labor, Traditional Quiltmaking, and Contemporary Art." Uncoverings 19 (1998): 109-136.

Lepore, Jill. A Is for American: Letters and Other Characters in the Newly United States. New York: Alfred A. Knopf, 2002.

Lerner, Gerda. "The Lady and the Mill Girl: Changes in the Status of Women in the Age of Jackson." MidContinent American Studies Journal 10 (1969): 5-15.

Lessons Stitched in Silk: Samplers from the Canterbury Region of New Hampshire. Hanover, NH: Hood Museum of Art, 1990.

Lipsett, Linda Otto. Elizabeth Roseberry Mitchell's Graveyard Quilt: An America Pioneer Saga. Dayton, OH: Halstead and Meadows Publishing, 1995.

—. Remember Me: Women and Their Friendship Quilts. San Francisco: The Quilt Digest Press, 1985.

Llewellyn, Nigel. "Elizabeth Parker's 'Sampler': Memory, Suicide and the Presence of the Artist." In Material Memories, edited by Marius Kwint, Christopher Breward and Jeremy Aynsley, 59-68. Oxford, England: Berg, 1999.

Locklair, Paula W. Quilts, Coverlets and Counterpanes: Bedcoverings from the MESDA and Old Salem Collections. Winston-Salem, NC: Old Salem, Inc., 1997.

Loscalzo, Anita B. "The History of the Sewing Machine and Its Use in Quilting in the United States." Uncoverings 26 (2005): 175-208.

Lovell, Margaretta L. Art in a Season of Revolution: Painters, Artisans, and Patrons in Early America. Philadelphia: University of Pennsylvania Press, 2005. 
Ludwig, Allan I. Graven Images: New England Stonecarving and Its Symbols 16501815. Middletown, CT: Wesleyan University Press, 1966.

Macdonald, Anne L. No Idle Hands: The Social History of American Knitting. New York: Ballantine Books, 1988.

MacDowell, Marsha and Ruth D. Fitzgerald, eds. Michigan Quilts: 150 Years of a Textile Tradition. East Lansing: Michigan State University Museum, 1987.

Macheski, Cecilia. "Penelope's Daughters: Images of Needlework in Eighteenth-Century Literature." In Fetter'd or Free?: British Women Novelists, 1670-1815, edited by Mary Anne Schofield and Cecilia Macheski, 85-100. Athens, OH: Ohio University Press, 1986.

Madden, Edward H. and James E. Hamilton. Freedom and Grace: The Life of Asa Mahan. Metuchen, NJ: The Scarecrow Press, Inc., 1982.

Maier, Pauline. American Scripture: Making the Declaration of Independence. New York: Alfred A. Knopf, 1997.

Marston, Gwen and Joe Cunningham. Mary Schafer and Her Quilts. East Lansing: Michigan State University Museum, 1990.

Martin, Ann Smart. "Makers, Buyers, and Users: Consumerism as a Material Culture Framework." Winterthur Portfolio 28 (1993): 141-157.

Mastromarino, Mark A. "Cattle Aplenty and Other Things in Proportion: The Agricultural Society and Fair in Franklin County, Massachusetts, 1810-1860." UCLA Historical Journal 5 (1984): 50-75.

—_. "Elkanah Watson and Early Agricultural Fairs, 1790-1860." Historical Journal of Massachusetts 17 (Summer 1989): 105-118.

Masur, Louis P. ““'Age of the First Person Singular”: the Vocabulary of the Self in New England, 1780-1850.” Journal of American Studies 25 (1991): 189-211.

Mathieson, Judy. "Some Published Sources of Design Inspiration for the Quilt Pattern Mariner's Compass $-17^{\text {th }}$ to $20^{\text {th }}$ Century." Uncoverings 2 (1981): 11-18.

Matthews, Jean V. ““'Woman's Place” and the Search for Identity in Ante-Bellum America." The Canadian Review of American Studies 10 (Winter 1979): 289-304.

Mauss, Marcel. The Gift: The Form and Reason for Exchange in Archaic Societies. New York: W.W. Norton, 1990. 
McInnis, Maurie D. The Politics of Taste in Antebellum Charleston. Chapel Hill: The University of North Carolina Press, 2005.

McNair, James Birtley. McNair, McNear, and McNeir Genealogies. Chicago: the author, 1923.

Meginness, John Franklin. Biographical Annals of Lancaster County, Pennsylvania. Chicago: J.H. Beers, 1903.

Meyer, Richard E., ed. Cemeteries and Gravemarkers: Voices of American Culture. Ann Arbor: UMI Research Press, 1989.

Meyer, Suellen. "Early Influences of the Sewing Machine and Visible Machine Stitching on Nineteenth-Century Quilts.” Uncoverings 10 (1989): 38-53.

Miller, Marla R. “"My Part Alone”: The World of Rebecca Dickinson, 1787-1802." New England Quarterly 71 (September 1998): 341-377.

- The Needle's Eye: Women and Work in the Age of Revolution. Amherst: University of Massachusetts Press, 2006.

Miller, Susan. Assuming the Positions: Cultural Pedagogy and the Politics of Commonplace Writing. Pittsburgh: University of Pittsburgh Press, 1998.

Minnesota Quilts: Creating Connections with Our Past. Stillwater, MN: Voyageur Press, 2005.

Monkhouse, Christopher. "The Spinning Wheel as Artifact, Symbol, and Source of Design." Nineteenth Century 8 (1982): 155-172.

Mosaic Quilts: Paper Template Piecing in the South Carolina Lowcountry. Greenville, SC: Curious Works Press, 2002.

Motz, Marilyn Ferris. True Sisterhood: Michigan Women and Their Kin 1820-1920. Albany: State University of New York Press, 1983.

—. "Visual Autobiography: Photograph Albums of Turn-of-the-Century Midwestern Women.” American Quarterly 41 (March 1989): 63-92.

Motz, Marilyn Ferris and Pat Browne, eds. Making the American Home: Middle-Class Women and Domestic Material Culture 1840-1940. Bowling Green, OH: Bowling Green State University Popular Press, 1988.

Myers, Thomas M. The Norris Family of Maryland. New York: W.M. Clemens, 1916. 
Neal, Roy. "A Chronological History of Ink." American Ink Maker 38 (September 1960): 38-41.

Nelson, Cyril I. and Carter Houck. Treasury of American Quilts. New York: Greenwich House, 1984.

Newell, Aimee E. "Island Pride: The Nantucket Agricultural Society Quilt." Piecework Magazine 14 (September/October 2006): 28-31.

—. "More than Warmth: Gift Quilts by Aging Women in Antebellum America." Uncoverings 29 (2008): 43-74.

—_. "No Harvest of Oil': Nantucket's Agricultural Fairs, 1856-1890." In New England Celebrates: Spectacle, Commemoration, and Festivity, edited by Peter Benes, 149-165. Boston: Boston University, 2002.

—_. "Paper-Template Piecing in Early-Nineteenth-Century America." Piecework Magazine 13 (September/October 2005): 40-43.

—. “'Tattered to Pieces': Amy Fiske's Sampler and the Changing Roles of Women in Antebellum New England." In Women and the Material Culture of Needlework and Textiles, 1750-1950, edited by Maureen Daly Goggin and Beth Fowkes Tobin. Aldershot, England: Ashgate Publishing Ltd., 2009.

—. "Tattered to Pieces': Samplers by Aging Women in Antebellum New England." Sampler and Antique Needlework Quarterly 13 (Fall 2007): 28-35.

Nicoll, Jessica F. Quilted for Friends: Delaware Valley Signature Quilts. Winterthur, DE: Winterthur Museum, 1986.

—. "Signature Quilts and the Quaker Community, 1840-1860." Uncoverings 7 (1986): 27-37.

Norling, Lisa. Captain Ahab Had a Wife: New England Women and the Whalefishery, 1720-1870. Chapel Hill: University of North Carolina Press, 2000.

Norton, Mary Beth. In the Devil's Snare: The Salem Witchcraft Crisis of 1692. New York: Alfred A. Knopf, 2002.

- Liberty's Daughters: The Revolutionary Experience of American Women, 17501800. Boston: Little, Brown and Company, 1980.

Nutter, Charles S. and Wilbur F. Tillett. The Hymns and Hymn Writers of the Church. New York: Eaton \& Mains, 1911. 
Nylander, Jane C. "Provision for Daughters: The Accounts of Samuel Lane." In House and Home, edited by Peter Benes, 11-27. Boston: Boston University, 1990.

Oliver, Celia Y. Enduring Grace: Quilts from the Shelburne Museum Collection. Lafayette, CA: C\&T Publishing, 1997.

Onuf, Peter, ed. All Over the Map: Rethinking American Regions, Baltimore: Johns Hopkins University Press, 1996.

Opal, J.M. "Exciting Emulation: Academies and the Transformation of the Rural North, 1780s-1820s." The Journal of American History 91 (September 2004): 445-470.

Orcutt, Samuel. The History of the Old Town of Derby, Connecticut, 1642-1880. Springfield, MA: Springfield Printing Company, 1880.

Ordonez, Margaret T. "Ink Damage on Nineteenth Century Cotton Signature Quilts." Uncoverings 13 (1992): 148-168.

Orlofsky, Patsy and Myron. Quilts in America. New York: Abbeville Press, 1992.

Osaki, Amy Boyce. "A "Truly Feminine Employment": Sewing and the Early Nineteenth-Century Woman.” Winterthur Portfolio 23 (Winter 1988): 225-241.

Otnes, Cele and Richard F. Beltramini, eds., Gift Giving: A Research Anthology. Bowling Green, OH: Bowling Green State University Popular Press, 1996.

Palmer, Heather Ruth. "Where is Nineteenth-Century Southern Decorative Needlework?" The Southern Quarterly 27 (1988): 57-71.

Parker, Rozsika. The Subversive Stitch: Embroidery and the Making of the Feminine. New York: Routledge, 1989.

Parmal, Pamela. Samplers from A to Z. Boston: MFA Publications, 2000.

Parry, Jonathan. "The Gift, the Indian Gift and the 'Indian Gift.'” Man 21 (September 1986): 453-473.

Payne, Michael R. and Suzanne Rudnick Payne. "A 'woman could paint a likeness?"” The Magazine Antiques 175 (January 2009): 178-185.

Peck, Amelia. American Quilts and Coverlets in the Metropolitan Museum of Art. New York: The Metropolitan Museum of Art, 2007.

Pecquet du Bellet, Louise. Some Prominent Virginia Families. Baltimore: Genealogical Pub. Co., 1976. 
Pierce, Frederick Clifton. Batchelder, Batcheller Genealogy. Chicago: W.B. Conkey Co., 1898.

—. Fiske and Fisk Family. Chicago: F.C. Pierce, 1896.

—. Whitney: The Descendants of John Whitney. Chicago: the author, 1895.

Pike, Martha. "In Memory Of: Artifacts Relating to Mourning in Nineteenth Century America." In Rituals and Ceremonies in Popular Culture, edited by Ray B. Browne, 296-315. Bowling Green, OH: Bowling Green University Popular Press, 1980.

Pike, Martha V. and Janice Gray Armstrong. A Time to Mourn: Expressions of Grief in Nineteenth Century America. Stony Brook, NY: The Museums at Stony Brook, 1980.

Premo, Terri L. ““AA Blessing to Our Declining Years”: Feminine Response to Filial Duty in the New Republic." International Journal of Aging and Human Development 20 (1984-1985): 69-74.

—. “"Like a Being Who Does Not Belong:" The Old Age of Deborah Norris Logan." Pennsylvania Magazine of History and Biography 107 (January 1983): 85-112.

- Winter Friends: Women Growing Old in the New Republic, 1785-1835. Urbana: University of Illinois Press, 1990.

Priddy, Sumpter T. American Fancy: Exuberance in the Arts, 1790-1840. Milwaukee: Chipstone Foundation, 2004.

Prown, Jules David. “Style as Evidence.” Winterthur Portfolio (1980): 197-210.

Prude, Jonathan. The Coming of the Industrial Order: Town and Factory Life in Rural Massachusetts 1810-1860. Cambridge: Cambridge University Press, 1983.

Purcell, Sarah J. Sealed with Blood: War, Sacrifice and Memory in Revolutionary America. Philadelphia: University of Pennsylvania Press, 2002.

Quilts and Quiltmakers: Covering Connecticut. Atglen, PA: Schiffer Publishing Ltd., 2002.

Ramsey, Bets and Merikay Waldvogel. The Quilts of Tennessee: Images of Domestic Life Prior to 1930. Nashville: Rutledge Hill Press, 1986.

- Southern Quilts: Surviving Relics of the Civil War. Nashville: Rutledge Hill Press, 1998. 
Range, Jane and Maris A. Vinovskis. "Images of the Elderly in Popular Magazines: A Content Analysis of Littell's Living Age, 1845-1882." Social Science History 5 (Spring 1981): 123-170.

Reddall, Winifred. "Pieced Lettering on Seven Quilts Dating from 1833 to 1891." Uncoverings 1 (1980): 56-63.

Rettew, Gayle A., William H. Siener and Janice Turner Wass. "Behold the Labour of my Tender Age": Children and Their Samplers, 1780-1850. Rochester, NY: Rochester Museum and Science Center, 1984.

Richter, Paula Bradstreet. "Lucy Cleveland, Folk Artist." The Magazine Antiques 158 (August 2000): 204-213.

—. Painted with Thread: The Art of American Embroidery. Salem, MA: Peabody Essex Museum, 2002.

Ring, Betty. American Needlework Treasures: Samplers and Silk Embroideries from the Collection of Betty Ring. New York: E.P. Dutton, 1987.

—. Girlhood Embroidery: American Samplers and Pictorial Needlework 1650-1850. New York: Alfred A. Knopf, 1993.

- Let Virtue Be a Guide to Thee: Needlework in the Education of Rhode Island Women, 1730-1830. Providence: Rhode Island Historical Society, 1983.

- "New England Heraldic Needlework of the Neoclassical Period." The Magazine Antiques 144 (October 1993): 484-493.

- "Samplers and Pictorial Needlework at the Chester County Historical Society." The Magazine Antiques 126 (December 1984): 1422-1433.

—. "Schoolgirl Embroideries: A Credit to the Teachers." Worcester Art Museum Journal 5 (1981/1982): 18-31.

Roach, Susan. "The Kinship Quilt: An Ethnographic Semiotic Analysis of a Quilting Bee." In Women's Folklore, Women's Culture, edited by Rosan A. Jordan and Susan J. Kalcik, 54-64. Philadelphia: University of Pennsylvania Press, 1985.

Robinson, Charles Seymour. Annotations Upon Popular Hymns. New York: Hunt and Eaton, 1893.

Roebuck, Janet. "Grandma as Revolutionary: Elderly Women and Some Modern Patterns of Social Change." International Journal of Aging and Human Development 17 (1983): 249-266. 
—. "When Does 'Old Age' Begin?: The Evolution of the English Definition." Journal of Social History 12 (Spring 1979): 416-428.

Rogers, Sherbrooke. Sarah Josepha Hale: A New England Pioneer 1788-1879.

Grantham, NH: Tompson and Rutter, 1985.

Rosenthal, Carolyn J. "Kinkeeping in the Familial Division of Labor." Journal of Marriage and the Family 47 (November 1985): 965-974.

Rubin, Stella. Miller's How to Compare and Value American Quilts. London: Octopus Publishing Group Ltd., 2001.

Rust, Marion. Prodigal Daughters: Susanna Rowson's Early American Women. Chapel Hill: University of North Carolina Press, 2008.

Ryan, Mary P. The Cradle of the Middle-Class: The Family in Oneida County, New York, 1780-1865. Cambridge: Cambridge University Press, 1978.

—. "The Power of Women's Networks: A Case Study of Female Moral Reform in Antebellum America." Feminist Studies 5 (Spring 1979): 66-85.

- Women in Public: Between Banners and Ballots, 1825-1880. Baltimore: The Johns Hopkins University Press, 1990.

Safford, Carleton L. and Robert Bishop. America's Quilts and Coverlets. New York: Weathervane Books, 1974.

St. George, Robert B. Conversing by Signs: Poetics of Implication in Colonial New England Culture. Chapel Hill: University of North Carolina Press, 1998.

Sale, Edith Tunis. Old Time Belles and Cavaliers. Philadelphia: J.B. Lippincott, 1912.

Salmon, Marylynn. Women and the Law of Property in Early America. Chapel Hill: The University of North Carolina Press, 1986.

Saxton, Martha. Being Good: Women's Moral Values in Early America. New York: Hill and Wang, 2003.

Schiffer, Margaret B. Historical Needlework of Pennsylvania. New York: Charles Scribner's Sons, 1968.

Schmeal, Jacqueline Andre. Patchwork: Iowa Quilts and Quilters. Iowa City: University of Iowa Press, 2003.

Schorsch, Anita. Mourning Becomes America: Mourning Art in the New Nation. Clinton, NJ: The Main Street Press, 1976. 
Schulz, Constance B. "Daughters of Liberty: The History of Women in the Revolutionary War Pension Records." Prologue 16 (Fall 1984): 139-153.

Schwartz, Barry. "Social Change and Collective Memory: The Democratization of George Washington.” American Sociological Review 56 (April 1991): 221-236.

- "The Social Context of Commemoration: A Study in Collective Memory." Social Forces 61 (December 1982): 374-402.

—. "The Social Psychology of the Gift." The American Journal of Sociology 73 (July 1967): 1-11.

Scott, Ann Firor. "The Ever Widening Circle: The Diffusion of Feminist Values from the Troy Female Seminary 1822-1872." History of Education Quarterly 19 (Spring 1979): 3-25.

Scott, Joan W. "Gender: A Useful Category of Historical Analysis." American Historical Review 91 (December 1986): 1053-1075.

Scott, Paula A. Growing Old in the Early Republic: Spiritual, Social, and Economic Issues, 1790-1830. New York: Garland Publishing, Inc., 1997.

—. "“Tis Not the Spring of Life with Me": Aged Women in Their Diaries and Letters, 1790-1830." Connecticut History 36 (1995): 12-30.

Seale, William. The Tasteful Interlude: American Interiors through the Camera's Eye, 1860-1917. New York: Praeger, 1975.

Sellers, Charles. The Market Revolution: Jacksonian America, 1815-1846. New York: Oxford University Press, 1991.

Shammas, Carole. "Re-Assessing the Married Women's Property Acts." Journal of Women's History 6 (Spring 1994): 9-30.

Sherman, Mimi. "A Fabric of One Family: A Saga of Discovery." The Clarion (Spring 1989): 55-62.

Showalter, Elaine. "Piecing and Writing." In The Poetics of Gender, edited by Nancy K. Miller, 222-247. New York: Columbia University Press, 1986.

Shurtleff, Benjamin and N.B. Shurtleff. The Descendants of William Shurtleff of Plymouth and Marshfield, Massachusetts. Revere, MA, 1912.

Silver, Allan. "Friendship in Commercial Society: Eighteenth-Century Social Theory and Modern Sociology." American Journal of Sociology 95 (May 1990): 1474-1504. 
Simons, D. Brenton and Peter Benes, eds. The Art of Family: Genealogical Artifacts in New England. Boston: New England Historic Genealogical Society, 2002.

Sklar, Kathryn Kish, Catharine Beecher: A Study in American Domesticity. New York: Norton, 1976.

—. "The Founding of Mount Holyoke College." In Women of America: A History, edited by Carol Ruth Berkin and Mary Beth Norton, 177-201. Boston: Houghton Mifflin Company, 1979.

- "The Schooling of Girls and Changing Community Values in Massachusetts Towns, 1750-1820." History of Education Quarterly 33 (Winter 1993): 511-542.

Sloat, Caroline F., ed. Meet Your Neighbors: New England Portraits, Painters, \& Society, 1790-1850. Sturbridge, MA: Old Sturbridge Village, 1992.

Smith, Daniel Scott. "Child Naming Practices, Kinship Ties, and Change in Family Attitudes in Hingham, Massachusetts, 1641-1880." Journal of Social History 18 (1985): 541-566.

Smith, Hilda L. "Cultural Constructions of Age and Aging - "Age": A Problematic Concept for Women.” Journal of Women's History 12 (Winter 2001): 77-86.

Smith-Rosenberg, Carroll. Disorderly Conduct: Visions of Gender in Victorian America. New York: Oxford University Press, 1985.

Smith-Rosenberg, Carroll and Charles Rosenberg. "The Female Animal: Medical and Biological Views of Woman and Her Role in Nineteenth-Century America." The Journal of American History 60 (September 1973): 332-356.

Snyder, Grace. No Time on My Hands. Lincoln: University of Nebraska Press, 1986.

Sobel, Mechal. Teach Me Dreams: The Search for Self in the Revolutionary Era. Princeton: Princeton University Press, 2000.

Spicker, Stuart F., Kathleen M. Woodward and David D. Van Tassel, eds., Aging and the Elderly: Humanistic Perspectives in Gerontology. Atlantic Highlands, NJ: Humanities Press, Inc., 1979.

Spitzer, Alan B. "The Historical Problem of Generations." The American Historical Review 78 (December 1973): 1353-1385.

Stabile, Susan M. Memory's Daughters: The Material Culture of Remembrance in Eighteenth-Century America. Ithaca: Cornell University Press, 2004. 
Stannard, David E., ed. Death In America. Philadelphia: University of Pennsylvania Press, 1975.

Staples, Kathleen. "Samplers from Charleston, South Carolina." The Magazine Antiques 169 (March 2006): 80-89.

—_. "Tangible Displays of Refinements: Southern Needlework at MESDA." The Magazine Antiques 171 (January 2007): 198-203.

Stavenuiter, Monique and Karin Bijsterveld. "Introduction: Long Lives, Silent Witnesses - Elderly Women in the Past.” Journal of Family History 25 (April 2000): 196-201.

Stearns, Peter N. “Old Women: Some Historical Observations.” Journal of Family History 5 (Spring 1980): 44-57.

Stearns, Peter N. and Jan Lewis, eds. An Emotional History of the United States. New York: New York University Press, 1998.

Stiles, Henry Reed. The Stiles Family in America. Jersey City: Doan \& Pilson, printers, 1895.

The Story of Samplers. Philadelphia: Philadelphia Museum of Art, 1971.

Strasser, Susan. Never Done: A History of American Housework. New York: Pantheon Books, 1982.

Strathern, Marilyn. The Gender of the Gift. Berkeley: University of California Press, 1992.

Studebaker, Sue. Ohio Is My Dwelling Place: Schoolgirl Embroideries 1800-1850. Athens: Ohio University Press, 2002.

—. Ohio Samplers: Schoolgirl Embroideries 1803-1850, Lebanon, OH: Warren County Historical Society, 1988.

Swan, Susan Burrows. “Appreciating American Samplers, Part II." Early American Life 15 (April 1984): 42-45, 72, 93.

- Plain and Fancy: American Women and Their Needlework, 1650-1850. Austin, TX: Curious Works Press, 1995.

—_. A Winterthur Guide to American Needlework. New York: Rutledge Books, 1976.

Sykes, Karen. Arguing with Anthropology: An Introduction to Critical Theories of the Gift. New York: Routledge, 2005. 
Taylor, Sarah Elizabeth. "Remembering Elderly Women in Early America: A survey of how aged women were memorialized in late eighteenth and early nineteenth-century tombstone inscriptions, death notices, funeral sermons, and memoirs." Master's thesis, Virginia Polytechnic Institute and State University, 2002.

Tennessee Stitches: Catalog to Accompany an Exhibit of Nineteenth Century Williamson County Samplers. Franklin, TN: The Carter House, 1993.

Teute, Fredrika J. "In 'the gloom of evening': Margaret Bayard Smith's View in Black and White of Early Washington Society." The Proceedings of the American Antiquarian Society 106 (1996): 37-58.

—. "Roman Matron on the Banks of Tiber Creek: Margaret Bayard Smith and the Politicization of Spheres in the Nation's Capital." In A Republic for the Ages: The United States Capitol and the Political Culture of the Early Republic, edited by Donald R.

Kennon, 89-121. Charlottesville: The University Press of Virginia, 1999.

Thane, Pat. "Social Histories of Old Age and Aging." Journal of Social History 37.1 (2003): 93-111.

Thomas, Nicholas. Entangled Objects: Exchange, Material Culture and Colonialism in the Pacific. Cambridge, MA: Harvard University Press, 1991.

Torsney, Cheryl B. and Judy Elsley, eds. Quilt Culture: Tracing the Pattern. Columbia: University of Missouri Press, 1994.

Travers, Len. Celebrating the Fourth: Independence Day and the Rites of Nationalism in the Early Republic. Amherst: University of Massachusetts Press, 1997.

Tricarico, Barbara. Quilts of Virginia 1607-1899: The Birth of America Through the Eye of a Needle. Atglen, PA: Schiffer Publishing Ltd., 2006.

Troyansky, David. "The History of Old Age in the Western World." Ageing and Society 16 (1996): 233-243.

Turkle, Sherry, ed. Evocative Objects: Things We Think With. Cambridge, MA: The MIT Press, 2007.

Ulrich, Laurel Thatcher. The Age of Homespun: Objects and Stories in the Creation of an American Myth. New York: Alfred A. Knopf, 2001.

—. "Furniture as Social History: Gender, Property, and Memory in the Decorative Arts." In American Furniture, edited by Luke Beckerdite, 39-68. Milwaukee: Chipstone Foundation, 1995. 
- Good Wives: Image and Reality in the Lives of Women in Northern New England 1650-1750. New York: Alfred A. Knopf, 1987.

—. "Hannah Barnard's Cupboard: Female Property and Identity in $18^{\text {th }}$-Century New England." In Through a Glass Darkly: Reflections on Personal Identity in Early America, edited by Ronald Hoffman, Mechal Sobel and Fredrika J. Teute, 238-273. Durham: University of North Carolina Press, 1997.

—. A Midwife's Tale: The Life of Martha Ballard, Based on her Diary, 1785-1812. New York: Alfred A. Knopf, 1990.

—. "Of Pens and Needles: Sources in Early American Women's History." The Journal of American History 77 (June 1990): 200-207.

—. "Wheels, Looms, and the Gender Division of Labor in Eighteenth-Century New England." William and Mary Quarterly 55 (January 1998): 3-38.

Valentine, Fawn. West Virginia Quilts and Quiltmakers: Echoes from the Hills. Athens: Ohio University Press, 2000.

Van Broekhoven, Deborah. The Devotion of These Women: Rhode Island in the Antislavery Network. Amherst: University of Massachusetts Press, 2002.

Van Burkleo, Sandra F. Belonging to the World: Women's Rights and American Constitutional Culture. New York: Oxford University Press, 2001.

Van De Krol, Yolanda. "Candlewicking." Piecework Magazine 5 (November/December 1997): 23-27.

Vanderpoel, Emily Noyes. Chronicles of a Pioneer School From 1792-1833.

Cambridge, MA: The University Press, 1903.

Van Horn, Jennifer. "Samplers, Gentility, and the Middling Sort." Winterthur Portfolio 40 (Winter 2006): 219-247.

Van Tassel, David and Peter N. Stearns, eds. Old Age in a Bureaucratic Society: The Elderly, the Experts, and the State in American History. New York: Greenwood Press, 1986.

Van Valin, Marsha, ed. Common Thread, Common Ground: A Collection of Essays on Early Samplers and Historic Needlework. Sullivan, WI: The Scarlet Letter, 2001.

Veasey, Patricia V. Virtue Leads and Grace Reveals: Embroideries and Education in Antebellum South Carolina. Greenville, SC: Curious Works Press, 2003.

Vedder, J.V.V. Historic Catskill. Catskill, NY, 1922. 
Vincent, Margaret. “May Useful Arts Employ My Youth”: The Hope R. Hacker Sampler Collection in the Allentown Art Museum. Allentown: Allentown Art Museum, 1987.

Vinovskis, Maris A. “Angels' Heads and Weeping Willows: Death in Early America." Proceedings of the American Antiquarian Society 86 (1976): 273-302.

Vinovskis, Maris A. and Richard M. Bernard. "Beyond Catharine Beecher: Female Education in the Antebellum Period." Signs 3 (1978): 856-869.

Waciega, Lisa Wilson. "A "Man of Business": The Widow of Means in Southeastern Pennsylvania, 1750-1850." The William and Mary Quarterly 44 (January 1987): 40-64.

Waldstreicher, David. In the Midst of Perpetual Fetes: The Making of American Nationalism, 1776-1820. Chapel Hill: University of North Carolina Press, 1997.

Waldvogel, Merikay. Childhood Treasures: Doll Quilts by and for Children. Intercourse, PA: Good Books, 2008.

Ward, Barbara McLean. "Women's Property and Family Continuity in EighteenthCentury Connecticut." In Early American Probate Inventories, edited by Peter Benes, 74-85. Boston: Boston University, 1987.

Warfield, Joshua Dorsey. The Founders of Anne Arundel and Howard Counties, Maryland. A Genealogical and Biographical Review from Wills, Deeds and Church Records. Baltimore: Kohn \& Pollock, 1905.

Warren, Elizabeth V. and Sharon L. Eisenstadt. Glorious American Quilts: The Quilt Collection of the Museum of American Folk Art. New York: Penguin Studio, 1996.

Wayland, John W. The Washingtons and Their Homes. Staunton, VA: McClure Printing Company, 1944.

Weiner, Annette B. Inalienable Possessions: The Paradox of Keeping-While-Giving. Berkeley: University of California Press, 1992.

—_. "Inalienable Wealth." American Ethnologist 12 (May 1985): 210-227.

Weinraub, Anita Zaleski, ed., Georgia Quilts: Piecing Together a History. Athens: University of Georgia Press, 2006.

Weissman, Judith Reiter and Wendy Lavitt. Labors of Love: America's Textiles and Needlework, 1650-1930. New York: Wings Books, 1987.

Welter, Barbara. Dimity Convictions: The American Woman in the Nineteenth Century. Athens: Ohio University Press, 1976. 
Welters, Linda and Margaret T. Ordonez, eds. Down by the Old Mill Stream: Quilts in Rhode Island. Kent, OH: The Kent State University Press, 2000.

Weybright, Victor. Spangled Banner: The Story of Francis Scott Key. New York: Farrar and Rinehart Inc., 1935.

What's American about American Quilts? A Research Forum on Regional

Characteristics. Washington, DC: National Museum of American History, 1995.

Wheeler, Candace. The Development of Embroidery in America. New York: Harper and Brothers, 1921.

White, Richard. Remembering Ahanagran: A History of Stories. New York: Hill and Wang, 1998.

Willard, Frances E. and Mary A. Livermore, eds. American Women: Fifteen Hundred Biographies. New York: Mast, Crowell \& Kirkpatrick, 1897.

Wilson, Lisa. Life After Death: Widows in Pennsylvania 1750-1850. Philadelphia: Temple University Press, 1992.

Woods, Marianne Berger, ed. Threads of Tradition: Northwestern Pennsylvania Quilts. Meadville, PA: Crawford County Historical Society, 1997.

Wulfert, Kimberly. "The Journey of a Whitework Wedding Quilt.” Piecework Magazine 14 (May/June 2006): 32-35.

Young, Alfred F. The Shoemaker and the Tea Party: Memory and the American Revolution. Boston: Beacon Press, 1999.

Zagarri, Rosemarie. "Morals, Manners, and the Republican Mother." American Quarterly 44 (June 1992): 192-215.

Zimmerman, Philip D. "Workmanship as Evidence: A Model for Object Study." Winterthur Portfolio (1981): 283-307.

Zonderman, David A. Aspirations and Anxieties: New England Workers and the Mechanized Factory System 1815-1850. New York: Oxford University Press, 1992. 